\title{
Highly Functionalized Piperidine Generation via Pyridine Repolarization and Hyper-Distorted Allyl Complexes of $\left\{\mathrm{TpW}(\mathrm{NO})\left(\mathrm{PMe}_{3}\right)\right\}$
}

\author{
Daniel Patrick Harrison \\ Midlothian, Virginia
}

B.S., Virginia Military Institute, 2004

\begin{abstract}
A Dissertation presented to the Graduate Faculty of the University of Virginia in Candidacy for the Degree of Doctor of Philosophy
\end{abstract}

Department of Chemistry

University of Virginia

February, 2011

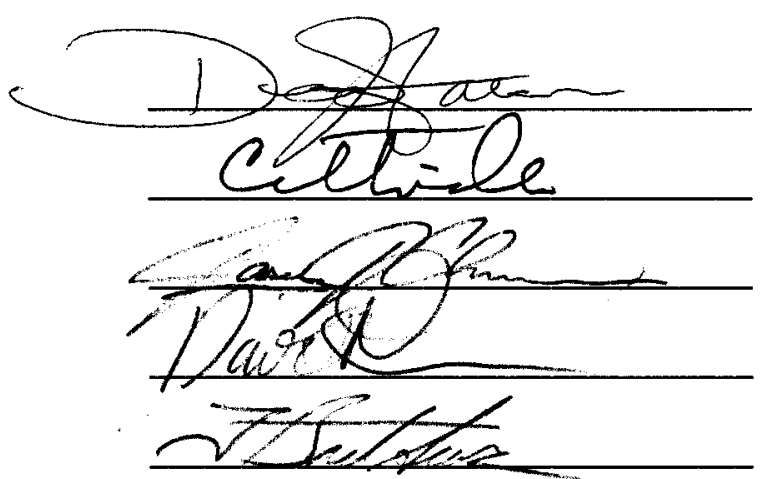




\begin{abstract}
Chapter 1 introduces the traditional organic chemistry of pyridine with an emphasis on its dearomatization. Organometallic methods of dearomatization are also discussed. Strategies for averting nitrogen coordination (i.e. $\mathrm{kN}$ ) in favor of haptotropic (i.e. $\left.\eta^{2}, \eta^{4}, \eta^{6}\right)$ pyridine coordination are discussed, as well as known modifications of these carbon-coordinated pyridines. The work previously performed by our group with $\left\{\mathrm{TpW}(\mathrm{NO})\left(\mathrm{PMe}_{3}\right)\right\}$ and our strategy to utilize this fragment is introduced.

Chapters 2 and 3 report our findings on the large scale synthesis of $\eta^{2}$-pyridine complexes of tungsten, utilizing a borane-protection strategy to avert $\mathrm{kN}$ coordination. The reactivity of complexes that result from the removal of the borane and replacement with alternative electrophilic groups are investigated. In particular, we have found that an acetyl group provides an isolable $\mathrm{N}$-acetylpyridinium complex, which allows for the mild regio- and stereoselective modification of the pyridine ring with nucleophiles.

Chapters 4 and 5 report on the fundamentally new chemistry of pyridine that results from the coordination of the $\left\{\mathrm{TpW}(\mathrm{NO})\left(\mathrm{PMe}_{3}\right)\right\}$. Tandem electrophilic followed by nucleophilic additions and cycloadditions with 1,2-dihydropyridine (DHP) complexes are reported. These findings suggest that the metal coordination reverses the polarization of the pyridine ring carbons such that electrophiles add $\alpha$-to- $\mathrm{N}$ rather than $\beta$-to-N. Importantly, we report the isolation of new 2-, 3-, or 4-substitituted piperidine compounds that result from this methodology.

Chapter 6 reports pyridine ring scission with nucleophiles capable of delivering 4 $\mathrm{e}^{-}(2 \sigma, 2 \pi)$ to the pyridine ring. The resulting conjugated complexes were probed for
\end{abstract}


fluorescent activity. While none was found for the metal complexes, photolysis liberated an organic cation that did display fluorescence.

Chapter 7 discusses our discovery of highly distorted allyl complexes of $\left\{\mathrm{TpW}(\mathrm{NO})\left(\mathrm{PMe}_{3}\right)\right\}$. Here we endeavor to understand the origin of the large distortions and orientations of allyls observed in crystal structures and reproduced by density functional theory (DFT) calculations. We propose that the nitrosyl is responsible for the distortion, while $\mathrm{Tp}$ is responsible for the orientation of the allyls distal to $\mathrm{PMe}_{3}$. 


\section{Acknowledgements}

Sir Isaac Newton once said, "If I have seen further it is only by standing on the shoulders of giants." This quote sums up my feeling toward my success in chemistry. While I feel as though I have contributed something to the field of chemistry, I cannot take all of credit for it. There have been many individuals who have had an integral part in my success.

From the lab research perspective, any success I have had as a graduate student is a result of 2 things: 1 ) the outstanding cumulative efforts of my predecessors and 2) the presence of my co-workers. I am always amazed that the Harman lab research projects stemmed from W. Dean Harman's characterization of some odd CV signals. He has taken his initial physical inorganic investigations and done what most organometallic chemists desire to do: expand the methodology to something more generally relevant than the initial discovery. Unfortunately, the potential of this work has not yet been realized by the broader chemical community. However this may soon change as Sigma-Aldrich has recently agreed to supply starting materials of the tungsten system. These chemicals will then undergo testing to determine their medicinal capabilities.

I have always considered myself fortunate to work for Dean for many reasons. For example, I knew the moment that I visited the UVa Chemistry department that I wanted to work for Dean because 1) I realized that his entire purpose is to nurture and teach, and therefore would be patient with my sometimes "schizophrenic" thoughts and ideas and 2) because the fundamental $d_{\pi}-p_{\pi}$ interaction that Dean drew at that first 
meeting captivated me. During the past five years, he has proven to be incredibly nurturing and caring and spent countless hours teaching and answering my questions that will help serve me forevermore. Not to mention, Dean has always gone to bat for us whenever we needed him too. Dean has a laissez-faire philosophy when it comes to graduate students and research. That is, Dean believes that we are here to make our Ph.D. what we want it to be and that he is here as a consultant. Although frustrating at times, this philosophy has allowed me to develop as a critical thinker and take responsibility for the evolution of my project, including both its successes and failures. I hope to be able to follow his example in my in my future projects.

One thing that I have learned about Dean is that he when he gives one criticism he always has pure intentions. Seemingly contradictorily, he has been willing to be completely and utterly honest with me in order to help me achieve my goals. Overall, I am very thankful Dean took a chance on me and allowed me to work in his lab. Everything he has done for me has really paid off and I cannot thank him enough for all of his effort.

Summers in the Harman lab would not be complete without the presence of our favorite University of Richmond professor, Bill Myers. It has been a riot getting to know him. I never tire of hearing his stories, even though I have heard many of them four or five times. His quirky sense of humor is refreshing and his kindness is rivaled only by Dean. Bill has an uncanny ability to patiently analyze 2D NMR spectra and has helped shape the way we characterize and think about multidimensional spectra. As a result he as developed clever naming schemes of $\mathrm{PzA}, \mathrm{PzB}$, and $\mathrm{PzC}$ of the $\mathrm{Tp}$ ligand. His 
willingness to assist with the collection of 2D NMR and HRMS data has been instrumental to my ability to quickly write numerous papers, as his instruments are outstanding and allow for the rapid analysis of compounds. I consider Bill a good friend and colleague and I treasure the time that we had together.

One of the neat things that Bill does for the group is to bring new undergraduate students to our lab each summer. I have enjoyed meeting them, developing friendships with them, and taking part in their chemical training. Most notably, I have enjoyed working with Diana lovan and Dalsher Nagra as they have each brought specific attributes to our lab. Diana is responsible for setting up many NMR experiments and HRMS data collection. It is clear that Diana will go far with her intelligence and willingness to work incredibly hard. Dalsher is one of the most charismatic individuals I have ever met. His willingness to ask questions will allow help him in his future endeavors.

\section{Predecessors:}

Although I spent varying amounts of time with others in lab, each and every person has enhanced my education, either scientific or otherwise, and as a result I consider myself a better person.

Ed Lis was my initial graduate mentor who taught me for the first six months. He taught me about quinolone and how he had achieved certain laboratory tasks (e.g. precipitations, glovebox transfers, etc.). When I first arrived, Kim Bassett was the mother figure of the lab. She taught me how to be considerate in a laboratory setting, a skill that has served me well for the last five years by allowing me to maintain positive 
interpersonal relationships. Becky Salomon and I attended many classes and went through candidacy together. Toward the end of her graduate career, good fortune shined on her and allowed her to capitalize on the properties of the tungsten system by trapping a much sought after aniline complex with acid. After its initial discovery, she successfully showed its utility by successfully extrapolating most of the reaction classes that have been found to work with the phenol complex to the anilinium complex.

George Kosturko always impressed me with his hard work, and as a result helped me set a standard for how much time I spent in the lab. We worked in adjacent ports and our close proximity allowed for many conversations about possible reactions to try with our complexes, life, etc. One of the most important things that George taught me was the importance of networking and keeping good inter-lab relationships healthy. If I am not mistaken, he was a key player in implementing the sharing of chemicals and resources between labs. Our ability to swap chemicals with other labs has been instrumental when we have tried to discover new reaction classes while still trying to save money.

Mike Todd and I shared Box 1 for all but about six months during his time at the lab. Mike is in general a quiet person whose intelligence was often revealed during our lunchtime conversations. I appreciate his time and patience while acclimating me to Box 1 , transferring the vacuum pump job to me, and his willingness to allow me to bounce ideas off of him. One somewhat funny thing that Mike did not know while he was here was that during my early days at group meetings, when I did not understand anything 
anyone was saying, I found refuge in counting the number of times Mike said "umm" (one time I stopped counting after 10 minutes when he hit 112)!

When I reflect back on who I would consider most crucial to my laboratory and mental training, Kevin Welch is that person. He brought me up to speed with the borane complex and let me run wild with it. Kevin was the first person who was able to explain 2D NMR data to me and in such a way that actually conveyed the importance and the usefulness of the techniques. The skills he taught me guided me throughout my time in the lab. Kevin and Vic got very good and giving me a hard time. I took being made fun of to mean that they thought I was an OK person and have carried on the tradition by teasing Jared. Not to mention, I enjoyed the attention of good people, especially since their comments allowed me to see faults and correct them. It was a true pleasure to work with, learn from, and be friends with Kevin. His intelligence always challenged me to think in ways that I was unaccustomed to.

Adam Christopher Nickols-Nielander and I worked on his first publication and my first primary author paper together, which was the beginning of a great friendship. I suppose he was technically "my undergrad" (after Mike left) at that stage, but only in the sense of teaching him how to do laboratory things. Adam is the most intelligent person that I know, flat out. He is another person who has really challenged me to think in different ways than I was accustomed to. I aspire to reach his potential. He was a real pleasure to work with, learn from, and on the rare occasion, stump. I have enjoyed chatting with him, even when he is at CalTech and I am on the east coast. I look forward to seeing what his contribution to the history of mankind turns out to be. 


\section{Current Lab Members:}

Vic Zottig and I have been good friends from the get go, even though he helped Kevin hone his skills at making fun of me. There are no words that can fully describe what an amazing friend Vic has been to me. I blame him, and my wife, for making me be "social" (completely against my will). I am of course a better person for it. When I was in limbo with my living situation (one lease was up and I could not move into married student housing yet), Vic was the person that kind enough to let me live on his couch for three months. He saved me thousands of dollars and the stress of moving multiple times. Vic was also the person that I vented to when I was upset about chemistry; we spent many hours standing in our adjacent hood spaces talking not only about chemistry but life things as well. I have to give props to Vic because he puts more time into lab than anyone else I know, including myself. Among other things, I will especially miss the time spent hiking and wine tastings. I will also miss ganging up with Vic to making fun of Jared.

Jared Pienkos... where should I start? Well, I think it is safe to say that Vic and I took great pleasure in making fun of the goofiest person I know. As we have said many times, we give him such a hard time because we truly like him. We especially like to give him a hard time when he dresses like a $10^{\text {th }}$ grade woman (i.e. no belt or wearing sweat pants to lab). One of my favorite moments with Jared was when we told the first year graduate students at their welcoming party that he was my mentor and I was his trainee. I am astounded that a graduate student has isolated new organic compounds 
within a year of joining the lab... unbelievable. Jared has great potential and I expect to see great things from him.

Laura was the first of two graduate students that I have trained in our laboratory (Note: all together, I have trained four but two have left). Laura and I have had a fragile, yet special, relationship that goes back to the first day I began training her. I have learned a lot from her interesting peculiarities and personality. I hope that Laura finds something interesting through her lab work and wish her all the best. A noteworthy and outstanding skill set that Laura has brought to the lab are her editorial skills. They have spawned many discussions about scientific writing that would not have happened otherwise. They are beyond that of anyone I know, which she derives great pleasure from. I think that these skills will come in handy for her in the future.

Sisi is the second of two graduate students that I have trained that has stayed with the Harman group. I believe that Sisi is quite intelligent but because of language barriers has not been able to fully utilize her abilities and apply them to her work. My hope is that this will change shortly and I am looking forward to learning about the discoveries that she will make in the near future. Is has been a pleasure to watch Sisi begin to think for herself.

Andrew Walden was technically Adam's undergraduate trainee but I still consider him one of "my undergrads". He is a really fun guy to talk to and I enjoyed working with him in box 1 , after he got kicked out of box 3 for a water splitting project. I wish him the best of luck as he heads of to graduate school. As for the newer undergrads, it has been a pleasure to meet Victor "Vic-THOR" or "little Vic" Teran (the 
best crap-talking undergrad ever) and Mengxun "Monica" Li (the most awkward super smart person I know). Best wishes in your future.

A couple of notes to future Harman group graduates: 1) I hope that all of you achieve your goals and which you a pleasurable journey on your way to achieving them. 2) This freaking acknowledgments section has taken longer to complete and was more difficult than any other part of my writing process. Prepare accordingly.

\section{Family and Friends:}

From outside the lab, I owe many thanks to all of my family and friends. Without their undying support, I would not be the person that I am today and I would certainly not have succeeded in getting through VMI or UVa. My parents have provided both emotional and monetary support for the last twenty-seven years. They have been proponents and enablers of my education as long as I can remember. Our dogs, Oz and Gibbs, would like to thank my dad for coming to visit them and for all the times that he has dog-sitted them and spoiled them with treats. My brother is also responsible for shaping me into the person that I am. Without sharing the beginning of our lives together, I do not know who I would be, but probably an even more awkward person. I would also like to thank my mother-in-law for all of the support, open discussions that we have had, and different viewpoint that she has had to offer me. I would like to make a shout out to all of my friends. I do not have that many close friends, but I value each of them dearly. You know who you are.

Finally, I would like to thank my beautiful wife, Brittany. She has enriched my life beyond what I thought possible and exposed me to many things I would not have been 
otherwise (i.e. dogs, horses, tractors, etc.). I enjoy every day that I spend with and learning about her. You can tell she loves me because, among other things, she makes sure that I eat properly. I once made the comment that the worst thing about my marriage was that she did not allow me to eat corn as often as I want. One of my friends responded that if I thought that was worst thing about being married, then I must have a wonderful marriage. I agree and it is mostly because of her! Brittany's support has been unwavering throughout the entire process of me obtaining my Ph.D., for which I am very appreciative. I love her very much and look forward to spending the rest of our lives together. 


\section{Table of Contents}

$\begin{array}{lc}\text { Abstract } & \text { ii } \\ \text { Acknowledgements } & \text { iv } \\ \text { Table of Contents } & \text { xiii } \\ \text { List of Figures } & \text { xvii } \\ \text { List of Schemes } & \text { xxi } \\ \text { List of Tables } & \text { xxvi } \\ \text { List of Equations } & \text { xxvii } \\ \text { List of Abbreviations } & \text { xxviii }\end{array}$

Chapter 1: A Brief Introduction to the Chemistry of Pyridine

$\begin{array}{ll}\text { and its Derivatives } & 1\end{array}$

Prevalence and Properties of Pyridine 2

Chemical Modification of Pyridine 4

Piperidine Syntheses Not Utilizing Pyridine as a Starting Material 12

$\begin{array}{ll}\text { Pyridine Ring Opening } & 13\end{array}$

Organometallic Dearomatization of Pyridine 16

$\begin{array}{ll}\text { References } & 26\end{array}$ 
Chapter 2: An Efficient Synthesis of an $\eta^{2}$-Pyridine Complex and a Preliminary Investigation of the Bound Heterocycle's Reactivity

Introduction

Chapter 3: Stereo- and Regioselective Nucleophilic Addition to Dihapto-Coordinated Pyridine Complexes

Introduction

Results and Discussion

Chapter 4: Reversing the Polarization of the Pyridine Ring: Highly Functionalized 
$\begin{array}{ll}\text { Introduction } & 90\end{array}$

Results and Discussion $\quad 91$

$\begin{array}{ll}\Delta^{3} \text {-Piperidine Demetallation } & 101\end{array}$

$\begin{array}{ll}\text { Conclusions } & 104\end{array}$

$\begin{array}{ll}\text { Experimental Section } & 105\end{array}$

$\begin{array}{ll}\text { References } & 140\end{array}$

Chapter 5: Reversing the Polarization of the Pyridine: Formal [4+2] Cycloadditions with Dihydropyridine Complexes of $\left\{\mathrm{TpW}\left(\mathrm{PMe}_{3}\right)(\mathrm{NO})\right\}$ and the Generation of Tri- and

$\begin{array}{ll}\text { Tetrasubstituted Piperidines. } & 144\end{array}$

$\begin{array}{ll}\text { Introduction } & 145\end{array}$

$\begin{array}{ll}\text { Result and Discussion } & 148\end{array}$

$\begin{array}{ll}\text { Post Cyclization Modification } & 161\end{array}$

$\begin{array}{ll}\text { Oxidative Demetallation } & 164\end{array}$

$\begin{array}{ll}\text { Concluding Remarks } & 166\end{array}$

$\begin{array}{ll}\text { Experimental Section } & 168\end{array}$

$\begin{array}{ll}\text { References } & 206\end{array}$

Chapter 6: Tungsten-Promoted Pyridine Ring Scission: The Selective Formation of $\eta^{2}-$

Cyanine and $\eta^{2}$-Merocyanine Complexes and their Derivatives 213 
Introduction

Results and Discussion

Photolytic Demetallation

Conclusions

Experimental Section

References

Chapter 7: Hyper-Distorted Tungsten Allyl Complexes and their Stereoselective Deprotonation to Form Dihapto-Coordinated Dienes

Introduction

Results and Discussion

I. Stereoselective Preparation of $\eta^{2}$-diene Complexes

II. Structural Analysis of TpW(NO)(PMe $)(\pi$-allyl) complexes

III. Calculations

253

IV. Reverse-Distorted Allyl Complexes

260

V. Reduction of TpW(NO)(PMe3)(allyl) complexes

Conclusions

References 


\section{List of Figures}

\section{Chapter 1:}

Figure 1: Natural products containing the pyridine core. Compound activities are listed below their names.

Figure 2: Resonance forms and experimental data for pyridine.

Figure 3: Polarization of pyridine.

Figure 4: Summary of Comins' methodology.

Figure 5: Back-bonding and activation of exposed diene.

\section{Chapter 2:}

Figure 1: ORTEP Diagram and resonance forms of 4.

\section{Chapter 3:}

Figure 1: Electrochemical and ${ }^{31} \mathrm{P}_{-}^{183} \mathrm{~W}$ coupling data used to monitor reactions.

Figure 2: ORTEP diagrams of 18 (left) and 15 (right).

\section{Chapter 4:}

Figure 1: Enamine versus metal influence.

Figure 2: Amide rotational isomerization and chemical exchange. 
Figure 4: ORTEP diagram of tetrahydropyridine complex 23.

\section{Chapter 5:}

Figure 1: Metal umpolung of DHP complexes produce novel piperidinamides.

Figure 2: Reaction of NOB with 3, 5, and $\mathbf{8}$, selected NOESY Interactions of cycloadducts (in blue), and crystal structure of 13 .

Figure 3: [4+2] Ts-ICN cyclcoadduct synthesis, NOE interactions (blue arrows) for 14-17, and X-ray structure of 16.

Figure 4: Synthesis of electrophilic substitution products of Ts-ICN and X-tal structure of 18 (hydrogen-bonded $\mathrm{H}_{2} \mathrm{O}$ omitted).

\section{Chapter 6:}

Figure 1: Front and side-view ORTEP of 2.

Figure 2: ORTEP diagrams of the dinitrile complex $\mathbf{7}$ and enal complex $\mathbf{9}$.

\section{Chapter 7:}

Figure 1: ORTEP diagrams (30\% probability) for allyl complexes $\left[\mathrm{TpW}(\mathrm{NO})\left(\mathrm{PMe}_{3}\right)\left(\pi-\mathrm{C}_{6} \mathrm{H}_{9}\right)\right] \mathrm{OTf}, \quad 3, \quad$ and $\quad\left[\mathrm{TpW}(\mathrm{NO})\left(\mathrm{PMe}_{3}\right)(\pi-\right.$ $\mathrm{C}_{7} \mathrm{H}_{10} \mathrm{NO}$ )]OTf, $\mathbf{5}$, showing $\eta^{3} \rightarrow \eta^{2}$ distortion (OTf omitted), and the dihydropyridine complex $\operatorname{TpW}(\mathrm{NO})\left(\mathrm{PMe}_{3}\right)\left(\eta^{2}-\mathrm{C}_{7} \mathrm{H}_{9} \mathrm{NO}\right), 7 \mathbf{d}$, for comparison. 
Figure 2: ORTEP diagrams (30\% probability) of $\left[\mathrm{TpW}(\mathrm{NO})\left(\mathrm{PMe}_{3}\right)\left(\pi-\mathrm{C}_{3} \mathrm{H}_{5}\right)\right] \mathrm{OTf}$, exo-11, and $\left[\mathrm{TpW}(\mathrm{NO})\left(\mathrm{PMe}_{3}\right)\left(\pi-\mathrm{C}_{6} \mathrm{H}_{11}\right)\right] \mathrm{OTf}$, exo-12.

Figure 3: The resonance forms and crystal structures (30\% ellipsoids) of $2 \mathrm{H}$ $m$-cresol (13) and $\mathrm{N}, \mathrm{N}$-dimethyl-2H-anilinium (14) complexes.

Figure 4: LUMO for the complex $\left[\mathrm{TpW}(\mathrm{NO})\left(\mathrm{PMe}_{3}\right)\left(\text { exo- } \mathrm{C}_{3} \mathrm{H}_{5}\right)\right]^{+}$(exo-11a) showing the large contribution from the $2 p$ orbital of $\mathrm{C} 1$.

Figure 5: Reaction coordinate diagram for allyl isomerization of $\left[\mathrm{W}\left(\mathrm{NH}_{3}\right)_{5}\right.$

$$
\left.{ }_{n}(\mathrm{NO})_{n}\left(\mathrm{C}_{3} \mathrm{H}_{5}\right)\right]^{(\mathrm{n}+1)+} \text {, where } \mathrm{n}=0,1 \text {. }
$$

Figure 6: Molecular orbitals for the allyl complex $\left[\mathrm{W}\left(\mathrm{NH}_{3}\right)_{4}(\mathrm{NO})\left(\mathrm{C}_{3} \mathrm{H}_{5}\right)\right]^{2+}$.

Figure 7: Schematic representation of the mixing of the HOMO of $\left\{\mathrm{W}\left(\mathrm{NH}_{3}\right)_{4}(\mathrm{NO})\right\}^{+}\left(\mathrm{d}_{\mathrm{xy}}\right)$ with the non-bonding $\left(\pi_{\mathrm{nb}}\right)$ and antibonding $\left(\pi^{*}\right)$ orbitals of $\mathrm{C}_{3} \mathrm{H}_{5}{ }^{+}$. Better overlap of $\mathrm{d}_{x y}$ and $\pi^{*}$ is achieved by partial rotation (moving C1 toward NO).

Figure 8: $\mathrm{HOMO}$ of the fragment $\left\{\mathrm{TpW}(\mathrm{NO})\left(\mathrm{PMe}_{3}\right)\right\}$ showing the participation of the pyrazole ring trans to the phosphine (note the asymmetric $d_{x y}$ orbital). The $\pi$ orbital of the heterocycle distorts and raises the energy of the HOMO.

Figure 9: Overlap of the allyl $\pi_{\mathrm{nb}}$ and $\pi^{*}$ orbital combination with the asymmetric HOMO $\left(d_{x y}\right)$ of $\left\{\mathrm{TpW}(\mathrm{NO})\left(\mathrm{PMe}_{3}\right)\right\}$ for the two possible $\eta^{3} \rightarrow \eta^{2}$

distortions of the allyl ligand.

Figure 10: Molecular structure of the aniline dication complex, 21p. 
Figure 11: Cyclic voltammetric data for (a) $\operatorname{TpW}(\mathrm{NO})\left(\mathrm{PMe}_{3}\right)\left(\mathrm{C}_{6} \mathrm{H}_{8}\right)$ (4), (b)

$\left[\mathrm{TpW}(\mathrm{NO})\left(\mathrm{PMe}_{3}\right)\left(\mathrm{C}_{3} \mathrm{H}_{5}\right)\right]^{+}$(11), and (c) $\left[\mathrm{TpW}(\mathrm{NO})\left(\mathrm{PMe}_{3}\right)\left(\mathrm{C}_{6} \mathrm{H}_{11}\right)\right]^{+}$(12).

Values are vs. NHE at $100 \mathrm{mV} / \mathrm{s}$ scan rate. 


\section{List of Schemes}

\section{Chapter 1:}

Scheme 1: Preferential formation of pyridinium compounds rather than EAS products.

Scheme 2: Examples of EAS with pyridine.

Scheme 3: Catalytic acylation cycle.

Scheme 4: Nucleophilic aromatic substitution of pyridine.

Scheme 5: Lithium halogen exchange and palladium cross-coupling reactions of halogenated pyridines.

Scheme 6: Reduction of pyridine or pyridinium and [4+2] cycloaddition with 1,2-dihydropyridines.

Scheme 7: Regioselective $y$ addition to pyridine.

Scheme 8: Examples of piperidine compounds synthesized by Charette and Marazano.

Scheme 9: Condensation of chiral $\beta$-hydroxy amines with racemic $\gamma$-aldehydic esters and their derivatization.

Scheme 10: Enantiomerically pure natural product synthesis using a chiral molybdenum complex.

Scheme 11: Pyridine ring-opening producing conjugated systems.

Scheme 12: Strategic pyridine substituent incorporation methodology. 
Scheme 13: Delivery of penta-2,4-dienal to secondary amines for Diels-Alder to produce strychnos alkyloids.

Scheme 14: Piperidine ring-opening producing saturated amines.

Scheme 15: $\eta^{6}$ pyridine formation and reactivity.

Scheme 16: Synthesis of $\eta^{6}$-pyridine complexes of $\mathrm{Ru}^{2+}$.

Scheme 17: $M o(0)$ synthesis of $\eta^{6}$ pyridine.

Scheme 18: $\eta^{2}$ complexes of $\mathrm{Nb}$ and Ta.

Scheme 19: Modification of pyridine ring with niobium complexation.

Scheme 20: $C-C \eta^{2}$ coordination with pyridines or pyridiniums.

Scheme 21: Substitution of pyridines with $\operatorname{TpW}(\mathrm{NO})\left(\mathrm{PMe}_{3}\right)\left(\eta^{2}\right.$-benzene).

Scheme 22: Isolation of $\eta^{2}$ pyridinium complex.

Scheme 23: [4+2] Diels-Alder cycloadditions with $\eta^{2}$-coordinated pyridines.

Scheme 24: Liberation of new organic compounds from cycloadduct complexes.

Scheme 25: Synthesis and isolation of an organic in an enantiomeric excess.

\section{Chapter 2:}

Scheme 1: Synthetic strategies.

Scheme 2: Improved Synthesis of Pyridinium $\mathbf{3 H}$.

Scheme 3: Tandem Addition of Acetone (30\% ellipsoids).

Scheme 4: Aza-Friedel-Crafts and Baylis-Hillman Reactions. 


\section{Chapter 3:}

Scheme 1: Synthetic Strategy.

Scheme 2. Electrophilic substitution at nitrogen.

Scheme 3: Reactivity screening of pyridinium compounds. 60

Scheme 4: Scope of nucleophilic additions to 6.65

\section{Chapter 4:}

Scheme 1: Two Pathways from a Pyridinium Complex to $\Delta^{3}$-Piperidines. $\quad 90$

Scheme 2: Broad Scope of Nucleophilic Addition to Acetylpyridinium 1. 91

Scheme 3: Deuteration of Dihydropyridine complex 3. 95

Scheme 4: Formation of the Reisert-like Allyl Complex 13.

Scheme 5: Stereoselective Nucleophilic Addition to C3. 98

Scheme 6: Stereoselective Nucleophilic Addition to C5. 99

Scheme 7: Elaboration of the Reissert-like Allyl Complex 13. 100

Scheme 8: Organic Products Recovered from Tetrahydropindine Complexes. $\quad 103$

\section{Chapter 5:}

Scheme 1: Synthesis of DHP complexes.

Scheme 2: MVK addition of $\mathbf{2}$ and key NOE interactions (in blue) for the major species.

Scheme 3: Electrophilic substitution with TCA-NCO. 
Scheme 5: Synthesis of $\mathbf{2 5}$ and nucleophilic deprotonation of $\mathbf{2 5 .}$

Scheme 6: Deprotonation of $\mathbf{2 6}$ to produce DHP $\mathbf{2 7}$ and X-ray structure of $27 . \quad 163$

Scheme 7: Nucleophilic addition to 26.

Scheme 8: Liberation of azabicyclooctene, diazabicyclooctane, and carboxamoyl piperidinamides.

\section{Chapter 6:}

Scheme 1: Indoline and malononitrile ring scission of 1.

Scheme 2: Addition of pyrroles to 1.

Scheme 3: Ring scission of 3.

\section{Chapter 7:}

Scheme 1: Enantioselective functionalization of cyclohexadiene.

Scheme 2: Synthesis of 6-membered cyclic allyl complexes.

Scheme 3: Stereoselective synthesis of $\eta^{2}$-cyclohexadiene complexes.

Scheme 4: Synthesis of $\mathbf{5}$ and its stereoselective nucleophilic addition and deprotonation.

Scheme 5: Synthesis of allyl complexes 11 and 12.

Scheme 6: Protonation and ${ }^{13} \mathrm{C} N M R$ chemical shift data for arenium complexes of osmium. 
Scheme 7: Expected distortion effects of donating $(X)$ and withdrawing $(Z)$ groups. The $\eta^{3} \rightarrow \eta^{2}$ distortion is enhanced by either a $\pi$-donor or $\pi$ acceptor at the distal carbon (Circle represents $\mathrm{p}$ orbital).

Scheme 8: Protonation results in a $\pi$-withdrawing group in conjugation with the allyl group.

Scheme 9: Reduction and manipulation of allyl 12.

\section{Chapter 8:}

Scheme 1: Modification of Pyridine with $\left\{\mathrm{TpW}(\mathrm{NO})\left(\mathrm{PMe}_{3}\right)\right\}$.

Scheme 2: Metal Re-Polarization of Pyridine Leading to the Isolation of Several Classes of Piperidines. 


\section{List of Tables}

\section{Chapter 3:}

Table 1: Properties of tungsten pyridine complexes.

\section{Chapter 7:}

Table 1: Experimental and [calculated] bond lengths for $\eta^{3}$-allyl and $\eta^{2}$ alkene complexes of the form $\mathrm{TpW}(\mathrm{NO})\left(\mathrm{PMe}_{3}\right)(\mathrm{L})$.

Table 2: Experimental and [calculated] bond lengths for "reverse-distorted" $\eta^{2}$-allyl complexes derived from aniline and phenol.

\section{Chapter 8:}

Table 1: Relative stereochemistry of piperidine substituents produced by selected research groups. 


\section{List of Equations and Insets}

Chapter 1:

Chapter 2:

Chapter 3:

54,

61

Chapter 6:

221,

222

Chapter 7:

239,

246,

247,

253 


\section{List of Abbreviations}

\begin{tabular}{|c|c|}
\hline CAN & Ceric ammonium nitrate \\
\hline $\mathrm{cd}$ & Coordination diasteriomer \\
\hline$c d r$ & Coordination diasteriomer ratio \\
\hline $\mathrm{Cp}$ & Cyclopentadienyl (Cyclopentadienide anion) \\
\hline$C p^{*}$ & Pentamethylcyclopentadienyl (Pentamethylcyclopentadienide anion) \\
\hline$d$ & Distal \\
\hline DABCO & 1,4-Diazabicyclo[2.2.2]octane \\
\hline DBU & 1,8-Diazabicyclo[5.4.0]undec-7-ene \\
\hline DCM & Dichloromethane \\
\hline DDQ & 2,3-Dichloro-5,6-dicyano-1,4-benzoquinone \\
\hline DMA & N,N-Dimethylacetamide \\
\hline DMAD & Dimethyl acetylenedicarboxylate \\
\hline DMAP & Dimethylaminopyridine \\
\hline DME & 1,2-dimethoxyethane \\
\hline DME & 1,2-Dimethoxyethane (Ethylene glycol dimethyl ether) \\
\hline DMF & $\mathrm{N}, \mathrm{N}$-Dimethylformamide \\
\hline DPhAT & Diphenyl ammonium triflate \\
\hline DTBP & 2,6-di-tert-butylpyridine \\
\hline EA & Elemental analysis \\
\hline ESI & Electrospray ionization \\
\hline $\mathrm{Et}_{2} \mathrm{O}$ & Diethyl ether \\
\hline EtOAc & Ethyl acetate \\
\hline
\end{tabular}




\begin{tabular}{|c|c|}
\hline EVK & Ethyl vinyl ketone \\
\hline HATR & Horizontal attenuated total reflectance \\
\hline IR & Infrared \\
\hline $\mathrm{KTp}$ & Potassium hydridotris(pyrazolyl)borate \\
\hline LiDMM & lithium dimethylmalonate \\
\hline maj & Major \\
\hline $\mathrm{MeCN}$ & Acetonitrile \\
\hline $\mathrm{MeNO}_{2}$ & Nitromethane \\
\hline $\mathrm{MgSO}_{4}$ & Magnesium sulfate \\
\hline $\min$ & Minor \\
\hline MMTP & Methyl trimethylsilyl dimethylketene acetal \\
\hline MS & Mass Spectrometry \\
\hline MVK & Methyl vinyl ketone \\
\hline $\mathrm{Na}_{2} \mathrm{SO}_{4}$ & Sodium sulfate \\
\hline $\mathrm{NEt}_{3}$ & Triethyl amine \\
\hline NHE & Normal hydrogen electrode \\
\hline NMM & $N$-Methylmaleimide \\
\hline NMR & Nuclear magnetic resonance \\
\hline NOB & Nitrosobenzene \\
\hline NOE & Nuclear Overhauser effect \\
\hline NOP & Nitrosopyridine \\
\hline NPM & $N$-phenyl meemememmeeaide \\
\hline ORTEP & Oak Ridge Thermal Ellipsoid Program \\
\hline OTf & Trifluoromethanesulfonate (Triflate) anion \\
\hline
\end{tabular}




$\begin{array}{ll}\mathrm{p} & \text { Proximal } \\ \mathrm{PB} & \text { Pyridine borane } \\ \mathrm{PMe}_{3} & \text { Trimethylphosphine } \\ \text { POV-Ray } & \text { Persistence of Vision Raytracer; used to make spiffy X-ray structure images } \\ \text { pz } & \text { A pyrazole group in hydridotris(pyrazolyl)borate } \\ \text { TBAH } & \text { Tetrabutylammonium hexafluorophosphate } \\ \text { TCA-ICN } & \text { Trichloroacetyl isocyanate } \\ \text { Tf }{ }_{2} \mathrm{O} & \text { Trifluoromethanesulfonic anhydride } \\ \text { THF } & \text { Tetrahydrofuran } \\ \text { TLC } & \text { Thin layer chromatography } \\ \text { TMS } & \text { Trimethylsilyl } \\ \text { Tp } & \text { Hydridotris(pyrazolyl)borate anion } \\ \text { Ts-ICN } & p \text {-Toluenesulfonyl isocyanate } \\ \end{array}$


Chapter 1

A Brief Introduction to the Chemistry of

Pyridine and its Derivatives 


\section{Prevalence and Properties of Pyridine:}

Heterocycles and their derivatives are found in numerous naturally occurring organic compounds and are commonly biologically active. Therefore, heterocycles attract a lot of attention from the synthetic chemistry community. Pyridines, a large class of aromatic heterocycles, is no exception. Nicotine, ${ }^{1}$ epibatidine, ${ }^{2}$ and anabasine ${ }^{3}$ are a few selected examples of natural products incorporating six-membered rings containing nitrogen (Figure 1). Other attractive attributes of pyridines include their commercial availability, often in large quantities, at a low cost, and their utility as highboiling basic solvents. ${ }^{4}$

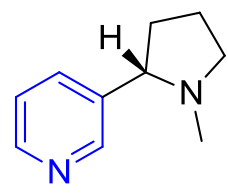

Nicotine (Stimulant)

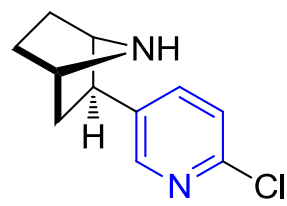

Epibatidine (Powerful analgesic)<smiles>c1cncc(C2CCCCN2)c1</smiles>

Anabasine (Teratogen)

Figure 1: Natural products containing the pyridine core. Compound activities are listed below their names.

Pyridines contain three double bonds. Given the right mindset and tools, these sites of unsaturation can be thought of as ideal starting materials to serve as the foundation of larger scaffolds of the saturated forms of pyridine, known as piperidines (Eqn. 1). Selective saturation of these sites has the potential to produce compounds 
resembling natural products or provide access to entirely new chemical space, both of which have potential to produce biologically-active compounds.<smiles>c1ccncc1</smiles>

Pyridine

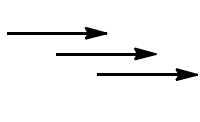

There are several barriers preventing mild modification and selective saturation of pyridine. First, pyridine is affected by a special resonance stability known as aromaticity. This special stabilization occurs when three or more conjugated double bonds are oriented in a cyclic structure containing $(4 n+2) \pi$ electrons, where $n=0$ or natural numbers. The atomic bond lengths and ${ }^{1} \mathrm{H}$ NMR chemical shifts of pyridine (and other aromatic systems) are affected by aromatic stabilization (Figure 1). For example, instead of possessing bonds of distinct single or double bond character, pyridine bonds are all of intermediate length. Also, ${ }^{1} \mathrm{H}$ NMR chemical shifts for protons at the three and four position of pyridine are significantly shifted downfield in ${ }^{1} \mathrm{H}$ NMR relative to that of unconjugated alkenes ( $\sim 5-6 \mathrm{ppm}$ ) due to an anisotropic effect. ${ }^{5,6}$ The ${ }^{1} \mathrm{H}$ chemical shift for $\mathrm{H} 2$ is largely unaffected by aromaticity, as it is a typical chemical shift for aldimines. The differences observed in bond length and chemical shifts indirectly imply that the reactivity of pyridine should be quite different than that of its isolated functional groups. 


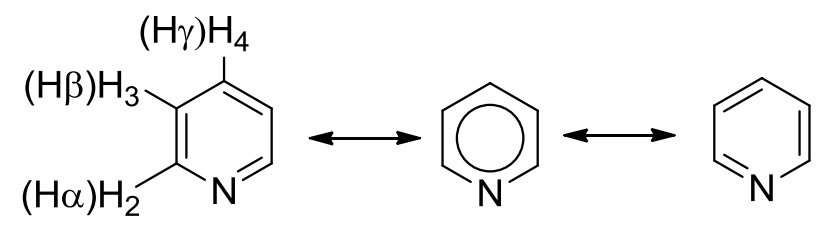

\begin{tabular}{|c|c|c|c|c|c|c|}
\hline \multicolumn{3}{|c|}{ Bond Lengths } & \multirow{2}{*}{\multicolumn{2}{|c|}{${ }^{1} \mathrm{H} \delta$ (ppm) }} & \multirow{2}{*}{\multicolumn{2}{|c|}{${ }^{13} \mathrm{C} \delta(\mathrm{ppm})$}} \\
\hline Standard & Pyridine & & & & & \\
\hline C-N: 1.47 & $\mathrm{~N}-\mathrm{C} 2:$ & 1.34 & $\mathrm{H} 2$ & 8.62 & $\mathrm{C} 2$ & 149.9 \\
\hline $\mathrm{C}=\mathrm{N}: 1.28$ & C2-C3: & 1.38 & H3 & 7.29 & C3 & 123.8 \\
\hline $\begin{array}{l}C-C: 1.53 \\
C=C: 1.33\end{array}$ & C3-C4: & 1.38 & $\mathrm{H} 4$ & 7.68 & C4 & 136.0 \\
\hline
\end{tabular}

Figure 2: Resonance forms and experimental data for pyridine.

Chemical shifts in $\mathrm{CDCl}_{3} .{ }^{5,6}$

\section{Chemical Modification of Pyridine:}

In most cases modification of the pyridine ring, requires aromatic stabilization to first be broken, or temporarily disrupted (Note: one example of an exception to this general statement is ortho-lithiation of pyridine; vide infra). With regard to electrophilic aromatic substitution $\left(S_{E} A r\right)$, this is even more difficult to do for pyridine relative to its carbocycle congener, benzene, due to the inductive effect of nitrogen reducing the overall electron density of the system. The second barrier to activation of pyridine results from the orthogonal lone pair of electrons on the nitrogen. These electrons preferentially react with electrophiles to generate pyridinium compounds, rather than 
allowing electrophiles to react directly with the aromatic $\pi$ system under strongly electrophilic conditions (Scheme 1).

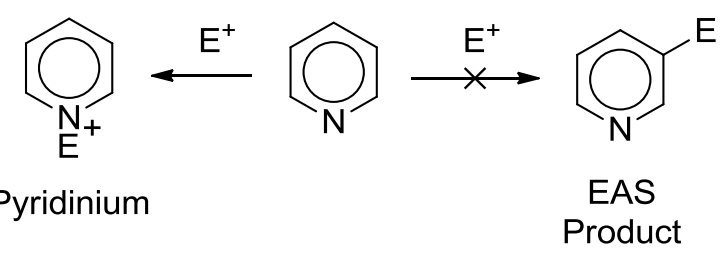

Scheme 1: Preferential formation of pyridinium compounds rather than $S_{E} A r$ products.

It is not unheard of that pyridine carbon atoms undergo $S_{E} A r$, but quite harsh reaction conditions are needed to effect these reactions. $S_{E} A r$ reactions of pyridine are hampered by the kinetic formation of $N$-subtituted pyridinium species with electrophiles. For example, heating $\mathrm{Cl}_{2}$ or $\mathrm{Br}_{2}$ with $\mathrm{AlCl}_{3}$ or in fuming sulfuric acid, respectively, can induce $S_{E} A r$ halogenation. ${ }^{7}$ Alternatively, mercuration or nitration $S_{E} A r$ can be achieved by heating with $\mathrm{Hg}(\mathrm{OAc})_{2}$ and $\mathrm{NaCl}(\mathrm{aq}), \mathrm{KNO}_{3}$ and $\mathrm{H}_{2} \mathrm{SO}_{4}$, or $\mathrm{HNO}_{3}$ and $\mathrm{Na}_{2} \mathrm{~S}_{2} \mathrm{O}_{5}{ }^{8-10}$

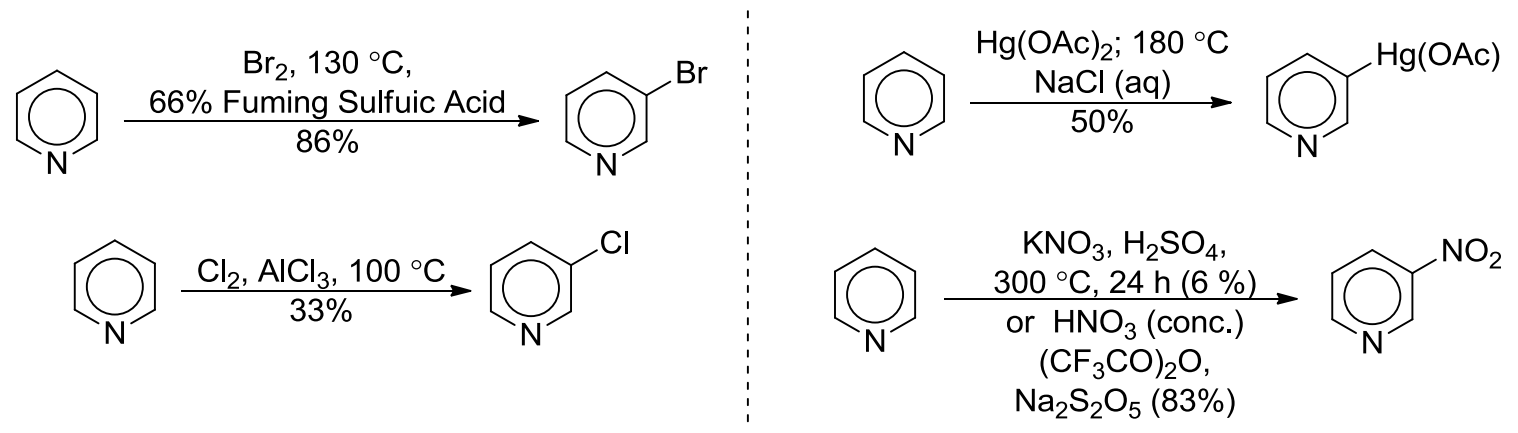

Scheme 2: Examples of $S_{E} A r$ with pyridine. 
When electrophiles perform $S_{E} A r$ reactions at carbon, addition occurs $\beta$-to-N. Because nitrogen is the most electronegative element in pyridine, electron density is stabilized on the nitrogen and polarizes the ring such that carbons $\beta$-to- $\mathrm{N}$ are nucleophilic while carbon atoms $\alpha$ and $\gamma$-to- $\mathrm{N}$ are electrophilic (Figure 3).

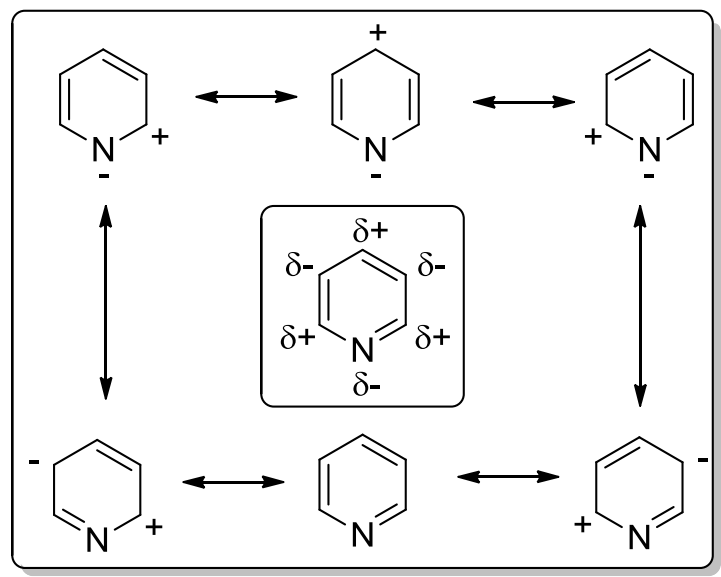

Figure 3: Polarization of pyridine.

One of the most common uses for pyridine, ${ }^{11}$ and more so for $4-\mathrm{N}, \mathrm{N}-$ dimethylaminopyridine (4-DMAP), ${ }^{12,13}$ is catalytic acylation of amines and alcohols with acetic anhydride (Scheme 3). Pyridines are better nucleophiles than alcohols and serve to displace the acetate group and activate the acyl group to weaker nucleophiles. Pyridine then acts as a better leaving group and activates the acyl group by producing a more electrophilic carbon in a charged intermediate (i.e. the $\mathrm{C}=\mathrm{O}$ of the acylpyridinium). This cycle is facile because pyridine's aromaticity is maintained, making it difficult for mild nucleophiles to react with the pyridine throughout the catalytic process. 


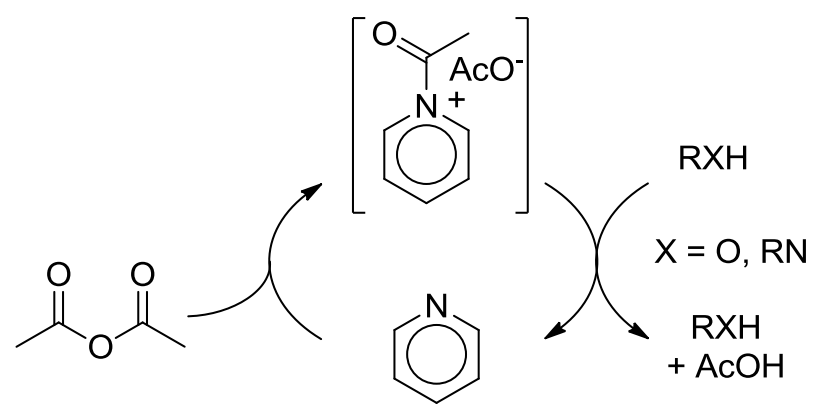

Scheme 3: Catalytic acylation cycle.

Nucleophilic aromatic substitution reactions with strong nucleophiles such as Grignard reagents occur at $\alpha$ and $\gamma$ positions of the pyridine ring to produce varying mixtures of regioisomeric products (Scheme 4). Addition to these positions allows the most electronegative element, nitrogen, to stabilize the anionic charge until such time that an anionic leaving group can be lost. When substituents are incorporated into the pyridine that can act as leaving groups (i.e. halogens), nucleophilic aromatic substitution becomes more facile and can even occur at the $\beta$ position, although the rate of deprotonation is slower than that of $\alpha$ and $\gamma$ leaving groups. ${ }^{4,14,15}$

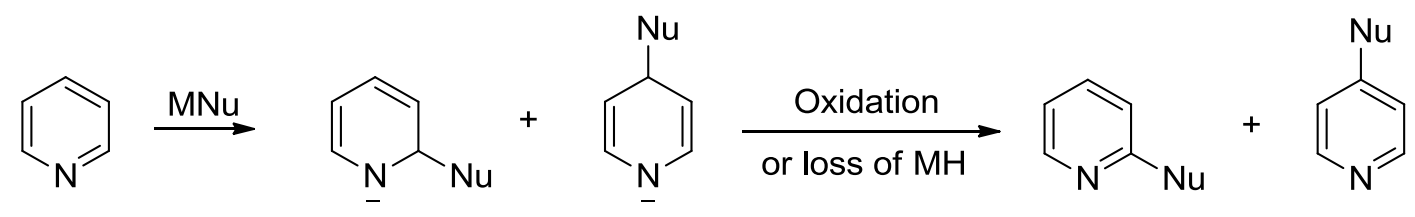

Scheme 4: Nucleophilic aromatic substitution of pyridine.

Additional methodologies that are capable of modifying pyridine while maintaining its aromaticity include lithium halogen exchange and palladium cross- 
coupling reactions (Scheme 5). ${ }^{16}$ Both of these methodologies change the nature of the carbon atom formerly attached to the halogen from being susceptible to nucleophilic attack, to itself effectively being a nucleophile. These conditions can be utilized to add electrophiles $\alpha$-to- $N$, which is difficult otherwise.

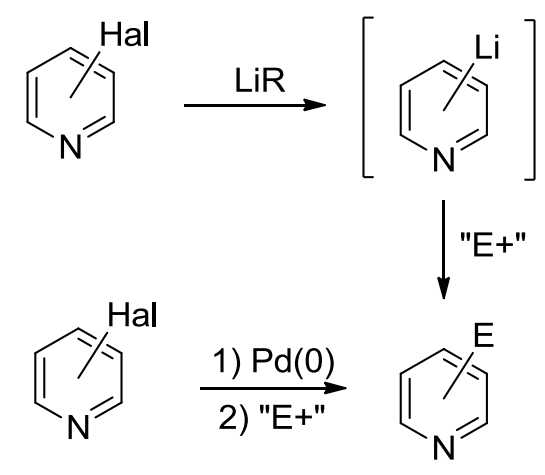

Scheme 5: Lithium halogen exchange and palladium cross-coupling reactions of halogenated pyridines.

Disruption of pyridine's (and more easily, pyridinium's) aromaticity by organic methods can be achieved by reduction of the pyridine ring with $\mathrm{H}_{2}$ or $\mathrm{H}^{-}$sources to generate semi-saturated or saturated pyridines, in some cases enantioselectively (Scheme 6). ${ }^{4,14,17-21}$ When electron-rich 1,2-dihydropyridines are produced, they can undergo [4+2] Diels-Alder cycloadditions. ${ }^{22-27}$ 


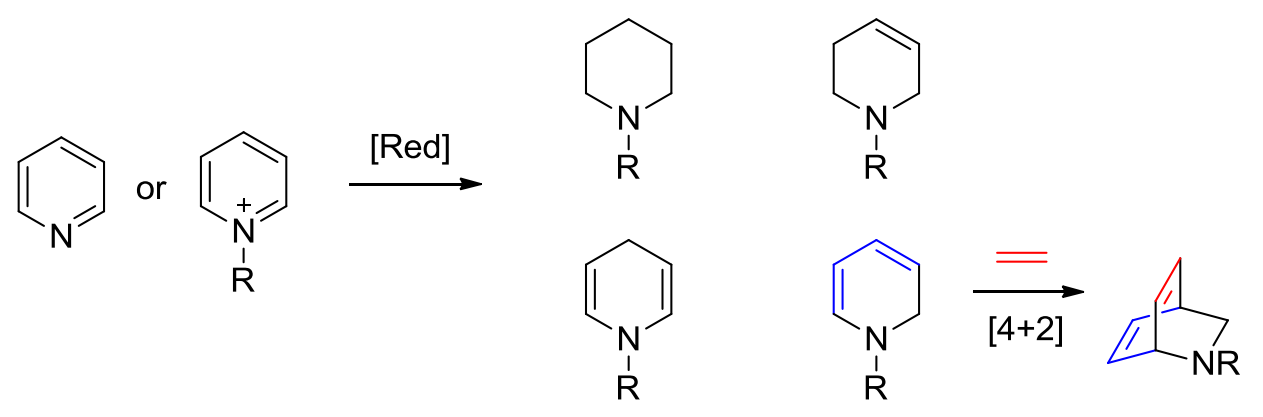

Scheme 6: Reduction of pyridine or pyridinium and

[4+2] cycloaddition with 1,2-dihydropyridines.

Other methods of dearomatization include nucleophilic addition to pyridine or acyl-pyridinium salts. As mentioned above, nucleophilic addition to pyridine often results in regiosomeric mixtures of $\alpha$ and $\gamma$ addition compounds. Some methodologies involving additives (e.g. triflic anhydride) $)^{28}$ or directing groups (e.g. OMe, TMS $)^{29}$ have been employed to effect regioselective $\alpha$ or $\gamma$ nucleophilic addition.

One of the rare cases of regioselective addition at the $\psi$ position of pyridine was reported in $2005 .^{28}$ When triflic anhydride, pyridine, and electron-rich arenes (or heterocycles) are mixed together at low temperature $\left(-30^{\circ} \mathrm{C}\right)$, exclusive nucleophilic addition at the $\gamma$ position occurs within 30 minutes (Scheme 7). When allyl tributyl tin was used as a nucleophile, a 2:3 mixture of 1,2- and 1,4-addition products was observed, while solely 1,2-addition product was isolated when a ${ }^{-} \mathrm{CN}$ source was used. These results indicate that selective 1,4-dihydropyridines synthesis with $\mathrm{Tf}_{2} \mathrm{O}$ is limited to electron-rich aromatic compounds but not for other mild nucleophiles. Oxidation proceeded quantitatively to generate 4-substituted pyridines. 


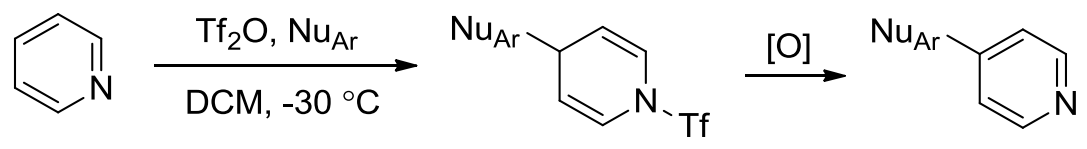

Scheme 7: Regioselective $\gamma$ addition to pyridine.

Alternatively, dearomatization methodologies that produce selective $\alpha$ nucleophilic addition of pyridinium salts have been more thoroughly explored. In particular, the Comins group has utilized 3-trialkylsilyl-4-methoxypyridine (alkyl = methyl or isopropyl) as a versatile starting material (Figure 4). ${ }^{29}$ The methoxy and silyl groups both serve to sterically prevent nucleophilic addition at the $\gamma$ position and one of the $\alpha$ positions of the pyridine ring, leaving only one position of the pyridine ring accessible to nucleophilic addition. When a chiral chloroformate group is used to generate the $\mathrm{N}$ acylpyridiniums salts of Comins' pyridines, nucleophilic addition (with Grignards, zinc enolates, etc.) thus becomes regio- and stereoselective at the $\alpha$ position of pyridine. Hydrolysis of the methoxy substituent and removal of silyl groups generates a wide range of very useful starting materials that have led to the elegant enantiomerically pure syntheses of more than 40 natural products. ${ }^{30}$

Utilizing a similar but, as of yet, less developed strategy to Comins, Charette ${ }^{31}$ and Marazano ${ }^{32,33}$ have utilized chiral pyridinium salts as starting materials to develop fairly complex enantiomerically enriched piperidine compounds (Scheme 8). 

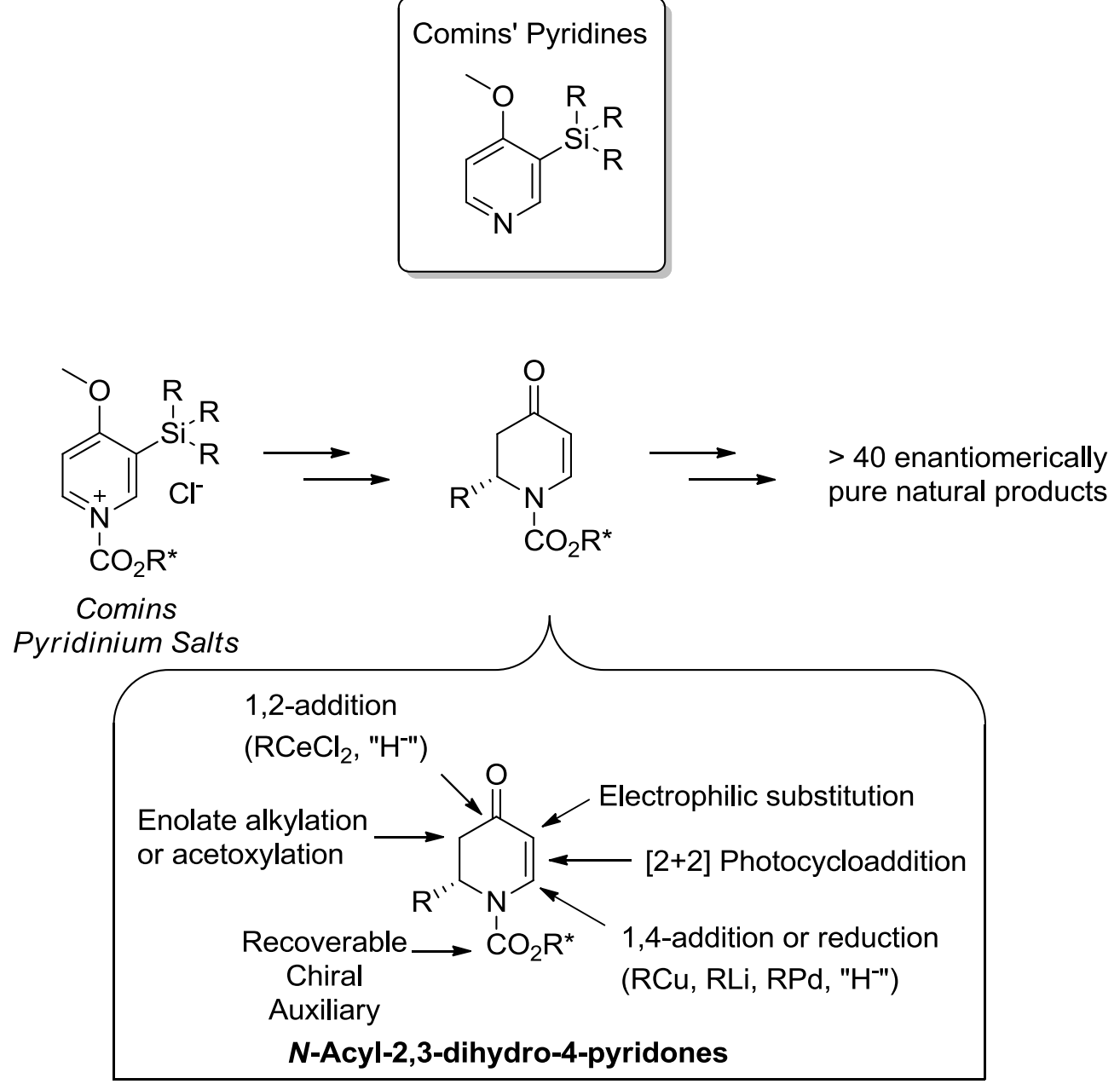

Figure 4: Summary of Comins' methodology.

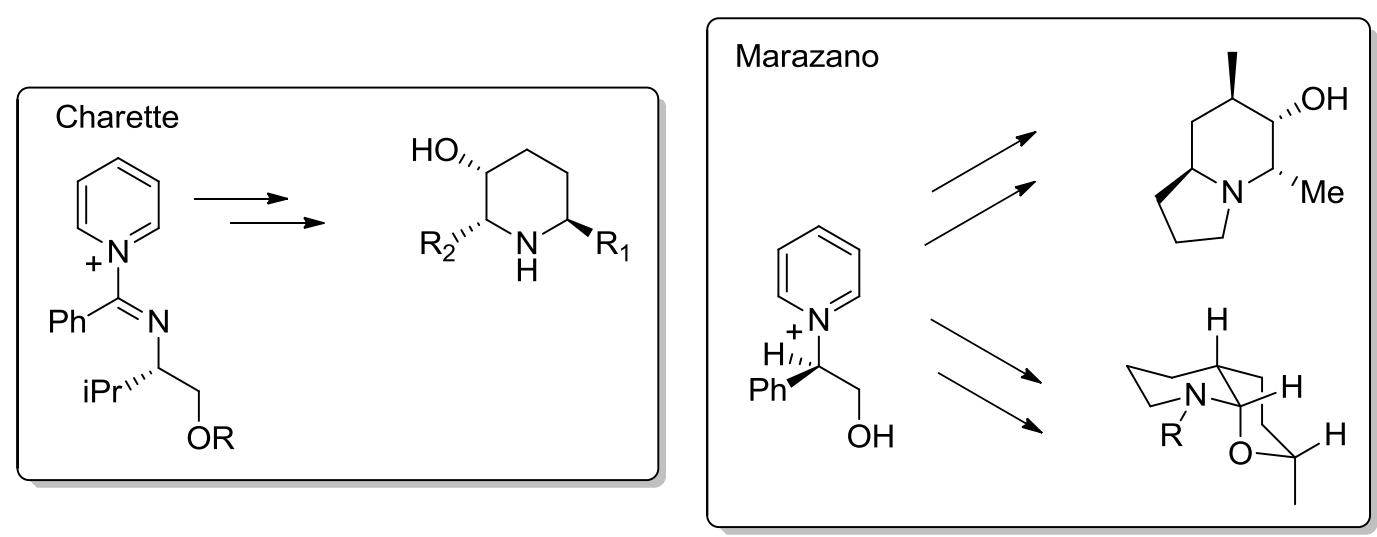

Scheme 8: Examples of piperidine compounds synthesized by Charette and Marazano. 


\section{Piperidine Syntheses Not Utilizing Pyridine as a Starting Material:}

Although pyridine is not utilized as the starting materials in reactions developed by Mercedes Amat and Joan Bosch at the University of Barcelona, their work toward the synthesis of enantiomerically pure piperidine compounds is noteworthy. Their strategy utilizes the condensation of chiral $\beta$-hydroxy amines with racemic $\gamma$-aldehydic esters to generate hydropyridinones that can be converted into a multitude of piperidines containing different structural motifs (Scheme 9). ${ }^{34-37}$

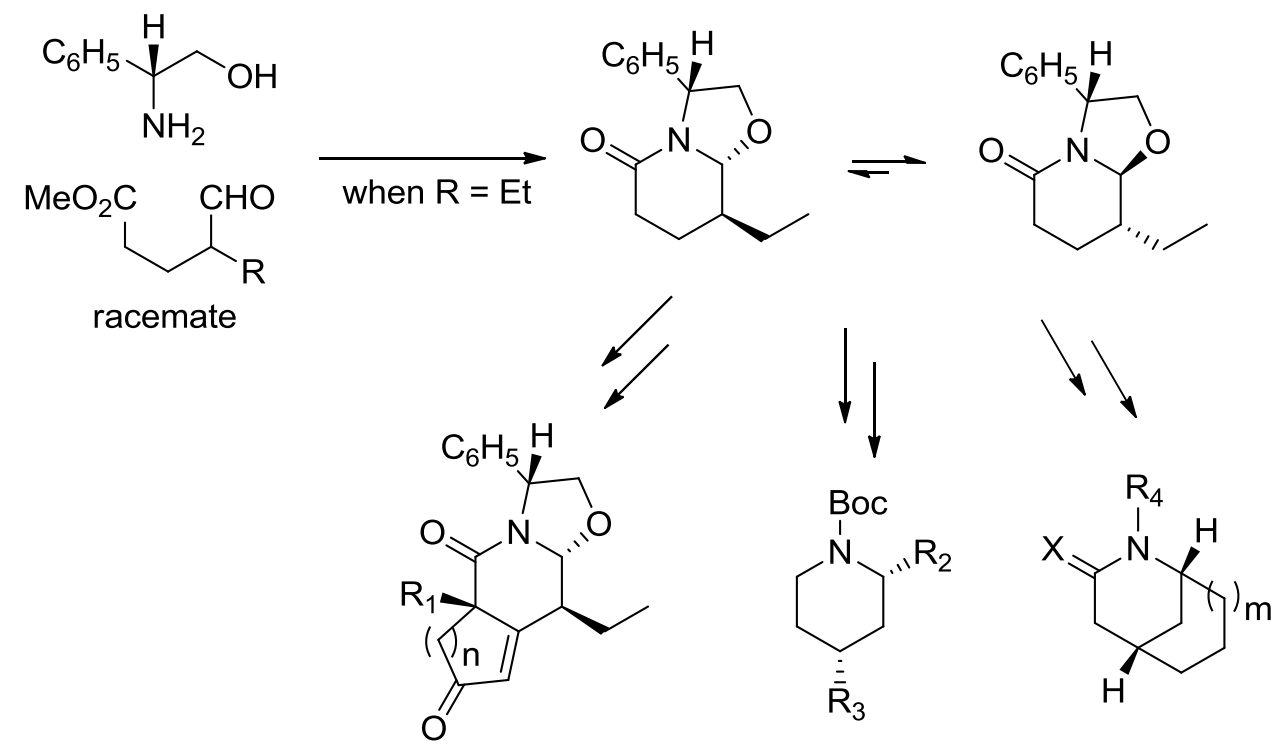

Scheme 9: Condensation of chiral $\beta$-hydroxy amines with racemic $\gamma$-aldehydic esters and their derivatization.

The Liebeskind group has recently developed a large scale synthesis of enantioenriched piperidinyl molybdenum complexes, derived from an aza-Achmatowicz rearrangement of furans (Scheme 10). Already, this starting material has produced a 
number of enantiomerically pure natural products and holds great promise as a useful starting material for even more enantiomerically pure piperidine compounds. ${ }^{38}$

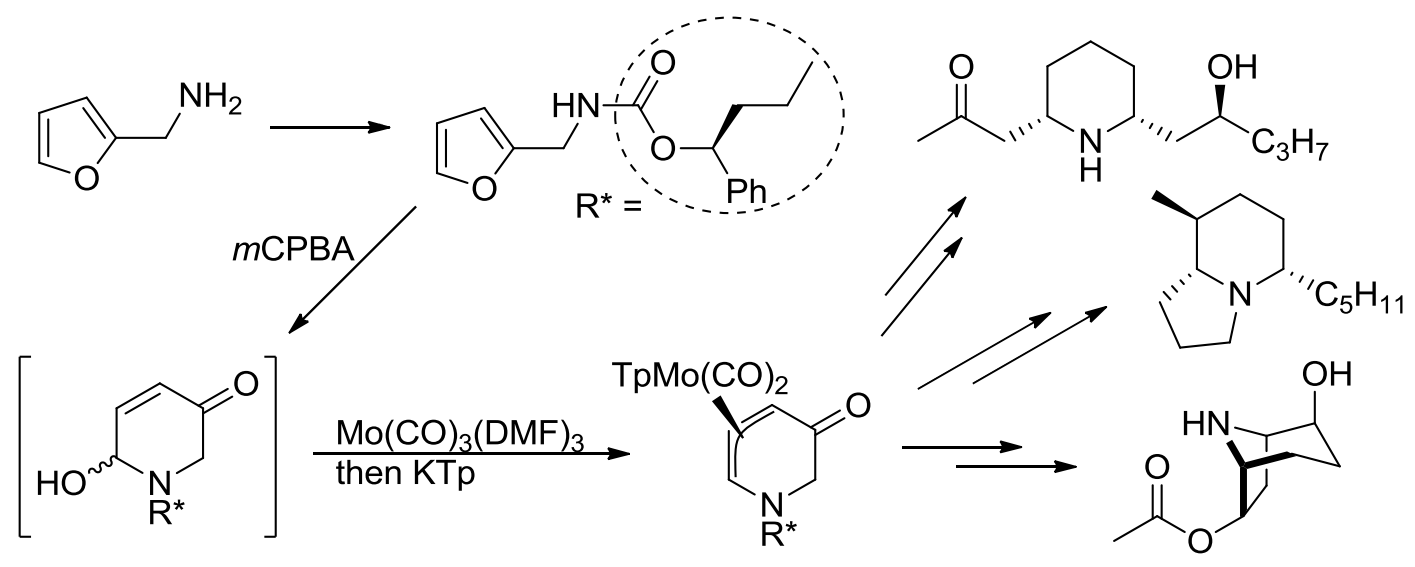

Scheme 10: Enantiomerically pure natural product synthesis using a chiral molybdenum complex.

\section{Pyridine Ring Opening:}

Pyridines are also subject to ring opening reactions. A useful starting material in the synthesis of linearly conjugated ring-opened systems is 1-(2,4dinitrophenyl)pyridinium chloride. ${ }^{39}$ When the salt is heated in the presence of a secondary amine in methanol, ring-scission occurs and produces intensely colored compounds (Scheme 11). These reactions are facile especially when the resulting ringopened organic cations offer extended conjugation beyond that of the original six $p$ orbitals of the parent pyridine. 


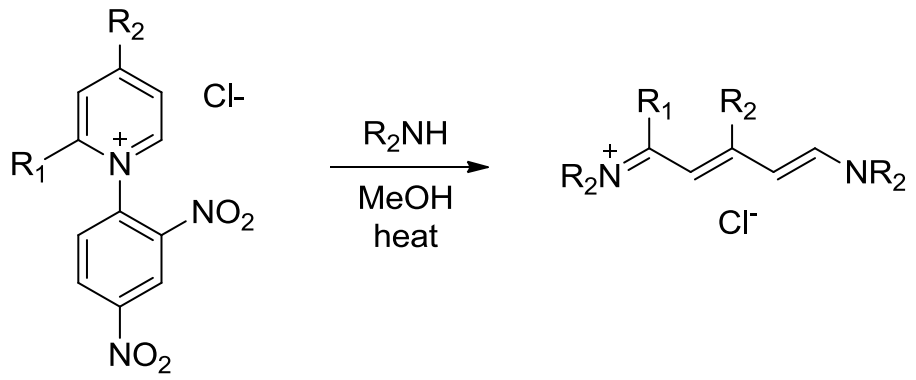

Scheme 11: Pyridine ring-opening producing conjugated systems.

Recently, the Vanderwal group has begun to utilize pyridine ring opening to develop complex products. One strategy directly incorporates key substituents and functional groups into the pyridine ring to set the stage for downstream reactions (Scheme 12). Arylation of the substituted pyridines with 2,4-dinitrochlorobenzene followed by ring opening and aqueous basic workup produces Zinche aldehydes. Natural products porothramycins $A$ and $B$ have been concisely synthesized in the described manner. ${ }^{40}$ Tying a stannylation/Stille coupling procedure to this strategy has allowed for the synthesis of polyunsaturated aldehydes. ${ }^{41}$ Also utilizing the same strategy, substituted polycyclic lactams can be synthesized very rapidly as well. ${ }^{42}$ An alternative strategy utilizes 1-(2,4-dinitrophenyl)pyridinium chloride to deliver a penta-2,4-dienal to secondary amines, which sets the stage for Diels-Alder cycloaddition reactions (Scheme 13). This strategy has been utilized in the very concise synthesis of strychnine and the strychnos alkyloids. $^{43,44}$ 

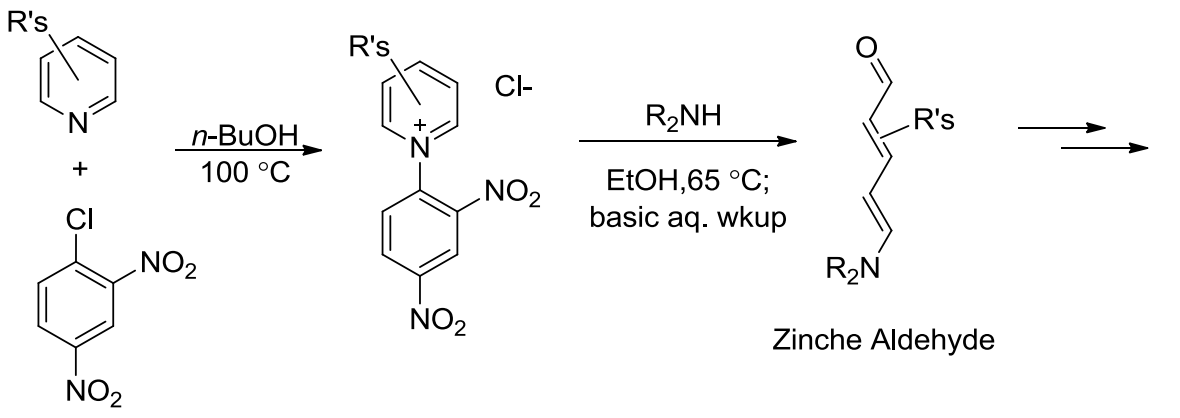

Porothramycins

Polyunsaturated aldehydes

Polycyclic lactams

Zinche Aldehyde

Scheme 12: Strategic pyridine substituent incorporation methodology.<smiles>O=[N+]([O-])c1ccc(-[n+]2ccccc2)c([N+](=O)[O-])c1</smiles><smiles>[R]NCCC</smiles><smiles>[R]N([R2])/C=C\C=C/C=O</smiles><smiles>C#CCCC</smiles>

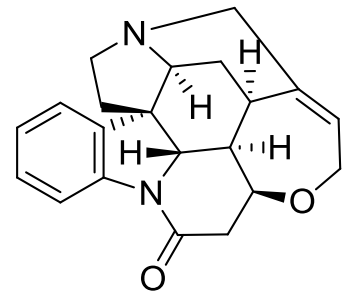

Strychnine

Scheme 13: Delivery of penta-2,4-dienal to secondary amines for Diels-Alder to produce strychnos alkyloids.

Alternatively, saturated ring-opened enantiomerically pure amines can be produced starting from Comins' pyridine or 4-methoxypyridine. ${ }^{45-47}$ Conversion to piperidines followed by treatment with cyanogen bromide opens the piperidines under a von Braun type ring-opening mechanism (Scheme 14).

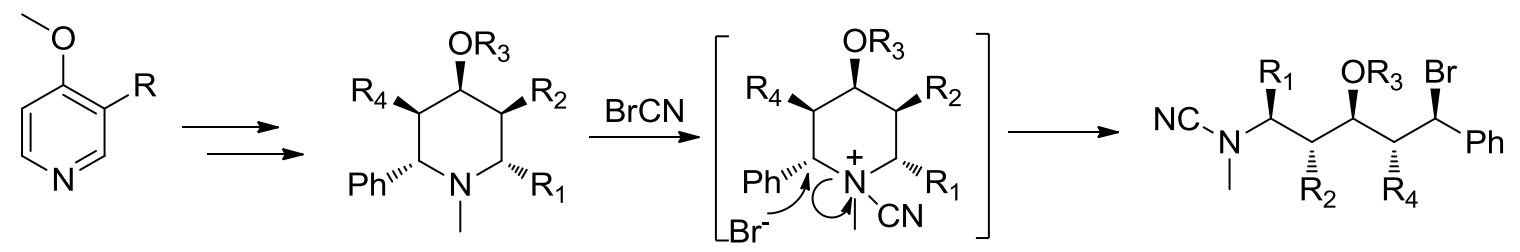

Scheme 14: Piperidine ring-opening producing saturated amines. 


\section{Organometallic Dearomatization of Pyridine:}

Pyridine's primary binding mode with most transition metal complexes is through nitrogen ( $\mathrm{k}^{1}$ or $\left.\mathrm{kN}\right)$, much like its tendency to react with organic electrophiles. However, several $\eta^{6}$ complexes and recently more $\eta^{2}$ complexes have been synthesized. Although $\eta^{6}$-pyridine complexes of $\operatorname{Cr}(0), \operatorname{Mo}(0)$, and $\operatorname{Re}(I)$ can be synthesized (vide infra), very little is known or reported about their transformation into organic compounds.

Formation of $\eta^{6}$-pyridine complexes can be accomplished by using electrondeficient metal fragments, usually in combination with one or two $\alpha$ substituents that flank the nitrogen, to sterically hinder nitrogen coordination. For example, $\eta^{6}$-pyridine complexes with the Lewis acidic metal fragment $\left\{\mathrm{Cr}(\mathrm{CO})_{3}\right\}$ can be synthesized by substitution of 2,6-bis(trimethylsilyl)pyridine or 2,6-lutidine for three CO ligands of $\mathrm{Cr}(\mathrm{CO})_{6}$ (Scheme 15). ${ }^{48-50}$ Removal of the trimethylsilyl groups can be accomplished with TBAF and allows for the isolation of the unsubstituted $\eta^{6}$ pyridine complex, $(\mathrm{CO})_{3} \mathrm{Cr}\left(\eta^{6}-\right.$ pyridine). ${ }^{49} \mathrm{~A}$ limited investigation into the reactivity of the complex revealed that the coordinated pyridine mirrors that of the free ligand, in which nucleophiles add to the 2position of the ring followed by electrophilic addition to the nitrogen to generate 1,2dihydropryidines. ${ }^{50}$ The complete regio and stereoselectivity of the coordinated ligand does contrast that of pyridine though, which often affords isomeric mixtures (vide supra).

Ruthenium(II) complexes are also capable of $\eta^{6}$ coordination of pyridine (Scheme 16). Anion metathesis of $[\mathrm{Cp} * \mathrm{RuCl}]$ with $\mathrm{KPF}_{6}$ in the presence of pyridine, ${ }^{51}$ or 
substituted pyridines, allows for their $\eta^{6}$ coordination. ${ }^{52}$ Also, precoordination of substituted pyridines with $\left\{\mathrm{CpRu}(\mathrm{MeCN})_{3}{ }^{+}\right\}$produces a $\mathrm{k}^{1}$ species. Ejection of the acetonitrile ligands, opens coordination sites and allows for substituted pyridines to increase their hapticity. This method has not been reported to work for pyridine with $\left\{\mathrm{CpRu}(\mathrm{MeCN})_{3}{ }^{+}\right\}$, but switching cyclopentadienide to permethylcyclopentadienide does allow for the isolation of the $\eta^{6}$-coordinated pyridine species. ${ }^{53,54}$
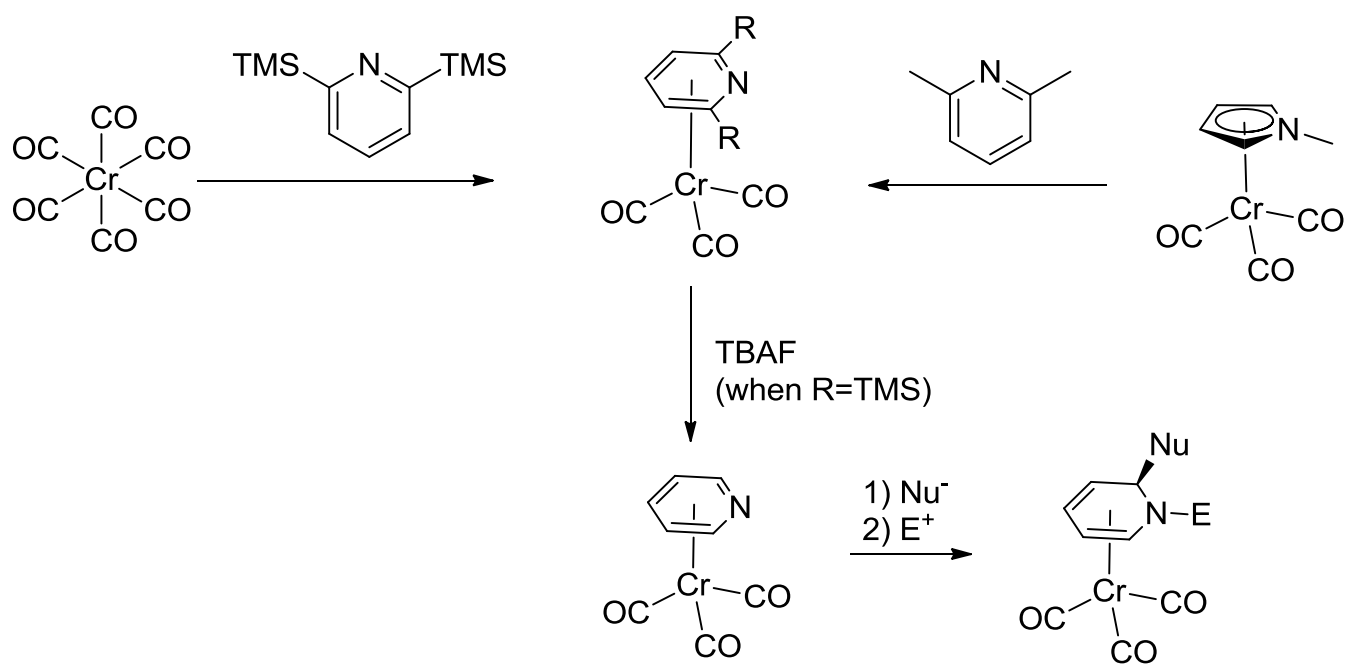

Scheme 15: $\eta^{6}$ pyridine formation and reactivity.
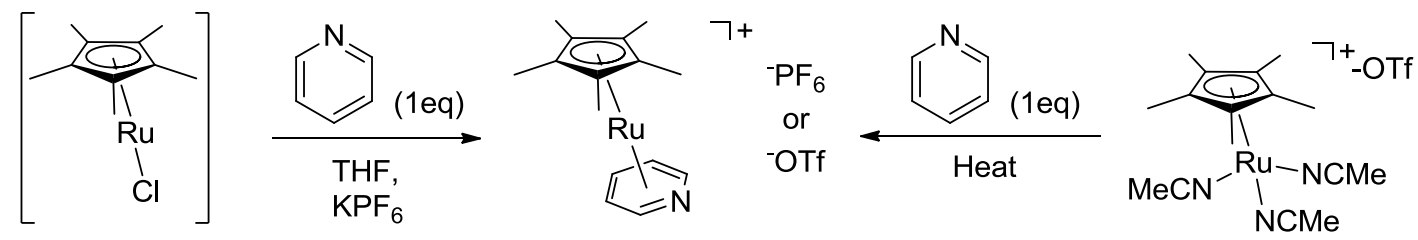

(or substituted pyridines)

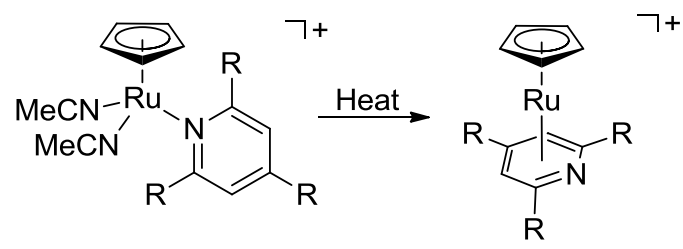

Scheme 16: Synthesis of $\eta^{6}$-pyridine complexes of $\mathrm{Ru}^{2+}$. 
A recent example from the Parkin group uses $\mathrm{Mo}\left(\mathrm{PMe}_{3}\right)_{6}$ to coordinate pyridine $\eta^{2}$, with the loss of $\mathrm{PMe}_{3}$ (Scheme 17)..$^{55}$ In this case, $\mathrm{k}^{2}$ coordination occurs through $\sigma$ bonds rather than the $\pi$ system, resulting from metal $\mathrm{C}-\mathrm{H}$ insertion into the $\alpha \mathrm{CH}$ bond. Heating the metal hydride produces $\left(\eta^{6}\right.$-pyridine)Mo( $\left(\mathrm{PMe}_{3}\right)_{3}$ with the loss of $\mathrm{PMe}_{3}$. Where the $\eta^{2}-\mathrm{CN}$ precursor reversibly reacts with $\mathrm{PMe}_{3}$ to regenerate starting material (or with $\mathrm{H}_{2}$ to produce a tetrahydride complex), the $\eta^{6}$ pyridine does not react with either $\mathrm{PMe}_{3}$ or $\mathrm{H}_{2}$ and is also fairly thermally stable. Modification of the coordinated ligand has not been reported.
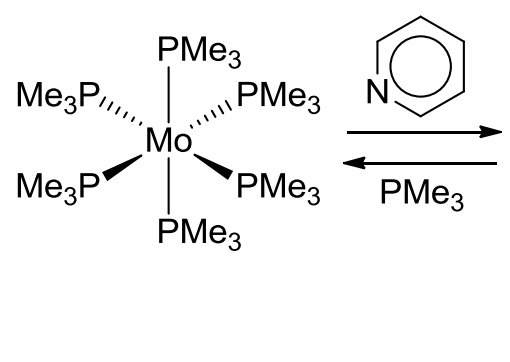

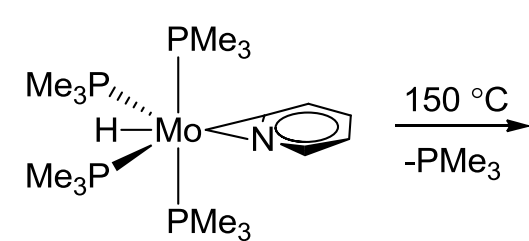

$\sqrt{60{ }^{\circ} \mathrm{C}}$

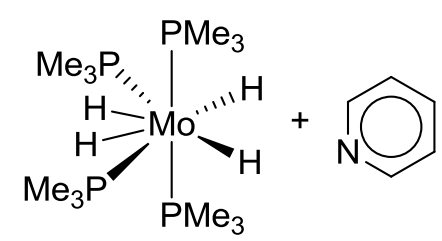

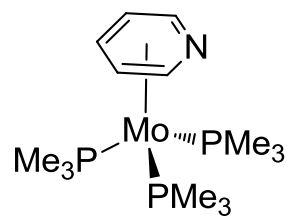

$\downarrow \begin{aligned} & 120^{\circ} \mathrm{C}, \\ & \mathrm{H}_{2}\end{aligned}$

No Reaction

Scheme 17: $\mathrm{Mo}(0)$ synthesis of $\eta^{6}$ pyridine.

Alternative coordination modes for pyridine are conceivable. Examples of tetrahapto pyridines are practically non-existent. $\eta^{4}$ Pyridine is proposed as an intermediate to hexahapto coordination of the ruthenium complexes above, however. ${ }^{52}$ 
Although still fairly rare, $\eta^{2}$ complexes of pyridine are more common than their tetrahapto cousins.

Examples of $\eta^{2}$-coordinated pyridine include those of tantalum and niobium. With each metal, C-N coordination is obtained (Scheme 18). ${ }^{56,57}$ This is true even when alkyl groups are flanking the nitrogen. With 2-picoline, C-N coordination occurs through $\mathrm{N}-\mathrm{C} 6$ to minimize the steric repulsion of the methyl group. In the case where 2,6-lutidine is coordinated to $\mathrm{Ta}(\text { silox })_{3}$, the metal kinetically inserts into the $\mathrm{H}-\mathrm{C} 4$ bond, which

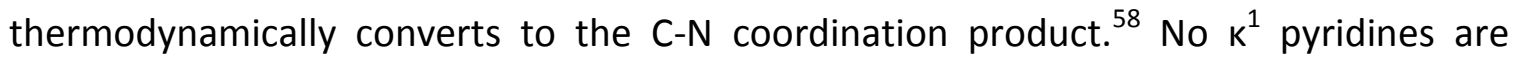
observed with these related systems.

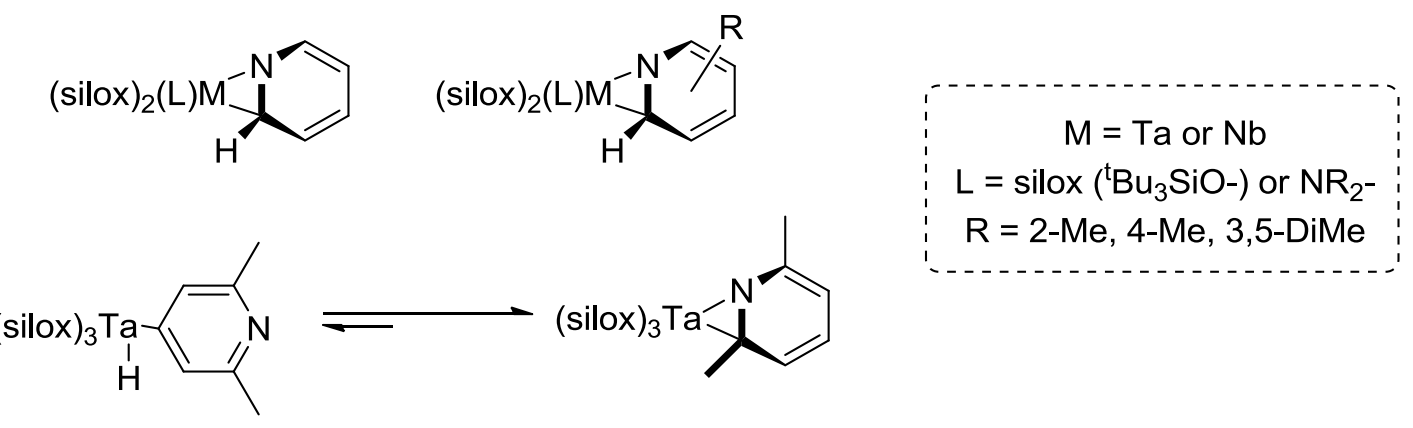

Scheme 18: $\eta^{2}$ complexes of $\mathrm{Nb}$ and Ta.

Little is known about the modified organic chemistry of these compounds, but mild oxidation (i.e. ethylene oxide, $\mathrm{N}_{2} \mathrm{O}$ ) liberates 4-picoline from (silox) ${ }_{3} \mathrm{Nb}\left(\eta^{2}-\mathrm{C}, \mathrm{N}-4-\right.$ picoline) via metal oxidation rather than reaction with the pyridine ring (Scheme 19). ${ }^{56}$ Also, heating (silox $)_{3} \mathrm{Nb}\left(\left(\eta^{2}-\mathrm{C}, \mathrm{N}\right.\right.$-pyridine) induces a ring opening of one equivalent of pyridine and the liberation of another molecule of pyridine, with the transfer of one $\mathrm{Nb}(\text { silox })_{3} \cdot{ }^{59}$ Alternatively, heating (silox $)_{3} \mathrm{Nb}\left(\left(\eta^{2}-\mathrm{C}, \mathrm{N}-3,5-\right.\right.$ picoline $)$ produces an 
intramolecular ring opening product incorporating one of the siloxy t-butyl groups of the metal ligand set. ${ }^{60}$
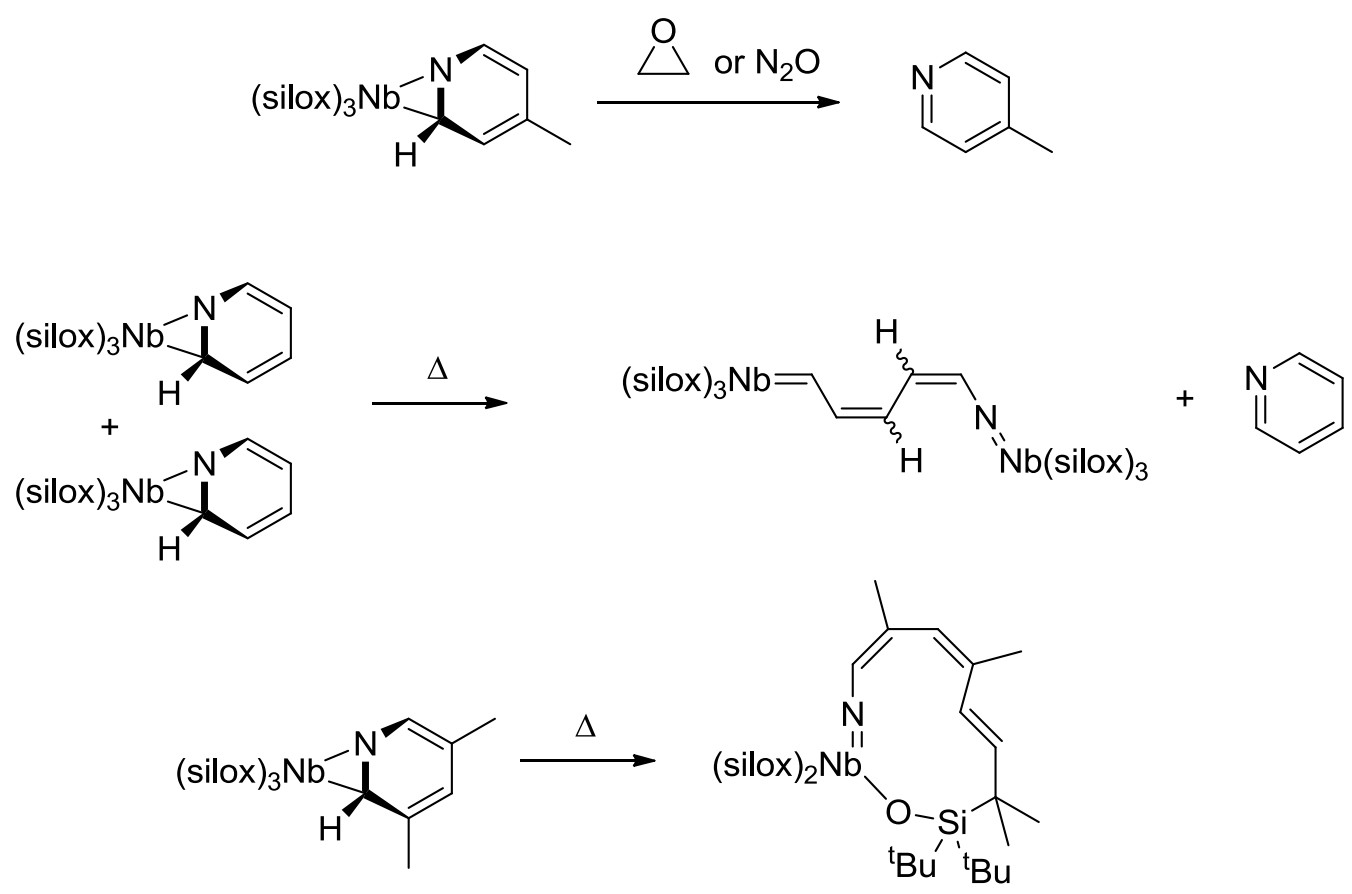

Scheme 19: Modification of pyridine ring with niobium complexation.

Moving to a more electron-rich osmium(II) system, $\left\{\left(\mathrm{NH}_{3}\right)_{5} \mathrm{Os}\right\}^{2+}$, pyridine as its conjugate acid can be coordinated through two carbon atoms of the heterocycle (Scheme 20). ${ }^{61}$ Deprotonation induces isomerization to the $N$-coordinated species. When the nitrogen is flanked by methyl groups (e.g. 2,6-lutidine), nitrogen coordination is averted to form a C-C $\eta^{2}$ species. This compound eventually converts to a tautomer, in which the osmium inserts into $\mathrm{H}-\mathrm{C} 4$ bond and tautomerizes to the $\mathrm{N}$-protonated species. Switching to a still more electron-rich system, $\{\operatorname{TpRe}(\mathrm{CO})(\mathrm{MeIm})\}, 2,6$-lutidine 
also coordinates to the metal through two carbon atoms. ${ }^{62}$ With either system, however, no organic modification of the coordinated ligand has been reported.
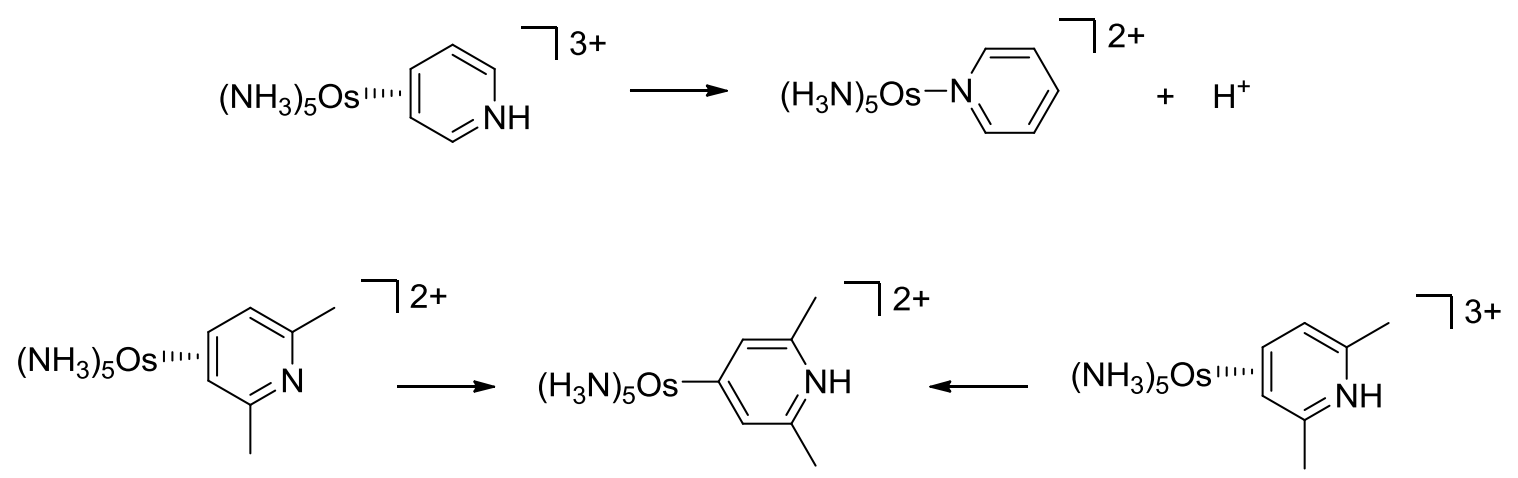

Scheme 20: $\mathrm{C}-\mathrm{C} \eta^{2}$ coordination with pyridines or pyridiniums.

Another metal system of the same family (i.e. $16 \mathrm{e}^{-}, \mathrm{d}^{6}$ metal fragments) as Os(II) and $\operatorname{Re}(\mathrm{I})$ is $\mathrm{W}(0) .^{63}$ The fragment $\left\{\mathrm{TpW}(\mathrm{NO})\left(\mathrm{PMe}_{3}\right)\right\}$ is considerably more electron-rich than its precursors, by virtue of its neutral oxidation state. It was expected that the increased electron density of the tungsten system would manifest itself in the uncoordinated $\pi$ system of the ligands, through the strong back-donation of metal into the LUMO of the aromatic ligands (i.e. $\mathrm{d} \pi \rightarrow \mathrm{p} \pi$ ) and thus activating the coordinated aromatic ligand to mild electrophilic addition reactions, prior to oxidation of the metal center (Figure 5). As an added benefit, it was expected that the metal fragment would prevent addition to the coordinated face of the ligand, enabling stereoselective additions to occur anti to the metal on the uncoordinated $\pi$ system. 


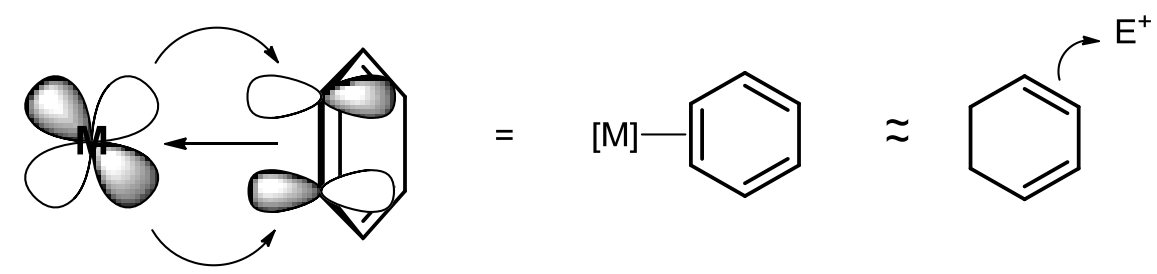

Figure 5: Back-bonding and activation of exposed diene.

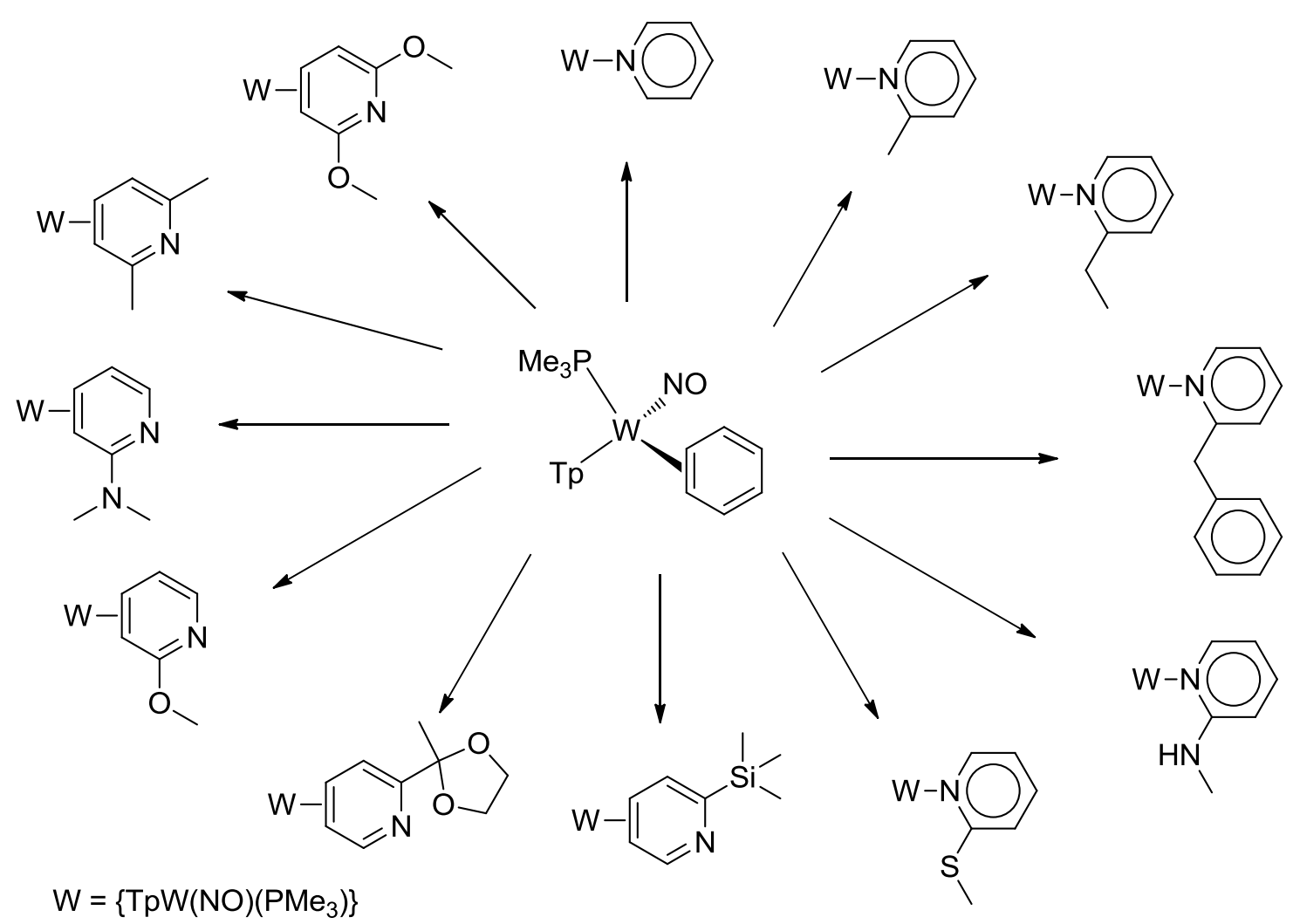

Scheme 21: Substitution of pyridines with $\operatorname{TpW}(\mathrm{NO})\left(\mathrm{PMe}_{3}\right)\left(\eta^{2}\right.$-benzene).

In general, these expectations held true for many coordinated arenes and resulted in the synthesis of some fairly complicated isolated organic compounds. ${ }^{64-69}$ Assuming that $\eta^{2}$ coordination would be achieved with pyridine, it too should lead to the activation of the aromatic ring towards these mild modifications. Substitution of pyridine failed to thermodynamically produce an unsubstituted $\eta^{2}$-pyridine complex and 
resulted an $\mathrm{N}$-coordinated product. ${ }^{70} \mathrm{~A}$ study was therefore performed to determine which pyridines would coordinate through two carbon atoms, and to gain an fundamental understanding of the properties that are required for $\eta^{2}$ coordination of pyridine (Scheme 21). In general, this study revealed that nitrogen coordination could be prevented by bulky substituents at the 2-position, small substituents at the 2-and 6positions, or small substituents that were electron donors at the 2-position.

Although it was isolated in very low yield (14\%), the study also produced a trapped $\eta^{2}$ pyridine, in the form of its conjugate acid (Scheme 22). Quantitative deprotonation of this species resulted in its isomerization to $\mathrm{k}^{1}$ pyridine with a relatively long $t_{1 / 2}$ (79 min.). Precoordination of pyridine followed by addition of acid did not produce the $\eta^{2}$ pyridine, but rather protonation of the metal resulted. The combination of these results indicated that $\eta^{2}$ pyridine was kinetically forming and being trapped with a conjugate acid prior to isomerization to the $N$-coordinated species.

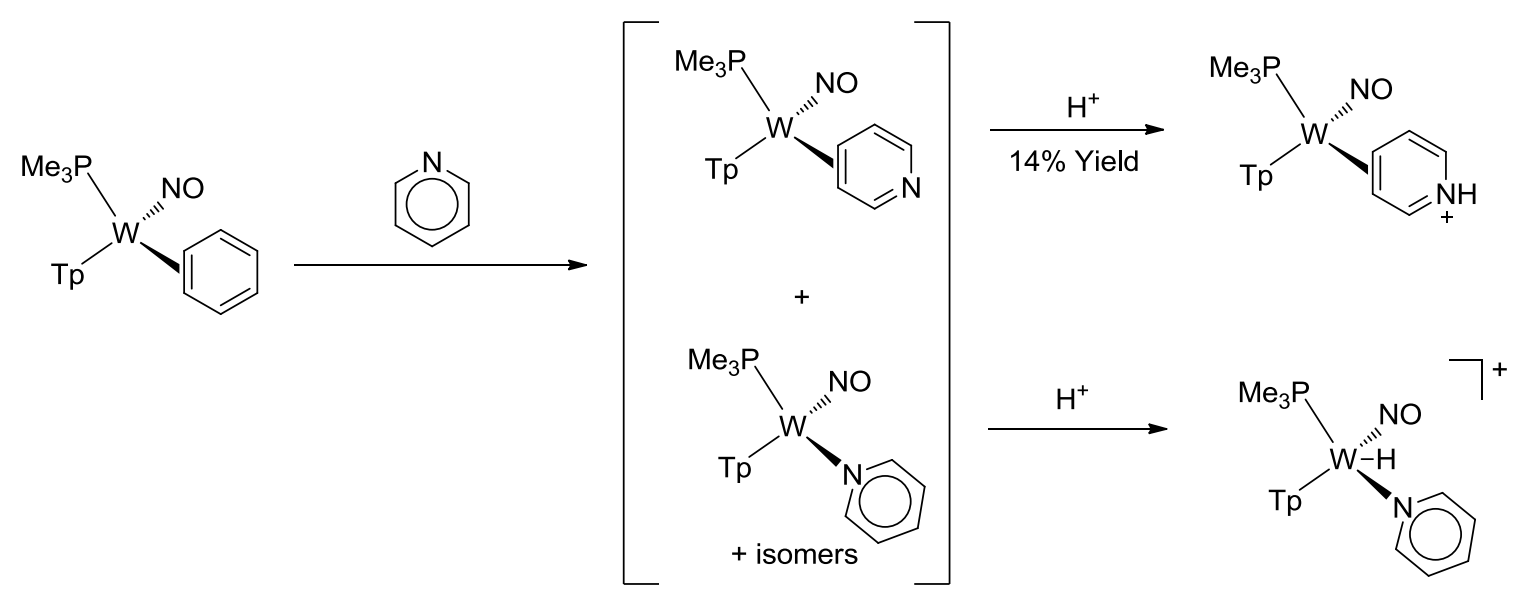

Scheme 22: Isolation of $\eta^{2}$ pyridinium complex. 
At the time of the above report, organic modification of the parent pyridine was hampered by the fact that coordination of pyridine failed to produce the desired coordination mode, without the use of an acid, and because a synthetically practical method of isolating its conjugate acid was not achieved in a reasonable yield. Other $\eta^{2}$ pyridine complexes have been isolated in reasonable yields. Theses coordinated ligands have been successfully modified under mild conditions. For example, 2-N,Ndimethylaminopyridine (2DMAP), 2,6-lutidine, and 2,6-dimethoxypyridine all undergo concerted [4+2] Diels-Alder cycloaddition reactions with the exposed and activated uncoordinated diene (Scheme 23). This reaction cannot be performed with such simple pyridines. $^{71,72-74}$

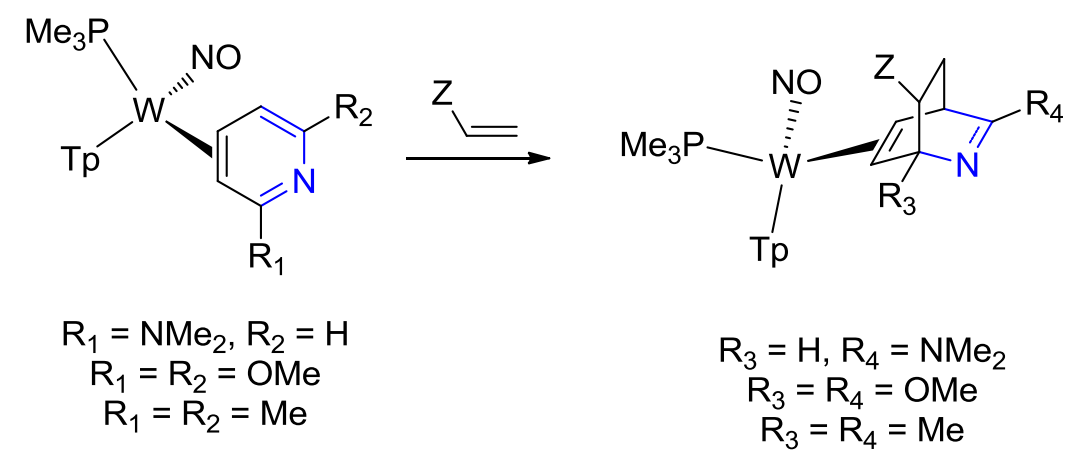

Scheme 23: [4+2] Diels-Alder cycloadditions with $\eta^{2}$-coordinated pyridines.

With these dearomatized compounds in hand, oxidation of the metal center allowed for the isolation of a variety of new organic compounds (Scheme 24). ${ }^{68,75}$ Importantly, it was demonstrated with one of the organic compounds that the products could be isolated in an enantiomeric excess (er 9:1; Scheme 25). The method employed 
utilized an imperfect procedure in which one enantiomer of the metal irreversibly binds to $(R)$ - $\alpha$-pinene prior to the coordination of the pyridine precursor while the other is substitutionally labile. $^{75}$

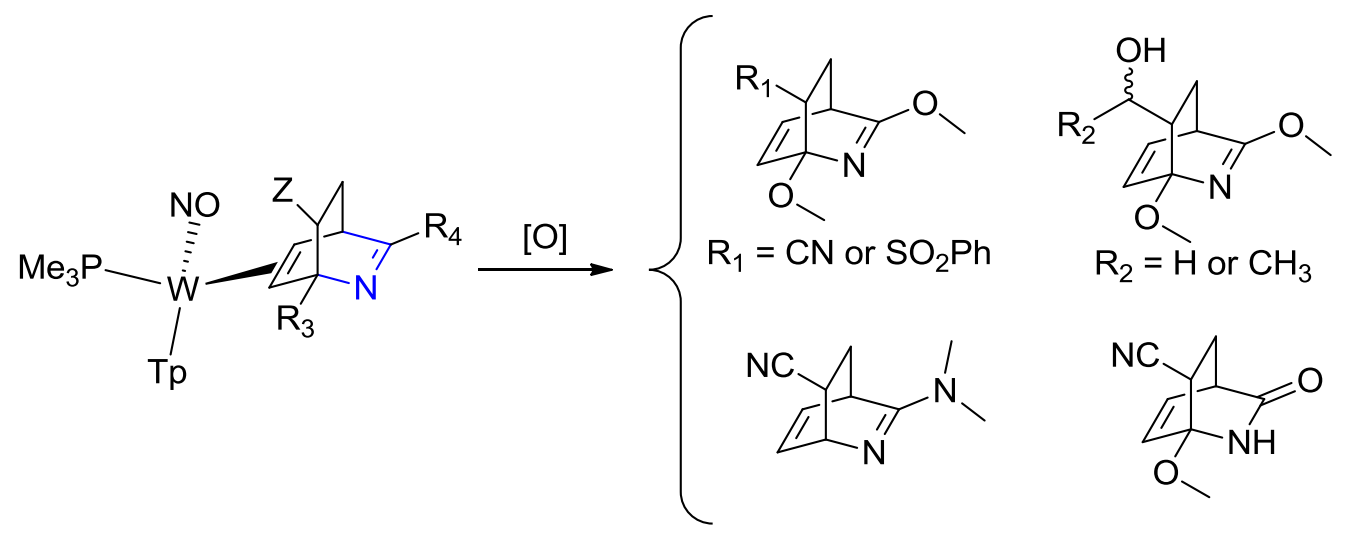

Scheme 24: Liberation of new organic compounds from cycloadduct complexes.
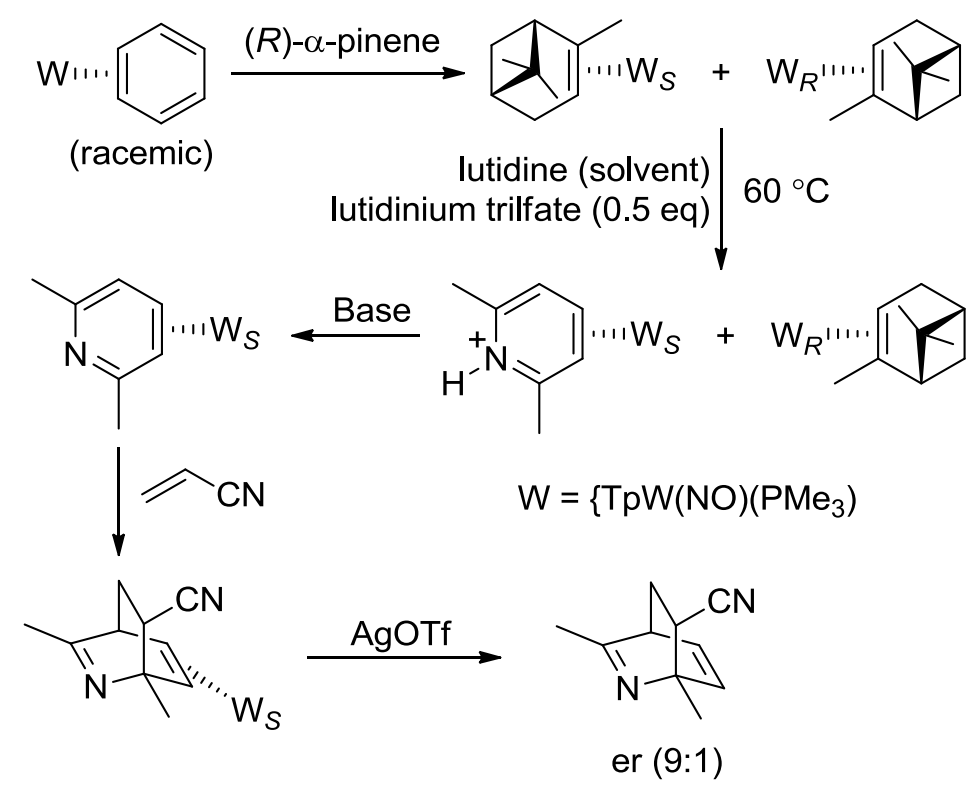

Scheme 25: Synthesis and isolation of an organic in an enantiomeric excess. 
For the pyridine family, these examples serve as a proof of concept that $\eta^{2}$ coordination of the parent pyridine would activate it toward mild addition reactions and allow for the isolation of new piperidine compounds. As pyridine does not have substituents to influence binding mode or reactivity, we hoped to gain a greater understanding of the fundamental chemistry of the metal-heterocycle system, elaborate additional possible synthetic pathways available to pyridine, and develop methodologies for the synthesis of new classes of piperidine compounds that its substituted forms do not have access to. We rationalized that the first step to reasonably investigating the fundamental influence the metal plays on the ligand would begin with isolating the complexed conjugate acids of pyridine of synthetically useful scales and then using that material as a starting point for a variety of reactions.

\section{References:}

(1) Gaigeot, M.-P.; Cimas, A.; Seydou, M.; Kim, J.-Y.; Lee, S.; Schermann, J.-P., Journal of the American Chemical Society 2010, 132 (51), 18067-18077.

(2) Aoyagi, S.; Tanaka, R.; Naruse, M.; Kibayashi, C., The Journal of Organic Chemistry 1998, $63(23), 8397-8406$.

(3) Green, B. T.; Lee, S. T.; Panter, K. E.; Welch, K. D.; Cook, D.; Pfister, J. A.; Kem, W. R., Neurotoxicology and Teratology 2010, 32 (3), 383-390.

(4) Joule, J. A.; Mills, K., Heterocyclic chemistry. 4th ed.; Blackwell Science: Malden, MA, 2000.

(5) Allen, F. H.; Kennard, O.; Watson, D. G.; Brammer, L.; Orpen, A. G.; Taylor, R., J Chem Soc Perk T 2 1987, (12), S1-S19. 
(6) Fulmer, G. R.; Miller, A. J. M.; Sherden, N. H.; Gottlieb, H. E.; Nudelman, A.; Stoltz, B. M.; Bercaw, J. E.; Goldberg, K. I., Organometallics 2010, 29 (9), 2176-2179.

(7) Pearson, D. E.; Hargrove, W. W.; Chow, J. K. T.; Suthers, B. R., The Journal of Organic Chemistry 1961, 26 (3), 789-792.

(8) McCleland, N. P.; Wilson, R. H., Journal of the Chemical Society (Resumed) 1932, 12631265.

(9) den Hertog, H. J.; Overhoff, J., Reel. Trav. Chim. Pays-Bas 1930, 49, 552.

(10) Katritzky, A. R.; Scriven, E. F. V.; Majumder, S.; Akhmedova, R. G.; Vakulenko, A. V.; Akhmedov, N. G.; Murugan, R.; Abboud, K. A., Org Biomol Chem 2005, 3 (3), 538-541.

(11) Fersht, A. R.; Jencks, W. P., Journal of the American Chemical Society 1970, 92 (18), $5432-5442$.

(12) Höfle, G.; Steglich, W.; Vorbrüggen, H., Angewandte Chemie International Edition in English 1978, 17 (8), 569-583.

(13) Scriven, E. F. V., Chem Soc Rev 1983, 12 (2), 129-161.

(14) Eisner, U.; Kuthan, J., Chem Rev 1972, 72 (1), 1-42.

(15) Stout, D. M.; Meyers, A. I., Chem Rev 1982, 82 (2), 223-243.

(16) Schlosser, M.; Mongin, F., Chem Soc Rev 2007, 36 (7), 1161-1172.

(17) Fowler, F. W., The Journal of Organic Chemistry 1972, 37 (9), 1321-1323.

(18) Bonfiglio, J. N.; Hasan, I.; Piwinski, J. J.; Weinstein, B.; Fowler, F. W., Journal of the American Chemical Society 1976, 98 (8), 2344-2345.

(19) Glorius, F.; Spielkamp, N.; Holle, S.; Goddard, R.; Lehmann, C. W., Angewandte Chemie International Edition 2004, 43 (21), 2850-2852.

(20) Legault, C. Y.; Charette, A. B., Journal of the American Chemical Society 2005, 127 (25), 8966-8967. 
(21) Steiner, H.; Giannousis, P.; Pische-Jacques, A.; Blaser, H. U., Topics in Catalysis 2000, 13 (3), 191-194.

(22) Fowler, F. W., Journal of the American Chemical Society 1972, 94 (16), 5926-5927.

(23) Weinstein, B.; Lin, L.-C. C.; Fowler, F. W., The Journal of Organic Chemistry 1980, 45 (9), $1657-1661$.

(24) Sundberg, R. J.; Bloom, J. D., The Journal of Organic Chemistry 1980, 45 (17), 3382-3387.

(25) Sundberg, R. J.; Bloom, J. D., The Journal of Organic Chemistry 1981, 46 (24), 4836-4842.

(26) Sundberg, R. J.; Hamilton, G.; Trindle, C., The Journal of Organic Chemistry 1986, 51 (19), 3672-3679.

(27) Knaus, E. E.; Avasthi, K.; Giam, C. S., Can J. Chem. 1980, 58, 2447-2451.

(28) Corey, E. J.; Tian, Y., Organic Letters 2005, 7 (24), 5535-5537.

(29) Comins, D. L.; O'Connor, S.; Al-awar, R. S., "Chemistry of Pyridines at Ring Positions". In Comprehensive Heterocyclic Chemistry III, Katritzky, R.; Ramsden, C. A.; Scriven, E. F. V.; Taylor, R. J. K., Eds. Elsevier: Oxford, Vol. 7, pp 41-100.

(30) Joseph, S.; Comins, D. L., Current Opinion in Drug Discovery \& Development 2002, 5 (6), 870-880.

(31) Lemire, A.; Charette, A. B., Organic Letters 2005, 7 (13), 2747-2750.

(32) Guilloteau-Bertin, B.; Compère, D.; Gil, L.; Marazano, C.; Das, Bhupesh C., European Journal of Organic Chemistry 2000, 2000 (8), 1391-1399.

(33) Maia, Alessandra A.; Mons, S.; Pereira de Freitas Gil, R.; Marazano, C., European Journal of Organic Chemistry 2004, 2004 (5), 1057-1062.

(34) Amat, M.; Escolano, C.; Lozano, O.; Llor, N.; Bosch, J., Organic Letters 2003, 5 (17), 31393142. 
(35) Amat, M.; Pérez, M.; Minaglia, A. T.; Bosch, J., The Journal of Organic Chemistry 2008, 73 (17), 6920-6923.

(36) Amat, M.; Brunaccini, E.; Checa, B. a.; Pérez, M.; Llor, N. r.; Bosch, J., Organic Letters 2009, 11 (19), 4370-4373.

(37) Amat, M.; Fabregat, R.; Griera, R.; Bosch, J., The Journal of Organic Chemistry 2009, 74 (4), 1794-1797.

(38) Coombs, T. C.; Lee; Wong, H.; Armstrong, M.; Cheng, B.; Chen, W.; Moretto, A. F.; Liebeskind, L. S., The Journal of Organic Chemistry 2008, 73 (3), 882-888.

(39) Parikh, I.; Hilpert, H.; Hermann, K.; Dreiding, A. S., Helvetica Chimica Acta 1986, 69 (7), $1588-1596$.

(40) Michels, T. D.; Kier, M. J.; Kearney, A. M.; Vanderwal, C. D., Organic Letters 2010, 12 (13), 3093-3095.

(41) Michels, T. D.; Rhee, J. U.; Vanderwal, C. D., Organic Letters 2008, 10 (21), 4787-4790.

(42) Steinhardt, S. E.; Vanderwal, C. D., Journal of the American Chemical Society 2009, 131 (22), 7546-7547.

(43) Martin, D. B. C.; Vanderwal, C. D., Chemical Science 2011.

(44) Martin, D. B. C.; Vanderwal, C. D., Journal of the American Chemical Society 2009, 131 (10), 3472-3473.

(45) McCall, W. S.; Comins, D. L., Organic Letters 2009, 11 (13), 2940-2942.

(46) McCall, W. S.; Grillo, T. A.; Comins, D. L., The Journal of Organic Chemistry 2008, 73 (24), 9744-9751.

(47) McCall, W. S.; Grillo, T. A.; Comins, D. L., Organic Letters 2008, 10 (15), 3255-3257.

(48) Goti, A.; Semmelhack, M. F., J Organomet Chem 1994, 470 (1-2), C4-C7. 
(49) Davies, S. G.; Shipton, M. R., Journal of the Chemical Society, Perkin Transactions 1 1991, (3), 501-507.

(50) Davies, S. G.; Shipton, M. R., Journal of the Chemical Society, Chemical Communications 1989, (15), 995-996.

(51) Chaudret, B.; Jalon, F. A., Journal of the Chemical Society, Chemical Communications 1988, (11), 711-713.

(52) Fish, R. H.; Fong, R. H.; Anh, T.; Baralt, E., Organometallics 1991, 10 (4), 1209-1212.

(53) Fish, R. H.; Kim, H. S.; Fong, R. H., Organometallics 1989, 8 (5), 1375-1377.

(54) Standfest-Hauser, C. M.; Mereiter, K.; Schmid, R.; Kirchner, K., Dalton T 2003, (11), 2329-2334.

(55) Zhu, G.; Pang, K.; Parkin, G., Inorg Chim Acta 2008, 361 (11), 3221-3229.

(56) Veige, A. S.; Kleckley, T. S.; Chamberlin, R. M.; Neithamer, D. R.; Lee, C. E.; Wolczanski, P. T.; Lobkovsky, E. B.; Glassey, W. V., J Organomet Chem 1999, 591 (1-2), 194-203.

(57) Neithamer, D. R.; Parkanyi, L.; Mitchell, J. F.; Wolczanski, P. T., Journal of the American Chemical Society 1988, 110 (13), 4421-4423.

(58) Covert, K. J.; Neithamer, D. R.; Zonnevylle, M. C.; LaPointe, R. E.; Schaller, C. P.; Wolczanski, P. T., Inorg Chem 1991, 30 (11), 2494-2508.

(59) Kleckley, T. S.; Bennett, J. L.; Wolczanski, P. T.; Lobkovsky, E. B., Journal of the American Chemical Society 1997, 119 (1), 247-248.

(60) Bonanno, J. B.; Veige, A. S.; Wolczanski, P. T.; Lobkovsky, E. B., Inorg Chim Acta 2003, $345,173-184$.

(61) Cordone, R.; Harman, W. D.; Taube, H., Journal of the American Chemical Society 1989, $111(8), 2896-2900$. 
(62) Meiere, S. H.; Brooks, B. C.; Gunnoe, T. B.; Sabat, M.; Harman, W. D., Organometallics 2001, 20 (6), 1038-1040.

(63) Keane, J. M.; Harman, W. D., Organometallics 2005, 24 (8), 1786-1798.

(64) Harrison, D. P.; Sabat, M.; Myers, W. H.; Harman, W. D., Journal of the American Chemical Society 2010, 132 (48), 17282-17295.

(65) Welch, K. D.; Harrison, D. P.; Sabat, M.; Hejazi, E. Z.; Parr, B. T.; Fanelli, M. G.;

Gianfrancesco, N. A.; Nagra, D. S.; Myers, W. H.; Harman, W. D., Organometallics 2009, 28 (20), 5960-5967.

(66) Salomon, R. J.; Lis, E. C.; Kasbekar, M. U.; Bassett, K. C.; Myers, W. H.; Trindle, C. O.; Sabat, M.; Harman, W. D., Organometallics 2009, 28 (16), 4724-4734.

(67) Lis, E. C.; Salomon, R. J.; Sabat, M.; Myers, W. H.; Harman, W. D., Journal of the American Chemical Society 2008, 130 (37), 12472-12476.

(68) Kosturko, G. W.; Graham, P. M.; Myers, W. H.; Smith, T. M.; Sabat, M.; Harman, W. D., Organometallics 2008, 27 (17), 4513-4522.

(69) Todd, M. A.; Sabat, M.; Myers, W. H.; Harman, W. D., Journal of the American Chemical Society 2007, 129 (36), 11010-11011.

(70) Delafuente, D. A.; Kosturko, G. W.; Graham, P. M.; Harman, W. H.; Myers, W. H.; Surendranath, Y.; Klet, R. C.; Welch, K. D.; Trindle, C. O.; Sabat, M.; Harman, W. D., Journal of the American Chemical Society 2006, 129 (2), 406-416.

(71) One specific example of a highly specialized pyridine cycloaddition is known and discovered independently by two groups. The product rapidly degrades to aromatic species. See the following reference.

(72) Neunhoeffer, H.; Lehmann, B., Justus Liebigs Annalen der Chemie 1975, 1975 (6), 11131119. 
(73) Gompper, R.; Heinemann, U., Angewandte Chemie International Edition in English 1980, $19(3), 216-217$.

(74) Boger, D. L., Chem Rev 1986, 86 (5), 781-793.

(75) Graham, P. M.; Delafuente, D. A.; Liu, W.; Myers, W. H.; Sabat, M.; Harman, W. D., Journal of the American Chemical Society 2005, 127 (30), 10568-10572. 
Chapter 2

An Efficient Synthesis of an $\eta^{2}$-Pyridine

Complex and a Preliminary Investigation of

the Bound Heterocycle's Reactivity 


\section{Introduction:}

Over the past two decades, our group has sought to develop new methods of functionalizing aromatic molecules. ${ }^{1,2}$ Our approach exploits the ability of certain $\pi$ basic transition metal complexes to bind aromatic molecules through two carbons, thereby localizing the remaining uncoordinated $\pi$-system. In this manner, $\eta^{2}$-arene, $\eta^{2}-$ pyrrole, and $\eta^{2}$-furan complexes have been utilized in novel organic syntheses. ${ }^{1-3}$ However, the development of parallel chemistry for pyridines, diazines, diazoles, and other basic aromatic heterocycles has been hampered by the thermodynamic preference of the transition metal to coordinate at nitrogen (Scheme 1, Path A). While such coordination for pyridines can be avoided by strategic placement of substituents (e.g., 2,6-disubstituted pyridines), ${ }^{4}$ we desired a more general method for the preparation of dihapto-coordinated complexes of basic heterocycles.

Using pyridine as a test case, our strategy was first to form a complex with a corresponding pyridinium ion, in which nitrogen coordination was no longer possible. Once the heterocycle was coordinated, we planned to remove the $\mathrm{N}$-substituent and utilize the $\eta^{2}$-pyridine ligand prior to its evolution to the $\mathrm{N}$-bound isomer. ${ }^{4}$ Unfortunately, when the synthon $\operatorname{TpW}(\mathrm{NO})\left(\mathrm{PMe}_{3}\right)\left(\eta^{2}\right.$-benzene) (1) was subjected to either pyridinium or methylpyridinium triflate, the tungsten complex underwent oxidative degradation (Scheme 1, Path B). ${ }^{4}$ We reasoned that a pyridine-borane adduct, being neutrally charged, would be less oxidizing than its cationic analogs and hence could potentially form an isolable complex (Scheme 1, Path C). 


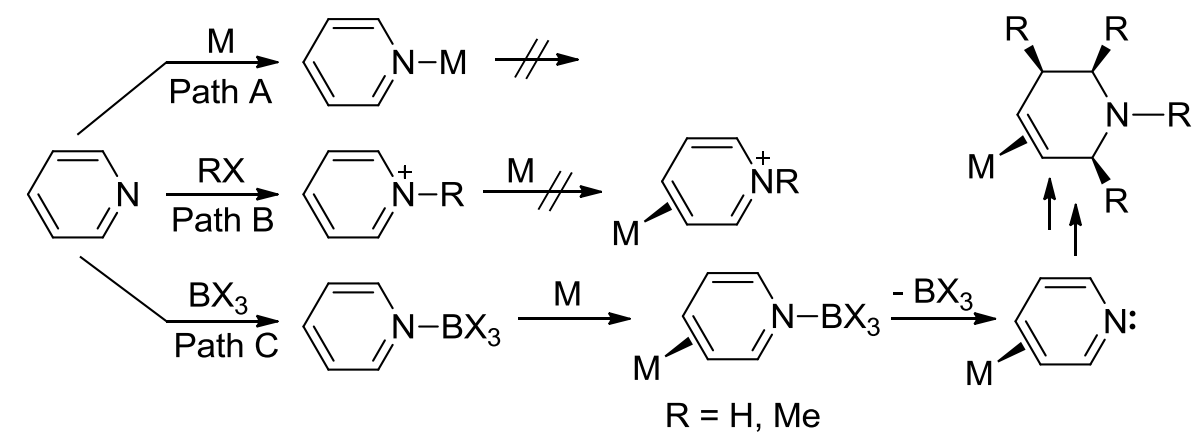

Scheme 1: Synthetic strategies.

\section{Results and Discussion:}

True to expectation, the treatment of $\operatorname{TpW}(\mathrm{NO})\left(\mathrm{PMe}_{3}\right)\left(\eta^{2} \text {-benzene }\right)^{5}$ with pyridine-borane (PB; Aldrich), generated a new compound, $\mathrm{TpW}(\mathrm{NO})\left(\mathrm{PMe}_{3}\right)\left(3,4-\eta^{2}-\mathrm{PB}\right)$, isolated as a 3:1 mixture of coordination diastereomers (2; 87\%; Scheme 2). The major isomer features five correlated ring proton resonances, two of which (2.18 and 3.76 ppm) being well upfield of the ${ }^{1} \mathrm{H}$ NMR signals for uncoordinated PB. The anodic peak potential $\left(E_{\mathrm{p}, \mathrm{a}}=+0.47 \mathrm{~V} @ 100 \mathrm{mV} / \mathrm{s} ; \mathrm{NHE}\right)$ of $\mathbf{2}$ is between those of the neutral $\eta^{2}-$ pyridine $(0.00 \mathrm{~V})$ and $\eta^{2}$-pyridinium complexes $(+0.83 \mathrm{~V}) .{ }^{4}$ The X-ray structure of $\mathbf{2}$ (Scheme 2) depicts the major coordination diastereomer present in solution, ${ }^{6}$ in which C4 is adjacent to the $\mathrm{PMe}_{3}$ ligand.

Treatment of a suspension of $\mathbf{2}$ in ether with acidified acetone (DPhAT = diphenylammonium triflate) smoothly unmasks the nitrogen, ${ }^{7}$ and the previously reported pyridinium complex $\mathbf{3 H}$ is isolated as an orange microcrystalline solid (92\%; cdr $=1: 1){ }^{4}$ The preparation of $\mathbf{3} \mathbf{H}$ from $\mathbf{1}$ in $80 \%$ yield over two steps represents a vast 
improvement from the impractical $14 \%$ reported from trapping procedures, ${ }^{4,8}$ and enables direct access to the parent $\eta^{2}$-pyridine complex (3) on a synthetic scale.

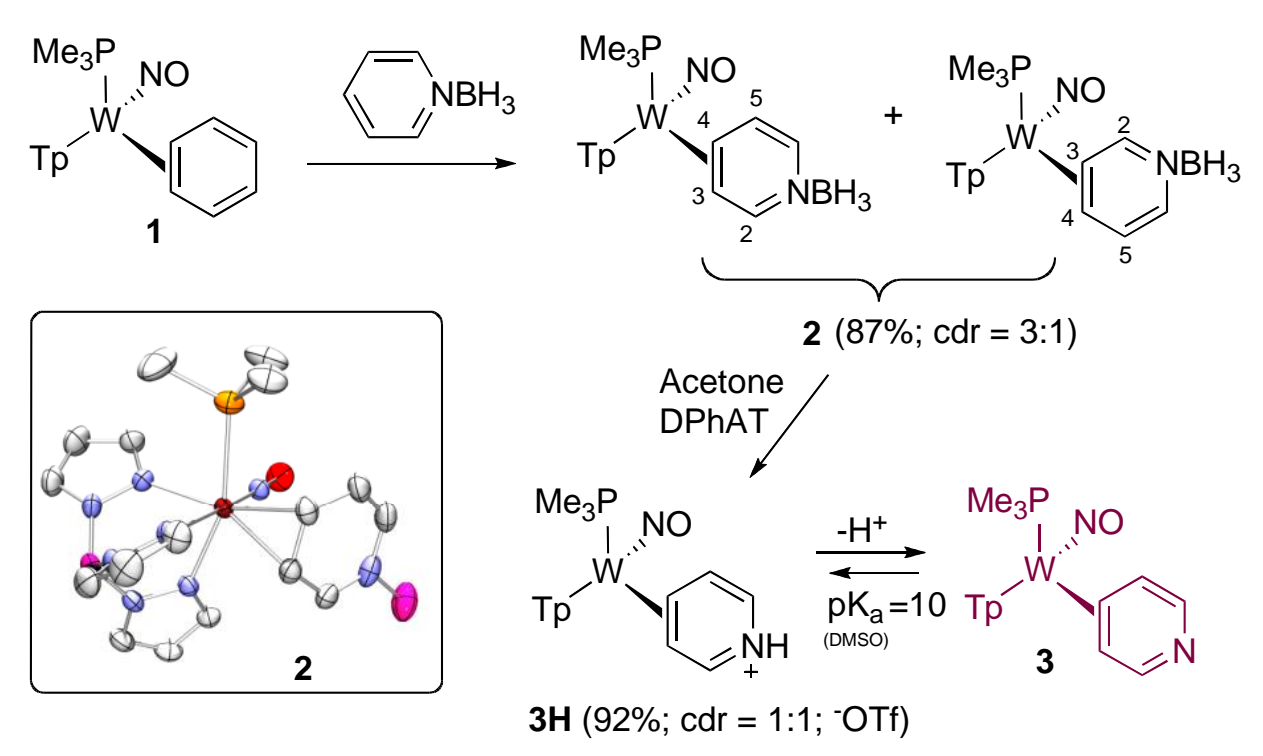

Scheme 2: Improved Synthesis of Pyridinium 3H.

The basicity of the $\eta^{2}$-pyridine $\mathbf{3}$ was found to be markedly greater than for pyridine itself $\left(\mathrm{pK}_{\mathrm{a}}(\mathrm{DMSO})\right.$ of $3 \mathbf{H}=10 ; c f .3 .4$ for $\left.\mathrm{pyH}^{+}\right)$, owing to the tungsten backbonding, hence we attempted its acylation. Deprotonation of $\mathbf{3 H}$ with 2,6-di-tertbutylpyridine (DTBP) in the presence of acetic anhydride results in the acetylpyridinum complex, 4. The initial coordination diastereomer ratio $(c d r=4: 1)^{5}$ is improved to $>10: 1$ upon heating $\left(55^{\circ} \mathrm{C}\right.$ for $\left.5.5 \mathrm{~h}\right),{ }^{6}$ and 4 was ultimately isolated in $94 \%$ yield ( $\left.\mathrm{cdr}>10: 1\right) .{ }^{9}$ This complex shows a CO stretching feature at $1733 \mathrm{~cm}^{-1}$ (IR), and CO and CN bond lengths of 1.19 and $1.41 \AA$ (X-ray), respectively, consistent with an acetylpyridinium species (resonance form a in Figure 1). However, the ${ }^{13} \mathrm{C}$ signal at $169.8 \mathrm{ppm}$ and weak 
interaction between $W$ and $C 2(2.88 \AA$ cf. $3.22 \AA$ for $W-C 5)$ in 4 indicate partial allyl/amide character (resonance form b). ${ }^{5}$ While acylpyridinum ions are commonly invoked as intermediates in pyridine (e.g., DMAP) catalyzed acylation reactions, they are normally far too unstable to isolate. ${ }^{10,11}$ In the case of $\mathbf{4}$, electron-donation from tungsten not only allows its isolation but renders the acetylpyridinium ligand stable to water, even at elevated temperatures $\left(55^{\circ} \mathrm{C} ; 0.5 \mathrm{~h} ; 30\right.$ eq water in acetone solution).
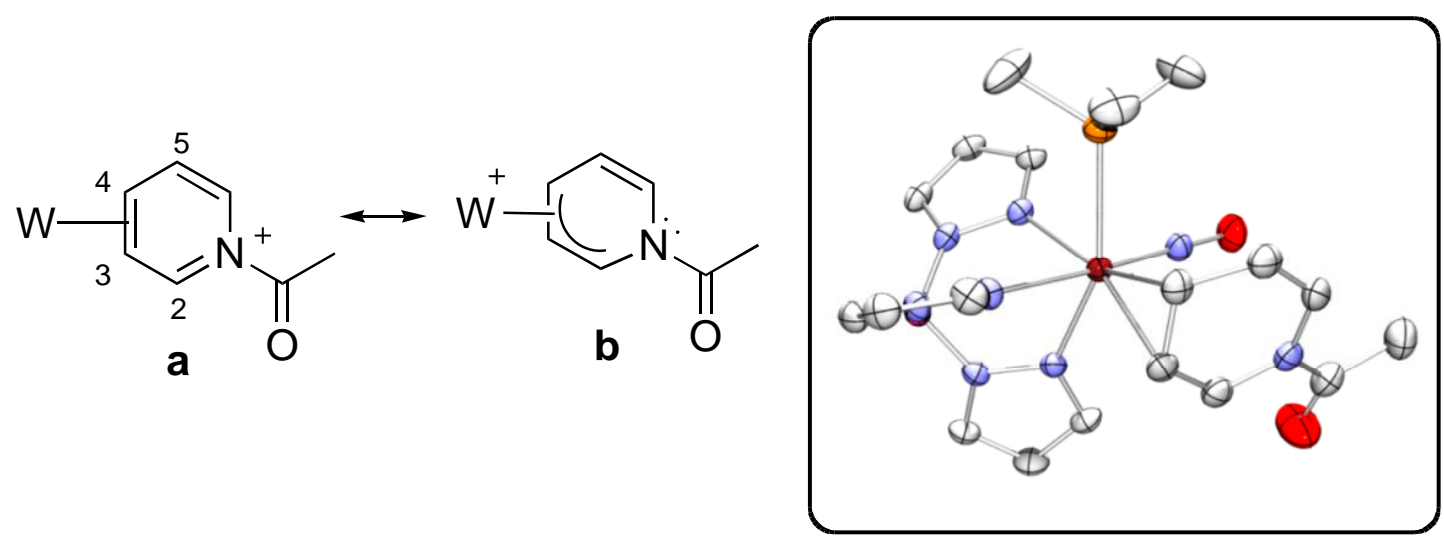

Figure 1: ORTEP Diagram and resonance forms of 4.

In order to determine if $\mathbf{4}$ was a viable acylation agent, we treated this complex with an acetone solution of morpholine (Scheme 3) and monitored the reaction with ${ }^{31} \mathrm{P}$ NMR. A 4 ppm upfield shift in ${ }^{31} \mathrm{P}$ NMR and a cyclic voltammogram with an $E_{\mathrm{p}, \mathrm{a}}$ of +0.54 $\mathrm{V}$ signaled that a neutral tungsten species had been produced. To our surprise, spectroscopic analysis of the isolated product, $\mathbf{5}$, indicates that acetone has added to $\mathrm{C} 2$ of the pyridinium ring (Scheme 2). 2D NMR analysis and X-ray diffraction studies confirm that the addition is highly stereoselective, with the presumed enol, enolate, or enamine 
intermediate adding anti to the metal. A more efficient method to synthesize $\mathbf{5}$ was ultimately found using the silyl-enol ether of acetone with DABCO added to remove the TMS group. ${ }^{12}$ This Mukiama-Mannich variation has the additional advantage that the product spontaneously precipitates from the $\mathrm{CH}_{3} \mathrm{CN} / \mathrm{DME}$ solution.

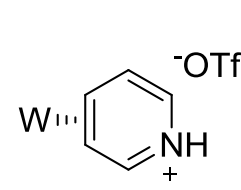

$3 \mathrm{H}$

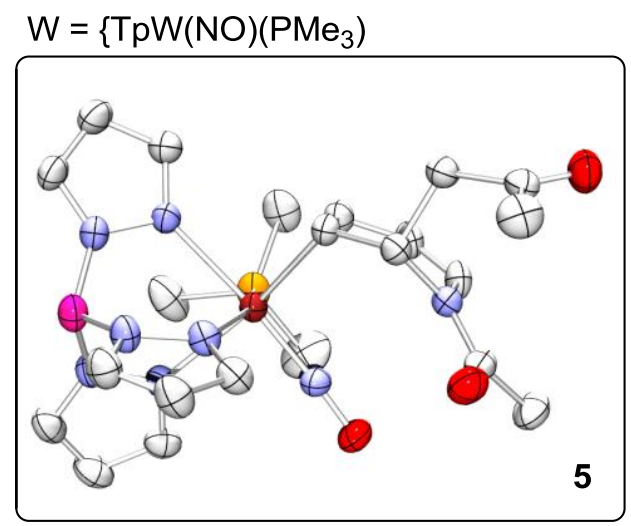

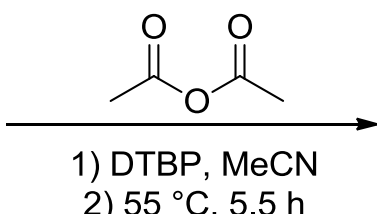

2) $55^{\circ} \mathrm{C}, 5.5 \mathrm{~h}$

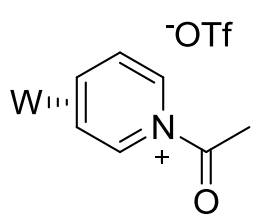

4 (94\%; dr >10:1)

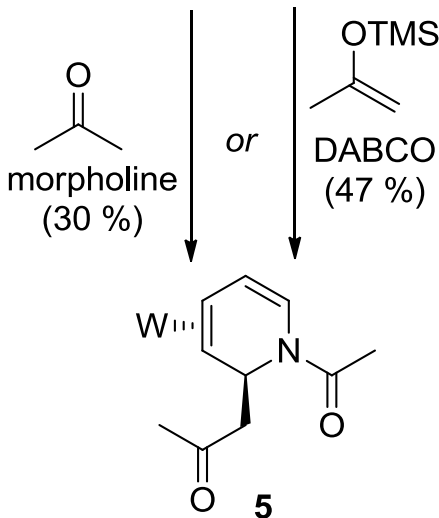

Scheme 3: Tandem Addition of Acetone (30\% ellipsoids).

Encouraged by this mild and selective C2 nucleophilic addition, we explored several other reagents that could serve as mild carbon nucleophiles for the Mannich reaction. Both pyrrole and indole successfully undergo reactions at C2 of the acetylpyridinum complex under mild conditions to form 6 and 7 respectively. Pyrrole selectively reacts at the $\alpha$ carbon (6; 51\%) while indole undergoes electrophilic substitution at the $\beta$ carbon of the heterocycle $(7 ; 61 \%)$. Notably, these aza-Friedel- 
Crafts alkylations proceed only in the presence of a modest base (2,6-lutidine). As with the acetone adduct 5, spectroscopic analysis confirms complete control of the stereochemistry at C2. Alternatively, the treatment of the acetylpyridinum complex 4 with acrolein and quinuclidine resulted in an aza-Morita-Baylis-Hillman reaction to form the enone $8(92 \%),{ }^{13}$ where X-ray data again confirm addition to pyridine anti to coordination. Attempts to carry out C2 nucleophilic addition reactions with pyridinium complex 3 or with free $\mathrm{N}$-acetylpyridinium (prepared in situ from pyridine and $\mathrm{Ac}_{2} \mathrm{O}$ ) were unsuccessful.
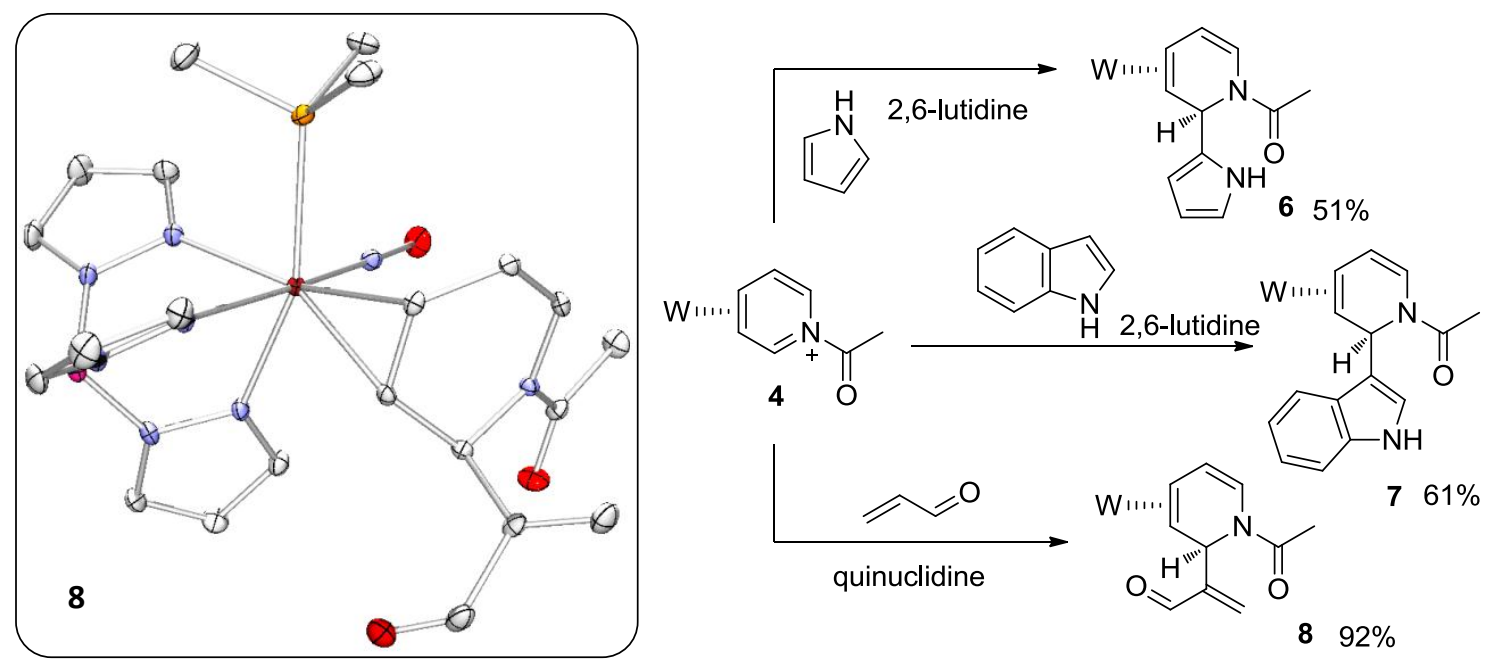

Scheme 4: Aza-Friedel-Crafts and Baylis-Hillman Reactions.

The successful liberation of 3 -(pyridin-2-yl)-1H-indole $(9 ; 31 \%$ isolated, unoptimized; Eqn 1) was accomplished by treating complex 7 with 2.5 equivalents of the oxidant $\mathrm{CuBr}_{2}$. Unfortunately, the dihydropyridine ring was also oxidized. While other 
methods for decomplexation are currently under investigation that will conserve the $\mathrm{C} 2$ stereocenter, we note that (2-piperidyl)indoles are common components of monoterpenoid indole alkaloids; ${ }^{14}$ the reaction sequence of $3 \mathbf{H} \rightarrow \mathbf{9}$ illustrates a approach to form (2-pyridyl)indoles that does not involve cross-coupling methods or arylmetallic reagents, is tolerant of oxygen and water, and does not require harsh acids or bases. This reaction sequence is complementary to that observed by Corey et al. in which weak nucleophiles successfully were added to a triflylpyridinium intermediate to generate 1,4 -dihydropyridines. ${ }^{15}$

In contrast to the reactivity of 4 , organic acylpyridiniums ${ }^{16,17}$ or $\eta^{6}$-pyridine complexes ${ }^{18}$ typically require strong nucleophiles such as metalloenolates and Grignard reagents to overcome the aromatic stabilization of the pyridine ring. Furthermore, without the use of directing groups, such nucleophilic addition reactions are often plagued by poor regioselectivity. ${ }^{16,17}$
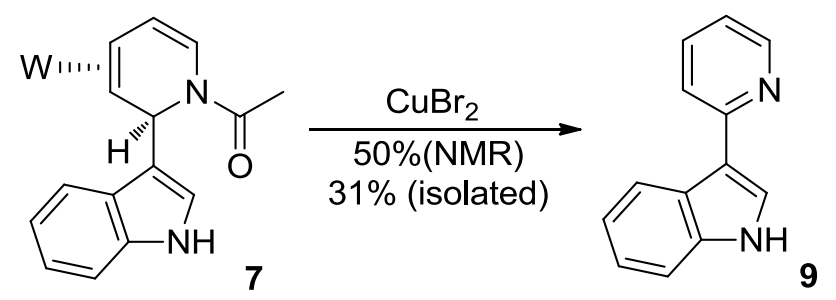

Eqn. 1

\section{Concluding Remarks:}

This preliminary study shows that a borane-adduct can be an effective synthon for the preparation of $\pi$-complexes of basic $N$-heterocycles that otherwise could bind through nitrogen. Once the heterocycle is coordinated through the $\pi$-system, the 
nitrogen can be deprotected and chemically accessed, pre-empting its coordination to the metal. In the present case, tungsten coordination of pyridine increases the basicity and nucleophilicity of the nitrogen, resulting in its facile acetylation. Yet remarkably, this dearomatized acetylpyridinium complex regio- and stereoselectively combines with mild carbon nucleophiles to give C2-substituted dihydropyridine complexes that could potentially be elaborated into highly functionalized piperidines. Further modification of the resulting enamide functionality is currently under investigation.

\section{Experimental Section:}

General Methods. NMR spectra were obtained on a 300 or $500 \mathrm{MHz}$ spectrometer (Varian INOVA or Avance Bruker). All chemical shifts are reported in ppm and proton and carbon shifts are referenced to tetramethylsilane (TMS) utilizing residual ${ }^{1} \mathrm{H}$ or ${ }^{13} \mathrm{C}$ signals of the deuterated solvents as an internal standard. Phosphorus NMR signals are referenced to $85 \% \mathrm{H}_{3} \mathrm{PO}_{4}(\delta=$ 0.00) using a triphenylphosphate external standard $(\delta=-16.58)$. Coupling constants $(J)$ are reported in hertz $(\mathrm{Hz})$. Infrared spectra (IR) were recorded on a MIDAC Prospect Series (Model PRS) spectrometer as a glaze on a Horizontal Attenuated Total Reflectance (HATR) accessory (Pike Industries). Electrochemical experiments were performed under a dinitrogen atmosphere using a BAS Epsilon EC-2000 potentiostat. Cyclic voltammetry data was taken at ambient temperature at $100 \mathrm{mV} / \mathrm{s}\left(25^{\circ} \mathrm{C}\right)$ in a standard three-electrode cell from +1.7 to $-1.7 \mathrm{~V}$ with a glassy carbon working electrode, $\mathrm{N}, \mathrm{N}$-dimethylacetamide (DMA) or acetonitrile (MeCN) solvent (unless otherwise specified), and tetrabutylammoniumhexaflurophosphate (TBAH) electrolyte (approx. 0.5 M). All potentials are reported versus NHE (Normal Hydrogen Electrode) using cobaltocenium hexafluorophosphate $\left(E_{1 / 2}=-0.78 \mathrm{~V}\right)$, ferrocene $\left(E_{1 / 2}=+0.55 \mathrm{~V}\right)$, or 
decamethylferrocene $\left(E_{1 / 2}=+0.04 \mathrm{~V}\right)$ as an internal standard. The peak-to-peak separation was less than $100 \mathrm{mV}$ for all reversible couples. Elemental analyses (EA) were obtained from Atlantic Microlabs and agree to within $0.4 \%$ for $\mathrm{C}, \mathrm{H}$, and $\mathrm{N}$. High resolution electrospray ionization mass spectrometry (ESI-MS) analyses were obtained from the University of Illinois at UrbanaChampaign Mass Spectrometry Laboratory. Unless otherwise noted, all synthetic reactions and electrochemical experiments were performed in a glovebox under a dry nitrogen atmosphere. $\mathrm{CH}_{2} \mathrm{Cl}_{2}$, benzene, and THF (tetrahydrofuran) were purified by passage through a column packed with activated alumina. Other solvents and liquid reagents were thoroughly purged with nitrogen prior to use. Triflate salts were synthesized by addition of an $\mathrm{Et}_{2} \mathrm{O}$ solution of triflic acid to the appropriate conjugate base solublized in $\mathrm{Et}_{2} \mathrm{O}$. Deuterated solvents were used as received from Cambridge Isotopes. General Proton Assignments are in accordance with the Figure S1. Pyrazole, Pz, protons of the (trispyrazolyl)borate, Tp, ligand were assigned using a combination of 2-dimensional NMR experiments and phosphorous-proton coupling when unambiguous assignments were possible (Figure S2). ${ }^{1}$ When unambiguous assignments were not possible the Pz protons are labeled as Tp protons. Coordination diastereomers are described by the defining feature's (i.e. heteroatom's) proximity to the $\mathrm{PMe}_{3}$ ligand relative to the $\mathrm{W}-\mathrm{PMe}_{3}$ bond (e.g. the fewer number of bonds from the $\mathrm{PMe}_{3}$ passing through the upper portion of the coordinated ring system to the defining feature dictates the proximal (P) ligand). Characterization of compound $3 \mathbf{H}$ was previously published. ${ }^{2}$ 2-(Trimethylsiloxy)propene ( $\left.\geq 85 \%\right)$ and pyridine borane are commercially available through Sigma-Aldrich and were used as received. Acetic anhydride was distilled from $\mathrm{CaH}_{2}$ at reduced pressure prior to use.

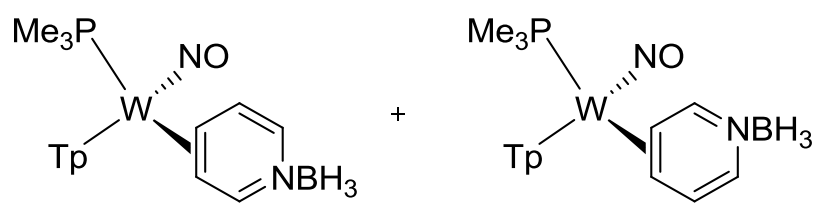


$\left.\operatorname{TpW}(\mathrm{NO})\left(\mathrm{PMe}_{3}\right)\left(3,4-\eta^{2} \text {-pyridine-borane) (2; D:P= 3:1). TpW(NO)(PMe}\right)_{3}\right)\left(\eta^{2}\right.$-benzene) $(5.00 \mathrm{~g}$, $8.61 \mathrm{mmol}$ ) was added to a $100 \mathrm{~mL}$ flame dried round bottom flask containing stirring neat pyridine borane $(30.0 \mathrm{~g}, 0.323 \mathrm{~mol})$. After stirring for 15 hours, the green solution was transferred to a 2 liter filter flask, diluted with $60 \mathrm{~mL} \mathrm{THF}$, followed by $250 \mathrm{mLEt}{ }_{2} \mathrm{O}$, then $900 \mathrm{~mL}$ of hexanes. The solution was allowed to settle for 15 minutes while a celite column $(2 \mathrm{~cm}$ tall $\mathrm{x}$ $3.5 \mathrm{~cm}$ wide) was prepared on a $30 \mathrm{~mL}$ medium porosity fritted funnel. The solution was decanted through the celite leaving a green oil. The oil was again diluted with $60 \mathrm{~mL} \mathrm{THF}$, followed by $250 \mathrm{mLEt}{ }_{2} \mathrm{O}$, then $900 \mathrm{~mL}$ of hexanes. The solution was once again decanted through the celite column. The green oil was diluted with $60 \mathrm{~mL}$ of THF, $250 \mathrm{~mL}$ of $\mathrm{Et}_{2} \mathrm{O}$, followed by $900 \mathrm{~mL}$ hexanes. The solution was decanted through the celite and a clumpy material remained in the original flask. The material captured by the celite was dissolved with 60 $\mathrm{mL}$ THF and returned to the original $2 \mathrm{~L}$ flask containing the clumped material. Upon complete dissolution of the material, the solution was diluted with $250 \mathrm{~mL} \mathrm{Et}_{2} \mathrm{O}$, followed by $1.5 \mathrm{~L}$ hexanes. The precipitate was recollected on the $30 \mathrm{~mL}$ celite fritted funnel. It was redissolved with $200 \mathrm{~mL}$ of THF into the original $2 \mathrm{~L}$ flask, diluted with $350 \mathrm{~mL} \mathrm{Et} \mathrm{E}_{2} \mathrm{O}$ followed by $1.5 \mathrm{~L}$ of hexanes. The yellow precipitate was collected on a $60 \mathrm{~mL}$ medium porosity fritted funnel and rinsed with $2 \times 30 \mathrm{~mL}$ hexanes. The wet solid was transferred to a vial and placed under dynamic vacuum. The residual precipitate was redissolved in $60 \mathrm{~mL} \mathrm{THF}$, diluted with $250 \mathrm{~mL}$ of $\mathrm{Et}_{2} \mathrm{O}$, and $900 \mathrm{~mL}$ hexanes. The precipitate was collected, rinsed with $2 \times 30 \mathrm{~mL}$ hexanes, transferred wet to a vial and placed under dynamic vacuum. The combined mass recovery resulted in the isolation of the desired complex in $87 \%$ yield $(4.469 \mathrm{~g}, 7.50 \mathrm{mmol})$ with minimal residual pyridine borane remaining. ${ }^{1} \mathrm{H}$ NMR $\left(\mathrm{CDCl}_{3}, \delta\right)$ : Major: $8.65(1 \mathrm{H}, \mathrm{d}, J=4.6, \mathrm{H} 2), 8.01(1 \mathrm{H}, \mathrm{d}, \mathrm{PzA} 3), 7.87(1 \mathrm{H}, \mathrm{d}$, PzB3), 7.79 (2H, d, 2 Tp), 7.65 (1H, d, Tp), 7.15 (1H, d, PzC3), 6.49 (1H, dd, J = 7.1, 4.5, H5), 6.44 $(1 \mathrm{H}, \mathrm{d}, J=7.1, \mathrm{H} 6), 6.28(2 \mathrm{H}, \mathrm{t}, 2 \mathrm{Tp}), 6.24(\mathrm{H}, \mathrm{t}, \mathrm{Tp}), 3.71(1 \mathrm{H}, \mathrm{ddd}, J=13.3,8.5,4.5, \mathrm{H} 4), 2.2-3.2$ 
$\left(3 \mathrm{H}, \mathrm{br} \mathrm{s}, \mathrm{BH}_{3}\right), 2.11(1 \mathrm{H}, \mathrm{dd}, J=8.5,4.6, \mathrm{H} 3), 1.25\left(9 \mathrm{H}, \mathrm{d}, J=8.4, \mathrm{PMe}_{3}\right)$; Minor (Tp protons of minor product not reported due to extensive overlap with corresponding major peaks): 8.56 $(1 \mathrm{H}, \mathrm{br} \mathrm{s}, \mathrm{H} 2), 6.81(1 \mathrm{H}, \mathrm{t}, J=6.5, \mathrm{H} 5), 6.33(1 \mathrm{H}, \mathrm{d}, J=6.5, \mathrm{H} 6), 3.36(1 \mathrm{H}$, buried, $\mathrm{H} 3), 2.2-3.2(3 \mathrm{H}$, br s, $\left.\mathrm{BH}_{3}\right), 2.29(1 \mathrm{H}, \mathrm{t}, J=6.5, \mathrm{H} 4), 1.32\left(9 \mathrm{H}, \mathrm{d}, J=8.1, \mathrm{PMe}_{3}\right) .{ }^{13} \mathrm{C} \mathrm{NMR}\left(\mathrm{CDCl}_{3}, \delta\right)$ (only signals for major isomer are reported): Major: 169.5 (s, C2), 144.4 (s, PzA3), 144.2 (s, PzB3), 140.1 (s, PzC3), 136.9 (s, Tp), 136.5 (s, Tp), 135.6 (s, Tp), 126.8 (s, C6), 124.7 (s, C5), 106.7 (s, Tp), 106.5 (s, $\mathrm{Tp}), 106.3(\mathrm{~s}, \mathrm{Tp}), 62.0(\mathrm{~d}, J=10.7, \mathrm{C} 4), 57.6(\mathrm{~s}, \mathrm{C} 3), 12.9$ (d, J = 28.8, $\left.\mathrm{PMe}_{3}\right) .{ }^{31} \mathrm{P} \mathrm{NMR}\left(\mathrm{CDCl}_{3}, \delta\right):-$ $12.98\left(2 \mathrm{D}, J_{\mathrm{WP}}=298 \mathrm{~Hz}\right),-15.18\left(2 \mathrm{P}, J_{\mathrm{WP}}=292 \mathrm{~Hz}\right) . \mathrm{CV}: E_{\mathrm{p}, \mathrm{a}}=+0.44 \mathrm{~V} ; E_{\mathrm{p}, \mathrm{c}}=-1.94 \mathrm{~V} . \quad$ IR: $v_{\mathrm{NO}}=1585$ $\mathrm{cm}^{-1}, v_{\mathrm{BH}(\text { sym,asym })}=2345,2294,2256 \mathrm{~cm}^{-1}, v_{\mathrm{BH}(\mathrm{T})}=2491 \mathrm{~cm}^{-1}$. Anal. Calc'd for $\mathrm{C}_{17} \mathrm{H}_{27} \mathrm{~B}_{2} \mathrm{~N}_{8} \mathrm{OPW} \cdot 1 / 4$ $\mathrm{Et}_{2} \mathrm{O}: \mathrm{C}, 35.14 ; \mathrm{H}, 4.84 ; \mathrm{N}, 18.24$. Found: $\mathrm{C}, 35.03 ; \mathrm{H}, 4.91 ; \mathrm{N}, 18.07$.

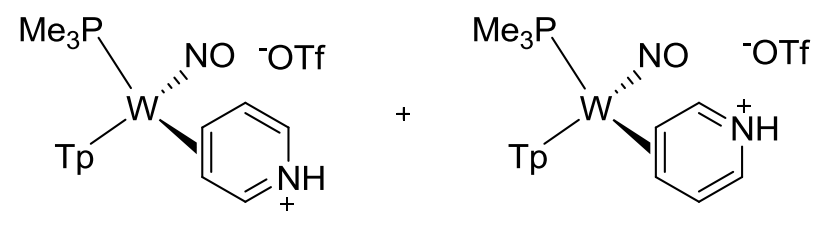

$\operatorname{TpW}(\mathrm{NO})\left(\mathrm{PMe}_{3}\right)\left(3,4-\eta^{2}\right.$-pyridinium)OTf (3H; D:P = 1:1).

In a $200 \mathrm{~mL}$ pear bottom flask, $1(3.420 \mathrm{~g}, 5.739 \mathrm{mmol})$ was suspended in stirring $\mathrm{Et}_{2} \mathrm{O}(145 \mathrm{~mL})$ for 15 minutes producing a yellow heterogeneous solution. Separately, diphenylamonium triflate (DPhAT) (1.792 g, $5.612 \mathrm{mmol})$ was dissolved in acetone (7.213 g) and the homogeneous solution was added to the suspension of $\mathbf{1}$ in $\mathrm{Et}_{2} \mathrm{O}$. Effervescence was immediately observed and the solution became an orange heterogeneous solution. The solution was allowed to stir for 14.5 hours. The orange precipitate was collected on a $30 \mathrm{~mL}$ medium porosity fritted funnel, washed with $\mathrm{Et}_{2} \mathrm{O}(2 \times 15 \mathrm{~mL})$, transferred to a vial and placed under dynamic vacuum $(92 \%$ yield, $3.851 \mathrm{~g}, 5.260 \mathrm{mmol})$. Characterization of $\mathbf{2}$ was previously published. ${ }^{2}$ 


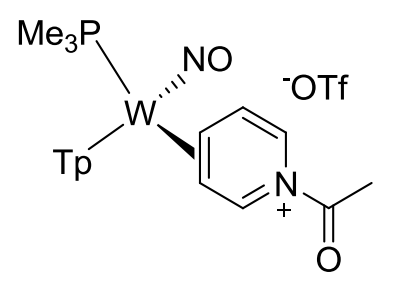

\section{$\operatorname{TpW}(\mathrm{NO})\left(\mathrm{PMe}_{3}\right)\left(3,4-\eta^{2}-N\right.$-acetylpyridinium)OTf (4; D:P >10:1).}

2,6-Ditert-butylpyridine (DTBP, $1.189 \mathrm{~g}, 6.215 \mathrm{mmol}$ ) was added to a $25 \mathrm{~mL}$ flame dried round bottom flask containing 3 (3.632 g, $4.961 \mathrm{mmol})$, acetic anhydride (7.603 g, $74.47 \mathrm{mmol})$, and MeCN (7.656 g). The resulting heterogeneous solution was allowed to stir for 1 hour and 35 minutes until it became deep red and nearly homogeneous. The flask was then placed in a $55{ }^{\circ} \mathrm{C}$ oil bath and allowed to stir for 5.5 hours. It was removed from the oil bath and allowed to cool for 10 minutes. The cool solution was filtered through a pipette, containing a Kimwipe covered with $1 \mathrm{~cm}$ of celite, into a $1 \mathrm{~L}$ filter flask containing $\mathrm{Et}_{2} \mathrm{O}(1270 \mathrm{~mL})$ precipitating an orange material. The precipitate was collected on a $60 \mathrm{~mL}$ medium porosity fritted funnel, washed with $\mathrm{Et}_{2} \mathrm{O}(5 \times 30 \mathrm{~mL})$, transferred to a vial and placed under dynamic vacuum in $94 \%$ yield $(3.593 \mathrm{~g}$, $4.641 \mathrm{mmol}) .{ }^{1} \mathrm{H} N M R\left(\mathrm{CD}_{3} \mathrm{CN}, \delta\right): 9.00(\mathrm{~d}, J=5.8,1 \mathrm{H}, \mathrm{H} 2), 8.1$ (d, $\left.1 \mathrm{H}, \mathrm{PzB} 3\right), 8.07(\mathrm{~d}, 1 \mathrm{H}, \mathrm{PzC}$ ), $8.03(d, 1 H, P z A 3), 8.01$ (d, 1H, PzB5), 7.86 (d, 1H, PzA5), 7.84 (d, 1H, PzC3), 6.53 (t, 1H, PzC4), $6.45(\mathrm{~m}, 3 \mathrm{H}, \mathrm{PzB} 4 / \mathrm{H} 5 / \mathrm{H} 6), 6.41(\mathrm{t}, 1 \mathrm{H}, \mathrm{PzA} 4), 4.29(\mathrm{~m}, 1 \mathrm{H}, \mathrm{H} 4), 3.50(\mathrm{t}, J=5.8,1 \mathrm{H}, \mathrm{H3}), 2.61(\mathrm{~s}$, 3H, Acetyl-Me), 1.23 (d, J = 9.6, 9H, PMe $)_{3} .{ }^{13} \mathrm{CNMR}\left(\mathrm{CD}_{3} \mathrm{CN}, \delta\right): 169.8(\mathrm{CO}), 159.9$ (C2), 148.7 (PzA3), 147.1 (PzB3), 142.9 (PzC3), 139.4 (PzC5), 138.5 (PzB5), 137.9 (PzA5), 125.2 (C5), 114.8 (C6), 108.9 (PzB4), 108.4 (PzC4), 108.3 (PzA4), 69.9 (C3), 66.2 (d, J = 14.0, C4), 22.5 (Me), 12.9 (d, $\left.J=32.0, \mathrm{PMe}_{3}\right) \cdot{ }^{31} \mathrm{P}$ NMR $\left(\mathrm{CDCl}_{3}, \delta\right):-9.61\left(J_{\mathrm{WP}}=283,4 \mathrm{D}\right),-14.33\left(J_{\mathrm{WP}}=276 \mathrm{~Hz}\right)(4 \mathrm{P}) . \mathrm{CV}: E_{\mathrm{p}, \mathrm{a}}=$ +1.13 V. IR: $v_{\mathrm{NO}}=1611 \mathrm{~cm}^{-1}, v_{\mathrm{CO}}=1733 \mathrm{~cm}^{-1}$ (weak). ESI-MS obs'd (\%), calc'd (\%), ppm $(\mathrm{M}+\mathrm{H})^{+}$: 623.1570 (85.7), 623.1582 (88.6), 1.9; 624.1590 (46.6), 624.1608 (81.7), 2.8; 625.1597 (100), 625.1609 (100), 1.9; 626.1631 (20.5), 626.1668 (43.7), 5.9; 627.1632 (93.2), 627.1652 (89.7), 3.3. Note: The initial ratio of the coordination diastereomers is $4: 1$ prior to heating the reaction 
solution. Isolating the products prior to isomerization allowed for the proton assignments of the ring protons in 4P (due to overlap of Tp protons with the other isomer, they are omitted below). ${ }^{1} \mathrm{H}$ NMR $\left(\mathrm{CDCl}_{3}, \delta\right): 9.38(1 \mathrm{H}, \mathrm{d}, J=5.8, \mathrm{H} 2), 6.82(1 \mathrm{H}, \mathrm{t}, J=6.9, \mathrm{H} 5), 6.6(1 \mathrm{H}$, buried, H6), 4.66 $(1 \mathrm{H}, \mathrm{dt}, J=6.1,5.8, \mathrm{H} 3), 3.06(1 \mathrm{H}, \mathrm{dd}, J=6.9,5.8, \mathrm{H} 4), 2.72(3 \mathrm{H}, \mathrm{s}$, methyl; overlaps with methyl of major isomer).

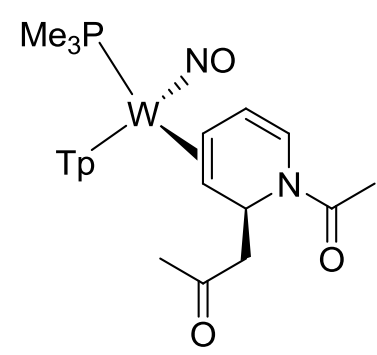

\section{$\operatorname{TpW}(\mathrm{NO})\left(\mathrm{PMe}_{3}\right)\left(3,4-\eta^{2}-(1-(1-a c e t y l-1,2-d i h y d r o p y r i d i n-2-y l) p r o p a n-2-o n e)\right)(5):$}

2-(Trimethylsiloxy)propene (0.113 g, $0.867 \mathrm{mmol} ; 0.096 \mathrm{~g}, 0.737 \mathrm{mmol}$ : adjusted for $85 \%$ purity) was added to a deep red homogeneous solution of 4 (0.324 g, $0.419 \mathrm{mmol})$ in $\mathrm{MeCN}(0.091 \mathrm{~g})$ and DME (0.316 g). DABCO (0.036 g, $0.321 \mathrm{mmol})$ was added to the resulting solution and it was allowed to stir for 16 hours. The heterogeneous solution was collected on a $15 \mathrm{ml}$ fine porosity fritted funnel and was washed with a small amount of DME $(<0.25 \mathrm{~g})$. The tan precipitate was dried under dynamic vacuum for a mass recovery of $0.141 \mathrm{~g}$. The precipitate was determined to contain a $5 \%$ mass impurity, by weight, of DABCO $\bullet$ HOTf resulting in an actual yield of 5 in $47 \%$ (0.134 g, $0.196 \mathrm{mmol}) .{ }^{1} \mathrm{H}$ NMR $\left(\mathrm{CD}_{3} \mathrm{CN}, \delta\right): 8.29$ (d, $\left.1 \mathrm{H}, \mathrm{PzA} 3\right), 8.01(\mathrm{~d}, 1 \mathrm{H}, \mathrm{PzB} 3), 7.86(\mathrm{~m}, 2 \mathrm{H}$, PzB5/PzC5), 7.78 (d, 1H, PzA5), 7.38 (d, 1H, PzC3), 6.37 (t, 1H, PzB4), 6.34 (t, 1H, PzA4), 6.29 (t, $1 \mathrm{H}, \mathrm{PzC} 4), 5.94(\mathrm{dd}, J=7.5,5.4,1 \mathrm{H}, \mathrm{H} 5), 5.85(\mathrm{t}, J=6.8,1 \mathrm{H}, \mathrm{H} 2), 5.80(\mathrm{~d}, J=7.5,1 \mathrm{H}, \mathrm{H} 6), 2.86$ (ddd, $J=12.9,10.4,5.4,1 \mathrm{H}, \mathrm{H} 4), 2.75\left(\mathrm{~d}, J=6.8,2 \mathrm{H}, 2^{\prime}-\mathrm{CH} 2-\right)$, $2.06\left(\mathrm{~s}, 3 \mathrm{H}, 2^{\prime}-\mathrm{CH} 3\right), 2.03(\mathrm{~s}, 3 \mathrm{H}, \mathrm{N}-$ acetyl-CH3), $1.44(\mathrm{~d}, J=10.4,1 \mathrm{H}, \mathrm{H} 3), 1.23\left(\mathrm{~d}, J=8.6,9 \mathrm{H}, \mathrm{PMe}_{3}\right) ;{ }^{13} \mathrm{C} \mathrm{NMR}\left(\mathrm{CD}_{3} \mathrm{CN}, \delta\right): 208.7$ (s, CO (ketone)), 168.7 (s, CO (amide)), 144.9 (s, PzA3), 144.3 (s, PzB3), 141.5 (s, PzC3), 137.8/137.3 (s, PzB5/PzC5), 136.9 (s, PzA5), 117.9 (s, C5), 117.5 (s, C6), 107.3 (s, PzB4), 107.1 (s, PzC4), 106.9 
(s, PzA4), 64.0 (s, C3), 52.1 (s, 2'-CH2-), 47.3 (s, C2), 45.0 (d, J = 9.9 hz, C4), 30.6 (s, 2'-CH3), 23.2 (s, N-acetyl-CH3), 13.6 (d, J = 28.8, PMe 3 ); ${ }^{31} \mathrm{P}$ NMR $\left(\mathrm{CD}_{3} \mathrm{CN}, \delta\right):-12.01\left(J_{\mathrm{WP}}=283 \mathrm{~Hz}\right),-9.20$ (minor cd-product); CV (MeCN): $\mathrm{E}_{p, a}=+0.54 \mathrm{~V} ; \mathrm{IR}: v_{\mathrm{NO}}=1562 \mathrm{~cm}^{-1}, v_{\text {amide }}=1616 \mathrm{~cm}^{-1}, v_{\mathrm{CO}}=1701$ $\mathrm{cm}_{-1}, v_{\mathrm{BH}}=2488 \mathrm{~cm}^{-1}$. ESI-MS obs'd (\%), calc'd (\%), ppm [(M+H) $\left.{ }^{+}\right]: 681.1989$ (85.7), 681.1976 (100.9), 1.9; 682.2009 (46.6), 682.2007 (78.8), 0.3; 683.2016 (100), 683.2000 (100), 2.3; 684.2050 (23.8), 684.2009 (52.2), 5.9; 685.2050 (93.2), 685.2051 (70.8), 0.1.

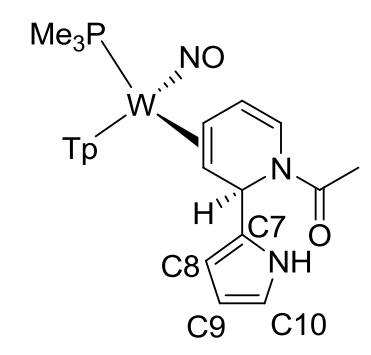

$\operatorname{TpW}(\mathrm{NO})\left(\mathrm{PMe}_{3}\right)\left(3,4-\eta^{2}-(1-(2-(1 H-p y r r o l-2-y l) p y r i d i n-1(2 H)-y l)\right.$ ethanone)) (6):

Lutidine $(0.072 \mathrm{~g}, 0.672 \mathrm{mmol})$ was added to a deep red homogeneous solution of $3(0.200 \mathrm{~g}$, $0.258 \mathrm{mmol}$ ) and pyrrole $(1.005 \mathrm{~g}, 14.980 \mathrm{mmol})$. After 30 minutes, the solution was removed from the glovebox, diluted with $2 \mathrm{~mL} \mathrm{DCM}$ and extracted with $3 \times 2 \mathrm{~mL}$ saturated $\mathrm{NaHCO}_{3}$ solution. The water fractions were back extracted with $3 \times 1 \mathrm{~mL}$ DCM. The DCM fractions were combined, dried with $\mathrm{MgSO}_{4}$, and filtered through celite. The solution was then further diluted with $50 \mathrm{~mL} \mathrm{DCM}$ and loaded onto a $5.5 \mathrm{~cm} \times 1.5 \mathrm{~cm} \mathrm{SiO}{ }_{2}$ column containing a sand bedding, which was prepared by making an $\mathrm{Et}_{2} \mathrm{O}$ slurry and washing with $20 \mathrm{~mL} \mathrm{DCM}$. The column was washed with $50 \mathrm{~mL}$ DCM, $150 \mathrm{~mL}$ 10\% EtOAc in $\mathrm{Et}_{2} \mathrm{O}$, followed by $100 \mathrm{~mL}$ acetone. The yellow band eluted with acetone and the solvent was removed in vacuo. The orange residue was dissolved in $\sim 0.3 \mathrm{~g}$ EtOAc and $8 \mathrm{~mL}$ of hexanes was added to the heterogeneous solution. The tan precipitate was collected on a $15 \mathrm{~mL}$ medium porosity fritted funnel. The precipitate remaining in the vial was redissolved in EtOAc and reprecipitated in hexanes twice more. The additional precipitate was collected on the same fritted funnel (51\% Yield, $0.091 \mathrm{~g}, 0.132 \mathrm{mmol}$ ). 
${ }^{1} \mathrm{H}$ NMR $\left(\mathrm{CD}_{3} \mathrm{CN}, \delta\right): 9.06$ (s (br), $\left.1 \mathrm{H}, \mathrm{NH}\right), 8.21$ (d, $\left.J=2.0,1 \mathrm{H}, \mathrm{PzA} 3\right), 8.03$ (d, $J=2.0,1 \mathrm{H}, \mathrm{PzB} 3$ ), $7.87(\mathrm{~d}, J=2.0,1 \mathrm{H}, \mathrm{PzB} 5), 7.86(\mathrm{~d}, J=2.0,1 \mathrm{H}, \mathrm{PzC} 5), 7.79(\mathrm{~d}, J=2.0,1 \mathrm{H}, \mathrm{PzA} 5), 7.48(\mathrm{~d}, J=2.0$, $1 \mathrm{H}, \mathrm{PzC} 3), 6.59(\mathrm{~m}, 1 \mathrm{H}, \mathrm{H} 10), 6.54(\mathrm{~s}, 1 \mathrm{H}, \mathrm{H} 2), 6.37(\mathrm{t}, J=2.0,1 \mathrm{H}, \mathrm{PzB} 4), 6.33(\mathrm{t}, J=2.0,1 \mathrm{H}$, PzA4), 6.3 (t, J = 2.0, 1H, PzC4), 5.97 (m, 3H, H5/H8/H9), 5.79 (d, J = 8.1, 1H, H6), 2.1 (s, 3H, AcylMe), $1.7(\mathrm{~d}, J=10.3,1 \mathrm{H}, \mathrm{H} 3), 1.21\left(\mathrm{~d}, J=8.6,9 \mathrm{H}, \mathrm{PMe}_{3}\right) ;{ }^{13} \mathrm{CNMR}\left(\mathrm{CD}_{3} \mathrm{CN}, \delta\right): 169.4(\mathrm{CO}), 144.4$ (PzB3), 144.3 (PzA3), 141.7 (PzC3), 137.8/137.4 (PzB5/PzC5), 137 (PzA5), 117.9 (C5/C6), 117.2 (C10), 107.7 (C8), 107.3/107.1/107.0 (PzA4/PzB4/PzC4), 106.1 (C9), 62.2 (C3), 47 (C2), 45.5 (d, J $=8.1, \mathrm{C} 4), 13.7\left(\mathrm{~d}, J=28.8, \mathrm{PMe}_{3}\right) ;{ }^{31} \mathrm{P} \mathrm{NMR}\left(\mathrm{CDCl}_{3}, \delta\right):-12.01\left(J_{\mathrm{WP}}=282 \mathrm{~Hz}, \mathrm{cdp}-\mathrm{d}\right),-9.20$ (minor cd-product); CV (DMA): $\mathrm{E}_{p, a}=+0.48 \mathrm{~V}$; IR: $v_{\mathrm{NO}}=1558 \mathrm{~cm}^{-1}, v_{\text {amide }}=1608 \mathrm{~cm}^{-1}, v_{\mathrm{BH}}=2488 \mathrm{~cm}^{-1}, v_{\mathrm{NH}}$ $=3113 \mathrm{~cm}^{-1}$. ESI-MS obs'd (\%), calc'd (\%), ppm [(M+H) $]$ : 690.1992 (85.7), 690.1976 (101.2), 2.3; 691.2012 (46.6), 691.1996 (99.7), 2.4; 692.2019 (100), 692.2017 (100), 0.3; 693.2053 (24.8), 693.2038 (62.2), 2.1; 694.2054 (93.2), 694.2054 (73.2), 0.1.
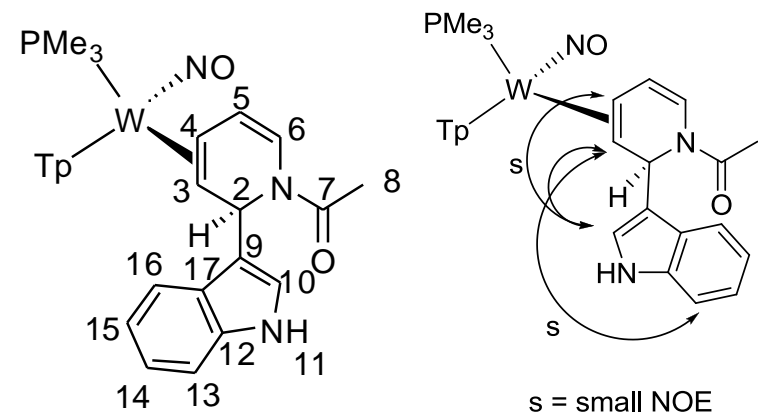

$\mathrm{TpW}(\mathrm{NO})\left(\mathrm{PMe}_{3}\right)\left(3,4-\eta^{2}-(1-(2-(1 H\right.$-indol-3-yl)pyridin-1(2H)-yl)ethanone)) (7):

Lutidine $(0.141 \mathrm{~g}, 1.316 \mathrm{mmol})$ was added to a deep red solution of $3(0.815 \mathrm{~g}, 1.053 \mathrm{mmol})$, indole $(0.155 \mathrm{~g}, 1.323 \mathrm{mmol})$, and DCM $(1.27 \mathrm{~g})$. After 8.5 hours, the precipitate from the reaction solution was collected on a $15 \mathrm{~mL}$ medium porosity fritted funnel and washed with 1 $\mathrm{mL}$ DCM. The pale white precipitate was placed under dynamic vacuum to obtain a $61 \%$ yield (0.479 g, 0.646 mmol). ${ }^{1} \mathrm{H}$ NMR (DMSO- $\left.d_{6}, \delta\right): 10.73$ (s, 1H, H11(NH)), 8.51 (d, J = 2.0, 1H, PzA3), $8.01(\mathrm{~d}, J=2.0,1 \mathrm{H}, \mathrm{PzB} 3), 7.99(\mathrm{~d}, J=2.0,1 \mathrm{H}, \mathrm{PzB} 5), 7.97(\mathrm{~d}, J=2.0,1 \mathrm{H}, \mathrm{PzC} 5), 7.87(\mathrm{~d}, J=2.0$, 
1H, PzA5), 7.71 (d, J = 7.9, 1H, H13), 7.63 (d, J= 2.0,1H, PzC3), 7.43 (d, J = 1.5, 1H, H10), 7.26 (d, $J=8.1,1 \mathrm{H}, \mathrm{H} 16), 6.97(\mathrm{t}, J=7.5,1 \mathrm{H}, \mathrm{H} 15), 6.87(\mathrm{t}, J=7.5,1 \mathrm{H}, \mathrm{H} 14), 6.77(\mathrm{~s}, 1 \mathrm{H}, \mathrm{H} 2), 6.4(\mathrm{~m}, 1 \mathrm{H}$, PzB4), 6.29 (m, 1H, PzC4), 5.91 (dd, J = 6.5, 1H, H5), 5.66 (d, J = 7.5, 1H, H6), 3.18 (ddd, J = 13.9, 10.4, 5.5, 1H, H4), 2.01 (s, 3H, Acyl-Me), $1.73(\mathrm{~d}, J=10.2,1 \mathrm{H}, \mathrm{H} 3), 1.23\left(\mathrm{~d}, J=8.5,9 \mathrm{H}, \mathrm{PMe}_{3}\right) ;{ }^{13} \mathrm{C}$ NMR (DMSO- $\left.d_{6}, \delta\right): 168.0$ (CO), 145 (PzA3), 143.9 (PzB3), 141.7 (PzC3), 137.7 (PzC5), 137.3 (PzB5), 137 (C12), 136.8 (PzA5), 127.5 (C17), 125.1 (C10), 121.5 (C9), 121.4 (C15), 120.4 (C13), 118.9 (C14), 118.2 (C6), 111.9 (C16), 107.28 (PzA4), 107.2 (PzC4), 106.82 (PzB4), 64.81 (C3), 45.86 (d, $J=8.8, \mathrm{C} 4$ ), 44.75 (C2), 24.08 (Acyl-Me), 13.95 (d, $\left.J=28.1, \mathrm{PMe}_{3}\right) ;{ }^{31}$ P NMR (DMSO- $d_{6}$, ס): $-10.59\left(J_{\mathrm{WP}}=283 \mathrm{~Hz}\right) ; \mathrm{CV}(\mathrm{MeCN}): E_{\mathrm{p}, \mathrm{a}}=+0.51 \mathrm{~V}$; IR: $v_{\mathrm{NO}}=1539 \mathrm{~cm}^{-1}, v_{\text {amide }}=1612 \mathrm{~cm}^{-1}, v_{\mathrm{BH}}=$ $2484 \mathrm{~cm}^{-1}, v_{\mathrm{NH}}=3223 \mathrm{~cm}^{-1}$. ESI-MS obs'd (\%), calc'd (\%), ppm [(M+H) $\left.{ }^{+}\right]: 685.1938$ (85.7), 685.1949 (88.1), 1.6; 686.1958 (46.6), 686.1979 (79.3), 3; 687.1965 (100), 687.1978 (100), 1.9; 688.2036 (23), 688.2010 (38.7), 3.7; 689.1999 (93.2), 689.1990 (83.7), 1.4.

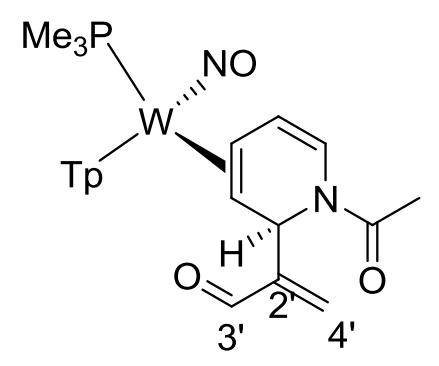

$\operatorname{TpW}(\mathrm{NO})\left(\mathrm{PMe}_{3}\right)\left(3,4-\eta^{2}-(2-(1-a c e t y l-1,2-d i h y d r o p y r i d i n-2-y l) a c r y l a l d e h y d e)\right)(8):$

In a hood, acrolein $(0.030 \mathrm{~g}, 0.535 \mathrm{mmol})$ was dissolved in DCM $(0.350 \mathrm{~g})$ followed by the addition of quinuclidine $(0.029 \mathrm{~g}, 0.261 \mathrm{mmol})$. The resulting solution was promptly added to 4 $(0.100 \mathrm{~g}, 0.129 \mathrm{mmol})$. After 30 minutes, the reaction solution was diluted with $\mathrm{DCM}(\sim 2 \mathrm{~mL})$ and extracted with saturated $\mathrm{NaHCO}_{3}$ solution $(4 \times 2 \mathrm{~mL})$. The water layers were combined and back extracted with DCM (5 × $3 \mathrm{~mL}$ ). The DCM solution was dried with $\mathrm{MgSO}_{4}$ and filtered through celite. The remaining $\mathrm{MgSO}_{4}$ was washed with $\mathrm{DCM}$ and filtered through the celite until the washings were nearly colorless. The solvent was removed in vacuo. EtOAc $(0.5 \mathrm{~g})$ was added 
to the resulting residue and the solution was triturated until a precipitate was visible. Hexanes $(5 \mathrm{~mL})$ was added to the heterogeneous stirring EtOAc solution and the precipitate was collected on a fine porosity fritted funnel. Residual precipitate remaining in the vial was redissolved in DCM and solvent removed in vacuo. EtOAc $(0.5 \mathrm{~g})$ was added to the resulting residue, followed by the addition of hexanes $(5 \mathrm{~mL})$. The precipitate was collected on the same fritted funnel. Again, the residual precipitate in the vial was redissolved in DCM and the solvent was removed in vacuo. EtOAc $(0.5 \mathrm{~g})$ was added to the residue followed by the addition of hexanes $(5 \mathrm{~mL})$. The resulting precipitate was again collected with the same fritted funnel. The isolated precipitate consisted of the product from the major coordination diastereomer of the $\mathbf{4}$ in $88 \%$ yield with a $2 \%$ impurity by mass $(77.0 \mathrm{mg}, 0.113 \mathrm{mmol})$. The filtrate was dried in vacuo and the isolated material was the product of the minor coordination diastereomer of 4 in $6.5 \%$ yield $(5.7 \mathrm{mg}$, $0.008 \mathrm{mmol})$. The isolated yield of the reaction is therefore $92 \%$. NOTE: 8 can be produced with a variety of bases in addition to quinuclidine, including $\mathrm{DABCO}$ and $\mathrm{PPh}_{3} .{ }^{1} \mathrm{HNMR}\left(\mathrm{CDCl}_{3}, \delta\right): 9.56$ (s, $1 \mathrm{H}, \mathrm{CHO}), 8.39(\mathrm{~d}, J=2.0,1 \mathrm{H}, \mathrm{PzA} 3), 7.99(\mathrm{~d}, J=2.0,1 \mathrm{H}, \mathrm{PzB} 3), 7.69(\mathrm{~d}, J=2.0,2 \mathrm{H}$, PzB5/PzC5), 7.6 (d, J = 2.0, 1H, PzA5), $7.2\left(\mathrm{~d}, J=2.0,1 \mathrm{H}, \mathrm{PzC}\right.$ ), $6.5(\mathrm{~s}, 1 \mathrm{H}, \mathrm{H} 2), 6.32\left(\mathrm{~s}, 1 \mathrm{H}, \mathrm{H} 4^{\prime}\right)$, $6.27(\mathrm{~m}, 2 \mathrm{H}, \mathrm{PzA} 4 / \mathrm{PzB} 4), 6.17(\mathrm{t}, J=2.0,1 \mathrm{H}, \mathrm{PzC} 4), 6(\mathrm{~d}, J=8.0,1 \mathrm{H}, \mathrm{H} 6), 5.99\left(\mathrm{~s}, 1 \mathrm{H}, \mathrm{H} 4{ }^{\prime}\right), 5.79$ $(\mathrm{dd}, J=8.0,5.6,1 \mathrm{H}, \mathrm{H} 5), 2.76(\mathrm{ddd}, J=12.8,10.2,5.6,1 \mathrm{H}, \mathrm{H} 4), 1.84(\mathrm{~d}, J=10.2,1 \mathrm{H}, \mathrm{H} 3), 1.21$ (d, $\left.J=8.3,9 \mathrm{H}, \mathrm{PMe}_{3}\right) ;{ }^{13} \mathrm{C} \mathrm{NMR}\left(\mathrm{CDCl}_{3}, \delta\right): 194.4$ ((CO)-aldehyde), 168.9 ((CO)-amide), 153.7 (C2'), 144.9 (PzA3), 143.3 (PzB3), 140 (PzC3), 136.7/136.1 (PzB5/PzC5), 135.8 (PzA5), 131.2 (C4'), 118.1 (C6), 115.9 (C5), 106.5/106.3 (PzA4/PzB4), 106.2 (PzC4), 61.3 (C3), 44.6 (d, $J=10.4, C 4), 23.3$ (Acyl-Me), $13.77\left(\mathrm{~d}, J=27.9, \mathrm{PMe}_{3}\right) ;{ }^{31} \mathrm{P} \mathrm{NMR}\left(\mathrm{CDCl}_{3}, \delta\right):-12.28\left(J_{\mathrm{WP}}=282 \mathrm{~Hz}\right) ; \mathrm{CV}(\mathrm{MeCN}): E_{\mathrm{p}, \mathrm{a}}=$ +0.54 V; IR: $v_{\mathrm{NO}}=1558 \mathrm{~cm}^{-1}, v_{\text {amide }}=1616 \mathrm{~cm}^{-1}, v_{\text {enone }}=1685 \mathrm{~cm}^{-1}, v_{\mathrm{BH}}=2491 \mathrm{~cm}^{-1} ;$ ESI-MS obs'd (\%), calc'd (\%), ppm [(M+H) $\left.{ }^{+}\right]: 679.1832$ (85.7), 679.1816 (91.2), 2.4; 680.1852 (46.6), 680.1837 
(85), 2.3; 681.186 (100), 681.1855 (100), 0.7; 682.1893 (23.8), 682.1877 (51), 2.4; 683.1894

(93.2), 683.1896 (79.3), 0.3.

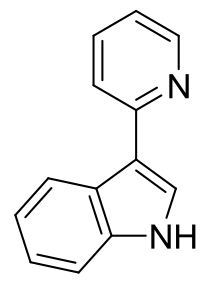

3-(pyridin-2-yl)-1H-indole: (9)

MeCN (2.02 g) was added to a vial containing $7(0.050 \mathrm{~g}, 0.0675 \mathrm{mmol})$ and $\mathrm{CuBr}_{2}(0.038 \mathrm{~g}, 0.170$ $\mathrm{mmol}$ ). The pale yellow heterogeneous solution became deep orange and homogeneous within about 1 minute. The solution was allowed to stir for 45 minutes when it was removed from the glovebox and diluted with $15 \mathrm{~mL}$ of DCM. Saturated aqueous $\mathrm{Na}_{2} \mathrm{CO}_{3}$ solution (15 mL) was added to the new solution to precipitate any insoluble salts. The DCM was removed and placed in a separate flask. The water layer was extracted with DCM $(2 \times 15 \mathrm{~mL})$. The combined DCM layers were washed with saturated aqueous $\mathrm{Na}_{2} \mathrm{CO}_{3}(15 \mathrm{~mL})$ and then dried with $\mathrm{MgSO}_{4}$. The $\mathrm{MgSO}_{4}$ was removed by filtering through a $30 \mathrm{~mL}$ medium porosity fritted funnel and was washed with DCM until the washings were nearly colorless. The solvent was removed in vacuo. The orange residue was slowly loaded onto a glass supported $\mathrm{Al}_{2} \mathrm{O}_{3}$ preparatory TLC plate $(1000$ micron $\times 20$ $\mathrm{cm} \times 20 \mathrm{~cm}$ ) and eluted with 2.5\% EtOAc in DCM (by volume). The alumina containing the blue fluorescent band with an $R_{f}=0.29$ was removed from the plate and was slowly washed with distilled $\mathrm{Et}_{2} \mathrm{O}(150 \mathrm{~mL})$ over a $15 \mathrm{~mL}$ fine porosity fritted funnel. $\mathrm{Et}_{2} \mathrm{O}$ was removed in vacuo yielding a solid residue in $31 \%$ yield $(0.004 \mathrm{~g}, 0.0206 \mathrm{mmol})$. Characterization of 9 has been previously published. ${ }^{3}$

\section{References:}

(1) Keane, J. M.; Harman, W. D. Organometallics 2005, 24, 1786-1798. 
(2) Harman, W. D. Chem. Rev. 1997, 97, 1953-1978.

(3) Smith, P. L.; Chordia, M. D.; Harman, W. D. Tetrahedron 2001, 8203-8225.

(4) Delafuente, D. A.; Kosturko, G. W.; Graham, P. M.; Harman, W.; Myers, W. H.; Surendranath, Y.; Klet, R. C.; Welch, K. D.; Trindle, C. O.; Sabat, M.; Harman, W. D. J. Am. Chem. Soc. 2007, 129, 406-416.

(5) Welch, K. D.; Harrison, D. P.; Lis, E. C., Jr.; Liu, W.; Salomon, R. J.; Harman, W. D.; Myers, W. H. Organometallics 2007, 26, 2791-2794.

(6) as determined by solution ${ }^{1} \mathrm{H}$ NMR data.

(7) Brown, H. C.; Murray, L. T. Inorg. Chem. 1984, 23, 2746-2753.

(8) A crystal structure determination of $\mathbf{3}$ was obtained but internal disorder prevented us from obtaining meaningful bond lengths and angles.

(9) 2D NMR techniques (COSY, HSQC, HMBC, NOESY) were used to analyze compounds 2, 4-8. Compounds 4-8 were all found to have $d r>10: 1$ in solution.

(10) Fersht, A. R.; Jencks, W. P. J. Am. Chem. Soc. 1970, 92, 5432-5433.

(11) Guibe-Jampel, E.; Le Corre, G.; Wakselman, M. Tetrahedron Lett. 1979, 1157-1160.

(12) Matsukawa, S.; Okano, N.; Imamoto, T. Tetrahedron Lett. 2000, 103-107.

(13) This reaction also occurs with DABCO or $\mathrm{PPh}_{3}$ in place of quinuclidine.

(14) Amat, M.; Hadida, S.; Bosch, J. Tetrahedron Lett. 1994, 35, 793-796.

(15) Corey, E. J.; Tian, Y. Org. Lett. 2005, 7, 5535-5537.

(16) Comins, D. L.; Abdullah, A. H. J. Org. Chem. 1982, 47, 4315-4319.

(17) Yamaguchi, R.; Nakazono, Y.; Kawanishi, M. Tetrahedron Lett. 1983, 24, 1801-1804.

(18) Davies, S. G.; Shipton, M. R. J. Chem. Soc., Chem. Commun. 1989, 995-996. 
Chapter 3

Stereo- and Regioselective Nucleophilic Addition to Dihapto-Coordinated Pyridine Complexes 


\section{Introduction:}

The chemical nature of aromatic molecules is fundamentally altered by their coordination to transition metals. ${ }^{1}$ For example, the arenes in complexes such as $\left(\eta^{6}-\right.$ arene $) \mathrm{Cr}(\mathrm{CO})_{3}{ }^{2,3}\left[\left(\eta^{6} \text {-arene }\right) \mathrm{Mn}(\mathrm{CO})_{3}\right]^{+},{ }^{4,5}\left[\left(\eta^{6} \text {-arene }\right) \mathrm{FeCp}\right]^{+},\left[\left(\eta^{6} \text {-arene }\right) \mathrm{RuCp}\right]^{+},{ }^{6-9}$ and $\left(\eta^{6}\right.$-arene) $\mathrm{Mo}(\mathrm{CO})_{3}{ }^{10}$ are susceptible to nucleophilic substitution, addition, or side-chain activation, $^{11}$ ultimately leading to the formation of substituted arenes or cyclohexadienes. Over the past four decades, the application of $\eta^{6}$-arene complexes to organic synthesis has been widely demonstrated. ${ }^{12}$ While such complexes are more reactive than their organic counterparts, an $\eta^{6}$-bound arene remains largely aromatic. $A$ complementary approach to activating aromatic molecules has been $\eta^{2}$-coordination. ${ }^{13}$ In this case, the metal-aromatic bond is stabilized primarily by interaction of a filled metal $d_{\pi}$ orbital with a $\pi^{*}$ orbital of the aromatic ligand, and through this interaction, the aromatic $\pi$ system becomes both more localized and more electron-rich. ${ }^{13}$

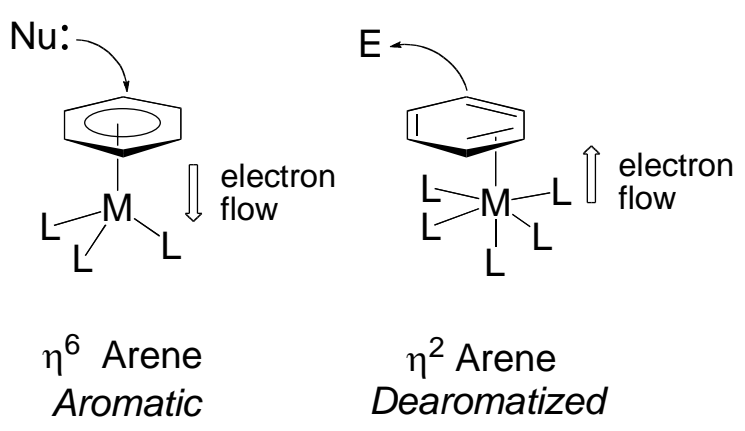

While the chemistry of arene $\pi$ complexes has been thoroughly explored, ${ }^{12}$ comparatively less is known about the chemistry of $\pi$-bound heterocycles. ${ }^{14-17}$ Consider 
the pyridine complex $\operatorname{TpW}(\mathrm{NO})\left(\mathrm{PMe}_{3}\right)\left(\eta^{2}\right.$-pyridine) $(\mathbf{1}),{ }^{18}$ in which the heterocycle is coordinated by $\mathrm{W}$ across $\mathrm{C} 3$ and $\mathrm{C} 4$ ( $\mathrm{M}$ in Scheme 1). As a consequence of metal-toligand $\pi$ backbonding, the nucleophilicity at nitrogen is enhanced, providing a route to stabilized pyridinium complexes. ${ }^{18}$ Such complexes were recently shown to undergo 5,6dialkoxylation $(\mathrm{X}=\mathrm{Y}=\mathrm{OR}$ ) without compromising the coordinating metal, and the subsequent addition of a nucleophile at C2 led to several novel $\Delta^{3}$-piperidines (Path 1). ${ }^{19}$ The goal of the present study is to explore the first step of the complementary reaction sequence (Path 2), and to compare this nucleophilic addition type to the analogous reaction for $\eta^{6}$-pyridines. ${ }^{14}$
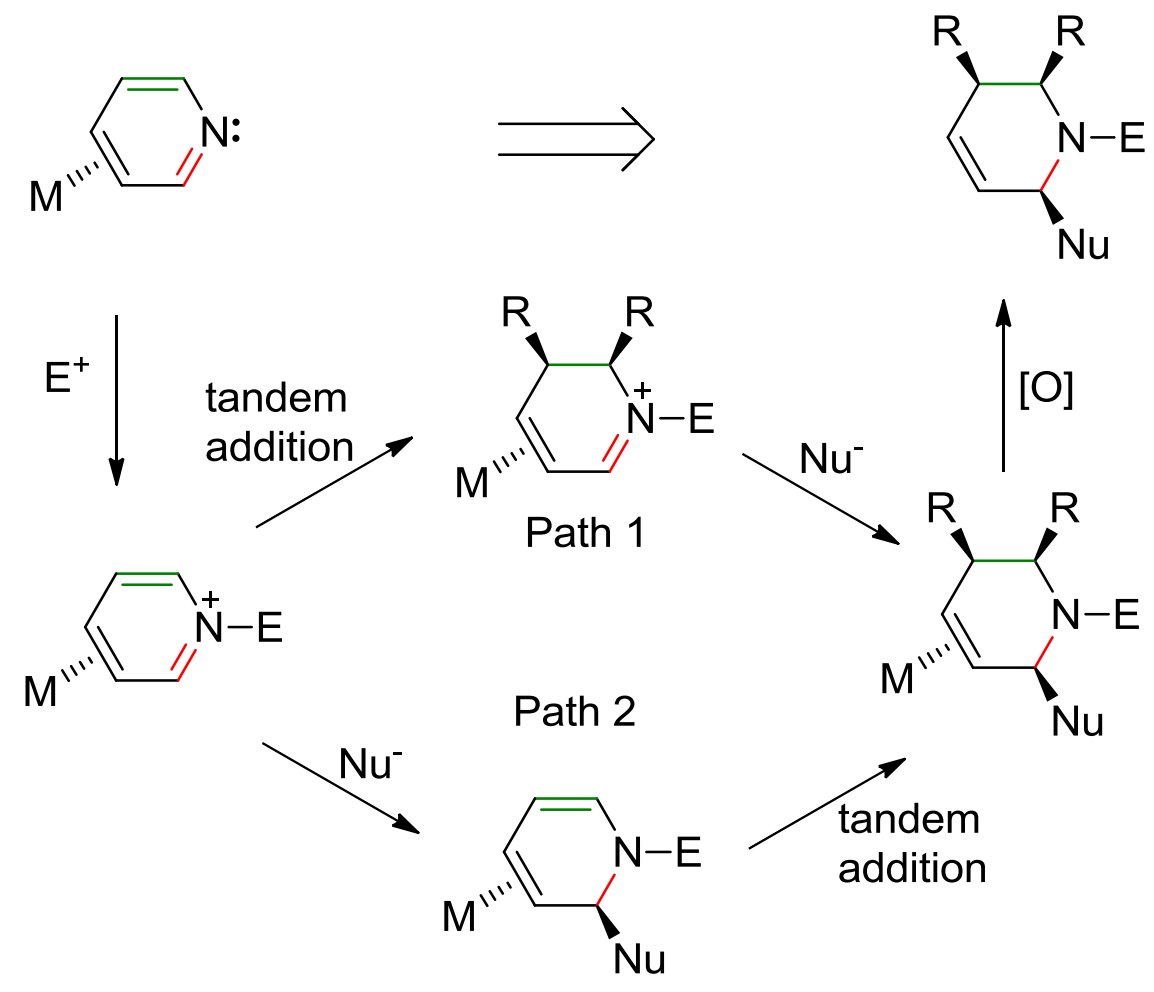

Scheme 1: Synthetic Strategy. 


\section{Results and Discussion:}

In earlier work, $\eta^{2}$-pyrrole and $\eta^{2}$-furan complexes of $\mathrm{Os}(\mathrm{II}), \operatorname{Re}(\mathrm{I})$, and $\mathrm{W}(0)$ were utilized in novel organic syntheses. ${ }^{16,20,21}$ However, until recently the development of parallel chemistry for pyridines, diazines, diazoles, and other elementary aromatic heterocycles has been hampered by a general thermodynamic preference of a transition metal to coordinate at nitrogen. ${ }^{22}$ In a recent communication, ${ }^{18}$ we reported a workaround for pyridine in which the nitrogen was temporarily blocked with $\mathrm{BH}_{3}$. Coordination followed by deprotection under acidic conditions led to the $\eta^{2}$-pyridinium complex, $\mathbf{1 H}$, which is the direct precursor to the $\eta^{2}$-pyridine complex $\mathbf{1}$ (the $\mathrm{pK}_{\mathrm{a}}$ of $\mathbf{1} \mathbf{H}$ is $\sim 10(\mathrm{DMSO})) .{ }^{18}$ The conversion of the $3,4-\eta^{2}$-pyridine complex to its $\kappa-\mathrm{N}$ isomer was found to have a sufficiently long half-life $\left(78\right.$ minutes at $22^{\circ} \mathrm{C}$ ) that electrophiles could be added to form stabilized pyridinium complexes (3-8 in Scheme 2).

Quantitative deprotonation of pyridinium $\mathbf{1 H}$ with DBU, followed by addition of MeOTf results in the synthesis of $\mathbf{3}$ (Scheme 2). Residual salts were removed by extraction with $\mathrm{NaHCO}_{3}$ (aq, sat'd) and precipitation from methylene chloride was induced by the addition of diethyl ether. ${ }^{1} \mathrm{H}$ NMR spectroscopy indicated that the methylpyridinium complex, $\mathbf{3}$, had an initial coordination diastereomer ratio $(\mathrm{cdr})^{13}$ of 2.4:1, similar to that observed for the parent pyridinium complex $\mathbf{1 H}$. Heating the complex at $105^{\circ} \mathrm{C}$ for $1 \mathrm{~h}$ changes the cdr from 2.4:1 to $1.2: 1$, and no further change is noted after $23 \mathrm{~h}$. In a similar manner, the pyridine complex 1 reacts with $\mathrm{BH}_{3} \bullet \mathrm{THF}$ to return the borane precursor (2) $\left({ }^{31} \mathrm{P} N \mathrm{NMR}\right)$. Alkylation could also be accomplished via a Michael addition reaction. For example, when a solution of 1 was treated with MVK and 
a catalytic amount of the base triethylamine, addition of the enone $\beta$ carbon to $\mathrm{N}$ occurs

smoothly to form 4. In an analogous manner, acrylonitrile can be combined with $\mathbf{1 H}$ to form pyridinium complex $\mathbf{5}$ (see Scheme 2). For all alkylated products, key spectroscopic features include a nitrosyl stretch feature at $1585 \mathrm{~cm}^{-1}$, and a $\mathrm{W}(\mathrm{I} / 0)$ reduction potential near one volt (vs. NHE; Table 1). ${ }^{23}$ COSY and HSQC, NOESY, and HMBC data confirm that the pyridine ring is still coordinated across the C3-C4 bond.
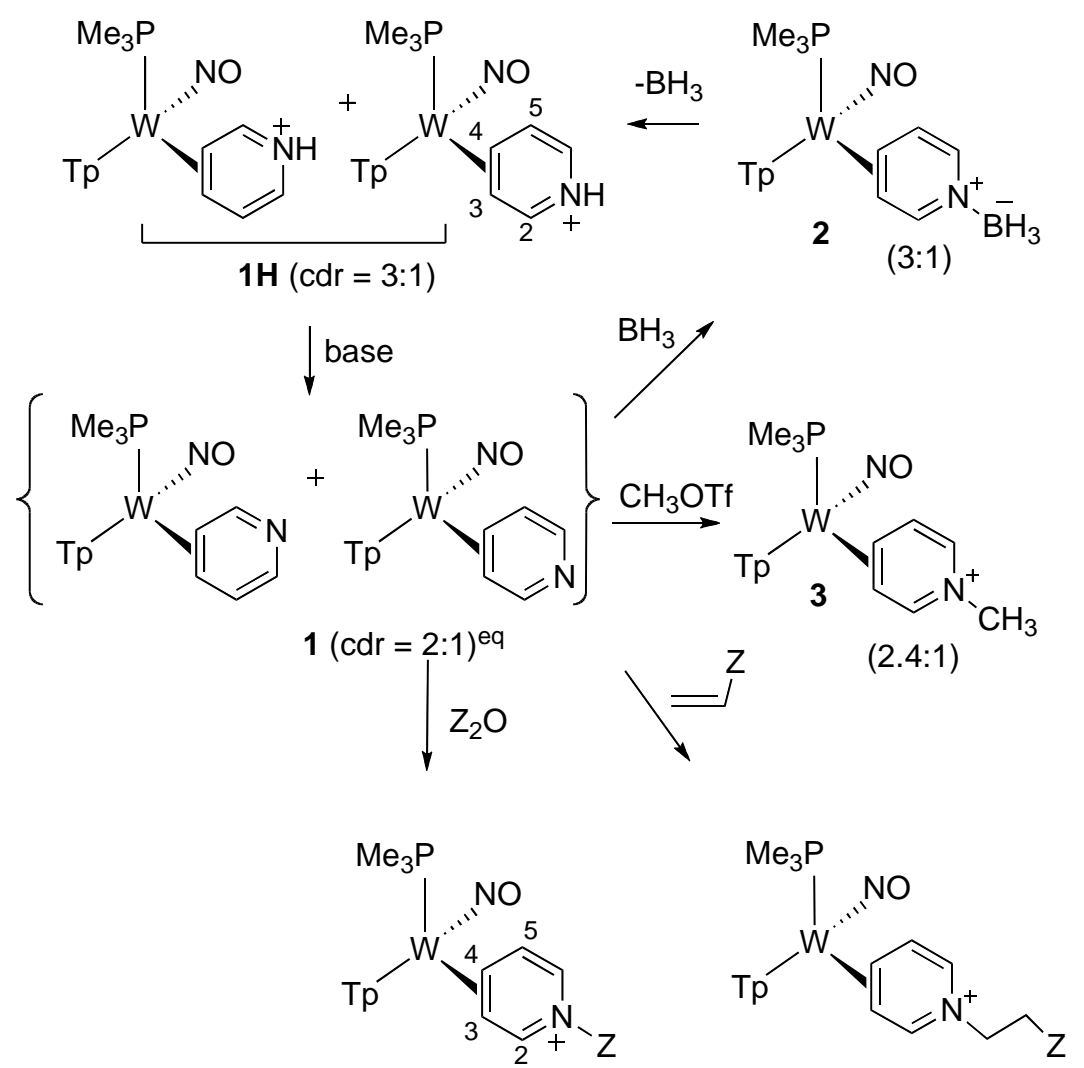

$6 Z=A c(10: 1)$

$7 \mathrm{Z}=\mathrm{BZ}(>20: 1)$

$8 Z=\operatorname{Tf}(>20: 1)$

$4 \mathrm{Z}=\mathrm{COMe}(1.5: 1)$

$5 Z=C N(2.6: 1)$

eq $=$ equilibrium ratio

Scheme 2. Electrophilic substitution at nitrogen. 
Deprotonation of $\mathbf{1 H}$ with 2,6-di-tert-butylpyridine (DTBP) provides an equilibrium concentration of $\mathbf{1}$ that readily reacts with acetic anhydride to form the acetylpyridinium complex 6 . Subsequent heating ( $55^{\circ} \mathrm{C}, 5.5 \mathrm{~h}$ ) allowed for the isolation of 6 in high yield (94\%) and in good $\mathrm{cdr}(>10: 1) .{ }^{18}$ The use of less bulky or more basic amines was found to be incompatible with the desired product. Preparation of the benzoyl analog 7 required the use of a stronger base (2,6-lutidine), which presumably generates a higher equilibrium concentration of $\mathbf{1}$ to react with the benzoic anhydride. But while 7 could be isolated, it was found to be contaminated with lutidinium salts. Subsequent heating of $7\left(2.5 \mathrm{~h}\right.$ at $\left.55^{\circ} \mathrm{C}\right)$ resulted in a cdr of $>20: 1$. In a similar manner, the reaction of $\mathbf{1}$ with triflic anhydride and DTBP led to the in situ generation of the triflyl analog 8 , this time with a cdr of $>20: 1$ and without the need for heating. Attempts to isolate this complex were unsuccessful, presumably owing to its chemical instability, but NMR, IR and electrochemical analysis confirm the addition of the triflyl group (Table 1).

\section{Nucleophilic Additions:}

Exploration of the chemistry of the parent pyridinium $\mathbf{1 H}$ is complicated by the incompatibility of an acidic proton with basic nucleophiles. Therefore, our preliminary screening of nucleophiles was carried out with three $\mathrm{N}$-substituted pyridinium complexes of differing electronic character. The methylpyridinium (3), pyridine borane (2), and acetylpyridinium (6) complexes provide a broad range of NO stretching frequencies and reduction potentials (Table 1). The acetylpyridinium, 6, shows a cdr 
slightly lower than that of the benzoyl (7) or trifyl (8) analogs, but it can be prepared in significantly higher yield, scale, and purity. Each of these pyridinium complexes (2, 3, and 6) were subjected to 2-(TMSO)propene, a reagent known to generate a dihydropyridine in combination with the organic $N$-carboethoxypyridinium salt. ${ }^{24}$ While backbonding is anticipated to lessen the electrophilicity at $\mathrm{C2}$, the localization of the $\pi$ system is expected to enhance the reactivity at this position. Whereas both the borane and methyl pyridinium complexes were unreactive to the silyl enolate, the acetylpyridinium complex 6 reacted (vide infra) to form product 9 (Scheme 3). Key spectroscopic features for this dihydropyridine complex include chemical shifts consistent with an organic alkene, $\mathrm{NOE}$ interactions between $\mathrm{C} 5$ and $\mathrm{PMe}_{3}$, and between $\mathrm{C} 2$ and the pyrazole ring trans to the phosphine $\left(\mathrm{pz}_{\mathrm{A} 3}\right) \cdot{ }^{18}$ Also of note, the $\mathrm{C} 6$ proton showed an NOE interaction with the enamide methyl group (also for 10-18; vide infra) indicating a major enamide conformer as depicted in Scheme 3. In contrast to what was observed with carboethyoxypyridinium ion, ${ }^{24,25}$ no C4-substitution was detected, and the cdr for the reaction products was $>10: 1$. In an attempt to carry out an intramolecular $\mathrm{C} 2$ reaction with an enolate, the MVK adduct 4 was treated with various bases, $\mathrm{KO}^{\mathrm{t}} \mathrm{Bu}$ being typical. For all attempts, the $\kappa-\mathrm{N}$ pyridine complex (1N; Scheme 3 ) was the only tungsten species detected $\left({ }^{31} \mathrm{P} N M R\right)$, presumably the result of a retroMichael reaction and isomerization of $\mathbf{1}$ to $\mathbf{1 N}$. 

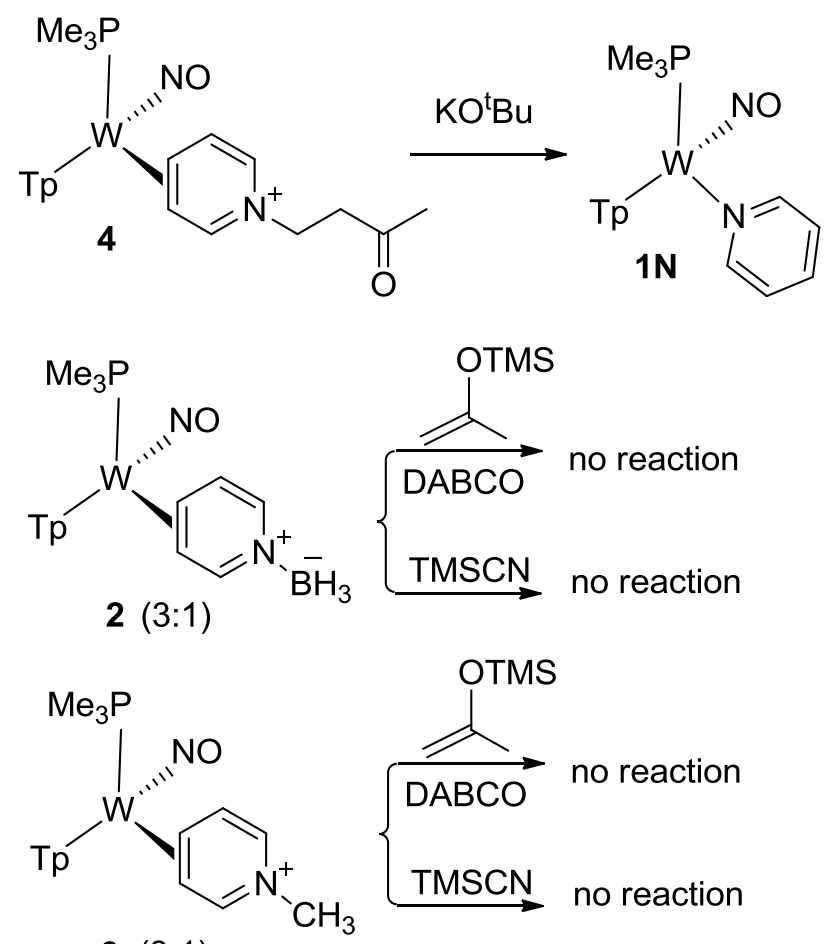

$3(3: 1)$

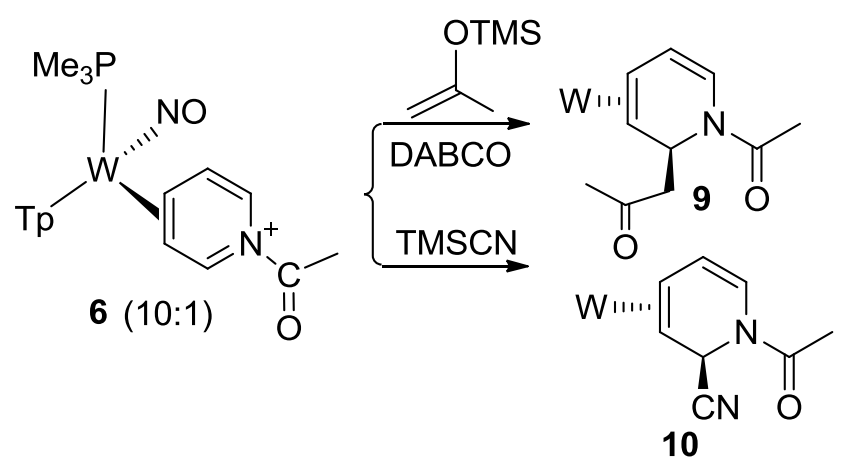

Scheme 3: Reactivity screening of pyridinium compounds.

Given the encouraging preliminary reactivity and stereoselectivity shown by acetylpyridinium 6, this compound was combined with a diverse range of nucleophiles in order to determine the compatibility of this tungsten system. Of key interest here was the relative ability of the nucleophile to attack the acetyl group, the pyridine ring, the nitrosyl group, ${ }^{26}$ or the metal itself (i.e., ligand substitution). Further, for cases in which the nucleophile would add to the pyridine ring, we sought to determine whether $\mathrm{C} 4$ 
addition would compete with $\mathrm{C} 2$ addition, given the dynamic nature of $\eta^{2}$-aromatic complexes. $^{23}$

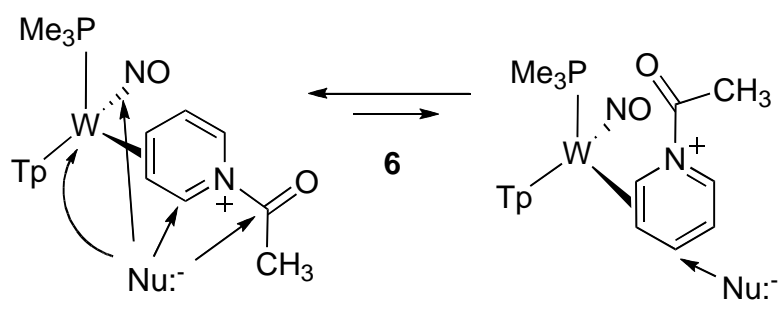

Electrochemical analysis using cyclic voltammetry (CV) proved to be a valuable tool for the rapid monitoring and analysis of reactions as the addition of nucleophiles to cationic species dramatically lowers the $W(I / 0)$ reduction potential $\left(E^{0}\right.$, as estimated from $\left.E_{p, a}\right)$. Monitoring reactions with ${ }^{31} P$ NMR was equally valuable, given the sensitivity of ${ }^{183} \mathrm{~W}-{ }^{31} \mathrm{P}$ coupling constants to the nature of the organic ligand (Figure 1). A complete list of electrochemical and ${ }^{31} \mathrm{P} N M R$ data along with ${ }^{1} \mathrm{H}$ NMR data for the key feature $\delta(\mathrm{H} 2)$ is provided in Table 1.

The addition of $\mathrm{NaBH}_{4}$ to a solution of the acetylpyridinium complex 6 in $\mathrm{MeOH}$, resulted in vigorous effervescence, a $3.81 \mathrm{ppm}$ upfield shift in ${ }^{31} \mathrm{P}$ NMR $(-9.20 \mathrm{ppm} \rightarrow-$ $13.01 \mathrm{ppm})$, and about $0.8 \mathrm{~V}$ negative shift $(1.20 \mathrm{~V} \rightarrow 0.36 \mathrm{~V})$ in the reduction potential of the product compared to its precursor. The ${ }^{31} \mathrm{P} N M R$ spectrum indicated the formation of a single new complex (10) while the electrochemical data indicated that the cationic complex had been neutralized (see Figure 1). A dichloromethane/ $\mathrm{NaHCO}_{3}$ (aq, sat'd) workup in air removed $\mathrm{MeOH}$ and salts generated in the reaction and subsequent precipitation allowed for the isolation of a tan solid in $89 \%$ yield. A ${ }^{1} \mathrm{H} N M R$ spectrum of the isolated material (10) contains a diastereotopic methylene group $(\Delta \delta=$ $1.2 \mathrm{ppm})$, two bound alkene resonances, two enamide alkene resonances, and the 
acetyl methyl group, as well as the typical spectroscopic features for $\left\{\mathrm{TpW}(\mathrm{NO})\left(\mathrm{PMe}_{3}\right)\right\}$. Comprehensive ${ }^{13} \mathrm{C}$ and ${ }^{1} \mathrm{H}$ characterization was achieved through analysis of COSY, NOESY, HSQC, and HMBC data.
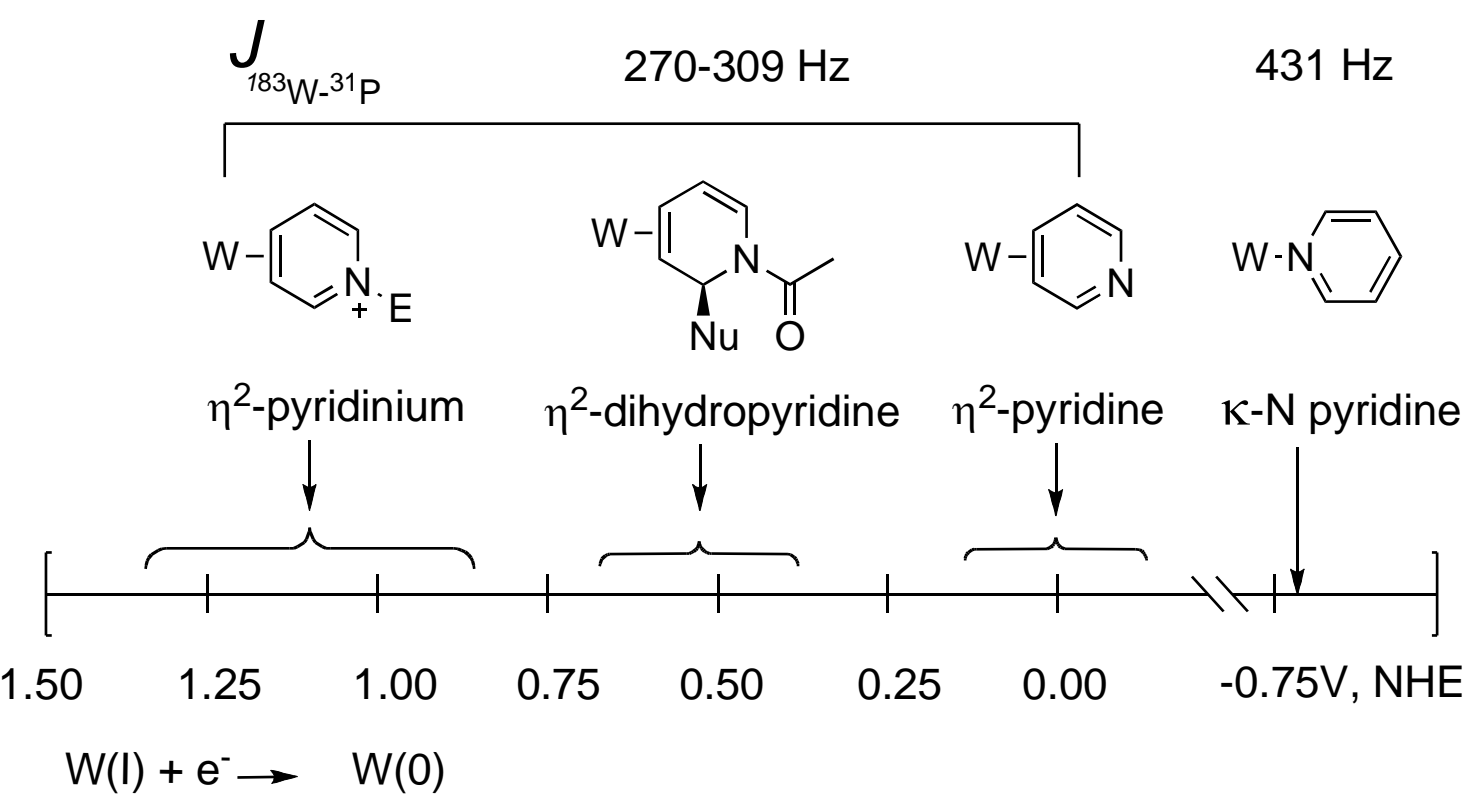

Figure 1: Electrochemical and ${ }^{31} \mathrm{P}-{ }^{183} \mathrm{~W}$ coupling data ${ }^{18}$ used to monitor reactions.

Cyanide addition to the acetylpyridinium complex (6) was attempted with $\mathrm{NaCN}$ but the formation of the intense turquoise color characteristic of $\mathbf{1 N}$ and a negative shift of more than $2 \mathrm{~V}$ in the reduction potential (see Figure 1 ) indicated that deacylation of the nitrogen had pre-empted nucleophilic addition to the ring. Using TMSCN as a source of cyanide, no deacylation was observed, however ${ }^{31} \mathrm{P}$ NMR data indicated that the reaction to form $\mathbf{1 1}$ did not go to completion. The addition of DABCO solved this problem by neutralizing the TMS group, thus completing the Reissert-like reaction sequence to form $\mathbf{1 1}$ in $88 \%$ yield. Proton and carbon resonances were similar to that of 
the parent dihydropyridine complex 10 , and IR data confirmed the presence of a nitrile. The chemical shift (6.41 ppm) of the methine proton $\mathrm{H} 2$ seemed anomalous at first, but 2D NMR and NOE data indicated that the methine is shifted downfield by the anisotropy of one of the pyrazole rings, in addition to its $\alpha$ position to the $\mathrm{CN}$ group. Proton coupling between $\mathrm{H} 2$ and $\mathrm{H} 3(<2 \mathrm{~Hz})$ indicated a Karplus angle near $90^{\circ}$, and therefore that the $\mathrm{CN}$ group has assumed an axial position. Both pyrrole and indole also were found to react at $\mathrm{C} 2$ of the acetylpyridinum complex (6) under mild conditions. Pyrrole selectively reacts at the $\alpha$ carbon (51\%) while indole undergoes electrophilic substitution at the $\beta$ carbon of the heterocycle $(12 ; 61 \%) .{ }^{18}$ Notably, these aza-FriedelCrafts alkylations proceed only in the presence of a modest base (2,6-lutidine). Spectroscopic analysis again confirms consistent control of the stereochemistry at $\mathrm{C2}$, in which addition occurs anti to the metal.

Given the important role that dihydropyridines have played in the synthesis of alkaloids, and the high degree of regio- and stereocontrol observed in the preliminary screening, we widened our study to include other C-C bond forming reactions that are mainstays of modern organic synthesis. For example, $\mathrm{ZnEt}_{2}$ and $\mathrm{MeMgBr}$ both successfully transferred alkyl groups to $\mathrm{C} 2$ with no detectable deacylation (CV and ${ }^{31} \mathrm{P}$ NMR), generating $13(88 \%)$ and 14 (57\%), respectively.

A Reformatsky reaction was achieved by reducing the $\mathrm{C}-\mathrm{Br}$ bond of methyl bromoacetate using $\mathrm{Zn}^{0}$ dust to form 15 in $87 \%$ yield. An X-ray analysis of a single crystal of $\mathbf{1 5}$ confirms the stereoselective anti-to-tungsten addition of the nucleophile to C2 (Figure 2). In a similar fashion, allyl bromide and $\mathrm{Zn}^{0}$, when combined with 6 , generated 
the 2-allylated dihydropyridine 16 (89\%). Deprotonation of ethynyltrimethylsilane with methyl lithium followed by addition to 6 resulted in a large amount of deacylation. However, the addition of $\mathrm{ZnBr}_{2}$ to the ((trimethylsilyl)ethynyl)lithium solution prior to addition provided for clean transfer of the alkynyl group to the ring yielding 17 (89\%). Triethylamine and DABCO were both found to produce intractable mixtures with 6 , but in the presence of nitromethane they are effective bases for the Henry reaction, delivering 18 in $85 \%$ yield. An X-ray analysis of 18 confirms the assigned stereochemistry (Figure 2).
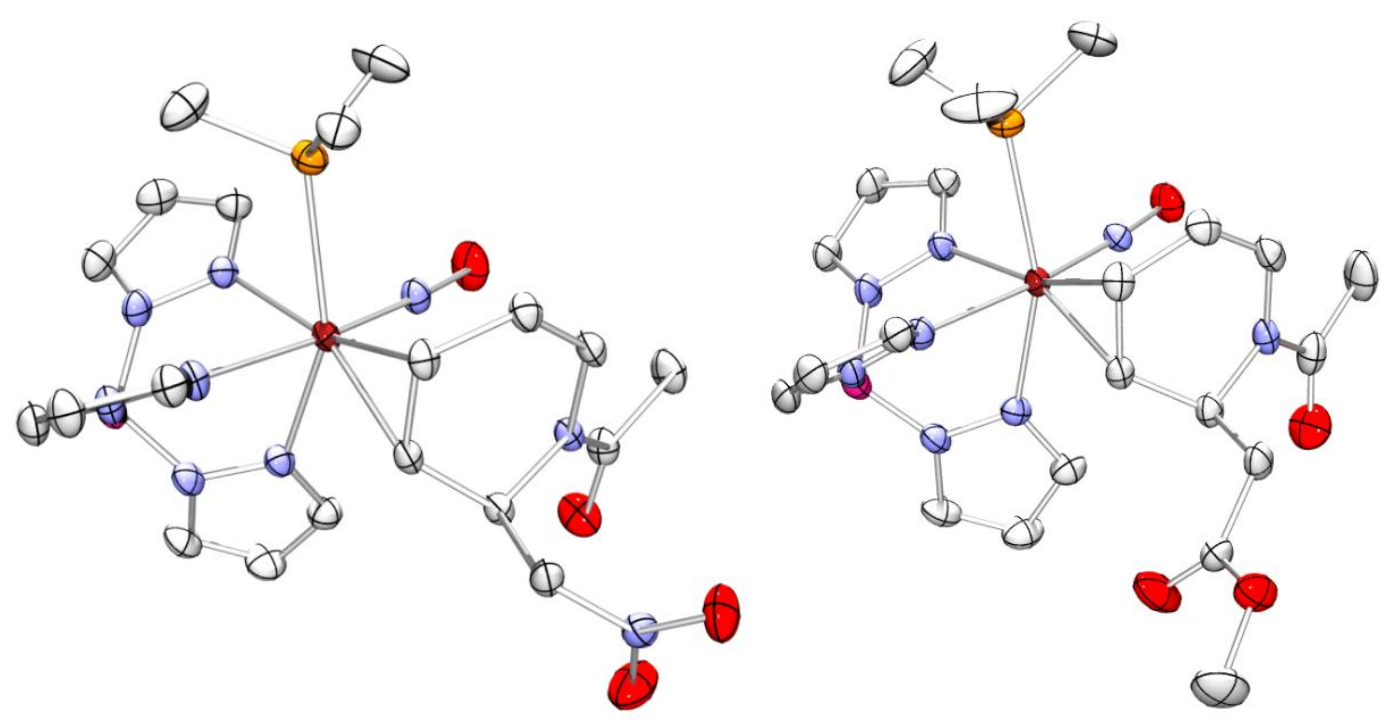

Figure 2: ORTEP diagrams of 18 (left) and 15 (right).

While many of the reactions portrayed in Scheme 4 are similar to known reaction chemistry of in situ-generated acyl pyridinium salts, ${ }^{27}$ often the latter reactions are plagued by poor regiochemistry of the nucleophilic addition. Several strategies have been developed to overcome this problem, most involve inserting a substituent at the 4position (e.g., $\mathrm{SnMe}_{3}, \mathrm{OMe}$ ) that can later be removed or chemically elaborated. In the 
present study, tungsten plays a similar role. Organic acylpyridiniums are typically far too reactive to be isolated, and it is remarkable that the tungsten pacifies the acyl group to the point that it can be readily isolated even in the presence of water. ${ }^{18}$

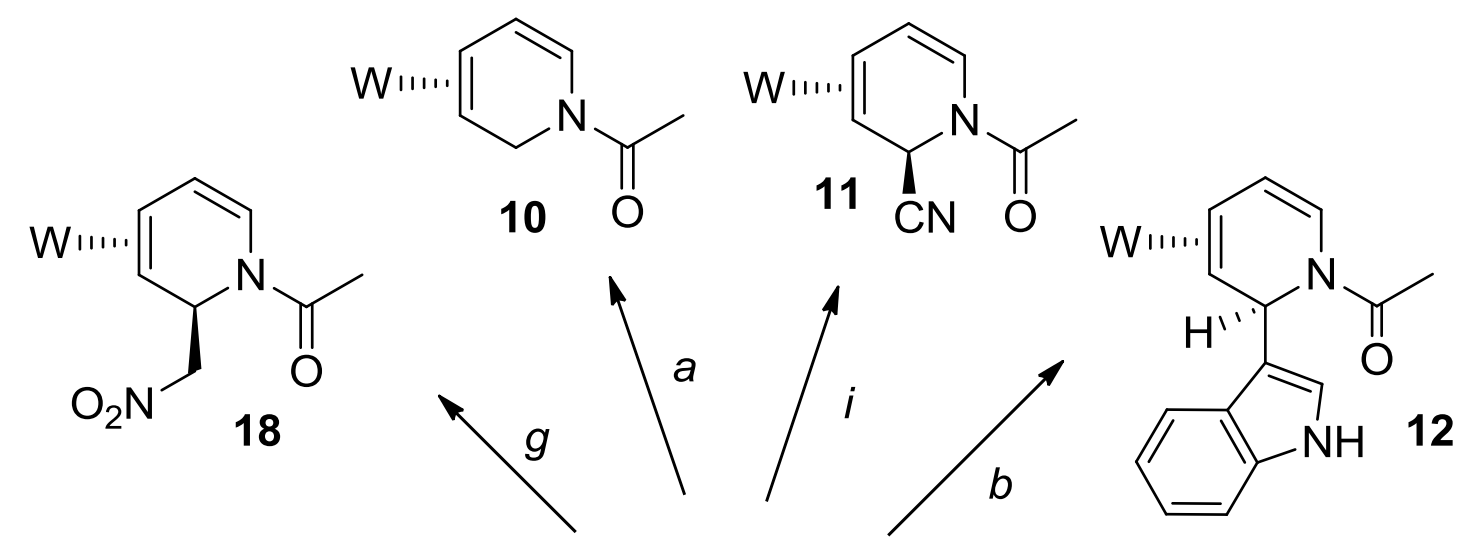

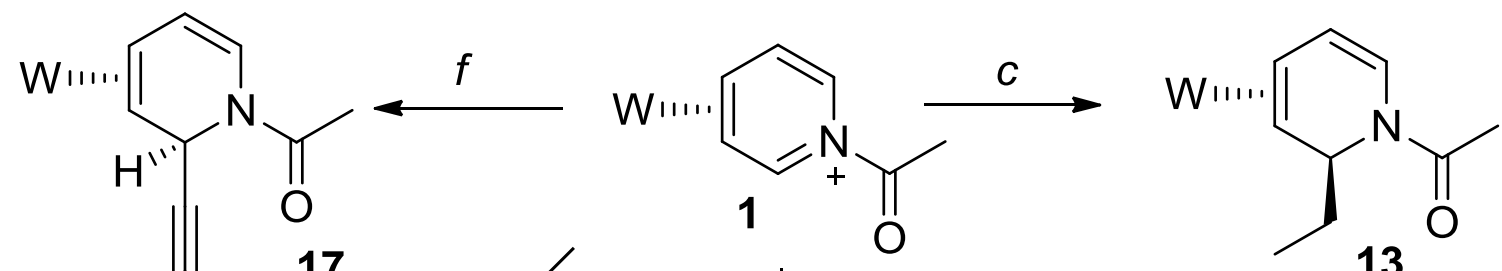<smiles>C#CCCCCCC</smiles><smiles>C=CC[C@H]1C=C(C#N)C=CN1C(C)=O</smiles><smiles>CC#CC1=CN(C(C)=O)[C@H](CC(=O)OC)C=C1</smiles>

13

Reagents and conditions: (a) $\mathrm{NaBH}_{4}, \mathrm{MeOH}, 89 \%$; (b) indole, lutidine, 61\%; (c) $\mathrm{ZnEt}_{2}, 88 \%$; (d) $\mathrm{MeMgBr}, 57 \%$; (e) $\mathrm{Zn}^{0}$, Allylbromide, CuCN, 89\%; (f) MeLi, ethynyltrimethylsilane, $\mathrm{ZnBr}_{2}, 89 \%$; (g) $\mathrm{MeNO}_{2}, \mathrm{NEt}_{3}$ or DABCO, 88\%; (h) $\mathrm{Zn}^{0}$, methyl 2-bromoacetate, 87\%; (i) TMSCN, DABCO, 88\%; (j) in all cases $\mathrm{W}=\left\{\mathrm{TpW}(\mathrm{NO})\left(\mathrm{PMe}_{3}\right)\right\}$ with coordination diastereomer ratio $(\mathrm{cdr})$ ratio $>10: 1$.

Scheme 4: Scope of nucleophilic additions to 6. 
Table 1: Properties of tungsten pyridine complexes.

\begin{tabular}{|c|c|c|c|c|}
\hline & $E_{\mathrm{p}, \mathrm{a}}(\mathrm{NHE})^{\mathrm{b}}$ & ${ }^{3 \mathrm{I}} \mathrm{P} \delta\left(J_{183 \mathrm{~W}-31 \mathrm{P}}\right)$ & $v(\mathrm{NO})\left(\mathrm{cm}^{-1}\right)$ & $\mathrm{H} 2 \delta^{\mathbf{h}}$ \\
\hline $1 \mathrm{~N}^{23}$ & $E_{1 / 2}=-0.78 V$ & $-10.02(431)^{g}$ & 1503 & $8.59,6.45$ \\
\hline $1 \mathrm{H}^{23}$ & $+0.83 \mathrm{~V}^{\mathrm{i}}$ & $-10.14(295)^{\mathrm{a}},-13.95(285)^{\mathrm{a}}$ & 1592 & $8.98,8.99^{\mathrm{a}}$ \\
\hline $1^{23}$ & $0.00 \mathrm{~V}$ & $-11.43(309)^{\mathrm{e}},-13.36(300)^{\mathrm{e}}$ & 1547 & $8.57,8.75^{\mathrm{d}}$ \\
\hline $2^{18}$ & $+0.44 \mathrm{~V}$ & $-12.98(298),-15.18(292)$ & 1585 & $8.65,8.56$ \\
\hline 3 & $+1.05 \mathrm{~V}$ & $-12.66(289),-16.07(280)$ & 1585 & $8.98,9.14$ \\
\hline 4 & $+0.97 \mathrm{~V}$ & $-12.56(286),-16.13(279)$ & 1585 & $9.20^{\mathrm{d}}, 9.22^{\mathrm{d}}$ \\
\hline 5 & $+1.02 \mathrm{~V}$ & $-10.93(292),-14.63(282)$ & 1585 & $9.30^{d}, 9.34^{d}$ \\
\hline $6^{18}$ & $+1.20 \mathrm{~V}^{\mathrm{i}}$ & $-9.61(283),-14.33(276)$ & 1611 & $9.00^{\mathrm{c}}, 9.38$ \\
\hline 7 & $+1.23 \mathrm{~V}$ & $-9.45(283),-14.38(276)$ & 1612 & $8.98^{\mathrm{c}-}, 9.23$ \\
\hline 8 & $+1.48 \mathrm{~V}$ & $-8.53(278),-14.52(270)$ & 1620 & $8.33,8.71$ \\
\hline 9 & $+0.54 \mathrm{~V}^{\mathrm{i}}$ & $-12.01(283)$ & 1562 & $5.85^{c}$ \\
\hline 10 & $+0.37 \mathrm{~V}$ & $-12.25(281)$ & 1558 & $5.43,4.21$ \\
\hline 11 & $+0.64 \mathrm{~V}$ & $-12.27(278)$ & 1566 & 6.41 \\
\hline 12 & $+0.51 \mathrm{~V}^{\mathrm{i}}$ & $-10.59(283)^{\mathrm{a}}$ & 1539 & $6.77^{\mathrm{a}}$ \\
\hline 13 & $+0.47 \mathrm{~V}$ & $-12.09(284)$ & 1562 & 5.31 \\
\hline 14 & $+0.45 \mathrm{~V}$ & $-12.14(282)$ & 1562 & 5.61 \\
\hline 15 & $+0.51 \mathrm{~V}$ & $-12.16(282)$ & 1562 & 5.91 \\
\hline 16 & $+0.51 \mathrm{~V}$ & $-12.12(282)$ & 1562 & 5.58 \\
\hline 17 & $+0.58 \mathrm{~V}$ & $-12.02(281)$ & 1566 & 6.28 \\
\hline 18 & $+0.60 \mathrm{~V}$ & $-12.28(282)$ & $1566^{\mathrm{f}}$ & 6.28 \\
\hline
\end{tabular}

a - DMSO- $d_{6}, b-$ recorded at $100 \mathrm{mV} / \mathrm{s}$ in DMAc/TBAH unless otherwise noted, c - recorded in $\mathrm{CD}_{3} \mathrm{CN}, \mathrm{d}$ acetone- $d_{6}$, e - generated in situ upon addition of DBU to $1 \mathrm{H}$ in DMSO- $d_{6}, \mathrm{f}-\mathrm{NO}_{2}, 1550 \mathrm{~cm}^{-1}, \mathrm{~g}$ - in situ substitution of pyridine (solvent), $\mathrm{h}$ - recorded in $\mathrm{CDCl}_{3}$ unless otherwise noted, i- recorded in $\mathrm{CH}_{3} \mathrm{CN}$.

The dearomatization agent $\left\{\mathrm{TpW}(\mathrm{NO})\left(\mathrm{PMe}_{3}\right)\right\}^{28-31}$ along with its predecessors $\left\{\mathrm{Os}\left(\mathrm{NH}_{3}\right)_{5}\right\}^{2+},{ }^{16}\{\mathrm{TpRe}(\mathrm{CO})(\mathrm{Melm})\}^{13,15,32}$ and $\{\mathrm{TpMo}(\mathrm{NO})(\mathrm{Melm})\}^{33}$, have been shown to 
tolerate a broad range of electrophiles including proton, acetals, activated alkenes and alkynes, alkyl halides, acylating reagents, and most recently electrophilic oxygen and halogen sources in their reaction with $\eta^{2}$-bound aromatic ligands. ${ }^{34}$ In contrast, only a handful of mild nucleophiles have been successfully added to $\eta^{2}$-bound ligands of these metal fragments (hydride, protected enolates, amines, $\mathrm{CN}^{-}$, alkoxides), and in no other case until now have they been added directly to an $\eta^{2}$-aromatic ligand. For $\eta^{6}$-pyridine complexes, the reported range of nucleophilic additions is even narrower (DIBAL and alkyl lithiums), ${ }^{35}$ owing in part to the difficulties in complexing the pyridine ligand and its aromatic nature. $^{14}$

\section{Concluding Remarks:}

With C3 and C4 of pyridine coordinated by the dearomatization agent $\left\{\mathrm{TpW}(\mathrm{NO})\left(\mathrm{PMe}_{3}\right)\right\}$, the heterocyclic nitrogen becomes 6-7 orders of magnitude more basic. This nitrogen can be acylated or alkylated forming stable pyridinium complexes. The acylated form of this complex readily undergoes regio- and stereoselective nucleophilic addition at $\mathrm{C} 2$ anti to the tungsten, whereas dihydropyridines are relatively fragile compounds in their uncoordinated state. ${ }^{36}$ Although $\eta^{2}$-dihydropyridine complexes can be converted into a free 2 -substitued pyridines (e.g., 12), ${ }^{18}$ their greatest potential may be as precursors to highly functionalized piperidines (Scheme 1). 


\section{Experimental Details:}

General Methods. NMR spectra were obtained on a 300 or $500 \mathrm{MHz}$ spectrometer (Varian INOVA or Bruker Avance). All chemical shifts are reported in ppm. Proton and carbon shifts are referenced to tetramethylsilane (TMS) utilizing residual ${ }^{1} \mathrm{H}$ or ${ }^{13} \mathrm{C}$ signals of the deuterated solvents as an internal standard. Phosphorus NMR signals are referenced to $85 \% \mathrm{H}_{3} \mathrm{PO}_{4}(\delta=$ 0.00) using a triphenylphosphate external standard $(\delta=-16.58)$. Coupling constants $(J)$ are reported in hertz $(\mathrm{Hz})$. Infrared spectra (IR) were recorded on a MIDAC Prospect Series (Model PRS) spectrometer as a glaze on a Horizontal Attenuated Total Reflectance (HATR) accessory (Pike Industries). Electrochemical experiments were performed under a dinitrogen atmosphere using a BAS Epsilon EC-2000 potentiostat. Cyclic voltammetry data was taken at ambient temperature at $100 \mathrm{mV} / \mathrm{s}\left(25^{\circ} \mathrm{C}\right)$ in a standard three-electrode cell from +1.7 to $-1.7 \mathrm{~V}$ with a glassy carbon working electrode, $\mathrm{N}, \mathrm{N}$-dimethylacetamide (DMA) or acetonitrile (MeCN) solvent (unless otherwise specified), and tetrabutylammonium hexaflurophosphate (TBAH) electrolyte (approx. 0.5 M). All potentials are reported versus NHE (Normal Hydrogen Electrode) using cobaltocenium hexafluorophosphate $\left(E_{1 / 2}=-0.78 \mathrm{~V}\right)$, ferrocene $\left(E_{1 / 2}=+0.55 \mathrm{~V}\right)$, or decamethylferrocene $\left(E_{1 / 2}=+0.04 \mathrm{~V}\right)$ as an internal standard. The peak-to-peak separation was $100 \mathrm{mV}$ or less for all reversible couples. High resolution electrospray ionization mass spectrometry (ESI-MS) analyses were obtained from the University of Illinois at UrbanaChampaign Mass Spectrometry Laboratory or at the University of Richmond on a Bruker BioTOFQ running in ESI mode. The latter from samples dissolved in water/acetonitrile solution containing trifluoroacetic acid and/or sodium trifluoroacetate (NaTFA), adn using $\left[\mathrm{Na}(\mathrm{NaTFA})_{\mathrm{x}}\right]^{+}$ clusters as an internal standard. Unless otherwise noted, all synthetic reactions were performed in a glovebox under a dry nitrogen atmosphere. Drisolve dichloromethane (DCM) and benzene was purified by passage through a column packed with activated alumina. Drisolve THF 
(tetrahydrofuran) was used as received. Other solvents and liquid reagents were thoroughly purged with nitrogen prior to use. Deuterated solvents were used as received from Cambridge Isotopes. Pyridine borane is commercially available through Sigma-Aldrich and was used as received. Acetic anhydride and benzoic anhydride were distilled from $\mathrm{CaH}_{2}$ at reduced pressure prior to use. Methyl bromoacetate is commercially available. General proton assignments were made in accordance with the Figure S1 (see supplemental information). Pyrazole, Pz, protons of the (tris-pyrazolyl)borate, Tp, ligand were uniquely assigned using a combination of 2dimensional NMR experiments and phosphorous-proton coupling (Figure S2, see supplemental information). ${ }^{1}$ When unambiguous assignments were not possible, $\mathrm{Pz}$ protons were labeled as Tp protons. Coordination diastereomers are described by the defining feature's (i.e. heteroatom's) proximity to the $\mathrm{PMe}_{3}$ ligand relative to the $\mathrm{W}-\mathrm{PMe}_{3}$ bond (e.g. the fewer number of bonds from the $\mathrm{PMe}_{3}$ passing through the upper portion of the coordinated ring system to the defining feature dictates the proximal (P) ligand).

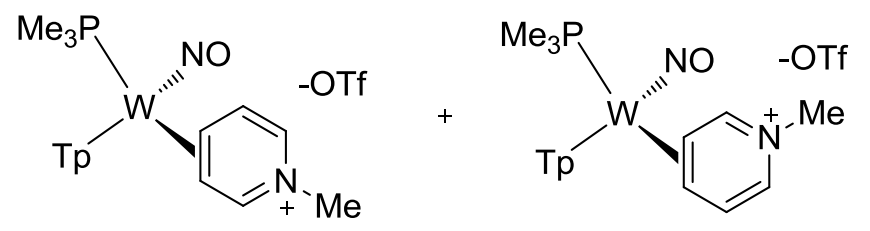

TpW(NO)(PMe $\left.)_{3}\right)\left(3,4-\eta^{2}-N\right.$-methylpyridinium)(OTf) (3): DBU (0.045 g, $\left.0.293 \mathrm{mmol}\right)$ in $\sim 1 / 2 \mathrm{~mL}$ of DCM was added to a heterogeneous orange solution of $1 \mathrm{H}(0.204 \mathrm{~g}, 0.278 \mathrm{mmol})$ in $\sim 1 \mathrm{~mL} \mathrm{DCM}$, completely dissolving the solid and giving a light yellow-green solution. After 1 min methyl triflate $(0.049 \mathrm{~g}, 0.299 \mathrm{mmol})$ was added, and the solution stirred for an additional $1 \mathrm{~min}$. The now bright red solution was removed from the glovebox and extracted with $3 \times 1 \mathrm{~mL} \mathrm{NaHCO} 3$ (aq, sat'd) and back-extracted with $\sim 1 \mathrm{~mL}$ of DCM. The DCM layer was dried over $\mathrm{MgSO}_{4}$ and filtered through a celite column. The solvent was evaporated, and the resulting residue was returned to the glovebox, dissolved in minimal $\mathrm{DCM}$, and added to $\mathrm{Et}_{2} \mathrm{O}$ ( $\sim 75 \mathrm{~mL}$ ) to precipitate 
a solid. The orange solid was collected by filtration using a $15 \mathrm{~mL}$ medium porosity fritted funnel and dried in vacuo to give a $3(0.198 \mathrm{~g}, 0.221 \mathrm{mmol}, 79 \%) .{ }^{1} \mathrm{H} N M R\left(\mathrm{CDCl}_{3}, \delta\right): 8.98(\mathrm{~d}, J=5.2,1 \mathrm{H}$, $\mathrm{H} 2$ ), 8.06 (d, $J=2.0,1 \mathrm{H}$, PzA3), $7.83(\mathrm{~m}, 3 \mathrm{H}, 3 \mathrm{Tp}$ 's), $7.74(\mathrm{~d}, J=2.0,1 \mathrm{H}, \mathrm{PzA} 5), 7.39$ (d, J=2.0, 1H, Tp), $6.74(\mathrm{dd}, J=7.4,5.4,1 \mathrm{H}, \mathrm{H} 5), 6.37$ (t, $J=2.0,1 \mathrm{H}, \mathrm{PzA} 4), 6.34(\mathrm{~m}, 2 \mathrm{H}, 2 \mathrm{Tp}$ 's), 5.96 (d, $J=7.4$, $1 \mathrm{H}, \mathrm{H} 6), 3.97$ (s, 3H, Me), 3.8 (ddd, $J=12.6,7.7,5.4,1 \mathrm{H}, \mathrm{H} 4$ ), 2.33 (dd, $J=7.7,5.2,1 \mathrm{H}, \mathrm{H} 3$ ), 1.19 $\left(\mathrm{d}, J=8.8,9 \mathrm{H}, \mathrm{PMe}_{3}\right)$, Minor Isomer, $9.14(\mathrm{~d}, J=4.4,1 \mathrm{H}, \mathrm{H} 2), 7.93(\mathrm{~d}, J=2.0,1 \mathrm{H}, \mathrm{PzA} 3), 7.9(\mathrm{~d}, J=$ 2.0, 1H, PzB3), 7.83 (m, 2H, 2Tp's), 7.7 (d, J = 2.0, 1H, PzA5), 7.22 (d, J = 2.0, 1H, PzC3), 6.92 (dd, J $=7.1,6.1,1 \mathrm{H}, \mathrm{H} 5), 6.34(\mathrm{~m}, 2 \mathrm{H}, 2 \mathrm{Tp}$ 's), $6.26(\mathrm{t}, J=2.0,1 \mathrm{H}, \mathrm{PzA} 4), 5.9(\mathrm{~d}, J=7.1,1 \mathrm{H}, \mathrm{H} 6), 4.00(\mathrm{~s}$, $3 \mathrm{H}, \mathrm{Me}), 3.53(\mathrm{~m}, 1 \mathrm{H}, \mathrm{H} 3), 2.41(\mathrm{dd}, J=8.1,6.1,1 \mathrm{H}, \mathrm{H} 4), 1.31\left(\mathrm{~d}, J=8.6,9 \mathrm{H}, \mathrm{PMe}_{3}\right) .{ }^{13} \mathrm{C} \mathrm{NMR}$ $\left(\mathrm{CDCl}_{3}, \delta\right): 171.5$ (C2), 145.9 (Tp), 144.9 (Tp), 141.1 (Tp), 137.8 (Tp), 137.4 (Tp), 136.4 (Tp), 127.8 (C5), 120.8 (C6), 107.4 (3Tp's), 64.7 (C4, d, J = 12.2), 58.5 (C3), 43.9 (Me), $12.8\left(\mathrm{PMe}_{3}, \mathrm{~d}, J=30.3\right.$ ), Minor Isomer, 167.8 (C2), 144.3 (PzB4), 140.9 (Tp), 140.8 (Tp), 137.7 (Tp), 137.1 (Tp), 136.3 (Tp), 130.8 (C5), 118.6 (C6), 107.3/106.3 (3Tp's), 61.6 (C3), 61 (C4, d, J = 5.5), 44.0 (Me), 13.2 ( $\mathrm{PMe}_{3}$ $\mathrm{d}, J=29.7) .{ }^{31} \mathrm{P}$ NMR $\left(\mathrm{CDCl}_{3}, \delta\right):$ major: $-12.66\left(J_{\mathrm{WP}}=289\right)$, minor: $-16.07\left(J_{\mathrm{WP}}=280\right) . \mathrm{CV}: E_{\mathrm{p}, \mathrm{a}}=$ +1.05 V. IR: $v_{\mathrm{NO}}=1585 \mathrm{~cm}^{-1}, V_{\mathrm{BH}}=2499 \mathrm{~cm}^{-1}$. ESI-MS: obs'd (\%), calc'd (\%), ppm, $\mathrm{M}^{+}: 595.1628$ (100), 595.1624 (86.6), 0.7; 596.1660 (92.7), 596.1650 (79.4), 1.6; 597.1649 (100), 597.1648 (100), 0.3; 598.1698 (37.3), 598.1691 (40.3), 1.2; 599.1679 (100), 599.1680 (84.8), 0.2.

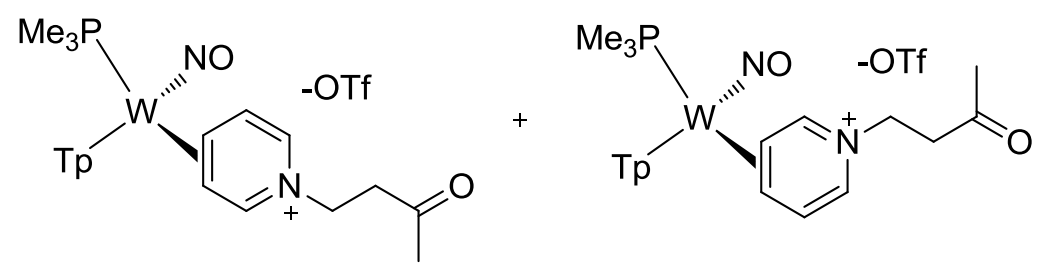

TpW(NO)(PMe 3 )(3,4- $\eta^{2}-N$-(3-oxobutyl)pyridinium)(OTf) (4): $\mathrm{NEt}_{3}(0.006 \mathrm{~g}, 0.058 \mathrm{mmol})$ in $\sim 1 / 2$ $\mathrm{mL}$ of DCM was added to a heterogeneous orange solution of $1 \mathbf{H}(0.078 \mathrm{~g}, 0.106 \mathrm{mmol})$ in $\sim 1 \mathrm{~mL}$ DCM, completely dissolving the solid and giving a bright red solution. After 1 min methyl vinyl ketone $(0.073 \mathrm{~g}, 1.044 \mathrm{mmol})$ was added and the resulting solution was stirred for $8 \mathrm{~h}$. The 
resulting red homogeneous solution was added to $\sim 50 \mathrm{~mL}$ of stirring $\mathrm{Et}_{2} \mathrm{O}$ to precipitate an orange solid. The orange solid was collected by filtration using a $15 \mathrm{~mL}$ medium porosity fritted funnel and dried in vacuo to give a $4(0.072 \mathrm{~g}, 0.089 \mathrm{mmol}, 84 \%) .{ }^{1} \mathrm{H}$ NMR (acetone- $\left.d_{6}, \delta\right)$ : Major: $9.20(\mathrm{~d}, J=5.7,1 \mathrm{H}, \mathrm{H} 2), 8.57(\mathrm{~d}, J=2.0,1 \mathrm{H}, \mathrm{Tp}), 8.15(\mathrm{~d}, J=2.0,1 \mathrm{H}, \mathrm{Tp}), 8.13(\mathrm{~d}, J=2.0$, $1 \mathrm{H}, \mathrm{Tp}), 8.08$ (d, J=2.0,1H, Tp), 7.94 (d, $J=2.0,1 \mathrm{H}, \mathrm{Tp}), 7.75$ (d, $J=2.0,1 \mathrm{H}, \mathrm{Tp}), 7.07$ (ddd, $J=$ 7.4, 5.6, 1.4, 1H, H5), $6.50(\mathrm{t}, J=2.0,1 \mathrm{H}, \mathrm{Tp}), 6.45(\mathrm{t}, J=2.0,1 \mathrm{H}, \mathrm{Tp}), 6.44(\mathrm{t}, J=2.0,1 \mathrm{H}, \mathrm{Tp}), 6.31$ $(\mathrm{dd}, J=7.4,1.2,1 \mathrm{H}, \mathrm{H6}), 4.51(\mathrm{dt}, J=12.9,4.0,1 \mathrm{H}, \beta$ to ketone), $4.22(\mathrm{dt}, J=12.9,4.4,1 \mathrm{H}, \beta$ to ketone), $4.03(\mathrm{ddd}, J=12.0,7.7,5.6,1 \mathrm{H}, \mathrm{H} 4), 3.15-3.30(\mathrm{~m}, 2 \mathrm{H}$, methylene $\alpha$ to ketone), 2.44 (dd, $J=7.7,5.7,1 \mathrm{H}, \mathrm{H3}), 2.02\left(\mathrm{~s}, 3 \mathrm{H}\right.$, methyl), 1.30 (d, $\left.J=9.1,9 \mathrm{H}, \mathrm{PMe}_{3}\right) ;$ Minor: 9.22 (d, $J=6.0$, $1 \mathrm{H}, \mathrm{H} 2), 8.57(\mathrm{~d}, J=2.0,1 \mathrm{H}, \mathrm{Tp}), 8.13(\mathrm{~d}, J=2.0,1 \mathrm{H}, \mathrm{Tp}), 8.12(\mathrm{~d}, J=2.0,1 \mathrm{H}, \mathrm{Tp}), 8.09(\mathrm{~d}, J=2.0$, $1 \mathrm{H}, \mathrm{Tp}), 7.97(\mathrm{~d}, J=2.0,1 \mathrm{H}, \mathrm{Tp}), 7.72(\mathrm{~d}, J=2.0,1 \mathrm{H}, \mathrm{Tp}), 7.07(\mathrm{dd}, J=7.8,5.8,1 \mathrm{H}, \mathrm{H} 5), 6.49$ (t, $J=$ 2.0, $1 \mathrm{H}, \mathrm{Tp}), 6.44(\mathrm{t}, J=2.0,1 \mathrm{H}, \mathrm{Tp}), 6.38(\mathrm{t}, J=2.0,1 \mathrm{H}, \mathrm{Tp}), 6.24(\mathrm{dd}, J=7.8,1.2,1 \mathrm{H}, \mathrm{H} 6), 4.55$ (dt, $J=12.9,3.9,1 \mathrm{H}, \beta$ to ketone), $4.26(\mathrm{dt}, J=12.9,5.0,1 \mathrm{H}, \beta$ to ketone), 3.80 (ddd, $J=13.4$, 8.6, 6.0, $1 \mathrm{H}, \mathrm{H} 3$ ), 3.00-3.15 ( $\mathrm{m}, 2 \mathrm{H}$, methylene $\alpha$ to ketone), $2.44(\mathrm{dd}, J=8.6,5.8,1 \mathrm{H}, \mathrm{H} 4), 2.07$ (s, 3H, methyl), $1.39\left(\mathrm{~d}, J=8.9,9 \mathrm{H}, \mathrm{PMe}_{3}\right) .{ }^{13} \mathrm{C}$ NMR (acetone- $d_{6}, \delta$ ) (for both isomers, the methyl resonances could not be observed as they are buried under the acetone- $d_{6}$ septuplet near 29 ppm): Major: 206.9 (carbonyl), 174.1 (C2), 147.7 (Tp), 146.2 (d, J = 2.3, Tp), 142.6 (Tp), 139.0 (Tp), 138.5 (Tp), 137.5 (Tp), 129.3 (d, J = 3.4, C5), 120.2 (C6), 108.4 (Tp), 108.0 (Tp), 107.7 (Tp), $65.9(\mathrm{~d}, J=12.1, \mathrm{C} 4), 58.7$ (C3), 53.3 ( $\beta$ to ketone), 44.1 ( $\alpha$ to ketone), $12.5(\mathrm{~d}, J=30.5$, $\mathrm{PMe}_{3}$ ); Minor: 206.5 (carbonyl), 170.2 (2), 145.3 (d, J = 2.1, Tp), 142.4 (Tp), 142.1 (Tp), 138.9 (Tp), 138.4 (Tp), 137.5 (Tp), 131.9 (d, J = 3.4, C5), 118.6 (C6), 108.2 (Tp), 108.1 (Tp), 107.2 (Tp), $63.4(d, J=2.6, C 4), 61.1(d, J=6.0, C 3), 53.6$ ( $\beta$ to ketone), 44.6 ( $\alpha$ to ketone), $13.5(d, J=29.9$, $\left.\mathrm{PMe}_{3}\right) .{ }^{31} \mathrm{P} \mathrm{NMR}\left(\mathrm{CDCl}_{3}, \delta\right)$ : major: $-12.56\left(J_{\mathrm{WP}}=286\right)$, minor: $-16.13\left(J_{\mathrm{WP}}=279\right) . \mathrm{CV}: E_{\mathrm{p}, \mathrm{a}}=+0.97 \mathrm{~V}$ IR: R: $v_{\mathrm{NO}}=1585 \mathrm{~cm}^{-1}, v_{\mathrm{CO}}=1701 \mathrm{~cm}^{-1}, v_{\mathrm{BH}}=2503 \mathrm{~cm}^{-1}$. ESI-MS: obs'd (\%), calc'd (\%), ppm, $\mathrm{M}^{+}$: 
651.1880 (75.8), 651.1887 (84.8), 1.0; 652.1923 (68.3), 652.1912 (80.1), 1.7; 653.1913 (100), 653.1911 (100), 0.4; 654.1958 (54), 654.1953 (42.7), 0.8; 655.1947 (100), 655.1943 (84), 0.5.
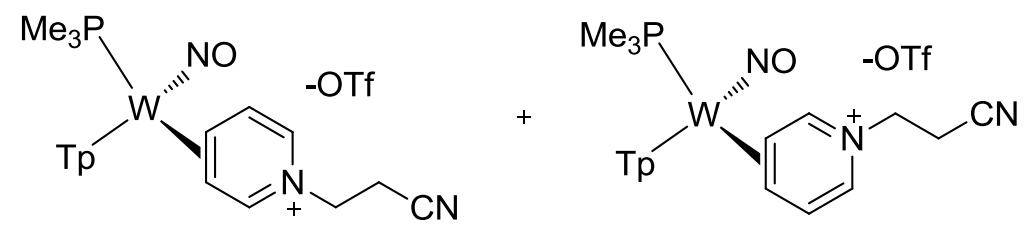

$\mathrm{TpW}(\mathrm{NO})\left(\mathrm{PMe}_{3}\right)\left(3,4-\eta^{2}-\mathrm{N}\right.$-(2-cyanoethyl)pyridinium)(OTf) (5): A solution of $\mathrm{NEt}_{3}(0.013 \mathrm{~g}, 0.125$ $\mathrm{mmol})$ in $\sim 2 \mathrm{~mL}$ of acrylonitrile was added to $\mathbf{1 H}(0.108 \mathrm{~g}, 0.147 \mathrm{mmol})$ completely dissolving the solid into a bright red solution. After $3 \mathrm{~h}$ the solution was added to $\sim 75 \mathrm{~mL}$ of stirring $\mathrm{Et}_{2} \mathrm{O}$ precipitating a solid. The orange solid was collected by filtration using a $15 \mathrm{~mL}$ medium porosity fritted funnel and dried in vacuo to give a 5 (0.094, $0.112 \mathrm{mmol}, 76 \%) .{ }^{1} \mathrm{H}$ NMR (acetone- $d_{6}, \delta$ ): Major: $9.30(\mathrm{~d}, J=5.9,1 \mathrm{H}, \mathrm{H} 2), 8.40(\mathrm{~d}, J=2.0,1 \mathrm{H}, \mathrm{Tp}), 8.12-8.20(3 \mathrm{H}, 3 \mathrm{Tp}), 7.95(\mathrm{~d}, J=2.0,1 \mathrm{H}$, Tp), $7.82(\mathrm{~d}, J=2.0,1 \mathrm{H}, \mathrm{Tp}), 7.11(\mathrm{ddd}, J=7.3,5.8,1.3,1 \mathrm{H}, \mathrm{H} 5), 6.52(\mathrm{t}, J=2.0,1 \mathrm{H}, \mathrm{Tp}), 6.48(\mathrm{t}, J$ $=2.0,1 \mathrm{H}, \mathrm{Tp}), 6.42(\mathrm{dd}, J=7.3,1.2,1 \mathrm{H}, \mathrm{H} 6), 6.37(\mathrm{t}, J=2.0,1 \mathrm{H}, \mathrm{Tp}), 4.45-4.65(\mathrm{~m}, 2 \mathrm{H}$, methylene $\beta$ to nitrile), 4.11 (ddd, $J=12.9,7.2,5.8,1 \mathrm{H}, \mathrm{H} 4), 3.05-3.30(\mathrm{~m}, 2 \mathrm{H}$, methylene $\alpha$ to nitrile), 2.57 (ddd, J =7.2, 5.9, 1.2, 1H, H3), 1.32 (d, J = 9.2, 9H, $\mathrm{PMe}_{3}$ ); Minor: 9.34 (d, J = 5.0, $1 \mathrm{H}, \mathrm{H} 2$ ), 8.12$8.20(3 \mathrm{H}, 3 \mathrm{Tp}), 8.11(\mathrm{~d}, J=2.0,1 \mathrm{H}, \mathrm{Tp}), 7.99(\mathrm{~d}, J=2.0,1 \mathrm{H}, \mathrm{Tp}), 7.76(\mathrm{~d}, J=2.0,1 \mathrm{H}, \mathrm{Tp}), 7.32(\mathrm{t}, J$ $=6.7,1 \mathrm{H}, \mathrm{H} 5), 6.51(\mathrm{t}, J=2.0,1 \mathrm{H}, \mathrm{Tp}), 6.46(\mathrm{t}, J=2.0,1 \mathrm{H}, \mathrm{Tp}), 6.39(\mathrm{t}, J=2.0,1 \mathrm{H}, \mathrm{Tp}), 6.36(\mathrm{dd}, J$ $=6.7,1.0,1 \mathrm{H}, \mathrm{H} 6)$, 4.45-4.65 (m, $2 \mathrm{H}$, methylene $\beta$ to nitrile), 3.91 (ddd, $J=8.0,5.2,5.0,1 \mathrm{H}, \mathrm{H} 3$ ), 3.05-3.30 (m, $2 \mathrm{H}$, methylene $\alpha$ to nitrile), $2.48(\mathrm{dd}, J=6.7,5.2,1 \mathrm{H}, \mathrm{H} 4), 1.40(\mathrm{~d}, J=8.6,9 \mathrm{H}$, $\mathrm{PMe}_{3}$ ). ${ }^{13} \mathrm{C}$ NMR (acetone- $d_{6}, \delta$ ): Major: 173.4 (C2), 146.9 (Tp), 146.4 (Tp), 142.7 (Tp), 139.0 (Tp), 138.6 (Tp), 137.7 (Tp), 129.2 (d, J = 2.7, C5), 120.1 (C6), 118.5 (CN), 108.4 (Tp), 108.0 (Tp), $107.6(\mathrm{Tp}), 66.4$ (d, $J=13.1, \mathrm{C} 4), 59.8(\mathrm{C} 3), 53.9$ ( $\beta$ to nitrile), 21.4 ( $\alpha$ to nitrile), 12.5 ( $d, J=30.8$, $\mathrm{PMe}_{3}$ ); Minor: 168.8 (C2), 145.5 (Tp), 142.5 (Tp), 142.0 (Tp), 138.9 (Tp), 138.4 (Tp), 137.6 (Tp), 132.1 (C5), 118.5 (CN), 118.0 (C6), 108.3 (Tp), 108.1 (Tp), 107.2 (Tp), 63.5 (C4), 62.2 (d, J = 13.1, 
C3), 53.7 ( $\beta$ to nitrile), 21.2 ( $\alpha$ to nitrile), $13.2\left(d, J=29.9, \mathrm{PMe}_{3}\right) .{ }^{31} \mathrm{P}$ NMR (Acetone- $\left.d_{6}, \delta\right)$ : major: $-10.93\left(J_{\mathrm{WP}}=292\right)$, minor: $-14.63\left(J_{\mathrm{WP}}=282\right) . \mathrm{CV}: E_{\mathrm{p}, \mathrm{a}}=+1.02 \mathrm{~V} . \mathrm{IR}: \mathrm{V}_{\mathrm{NO}}=1585 \mathrm{~cm}^{-1}, \mathrm{~V}_{\mathrm{CN}}=2252$ $\mathrm{cm}^{-1}, \mathrm{v}_{\mathrm{BH}}=2499 \mathrm{~cm}^{-1}$. ESI-MS: obs'd (\%), calc'd (\%), ppm, $\mathrm{M}^{+}: 634.1739$ (84.7), 634.1734 (85.3), 0.8; 635.1767 (81.1), 635.1759 (80), 1.2; 636.1760 (100), 636.1757 (100), 0.4; 637.1800 (51.6), 637.1799 (42), $0.2 ; 638.1803(100), 638.1790$ (84.2), 2.0.

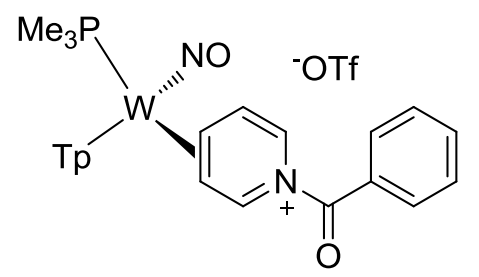

$\operatorname{TpW}(\mathrm{NO})\left(\mathrm{PMe}_{3}\right)\left(3,4-\eta^{2}-\mathrm{N}\right.$-benzoylpyridinium)(OTf) (7): 2,6-Lutidine was added to a heterogeneous orange solution of $\mathbf{1 H}(0.200 \mathrm{~g}, 2.730 \mathrm{mmol})$ and benzoic anhydride $(0.381 \mathrm{~g}$, $1.685 \mathrm{mmol}$ ) in MeCN (1.42 g) giving a deep red and homogenous solution within several minutes. The reaction solution was placed in a $55^{\circ} \mathrm{C}$ oil bath, and allowed to stir for $2.75 \mathrm{~h}$, then removed from heat and The solution was then added to $80 \mathrm{~mL}$ of stirring $\mathrm{Et}_{2} \mathrm{O}$. After stirring for about 15 minutes, the red-orange precipitate was collected on a $15 \mathrm{~mL}$ medium porosity fritted funnel, washed with $5 \times 5 \mathrm{~mL}$ portions of $\mathrm{Et}_{2} \mathrm{O}$, then redissolved in $\mathrm{MeCN}(1.40 \mathrm{~g})$. The resulting deep red solution was added to another $80 \mathrm{~mL}$ of stirring $\mathrm{Et}_{2} \mathrm{O}$, precipitting a red-orange solid. This precipitate was collected on a $15 \mathrm{~mL}$ medium porosity fritted funnel, washed with $5 \times 5 \mathrm{~mL}$ portions of $\mathrm{Et}_{2} \mathrm{O}$, and dried under vacuum yielding $0.154 \mathrm{~g}(0.184 \mathrm{mmol}, 67 \%) ; 0.125 \mathrm{~g}$ (0.149 mmol, 63\%) after adjustment for the lutidinium impurity, as determined by ${ }^{1} \mathrm{H}$ NMR. Removal of the lutidinium salt was possible but rely on several more re-precipitations. ${ }^{1} \mathrm{H} N M R\left(\mathrm{CD}_{3} \mathrm{CN}, \delta\right)$ : $8.98(\mathrm{~d}, J=5.7,1 \mathrm{H}, \mathrm{H} 2), 8.15(\mathrm{~d}, J=2.0,1 \mathrm{H}, \mathrm{PzB} 3), 8.08(\mathrm{~d}, J=2.0,1 \mathrm{H}, \mathrm{PzC} 5), 8.07(\mathrm{~d}, J=2.0,1 \mathrm{H}$, PzA3), $8.03(\mathrm{~d}, J=2.0,1 \mathrm{H}, \mathrm{PzB} 4), 7.86(\mathrm{~d}, J=2.0,1 \mathrm{H}, \mathrm{PzA} 5), 7.84(\mathrm{~d}, J=2.0,1 \mathrm{H}, \mathrm{PzC}$ ) $7.79(\mathrm{~m}$, $2 \mathrm{H}, \mathrm{H9}), 7.74(\mathrm{~m}, 1 \mathrm{H}, \mathrm{H} 11), 7.62(\mathrm{~m}, 2 \mathrm{H}, \mathrm{H} 10), 6.53(\mathrm{t}, J=2.0,1 \mathrm{H}, \mathrm{PzA} 4), 6.49(\mathrm{t}, J=2.0,1 \mathrm{H}$, PzB4), $6.41(\mathrm{~m}, 2 \mathrm{H}, \mathrm{C} 5 / \mathrm{C} 6), 6.37(\mathrm{t}, J=2.0,1 \mathrm{H}, \mathrm{PzC} 4), 4.28(\mathrm{dt}, J=11.8,6.0,1 \mathrm{H}, \mathrm{C} 4), 3.55$ (dd, $J=$ 
6.0, 5.7, $1 \mathrm{H}, \mathrm{C} 3$ ), $1.22\left(\mathrm{~d}, J=9.5,9 \mathrm{H}, \mathrm{PMe}_{3}\right) .{ }^{13} \mathrm{C} \mathrm{NMR}\left(\mathrm{CD}_{3} \mathrm{CN}, \delta\right): 169.7$ (Amide-CO), 163.1 (C2), 148.2 (PzA3), 147.1 (PzB3), 142.9 (PzC3), 139.5 (Tp), 139.3 (Tp), 138.6 (Tp), 133.9 (C11), 131.6 (C8), 130 (C9/C10), 121.5/117.6 (C5/C6), 109 (PzB4), 108.4 (PzA4), 66.9 (C3), 66.4 (d, J = 13.3, C4), $13.0\left(\mathrm{~d}, J=32.1, \mathrm{PMe}_{3}\right) .{ }^{31} \mathrm{P} \mathrm{NMR}\left(\mathrm{CDCl}_{3}, \delta\right)$ : major: -9.45 ppm $\left(J_{\mathrm{WP}}=283\right)$, minor: $-14.38\left(J_{\mathrm{WP}}\right.$ = 276). CV: $E_{\mathrm{p}, \mathrm{a}}=+1.23$ V. IR: $v_{\mathrm{NO}}=1612 \mathrm{~cm}^{-1}, v_{\mathrm{CO}}=1708 \mathrm{~cm}^{-1}, v_{\mathrm{BH}}=2507 \mathrm{~cm}^{-1}$. ESI-MS: obs'd (\%), calc'd (\%), ppm, $\mathrm{M}^{+}: 685.1727$ (85.7), 685.1736 (82.2), 1.4; 686.1747 (46.6), 686.1762 (80.6), 2.2; 687.1754 (100), 687.1761 (100), 1.0; 688.1787 (26), 688.1801 (45.3), 2.0; 689.1788 (93.2), $689.1793(83.5), 0.7$.

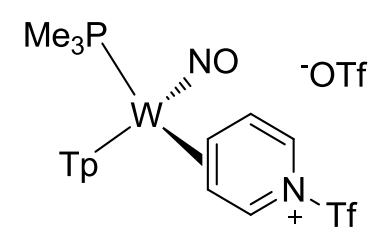

$\mathrm{TpW}(\mathrm{NO})\left(\mathrm{PMe}_{3}\right)\left(3,4-\eta^{2}-\mathrm{N}\right.$-(trifluoromethylsulfonyl)pyridinium) (OTf) (8): $\mathrm{Tf}_{2} \mathrm{O}$ (0.011 mg, 0.040 $\mathrm{mmol})$ was added to a heterogeneous orange solution of $\mathbf{1 H}(0.024 \mathrm{~g}, 0.033 \mathrm{mmol})$, DTBP $(0.009$ $\mathrm{g}, 0.048 \mathrm{mmol})$, and $\mathrm{CDCl}_{3}(0.87 \mathrm{~g})$ to become a deep red homogeneous solution over a couple of minutes. ${ }^{1} \mathrm{H}$ NMR $\left(\mathrm{CDCl}_{3}, \delta\right)$ : Tp and DTBP signals are omitted; only pyridinium ring protons reported as determined by COSY. Major: $8.33(\mathrm{~d}, J=5.5,1 \mathrm{H}, \mathrm{H} 2$ ), 6.55 (burried, $1 \mathrm{H}, \mathrm{H} 5$ ), 6.08 (d, $J=7.6,1 \mathrm{H}, \mathrm{H} 6), 4.51(\mathrm{dt}, J=11.0,5.8,1 \mathrm{H}, \mathrm{H} 4), 3.73(\mathrm{dd}, J=5.8,5.5,1 \mathrm{H}, \mathrm{H} 3), 1.27(\mathrm{~d}, J=9.5,9 \mathrm{H}$, PMe ${ }_{3}$ ). Minor: $8.71(\mathrm{~d}, J=5.0,1 \mathrm{H}, \mathrm{H} 2), 6.56(\mathrm{t}, J=6.9,1 \mathrm{H}, \mathrm{H} 5), 6.01(\mathrm{~d}, J=6.9,1 \mathrm{H}, \mathrm{H6}), 5.00(\mathrm{dt}, J$ $=5.7,5.0,1 \mathrm{H}, \mathrm{H} 3), 3.10(\mathrm{t}, J=6.9,1 \mathrm{H}, \mathrm{H} 4), 1.29\left(\mathrm{~d}, J=8.9,9 \mathrm{H}, \mathrm{PMe}_{3}\right) .{ }^{31} \mathrm{P} \mathrm{NMR}\left(\mathrm{CDCl}_{3}, \delta\right):-8.53$ $\left(J_{\mathrm{WP}}=278\right)$, minor: $-14.52\left(J_{\mathrm{WP}}=270\right) . \mathrm{CV}: E_{\mathrm{p}, \mathrm{a}}=+1.48 \mathrm{~V} . \mathrm{IR}: v_{\mathrm{NO}}=1620 \mathrm{~cm}^{-1}, v_{\mathrm{BH}}=2519 \mathrm{~cm}^{-1}$.<smiles>CC(=O)N1C=CC([N+]([O-])([O-])[O-])=CC1</smiles> 
TpW(NO)(PMe $\left.{ }_{3}\right)\left(3,4-\eta^{2}\right.$-(1-(pyridin-1(2H)-yl)ethanone)) (10): $\mathrm{NaBH}_{4}(2.480 \mathrm{~g}, 65.56 \mathrm{mmol})$ was added to a $50 \mathrm{~mL}$ Erlenmeyer flask containing methanol $(21.5 \mathrm{~mL})$ giving a white slurry which was quickly added to a flame dried 1 L Erlenmeyer flask containing a homogeneous deep red solution of $6(5.009 \mathrm{~g}, 6.470 \mathrm{mmol})$ in methanol $(25.0 \mathrm{~mL})$. The mixture vigorously effervesced and turned green. The solution was allowed to cool for about 5 minutes then removed from the glovebox. Upon exposure to air, the green color dissipated (due to the rapid oxidation of a very small amount of byproduct $1 \mathrm{~N}$ oxidation in air). The reaction solution was diluted with $85 \mathrm{~mL}$ DCM and washed with $5 \times 40 \mathrm{~mL}$ portions of $\mathrm{NaHCO}_{3}$ (aq, sat'd). The combined water layer was back-extracted with $3 \times 30 \mathrm{~mL}$ portions of DCM. The combined DCM layers were dried with $\mathrm{Na}_{2} \mathrm{SO}_{4}$, filtered through a $150 \mathrm{~mL}$ course porosity fritted funnel and the solvent removed in vacuo. The residue was dissolved in $15 \mathrm{~mL} \mathrm{DCM}$, then $15 \mathrm{~mL}$ EtOAc, and then $300 \mathrm{~mL}$ hexanes was added to precipitate a tan solid. The solution was cooled with an ice bath for 0.5 hour and the precipitate collected on a $60 \mathrm{~mL}$ medium porosity fritted funnel. The residue on the flask was redissolved in $8 \mathrm{~mL} \mathrm{DCM}$, then $8 \mathrm{~mL}$ EtOAc, and then $150 \mathrm{~mL}$ of hexanes were added giving a precipitate which was collected on the same $60 \mathrm{~mL}$ funnel, washed with $2 \times 30 \mathrm{~mL}$ portions of hexanes, and dried under vacuum (3.615 g, $5.774 \mathrm{mmol}, 89 \%) .{ }^{1} \mathrm{H} \mathrm{NMR}\left(\mathrm{CDCl}_{3}, \delta\right): 8.34(\mathrm{~d}, J=$ 2.0, 1H, PzA3), 7.99 (d, J = 2.0, 1H, PzB3), 7.69 (m, 2H, PzB5/PzC5), 7.58 (d, J = 2.0, 1H, PzA5), $7.23(\mathrm{~d}, J=2.0,1 \mathrm{H}, \mathrm{PzC} 3), 7.26(\mathrm{t}, J=2.0,1 \mathrm{H}, \mathrm{PzB} 4), 7.24(\mathrm{t}, J=2.0,1 \mathrm{H}, \mathrm{PzA} 4), 6.19(\mathrm{t}, J=2.0,1 \mathrm{H}$, PzC4), 5.98 (d, $J=7.5,1 \mathrm{H}, \mathrm{H6}$ ), 5.82 (dd, $J=7.5,5.3,1 \mathrm{H}, \mathrm{H} 5), 5.43$ (d, $J=13.4,1 \mathrm{H}, \mathrm{H} 2($ syn)), 4.21 (dd, $J=13.4,2.7,1 \mathrm{H}, \mathrm{H} 2$ (anti)), 2.83 (ddd, $J=13.3,10.3,5.3,1 \mathrm{H}, \mathrm{H} 4$ ), 2.16 (s, 1H, Amide-Me), $1.69(\mathrm{~d}, J=10.3,1 \mathrm{H}, \mathrm{H} 3), 1.25\left(\mathrm{~d}, J=8.3,9 \mathrm{H}, \mathrm{PMe}_{3}\right) .{ }^{13} \mathrm{C}$ NMR $\left(\mathrm{CDCl}_{3}, \delta\right): 169.0$ (Amide-CO), 144.9 (PzA3), 143.3 (PzB3), 139.9 (PzC3), 136.6/136.0 (PzB5/PzC5), 135.4 (PzA5), 119.9 (C6), 116.7 (C5), 106.4 (PzA4/PzB4), 106.0 (PzC4), 58.7 (C3), 45.9 (C4, d, J = 10.3), 41.0 (C2), 22.7 (AmideMe), $14.0\left(\mathrm{PMe}_{3}, \mathrm{~d}, J=27.9\right) .{ }^{31} \mathrm{P} \mathrm{NMR}\left(\mathrm{CDCl}_{3}, \delta\right):-12.25\left(J_{\mathrm{WP}}=281\right) . \mathrm{CV}: E_{\mathrm{p}, \mathrm{a}}=+0.37$ V. IR: $v_{\mathrm{NO}}=$ 
$1558 \mathrm{~cm}^{-1}, v_{\text {amide }}=1612 \mathrm{~cm}^{-1}, v_{\text {alkene }}=1635 \mathrm{~cm}^{-1}, v_{\mathrm{BH}}=2488 \mathrm{~cm}^{-1}$. ESI-MS: obs'd (\%), calc'd (\%), ppm, $(\mathrm{M}+\mathrm{H})^{+}: 625.1724$ (90.3), 625.1730 (85.9), 1.0; 626.1770 (82.5), 626.1756 (79.6), 2.3; 627.1782 (100), 627.1754 (100), 4.5; 628.1833 (48.8), 628.1797 (41.2), 5.9; 629.1816 (95.1), $629.1786(84.6), 4.8$.

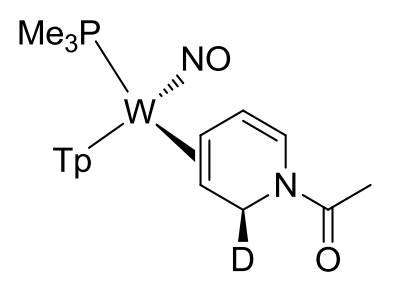

TpW(NO)(PMe 3 )(3,4- $\eta^{2}$-(1-(2-deuteropyridin-1(2H)-yl)ethanone)) (10-Deutero): $\mathrm{NaBD}_{4}(0.276 \mathrm{~g}$, $6.59 \mathrm{mmol})$ was added to MeOD $(1.707 \mathrm{~g})$ and the heterogeneous solution was quickly added to a $500 \mathrm{~mL}$ flame dried Erlenmeyer flask containing a homogeneous deep red solution of 6 (0.500 $\mathrm{g}, 0.646 \mathrm{mmol})$ in MeOD (1.973 g). The mixture vigorously effervesced and turned green. The solution was allowed to cool for about 5 minutes then removed from the glovebox. Upon exposure to air, the green color dissipated (due to the rapid oxidation of a very small amount of byproduct $1 \mathrm{~N}$ oxidation in air). The solution was diluted with $\mathrm{DCM}(20 \mathrm{~mL})$ and extracted with 3 x $20 \mathrm{~mL}$ portions of $\mathrm{NaHCO}_{3}$ (aq, sat'd). The combined aqueous solution was back-extracted with $2 \times 20 \mathrm{~mL}$ portions of DCM and combined with the original DCM extract. The DCM layer was dried with $\mathrm{Na}_{2} \mathrm{SO}_{4}$, filtered through a $30 \mathrm{~mL}$ medium porosity fritted funnel, and the solvent removed in vacuo. The residue was dissolved in $2 \mathrm{~mL} \mathrm{DCM}$, then $2 \mathrm{mLEtOAc}$, and then $25 \mathrm{~mL}$ of hexanes were added to precipitate a tan solid that was collected on a $30 \mathrm{~mL}$ medium porosity fritted funnel. The solid residue remaining in the precipitation flask was redissolved with $1 \mathrm{~mL}$ DCM, then $1 \mathrm{~mL}$ EtOAc, and then precipitated with $13 \mathrm{~mL}$ hexanes. The precipitate was collected on the same $30 \mathrm{~mL}$ medium porosity fritted funnel as the first precipitate and was washed with $2 \times 15 \mathrm{~mL}$ portions of hexanes, and the combined precipitate was dried under vacuum $(0.335 \mathrm{~g}$, $0.534 \mathrm{mmol}, 83 \%) .{ }^{1} \mathrm{H}$ NMR $\left(\mathrm{CDCl}_{3}, \delta\right): 8.33(\mathrm{~d}, J=2.0,1 \mathrm{H}, \mathrm{PzA} 3), 7.98(\mathrm{~d}, J=2.0,1 \mathrm{H}, \mathrm{PzB} 3), 7.68$ 
(t, $J=2.0,2 \mathrm{H}, \mathrm{PzB} 5 / \mathrm{PzC} 5), 7.57(\mathrm{~d}, J=2.0,1 \mathrm{H}, \mathrm{PzA} 5), 7.22(\mathrm{~d}, J=2.0,1 \mathrm{H}, \mathrm{PzC} 3), 6.25(\mathrm{t}, J=2.0$, 1H, PzB4), $6.22(\mathrm{t}, J=2.0,1 \mathrm{H}, \mathrm{PzA} 4), 6.19(\mathrm{t}, J=2.0,1 \mathrm{H}, \mathrm{PzC} 4), 5.97(\mathrm{~d}, J=7.4,1 \mathrm{H}, \mathrm{H} 6), 5.81$ (dd, $J=7.4,5.4,1 \mathrm{H}, \mathrm{H} 5), 5.40(\mathrm{~s}, 1 \mathrm{H}, \mathrm{H} 2), 2.82(\mathrm{ddd}, J=15.5,10.3,5.4,1 \mathrm{H}, \mathrm{H} 4), 2.16(\mathrm{~s}, 3 \mathrm{H}$, Amide$\mathrm{Me}), 1.67(\mathrm{~d}, J=10.3,1 \mathrm{H}, \mathrm{H} 3), 1.24\left(\mathrm{~d}, J=8.2,9 \mathrm{H}, \mathrm{PMe}_{3}\right) .{ }^{13} \mathrm{C} \mathrm{NMR}\left(\mathrm{CDCl}_{3}, \delta\right): 168.9$ (Amide-CO), 144.8 (PzA3), 143.2 (PzB3), 139.8 (PzC3), 136.4/136.0 (PzB4/BzC5), 135.3 (PzA5), 119.8 (C6), 116.7 (C5), 106.3 (2 Tp's), 106.0 (Tp), 58.5 (C3), 45.8 (C4, d, J = 10.7), 40.5 (C2, s=1 t, J = 21.0), 22.8 (Amide-Me), $13.9\left(\mathrm{PMe}_{3}, \mathrm{~d}, J=27.9\right) .{ }^{31} \mathrm{P} \mathrm{NMR}\left(\mathrm{CDCl}_{3}, \delta\right):-12.22\left(J_{\mathrm{WP}}=282\right) . \mathrm{CV}: E_{\mathrm{p}, \mathrm{a}}=+0.43$ V. IR: $v_{\mathrm{NO}}=1562 \mathrm{~cm}^{-1}, v_{\text {alkene }}=1643 \mathrm{~cm}^{-1}, v_{\text {amide }}=1616 \mathrm{~cm}^{-1}, v_{\mathrm{BH}}=2484 \mathrm{~cm}^{-1}$. ESI-MS: obs'd (\%), calc'd (\%), ppm, $(\mathrm{M}+\mathrm{H})^{+}: 626.1784$ (93.5), 626.1799 (85.8), 2.4; 627.1799 (93.8), 627.1824 (79.6), 4.0; 628.1823 (100), 628.1823 (100), 0.0; 629.1853 (56.4), 629.1865 (41.2), 1.9; 630.1840 (81.5), 630.1855 (84.6), 2.4.

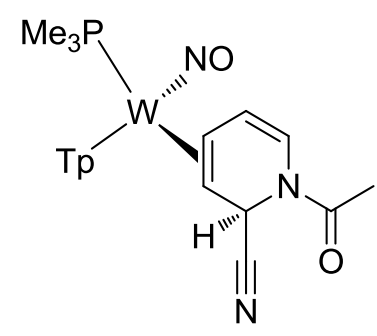

TpW(NO)(PMe $)\left(3,4-\eta^{2}\right.$-(1-acetyl-1,2-dihydropyridine-2-carbonitrile) (11): TMSCN (1.975 g, $19.907 \mathrm{mmol})$ was added to a deep red solution of $6(3.003 \mathrm{~g}, 3.879 \mathrm{mmol})$ in DCM $(9.75 \mathrm{~g})$. Upon the addition of DABCO $(0.438 \mathrm{~g}, 3.905 \mathrm{mmol})$ the solution became warm and gently boiled for a few seconds. Over the course of 3 hours the solution cooled and turned dark yellow. The reaction was removed from the glovebox, diluted with $25 \mathrm{~mL} \mathrm{DCM}$, and was extracted with $5 \mathrm{x}$ $25 \mathrm{~mL}$ portions of $\mathrm{NaHCO}_{3}$ (aq, sat'd). The water layers were combined and back-extracted with $3 \times 20 \mathrm{~mL}$ portions of DCM. The combined DCM layers were dried with $\mathrm{Na}_{2} \mathrm{SO}_{4}$, filtered through a $60 \mathrm{~mL}$ course fritted funnel, and the solvent removed in vacuo. The residue was dissolved in 12 $\mathrm{mL} \mathrm{DCM}$, then $12 \mathrm{~mL}$ EtOAc, and then $200 \mathrm{~mL}$ hexanes were added to precipitate a tan solid that 
was collected on a $60 \mathrm{~mL}$ medium porosity fritted funnel. The solid residue remaining in the flask was dissolved in $6 \mathrm{~mL} \mathrm{DCM}$, then $6 \mathrm{~mL}$ EtOAc, and then $100 \mathrm{~mL}$ hexanes were added giving a precipitate that was collected with the original material. The combined product was washed with $2 \times 30 \mathrm{~mL}$ portions of hexanes and dried under vacuum $(2.210 \mathrm{~g}, 3.394 \mathrm{mmol}, 88 \%) .{ }^{1} \mathrm{H}$ $\operatorname{NMR}\left(\mathrm{CDCl}_{3}, \delta\right): 8.10(\mathrm{~d}, J=2.0,1 \mathrm{H}, \mathrm{PzA} 3), 7.98(\mathrm{~d}, J=2.0,1 \mathrm{H}, \mathrm{PzB} 3), 7.73(\mathrm{~d}, J=2.0,1 \mathrm{H}, \mathrm{PzC} 5)$, $7.71(\mathrm{~d}, J=2.0,1 \mathrm{H}, \mathrm{PzB} 5), 7.61$ (d, $J=2.0,1 \mathrm{H}, \mathrm{PzA} 5), 7.26$ (d, $J=2.0,1 \mathrm{H}, \mathrm{PzC} 3), 6.41(\mathrm{~s}, 1 \mathrm{H}, \mathrm{H} 2)$, $6.28(\mathrm{t}, J=2.0,1 \mathrm{H}, \mathrm{PzB} 4), 6.26(\mathrm{t}, J=2.0,1 \mathrm{H}, \mathrm{PzA} 4), 6.25(\mathrm{t}, J=2.0,1 \mathrm{H}, \mathrm{PzC} 4), 6.02(\mathrm{dd}, J=7.4$, 5.5, 1H, H5), 5.96 (d, J = 7.4, 1H, H6), 2.91 (ddd, J = 13.0, 10.1, 5.5, 1H, H4), 2.22 (s, 3H, Acyl-Me), $1.93(\mathrm{~d}, J=10.1,1 \mathrm{H}, \mathrm{H} 3), 1.25(\mathrm{~d}, J=8.4,9 \mathrm{H}, \mathrm{PMe} 3) .{ }^{13} \mathrm{C} \mathrm{NMR}\left(\mathrm{CDCl}_{3}, \delta\right): 169.0(\mathrm{CO}), 144.63$ (PzA3), 143.4 (PzB3), 140.1 (PzC3), 136.8 (PzC5), 136.5 (PzB5), 135.8 (PzA5), 123.1 (CN), 117.6 (C5), 116.9 (C6), 106.8 (PzB4), 106.7 (PzA4), 106.4 (PzC4), 61.2 (C4), 44.1 (d, J = 11.2, C3), 41.6 (C2), 22.6 (Acyl-Me), 13.7 (d, J= 28.7, PMe3). ${ }^{31} \mathrm{P}$ NMR $\left(\mathrm{CDCl}_{3}, \delta\right):-12.27\left(J_{\mathrm{WP}}=278\right) . \mathrm{CV}: E_{\mathrm{p}, \mathrm{a}}=$ +0.64 V. IR: $v_{\mathrm{NO}}=1566 \mathrm{~cm}-1, v_{\text {amide }}=1620 \mathrm{~cm}-1, v_{\text {alkene }}=1651 \mathrm{~cm}-1, v_{\mathrm{CN}}=2225 \mathrm{~cm}-1, v_{\mathrm{BH}}=2492$ $\mathrm{cm}^{-1}$. ESI-MS: obs'd (\%), calc'd (\%), ppm, $(\mathrm{M}+\mathrm{H})^{+}: 650.167$ (88.7), 650.1689 (85.1), 2.9; 651.1767 (83.5), 651.1714 (79.9), 8.1; 652.171 (100), 652.1712 (100), 0.3; 653.1769 (45), 653.1754 (42.1), $2.3 ; 654.178(90.6), 654.1745(84.2), 5.4$.

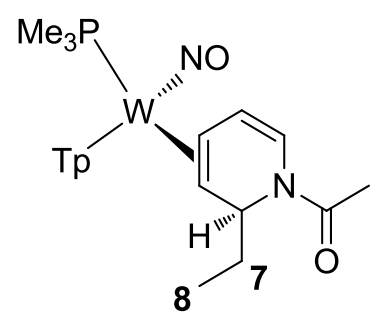

TpW(NO)(PMe 3 )(3,4- $\eta^{2}$-(1-(2-ethylpyridin-1(2H)-yl)ethanone)) (13): $\mathrm{ZnEt}_{2}$ (1.445 g, 11.70 mmol) in THF (1.77 g) was added to a flame dried $125 \mathrm{~mL}$ Erlenmeyer flask containing a deep red slurry of 6 (3.004 g, $3.880 \mathrm{mmol})$ in THF (7.17 g) and was allowed to stir for 40 minutes as it became homogeneous and dark yellow. The solution was diluted with $25 \mathrm{~mL} \mathrm{DCM}$ and slowly neutralized 
with $\mathrm{NH}_{4} \mathrm{Cl}$ (aq, sat'd) in a glovebox. The dark yellow solution was removed from the glovebox and extracted with $3 \times 50 \mathrm{~mL}$ portions of $\mathrm{NH}_{4} \mathrm{Cl}$ (aq, sat'd). The combined water layers were backed extracted with $3 \times 20 \mathrm{~mL}$ portions of DCM. The combined DCM layers were dried with $\mathrm{Na}_{2} \mathrm{SO}_{4}$, filtered through a $150 \mathrm{~mL}$ course porosity fritted funnel, and the solvent removed in vacuo. The residue was dissolved with $11 \mathrm{~mL} \mathrm{DCM}$, then $11 \mathrm{~mL}$ EtOAc, and then the material precipitated with $300 \mathrm{~mL}$ hexanes. The tan precipitate was collected on a $150 \mathrm{~mL}$ medium porosity fritted funnel. The residue remaining in the flask was dissolved in $4 \mathrm{~mL} \mathrm{DCM}$, then $4 \mathrm{~mL}$ EtOAc, and then precipitated with $100 \mathrm{~mL}$ hexanes. The combined precipitate was collected on the original frit and the material was washed with $2 \times 75 \mathrm{~mL}$ portions of hexanes, and dried under vacuum (2.233 g, $3.414 \mathrm{mmol}, 88 \%) .{ }^{1} \mathrm{H}$ NMR $\left(\mathrm{CD}_{3} \mathrm{CN}, \delta\right): 8.33(\mathrm{~d}, J=2.0,1 \mathrm{H}, \mathrm{PzA} 3), 8.01$ (d, $J=2.0,1 \mathrm{H}$, PzB3), 7.86 (s (br), 2H, PzB5/PzC5), 7.77 (d, J=2.0, 1H, PzA5), 7.39 (d, $J=2.0,1 \mathrm{H}$, PzC3), $6.36(\mathrm{t}, J=2.0,1 \mathrm{H}, \mathrm{PzB} 4), 6.31(\mathrm{t}, J=2.0,1 \mathrm{H}, \mathrm{PzA} 4), 6.29(\mathrm{t}, J=2.0,1 \mathrm{H}, \mathrm{PzC} 4), 5.88(\mathrm{dd}, J=$ 7.5, 5.4, $1 \mathrm{H}, \mathrm{H} 5), 5.78(\mathrm{~d}, J=7.5,1 \mathrm{H}, \mathrm{H} 6), 5.31$ (ddd, $J=6.5,5.2,1.1,1 \mathrm{H}, \mathrm{H} 2$ ), 2.87 (ddd, $J=13.4$, 10.4, 5.4, 1H, H4), 2.07 (s, 3H, Acetyl-Me), $1.78(\mathrm{~m}, 1 \mathrm{H}, \mathrm{H} 7), 1.49\left(\mathrm{~m}, 2 \mathrm{H}, \mathrm{H} 7^{\prime} / \mathrm{H} 3\right), 1.24$ (d, J = 8.5, $\left.9 \mathrm{H}, \mathrm{PMe}_{3}\right), 0.81(\mathrm{t}, J=7.4,3 \mathrm{H}, \mathrm{H} 8) .{ }^{13} \mathrm{C} \mathrm{NMR}\left(\mathrm{CD}_{3} \mathrm{CN}, \delta\right): 169$ (Amide-CO), 145.1 (PzA3), 144.0 (PzB3), 141.2 (PzC3), 137.0/137.5 (PzB5/PzC5), 136.6 (PzA5), 118.0 (C5), 117.6 (C6), 107.1/106.9/106.7 (PzA4/PzB4/PzC4), 64.4 (C3), 50.9 (C2), 45.3 (C4, d, J = 9.7), 31.3 (C7), 23.4 (Acetyl-Me), $13.7\left(\mathrm{PMe}_{3}, \mathrm{~d}, J=28.4\right), 11.9(\mathrm{C} 8) .{ }^{31} \mathrm{P} \mathrm{NMR}\left(\mathrm{CDCl}_{3}, \delta\right):-12.09\left(J_{\mathrm{WP}}=284\right) . \mathrm{CV}: E_{\mathrm{p}, \mathrm{a}}=$ +0.47 V. IR: $v_{\mathrm{NO}}=1562 \mathrm{~cm}^{-1}, v_{\text {amide }}=1612 \mathrm{~cm}^{-1}, v_{\mathrm{BH}}=2488 \mathrm{~cm}^{-1}$. ESI-MS: obs'd (\%), calc'd (\%), ppm, $(\mathrm{M}+\mathrm{H})^{+}: 653.2016$ (83.0), 653.2044 (84.8), 4.2; 654.2053 (79.7), 654.2069 (80.1), 2.5; 655.2056 (100), 655.2067 (100), 1.8; 656.2079 (74.3), 656.2109 (42.7), 4.6; 657.2094 (100), $657.2100(84.0), 0.9$. 


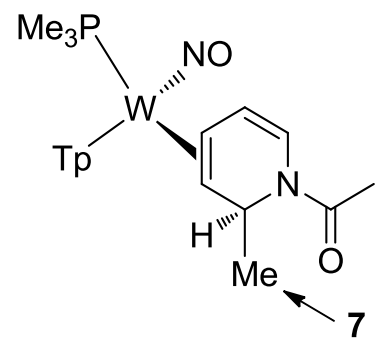

$\operatorname{TpW}(\mathrm{NO})\left(\mathrm{PMe}_{3}\right)\left(3,4-\eta^{2}\right.$-(1-(2-methylpyridin-1(2H)-yl)ethanone)) (14): $\mathrm{MeMgBr}(1.4 \mathrm{M}, 2.06 \mathrm{~mL}$, $2.884 \mathrm{mmol}$ ) was added to THF $(24.6 \mathrm{~mL})$. The resulting solution was added to a $100 \mathrm{~mL}$ flame dried round bottom flask containing a deep red slurry of $6(2.189 \mathrm{~g}, 2.828 \mathrm{mmol})$ in THF (24.6 $\mathrm{mL}$ ). The solution was allowed to stir for 15 minutes, removed from the glovebox, transferred to a $1 \mathrm{~L}$ Erlenmeyer flask, and $875 \mathrm{~mL}$ of $\mathrm{Et}_{2} \mathrm{O}$ was added. The resulting solution was filtered through a $150 \mathrm{~mL}$ medium porosity fritted funnel containing celite $(2 \mathrm{~cm})$. The filter bed was washed with $2 \times 50 \mathrm{~mL}$ portions of $\mathrm{Et}_{2} \mathrm{O}$. The filter bed was discarded and the solvent from the filtrate was removed in vacuo. The residue was dissolved in $11 \mathrm{~mL} \mathrm{DCM}$, then $11 \mathrm{~mL}$ EtOAc, and then $185 \mathrm{~mL}$ hexanes was added to this solution to precipitate a pale pink solid. The solution was cooled in an ice water bath to help precipitate any remaining material. The precipitate was collected on a $150 \mathrm{~mL}$ medium porosity fritted funnel and washed with $2 \times 20 \mathrm{~mL}$ portions of hexanes $(1.034 \mathrm{~g}, 1.615 \mathrm{mmol}, 57 \%)$. The highest purity was obtained with a $\mathrm{DCM} / \mathrm{NaHCO}_{3}$ (aq, sat'd) extraction. ${ }^{1} \mathrm{H}$ NMR $\left(\mathrm{CDCl}_{3}, \delta\right): 8.30$ (d, $\left.J=2.0,1 \mathrm{H}, \mathrm{PzA} 3\right), 7.97(\mathrm{~d}, J=2.0,1 \mathrm{H}, \mathrm{PzB} 3), 7.70$ $(\mathrm{d}, J=2.0,1 \mathrm{H}, \mathrm{PzC} 5), 7.68(\mathrm{~d}, J=2.0,1 \mathrm{H}, \mathrm{PzB} 5), 7.58(\mathrm{~d}, J=2.0,1 \mathrm{H}, \mathrm{PzA} 5), 7.25(\mathrm{~d}, J=2.0,1 \mathrm{H}$, PzC3), $6.25(\mathrm{t}, J=2.0,1 \mathrm{H}, \mathrm{PzB} 4), 6.23(\mathrm{t}, J=2.0,1 \mathrm{H}, \mathrm{PzA} 4), 6.2(\mathrm{t}, J=2.0,1 \mathrm{H}, \mathrm{PzC} 4), 5.79(\mathrm{~m}, 2 \mathrm{H}$, H5/H6), 5.61 (q, $J=6.1,1 \mathrm{H}, \mathrm{H} 2$ ), 2.86 (dddd, $J=14.8,10.3,4.6,1.1,1 \mathrm{H}, \mathrm{H} 4), 2.16$ (s, 3H, AcylMe), $1.55(\mathrm{~d}, J=10.3,1 \mathrm{H}, \mathrm{H} 3), 1.34(\mathrm{~d}, J=6.1,3 \mathrm{H}, \mathrm{H} 7), 1.25\left(\mathrm{~d}, J=8.2,9 \mathrm{H}, \mathrm{PMe}_{3}\right) .{ }^{13} \mathrm{C} \mathrm{NMR}$ $\left(\mathrm{CDCl}_{3}, \delta\right): 168.3$ (Amide-CO), 145.0 (PzA3), 143.3 (PzB3), 139.9 (PzC3), 136.4 (PzC5), 136.0 (PzB5), 135.4 (PzA5), 117.1/115.9 (C5/C6), 106.3 (PzA4/PzB4), 106 (PzC4), 65.4 (C3), 45 (C2), $44.6(C 4, d, J=9.7), 23.3(C 7), 23.2$ (Amide-Me), $13.9\left(\mathrm{PMe}_{3}, \mathrm{~d}, J=27.8\right) .{ }^{31} \mathrm{P} \mathrm{NMR}\left(\mathrm{CDCl}_{3}, \delta\right):-$ 
$12.14\left(J_{\mathrm{WP}}=282\right) . \mathrm{CV}: E_{\mathrm{p}, \mathrm{a}}=+0.45$ V. IR: $v_{\mathrm{NO}}=1562 \mathrm{~cm}^{-1}, v_{\text {amide }}=1612 \mathrm{~cm}^{-1}, v_{\text {alkene }}=1640 \mathrm{~cm}^{-1}, v_{\mathrm{BH}}$ $=2484 \mathrm{~cm}^{-1}$. ESI-MS obs'd (\%), calc'd (\%), ppm (M+H) ${ }^{+}: 639.1875$ (94.5), 639.1893 (85.3), 2.8; 640.1887 (92.4), 640.1918 (79.8), 4.8; 641.1905 (100), 641.1917 (100), 1.9; 642.1933 (51.8), 642.1959 (41.9), 4.0; 643.1913 (79.7), 643.1949 (84.3), 5.6.

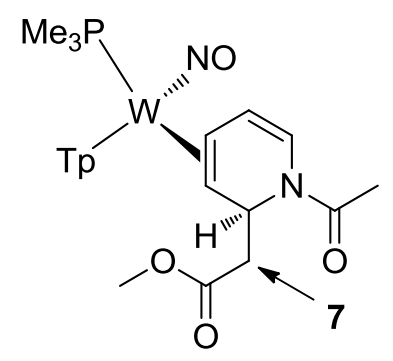

TpW(NO)(PMe $)\left(3,4-\eta^{2}\right.$-(methyl-2-(1-acetyl-1,2-dihydropyridin-2-yl)acetate)) (15): Methyl bromoacetate $(193 \mathrm{mg}, 1.262 \mathrm{mmol}$ ) was diluted with THF (5.0 g). The resulting solution was added to a vial containing $6(778 \mathrm{mg}, 1.005 \mathrm{mmol})$ and $\mathrm{Zn}^{0}$ dust $(167 \mathrm{mg}, 2.554 \mathrm{mmol}$ ) and the deep red slurry was allowed to stir rapidly for 80 minutes as the solution became dark yellow and mostly homogeneous (except for residual $\mathrm{Zn}^{0}$ dust). The solution was filtered through celite to remove any remaining $\mathrm{Zn}^{0}$ dust. The filtrate was diluted with $15 \mathrm{~mL}$ DCM and extracted with 3 x $10 \mathrm{~mL}$ portions $\mathrm{NaHCO}_{3}(a q$, sat'd). The combined water layers were back-extracted with $3 \times 5$ $\mathrm{mL}$ portions of DCM. The combined DCM layer was dried with $\mathrm{Na}_{2} \mathrm{SO}_{4}$, which was removed via filtration over a $15 \mathrm{~mL}$ medium porosity fritted funnel, and the solvent removed in vacuo. The residue was dissolved in $2.5 \mathrm{~mL}$ DCM and $2.5 \mathrm{~mL}$ EtOAc. Hexanes (50 mL) was added to precipitate a tan solid that was collected on a $30 \mathrm{~mL}$ medium porosity fritted funnel. Solid material remaining in the precipitation flask was redissolved in $1 \mathrm{~mL} D C M$ and $1 \mathrm{~mL}$ EtOAc and precipitated with $20 \mathrm{~mL}$ hexanes. The second precipitate was collected on the same funnel as the first precipitate $(0.611 \mathrm{~g}, 0.8708 \mathrm{mmol}, 87 \%) .{ }^{1} \mathrm{H} \mathrm{NMR}\left(\mathrm{CDCl}_{3}, \delta\right): 8.34(\mathrm{~d}, J=2.0,1 \mathrm{H}, \mathrm{PzA} 3)$, $7.97(\mathrm{~d}, J=2.0,1 \mathrm{H}, \mathrm{PzB} 3), 7.69$ (d, J = 2.0, 1H, PzB5), 7.67 (d, J = 2.0, 1H, PzC5), 7.57 (d, J = 2.0, 1H, PzA5), 7.21 (d, J = 2.0, 1H, PzC3), 6.24 (m, 2H, PzA4/PzB4), 6.19 (t, J = 2.0, 1H, PzC4), 5.91 (t, J 
$=6.8,1 \mathrm{H}, \mathrm{H} 2), 5.82(\mathrm{~m}, 2 \mathrm{H}, \mathrm{H} 5 / \mathrm{H} 6), 3.54(\mathrm{~s}, 3 \mathrm{H}$, Ester-Me), $2.82(\mathrm{~m}, 1 \mathrm{H}, \mathrm{H} 4), 2.8(\mathrm{dd}, J=13.2$, 6.8, 1H, H7), $2.53\left(\mathrm{dd}, J=13.2,6.8,1 \mathrm{H}, \mathrm{H7} \mathrm{H}^{\prime}\right), 2.14(\mathrm{~s}, 1 \mathrm{H}$, Amide-Me), $1.61(\mathrm{~d}, J=10.2,1 \mathrm{H}, \mathrm{H} 3$ ), $1.22\left(\mathrm{~d}, \mathrm{~J}=8.3,9 \mathrm{H}, \mathrm{PMe}_{3}\right) .{ }^{13} \mathrm{C} \mathrm{NMR}\left(\mathrm{CDCl}_{3}, \delta\right): 172.8$ (Ester-CO), 168.6 (Amide-CO), 145.1 (PzA3), 143.2 (PzB3), 139.9 (PzC3), 136.5/136.0 (PzB5/PzC5), 135.4 (PzA5), 117.2/116.3 (C5/C6), 106.4/106.1 (PzA4/PzB4), 105.9 (PzC4), 63.4 (C3), 51.6 (Ester-Me), 47.2 (C2), 44.9 (C4, d, J = 9.9), 42.2 (C7), 23 (Amide-Me), $13.8\left(\mathrm{PMe}_{3}, \mathrm{~d}, J=27.8\right) .{ }^{31} \mathrm{P} \mathrm{NMR}\left(\mathrm{CDCl}_{3}, \delta\right):-12.16\left(J_{\mathrm{wP}}=282\right) . \mathrm{CV}: E_{\mathrm{p}, \mathrm{a}}$ $=+0.51 \mathrm{~V} . \mathrm{IR}: v_{\mathrm{NO}}=1562 \mathrm{~cm}^{-1}, v_{\text {amide }}=1616 \mathrm{~cm}^{-1}, v_{\text {alkene }}=1643 \mathrm{~cm}^{-1}, v_{\text {ester }}=1732 \mathrm{~cm}^{-1}, V_{\mathrm{BH}}=2497$ $\mathrm{cm}^{-1}$. ESI-MS: obs'd (\%), calc'd (\%), ppm, (M+H)+: 697.1934 (93.5), 697.1948 (83.9), 2.0; 698.1959 (93.8), 698.1973 (80.1), 2.0; 699.1959 (100), 699.1972 (100), 1.9; 700.1996 (56.4), 700.2013 (43.6), 2.4; 701.1993 (81.5), 701.2004 (83.8), 1.6.

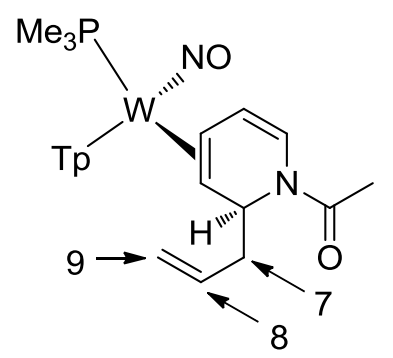

TpW(NO)(PMe 3 )(3,4- $\eta^{2}$-(1-(2-allylpyridin-1(2H)-yl)ethanone)) (16): 6 (0.776 g, 1.002 mmol) was added to a rapidly stirring heterogeneous solution of $\mathrm{Zn}^{0}(0.130 \mathrm{~g}, 2.050 \mathrm{mmol})$ and allyl bromide ( $0.188 \mathrm{~g}, 1.554 \mathrm{mmol})$ in THF (6.24 g). After 2.5 hours the dark yellow reaction solution was filtered through a $15 \mathrm{~mL}$ medium porosity fritted funnel containing celite $(1 \mathrm{~cm})$ and diluted with $20 \mathrm{~mL}$ DCM. The solution was extracted with $5 \times 20 \mathrm{~mL}$ portions of $\mathrm{NaHCO}_{3}$ (aq, sat'd) and the combined water layers were back-extracted with $3 \times 20 \mathrm{~mL} \mathrm{DCM}$, and the combined DCM layer was dried with $\mathrm{Na}_{2} \mathrm{SO}_{4}$. The drying agent was removed via filtration through a $150 \mathrm{~mL}$ course porosity fritted funnel and the solvent removed in vacuo. The residue was dissolved in 2 $\mathrm{mL} \mathrm{DCM}$ and $6 \mathrm{~mL}$ EtOAc and a tan precipitate formed upon the addition of $100 \mathrm{~mL}$ hexanes. The solution was cooled to $0{ }^{\circ} \mathrm{C}$ for 0.5 hours to aid in precipitation. The precipitate was 
collected on a $30 \mathrm{~mL}$ medium porosity fritted funnel, washed with $2 \times 15 \mathrm{~mL}$ portions of hexanes, transferred to a vial, and placed under vacuum $(0.596 \mathrm{~g}, 0.895 \mathrm{mmol}, 89 \%) .{ }^{1} \mathrm{H}$ NMR $\left(\mathrm{CDCl}_{3}, \delta\right): 8.39(\mathrm{~d}, J=2.0,1 \mathrm{H}, \mathrm{PzA} 3), 7.97(\mathrm{~d}, J=2.0,1 \mathrm{H}, \mathrm{PzB} 3), 7.7(\mathrm{~d}, J=2.0,1 \mathrm{H}, \mathrm{PzC} 5), 7.68(\mathrm{~d}$, $J=2.0,1 \mathrm{H}, \mathrm{PzB} 5), 7.57(\mathrm{~d}, J=2.0,1 \mathrm{H}, \mathrm{PzA} 5), 7.23(\mathrm{~d}, J=2.0,1 \mathrm{H}, \mathrm{PzC} 3), 6.24(\mathrm{t}, J=2.0,1 \mathrm{H}, \mathrm{PzB} 4)$, $6.23(\mathrm{t}, J=2.0,1 \mathrm{H}, \mathrm{PzA} 4), 6.2(\mathrm{t}, J=2.0,1 \mathrm{H}, \mathrm{PzC} 4), 5.84(\mathrm{~m}, 1 \mathrm{H}, \mathrm{H} 8), 5.80(\mathrm{~m}, 2 \mathrm{H}, \mathrm{H} 5 / \mathrm{H} 6), 5.58(\mathrm{t}$, $J=6.9,1 \mathrm{H}, \mathrm{H} 2), 4.95(\mathrm{dd}, J=17.0,2.1,1 \mathrm{H}, \mathrm{H} 9), 4.88\left(\mathrm{dd}, J=10.1,2.1,1 \mathrm{H}, \mathrm{H} 9^{\prime}\right), 2.84(\mathrm{~m}, 1 \mathrm{H}, \mathrm{H} 4)$, $2.59(\mathrm{~m}, 1 \mathrm{H}, \mathrm{H7}), 2.28\left(\mathrm{~m}, 1 \mathrm{H}, \mathrm{H} 7^{\prime}\right), 2.15(\mathrm{~s}, 3 \mathrm{H}$, Amide-Me), $1.66(\mathrm{~d}, J=10.3,1 \mathrm{H}, \mathrm{H3}), 1.23$ (d, J = 8.2, 9H, $\left.\mathrm{PMe}_{3}\right) .{ }^{13} \mathrm{C} \mathrm{NMR}\left(\mathrm{CDCl}_{3}, \delta\right): 168.8$ (Amide-CO), 145.3 (PzA3), 143.3 (PzB3), 139.8 (PzC3), 137.4 (C8), 136.5 (PzC5), 136.0 (PzB5), 135.4 (PzA5), 117.4/116.4 (C5/C6), 115.6 (C9), 106.6/106.3 (PzA4/PzB4), 106.0 (PzC4), 63.9 (C3), 48.9 (C2), 44.9 (C4, d, J = 9.7), 42.6 (C7), 23.1 (Amide-Me), $13.9\left(\mathrm{PMe}_{3}, \mathrm{~d}, J=27.8\right) .{ }^{31} \mathrm{P} \mathrm{NMR}(\mathrm{CDCl}, \delta):-12.12\left(J_{\mathrm{WP}}=282\right) . \mathrm{CV}: E_{\mathrm{p}, \mathrm{a}}=+0.51 \mathrm{~V}$. IR: $v_{\mathrm{NO}}=1562 \mathrm{~cm}^{-1}, v_{\text {amide }}=1612 \mathrm{~cm}^{-1}, v_{\text {alkene }}=1635 \mathrm{~cm}^{-1}, v_{\mathrm{BH}}=2484 \mathrm{~cm}^{-1}$. ESI-MS: obs'd (\%), calc'd (\%), ppm (M+H)+: $665.2038(85.5), 665.2044$ (84.2), 0.8; 666.2070 (73.1), 666.2069 (80.3), 0.2; 667.2031 (100), 667.2068 (100), 5.5; 668.2049 (59.7), 668.2109 (43.4), 9.0; 669.2081 (100), $669.2100(83.8), 2.9$.

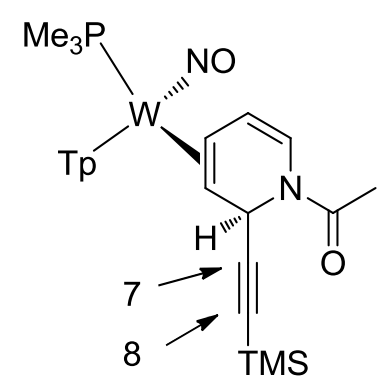

TpW(NO)(PMe $)\left(3,4-\eta^{2}-(1-(2-((t r i m e t h y l s i l y l) e t h y n y l) p y r i d i n-1(2 H)-y l) e t h a n o n e)\right) \quad$ (17): MeLi $(0.780 \mathrm{~mL}, 1.248 \mathrm{mmol})$ was added to a solution of TMS-acetylene $(0.148 \mathrm{~g}, 1.507 \mathrm{mmol})$ in THF (6.79g), which became warm. The light yellow solution was then added to a vial containing $\mathrm{ZnBr}_{2}$ (0.396 $\mathrm{g}, 1.758 \mathrm{mmol})$. The resulting solution was then added to a vial containing a deep red slurry of $6(0.775 \mathrm{~g}, 1.001 \mathrm{mmol})$ in THF (1.08 g) and the mixture was allowed to stir for 1 hour. 
The homogeneous dark yellow reaction solution was diluted with $20 \mathrm{~mL}$ DCM and extracted with $5 \times 30 \mathrm{~mL}$ portions of $\mathrm{NaHCO}_{3}$ (aq, sat'd). The combined water layer was back-extracted with $3 \times 20 \mathrm{~mL}$ portions of DCM, dried with $\mathrm{Na}_{2} \mathrm{SO}_{4}$, filtered through a $150 \mathrm{~mL}$ course porosity fritted funnel, and the solvent removed in vacuo. The residue was dissolved in $2 \mathrm{~mL} \mathrm{DCM}, 6 \mathrm{~mL}$ EtOAc, and then a tan solid precipitated upon the addition of $100 \mathrm{~mL}$ hexanes. The solution was cooled using an ice bath for 0.5 hour to aid in precipitation. The tan precipitate was collected on a $60 \mathrm{~mL}$ medium porosity fritted funnel, washed with $2 \times 20 \mathrm{~mL}$ hexanes, and dried under vacuum (0.640 g, $0.886 \mathrm{mmol}, 89 \%) .{ }^{1} \mathrm{H}$ NMR $\left(\mathrm{CDCl}_{3}, \delta\right): 8.23(\mathrm{~d}, J=2.0,1 \mathrm{H}, \mathrm{PzA} 3), 7.95(\mathrm{~d}, J=$ 2.0, 1H, PzB3), 7.71 (d, $J=2.0,1 \mathrm{H}, \mathrm{PzC} 5), 7.68$ (d, $J=2.0,1 \mathrm{H}, \mathrm{PzB} 5), 7.57$ (d, $J=2.0,1 \mathrm{H}, \mathrm{PzA} 5)$, $7.29(\mathrm{~d}, J=2.0,1 \mathrm{H}, \mathrm{PzC} 3), 6.28(\mathrm{~s}, 1 \mathrm{H}, \mathrm{H} 2), 6.25(\mathrm{t}, J=2.0,1 \mathrm{H}, \mathrm{PzB} 4), 6.23(\mathrm{t}, J=2.0,1 \mathrm{H}, \mathrm{PzA} 4)$, $6.22(\mathrm{t}, J=2.0,1 \mathrm{H}, \mathrm{PzC} 4), 5.92(\mathrm{~m}, 2 \mathrm{H}, \mathrm{H} 5 / \mathrm{H} 6), 2.90$ (dddd, $J=13.9,10.1,4.1,1.8,1 \mathrm{H}, \mathrm{H} 4), 2.20$ (s, 3H, Amide-Me), 1.94 (d, $J=10.1,1 \mathrm{H}, \mathrm{H} 3), 1.25\left(\mathrm{~d}, J=8.4,9 \mathrm{H}, \mathrm{PMe}_{3}\right), 0.10$ (s, 9H, TMS). ${ }^{13} \mathrm{C}$ NMR (CDCl 3 , ס): 168.6 (Amide-CO), 145 (PzA3), 143.3 (PzB3), 140.2 (PzC3), 136.5 (PzC5), 136.1 (PzB5), 135.5 (PzA5), 117.6/116.7 (C5/C6), 111.1 (C7), 106.6/106.4/106.1 (PzA4/PzB4/PzC4), $83.3(\mathrm{C} 8), 64.6$ (C3), 44.4 (C4, d, J = 10.7), 42.0 (C2), 23.1 (Amide-Me), $28.0\left(\mathrm{PMe}_{3}, \mathrm{~d}, J=28.0\right.$ ), 0.5 (TMS). ${ }^{31} \mathrm{P} \mathrm{NMR}\left(\mathrm{CDCl}_{3}, \delta\right):-12.02\left(J_{\mathrm{WP}}=281\right) . \mathrm{CV}: E_{\mathrm{p}, \mathrm{a}}=+0.58 \mathrm{~V} . \mathrm{IR}: v_{\mathrm{NO}}=1566 \mathrm{~cm}^{-1}, v_{\mathrm{amide}}=$ $1620 \mathrm{~cm}^{-1}, v_{\text {alkene }}=1643 \mathrm{~cm}^{-1}, v_{\text {alkyne }}=2160 \mathrm{~cm}^{-1}, v_{\mathrm{BH}}=2488 \mathrm{~cm}^{-1}$. ESI-MS: obs'd (\%), calc'd (\%), ppm, (M-H) ${ }^{+}: 719.1955$ (72), 719.1970 (78.6), 2.0; 720.1975 (81.4), 720.1993 (80), 2.6; 721.1988 (100), 721.1992 (100), 0.6; 722.2035 (73.3), 722.2026 (49.2), 1.2; 723.2017 (100), 723.2024 (83.1), 1.0.

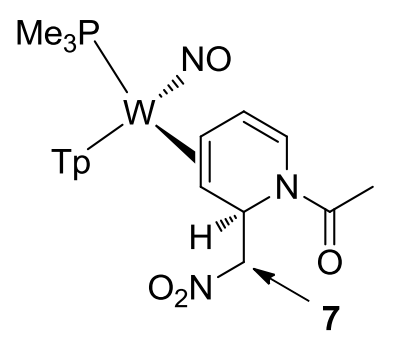


$\mathrm{TpW}(\mathrm{NO})\left(\mathrm{PMe}_{3}\right)\left(3,4-\eta^{2}-(1-(2-(\right.$ nitromethyl)pyridin-1(2H)-yl)ethanone)) (18): Procedure 1: A solution of $\mathrm{NEt}_{3}(0.109 \mathrm{~g}, 1.077 \mathrm{mmol})$ in $\mathrm{DCM}(1.01 \mathrm{~g})$ was added dropwise to a stirring, homogeneous, deep red solution of 6 (0.777 g, $1.004 \mathrm{mmol}), \mathrm{MeNO}_{2}(2.08 \mathrm{~g})$, and $\mathrm{DCM}(2.99 \mathrm{~g})$ making a dark yellow-green solution. The solution was allowed to stir for 40 minutes and then was removed from the glovebox. The solution was diluted with DCM $(20 \mathrm{~mL})$ and extracted with $3 \times 20 \mathrm{~mL}$ portions of $\mathrm{NaHCO}_{3}(\mathrm{aq}$, sat'd). The combined water layer was extracted with $2 \times 20$ $\mathrm{mL}$ portions of DCM. The combined organic layer was dried with $\mathrm{Na}_{2} \mathrm{SO}_{4}$, filtered through a 150 $\mathrm{mL}$ course porosity fritted funnel, and the solvent removed in vacuo. The solid residue was broken up with $3 \mathrm{~mL} \mathrm{DCM}$, then $6 \mathrm{~mL}$ EtOAc, and then precipitated further with the addition of $50 \mathrm{~mL}$ hexanes. The solution was cooled using in ice bath for 0.5 hours. The tan solid was collected on a $30 \mathrm{~mL}$ medium porosity fritted funnel, washed with $2 \times 15 \mathrm{~mL}$ portions of hexanes, and dried under vacuum $(0.606 \mathrm{~g}, 0.885 \mathrm{mmol}, 88 \%)$. Procedure 2 : A murky solution of $\operatorname{DABCO}(0.121 \mathrm{~g}, 1.079 \mathrm{mmol}), \mathrm{MeNO}_{2}(0.20 \mathrm{~g})$, and $\mathrm{DCM}(2.0 \mathrm{~g})$ was slowly added to a homogeneous deep red solution of 6 (0.775 g, $1.001 \mathrm{mmol})$ in $\mathrm{MeNO}_{2}(2.01 \mathrm{~g})$ and DCM (2.02 g). After 30 minutes the dark yellow/green solution was removed from the glovebox, diluted with $20 \mathrm{~mL} \mathrm{DCM}$, and extracted with $3 \times 20 \mathrm{~mL}$ portions of $\mathrm{NaHCO}_{3}$ (aq, sat'd). The combined water layer was extracted with $2 \times 20 \mathrm{~mL}$ portions of DCM. The combined organic layer was dried with $\mathrm{Na}_{2} \mathrm{SO}_{4}$, filtered through a $30 \mathrm{~mL}$ course porosity fritted funnel, and the solvent removed in vacuo. The solid residue was broken up with $2.5 \mathrm{~mL} \mathrm{DCM}$, then $2.5 \mathrm{~mL}$ EtOAc, and then precipitated further with $50 \mathrm{~mL}$ hexanes. The tan/green precipitate was collected on a $30 \mathrm{~mL}$ medium porosity fritted funnel. Residue remaining in the flask was dissolved in $1 \mathrm{~mL} \mathrm{DCM}$ and 1 $\mathrm{mL}$ EtOAc and precipitated with $40 \mathrm{~mL}$ hexanes. The precipitate was collected on the same frit and the combined precipitates were washed with $2 \times 15 \mathrm{~mL}$ portions of hexanes, and dried under vacuum $\left(0.633 \mathrm{~g}, 0.924 \mathrm{mmol}, 92 \%\right.$, with $\mathrm{MeNO}_{2}$ impurity). ${ }^{1} \mathrm{H} \mathrm{NMR}\left(\mathrm{CDCl}_{3}, \delta\right): 8.35$ (d, $\mathrm{J}=$ 
2.0, 1H, PzA3), 8.01 (d, $J=2.0,1 \mathrm{H}, \mathrm{PzB} 3), 7.75$ (d, $J=2.0,2 \mathrm{H}, \mathrm{PzB} 5 / \mathrm{PzC} 5), 7.63(\mathrm{~d}, J=2.0,1 \mathrm{H}$, PzA5), 7.25 (d, J = 2.0, 1H, PzC3), 6.28 (m, 4H, H2/PzA4/PzB4/PzC4), 5.91 (m, 2H, H5/H6), 4.74 $(\mathrm{dd}, J=10.0,8.7,1 \mathrm{H}, \mathrm{H} 7), 4.48\left(\mathrm{dd}, J=10.0,5.0,1 \mathrm{H}, \mathrm{H} 7^{\prime}\right), 2.84(\mathrm{~m}, 1 \mathrm{H}, \mathrm{H} 4), 2.2(\mathrm{~s}, 3 \mathrm{H}$, Amide$\mathrm{Me}), 1.55(\mathrm{~d}, J=9.7,1 \mathrm{H}, \mathrm{H} 3), 1.26\left(\mathrm{~d}, J=8.4,9 \mathrm{H}, \mathrm{PMe}_{3}\right) .{ }^{13} \mathrm{C} \mathrm{NMR}\left(\mathrm{CDCl}_{3}, \delta\right): 169.3$ (Amide-CO), 145.1 (PzA3), 143.3 (PzB3), 139.8 (PzC3), 136.7/136.3 (PzB5/PzC5), 135.6 (PzA5), 116.6 (C5/C6), 106.7/106.5/106.3 (PzA4/PzB4/PzC4), 80.1 (C7), 59.4 (C3), 48.9 (C2), 44.7 (C4, d, J = 10.2), 22.8 (Amide-Me), $13.7\left(\mathrm{PMe}_{3}, \mathrm{~d}, J=28.4\right) .{ }^{31} \mathrm{P} \mathrm{NMR}(\mathrm{CDCl}, \delta):-12.28\left(J_{\mathrm{WP}}=282\right) . \mathrm{CV}: E_{\mathrm{p}, \mathrm{a}}=+0.60 \mathrm{~V}$. IR: $v_{\mathrm{NO} 2(\mathrm{sym})}=1385 \mathrm{~cm}^{-1}, v_{\mathrm{NO} 2 \text { (asy) }}=1550 \mathrm{~cm}^{-1}, v_{\mathrm{NO}}=1566 \mathrm{~cm}^{-1}, v_{\text {amide }}=1620 \mathrm{~cm}^{-1}, v_{\text {alkene }}=1651 \mathrm{~cm}^{-}$ ${ }^{1}, v_{\mathrm{BH}}=2492 \mathrm{~cm}^{-1}$. ESI-MS: obs'd (\%), calc'd (\%), ppm $(\mathrm{M}+\mathrm{H})^{+}: 684.1735$ (93.5), 684.1743 (84.8), 1.2; 685.1763 (93.8), 685.1769 (79.7), 0.9; 686.1763 (100), 686.1767 (100), 0.6; 687.1798 (56.4), 687.1808 (42.4), 1.5; $688.1804(81.5), 688.18(84.3), 0.6$.

\section{References:}

(1) Collman, J. P.; Hegedus, L. S.; Norton, J. R.; Finke, R. G. Principles and Applications of Organotransition Metal Chemistry; 2nd ed.; University Science Books: Mill Valley, 1987.

(2) Semmelhack, M. F. In Comprehensive Organometallic Chemistry II; Abel, E. W., Stone, F. G. A., Wilkinson, G., Eds.; Pergammon: Oxford, 1995; Vol. 12, p 979-1015.

(3) Semmelhack, M. F.; Trost, B. M., Fleming, I., Eds.; Pergamon: Oxford, 1992; Vol. 4.

(4) Pike, R. D.; Sweigart, D. A. Synlett 1990, 565.

(5) Sun, S.; Dullaghan, C. A.; Sweigart, D. A. J. Chem. Soc., Dalton Trans. 1996, 4493.

(6) Astruc, D. Tetrahedron 1983, 39, 4027-4095.

(7) Kane-Maguire, L. A. P.; Honig, E. D.; Sweigart, D. A. Chemical Reviews 1984, 84, 525.

(8) Pearson, A. J.; Park, J. G. J. Org. Chem. 1992, 57, 1744.

(9) Pearson, A. J.; Chelliah, M. V. J. Org. Chem. 1998, 63, 3087. 
(10) Kündig, E. P.; Fabritius, C.-H.; Grossheimann, G.; Romanens, P.; Butenschon, H.; Wey, H. G. Organomet. 2004, 23, 3741.

(11) Davies, S. G.; McCarthy, T. D. In Comprehensive Organometallic Chemistry II; Abel, E. W., Ed.; Pergamon Press: Oxford, 1995; Vol. 12, Chapter 9.3.

(12) Kundig, E. P. Transition Metal Arene Complexes in Organic Synthesis and Catalysis; Springer: Berlin, 2004; Vol. 7.

(13) Keane, J. M.; Harman, W. D. Organometallics 2005, 24, 1786.

(14) Davies, S. G.; Shipton, M. R. J. Chem. Soc., Perkin Trans. 1991, 501.

(15) You, F.; Friedman, L. A.; Bassett, K. C.; Lin, Y.; Sabat, M.; Harman, W. D. Organometallics 2005, 24, 2903.

(16) Smith, P. L.; Chordia, M. D.; Harman, W. D. Tetrahedron 2001, 8203.

(17) Hodges, L. M.; Harman, W. D., in Advances in Nitrogen Heterocycles, Moody, C. J. Ed.; JAl Press Inc.: London, 1998; Vol. 3. 1.

(18) a) Harrison, D. P.; Welch, K. D.; Nichols-Nielander, A. C.; Sabat, M.; Myers, W. H.; Harman, W. D. J. Am. Chem. Soc. 2008, 130, 16844. b) Welch, K. D.; Harrison, D. P.; Lis, E. C.; Liu, W.; Salomon, R. J.; Harman, W. D.; Myers, W. H. Organometallics 2007, 26, 2791.

(19) Kosturko, G. W.; Harrison, D. P.; Sabat, M.; Myers, W. H.; Harman, W. D. Organometallics 2009, 28, 387.

(20) Keane, J. M.; Harman, W. D. Organometallics 2005, 24, 1786.

(21) Harman, W. D. Chem. Rev. 1997, 97, 1953.

(22) Neithamer, D. R.; Parkanyi, L.; Mitchell, J. F.; Wolczanski, P. T. J. Am. Chem. Soc. 1988, $110,4421$. 
(23) Delafuente, D. A.; Kosturko, G. W.; Graham, P. M.; Harman, W. H.; Myers, W. H.;

Surendranath, Y.; Klet, R. C.; Welch, K. D.; Trindle, C. O.; Sabat, M.; Harman, W. D. J. Am. Chem. Soc. 2007, 129, 406.

(24) Itoh, T.; Miyazaki, M.; Nagata, K.; Ohsawa, A. Heterocycles 1997, 46, 83.

(25) Duarte, F. F.; Popp, F. D.; Holder, A. J. J. Heterocycl. Chem. 1993, 30, 893.

(26) Doctorovich, F.; Di Salvo, F. Accounts of Chemical Research 2007, 40, 985.

(27) Comins, D. L.; Joseph, S. P. In Comprehensive Heterocyclic Chemistry II; Elsevier: Oxford, 1996.

(28) Lis, E. C.; Salomon, R. J.; Sabat, M.; Myers, W. H.; Harman, W. D. J. Am. Chem. Soc. 2008, $130,12472$.

(29) Bassett, K. C.; You, F.; Graham, P. M.; Myers, W. H.; Sabat, M.; Harman, W. D. Organometallics 2005, 25, 435.

(30) Graham, P.; Meiere, S. H.; Sabat, M.; Harman, W. D. Organometallics 2003, 22, $4364-$ 4366.

(31) Graham, P. M.; Delafuente, D. A.; Liu, W.; Myers, W. H.; Sabat, M.; Harman, W. D. J. Am. Chem. Soc. 2005, 127, 10568.

(32) Friedman, L. A.; You, F.; Sabat, M.; Harman, W. D. J. Am. Chem. Soc. 2003, 125, 14980.

(33) Mocella, C. J.; Delafuente, D. A.; Keane, J. M.; Warner, G. R.; Friedman, L. A.; Sabat, M.; Harman, W. D. Organometallics 2004, 23, 3772.

(34) Todd, M. A.; Sabat, M.; Myers, W. H.; Smith, T. M.; Harman, W. D. J. Am. Chem. Soc. 2008, 130, 6906-6907.

(35) Davies, S. G.; Shipton, M. R. J. Chem. Soc., Chem. Commun. 1989, 995.

(36) Fowler, F. W. J. Org. Chem. 1972, 37, 1321. 
Chapter 4

\section{Polarization of the Pyridine Ring:}

Highly Functionalized Piperidines from

Tungsten-Pyridine Complex 


\section{Introduction:}

Pyridines most commonly form complexes with transition metals via nitrogen coordination, but reports of $\eta^{6}$ - and $\eta^{2}$-bound complexes have also emerged. ${ }^{1-10}$ The latter types of complexes have shown potential as reagents for organic synthesis owing to the ability of the metal to modulate the reactivity of the pyridine ring through the $\pi$ system. ${ }^{11}$ For example, the complex $\operatorname{TpW}(\mathrm{NO})\left(\mathrm{PMe}_{3}\right)\left(\eta^{2}-N\right.$-acetylpyridinium), ${ }^{12,13}$ (1), prepared from pyridine borane and $\mathrm{TpW}(\mathrm{NO})\left(\mathrm{PMe}_{3}\right)\left(\eta^{2}\right.$-benzene), smoothly undergoes 5,6-dialkoxylation (Scheme 1; $\mathrm{X}=\mathrm{Y}=\mathrm{OR}$ ) when treated with Selectfluor ${ }^{\circledR}$ in an alcoholic solvent, ${ }^{14}$ without compromising the coordinating metal complex. Subsequent addition of a nucleophile followed by oxidative decomplexation has led to several novel $\Delta^{3}$ piperidines (Scheme 1, path 1). ${ }^{14}$ The goal of the present study is to explore the complementary reaction sequence (path 2), where nucleophilic addition at C2 provides an $\eta^{2}$-dihydropyridine ${ }^{15}$ complex that is activated by the metal toward additional elaboration at the remaining exposed alkene (see Scheme 1).

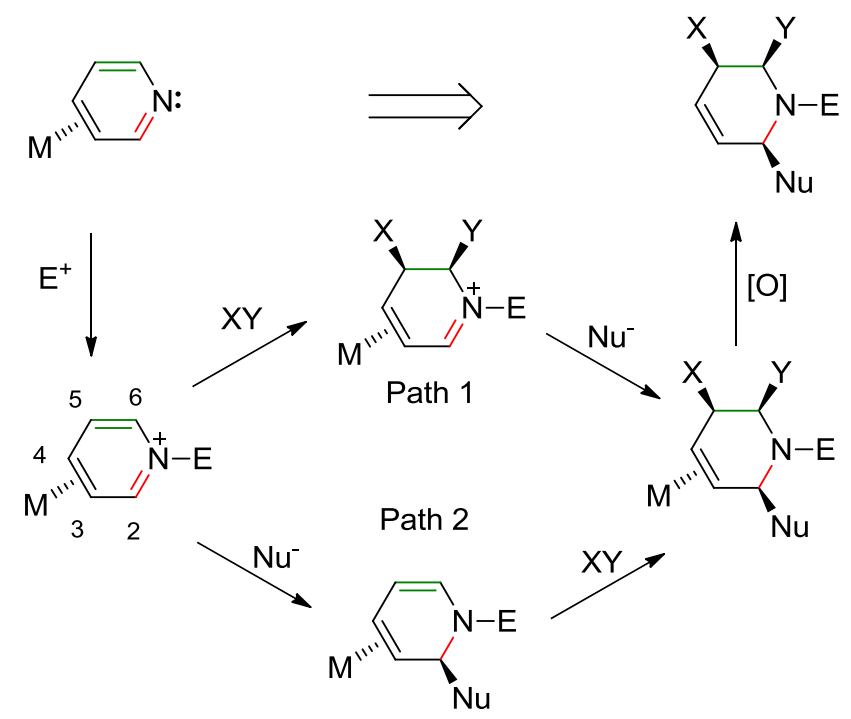

Scheme 1: Two Pathways from a Pyridinium Complex to $\Delta^{3}$-Piperidines. 


\section{Results and Discussion:}

The acylpyridinium complex (1) has been shown to react with a broad range of nucleophilic reagents common to conventional organic synthesis (Scheme 2). ${ }^{16}$ In every case examined, the nucleophile adds to C2 of the pyridine ring with complete stereocontrol, where the nucleophile adds anti to the metal fragment. With a full range of $\eta^{2}$-1,2-dihydropyridine (DHP) complexes in hand (Scheme 2), we set out to functionalize the remaining double bond ( $\mathrm{C} 5-\mathrm{C} 6)$.

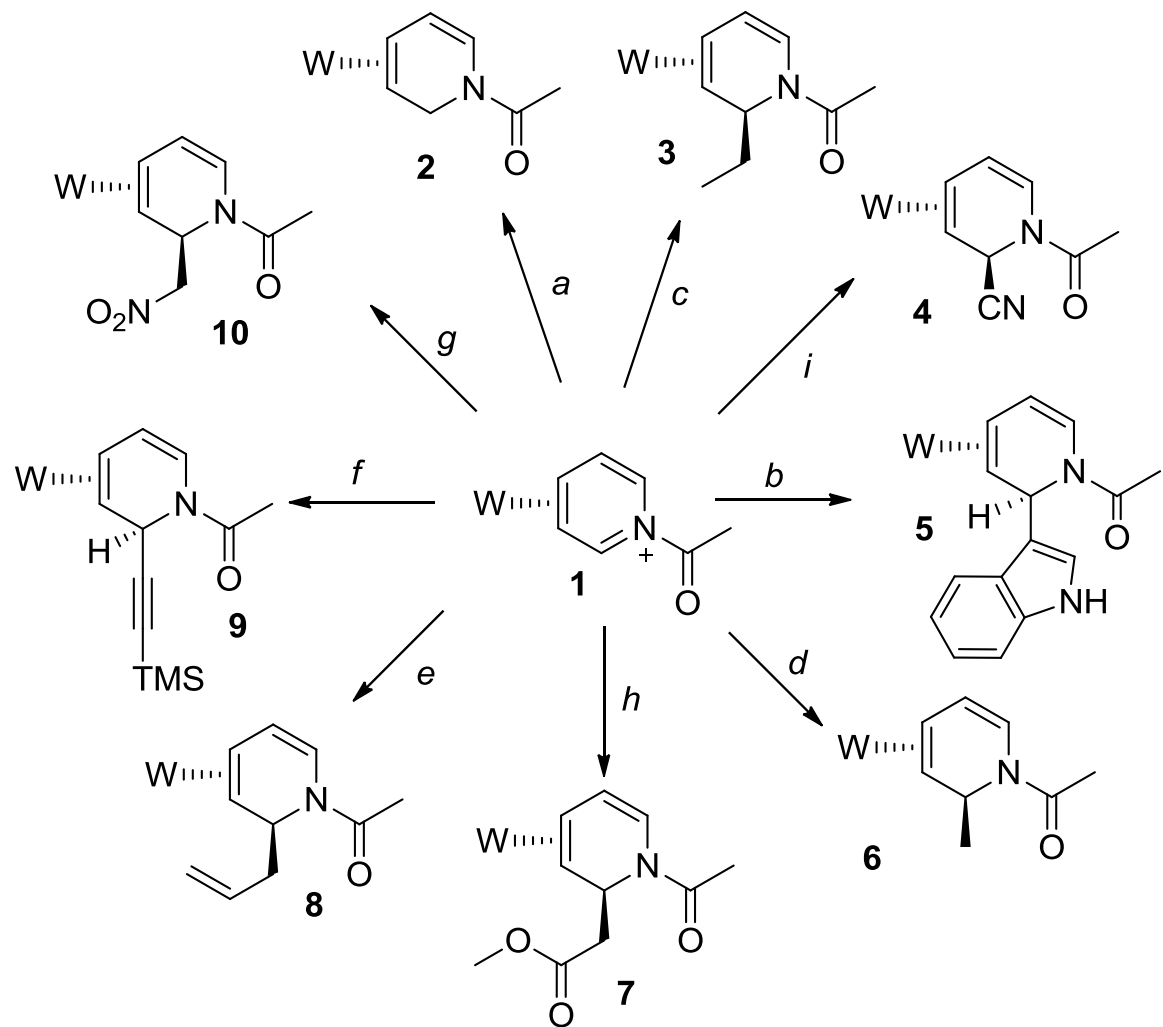

Reagents and conditions: (a) $\mathrm{NaBH}_{4}, \mathrm{MeOH}, 89 \%$; (b) indole, lutidine, 61\%; (c) $\mathrm{ZnEt}_{2}, 88 \%$; (d) $\mathrm{MeMgBr}, 57 \%$; (e) $\mathrm{Zn}^{0}$, Allylbromide, CuCN, 89\%; (f) MeLi, ethynyltrimethylsilane, $\mathrm{ZnBr}_{2}, 89 \%$; (g) $\mathrm{MeNO}_{2}, \mathrm{NEt}_{3}$ or DABCO, 88\%; (h) $\mathrm{Zn}^{0}$, methyl 2-bromoacetate, $87 \%$; (i) TMSCN, DABCO, 88\%; (j) in all cases $\mathrm{W}=\left\{\mathrm{TpW}(\mathrm{NO})\left(\mathrm{PMe}_{3}\right)\right\}$ with coordination diastereomer ratio $(\mathrm{cdr})$ ratio $>10: 1$.

Scheme 2: Broad Scope of Nucleophilic Addition to Acetylpyridinium complex 1.

Enamides, like enamines, are polarized such that the $\beta$-carbon is nucleophilic. ${ }^{17}$ In the case of the DHP complexes 2-10 (see Scheme 2), this implies that addition of an 
electrophile would occur at C5, as shown in Figure 1. However, previous studies of $\eta^{2}$ coordinated 1,3-diene complexes with $\pi$-basic metals indicate a clear regiochemical preference for electrophilic addition at the uncoordinated terminal alkene carbon. ${ }^{18,19}$ By analogy, electrophiles would react with DHP complexes at C6. Thus, the conjugation of the $\mathrm{C} 5-\mathrm{C} 6$ bond to both the nitrogen and the tungsten presented the opportunity to determine which effect dominates.

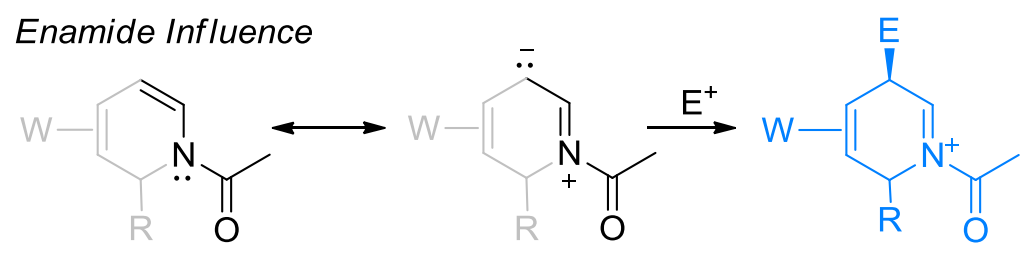

vs.

Metal Influence

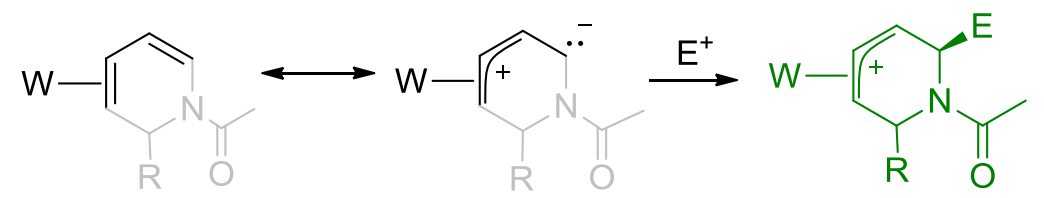

Figure 1: Enamine versus metal influence.

To address this issue for the case in which the electrophile $\left(E^{+}\right)$is $\mathrm{H}^{+}$(Figure 1 ), the acid diphenylammonium triflate (DPhAT, $0.016 \mathrm{~g}, 0.050 \mathrm{mmol}$ ) was added to a solution of dihydropyridine complex $2(0.026 \mathrm{~g}, 0.042 \mathrm{mmol})$ in $\mathrm{MeCN}(0.30 \mathrm{~g})$. Monitoring the reaction via ${ }^{31} \mathrm{P}$ NMR revealed an immediate reaction (i.e. $<3 \mathrm{~min}$ ). The appearance of two new downfield ${ }^{31} \mathrm{P}$ resonances and an accompanying shift in the nitrosyl stretching frequency from 1558 (for 2) to $1643 \mathrm{~cm}^{-1}$ indicated a significant reduction of the electron density on the metal. ${ }^{13}$ Precipitation of complex, 11, with 
diethyl ether was accomplished in $96 \%$ yield. $A{ }^{1} \mathrm{H}$ NMR spectrum indicated the presence of two complexes (a, b) in a 3:1 ratio, each signified by two diastereotopic methylene groups, and the absence of any deshielded resonance that could correspond to an acyl-iminium proton. COSY data supported the notion that both components (11a, 11b) were allyl complexes; however, many of the resonances were overlapped making a complete ${ }^{1} \mathrm{H}$ NMR assignment difficult. Clarifying matters was a NOESY spectrum of $\mathbf{1 1}$, which not only supported the structural features shown in Figure 2 but also revealed a chemical exchange (CE) between the two species, occurring on the time scale of proton relaxation. Taken together, these data are most consistent with $1 \mathbf{1 a}$ and $\mathbf{1 1} \mathbf{b}$ being $\mathrm{C}-\mathrm{N}$ rotational isomers, distinguished by the orientation of the amide group (see Figure 2). Similar results were obtained when the ethyl analogue $\mathbf{3}$ was treated with triflic acid in MeCN (Figure 2), in this case forming allyl 12 (97\% yield) as a 2.7:1 ratio of conformational isomers.

A crystal of $\mathbf{1 1}$ was grown suitable for X-ray analysis, which confirmed the expected structure (Figure 3). A comparison of bond lengths in allyl complex 11 reveals that the allyl ligand is highly asymmetric (i.e., $\sigma-\pi$ distortion) with C3 much farther from the tungsten atom $(2.59 \AA)$ than the other terminal allyl carbon C5 (2.28 $; \Delta=0.31 \AA$ ). Pioneering work by Faller, Hoffmann, et al. demonstrated that asymmetry in a $\pi$ allyl ligand can lead to highly selective nucleophilic additions to a terminal carbon, ${ }^{20}$ a feature we hoped to utilize (vide infra). More recently, Liebeskind ${ }^{21}$ and Legzdins ${ }^{22}$ have each reported asymmetrically bound allyl complexes for group VI metals (referred to by Liebeskind as " $\eta^{2}$-allyls"). This type of allylic distortion, which we attribute to the 
interaction of the allyl $\pi^{*}$ orbital and the $d$ orbital orthogonal to the NO, has also been observed by our group for a molybdenum system $(\Delta=0.31 \AA ̊) .{ }^{23}$

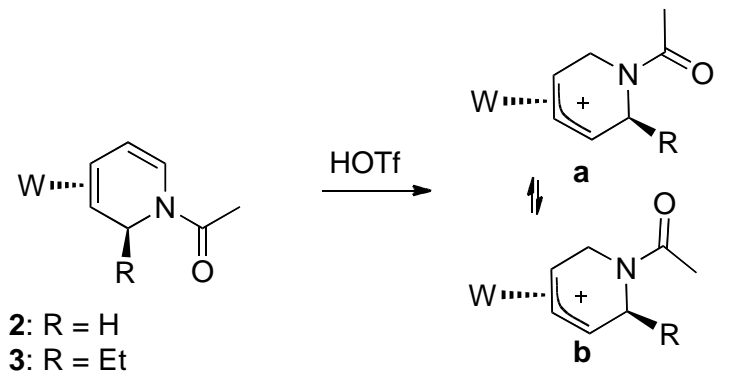

11: $\mathrm{R}=\mathrm{H}$

12: $R=E t$

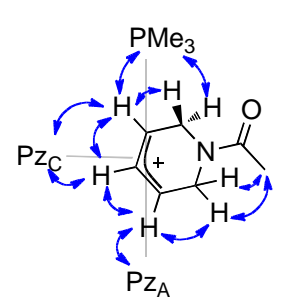

NOE interactions for 11a

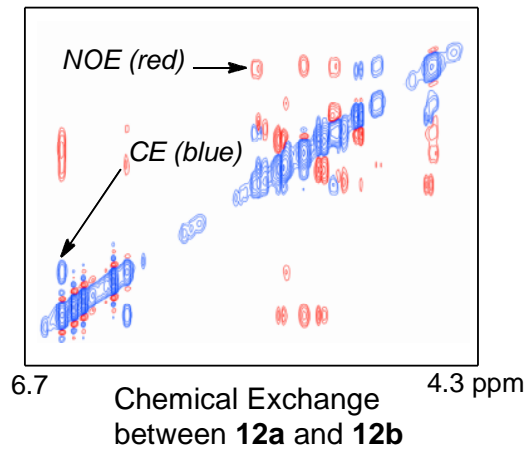

Figure 2: Amide rotational isomerization and chemical exchange.

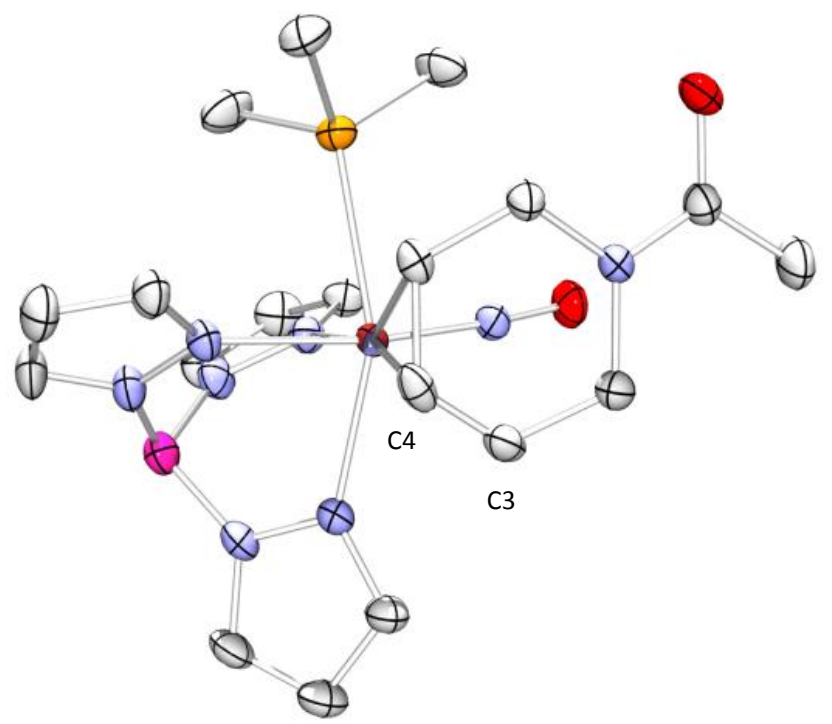

Figure 3: ORTEP diagram of allyl complex 11. W-C3: $2.590 \AA$ A-C4: $2.289 \AA$ W-C5:

2.284 Å C3-C4: $1.435 \AA$ C4-C5: $1.358 \AA$ A. Triflate anion omitted. 
Deuterium studies were undertaken to probe the possibility that the kinetically controlled site of protonation might be the C5 pyridine carbon (see Figure 1). Addition of a DOTf/MeOD solution to the ethyldihydropyridine complex 3 resulted in $>90 \%$ incorporation of deuterium at the exo position of the C6 methylene group (12- $d$ ) (Scheme 3). No incorporation was detected at any other ring-hydrogen. Alternatively, the addition of $\mathrm{MeOD}$ to a $\mathrm{CD}_{3} \mathrm{CN}$ solution of 12 resulted in nearly complete deuterium incorporation after $24 \mathrm{~h}$ at both of the $\mathrm{C} 6$ diastereotopic methylene protons. As before, no other ring protons suffered exchange. We note that while deuterium was not incorporated at $\mathrm{C} 5$, these experiments do not rule out this carbon from being transiently deuterated. $^{24}$

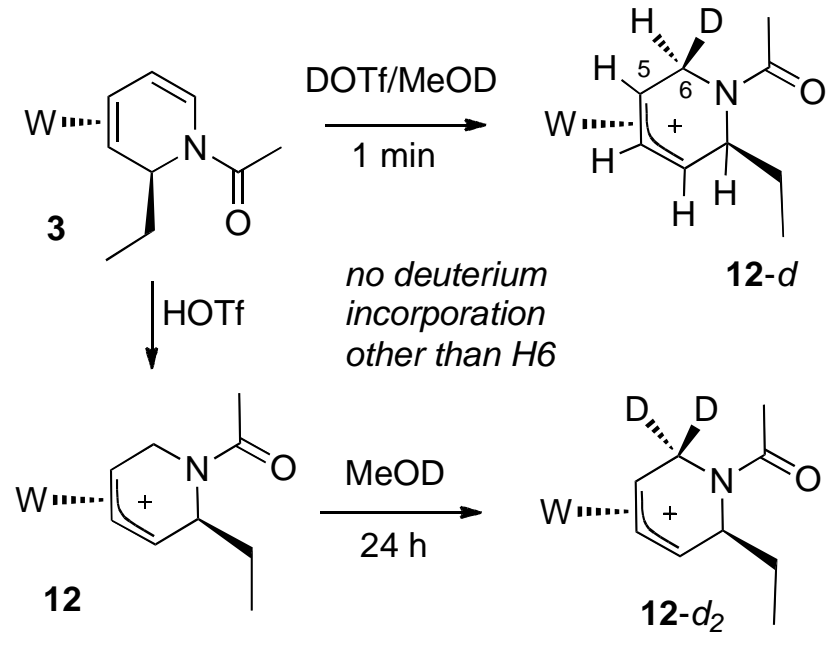

Scheme 3: Deuteration of Dihydropyridine complex 3.

Addition of HOTf to the cyano-substituted dihydropyridine complex 4 results in a deep red solution. Proton NMR resonances of the resulting species 13 again suggest significant $\eta^{2}$-allyl character; the protons associated with the bound carbons C4 and C5 
show nearly identical chemical shifts of $4.35 \mathrm{ppm}\left({ }^{13} \mathrm{C}: 61.2\right.$ and $\left.78.9 \mathrm{ppm}\right)$, while the chemical shift of $\mathrm{H} 3$ is $8.42 \mathrm{ppm}\left({ }^{13} \mathrm{C}: 147.9 \mathrm{ppm}\right)$. Although a ${ }^{1} \mathrm{H}$ chemical shift of 8.42 ppm is not inconsistent with an iminium signal (resulting from C5 protonation), detailed COSY and NOESY analyses clearly indicate that $\mathbf{1 3}$ is a $\pi$-allyl complex, similar to its 2ethyl and 2-hydrido cousins. The most deshielded signal (8.42 ppm) shows a coupling with one of the hydrogen atoms of the two bound carbons. Additionally, the $8.42 \mathrm{ppm}$ signal shows a large nuclear Overhauser effect with the pyrazole trans-to- $\mathrm{PMe}_{3}$ and no coupling with the geminal methylene group adjacent to piperidine nitrogen. Although these data are consistent with an allylic species similar to $\mathbf{1 1}$ and 12, several spectroscopic features indicated that it was an entirely different class of compound. In the ${ }^{1} \mathrm{H}$ NMR spectrum, the amide methyl signal is no longer at $2.1 \mathrm{ppm}$ as is typical of acetamides, but rather at $2.77 \mathrm{ppm}$. Also present is a broad singlet with an integration of two protons at $8.1 \mathrm{ppm}$. The IR spectrum did not show any absorption consistent with a nitrile $\mathrm{CN}$ stretch, nor was any signal present in the ${ }^{13} \mathrm{C} N \mathrm{NR}$ spectrum attributable to a nitrile ${ }^{13} \mathrm{CN}$. Instead, three new chemical shifts at $103.1,159.1$, and 159.4 ppm were present. These data, combined with HSQC and HMBC studies, confirmed the formation of a dicationic allylic isoxazolium ring (Scheme 4), often referred to as a Riessert salt. ${ }^{25-27}$ Addition of DABCO to 13 results in the isolation of compound 14, a tautomer of 4 . Returning a sample of $\mathbf{1 4}$ to an acidic acetonitrile solution quantitatively regenerated allyl 13 . 


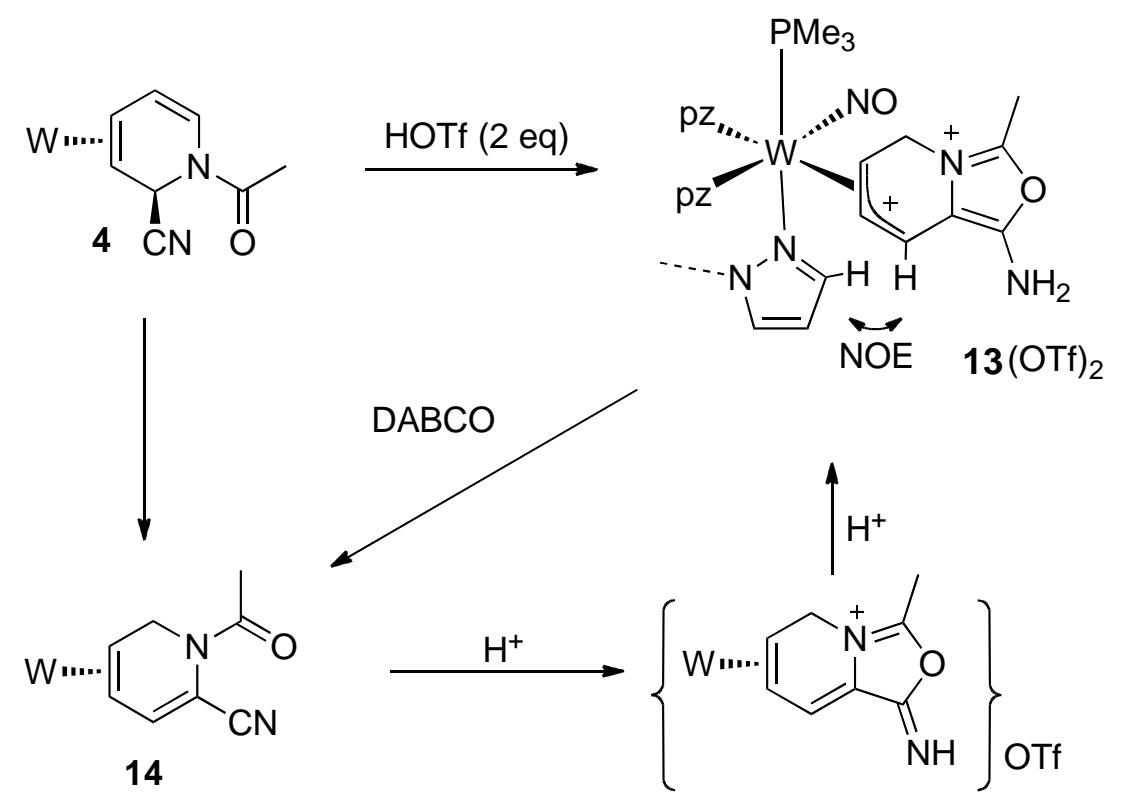

Scheme 4: Formation of the Reisert-like Allyl Complex 13.

The asymmetric nature identified in the crystal structure of allyl $\mathbf{1 1}$ suggests that the pyridine ring carbon $\mathrm{C} 3$ may be considerably more electrophilic than $\mathrm{C} 5$, and ${ }^{13} \mathrm{C}$ NMR data for these two carbons further supports this hypothesis, showing a dramatic contrast (64.6 vs $130.5 \mathrm{ppm}, \mathrm{CD}_{2} \mathrm{Cl}_{2}$ ) in the two terminal allyl resonances. True to expectation, when a series of nucleophilic reagents was introduced to the allyl complex 11, addition occurred exclusively at the C3 position, thereby desymmetrizing the heterocyclic ring.

Although deprotonation sometimes pre-empted addition, the reaction of many nucleophiles with the parent allylic piperidine 11 produced $\Delta^{3}$-piperidinamides (15-18). Following these reactions via ${ }^{31} \mathrm{P}$ NMR often revealed two major isomers (>90\%) with a small amount of deprotonation of the homoallylic protons ( $<10 \%)$. NOESY analysis of isolated samples of 15-17 all displayed chemical exchange, signifying amide 
conformational isomers (vide supra). Of note, the two isomers (4:1 ratio) of 18 failed to display chemical exchange in $\mathrm{CDCl}_{3}$. However, dissolution of a sample in acetone- $d_{6}$ resulted in a ratio of nearly 1:1 for the two isomers and chemical exchange was observed via NOESY. Evaporation of the NMR solvent and redissolving the residue of the sample in $\mathrm{CDCl}_{3}$ returned the equilibrium ratio to $4: 1$, providing good support that the two isomers of $\mathbf{1 8}$ are also amide conformational isomers (Scheme 5).

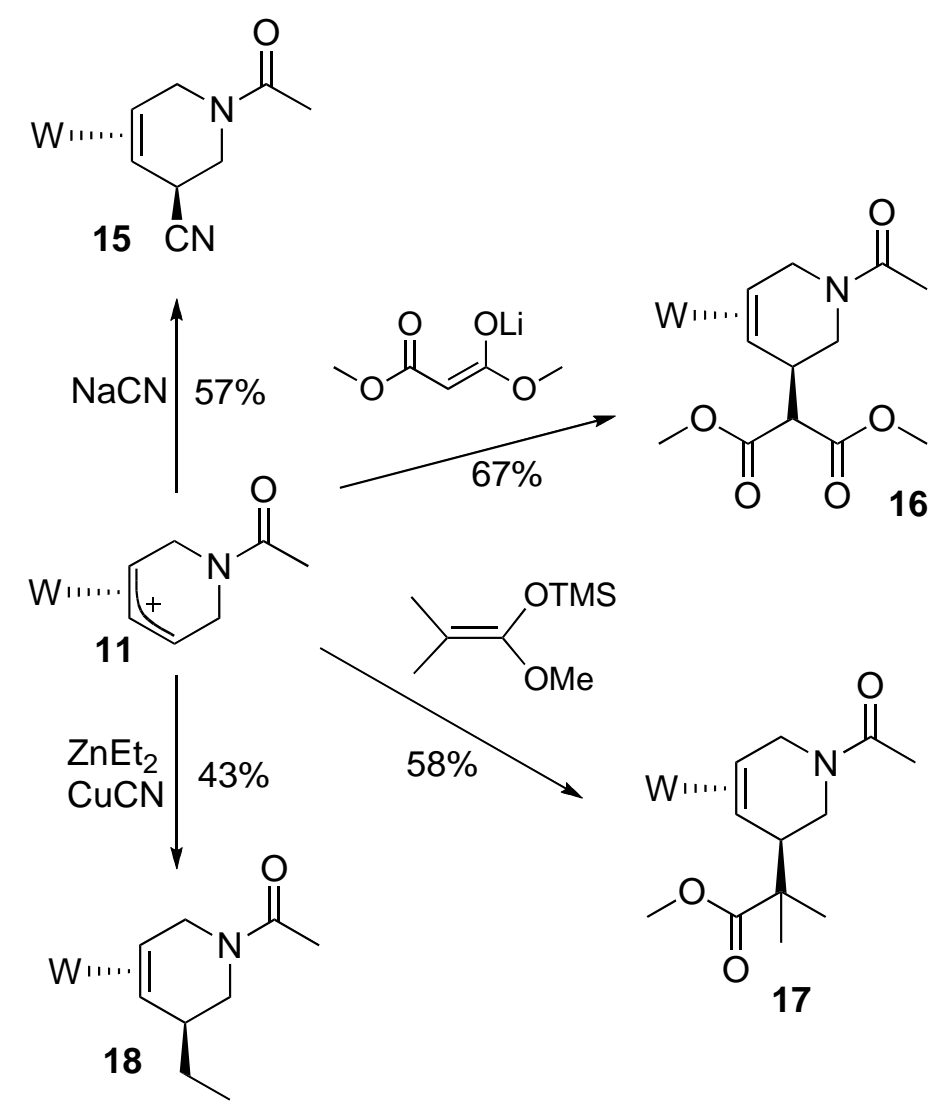

Scheme 5: Stereoselective Nucleophilic Addition to C3.

Addition of nucleophiles to the ethyl derivative $\mathbf{1 2}$ often resulted in deprotonation of a homo-allylic proton, regenerating 3 (Scheme 6). However, under 
optimized reaction conditions, nucleophilic addition was effected. For example, when $\mathrm{ZnEt}_{2}$ was combined with $\mathbf{1 2}$ in the presence of $\mathrm{CuCN}$, nucleophilic addition resulted in complex 19 along with varying amounts of the dihydropyridine $3\left(1.9: 1\right.$ at $\left.-30{ }^{\circ} \mathrm{C}\right)$. In a similar vein, treatment of $\mathbf{1 2}$ with lithium dimethyl malonate mostly resulted in the dihydropyridine precursor at ambient temperature, but repeating this reaction at $0{ }^{\circ} \mathrm{C}$ provided a nucleophilic addition product, 20 (Scheme 6). A full NMR analysis (COSY, NOESY , HSQC, HMBC) indicated that these nucleophiles did not add to the pyridine ring C3 but rather at the other allylic position, C5 (Scheme 6). Presumably, the vicinal addition of two nucleophiles creates a steric interaction that overcomes the electronic bias for C2 addition described in earlier reactions (Scheme 5).
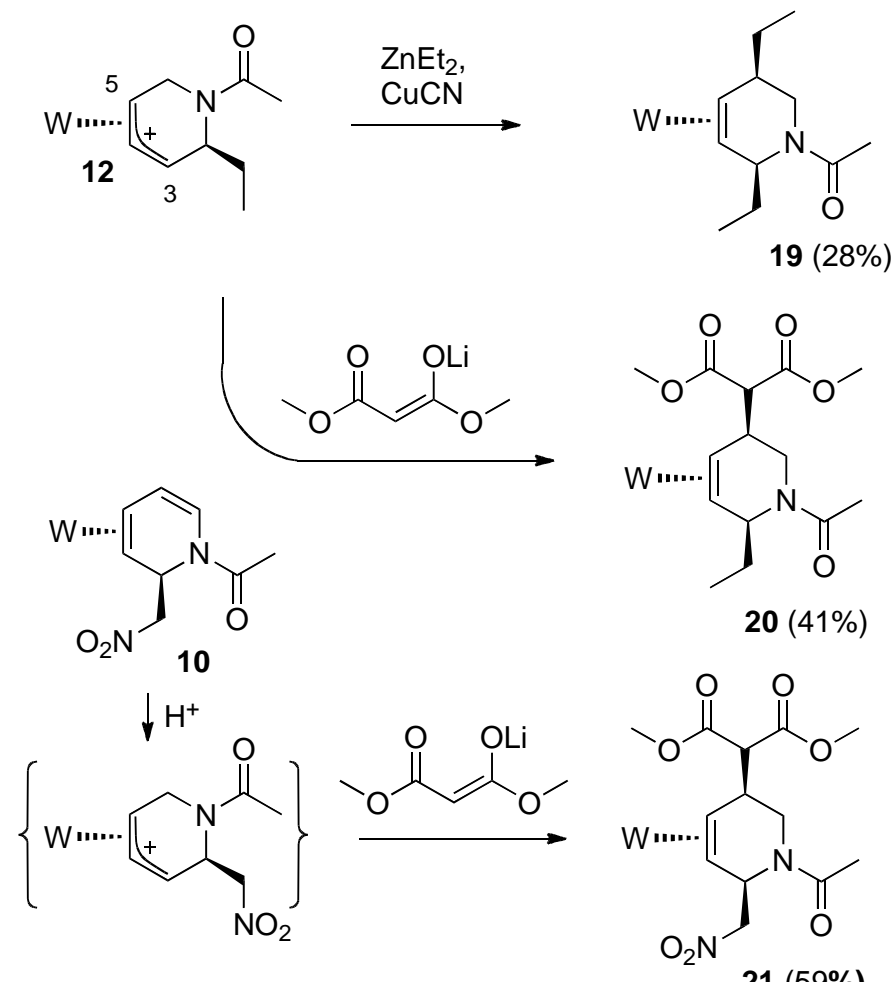

Scheme 6: Stereoselective Nucleophilic Addition to C5. 
<smiles>Cc1oc(N)c2[n+]1CC(C)C=C2</smiles>
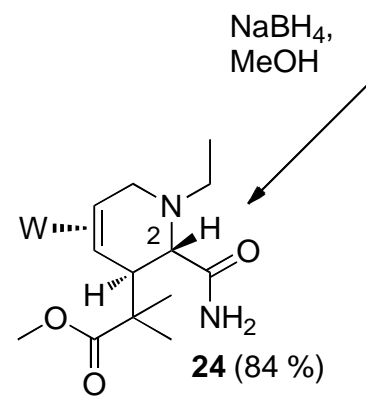
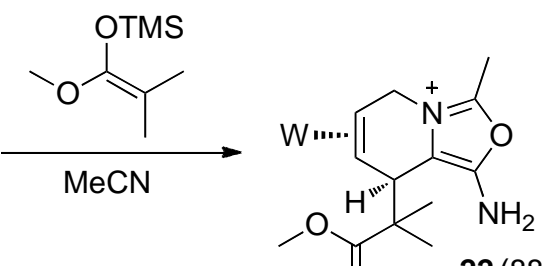

$22(88 \%)$ OTf

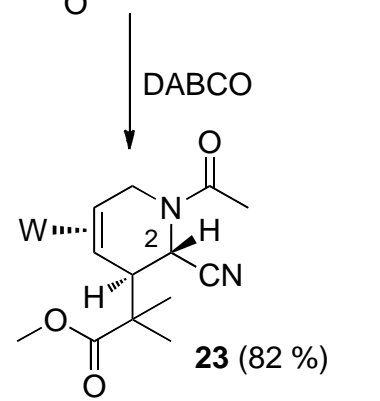

Scheme 7: Elaboration of the Reissert-like Allyl Complex 13.

Given that the isoxazolium portion of $\mathbf{1 3}$ is presumably coplanar with the allylic portion of the complex, it is likely to be less sterically demanding than an ethyl or nitro group. Addition of (1-methoxy-2-methyl-1-propenyloxy)trimethylsilane (MMTP) to a solution of 13 produces a single new compound, 22. ${ }^{1} \mathrm{H},{ }^{13} \mathrm{C},{ }^{19} \mathrm{~F}, \mathrm{HSQC}, \mathrm{HMBC}, \mathrm{NOESY}$, and COSY NMR data confirm that MMTP added to the carbon adjacent to the still-intact isoxazolium ring (Scheme 7). Attempts to add other nucleophiles (e.g. LiDMM, ZnEt 2 , $\mathrm{NaCN}$ ) that successfully added to the hydrido- or ethylallyl complexes $\mathbf{1 1}$ and $\mathbf{1 2}$, resulted in deprotonation of the complex to generate the diene 14 (see Scheme 4). Addition of DABCO to $\mathbf{2 2}$ resulted in a 2-cyanopiperidine complex (Scheme 7). Alternatively, reduction of $\mathbf{2 2}$ with $\mathrm{NaBH}_{4}$ in $\mathrm{MeOH}$ resulted in the 2-substituted primary amide, 24. For both 23 and 24, a $\mathrm{H} 2-\mathrm{H} 3$ coupling of $<3 \mathrm{~Hz}$ indicates a similar stereochemistry for these protons. Full 2D NMR analysis (COSY, NOESY, HSQC, and $\mathrm{HMBC}$ ) confirms the structural assignments of $\mathbf{2 3}$ and $\mathbf{2 4}$ provided in Scheme 7, where protonation at $\mathrm{C} 2$ late in the reaction sequence forces the cyano or amide group syn to 
the metal. X-ray analysis of a suitable crystal of $\mathbf{2 3}$ provides confirmation of its structure (Figure 4).

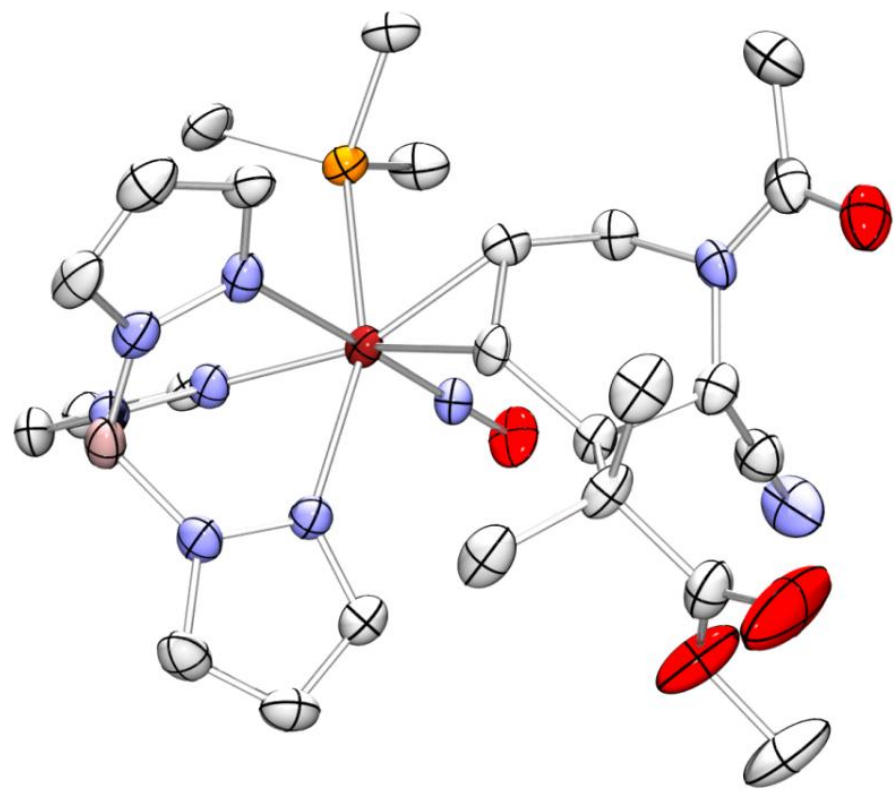

Figure 4: ORTEP diagram of tetrahydropyridine complex 23.

\section{$\Delta^{3}$-Piperidine Demetalation:}

With the $\Delta^{3}$-piperidine complexes $\mathbf{1 5 - 2 4}$ in hand, our focus turned to the decomplexation and isolation of the organic $\Delta^{3}$-piperidines. The strategy most commonly utilized for removal of the $\left\{\mathrm{TpW}(\mathrm{NO})\left(\mathrm{PMe}_{3}\right)\right\}$ fragment involves oxidation of the metal, which curtails the metal-ligand back-bonding. ${ }^{13,28}$ Treatment of various $\Delta^{3}$ piperidine complexes with 1 equiv of ceric ammonium nitrate (CAN) successfully liberated the alkaloid ligand (Scheme 8). Additionally, $I_{2}$ and dichlorodicyanoquinone (DDQ) could be used as effective oxidants (Scheme 8). We also explored the ability of molecular oxygen as a decomplexing agent. The highest recovery of organic compound 
by this method was obtained by stirring $\mathrm{MeCN}$ or EtOAc solutions of the complex and silica ${ }^{29}$ overnight in a flask under $1 \mathrm{~atm}$ of $\mathrm{O}_{2(\mathrm{~g})}$. Analysis revealed that complexes with anodic peak potentials $\left(\mathrm{E}_{p, a}\right)$ of more than $\sim 0.5 \mathrm{~V}$ (vs. NHE), were resistant to oxidation with $\mathrm{O}_{2(\mathrm{~g})}$. In these cases, CAN could still be utilized to liberate the piperidines (vide supra). Likewise, when the decomplexation study was expanded to include selected dihydropyridine complexes, those with anodic peak potentials of greater than $0.5 \mathrm{~V}$

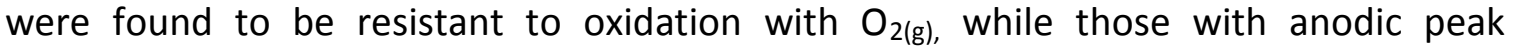
potentials less than $0.5 \mathrm{~V}$ reacted with $\mathrm{O}_{2}$ to give only ill-defined paramagnetic complexes. In no case were 2-substituted pyridines recovered from these oxidative decomplexation procedures. Isolating the tetrahydropyridine (THP) complexes by their precipitation was often inefficient (see $\mathbf{2 9}$ in Scheme 8), so we settled on a procedure where the THP complexes were generated in situ. Several examples of DHP elaboration into organic piperidinamides $(\mathbf{2 5 - 2 7 , 2 9 - 3 6 )}$ are summarized in Scheme 8.

The reactions described above constitute a procedure to generate piperidinamides with a diverse range of substituents, all from pyridine-borane in overall yields of $21-28 \%$ for a five-step process ( $>75 \% / s t e p)$. Although examples of nucleophilic additions to $\mathrm{C} 3$ or $\mathrm{C5}$ of the pyridine ring are possible using palladium coupling techniques, ${ }^{30-32}$ we have found no examples where aromaticity of the pyridine is not regained. Intramolecular radical cyclizations of open-chain enamides have been used to generate 3-substituted piperidines. ${ }^{33,34}$ Other examples use 3-substituted piperidines, synthesized via ring-closing metathesis, ${ }^{35-37}$ to generate asymmetric palladium piperidine-allyl species via displacement of a leaving group. Addition of nucleophiles 

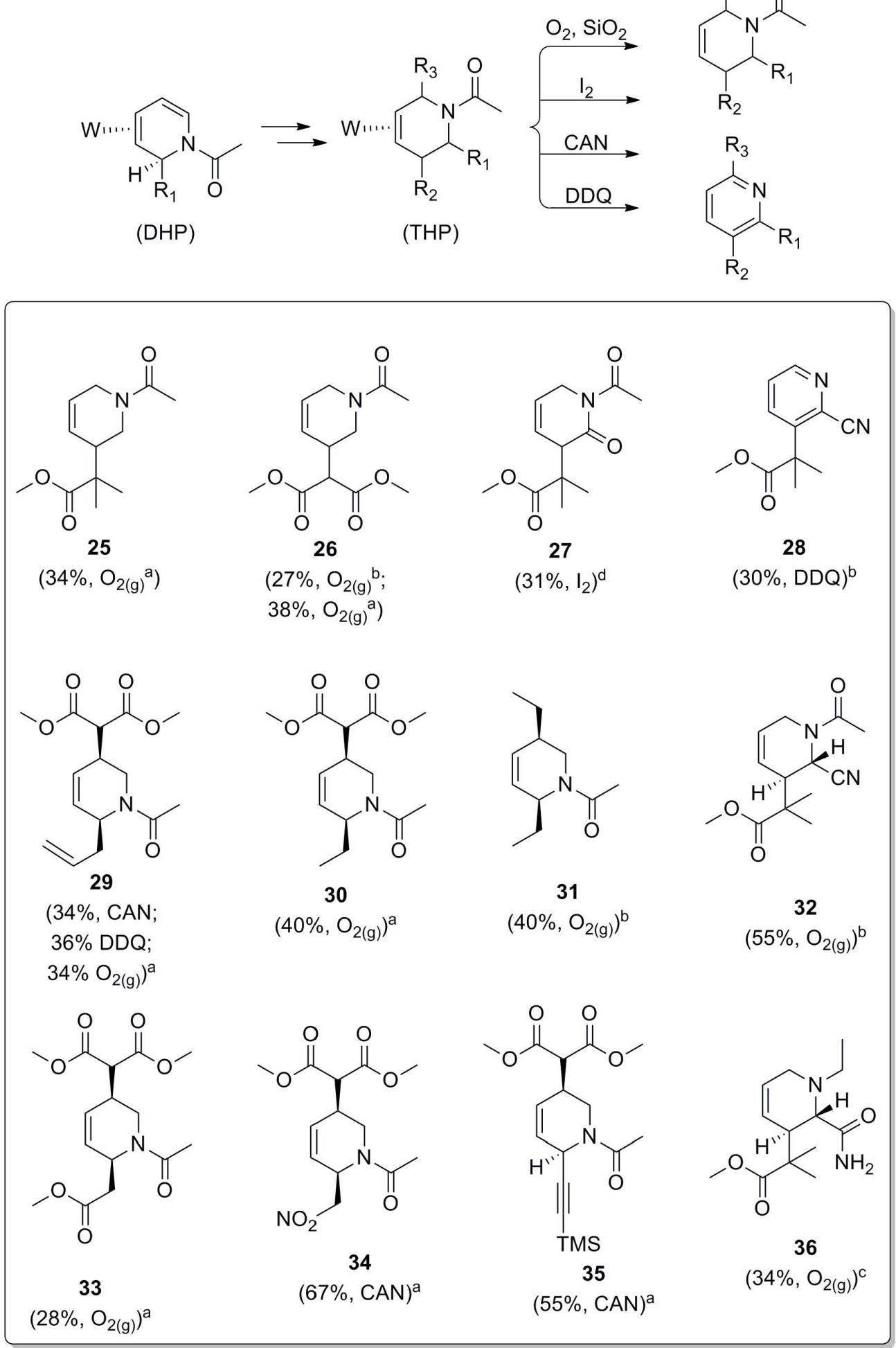

a - from DHP (3 step, 1 pot), b - from THP (1 step),

c - from 22 (2 steps, 1 pot), d - from 22 (1 step)

Scheme 8: Organic Products Recovered from Tetrahydropindine Complexes. 
such as malonates and amines, generate 3-substituted piperidines in good yield and enantiomeric excess. While catalytic palladium has been utilized to generate allylic species similar to that of the tungsten allyl complexes (which are generated by addition of an electrophile rather than displacement of a nucleophile), we have found no examples where this has occurred with a second substituent on the piperidine ring, as is the case with dihydropyridine precursor complexes presented in this report.

\section{Conclusions:}

In previous work, the $\pi$ base $\left\{\mathrm{TpW}(\mathrm{NO})\left(\mathrm{PMe}_{3}\right)\right\}$ was used to generate a wide range of $\mathrm{N}$-acetylated 2-substituted dihydropyridine complexes. ${ }^{16}$ In this study, the potential synthetic value of these DHP complexes is demonstrated. Tungsten coordination directs protonation to $\mathrm{C} 6$ of the DHP ring, forming asymmetric $\pi$-allyl complexes. In this regard, the tungsten fragment can be thought of as an electrondonating group; the tungsten system is more effective at polarizing the $\mathrm{C} 5$ - $\mathrm{C} 6$ bond than is the conjugated acetamide. Additionally, the metal fragment stereoselectively directs a subsequent nucleophilic addition anti to the metal, while the high electronic asymmetry influences the regiochemistry of the addition. Oxidative demetalation yields a diverse array of new $\Delta^{3}$-piperidines with unusual substitution patterns, the formation of which signifies a reversal (i.e. umpolung) of the typical chemical reactivity associated with the C5-C6 segment of a pyridine ring. 


\section{Experimental Section:}

General Methods. NMR spectra were obtained on a 300, 500, or $600 \mathrm{MHz}$ spectrometer (Varian INOVA or Bruker Avance). All chemical shifts are reported in ppm. Proton and carbon shifts are referenced to tetramethylsilane (TMS) utilizing residual ${ }^{1} \mathrm{H}$ or ${ }^{13} \mathrm{C}$ signals of the deuterated solvents as an internal standard. Phosphorus NMR signals are referenced to $85 \%$ $\mathrm{H}_{3} \mathrm{PO}_{4}(\delta=0.00)$ using a triphenylphosphate external standard $(\delta=-16.58)$. Coupling constants $(J)$ are reported in hertz $(\mathrm{Hz})$. Infrared spectra (IR) were recorded on a MIDAC Prospect Series (Model PRS) spectrometer as a glaze on a Horizontal Attenuated Total Reflectance (HATR) accessory (Pike Industries) or a Nicolet Avatar 320 FT-IR spectrometer with a diamond HATR attachment. Electrochemical experiments were performed under a dinitrogen atmosphere using a BAS Epsilon EC-2000 potentiostat. Cyclic voltammetry data was taken at ambient temperature at $100 \mathrm{mV} / \mathrm{s}\left(25^{\circ} \mathrm{C}\right)$ in a standard three-electrode cell with a glassy carbon working electrode using tetrabutylammonium hexaflurophosphate (TBAH) as an electrolyte (approx. $0.5 \mathrm{M}$ in an appropriate solvent). All potentials are reported versus NHE (Normal Hydrogen Electrode) using cobaltocenium hexafluorophosphate $\left(E_{1 / 2}=-0.78 \mathrm{~V}\right)$, ferrocene $\left(E_{1 / 2}=+0.55 \mathrm{~V}\right)$, or decamethylferrocene $\left(E_{1 / 2}=+0.04 \mathrm{~V}\right)$ as an internal standard. The peak-to-peak separation was $100 \mathrm{mV}$ or less for all reversible couples. High resolution electrospray ionization mass spectrometry (ESI-MS) analyses were obtained from the University of Illinois at UrbanaChampaign Mass Spectrometry Laboratory, or at the University of Richmond on a Bruker BioTOF-Q running in ESI mode, the latter from samples dissolved in 1:3 water/acetonitrile solution containing trifluoroacetic acid and/or sodium trifluoroacetate ( $\mathrm{NaTFA}$ ), and using $\left[\mathrm{Na}(\mathrm{NaTFA})_{\mathrm{x}}\right]^{+}$clusters as an internal standard. Unless otherwise noted, all synthetic reactions were performed in a glovebox under a dry nitrogen atmosphere. Drisolve dichloromethane (DCM) and benzene were purified by passage through a column packed with activated alumina. 
Drisolve tetrahydrofuran (THF) was used as received. These and other solvents and liquid reagents were thoroughly purged with nitrogen prior to use. Deuterated solvents were used as received from Cambridge Isotopes. MMTP and $\mathrm{ZnEt}_{2}$ are commercially available and used as received. Lithium dimethyl malonate was prepared by the addition of MeLi to a stirring solution of dimethyl malonate in $\mathrm{Et}_{2} \mathrm{O}$ precipitating a white solid that was filtered and used without further purification. Triflate salts were synthesized by slow addition of $\mathrm{Et}_{2} \mathrm{O}$ to an ice cooled vial containing triflic acid followed by addition of this solution to an appropriate conjugate base dissolved in $\mathrm{Et}_{2} \mathrm{O}$. General proton assignments were made in accordance with the Figure $\mathrm{S} 1$ (see supplemental information). Pyrazole, Pz, protons of the (tris-pyrazolyl)borate, Tp, ligand were uniquely assigned using a combination of 2-dimensional NMR experiments and phosphorousproton coupling (Figure S2, see supplemental information). When unambiguous assignments were not possible, $\mathrm{Pz}$ protons were labeled as $\mathrm{Tp}$ protons. Coordination diastereomers are described by the defining feature's (i.e. heteroatom's) proximity to the $\mathrm{PMe}_{3}$ ligand relative to the W-PMe ${ }_{3}$ bond (e.g. the fewer number of bonds from the $\mathrm{PMe}_{3}$ passing through the upper portion of the coordinated ring system to the defining feature dictates the proximal (P) ligand).

Crystallography. The molecular structures of compounds $\mathbf{1 1}$ and $\mathbf{2 3}$ were solved by direct methods in SHELXTL. For compound 11, difference Fourier maps revealed the presence of two triflate moieties. One of the moieties occupied general positions and its atoms were refined with anisotropic thermal displacement parameters and occupancies of 1.0. However, the other triflate anion was found on an inversion center located halfway between the $S$ and $C$ atoms. The disorder was modeled by using half of the triflate moiety in which the atomic scattering factors were $(0.5 \mathrm{O}+0.5 \mathrm{~F})$ for the overlapping $\mathrm{F}$ and $\mathrm{O}$ atoms and $(0.5 \mathrm{~S}+0.5 \mathrm{C})$ for the overlapping $\mathrm{S}$ and $\mathrm{C}$ atoms. The final refinement supported this model resulting in reasonable thermal and metric parameters. In addition, a careful inspection of the difference Fourier maps revealed the 
presence of a $\mathrm{H}$ atom bound to the amide $\mathrm{O}$ atom. This $\mathrm{H}$ atom is involved in a strong $\mathrm{H}$ bonding between the $\mathrm{O}$ atoms of the amide groups (O..H..O distance is $2.41 \AA$ ) from two complex molecules related by an inversion center. The observed arrangement of the $\mathrm{H}$ atom imposes a disorder, which was modeled by refining the $\mathrm{H}$ atom with an isotropic thermal displacement parameter and a population parameter of 0.5 . The final refinement gave reasonable values of the thermal factors and the metric parameters describing the $\mathrm{H}$ bond system.

General Procedure 1 - In situ generated tetrahydropyridine complexes: A solution of HOTf in MeCN was added to an oven dried test tube containing the appropriate dihydropyridine complex precursor and was then placed into a $0{ }^{\circ} \mathrm{C}$ cold bath next to a separate oven dried test tube containing a solution of LiDMM in MeCN. The solutions were allowed to cool for 10 minutes. The LiDMM solution was then quickly added to the tungsten allyl solution and allowed to stir at $0{ }^{\circ} \mathrm{C}$ for 30 minutes. The solution was then removed from the cold bath and taken out of the glovebox to stir at room temperature. After 15 minutes, the solution was diluted with 20 $\mathrm{mL} \mathrm{DCM}$, extracted with $3 \times 10 \mathrm{~mL} \mathrm{NaHCO}$ (saturated, aqueous), back-extracted with $2 \times 10 \mathrm{~mL}$ $\mathrm{DCM}$, the combined organic layers were dried $\mathrm{MgSO}_{4}$, filtered through a $60 \mathrm{~mL}$ coarse porosity fritted funnel, and the solvent removed in vacuo to leave a residue.

General Procedure 2 - Demetallation-Oxidation with $\mathrm{O}_{2(\mathrm{~g})}$ : Outside of the glovebox, the residue from general procedure 1 was transferred to a 250 or $500 \mathrm{~mL}$ round bottom flask containing a side arm attached to a balloon. The flask was charged with a Teflon stirbar, $\mathrm{SiO}_{2}(\sim 10 \mathrm{~g})$, and 100 $\mathrm{mL}$ EtOAc. The balloon was filled with $\mathrm{O}_{2}(\mathrm{~g})$, was vented, and then refilled with $\mathrm{O}_{2}$ (g). The heterogeneous solution was stirred rapidly overnight, after which time the reaction solution was filtered through a $150 \mathrm{~mL}$ medium porosity fritted funnel and washed with $250 \mathrm{~mL}$ of EtOAc. The solvent was removed in vacuo, the residue was transferred to a 4 dram vial and the solvent was 
removed in vacuo once more. The organic compound was isolated according to general procedure 5.

General Procedure 3 - Demetallation-Oxidation with CAN: Outside of the glovebox, CAN was added to the flask containing the residue from general procedure 1 followed by acetone. The solution was allowed to stir as the color changed from brown-orange to yellow over the course of one hour. After this 1 hour, the reaction solution was transferred to a separatory funnel containing $50 \mathrm{~mL} \mathrm{NaHCO}_{3}$ (saturated, aqueous) with $2 \times 1 \mathrm{~mL}$ portions of acetone and a white material precipitated. The water layer was extracted with $5 \times 25 \mathrm{~mL}$ DCM, the combined organic layers were dried $\mathrm{MgSO}_{4}$, filtered through a $150 \mathrm{~mL}$ coarse porosity fritted funnel, and the solvent removed in vacuo to yield a residue. The residue was transferred to a 4 dram vial with DCM and the solvent was removed in vacuo once more. The organic compound was isolated according to general procedure 5.

General Procedure 4 - Demetallation-Oxidation with DDQ: The residue from general procedure 1 was diluted with a solution of DDQ in acetone and allowed to react for 1-2 hours. The reaction solution was then removed from the glovebox, diluted with $20 \mathrm{~mL} D C M$, extracted with $3 \times 10 \mathrm{~mL}$ $\mathrm{NaHCO}_{3}$ (saturated, aqueous), back-extracted with $3 \times 10 \mathrm{~mL} \mathrm{DCM}$, the combined organic layers were dried with $\mathrm{MgSO}_{4}$, filtered through a $30 \mathrm{~mL}$ medium porosity fritted funnel, and the solvent removed by rotary evaporation. The residue was transferred to a 4 dram vial with DCM and the solvent was removed once more. The organic compound was isolated according to general procedure 5 .

General Procedure 5 - Isolation of Liberated Alkene: Outside of the glovebox, the residue was loaded onto a $20 \mathrm{~cm} \times 20 \mathrm{~cm} \times 500 \mu \mathrm{m} \mathrm{SiO}$ preparatory TLC plate and a $20 \mathrm{~cm} \times 2 \mathrm{~cm}$ (wide) $\times$ 500 micrometer $\mathrm{SiO}_{2}$ preparatory TLC plate with $4 \times 0.3 \mathrm{~g} \mathrm{DCM}$ and one or more $1 \mathrm{~mL}$ syringes. The preparatory TLC plates were eluted side-by-side with an appropriate solvent. Once elution 
was complete the $2 \mathrm{~cm}$ wide plate was stained with $\mathrm{KMnO}_{4}$ to help visualize the location of the liberated alkene. The band corresponding to the organic compound was scraped from the $20 \mathrm{~cm}$ wide plate, placed in a test tube with $15 \mathrm{~mL}$ EtOAc, and sonicated for 10 minutes to break up the silica. The silica was collected on a $30 \mathrm{~mL}$ medium porosity fritted funnel, washed with $200 \mathrm{~mL}$ EtOAc, and the solvent removed from the filtrate. The residue was then transferred to a tared vial with DCM, the solvent removed by rotary evaporation, and the product dried in vacuo overnight.

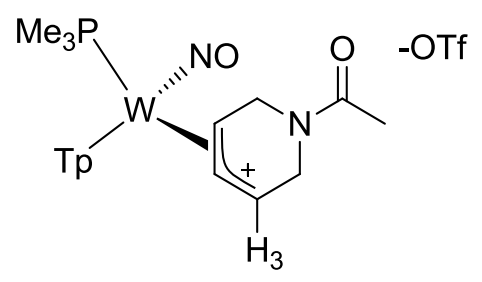

$\operatorname{TpW}(\mathrm{NO})\left(\mathrm{PMe}_{3}\right)\left(4,5-\eta^{2}\right.$-(1-acetylpiperidin-4-ylium)(OTf). 11. A solution of HOTf (0.269 g, 1.792 $\mathrm{mmol})$ in DCM $(2.1 \mathrm{~g})$ was added to a dark yellow solution of $2(1.000 \mathrm{~g}, 1.597 \mathrm{mmol})$ in DCM $(4.1 \mathrm{~g})$. After 2 minutes the reaction solution was diluted with DCM $(6 \mathrm{~g})$. It was then added to $300 \mathrm{~mL}$ of stirring $\mathrm{Et}_{2} \mathrm{O}$ to form a tan precipitate. The slurry was allowed to stir for $0.5 \mathrm{~h}$ and the precipitate was collected on a $15 \mathrm{~mL}$ medium porosity fritted funnel, washed with $2 \times 15 \mathrm{~mL} \mathrm{Et}{ }_{2} \mathrm{O}$, and placed under vacuum (1.193 g, $1.537 \mathrm{mmol}, 96 \%$ yield). ${ }^{1} \mathrm{H}$ NMR $\left(\mathrm{CD}_{2} \mathrm{Cl}_{2}, \delta\right): 8.34(\mathrm{~d}, J=2.0$, 1H, PzB3), 8.23 (d, $J=2.0,1 \mathrm{H}, \mathrm{PzA} 3), 8.10(\mathrm{~d}, J=2.0,1 \mathrm{H}, \mathrm{PzC}$ ), 7.99 (d, $J=2.0,1 \mathrm{H}, \mathrm{PzC}$ ), 7.91 (d, $J=2.0,1 \mathrm{H}, \mathrm{PzB} 5), 7.75(\mathrm{~d}, J=2.0,1 \mathrm{H}, \mathrm{PzA} 5), 6.67(\mathrm{~d}(\mathrm{br}), J=7.2,1 \mathrm{H}, \mathrm{H} 3), 6.61(\mathrm{t}, J=2.0,1 \mathrm{H}$, PzC4), $6.54(\mathrm{t}, J=2.0,1 \mathrm{H}, \mathrm{PzB} 4), 6.36(\mathrm{t}, J=2.0,1 \mathrm{H}, \mathrm{PzA} 4), 5.27(\mathrm{~d}, J=19.5,1 \mathrm{H}, \mathrm{H} 2), 5.13(\mathrm{t}, J=$ $7.8,1 \mathrm{H}, \mathrm{H} 4), 4.99\left(\mathrm{~d}, J=19.5,1 \mathrm{H}, \mathrm{H} 2^{\prime}\right), 4.90(\mathrm{~d}, J=14.5,1 \mathrm{H}, \mathrm{H} 6), 4.82\left(\mathrm{~d}, J=14.5,1 \mathrm{H}, \mathrm{H} 6^{\prime}\right), 4.34$ (m, 1H, H5), $2.26\left(\mathrm{~s}, 3 \mathrm{H}\right.$, Amide-Me), $1.26\left(\mathrm{~d},{ }^{2} \mathrm{~J}_{\mathrm{PH}}=9.6,9 \mathrm{H}, \mathrm{PMe}_{3}\right)$, Selected Minor Isomer Signals: $8.12(\mathrm{~d}, J=2.0,1 \mathrm{H}, \mathrm{PzA} 3), 6.27(\mathrm{~m}, 1 \mathrm{H}, \mathrm{H} 3), 5.40(\mathrm{~d}, J=18.6,1 \mathrm{H}, \mathrm{H} 6), 5.24$ (buried, $1 \mathrm{H}$, $\mathrm{H} 4), 4.70(\mathrm{~m}, 1 \mathrm{H}, \mathrm{H} 5), 2.23\left(\mathrm{~s}, 3 \mathrm{H}\right.$, Amide-Me), $1.27\left(\mathrm{~d},{ }^{2} \mathrm{~J}_{\mathrm{PH}}=9.6,9 \mathrm{H}, \mathrm{PMe}_{3}\right) .{ }^{13} \mathrm{C} \mathrm{NMR}\left(\mathrm{CD}_{2} \mathrm{Cl}_{2}, \delta\right)$ : 173.3 (Amide-CO), 148.8 (PzA3), 145.0 (PzB3), 142.6 (PzC3), 139.3 (PzC5), 138.9 (PzA5/PzB5), 
130.5 (C3), 109.2/109.1 (PzB4/PzC4), 108.0 (PzA4), 96.4 (C4), 64.6 (d, $\left.{ }^{2} J_{P C}=15.4, C 5\right), 46.9$ (C2), 42.0 (C6), 21.8 (Amide-Me), $13.3\left(\mathrm{~d},{ }^{1} J_{\mathrm{PC}}=32.9, \mathrm{PMe}_{3}\right.$ ), Selected Minor Isomer Signals: 122.8 (C3), 98.5 (C4), 67.6 (C5), 46.8 (C6), $13.4\left(\mathrm{~d},{ }^{1}{ }^{\mathrm{P}} \mathrm{PC}=32.7, \mathrm{PMe}_{3}\right) .{ }^{31} \mathrm{P} \mathrm{NMR}\left(\mathrm{CD}_{2} \mathrm{Cl}_{2}, \delta\right):-6.73\left(J_{\mathrm{WP}}=\right.$ 261), $-7.80\left(J_{\mathrm{WP}}=260\right)$. Isomer Ratio: $3.1: 1$ (Chemical Exchange observed). IR: $v_{\mathrm{No} / \mathrm{amide}}=1643$ $\mathrm{cm}^{-1}, v_{\mathrm{BH}}=2515 \mathrm{~cm}^{-1} . \mathrm{CV}(\mathrm{MeCN}): E_{\mathrm{p}, \mathrm{a}}=+2.05 \mathrm{~V}, E_{\mathrm{p}, \mathrm{c}}=-0.81 \mathrm{~V}$. ESI-MS: obs'd (\%), calc'd (\%), ppm $(\mathrm{M}-\mathrm{OTf})^{+}: 625.1687$ (98.5), 625.1736 (85.8), 7.8; 626.1747 (76.9), 626.1761 (79.6), 2.2; 627.1763 (100), 627.176 (100), 0.5; 628.1785 (50.9), 628.1802 (41.2), 2.7; 629.1817 (59.4), 629.1792 (84.6), 4.0. Anal. Calc'd for $\mathrm{C}_{20} \mathrm{H}_{29} \mathrm{BF}_{3} \mathrm{~N}_{8} \mathrm{O}_{5} \mathrm{PSW} \cdot \mathrm{CH}_{2} \mathrm{Cl}_{2}$ : C, 29.29; $\mathrm{H}, 3.63 ; \mathrm{N}, 13.01$; Found: $\mathrm{C}$, 29.50; H, 3.82; N, 12.95.

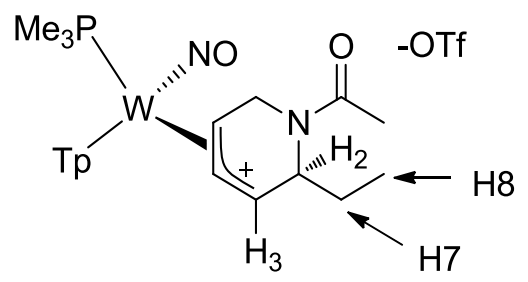

$\operatorname{TpW}(\mathrm{NO})\left(\mathrm{PMe}_{3}\right)\left(4,5-\eta^{2}\right.$-(1-acetyl-2-ethylpiperidin-4-ylium))(OTf). 12. A solution of HOTf (0.241 $\mathrm{g}, 1.606 \mathrm{mmol})$ in $\mathrm{MeCN}(1.01 \mathrm{~g})$ was added to a heterogeneous solution of 3 (1.007 $\mathrm{g}, 1.539$ $\mathrm{mmol}$ ) in MeCN (1.05 g) to make a homogeneous dark yellow solution. After 1 minute, the reaction solution was added to $400 \mathrm{~mL}$ of stirring $\mathrm{Et}_{2} \mathrm{O}$ to produce a tan precipitate. The precipitate was collected on a $30 \mathrm{~mL}$ medium porosity fritted funnel, washed with $2 \times 10 \mathrm{~mL} \mathrm{Et}{ }_{2} \mathrm{O}$, and placed under vacuum $\left(1.200 \mathrm{~g}, 1.492 \mathrm{mmol}, 97 \%\right.$ yield with $<1: 1$ molar ratio of $\mathrm{Et}_{2} \mathrm{O}$ to product via ${ }^{1} \mathrm{H}$ NMR). ${ }^{1} \mathrm{H}$ NMR $\left(\mathrm{CD}_{3} \mathrm{CN}, \delta\right): 8.38 / 8.34(\mathrm{~d}, J=2.0,1 \mathrm{H}, \mathrm{PzB} 3)$ 8.27/8.17 (d, $J=2.0$, $1 \mathrm{H}, \mathrm{PzA} 3), 8.06$ (d, $J=2.0,1 \mathrm{H}, \mathrm{PzC} 5), 8.02 / 8.00(\mathrm{~d}, J=2.0,1 \mathrm{H}, \mathrm{PzC} 3), 7.98(\mathrm{~d}, J=2.0,1 \mathrm{H}, \mathrm{PzB} 5)$, 7.86/7.84 (d, J = 2.0, 1H, PzA5), $6.59(\mathrm{~m}, 1 \mathrm{H}, \mathrm{PzC} 4), 6.54(\mathrm{~m}, 1 \mathrm{H}, \mathrm{PzB} 4), 6.39$ (m, 1H, PzA4), 6.37/5.85 (m, 1H, H3), 5.57/5.53 (m, 1H, H2), 5.35/5.23 (t, J = 7.7, 1H, H4), 5.19/4.32 (d, J = 15.5, $\left.2 \mathrm{H}, \mathrm{H6} / \mathrm{H}^{\prime}\right), 4.94 / 4.68\left(\mathrm{~d}, J=15.5,2 \mathrm{H}, \mathrm{H} 6 / \mathrm{H}^{\prime}\right)$ 4.69/4.30 (m, 1H, H5), 2.24/2.21 (s, 3H, AmideMe), 2.07/1.95 (m, 2H, H7/H7'), 1.21 (d, $\left.J=10.0,9 \mathrm{H}, \mathrm{PMe}_{3}\right), 1.20$ (d, $\left.{ }^{2} J_{\mathrm{PH}}=9.9,9 \mathrm{H}, \mathrm{PMe}_{3}(\mathrm{~min})\right)$, 
1.09/0.99 (t, $J=7.5$, Ethyl- $\left.\mathrm{CH}_{3}(\mathrm{maj} / \mathrm{min})\right) .{ }^{13} \mathrm{C} \mathrm{NMR}\left(\mathrm{CD}_{3} \mathrm{CN}, \delta\right): 172.9 / 172.6$ (Amide-CO), 149.2/148.5 $\quad$ (PzA3), $\quad 145.4 / 145.1 \quad$ (PzB3), $\quad 143.5 / 143.3 \quad$ (PzC3), $\quad 139.9 / 139.7 / 139.5$ (PzA5/PzB5/PzC5), 131.2/122.3 (C3(maj/min)), 109.5 (PzB4), 109.1/109.2 (PzC4), 108.2 (PzA4), 99.3/98.1 (C4(min/maj)), $72.7(C 5(m i n)), 66.2\left(d,{ }^{2} J_{P C}=15.0, C 5(m a j)\right), 57.1 / 54.6(C 2), 47.1 / 41.0$ (C6), 31.2/30.0 (C7), 22.0/21.9 (Amide-Me), 12.9 (d, $\left.{ }^{1} J_{\mathrm{PC}}=33.4, \mathrm{PMe}_{3}\right), 9.4 / 9.1\left(\right.$ Ethyl- $\left.\mathrm{CH}_{3}\right) .{ }^{31} \mathrm{P}$ $\operatorname{NMR}\left(\mathrm{CDCl}_{3}, \delta\right):-5.84\left(J_{\mathrm{WP}}=262\right),-7.05\left(J_{\mathrm{WP}}=259\right)$. Isomer ratio: 2.7:1 (Chemical Exchange Observed) IR: $v_{\mathrm{BH}}=2511 \mathrm{~cm}^{-1}, v_{\mathrm{NO} / \mathrm{amide}}=1643 \mathrm{~cm}^{-1} . \mathrm{CV}(\mathrm{MeCN}): E_{\mathrm{p}, \mathrm{a}}=+1.98 \mathrm{~V}, E_{\mathrm{p}, \mathrm{c}}=-0.84 \mathrm{~V} . \mathrm{ESI}-$ MS: obs'd (\%), calc'd (\%), ppm (M-OTf) ${ }^{+}: 653.199$ (97.5), 653.205 (84.7), 9.2; 654.2001 (96.7), 654.206 (80), 9; 655.2076 (100), 655.2073 (100), 0.5; 656.205 (60.3), 656.2115 (42.6), 9.9; 657.2084 (73.9), 657.2106 (84), 3.3.

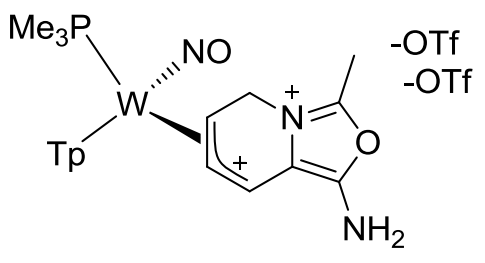

[TpW(NO)(PMe $)\left(6,7-\eta^{2}\right.$-(1-amino-3-methyl-5,6,7,8-tetrahydrooxazolo[3,4-a]pyridin-4-ium-8-

ylium $)]\left[(\mathrm{OTf})_{2}\right]$. 13. A solution of HOTf $(0.659 \mathrm{~g}, 4.390 \mathrm{mmol})$ in $\mathrm{MeCN}(0.50 \mathrm{~g})$ was quickly added to a vial containing a heterogeneous solution of 4 (1.303 g, $2.001 \mathrm{mmol})$ in MeCN (2.13 g) to make a deep red homogeneous solution upon manual mixing with a pipette. Once the solution was homogenenous, the solution was added to $500 \mathrm{~mL}$ stirring $\mathrm{Et}_{2} \mathrm{O}$ and the resulting orange microcrystalline precipitate was collected on a $60 \mathrm{~mL}$ medium porosity fritted funnel, washed with $2 \times 30 \mathrm{mLEt}{ }_{2} \mathrm{O}$, and placed under vacuum $(2.010 \mathrm{~g}$, with a 1:3 molar ratio of product: $\mathrm{Et}_{2} \mathrm{O} ; 1.573 \mathrm{~g}, 1.964 \mathrm{mmol}, 98 \%$ estimated yield after adjustment for $\left.\mathrm{Et}_{2} \mathrm{O}\right) .{ }^{1} \mathrm{H} \mathrm{NMR}$ $\left(\mathrm{CD}_{3} \mathrm{CN}, \delta\right): 8.42(\mathrm{~d}, J=7.4,1 \mathrm{H}, \mathrm{H} 8), 8.18(\mathrm{~d}, J=2.0,1 \mathrm{H}, \mathrm{PzB} 3), 8.08(\mathrm{~d}+\mathrm{s}(\mathrm{br}), 4 \mathrm{H}$, $\left.\mathrm{PzC} 3 / \mathrm{PzC} 5 / \mathrm{NH}_{2}\right), 8.01(\mathrm{~d}, J=2.0,1 \mathrm{H}, \mathrm{PzB} 5), 7.97(\mathrm{~d}, J=2.0,1 \mathrm{H}, \mathrm{PzA} 3), 7.84(\mathrm{~d}, J=2.0,1 \mathrm{H}, \mathrm{PzA} 5)$, $6.60(\mathrm{t}, J=2.0,1 \mathrm{H}, \mathrm{PzC} 4), 6.53(\mathrm{t}, J=2.0,1 \mathrm{H}, \mathrm{PzB} 4), 6.41(\mathrm{t}, J=2.0,1 \mathrm{H}, \mathrm{PzA} 4), 6.02(\mathrm{dd}, J=15.2$, 
3.7, $1 \mathrm{H}, \mathrm{H} 5), 5.11\left(\mathrm{~d}, J=15.2,1 \mathrm{H}, \mathrm{H} 5^{\prime}\right), 4.35(\mathrm{~m}, 2 \mathrm{H}, \mathrm{H} 6 / \mathrm{H} 7), 2.77$ (s, 3H, Amide-Me), $1.19\left(\mathrm{~d},{ }^{2} \mathrm{~J}_{\mathrm{PH}}\right.$ $\left.=9.8,9 \mathrm{H}, \mathrm{PMe}_{3}\right) .{ }^{13} \mathrm{C}$ NMR $\left(\mathrm{CD}_{3} \mathrm{CN}, \delta\right): 159.4$ (C3), 159.1 (C1), 150.6 (PzA3), 147.9 (C8), 146.7 (PzB4), 143.0 (PzC3), 140.0/139.8 (PzB5/PzC5), 139.0 (PzA5), 109.7 (PzC4), 109.0 (PzB4), 108.4 (PZA4), 103.1 (C2), 78.9 (C7), $61.2\left(\mathrm{~d},{ }^{2} \mathrm{~J}_{\mathrm{PC}}=14.7, \mathrm{C} 6\right), 49.5(\mathrm{C} 5), 12.9\left(\mathrm{~d},{ }^{1} \mathrm{~J}_{\mathrm{PC}}=32.9, \mathrm{PMe}_{3}\right), 12.3$ (Amide-Me). ${ }^{31} \mathrm{P} \mathrm{NMR}\left(\mathrm{CD}_{3} \mathrm{CN}, \delta\right):-4.51\left(J_{\mathrm{WP}}=267\right)$. IR: $v_{\mathrm{BH}}=2519 \mathrm{~cm}^{-1}, v_{\mathrm{CN}}=2252 \mathrm{~cm}^{-1}, v_{\mathrm{NO}}=v=$ $1685 \mathrm{~cm}^{-1}, v=1620 \mathrm{~cm}^{-1}, v=1540 \mathrm{~cm}^{-1} . \mathrm{CV}(\mathrm{MeCN}): E_{\mathrm{p}, \mathrm{a}}=+2.04 \mathrm{~V}, E_{\mathrm{p}, \mathrm{c}}=-0.52 \mathrm{~V}$. ESI-MS: obs'd (\%), calc'd (\%), ppm (M-OTf) ${ }^{+}: 650.1693$ (85.0), 650.167 (85.1), 3.5; 651.1681 (82.0), 651.1713 (79.9), 4.9; 652.1679 (100), 652.171 (100), 4.8; 653.1736 (46.6), 653.1715 (42.1), 3.2; 654.1749 (84.6), 654.178 (84.2), 4.7. UV-Vis (MeCN; $\lambda, \mathrm{nm}\left(\varepsilon, \mathrm{cm}^{-1} \mathrm{M}^{-1}\right): 229$ (strong), 410 (weak). Anal. Calc'd for $\mathrm{C}_{22} \mathrm{H}_{31} \mathrm{BF}_{6} \mathrm{~N}_{9} \mathrm{O}_{8} \mathrm{PS}_{2} \mathrm{~W} \cdot 2 \mathrm{H}_{2} \mathrm{O}: \mathrm{C}, 26.76 ; \mathrm{H}, 3.37 ; \mathrm{N}, 12.77$; Found: $\mathrm{C}, 26.88 ; \mathrm{H}, 3.42 ; \mathrm{N}$, 12.50.

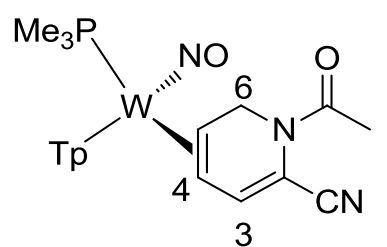

TpW(NO)(PMe 3 )(4,5- $\eta^{2}$-(1-acetyl-1,6-dihydropyridine-2-carbonitrile). 14. DABCO (0.114 g, $1.016 \mathrm{mmol})$ was added to a dark red solution of 13 ( $0.808 \mathrm{~g} ; 0.646 \mathrm{~g}$ estimated after correction for $\mathrm{Et}_{2} \mathrm{O}$ in the sample, $0.806 \mathrm{mmol}$ ) in $\mathrm{DCM}(23 \mathrm{~g})$ to make a dark yellow homogeneous solution. After several minutes, the solution was diluted with $25 \mathrm{~mL} \mathrm{DCM}$, extracted with $3 \times 25$ $\mathrm{mL} \mathrm{NaHCO}_{3}$ (saturated, aqueous), back-extracted with $2 \times 20 \mathrm{~mL} D C M$, the combined organic layers were dried with $\mathrm{Na}_{2} \mathrm{SO}_{4}$, filtered through a $30 \mathrm{~mL}$ fine porosity fritted funnel, and the solvent removed in vacuo. MeCN (12 mL) was added to the residue and a yellow solid precipitated. The precipitate was collected on a $30 \mathrm{~mL}$ medium porosity fritted funnel, washed with $2 \times 1 \mathrm{~mL}$ MeCN, and placed under vacuum $\left(0.201 \mathrm{~g}, 0.309 \mathrm{mmol}, 37 \%\right.$ yield). ${ }^{1} \mathrm{H}$ NMR $\left(\mathrm{CDCl}_{3}\right.$, $\delta): 8.04(\mathrm{~d}, J=2.0,1 \mathrm{H}, \mathrm{PzA} 3), 8.00(\mathrm{~d}, J=2.0,1 \mathrm{H}, \mathrm{PzB} 3), 7.75(\mathrm{~m}, 2 \mathrm{H}, \mathrm{PzB} 5 / \mathrm{PzC} 5), 7.58(\mathrm{~d}, J=2.0$, 
1H, PzA5), $7.42(\mathrm{~d}, J=7.1,1 \mathrm{H}, \mathrm{H} 3), 7.37(\mathrm{~d}, J=2.0,1 \mathrm{H}, \mathrm{PzC} 3), 6.32(\mathrm{t}, J=2.0,1 \mathrm{H}, \mathrm{PzB} 4), 6.25(\mathrm{t}, J$ $=2.0,1 \mathrm{H}, \mathrm{PzC} 4), 6.22(\mathrm{t}, J=2.0,1 \mathrm{H}, \mathrm{PzA} 4), 5.57(\mathrm{~d}, J=13.0,1 \mathrm{H}, \mathrm{H} 6$ (syn-to-W)), $4.44(\mathrm{~d}(\mathrm{br}), J=$ 13.0, 1H, H6 (anti-to-W)), 3.20 (ddd, $J=13.0,10.0,3.0,1 \mathrm{H}, \mathrm{H} 5), 2.40$ (s, 3H, Acetyl-Me), 1.80 (dd, $J=10.0,7.1,1 \mathrm{H}, \mathrm{H} 4), 1.22\left(\mathrm{~d}, J=8.6,9 \mathrm{H}, \mathrm{PMe}_{3}\right) .{ }^{13} \mathrm{C} \mathrm{NMR}\left(\mathrm{CDCl}_{3}, \delta\right): 170.3$ (Amide-CO), 148.26 (C3), 145.6 (PzA3), 143.3 (PzB3), 140.1 (PzC3), 137.1/136.5 (PzB5/PzC5), 135.4 (PzA5), 118.1 (nitrile), 107.1 (PzB4), 106.3 (PzC4), 106.2 (PzA4), 101.8 (C2), 66.8 (C5, d, J = 14.1), 48.1 (C4), 44.8 (C6), 25.5 (Acetyl-Me), $13.4\left(\mathrm{PMe}_{3}, \mathrm{~d}, J=28.8\right) .{ }^{31} \mathrm{P} \mathrm{NMR}\left(\mathrm{CDCl}_{3}, \delta\right):-9.35\left(J_{\mathrm{WP}}=276\right)$. IR: $v_{\mathrm{BH}}=$ $2511 \mathrm{~cm}^{-1}, v_{\mathrm{CN}}=2202 \mathrm{~cm}^{-1}, v_{\mathrm{NO}}=1554 \mathrm{~cm}^{-1}, v=1635 \mathrm{~cm}^{-1}, v=1589 \mathrm{~cm}^{-1} . \mathrm{CV}$ (DMA): $E_{\mathrm{p}, \mathrm{a}}=+0.77$ V. ESI-MS: obs'd (\%), calc'd (\%), ppm (M+H) ${ }^{+}: 650.1679$ (85.7), 650.1689 (85.1), 1.5; 651.1699 (46.6), 651.1714 (79.9), 2.3; 652.1706 (100), 652.1712 (100), 0.9; 653.174 (21.6), 653.1754 (42.1), 2.2; 654.1741 (93.2), 654.1745 (84.2), 0.7. Anal. Calc'd for $\mathrm{C}_{20} \mathrm{H}_{27} \mathrm{BN}_{9} \mathrm{O}_{2} \mathrm{PW}: \mathrm{C}, 36.89 ; \mathrm{H}$, 4.18; N, 19.36; Found: C, 36.72; H, 4.14; N, 18.90.

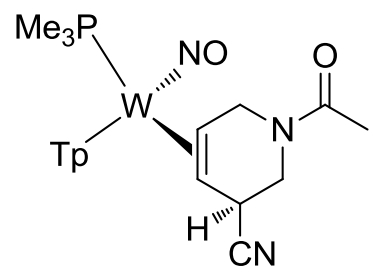

$\operatorname{TpW}(\mathrm{NO})\left(\mathrm{PMe}_{3}\right)\left(4,5-\eta^{2}-(1-a c e t y l-1,2,3,6-\right.$ tetrahydropyridine-3-carbonitrile). 15. In separate oven dried test tubes, a solution of $11(0.254 \mathrm{~g}, 0.327 \mathrm{mmol})$ in DCM (4.23 g) and a solution of $\operatorname{NaCN}(0.072 \mathrm{~g}, 1.469 \mathrm{mmol}), \mathrm{DMSO}(1.93 \mathrm{~g})$, and DCM (1.91 g) were prepared and placed in a 0 ${ }^{\circ} \mathrm{C}$ cold bath. After $\mathbf{2} \mathrm{h}$, the solution of $\mathbf{1 1}$ was quickly added to the $\mathrm{NaCN}$ solution and mixed solution allowed to stir for $1 \mathrm{~h}$. The reaction solution was removed from the cold bath and glovebox. The reaction solution was extracted with $3 \times 10 \mathrm{~mL} \mathrm{NH}{ }_{4} \mathrm{Cl}$ (saturated, aqueous), backextracted with $3 \times 5 \mathrm{~mL} \mathrm{DCM}$, the combined organic layers were dried with $\mathrm{Na}_{2} \mathrm{SO}_{4}$, filtered through a $60 \mathrm{~mL}$ coarse porosity fritted funnel, and the solvent removed. The residue was dissolved in $1 \mathrm{~mL} \mathrm{DCM}$, and $1 \mathrm{~mL}$ EtOAc was added followed by the addition of hexanes ( $35 \mathrm{~mL}$ ) 
to precipitate an off-white solid. The solution was cooled to $0{ }^{\circ} \mathrm{C}$ for 20 minutes, and the precipitate collected on a $15 \mathrm{~mL}$ medium porosity fritted funnel. The filtrate was colorless. The remaining uncollected material on the flask was redissolved in $1 \mathrm{~mL} D C M$ and $1 \mathrm{~mL}$ EtOAC followed by the addition of hexanes $(35 \mathrm{~mL})$ to precipitate an off-white solid that was collected on a separate $15 \mathrm{~mL}$ medium porosity fritted funnel and washed with $2 \times 10 \mathrm{~mL}$ hexanes (combined yield: $0.119 \mathrm{~g}, 0.182 \mathrm{mmol}, 57 \%$ yield, with minor DMSO impurity). ${ }^{1} \mathrm{H} \mathrm{NMR}\left(\mathrm{CDCl}_{3}\right.$,

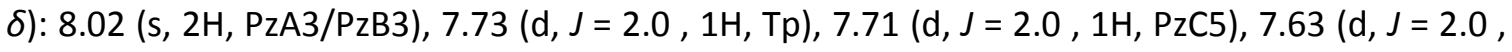
$1 \mathrm{H}, \mathrm{Tp}), 7.21(\mathrm{~d}, J=2.0,1 \mathrm{H}, \mathrm{PzC} 3), 6.32 / 6.26(\mathrm{t}, J=2.0,1 \mathrm{H}, \mathrm{PzA} 4 / \mathrm{PzB} 4), 6.2(\mathrm{t}, J=2.0,1 \mathrm{H}, \mathrm{PzC} 4)$, $5.20(\mathrm{dd}, J=13.9,6.0,1 \mathrm{H}, \mathrm{H} 6($ anti)), 4.46 (dd, $J=13.3,7.2, \mathrm{H}, \mathrm{H} 6$ (anti, rotamer)), 4.16 (dd, $J=$ 13.9, 6.0, $1 \mathrm{H}, \mathrm{H} 6(\mathrm{syn})), 3.92(\mathrm{~m}, 2 \mathrm{H}, \mathrm{H} 3 / \mathrm{H} 2), 3.66\left(\mathrm{dd}, J=13.4,8.4,1 \mathrm{H}, \mathrm{H} 2{ }^{\prime}\right), 2.71(\mathrm{~m}, 1 \mathrm{H}, \mathrm{H} 5)$, $1.21\left(\mathrm{~d}, J=8.3,9 \mathrm{H}, \mathrm{PMe}_{3}\right) .{ }^{13} \mathrm{C} \mathrm{NMR}\left(\mathrm{CDCl}_{3}, \delta\right): 169.7$ (Amide-CO), 143.6/143.3 (PzA3/PzB3), 140.2 (PzC), 136.9/136.4/136.0 (PzA5/PzB5/PzC5), 124.6 (CN), 106.8 (Tp), 106.3 (PzC4), 105.6 (Tp), 49.1 (C4), 48.9 (C5, d, $J=12.5$ ), 43.2 (C6), 31.2 (C3), 22.3 (Amide-Me), $13.8\left(\mathrm{PMe}_{3}, \mathrm{~d}, J=\right.$ 28.5). ${ }^{31} \mathrm{P} \mathrm{NMR}\left(\mathrm{CDCl}_{3}, \delta\right):-11.43\left(J_{\mathrm{WP}}=272\right),-12.25$ (rotamer). Ratio of rotational isomers: $3.6: 1$ (Chemical Exchange Observed). IR: $v_{\mathrm{BH}}=2488 \mathrm{~cm}^{-1}, v_{\text {nitrile }}=2225 \mathrm{~cm}^{-1}, v_{\text {amide }}=1624 \mathrm{~cm}^{-1}, v_{\mathrm{NO}}=$ $1550 \mathrm{~cm}^{-1} . \mathrm{CV}(\mathrm{DMA}): E_{\mathrm{p}, \mathrm{a}}=+0.71 \mathrm{~V} . \mathrm{ESI}-\mathrm{MS}:$ obs'd (\%), calc'd (\%), ppm, $(\mathrm{M}+\mathrm{Na})^{+}: 674.1642$ (70.2), 674.1659 (85.1), 2.4; 675.1663 (100), 675.1684 (79.9), 3.1; 676.1684 (78.2), 676.1682 (100), 0.2; 677.1719 (37.3), 677.1724 (42.2), 0.8; 678.1707 (99.9), 678.1715 (84.2), 1.2.

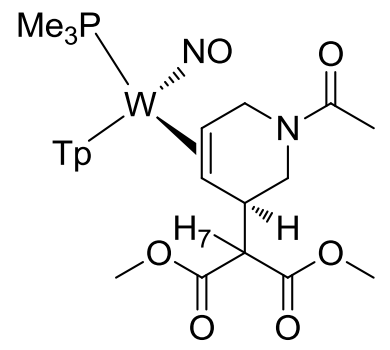

$\operatorname{TpW}(\mathrm{NO})\left(\mathrm{PMe}_{3}\right)\left(4,5-\eta^{2}\right.$-(dimethyl-2-(1-acetyl-1,2,3,6-tetrahydropyridin-3-yl)malonate). 16. To separate flame dried test tubes, a homogeneous solution of $\mathbf{1 1}(0.503 \mathrm{~g}, 0.648 \mathrm{mmol})$ and DCM 
(1.51 g) and a heterogeneous solution of LiDMM $(0.191 \mathrm{~g}, 1.38 \mathrm{mmol})$ in DCM (1.52 $\mathrm{g})$ were each placed in a $0{ }^{\circ} \mathrm{C}$ cold bath. After 15 minutes, the LiDMM solution was quickly added to the solution of 11 and the mixture was allowed to stir. After $1 \mathrm{~h}$ and 20 minutes, the reaction solution was removed from the cold bath and glovebox, diluted with $5 \mathrm{~mL} \mathrm{DCM}$, extracted with $3 \times 2 \mathrm{~mL} \mathrm{NaHCO}$ (saturated, aqueous), back extracted with $2 \times 2 \mathrm{~mL} \mathrm{DCM}$, the combined organic layers were dried with $\mathrm{Na}_{2} \mathrm{SO}_{4}$, filtered through a $30 \mathrm{~mL}$ coarse porosity fritted funnel, washed with DCM and the solvent removed in vacuo. The residue was dissolved in $2.5 \mathrm{~mL} \mathrm{DCM}$ followed by $2.5 \mathrm{~mL} E t O A c$, then $\mathrm{Et}_{2} \mathrm{O}(50 \mathrm{~mL})$ was added to precipitate an off-white solid. The solution was cooled to $0{ }^{\circ} \mathrm{C}$ and stirred for $0.5 \mathrm{~h}$ and the solid collected on a $30 \mathrm{~mL}$ medium porosity fritted funnel and placed under vacuum $(0.331 \mathrm{~g}, 0.437 \mathrm{mmol}, 67 \%$ yield). More material could be isolated by further precipitation of the filtrate residue with DCM, EtOAc, using hexanes in place of $\mathrm{Et}_{2} \mathrm{O} .{ }^{1} \mathrm{H}$ NMR $\left(\mathrm{CDCl}_{3}, \delta\right): 8.07(\mathrm{~d}, J=2.0,1 \mathrm{H}, \mathrm{PzB} 3), 8.06(\mathrm{~d}, J=2.0,1 \mathrm{H}, \mathrm{PzA} 3), 7.71(\mathrm{~d}, J=$ 2.0, 1H, PzB5), 7.69 (d, $J=2.0,1 \mathrm{H}, \mathrm{PzC} 5), 7.61(\mathrm{~d}, J=2.0,1 \mathrm{H}, \mathrm{PzA} 5), 7.20$ (d, $J=2.0,1 \mathrm{H}, \mathrm{PzC} 3$ ), $6.31(\mathrm{t}, J=2.0,1 \mathrm{H}, \mathrm{PzB} 4), 6.24(\mathrm{t}, J=2.0,1 \mathrm{H}, \mathrm{PzA} 4), 6.18(\mathrm{t}, J=2.0,1 \mathrm{H}, \mathrm{PzC} 4), 5.16(\mathrm{dd}, J=14.0$, 6.3, $1 \mathrm{H}, \mathrm{H} 6), 4.58\left(\mathrm{~d}, J=14.0,1 \mathrm{H}, \mathrm{H} 6^{\prime}\right), 3.94(\mathrm{dd}, J=13.1,4.5,1 \mathrm{H}, \mathrm{H} 2$ ), $3.76(\mathrm{~d}, J=9.5,1 \mathrm{H}, \mathrm{H} 7$ ), $3.73\left(\mathrm{~s}, 3 \mathrm{H}\right.$, Ester-Me), 3.66 (m (broad), 1H, H3), 3.51 (dd, $\left.J=13.1,1.6,1 \mathrm{H}, \mathrm{H} 2{ }^{\prime}\right), 3.41(\mathrm{~s}, 3 \mathrm{H}$, Ester-Me'), 2.77 (dddd, $J=13.9,11.2,6.6,2.2,1 \mathrm{H}, \mathrm{H} 5), 2.03$ (s, 3H, Amide-Me), 1.17 (d, 8.2, 9H, $\left.\mathrm{PMe}_{3}\right), 0.92(\mathrm{~d}, J=11.2,1 \mathrm{H}, \mathrm{H} 4)$. Non-overlapping minor isomer signals: 4.73 (dd, $J=13.2,9.1$, $1 \mathrm{H}, \mathrm{H} 6), 4.32\left(\mathrm{dd}, J=13.2,4.4,2 \mathrm{H}, \mathrm{H} 6^{\prime} / \mathrm{H}^{\prime}\right), 3.59(\mathrm{~d}, J=9.8,1 \mathrm{H}, \mathrm{H} 7), 3.31$ (dd, $J=13.2,4.0,1 \mathrm{H}$, H2), 3.15 (s, 3H, Ester-Me'), 2.95 (m, 1H, H5), 2.16 (s, 3H, Amide-Me), 0.73 (d, J = 11.2, 1H, H4). ${ }^{13} \mathrm{C} \mathrm{NMR}\left(\mathrm{CDCl}_{3}, \delta\right): 170.6$ (Amide-CO), 169.7 (Ester-CO), 169.1 (Ester-CO'), 143 (PzA3/PzB3), 139.8 (PzC3), 136.5 (PzC5), 135.9 (PzB5), 135.7 (PzA5), 106.6 (PzB4), 106 (PzC4), 105.8 (PzA4), 59.6 (C7), 52.5 (Ester-Me), 52.1 (Ester-Me'), 50.9 (C4), 48.8 (C5, d, J = 11.8), 46.2 (C2), 43.5 (C6), 39.2 (C3), 22.0 (Amide-Me), $13.4\left(\mathrm{PMe}_{3}, \mathrm{~d}, J=28.1\right) .{ }^{31} \mathrm{P} \mathrm{NMR}\left(\mathrm{CDCl}_{3}, \delta\right):-10.31\left(J_{\mathrm{WP}}=279\right)$, - 
11.08 (rotamer). Isomer Ratio: 6.3:1 (Chemical Exchange Observed). IR: $v_{\mathrm{BH}}=2488 \mathrm{~cm}^{-1}, v_{\text {ester }}=$ $1732 \mathrm{~cm}^{-1}, v_{\text {amide }}=1624 \mathrm{~cm}^{-1}, v_{\mathrm{NO}}=1547 \mathrm{~cm}^{-1} . \mathrm{CV}$ (DMA): $E_{\mathrm{p}, \mathrm{a}}=+0.49 \mathrm{~V}$. ESI-MS obs'd (\%), calc'd (\%), ppm (M+H)+: 757.2151 (86.9), 757.2159 (82.5), 1.1; 758.2173 (81.8), 758.2185 (80.3), 1.6; 759.2201 (100), 759.2184 (100), 2.2; 760.2237 (49.5), 760.2224 (45.2), 1.7; 761.2219 (80.5), $761.2216(83.4), 0.4$.

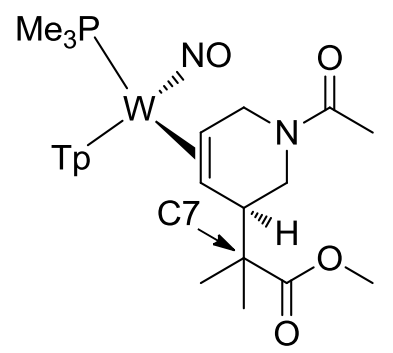

\section{$\mathrm{TpW}(\mathrm{NO})\left(\mathrm{PMe}_{3}\right)\left(4,5-\eta^{2}\right.$-(methyl-2-(1-acetyl-1,2,3,6-tetrahydropyridin-3-yl)-2-}

methylpropanoate). 17. A solution of MMTP $(0.250 \mathrm{~g}, 1.434 \mathrm{mmol})$ in DCM $(7.96 \mathrm{~g})$ was added in one portion to a $40 \mathrm{~mL}$ flame dried beaker containing a rapidly stirring solution of $\mathbf{1 1}(0.501 \mathrm{~g}$, $0.645 \mathrm{mmol}$ ) in DCM $(8.1 \mathrm{~g})$. After 10 minutes, the solution was diluted with $20 \mathrm{~mL} \mathrm{DCM}$, extracted with $3 \times 20 \mathrm{~mL} \mathrm{NaHCO}$ (saturated, aqueous), back-extracted with $2 \times 20 \mathrm{~mL} \mathrm{DCM}$, the combined organic layers were dried with $\mathrm{Na}_{2} \mathrm{SO}_{4}$, filtered through a $150 \mathrm{~mL}$ coarse porosity fritted funnel, and the solvent removed. The residue was dissolved in $10 \mathrm{~mL} \mathrm{DCM}$, then $10 \mathrm{~mL}$ EtOAc and a precipitate formed upon the addition of $100 \mathrm{~mL}$ of $\mathrm{Et}_{2} \mathrm{O}$. The tan precipitate was collected on a $15 \mathrm{~mL}$ medium porosity fritted funnel and washed with $2 \times 10 \mathrm{~mL} \mathrm{Et} \mathrm{t}_{2} \mathrm{O}$. The filtrate solvent was removed in vacuo, the residue was dissolved in $5 \mathrm{~mL}$ EtOAc and $75 \mathrm{~mL}$ hexanes added to precipitate a tan-pink solid that was further precipitated with cooling in an ice bath for $0.5 \mathrm{~h}$. The precipitate was collected on a $15 \mathrm{~mL}$ medium porosity fritted funnel, washed with $2 \times 10 \mathrm{~mL}$ hexanes, and placed under vacuum (combined yield: $0.274 \mathrm{~g}, 0.376 \mathrm{mmol}, 58 \%$ yield). ${ }^{1} \mathrm{H} \operatorname{NMR}\left(\mathrm{CDCl}_{3}, \delta\right): 8.09$ (d, $\left.J=2.0,1 \mathrm{H}, \mathrm{PzA} 3\right), 8.04(\mathrm{~d}, J=2.0,1 \mathrm{H}, \mathrm{PzB} 3), 7.69(\mathrm{~m}, 2 \mathrm{H}, \mathrm{PzB} 5 / \mathrm{BzC} 3)$, $7.63(\mathrm{~d}, J=2.0,1 \mathrm{H}, \mathrm{PzA} 5), 7.26(\mathrm{~d}, J=2.0,1 \mathrm{H}, \mathrm{PzC} 3), 6.29(\mathrm{t}, J=2.0,1 \mathrm{H}, \mathrm{PzB} 4), 6.23(\mathrm{t}, J=2.0$, 
1H, PzA4), 6.21 (t, J = 2.0, 1H, PzC4), 5.25 (dd, $J=14.3,7.7,1 \mathrm{H}, \mathrm{H} 6($ anti)), 4.33 (d, $J=14.3,1 \mathrm{H}$, H6(syn)), 3.75 (dd, $J=13.9,5.7,1 \mathrm{H}, \mathrm{H} 2$ (syn)), 3.47 (s, 3H, Ester-Me), 3.45 (d, $J=13.9,1 \mathrm{H}$, $\mathrm{H} 2$ (anti)), 3.34 (d, $J=5.7,1 \mathrm{H}, \mathrm{H} 3$ ), 2.9 (dddd, $\left.J=11.5,7.5,2.4,{ }^{3} \mathrm{PH}_{\mathrm{PH}}=14.0,1 \mathrm{H}, \mathrm{H} 5\right), 2.1(\mathrm{~s}, 3 \mathrm{H}$, Amide-Me), 1.26 (s, 3H, Gem-Me), 1.17 (d, J = 8.1, 9H, PMe P $^{2}, 1.05$ (s, 3H, Gem-Me'), 1.03 (d, $J=$ $11.5,1 \mathrm{H}, \mathrm{H} 4)$. Non-overlapping minor isomer signals: $4.71(\mathrm{dd}, J=13.1,9.0,1 \mathrm{H}, \mathrm{H6}), 4.51(\mathrm{~d}, J=$ $14.3,1 \mathrm{H}, \mathrm{H} 2$ ), $3.14(\mathrm{dd}, J=14.1,5.3,1 \mathrm{H}, \mathrm{H} 2), 3.06$ (dddd, $J=11.3,8.7,3.7,{ }^{2} J_{\mathrm{PH}}=15.2,1 \mathrm{H}, \mathrm{H} 5$ ), 3.05 (s, 3H, Ester-Me), 2.09 (s, 3H, Amide-Me), 1.31 (s, 3H, Gem-Me), 1.19 (d, J = 7.9, 9H, $\mathrm{PMe}_{3}$ ), $1.12(\mathrm{~s}, 3 \mathrm{H}, \mathrm{Gem}-\mathrm{Me}), 0.80(\mathrm{~d}, J=11.3,1 \mathrm{H}, \mathrm{H} 4) .{ }^{13} \mathrm{C} \mathrm{NMR}\left(\mathrm{CDCl}_{3}, \delta\right): 179.0$ (Ester-CO), 169.9 (Amide-CO), 168.3 (Amide-CO(rot)), 143.1 (PzA3), 142.5 (PzB3), 139.8 (PzC3), 136.2/136.1/136.0 (PzA5/PzB5/PzC5), 106.6 (PzB4), 106.2 (PzC4), 105.6 (PzA4), 51.6 (Ester-Me), 50.4 (C7), 49.8 (C4), $49.1(\mathrm{~d}, J=11.3, \mathrm{C} 5), 44.8$ (C3), 44.6 (C2), 44.4 (C6), 24.5 (Gem-Me), 22.3 (Amide-Me), 22.1 (Gem-Me'), $13.7\left(\mathrm{~d}, J=27.8, \mathrm{PMe}_{3}\right) .{ }^{31} \mathrm{P}$ NMR $\left(\mathrm{CDCl}_{3}, \delta\right):-10.30$ ( $\left.J_{\mathrm{WP}}=282\right),-11.03$ (Rotamer). Isomer Ratio: 5:1 (Chemical Exchange Observed). IR: $v_{\mathrm{BH}}=2488 \mathrm{~cm}^{-1}, v_{\text {ester }}=1724 \mathrm{~cm}^{-1}, v_{\text {amide }}=$ $1620 \mathrm{~cm}^{-1}, v_{\mathrm{NO}}=1543 \mathrm{~cm}^{-1} . \mathrm{CV}(\mathrm{DMA}): E_{\mathrm{p}, \mathrm{a}}=+0.45 \mathrm{~V} . \mathrm{ESI}-\mathrm{MS}:$ obs'd (\%), calc'd (\%), ppm, $(\mathrm{M}+\mathrm{H})^{+}:$ 726.2326 (76.7), 726.2333 (82.8), 1.1; 727.2353 (69.3), 727.2359 (80.5), 0.8; 728.2363 (100), 728.2358 (100), 0.7; 729.2401 (39.9), 729.2398 (45.0), 0.4; 730.2388 (76.5), 730.239 (83.3), 0.3. Anal. Calc'd for $\mathrm{C}_{24} \mathrm{H}_{38} \mathrm{BN}_{8} \mathrm{O}_{4} \mathrm{PW} \cdot \mathrm{H}_{2} \mathrm{O}: \mathrm{C}, 38.63 ; \mathrm{H}, 5.40 ; \mathrm{N}, 15.02$; Found: $\mathrm{C}, 38.96, \mathrm{H}, 5.31 ; \mathrm{N}$, 15.35 .

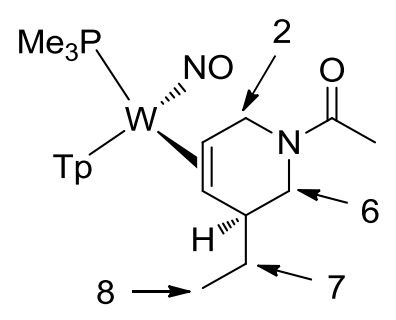

TpW(NO)(PMe $)\left(3,4-\eta^{2}\right.$-(1-(5-ethyl-5,6-dihydropyridin-1(2H)-yl)ethanone)). 18 . To three separate oven dried test tubes, a solution of 11 (0.225 g, $0.290 \mathrm{mmol})$ in DCM (5.16 g), CuCN 
$(0.133 \mathrm{~g}, 1.485 \mathrm{mmol})$, and a solution of $\mathrm{ZnEt}_{2}(0.118 \mathrm{~g}, 0.955 \mathrm{mmol}), \mathrm{DCM}(3.05 \mathrm{~g})$, and THF ( $0.116 \mathrm{~g}$ ) were added to a $0{ }^{\circ} \mathrm{C}$ cold bath. After 20 minutes, the 11 solution was quickly added to the CuCN containing tube and the suspension was quickly added to the $\mathrm{ZnEt}_{2}$ solution and allowed to stir for $3 \mathrm{~h}$. The solution was removed from the glovebox and neutralized under a stream of $\mathrm{N}_{2}$ (g) with $\mathrm{NH}_{4} \mathrm{Cl}$ (saturated, aqueous) solution. The solution was diluted with $5 \mathrm{~mL}$ DCM, extracted with $5 \times 10 \mathrm{~mL} \mathrm{NH}_{4} \mathrm{Cl}$ (saturated, aqueous), and back-extracted with $2 \times 4 \mathrm{~mL} \mathrm{DCM}$. The combined organic layers were dried over $\mathrm{Na}_{2} \mathrm{SO}_{4}$ for $2 \mathrm{~h}$, filtered through a $30 \mathrm{~mL}$ coarse porosity fritted funnel, and the solvent removed. The residue was dissolved in $1 \mathrm{~mL} \mathrm{DCM}$, then 1 $\mathrm{mL}$ EtOAc followed by the addition of $\mathrm{Et}_{2} \mathrm{O}(35 \mathrm{~mL})$ to precipitate a dark brown solid that was collected on a $15 \mathrm{~mL}$ medium porosity fritted funnel and discarded. The filtrate solvent was concentrated in vacuo and the residue was dissolved in $1 \mathrm{~mL} \mathrm{DCM}$, then $1 \mathrm{~mL}$ EtOAc followed by the addition of hexanes $(35 \mathrm{~mL})$ to precipitate an off-white solid. The solution was cooled to $0{ }^{\circ} \mathrm{C}$ for 30 minutes, and the precipitate collected on a $15 \mathrm{~mL}$ medium porosity fritted funnel $(0.082$ g, $0.125 \mathrm{mmol}, 43 \%$ yield). ${ }^{1} \mathrm{H}$ NMR $\left(\mathrm{CDCl}_{3}, \delta\right): 8.08$ (d, $\left.J=2.0,1 \mathrm{H}, \mathrm{PzA} 3\right), 8.04(\mathrm{~d}, J=2.0,1 \mathrm{H}$, PzB3), $7.70(\mathrm{~m}, 2 \mathrm{H}, \mathrm{PzB} 5 / \mathrm{PzC} 5), 7.62(\mathrm{~d}, J=2.0,1 \mathrm{H}, \mathrm{PzA} 5), 7.23(\mathrm{~d}, J=2.0,1 \mathrm{H}, \mathrm{PzC} 3), 6.29(\mathrm{t}, J=$ 2.0, 1H, PzB4), $6.20(\mathrm{t}, J=2.0,1 \mathrm{H}, \mathrm{PzA} 4), 6.19(\mathrm{t}, J=2.0,1 \mathrm{H}, \mathrm{PzC} 4), 5.08(\mathrm{dd}, J=13.7,6.5,1 \mathrm{H}$, H2), $4.48\left(\mathrm{dd}, J=13.7,3.2,1 \mathrm{H}, \mathrm{H} 2^{\prime}\right), 3.83(\mathrm{dd}, J=12.4,5.0,1 \mathrm{H}, \mathrm{H} 6), 3.13(\mathrm{dd}, J=12.4,6.1,1 \mathrm{H}$, H6'), 2.90 (s (br), 1H, H5), 2.75 (m, 1H, H3), 2.11 (s, 3H, Amide-Me), 1.59 (m, 1H, H7), 1.49 (m, $\left.1 \mathrm{H}, \mathrm{H}^{\prime}\right), 1.21\left(\mathrm{~d}, J=8.7,9 \mathrm{H}, \mathrm{PMe}_{3}\right), 1.10(\mathrm{~d}, J=11.4,1 \mathrm{H}, \mathrm{H} 4), 0.95$ (t, $J=7.5$, Ethyl-CH3). Nonoverlapping minor isomer signals: $8.11(\mathrm{~d}, J=2.0,1 \mathrm{H}, \mathrm{PzA} 3), 8.02(\mathrm{~d}, J=2.0,1 \mathrm{H}, \mathrm{PzB} 3), 7.17$ (d, $J=2.0,1 \mathrm{H}, \mathrm{PzC} 3), 4.46$ (m(buried), 1H, H2), 4.20 (dd, $\left.J=13.2,6.5,1 \mathrm{H}, \mathrm{H} 2{ }^{\prime}\right), 3.91(\mathrm{dd}, J=12.5$, 4.6, 1H, H6), 3.16 (m(shoulder), $\left.1 \mathrm{H}, \mathrm{H} 6^{\prime}\right), 2.18$ (s, 3H, Amide-Me), 1.24 (d, $\left.J=7.9,9 \mathrm{H}, \mathrm{PMe}_{3}\right) .{ }^{13} \mathrm{C}$ NMR (CDCl, ס): 169.9 (Amide-CO), 143.3 (PzB3), 142.6 (PzA3), 140.1 (PzC3), 136.5/135.8 (PzA5/PzB5/PzC5), 106.5 (PzB4), 106.0/105.5 (PzA4/PzC4), 55.0 (C4), 50.6 (C3, d, J = 11.7), 49.9 
(C6), 44.6 (C2), 40.7 (C5), 32.0 (C7), 22.4 (Amide-Me), $13.8\left(\mathrm{PMe}_{3}, \mathrm{~d}, J=27.9\right), 12.6($ Ethyl-CH$)$. Non-overlapping minor isomer signals: 168.8 (Amide-CO), 143.4 (PzB3), 143.2 (PzA3), 140.0 (PzC3), 50.3 (C2), 47.8 (C6), 22.3 (Amide-Me), $14.2\left(\mathrm{PMe}_{3}, \mathrm{~d}, J=28.1\right) .{ }^{31} \mathrm{P} \mathrm{NMR}\left(\mathrm{CDCl}_{3}, \delta\right):-11.45$ $\left(J_{\mathrm{WP}}=271\right),-12.27$ (rotamer). Isomer Ratio: 4.3:1 (Chemical Exchange Observed). IR: $v_{\mathrm{BH}}=2480$ $\mathrm{cm}^{-1}, v_{\text {amide }}=1620 \mathrm{~cm}^{-1}, v_{\mathrm{NO}}=1547 \mathrm{~cm}^{-1} . \mathrm{CV}(\mathrm{DMA}): E_{\mathrm{p}, \mathrm{a}}=+0.46 \mathrm{~V}$. ESI-MS: obs'd (\%), calc'd (\%), ppm, $(\mathrm{M}+\mathrm{H})^{+}: 655.2182$ (79.3), 655.22 (84.8), 2.7; 656.2195 (84.7), 656.2226 (80.1), 4.7; 657.2219 (100), 657.2224 (100), 0.7; 658.2263 (61.5), 658.2266 (42.7), 0.4; 659.2232 (74.9), $659.2256(84), 3.7$.

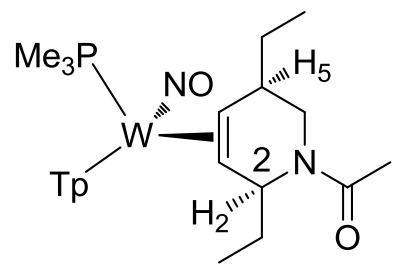

$\operatorname{TpW}(\mathrm{NO})\left(\mathrm{PMe}_{3}\right)\left(3,4-\eta^{2}-(1-(2,5-d i e t h y l-5,6-d i h y d r o p y r i d i n-1(2 \mathrm{H})-y l)\right.$ ethanone). $19 . \quad$ In three separate oven dried test tubes, a dark yellow homogeneous solution of 12 (0.500 g, 0.622 $\mathrm{mmol})$ in DCM (10.05 g), a solution of $\mathrm{ZnEt}_{2}(0.232 \mathrm{~g}, 1.88 \mathrm{mmol})$ in DCM (10.05 g) and THF $(0.242 \mathrm{~g})$, and CuCN $(0.232 \mathrm{~g}, 2.59 \mathrm{mmol})$ were all placed in a $-35^{\circ} \mathrm{C}$ cold bath. After 20 minutes, the solution of $\mathbf{1 2}$ was added to the tube containing $\mathrm{CuCN}$ and the suspension was transferred to the test tube containing the $\mathrm{ZnEt}_{2}$ solution at $-32{ }^{\circ} \mathrm{C}$ and the mixture was allowed to stir. After $52 \mathrm{~h}$, the mixture was removed from the now $-30{ }^{\circ} \mathrm{C}$ cold bath and allowed to warm to room temperature outside the glovebox under a stream of $\mathrm{N}_{2}$ (g) for 15 minutes. The solution was neutralized with $\mathrm{NH}_{4} \mathrm{Cl}$ (saturated, aqueous) until effervescence stopped. The solution was then extracted with $5 \times 20 \mathrm{~mL} \mathrm{NH}{ }_{4} \mathrm{Cl}$ (saturated, aqueous), back-extracted with $2 \times 20 \mathrm{~mL} \mathrm{DCM}$, the combined organic layers were dried with $\mathrm{MgSO}_{4}$, filtered through a $60 \mathrm{~mL}$ coarse porosity fritted funnel, and the solvent removed. The residue was dissolved in $2.5 \mathrm{~mL} \mathrm{DCM}$, then $2.5 \mathrm{~mL}$ EtOAc, and $50 \mathrm{~mL} \mathrm{Et}{ }_{2} \mathrm{O}$ was added to precipitate a brown solid. The solid was collected on a $30 \mathrm{~mL}$ 
medium porosity fritted funnel, washed with $2 \times 15 \mathrm{~mL} \mathrm{Et}{ }_{2} \mathrm{O}$, and discarded. The filtrate solvent was removed in vacuo and the residue dissolved in $1 \mathrm{~mL} \mathrm{DCM}$, then $1 \mathrm{~mL}$ EtOAc, and $50 \mathrm{~mL}$ hexanes was added to precipitate a tan-pink solid. The solution was cooled in an ice bath for $1 \mathrm{~h}$ and the solid collected on a $30 \mathrm{~mL}$ medium porosity fritted funnel, washed with $2 \times 10 \mathrm{~mL}$ hexanes, and placed under vacuum $(0.180 \mathrm{~g}$ of a 1.9:1 mixture of 19:3; $0.118 \mathrm{~g}, 0.172 \mathrm{mmol}$, $28 \%$ yield of desired product). ${ }^{1} \mathrm{H}$ NMR $\left(\mathrm{CDCl}_{3}, \delta\right): 8.90(\mathrm{~d}, J=2.0,1 \mathrm{H}, \mathrm{PzA} 3), 7.97(\mathrm{~d}, J=2.0,1 \mathrm{H}$, PzB3), $7.69(\mathrm{~d}, J=2.0,1 \mathrm{H}, \mathrm{Tp}), 7.65(\mathrm{~d}, J=2.0,1 \mathrm{H}, \mathrm{Tp}), 7.57$ (d, $J=2.0,1 \mathrm{H}, \mathrm{Tp}), 7.17$ (d, J = 2.0, 1H, PzC3), 6.25-6.17 (m, 3H, Tp), 5.52 (t(br), J = 7.3, 1H, H2), 3.66 (dd, $J=12.8,6.5,1 \mathrm{H}, \mathrm{H} 6), 2.94$ (q(br) $, J=7.9,1 \mathrm{H}, \mathrm{H} 5), 2.84\left(\mathrm{dd}, J=12.8,9.7,1 \mathrm{H}, \mathrm{H} 6^{\prime}\right), 2.49\left(\mathrm{ddd}, J=11.4,2.0,{ }^{3} J_{\mathrm{PH}}=13.7,1 \mathrm{H}\right.$, $\mathrm{H} 4), 2.14\left(\mathrm{~s}, 3 \mathrm{H}\right.$, Amide-Me), $1.86\left(\mathrm{~m}, 2 \mathrm{H}\right.$, Ethyl- $\left.\mathrm{CH}_{2}\right), 1.53\left(\mathrm{~m}, 2 \mathrm{H}\right.$, Ethyl- $\left.\mathrm{CH}_{2}\right), 1.15\left(\mathrm{~d},{ }^{2} J_{\mathrm{PH}}=8.1\right.$, $9 \mathrm{H}, \mathrm{PMe}_{3}$ ), $1.04\left(\mathrm{t}, J=7.5,3 \mathrm{H}\right.$, Ethyl- $\left.\mathrm{CH}_{3}\right), 0.96(\mathrm{~d}, J=11.4,1 \mathrm{H}, \mathrm{H} 3), 0.79(\mathrm{t}, J=7.3,3 \mathrm{H}$, Ethyl$\mathrm{CH}_{3}$ ). ${ }^{1} \mathrm{H}$ assignments were made using a combination of $2 \mathrm{D}$ experiments of the mixture (COSY, NOESY, HSQC, HMBC) and difference spectra with authentic 3 and the isolated mixture. IR: $v_{B H}=$ $2488 \mathrm{~cm}^{-1}, v_{\text {amide }}=1620 \mathrm{~cm}^{-1}, v_{\mathrm{NO}}=1550 \mathrm{~cm}^{-1} . \mathrm{CV}(\mathrm{DMA}): E_{\mathrm{p}, \mathrm{a}}=+0.35 \mathrm{~V} . \mathrm{ESI}-\mathrm{MS}:$ obs'd (\%), calc'd (\%), ppm, (M+H) ${ }^{+}: 683.2474$ (85.8), 683.2513 (83.7), 5.8; 684.2519 (95.5), 684.2539 (80.5), 2.8; 685.2538 (100), 685.2537 (100), 0.1; 686.255 (65.3), 686.2578 (44.1), 4.1; 687.2574 (100), 687.257 (83.5), 0.6.

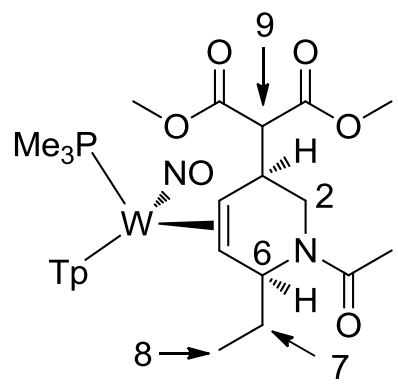

TpW(NO)(PMe 3 )(4,5- $\eta^{2}$-(dimethyl-2-(1-acetyl-6-ethyl-1,2,3,6-tetrahydropyridin-3-

yl)malonate). 20. To separate oven dried test tubes, a solution of $12(0.503 \mathrm{~g}, 0.648 \mathrm{mmol})$ in 
MeCN (4.22 g) and a solution of LiDMM (0.183 g, $1.326 \mathrm{mmol})$ in MeCN (4.21 g) and the tubes were placed in a $0{ }^{\circ} \mathrm{C}$ cold bath. After $0.5 \mathrm{~h}$, the 12 solution was quickly added to the LiDMM solution and the mixture was allowed to stir for $2 \mathrm{~h}$. The reaction solution was removed from the cold bath, diluted with $10 \mathrm{~mL} \mathrm{DCM}$, extracted with $3 \times 10 \mathrm{~mL} \mathrm{NaHCO}$ (saturated, aqueous), back-extracted with $2 \times 10 \mathrm{~mL} \mathrm{DCM}$, the combined organic layers were dried with $\mathrm{Na}_{2} \mathrm{SO}_{4}$, filtered through a $60 \mathrm{~mL}$ coarse porosity fritted funnel, and the solvent removed. The residue was dissolved in $2.5 \mathrm{~mL} \mathrm{DCM}$, then $2.5 \mathrm{~mL}$ EtOAc followed by the addition of $\mathrm{Et}_{2} \mathrm{O}(50 \mathrm{~mL})$ to precipitate a brown solid that was discarded. The yellow filtrate solvent was removed and the residue was dissolved in $1 \mathrm{~mL} D C M$, then $1 \mathrm{~mL}$ EtOAc and hexanes (35 mL) was added to precipitate a tan solid. The solution was cooled to $0{ }^{\circ} \mathrm{C}$ for 30 minutes, and the precipitate collected on a $15 \mathrm{~mL}$ medium porosity fritted funnel, and was washed with $2 \times 5 \mathrm{~mL}$ hexanes, and placed under vacuum $\left(0.211 \mathrm{~g}, 0.268 \mathrm{mmol}, 41 \%\right.$ yield). ${ }^{1} \mathrm{H} \mathrm{NMR}\left(\mathrm{CDCl}_{3}, \delta\right): 8.53(\mathrm{~d}, J=2.0,1 \mathrm{H}$, PzA3), 8.01 (d, $J=2.0,1 \mathrm{H}, \mathrm{PzB} 3$ ), 7.71/7.58 (d, $J=2.0,2 \mathrm{H}, \mathrm{PzA} 5 / \mathrm{PzC} 5), 7.67$ (d, $J=2.0,1 \mathrm{H}, \mathrm{PzB} 5)$, $7.14(\mathrm{~d}, J=2.0,1 \mathrm{H}, \mathrm{PzC} 3), 6.24(\mathrm{t}, J=2.0,1 \mathrm{H}, \mathrm{PzB} 4), 6.20(\mathrm{t}, J=2.0,2 \mathrm{H}, \mathrm{PzA} 4 / \mathrm{PzC} 4), 5.32(\mathrm{t}(\mathrm{br}), J$ $=6.8,1 \mathrm{H}, \mathrm{H} 6), 4.10(\mathrm{~d}, J=8.0,1 \mathrm{H}, \mathrm{H9}), 3.85(\mathrm{~s}, 3 \mathrm{H}$, Ester-Me), 3.81 (s, 3H, Ester-Me'), 3.72 (dd, $J$ $=12.9,5.8,1 \mathrm{H}, \mathrm{H} 2), 3.62(\mathrm{q}(\mathrm{br}), J=6.4,1 \mathrm{H}, \mathrm{H} 3), 3.36\left(\mathrm{dd}, J=12.9,5.5,1 \mathrm{H}, \mathrm{H} 2^{\prime}\right), 2.34$ (ddd, $J=$ $\left.11.7,2.2,{ }^{3} J_{P H}=11.7,1 \mathrm{H}, \mathrm{H} 4\right), 2.08\left(\mathrm{~s}, 3 \mathrm{H}\right.$, Acyl-Me), $2.02(\mathrm{~m}, 1 \mathrm{H}, \mathrm{H} 7), 1.6\left(\mathrm{~m}, 1 \mathrm{H}, \mathrm{H} 7^{\prime}\right), 1.22(\mathrm{~d}, J=$ 8.0, 9H, $\left.\mathrm{PMe}_{3}\right), 1.16(\mathrm{~d}(\mathrm{br}), J=11.7,1 \mathrm{H}, \mathrm{H} 5), 0.82\left(\mathrm{t}, J=7.5,3 \mathrm{H}\right.$, Methyl). ${ }^{13} \mathrm{C} \mathrm{NMR}\left(\mathrm{CDCl}_{3}, \delta\right)$ : 171.5 (Amide-CO), 169.7 (Ester-CO/Ester-CO'), 144.2 (PzA3), 143.4 (PzB3), 140.1 (PzC3), 136.7/136.0/135.9 (PzA5/PzB5/PzC5), 106.3/106.1/105.9 (PzA4/PzB4/PzC4), 59.4 (C9), 55.4 (C5), 52.7 (Ester-Me), 52.6 (Ester-Me'), 51.9 (C6), 47.5 (d, J = 11.1, C4), 43.5 (C2), 38.1 (C3), 34.2 (C7), 23.3 (Amide-Me), 14.1 (d, $\left.J=27.5, \mathrm{PMe}_{3}\right), 11.9(\mathrm{C} 8) .{ }^{31} \mathrm{P} \mathrm{NMR}\left(\mathrm{CDCl}_{3}, \delta\right):-12.04\left(J_{\mathrm{WP}}=279\right) . \mathrm{IR}: v_{\mathrm{BH}}$ $=2480 \mathrm{~cm}^{-1}, v_{\text {ester }}=1732 \mathrm{~cm}^{-1}, v_{\text {amide }}=1624 \mathrm{~cm}^{-1}, v_{\mathrm{NO}}=1554 \mathrm{~cm}^{-1} . \mathrm{CV}(\mathrm{DMA}): E_{\mathrm{p}, \mathrm{a}}=+0.41 \mathrm{~V} . \mathrm{ESI}-$ MS: obs'd (\%), calc'd (\%), ppm, (M+Na) ${ }^{+}: 807.2262$ (75.6), 807.2286 (81.4), 3.1; 808.2306 (82), 
808.2312 (80.7), 0.7; 809.2283 (100), 809.2311 (100), 3.4; 810.2332 (47), 810.235 (46.6), 2.3; 811.2333 (85), 811.2343 (83), 1.2. Anal. Calc'd for $\mathrm{C}_{26} \mathrm{H}_{40} \mathrm{BN}_{8} \mathrm{O}_{6} \mathrm{PW}$ : C, 39.72; $\mathrm{H}, 5.13 ; \mathrm{B}, 1.37 ; \mathrm{N}$, 14.25; Found: C, 39.38; H, 5.23; N, 14.28.

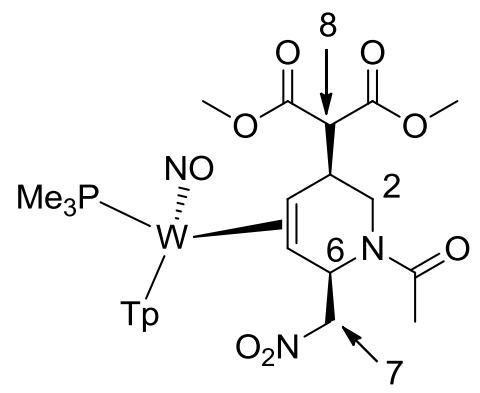

\section{TpW(NO)(PMe 3 )(3,4- $\eta^{2}$-(dimethyl-2-(1-acetyl-6-(nitromethyl)-1,2,3,6-tetrahydropyridin-3-}

yl)malonate). 21. General procedure 1 was used to generate the tetrahydropyridine complex precursor. Test tube 1: 10 (0.104 g, $0.152 \mathrm{mmol}) ; \mathrm{HOTf}(0.024 \mathrm{~g}, 0.159 \mathrm{mmol}) ; \mathrm{MeCN}(1.17 \mathrm{~g})$. Test tube 2: $\operatorname{LiDMM}(0.061 \mathrm{~g}, 0.442 \mathrm{mmol}) ; \operatorname{MeCN}(0.73 \mathrm{~g})$. Oxidation with $\mathrm{O}_{2(\mathrm{~g})}$ failed to liberate the organic compound following general procedure $2 . \mathrm{SiO}_{2}(10.1 \mathrm{~g})$; reaction time: $16 \mathrm{~h}$. The complex was isolated in a manner analogous to general procedure 5. Yellow-tan solid located between $r_{f}=0.18$ and $r_{f}=0.38$ when $5 \%$ hexanes in EtOAc was used as the eluent $(0.073 \mathrm{~g}$, $0.089 \mathrm{mmol}, 59 \%$ yield). ${ }^{1} \mathrm{H} \mathrm{NMR}\left(\mathrm{CDCl}_{3}, \delta\right): 8.32$ (d, $\left.J=2.0,1 \mathrm{H}, \mathrm{PzA} 3\right), 8.01$ (d, $J=2.0,1 \mathrm{H}, \mathrm{PzB} 3$ ), $7.71(\mathrm{~d}, J=2.0,1 \mathrm{H}, \mathrm{PzC} 5), 7.69(\mathrm{~d}, J=2.0,1 \mathrm{H}, \mathrm{PzB} 5), 7.58(\mathrm{~d}, J=2.0,1 \mathrm{H}, \mathrm{PzA} 5), 7.12(\mathrm{~d}, J=2.0$, $1 \mathrm{H}, \mathrm{PzC} 3), 6.27(\mathrm{t}, J=2.0,1 \mathrm{H}, \mathrm{PzB} 4), 6.24(\mathrm{t}, J=2.0,1 \mathrm{H}, \mathrm{PzA} 4), 6.20(\mathrm{t}, J=2.0,1 \mathrm{H}, \mathrm{PzC} 4), 6.15$ $(\mathrm{t}(\mathrm{br}), J=6.9,1 \mathrm{H}, \mathrm{H} 6), 5.05(\mathrm{dd}, J=11.0,6.0,1 \mathrm{H}, \mathrm{H7}), 4.61\left(\mathrm{dd}, J=11.0,8.0,1 \mathrm{H}, \mathrm{H} 7^{\prime}\right), 3.88(\mathrm{~d}, J=$ 8.7, $1 \mathrm{H}, \mathrm{H} 8$ ), 3.85 (dd, $J=13.0,5.7,1 \mathrm{H}, \mathrm{H} 2$ ), 3.84 (s, 3H, Ester-Me), 3.83 (s, 3H, Ester-Me'), 3.64 (s(br), $1 \mathrm{H}, \mathrm{H} 3), 3.35\left(\mathrm{dd}, J=13.0,3.7,1 \mathrm{H}, \mathrm{H} 2^{\prime}\right), 2.22\left(\mathrm{ddd}, J=11.3,1.8,{ }^{3} \mathrm{JPH}_{\mathrm{PH}}=11.3,1 \mathrm{H}, \mathrm{H} 4\right), 2.07$ (s, 3H, Amide-Me), 1.20 (d, $\left.J=8.1,9 \mathrm{H}, \mathrm{PMe}_{3}\right), 1.07$ (d, $\left.J=11.3,1 \mathrm{H}, \mathrm{H} 5\right) .{ }^{13} \mathrm{C} \mathrm{NMR}\left(\mathrm{CDCl}_{3}, \delta\right)$ : 172.6 (Amide-CO), 169.5 (Ester-CO), 169.4 (Ester-CO'), 143.6 (PzA3), 143.3 (PzB3), 140.1 (PzC3), 137.0 (PzC5), 136.3/136.2 (PzA5/PzB5), 106.6 (PzB4), 106.4 (PzA4), 106.2 (PzC4), 83.2 (C7), 60.0 
(C8), 52.9 (Ester-Me), 52.7 (Ester-Me'), 50.4 (C6), 49.8 (C5), 48.0 (d, ${ }^{2} J_{\mathrm{PC}}=12.2, \mathrm{C} 4$ ), 44.6 (C2), 37.9 (C3), 23.2 (Amide-Me), $13.8\left(\mathrm{~d},{ }^{1} \mathrm{~J}_{\mathrm{PC}}=28.0, \mathrm{PMe}_{3}\right) .{ }^{31} \mathrm{P} \mathrm{NMR}\left(\mathrm{CDCl}_{3}, \delta\right):-11.86\left(J_{\mathrm{WP}}=278\right) . \mathrm{IR}$ : $v_{\mathrm{BH}}=2488 \mathrm{~cm}^{-1}, v_{\text {ester }}=1732 \mathrm{~cm}^{-1}, v_{\text {amide }}=1643 \mathrm{~cm}^{-1}, v_{\mathrm{NO}}=1547 \mathrm{~cm}^{-1} . \mathrm{CV}(\mathrm{MeCN}): E_{\mathrm{p}, \mathrm{a}}=+0.66 \mathrm{~V}$. ESI-MS: obs'd (\%), calc'd (\%), ppm, $(\mathrm{M}+\mathrm{Na})^{+}: 838.1979$ (89.2), 838.198 (81.5), 0.2; 839.1999 (84.3), 839.2006 (80.4), 0.8; 840.1996 (100), 840.2005 (100), 1.0; 841.2036 (44.1), 841.2044 (46.4), 1.0; 842.2028 (76.5), 842.2037 (83.3), 1.1.

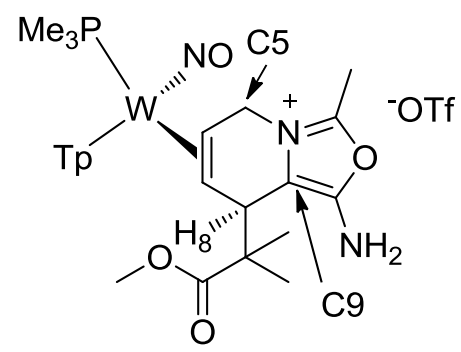

[TpW(NO)(PMe $)\left(6.7-\eta^{2}\right.$-(1-amino-8-(1-methoxy-2-methyl-1-oxopropan-2-yl)-3-methyl-5,8dihydrooxazolo[3,4-a]pyridin-4-ium)][OTf]. 22. A solution of MMTP $(0.504 \mathrm{~g}, 2.89 \mathrm{mmol})$ in MeCN (0.502 g) was quickly added to a vial containing a deep red solution of 13 (1.247 g including $\mathrm{Et}_{2} \mathrm{O}$ impurity; estimated $1.0 \mathrm{~g}$ with correction for $\left.\mathrm{Et}_{2} \mathrm{O}, 1.3 \mathrm{mmol}\right)$ in $\mathrm{MeCN}(4.52 \mathrm{~g})$ to give a dark-brown solution. After 10 minutes, the solution was removed from the glovebox, diluted with $20 \mathrm{~mL} \mathrm{DCM}$, extracted with $3 \times 10 \mathrm{~mL}$ of $\mathrm{NaHCO}_{3}$ (saturated, aqueous), backextracted with $3 \times 20 \mathrm{~mL} \mathrm{DCM}$, the combined organic layers were dried with $\mathrm{MgSO}_{4}$, filtered through a $60 \mathrm{~mL}$ coarse fritted funnel, and the solvent removed. The residue was dissolved in 5 $\mathrm{mL} \mathrm{DCM}$, then diluted with $5 \mathrm{~mL}$ EtOAc, followed by the addition of $100 \mathrm{~mL}$ hexanes to precipitate an off-white solid that was collected on a $30 \mathrm{~mL}$ medium porosity fritted funnel. The remaining material on the precipitation glassware was redissolved in $2.5 \mathrm{~mL} \mathrm{DCM}$, diluted with $2.5 \mathrm{~mL}$ EtOAc, and precipitated with $50 \mathrm{~mL}$ hexanes and was collected on the same funnel. The combined precipitate was washed with $2 \times 15 \mathrm{~mL}$ hexanes and placed under vacuum $(0.860 \mathrm{~g}$, $1.142 \mathrm{mmol}, 88 \%$ yield). ${ }^{1} \mathrm{H}$ NMR $\left(\mathrm{CD}_{3} \mathrm{CN}, \delta\right): 7.94(\mathrm{~d}, J=2.0,1 \mathrm{H}, \mathrm{PzB} 3), 7.87(\mathrm{~m}, 4 \mathrm{H}, \mathrm{Tp}), 7.43$ (d, 
$J=2.0,1 \mathrm{H}, \mathrm{PzC} 3), 6.38(\mathrm{~m}, 3 \mathrm{H}, \mathrm{Tp}), 5.73(\mathrm{dd}, J=14.5,3.7,1 \mathrm{H}, \mathrm{H} 5), 4.92(\mathrm{~d}+\mathrm{s}, J=14.5,3 \mathrm{H}$, $\left.\mathrm{H}^{\prime} / \mathrm{NH} 2\right), 4.27(\mathrm{~s}, 1 \mathrm{H}, \mathrm{H} 8), 3.33\left(\mathrm{~s}, 3 \mathrm{H}\right.$, Ester-Me), $2.90\left(\mathrm{ddd}, J=11.3,3.7,{ }^{3} J_{\mathrm{PH}}=11.3,1 \mathrm{H}, \mathrm{H} 6\right)$, $2.63\left(\mathrm{~s}, 3 \mathrm{H}\right.$, Amide-Me), 1.34 (s, 3H, Gem-Me), 1.26 (s, 3H, Gem-Me), $1.16\left(\mathrm{~d},{ }^{2} J_{\mathrm{PH}}=8.4,9 \mathrm{H}\right.$, $\left.\mathrm{PMe}_{3}\right), 0.94(\mathrm{~d}, J=11.3,1 \mathrm{H}, \mathrm{H} 7) .{ }^{13} \mathrm{C}$ NMR $\left(\mathrm{CD}_{3} \mathrm{CN}, \delta\right): 178.2$ (Ester-CO), $155.2(\mathrm{C} 3), 152.3(\mathrm{C} 1)$, 144 (РzB3), 143.6 (PzA3), 141.6 (PzC3), 138.2/137.9 (PzA5/PzB5/PzC5), 107.8/107.7/107.1 (PzA4/PzB4/PzC4), 107.0 (C9), 53.3 (C10), 52.3 (Ester-Me), 50.7 (d, J = 2.5, C5), 48.4 (d, J = 1.5, C7), $44.1\left(\mathrm{~d},{ }^{2} J_{\mathrm{PC}}=12.1, \mathrm{C} 6\right), 42.6(\mathrm{C} 8), 24.4$ (Gem-Me), $21.5(\mathrm{Gem}-\mathrm{Me}), 12.8\left(\mathrm{~d},{ }^{1} \mathrm{JPC}_{\mathrm{PC}}=29.3\right.$, $\left.\mathrm{PMe}_{3}\right), 12.5$ (Amide-Me). ${ }^{31} \mathrm{P} \mathrm{NMR}\left(\mathrm{CDCl}_{3}, \delta\right):-12.57\left(J_{\mathrm{WP}}=268\right) . \mathrm{IR}: v_{\mathrm{BH}}=2495 \mathrm{~cm}^{-1}, v_{\text {ester }}=1724$ $\mathrm{cm}^{-1}, v=1689 \mathrm{~cm}^{-1}, v=1616 \mathrm{~cm}^{-1}, v_{\mathrm{NO}}=1547 \mathrm{~cm}^{-1} . \mathrm{CV}$ (DMA): $E_{\mathrm{p}, \mathrm{a}}=+0.80$ V. ESI-MS: obs'd (\%), calc'd (\%), ppm, (M-H)+: 752.2367 (93.5), 752.2364 (84.8), 0.3; 753.2390 (93.8), 753.2390 (79.7), 0.0; 754.2391 (100), 754.2389 (100), 0.3; 755.2415 (56.4), 755.2428 (42.4), 1.8; 756.2401 (81.5), 756.2421 (84.3), 2.7. Anal. Calc'd for $\mathrm{C}_{26} \mathrm{H}_{45} \mathrm{BF}_{3} \mathrm{~N}_{9} \mathrm{O}_{7} \mathrm{PSW} \cdot \mathrm{H}_{2} \mathrm{O}: \mathrm{C}, 33.89 ; \mathrm{H}, 4.38 ; \mathrm{N}, 13.68$; Found: C, 33.90; H, 4.30; N, 13.73 .

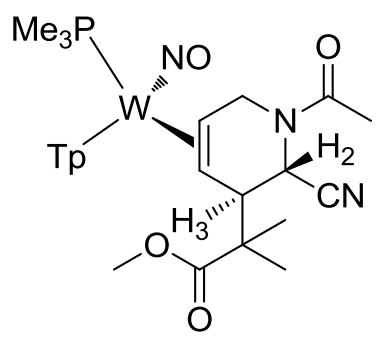

[TpW(NO)(PMe $)\left(4,5-\eta^{2}\right.$-(1-acetyl-2-cyanopiperidin-4-ylium)][OTf]. 23. A solution of DABCO $(0.061 \mathrm{~g}, 0.544 \mathrm{mmol})$ in $\mathrm{MeCN}(1.01 \mathrm{~g})$ was added to a homogeneous tan solution of 22 (0.100 $\mathrm{g}, 0.111 \mathrm{mmol})$ in $\mathrm{MeCN}(1.91 \mathrm{~g})$ and the solution allowed to stir in a $58{ }^{\circ} \mathrm{C}$ oil bath. After $7.5 \mathrm{~h}$, the reaction solution was removed from the oil bath and glovebox, diluted with $30 \mathrm{~mL} D C M$, extracted with $3 \times 15 \mathrm{~mL} \mathrm{NaHCO}$ (saturated, aqueous), back extracted with $2 \times 15 \mathrm{~mL} \mathrm{DCM}$, the combined organic layers were dried with $\mathrm{MgSO}_{4}$, filtered through a $60 \mathrm{~mL}$ coarse porosity fritted funnel, and the solvent was removed in vacuo. The residue was dissolved in $1 \mathrm{~mL} \mathrm{DCM}$, then 1 
$\mathrm{mL}$ EtOAc, and the solution was diluted with $50 \mathrm{~mL}$ hexanes to precipitate a tan solid. The solution was cooled to $0{ }^{\circ} \mathrm{C}$ for $1.5 \mathrm{~h}$, then the solid was collected with a $15 \mathrm{~mL}$ fine porosity fritted funnel, rinsed with $30 \mathrm{~mL}$ hexanes, then placed under vacuum $(0.068 \mathrm{~g}, 0.090 \mathrm{mmol}, 82 \%$ yield). ${ }^{1} \mathrm{H}$ NMR $\left(\mathrm{CDCl}_{3}, \delta\right): 8.14(\mathrm{~m}, 2 \mathrm{H}, \mathrm{PzA} 3 / \mathrm{PzB} 3), 7.74$ (d, $J=2.0,1 \mathrm{H}, \mathrm{PzC}$ ), 7.72/7.66 (d, $J=$ 2.0, 2H, PzB5/PzC5), 7.13 (d, $J=2.0,1 \mathrm{H}, \mathrm{PzC} 3), 6.31 / 6.29(\mathrm{t}, J=2.0,2 \mathrm{H}, \mathrm{PzA} 4 / \mathrm{PzB} 4), 6.26(\mathrm{t}, J=$ 2.0, 1H, PzC4), $5.82(\mathrm{~s}(\mathrm{br}), 1 \mathrm{H}, \mathrm{H} 2), 4.31$ (dd, $J=14.2,8.2,1 \mathrm{H}, \mathrm{H} 6), 4.25(\mathrm{dd}, J=14.2,7.5,1 \mathrm{H}$, $\left.\mathrm{H} 6^{\prime}\right), 3.56(\mathrm{~s}(\mathrm{br}), 1 \mathrm{H}, \mathrm{H} 3), 3.11$ (m, 4H, H5/Ester-Me), 2.21 (s, 3H, Amide-Me), $1.31\left(\mathrm{~d},{ }^{2} J_{\mathrm{PH}}=8.1\right.$, 9H, $\mathrm{PMe}_{3}$ ), 1.19 (s, 3H, Gem-Me), 0.88 (s, 3H, Gem-Me'), 0.45 (d, J = 11.5, 1H, H4). ${ }^{13} \mathrm{C}$ NMR $\left(\mathrm{CDCl}_{3}, \delta\right): 177.4$ (Ester-CO), 168.1 (Amide-CO), 143.9/143.4 (PzA3/PzB3), 139.7 (PzC3), 136.2 (PzA5/PzB5/PzC5), 118.9 (CN), 106.6/106.5/106.4 (PzA4/PzB4/PzC4), 51.4 (Ester-Me), 51.2 (C7), 49.2 (C4), 47.6 (C6), 46.7 (C3), 46.4 (C5), 29.4 (C2), 22.3 (Gem-Me), 21.8 (Amide-Me), 20.9 (Gem$\left.M e^{\prime}\right), 14.1\left(\mathrm{~d},{ }^{1} J_{\mathrm{PC}}=27.9, \mathrm{PMe}_{3}\right) \cdot{ }^{31} \mathrm{P}\left(\mathrm{CDCl}_{3}, \delta\right):-12.51\left(J_{\mathrm{WP}}=268 \mathrm{~Hz}\right),-12.34$ (Amide confomer; 4.9:1, respectively). IR: $v_{\mathrm{BH}}=2488 \mathrm{~cm}^{-1}, v_{\text {nitrile }}=2233 \mathrm{~cm}^{-1}$ (weak) $, v_{\text {ester }}=1724 \mathrm{~cm}^{-1}, v_{\text {amide }}=1643 \mathrm{~cm}^{-}$ ${ }^{1}, v_{\mathrm{NO}}=1562 \mathrm{~cm}^{-1} . \mathrm{CV}(\mathrm{MeCN}): E_{\mathrm{p}, \mathrm{a}}=+0.60 \mathrm{~V} . \mathrm{ESI}-\mathrm{MS}$ : obs'd (\%), calc'd (\%), ppm, (M+Na)+: 774.2184 (61), 774.2184 (82.1), 0.0; 775.2208 (61.2), 775.2209 (80.8), 0.1; 776.2209 (100), 776.2208 (100), 0.0; 777.2246 (47.7), 777.2248 (45.9), 0.3; 778.223 (65.1), 778.2241 (83), 1.3. Anal. Calc'd for $\mathrm{C}_{25} \mathrm{H}_{37} \mathrm{BN}_{9} \mathrm{O}_{4} \mathrm{PW} \cdot \mathrm{H}_{2} \mathrm{O}$ : C, 39.39; $\mathrm{H}, 5.02 ; \mathrm{N}, 16.54$; Found: $\mathrm{C}, 39.36 ; \mathrm{H}, 4.77 ; \mathrm{N}$, 16.19.

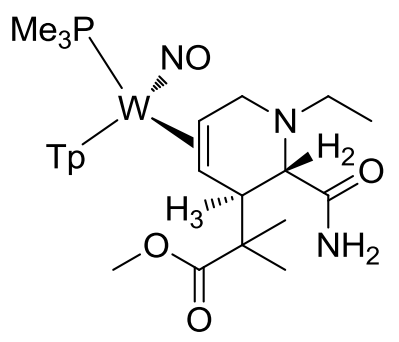

$\operatorname{TpW}(\mathrm{NO})\left(\mathrm{PMe}_{3}\right)\left(4.5-\eta^{2}\right.$-(methyl 2-carbamoyl-1-ethyl-1,2,3,6-tetrahydropyridin-3-yl)-2methylpropanoate). 24. $\mathrm{NaBH}_{4}(0.102 \mathrm{~g}, 2.70 \mathrm{mmol})$ was directly added to a flame dried $40 \mathrm{~mL}$ 
beaker containing a stirring tan homogeneous solution of $22(0.101 \mathrm{~g}, 0.112 \mathrm{mmol})$ in $\mathrm{MeOH}$ (4.70 g) to effervesce vigorously. After 10 minutes, once effervescence had settled, the sample was removed from the glovebox, diluted with $50 \mathrm{~mL} \mathrm{DCM}$, extracted with $3 \times 20 \mathrm{~mL} \mathrm{NaHCO}_{3}$ (saturated, aqueous), back-extracted with $2 \times 20 \mathrm{~mL} \mathrm{DCM}$, the combined organic layers were dried with MgSO4, filtered through a $60 \mathrm{~mL}$ coarse porosity fritted funnel, and the solvent removed in vacuo. The residue was dissolved in $1 \mathrm{~mL} \mathrm{DCM}$, then $1 \mathrm{~mL}$ EtOAc, and $50 \mathrm{~mL}$ hexanes added to precipitate a fine tan solid. The solution was cooled to $0{ }^{\circ} \mathrm{C}$ for $\sim 20$ minutes and the precipitate collected on a $15 \mathrm{~mL}$ medium porosity fritted funnel, rinsed with 20 $\mathrm{mL}$ hexanes, and placed under vacuum $(0.071 \mathrm{~g}, 0.094 \mathrm{mmol}, 84 \%$ yield $) .{ }^{1} \mathrm{H} N M R\left(\mathrm{CDCl}_{3}, \delta\right): 8.98(\mathrm{~s}, 1 \mathrm{H}, \mathrm{NH})$, $8.19(\mathrm{~d}, J=2.0,1 \mathrm{H}, \mathrm{PzA} 3), 8.06(\mathrm{~d}, J=2.0,1 \mathrm{H}, \mathrm{PzB} 3), 7.70(\mathrm{~d}, J=2.0,1 \mathrm{H}, \mathrm{PzB} 5), 7.67(\mathrm{~d}, J=2.0$, 1H, PzC5), 7.61 (d, J = 2.0, 1H, PzA5), 7.20 (d, J = 2.0, 1H, PzC3), 6.29 (t, J = 2.0, 1H, PzB4), 6.25 (t, $J=2.0,1 \mathrm{H}, \mathrm{PzA} 4), 6.20(\mathrm{t}, J=2.0,1 \mathrm{H}, \mathrm{PzC} 4), 5.10(\mathrm{~s}, 1 \mathrm{H}, \mathrm{NH}), 4.03(\mathrm{dd}, J=11.6,2.5,1 \mathrm{H}, \mathrm{H} 6), 3.64$ $\left(\mathrm{d}, J=11.6,1 \mathrm{H}, \mathrm{H} 6^{\prime}\right), 3.43(\mathrm{~d}, J=2.5,1 \mathrm{H}, \mathrm{H} 3), 2.95\left(\mathrm{ddd}, J=11.8,2.5,{ }^{3} J_{\mathrm{PH}}=11.8,1 \mathrm{H}, \mathrm{H} 5\right), 2.86(\mathrm{~s}$, 3H, Ester-Me), $2.80(\mathrm{~d}, J=4.9,1 \mathrm{H}, \mathrm{H} 2), 2.59(\mathrm{~m}, 1 \mathrm{H}, \mathrm{H} 7), 2.18\left(\mathrm{~m}, 1 \mathrm{H}, \mathrm{H} 7^{\prime}\right), 1.30$ (s, 3H, Gem-Me), $1.23\left(\mathrm{~d},{ }^{2} J_{\mathrm{PH}}=8.0,9 \mathrm{H}, \mathrm{PMe}_{3}\right), 1.20\left(\mathrm{~s}, 3 \mathrm{H}, \mathrm{Gem}-\mathrm{Me}^{\prime}\right), 1.13\left(\mathrm{t}, J=7.1,3 \mathrm{H}\right.$, Ethyl- $\left.\mathrm{CH}_{3}\right), 0.43(\mathrm{~d}, J=$

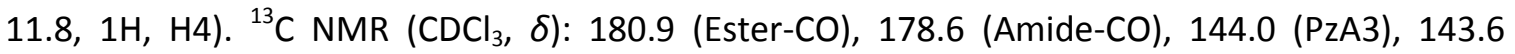
(PzB3), 139.6 (PzC3), 136.3 (PzC5), 135.9 (PzB5), 135.4 (PzA5), 106.6 (PzB4), 106.4 (PzC4), 106.2 (PzA4), 65.6 (C2), 52.5 (C9), $52.2\left(\mathrm{~d},{ }^{2} \mathrm{~J}_{\mathrm{PH}}=11.8, \mathrm{C} 5\right), 51.2$ (C4), 51.1 (C6/C7), 50.8 (Ester-Me), 45.1 (C3), 24.7 (Gem-Me), 20.4 (Gem-Me'), $13.3\left(\mathrm{~d},{ }^{1} \mathrm{~J}_{\mathrm{PC}}=27.1, \mathrm{PMe}_{3}\right), 12.8\left(\right.$ Ethyl- $\left.\mathrm{CH}_{3}\right) .{ }^{31} \mathrm{P}\left(\mathrm{CDCl}_{3}, \delta\right)$ : $-10.26\left(J_{\mathrm{WP}}=278 \mathrm{~Hz}\right) . \mathrm{IR}: v_{\mathrm{BH}}=2484 \mathrm{~cm}^{-1}, v_{\mathrm{ester}}=1724 \mathrm{~cm}^{-1}, v_{\text {amide }}=1682 \mathrm{~cm}^{-1}, v_{\mathrm{NO}}=1539 \mathrm{~cm}^{-1} . \mathrm{CV}$ (MeCN): $E_{p, a}=+0.41$. ESI-MS: obs'd $(\%)$, calc'd (\%), ppm, $(M+H)^{+}: 756.2666(80.9), 756.2677$ (82.1), 1.4; 757.2695 (71.7), 757.2703 (80.8), 1.0; 758.2694 (100), 758.2702 (100), 1.1; 759.2729 (39.7), 759.2741 (46), 1.6; 760.2726 (72.2), 760.2734 (83), 1.1. 


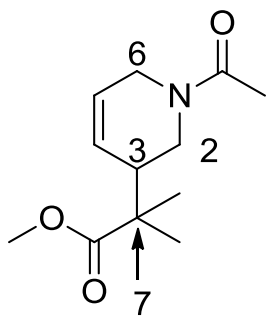

Methyl 2-(1-acetyl-1,2,3,6-tetrahydropyridin-3-yl)-2-methylpropanoate. 25. $\mathrm{O}_{2}$ (g) oxidation of $17(0.095 \mathrm{~g}, 0.130 \mathrm{mmol})$ was performed in a manner analogous to general procedure $2 . \mathrm{SiO}_{2}$ (10.5 g); reaction time: $16 \mathrm{~h}$. The piperidine was isolated following general procedure 5. Pale

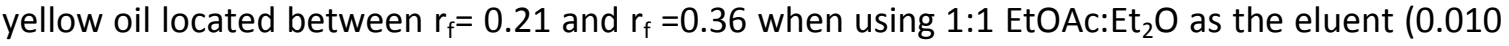
g, $0.0448 \mathrm{mmol}, 34 \%$ yield). ${ }^{1} \mathrm{H}$ NMR $\left(\mathrm{CDCl}_{3}, \delta\right)$ : Major: 5.83 (ddd, $\left.J=10.4,5.3,2.6,1 \mathrm{H}, \mathrm{H} 5\right), 5.71$ (ddd, $J=10.4,4.8,2.7,1 \mathrm{H}, \mathrm{H} 4), 4.31$ (ddd, $J=18.9,5.3,3.0,1 \mathrm{H}, \mathrm{H} 6), 3.71$ (s, 3H, Ester-Me), 3.68 (buried, 1H, H6'), 3.59 (dd, J = 13.3, 4.8, 1H, H2), 3.20 (dd, J=13.3, 8.5, 1H, H2'), $2.62(\mathrm{~m}, 1 \mathrm{H}$, H3), 2.11 (s, 3H, Amide-Me), 1.22 (s, 3H, Gem-Me), 1.16 (s, 3H, Gem-Me'), Minor: 5.75 (m, 2H, H4/H5), 4.05 (dd, $J=13.0,5.4,1 \mathrm{H}, \mathrm{H} 2$ ), $3.93(\mathrm{dd}, J=18.2,3.5,1 \mathrm{H}, \mathrm{H} 6), 3.85$ (dd, $J=18.2,2.5,1 \mathrm{H}$, H6'), 3.69 (s, 3H, Ester-Me), $3.18(\mathrm{dd}, \mathrm{J}=13.0,8.7,1 \mathrm{H}, \mathrm{H} 2$ '), $2.62(\mathrm{~m}, 1 \mathrm{H}, \mathrm{H} 3), 2.08(\mathrm{~s}, 1 \mathrm{H}$, AmideMe). ${ }^{13} \mathrm{C} \mathrm{NMR}\left(\mathrm{CDCl}_{3}, \delta\right)$ : Major: 177.3 (Ester-CO), 169.7 (Amide-CO), 126.7 (C5), 125.4 (C4), 52.2 (Ester-Me), 45.1 (C2), 44.6 (C7), 42.8 (C3), 42.2 (C6), 23.4 (Gem-Me), 21.5 (Amide-Me), 21.4 (Gem-Me'), Minor: 177.3 (Ester-CO), 169.6 (Amide-CO), 127.8/124.7 (C4/C5), 52.0 (Ester-Me), 45.6 (C6), 44.8 (C7), 41.8 (C3), 39.4 (C2), 23.0 (Gem-Me), 22.1 (Gem-Me'), 21.6 (Amide-Me). Isomer Ratio: 1.1:1 (Chemical Exchange Observed). IR: $v_{\text {ester }}=1727 \mathrm{~cm}^{-1}, v_{\text {amide }}=1640 \mathrm{~cm}^{-1}$. ESIMS: obs'd (\%), calc'd (\%), ppm, (M+Na)+: 248.1257 (100), 248.1253 (100), 1.7.

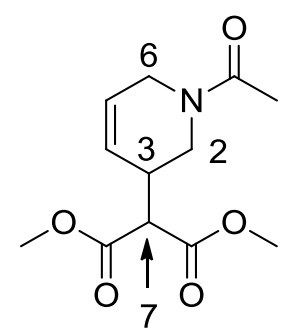


Dimethyl 2-(1-acetyl-1,2,3,6-tetrahydropyridin-3-yl)malonate. 26. Method 1: $\mathrm{O}_{2(\mathrm{~g})}$ oxidation of $16(0.100 \mathrm{~g}, 0.132 \mathrm{mmol})$ was performed in a manner analogous to general procedure $2 . \mathrm{SiO}_{2}$ (10.0 g); reaction time: $18 \mathrm{~h}$. The piperidine was isolated following general procedure 5 . Pale yellow oil located between $r_{f}=0.18$ and $r_{f}=0.31$ when using 1:1 EtOAc:Et ${ }_{2} \mathrm{O}$ as an eluent $(0.009$ g, $0.0353 \mathrm{mmol}, 27 \%$ yield). One pot method: A solution of HOTf $(0.025 \mathrm{~g}, 0.167 \mathrm{mmol})$ in DCM $(2.08 \mathrm{~g})$ was added to an oven dried test tube containing $2(0.085 \mathrm{~g}, 0.136 \mathrm{mmol})$ and was placed into a $0{ }^{\circ} \mathrm{C}$ cold bath next to a separate oven dried test tube containing a solution of LiDMM (0.056 g, $0.406 \mathrm{mmol})$ and DCM (1.75 g). The solutions were allowed to cool for 10 minutes. The LiDMM solution was then quickly added to the tungsten allyl solution and allowed to stir at $0{ }^{\circ} \mathrm{C}$ for 30 minutes. The solution was then removed from the cold bath and taken outside of the glovebox to stir at room temperature. After 15 minutes, the solution was diluted with $20 \mathrm{~mL} \mathrm{DCM}$, extracted with $3 \times 10 \mathrm{~mL} \mathrm{NaHCO}$ (saturated, aqueous), back-extracted with $2 \times 10 \mathrm{~mL} \mathrm{DCM}$, the combined organic layers were dried with $\mathrm{MgSO}_{4}$, filtered through a $60 \mathrm{~mL}$ coarse porosity fritted funnel, and the solvent removed to leave a yellow-brown residue. Crude 16 was oxidized with $\mathrm{O}_{2(\mathrm{~g})}$ in a similar manner to that of general procedure 2. $\mathrm{SiO}_{2}(10.0 \mathrm{~g})$; reaction time: $20 \mathrm{~h}$. General procedure 5 was followed to isolate the product. Pale yellow oil located between $r_{f}=0.17$ and $r_{f}=0.32$ when $1: 1$ EtOAc:Et ${ }_{2} \mathrm{O}$ was used as the eluent $(0.013 \mathrm{~g}$, $0.0517 \mathrm{mmol}, 38 \%$ yield). ${ }^{1} \mathrm{H}$ NMR $\left(\mathrm{CDCl}_{3}, \delta\right)$ : Major: $5.69-5.86(\mathrm{~m}, 2 \mathrm{H}, \mathrm{H} 4 / \mathrm{H} 5), 4.09$ (ddd, $J=$ 19.3, 2.5, 2.4, 1H, H6), 3.97 (ddd, $J=19.3,2.6,2.4,1 \mathrm{H}, \mathrm{H} 6$ ), 3.76 (s(shoulder), 3H, Ester$\operatorname{Me}($ maj, $\min )), 3.75(\mathrm{~s}, 3 \mathrm{H}$, Ester-Me'), $3.63(\mathrm{dd}, J=13.8,4.3,1 \mathrm{H}, \mathrm{H} 2), 3.53(\mathrm{dd}, J=13.8,5.5,1 \mathrm{H}$, H2'), $3.40(\mathrm{~d}, J=9.4,1 \mathrm{H}, \mathrm{H7}), 3.03$ (s(broad), 1H, H3), 2.09 (s, 3H, Amide-Me), Minor: 5.69-5.86 (m(overlap with maj), 2H, H4/H5), 3.93 ( $m, 2 \mathrm{H}, \mathrm{H6} / \mathrm{H6}$ '), 3.76 (s(shoulder of maj)), 3H, Ester-Me), 3.73 (s, 3H, Ester-Me'), 3.86 (dd, $J=13.4,4.9,1 \mathrm{H}, \mathrm{H} 2$ ), 3.49 (dd, $J=13.4,4.4,1 \mathrm{H}, \mathrm{H} 2$ '), 3.34 (d, $J=$ 9.5, $1 \mathrm{H}, \mathrm{H} 7), 3.03$ (s(broad, overlap of maj), $1 \mathrm{H}, \mathrm{H} 3), 2.10$ (s, 3H, Amide-Me). ${ }^{13} \mathrm{C} \mathrm{NMR}\left(\mathrm{CDCl}_{3}, \delta\right)$ : 
Major: 170.2 (Amide-CO), 168.6 (Ester-CO), 168.3 (Ester-CO'), 127.4/125.4 (C4/C5), 53.9 (C7), 52.9 (Ester-Me), 52.8 (Ester-Me'), 46.0 (C2), 42.2 (C6), 35.6 (C3), 21.3 (Amide-Me). Minor: 169.8 (Amide-CO), 168.3 (Ester-CO), 168.2 (Ester-CO'), 127.3/125.7 (C4/C5), 54.2 (C7), 52.9 (Ester-Me), 52.7 (Ester-Me'), 45.8 (C6), 41.1 (C2), 34.9 (C3), 21.9 (Amide-Me). Isomer ratio: 1.7:1 (Chemical Exchange Observed). IR: $v_{\text {ester }}=1732 \mathrm{~cm}^{-1}, v_{\text {amide }}=1639 \mathrm{~cm}^{-1}$. ESI-MS: obs'd (\%), calc'd (\%), ppm, $(\mathrm{M}+\mathrm{Na})^{+}: 278.0987(100), 278.0999(100), 4.4$.

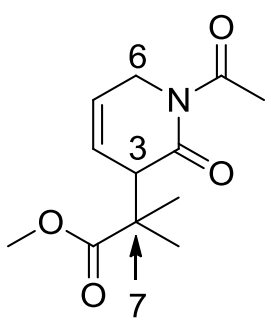

Methyl 2-(1-acetyl-2-oxo-1,2,3,6-tetrahydropyridin-3-yl)-2-methylpropanoate. 27. Acetone (4.17g) was added to a vial containing $22(0.102 \mathrm{~g}, 0.135 \mathrm{mmol})$ and $\mathrm{I}_{2}(0.207 \mathrm{~g}, 0.816 \mathrm{mmol})$ and the dark brown solution was allowed to stir. After 1 hour the reaction solution was transferred to a separatory funnel containing $50 \mathrm{~mL} \mathrm{NaHCO}$ (saturated, aqueous) to precipitate a brown solid, which dissolved in the following $5 \times 25 \mathrm{~mL}$ DCM extractions. The organic layer was dried with $\mathrm{MgSO}_{4}$, filtered through a $60 \mathrm{~mL}$ coarse porosity fritted funnel, the solvent removed in vacuo, and the residue transferred to a vial with DCM which was then removed in vacuo. The residue was transferred to a preparatory TLC plate with 4x0.3 g DCM and two $1 \mathrm{~mL}$ syringes. The plate was eluted with 4:1 hexanes:Et ${ }_{2} \mathrm{O}$. The band between $\mathrm{r}_{\mathrm{f}}=0.15$ and $\mathrm{r}_{\mathrm{f}}=0.27$ was removed, placed in a test tube with $15 \mathrm{~mL}$ EtOAc and sonicated for 10 minutes. The silica for this band was collected on a $30 \mathrm{~mL}$ medium porosity fritted funnel, and the product washed off of the silica with $200 \mathrm{~mL}$ EtOAc, solvent removed from the filtrate in vacuo and the residue transferred to a tared vial with DCM, and the solvent was removed in vacuo. The vial was placed under vacuum overnight yielding a colorless oil $\left(0.010 \mathrm{~g}, 0.042 \mathrm{mmol}, 31 \%\right.$ yield). ${ }^{1} \mathrm{H} \mathrm{NMR}\left(\mathrm{CDCl}_{3}, \delta\right)$ : Major: 
6.01 (ddt, $J=10.1,3.5,1.6,1 \mathrm{H}, \mathrm{H} 5$ ), 5.80 (ddt, $J=10.1,3.8,1.9,1 \mathrm{H}, \mathrm{H} 4$ ), 4.23 (ddd, $J=3.5,3.3$, 1.9, 2H, H6/H6'), 3.74 (s, 3H, Ester-Me), 3.55 (ddd, J = 3.8, 3.3, 1.6, 1H, H3), 2.53 (s, 3H, AcylMe), 1.26 (s, 3H, Gem-Me), 1.19 (s, 3H, Gem-Me'). Minor: 5.94/5.74 (m, 2H, H5/H4), 3.93 (m, $2 \mathrm{H}, \mathrm{H6} / \mathrm{H6}^{\prime}$ ), 3.73 (s, 3H, Ester-Me), 3.44 (ddd, $J=8.4,4.2,1.6,1 \mathrm{H}, \mathrm{H} 3$ ), 1.23 (s, 3H, Gem-Me), $1.2\left(\mathrm{~s}, 3 \mathrm{H}, \mathrm{Gem}-\mathrm{Me}\right.$ ). ${ }^{13} \mathrm{C}$ NMR $\left(\mathrm{CDCl}_{3}, \delta\right)$ : Major: 176.8 (Ester-CO), 173.6 (Amide-CO), 171.7 (C2), 124.4 (C5), 122.9 (C4), 52.4 (Ester-Me), 51.7 (C2), 46.5 (C7), 45.6 (C6), 27.7 (Amide-Me), 24.0 (Gem-Me), 21.1 (Gem-Me'), Minor: 123.7/123.5 (C4/C5), 52.2 (Ester-Me), 47.9 (C3), 46.2 (C7), 43.8 (C6), 23.3 (Gem-Me), 21.4 (Gem-Me'). Isomer ratio: 4.6:1. IR: $v_{\text {ester }}=1733 \mathrm{~cm}^{-1}, v_{\text {imide }}=1698$ $\mathrm{cm}^{-1}$. ESI-MS: obs'd (\%), calc'd (\%), ppm, (M+Na) ${ }^{+}: 262.1050$ (100), 262.1050 (100), 0.0.<smiles>[3H]C(C)(C)c1cccnc1C#N</smiles>

Methyl 2-(2-cyanopyridin-3-yl)-2-methylpropanoate. 28. Acetone (4.01 g) was added to a vial containing $22(0.100 \mathrm{~g}, 0.133 \mathrm{mmol})$ and $\mathrm{DDQ}(0.123 \mathrm{~g}, 0.542 \mathrm{mmol})$ to give a dark red homogeneous solution that was removed from the glovebox after several minutes and exposed to air for 0.5 hours. The reaction was allowed to stir for 14 hours, then was diluted with $20 \mathrm{~mL}$ DCM, extracted with $3 \times 10 \mathrm{~mL} \mathrm{NaHCO}$ (saturated, aqueous), back-extracted with $3 \times 10 \mathrm{~mL} \mathrm{DCM}$, the combined organic layers were dried with $\mathrm{MgSO}_{4}$, filtered through a $60 \mathrm{~mL}$ coarse porosity fritted funnel, and the solvent removed in vacuo. The residue was transferred to a 4 dram vial with DCM and the solvent was removed once more in vacuo. The residue was loaded onto a 20 $\mathrm{cm} \times 20 \mathrm{~cm} \times 500$ micrometer $\mathrm{SiO}_{2}$ preparatory TLC plate with $4 \times 0.3 \mathrm{~g}$ DCM and a $1 \mathrm{~mL}$ syringe. The preparatory TLC plate was eluted with $\mathrm{Et}_{2} \mathrm{O}$ and the band that was UV active between $r_{f}=$ 0.55 and $r_{f}=0.69$ was removed from the TLC plate, placed in a test tube with $15 \mathrm{~mL}$ EtOAc, and sonicated for 10 minutes to break up the silica. The silica was collected on a $30 \mathrm{~mL}$ medium 
porosity fritted funnel, washed with $200 \mathrm{~mL}$ EtOAc, and the solvent removed from the filtrate in vacuo. The residue was then transferred to a tared vial with $\mathrm{DCM}$, the solvent removed, and the resulting material placed under vacuum overnight (colorless oil, $0.008 \mathrm{~g}, 0.039 \mathrm{mmol}, 30 \%$ yield). ${ }^{1} \mathrm{H} \mathrm{NMR}\left(\mathrm{CDCl}_{3}, \delta\right): 8.60(\mathrm{dd}, J=4.8,1.5,1 \mathrm{H}, \mathrm{H} 6) 7.83(\mathrm{dd}, J=8.2,1.5,1 \mathrm{H}, \mathrm{H} 4), 7.52$ (dd, $J$ $=8.2,4.8,1 \mathrm{H}, \mathrm{H} 5), 3.79\left(\mathrm{~s}, 3 \mathrm{H}\right.$, Ester-Me), 1.71 (s, 6H, Gem-DiMe). ${ }^{13} \mathrm{C} \mathrm{NMR}\left(\mathrm{CDCl}_{3}, \delta\right): 175.7$ (Ester-CO) 148.8 (C6), 145.2 (C3), 134.2 (C4), 133.8 (C2), 126.8 (C5), 116.6 (CN), 53.1 (Ester-Me), 46.3 (C7), 26.6 (Gem-DiMe). IR: $v_{\text {nitrile }}=2233 \mathrm{~cm}^{-1}, v_{\mathrm{ester}}=1735 \mathrm{~cm}^{-1}$. ESI-MS: obs'd (\%), calc'd (\%), ppm, $(\mathrm{M}+\mathrm{Na})^{+}: 227.0798(100), 227.0791(100), 2.9$.

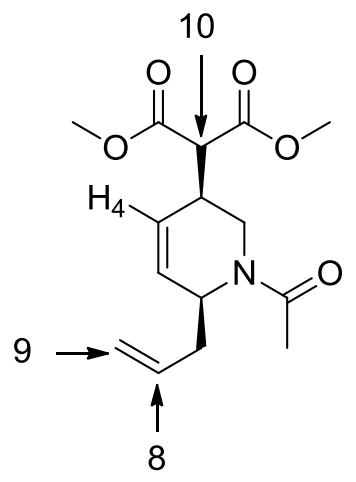

Dimethyl 2-(1-acetyl-6-allyl-1,2,3,6-tetrahydropyridin-3-yl)malonate. 29. One pot method 1: General procedure 1 was used to generate the tetrahydropyridine complex precursor. Test tube 1: 8 (0.105 g, $0.158 \mathrm{mmol}) ;$ HOTf (0.025 g, $0.165 \mathrm{mmol}) ;$ MeCN (1.26 g). Test tube 2: LiDMM (0.063 g, $0.456 \mathrm{mmol})$; $\mathrm{MeCN}$ (0.73 g). Oxidation of the complex was performed following general procedure $2 . \mathrm{SiO}_{2}(10.1 \mathrm{~g})$; reaction time: $15 \mathrm{~h}$. General procedure 5 was followed to isolate the product. Pale yellow oil located between $r_{f}=0.21$ and $r_{f}=0.33$ when $\mathrm{Et}_{2} \mathrm{O}$ was used as the eluent $(0.016 \mathrm{~g}, 0.0535 \mathrm{mmol}, 34 \%$ yield). One pot method 2: General procedure 1 was used to generate the tetrahydropyridine complex precursor. Test tube 1: $8(0.100 \mathrm{~g}, 0.150$ mmol); HOTf (0.024 g, $0.161 \mathrm{mmol}) ;$ MeCN (1.19 g). Test tube 2: LiDMM (0.063 g, $0.456 \mathrm{mmol}) ;$ MeCN (0.80 g). Oxidation of the complex was performed following general procedure 3. Acetone (4.04 g); CAN (0.083 g, $0.152 \mathrm{mmol})$; reaction time: $1 \mathrm{~h}$. General procedure 5 was 
followed to isolate the product. Pale yellow oil located between $r_{f}=0.21$ and $r_{f}=0.35$ when $\mathrm{Et}_{2} \mathrm{O}$ was used as the eluent $(0.015 \mathrm{~g}, 0.0508 \mathrm{mmol}, 34 \%$ yield $)$. One pot method 3: General procedure 1 was used to generate the tetrahydropyridine complex precursor. Test tube 1: 8 ( $0.100 \mathrm{~g}, 0.150$ mmol); HOTf (0.024 g, $0.158 \mathrm{mmol}) ; \operatorname{MeCN}(1.16 \mathrm{~g})$. Test tube 2: LiDMM (0.064 g, $0.464 \mathrm{mmol}) ;$ MeCN (0.74 g). Oxidation of the complex was performed following general procedure 4. Acetone $(2.05 \mathrm{~g})$; DDQ (0.069 g, $0.304 \mathrm{mmol})$; reaction time: $1.5 \mathrm{~h}$. General procedure 5 was followed to isolate the product. Pale yellow oil located between $r_{f}=0.20$ and $r_{f}=0.35$ when $E t_{2} \mathrm{O}$ was used as the eluent $\left(0.016 \mathrm{~g}, 0.0535 \mathrm{mmol}, 36 \%\right.$ yield). ${ }^{1} \mathrm{H} \mathrm{NMR}\left(\mathrm{CDCl}_{3}, \delta\right): 5.84-5.73(\mathrm{~m}, 2 \mathrm{H}$, $\mathrm{H} 4($ maj, $\min ) / \mathrm{H} 5(\operatorname{maj}, \min ) / \mathrm{H} 8(\min )) 5.61(\mathrm{~d}, J=10.3,1 \mathrm{H}, \mathrm{H} 8(\min )), 5.15-5.00(\mathrm{~m}, 2 \mathrm{H}$, $\left.\mathrm{H9}(\mathrm{maj}, \mathrm{min}) / \mathrm{Hg}^{\prime}(\mathrm{maj} / \mathrm{min})\right), 4.92(\mathrm{~m}, 1 \mathrm{H}, \mathrm{H6}), 4.66(\mathrm{dd}, J=12.5,5.3,1 \mathrm{H}, \mathrm{H} 2(\mathrm{~min})), 4.15(\mathrm{~m}, 1 \mathrm{H}$, $\mathrm{H6}(\min )), 3.89(\mathrm{dd}, J=12.5,3.1,1 \mathrm{H}, \mathrm{H} 2), 3.77 / 3.76 / 3.74(\mathrm{~s}, 6 \mathrm{H}$, Ester-Me(maj,min)/Ester$\left.\mathrm{Me}^{\prime}(\operatorname{maj}, \min )\right), 3.37$ (d, $J=7.1,1 \mathrm{H}, \mathrm{H} 10$ (min)), 3.34 (d, $\left.J=7.4,1 \mathrm{H}, \mathrm{H} 10\right), 3.02$ (dd, $J=12.5,11.1$, $\left.1 \mathrm{H}, \mathrm{H} 2^{\prime}\right), 2.97(\mathrm{~m}, 1 \mathrm{H}, \mathrm{H} 3(\mathrm{maj}, \mathrm{min})), 2.63\left(\mathrm{dd}, J=12.5,11.3,1 \mathrm{H}, \mathrm{H} 2^{\prime}(\min )\right), 2.35(\mathrm{t}, J=7.1,1 \mathrm{H}$, $\left.\mathrm{H} 7(\min ) / H 7^{\prime}(\min )\right) 2.30\left(\mathrm{t}, J=7.1,1 \mathrm{H}, \mathrm{H} 7 / \mathrm{H} 7^{\prime}\right), 2.12(\mathrm{~s}, 3 \mathrm{H}$, Amide-Me), 2.09 (s, 3H, Amide$\mathrm{Me}(\mathrm{min})) .{ }^{13} \mathrm{C}$ NMR $\left(\mathrm{CDCl}_{3}, \delta\right): 169.3$ (Amide-CO(maj,min)) 168.2 (Ester-CO(maj,min),EsterCO'(maj,min)), 134.4/130.7 (C4/C5), 133.6/128.8/127.9 (C4(min)/C5(min)/C8(min)), 126.1 (C8), $118.8(\mathrm{C9}(\mathrm{min})), 117.6(\mathrm{C9}), 54.6(\mathrm{C} 6(\min )), 53.8(\mathrm{C} 10), 53.6(\mathrm{C} 10(\mathrm{~min})), 52.0 / 52.8 / 52.6$ (EsterMe(maj,min),Ester-Me'(maj,min)), 49.9 (C6), 43.6 (C2), 39.0 (C7(min)) 38.0 (C7), 37.6 (C2(min)), 35.5 (C3), 34.6 (C3(min)), 21.9 (Amide-Me), 21.8 (Amide-Me(min)). Isomer Ratio: 2.3:1 (Chemical Exchange Observed). IR: $v_{\text {ester }}=1734 \mathrm{~cm}^{-1}, v_{\text {amide }}=1639 \mathrm{~cm}^{-1}$. ESI-MS: obs'd (\%), calc'd (\%), ppm, $(\mathrm{M}+\mathrm{Na})^{+}: 318.1319(100), 318.1312(100), 2.2$. 


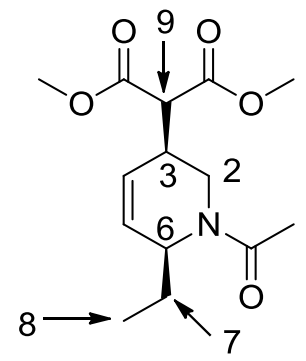

Dimethyl 2-((3S,6S)-1-acetyl-6-ethyl-1,2,3,6-tetrahydropyridin-3-yl)malonate. 30. General procedure 1 was used to generate the tetrahydropyridine complex precursor. Test tube 1: 3 (0.103 g, $0.157 \mathrm{mmol}) ;$ HOTf (0.025 g, $0.168 \mathrm{mmol}) ; \mathrm{MeCN}$ (1.10 g). Test tube 2: LiDMM (0.070 g, $0.507 \mathrm{mmol}) ; \mathrm{MeCN}(0.74 \mathrm{~g})$. Oxidation of the complex was performed following general procedure $2 . \mathrm{SiO}_{2}(10.3 \mathrm{~g})$; reaction time: $15 \mathrm{~h}$. General procedure 5 was followed to isolate the product. Pale yellow oil from the band located between $r_{f}=0.28$ and $r_{f}=0.43$ using 9:1 $\mathrm{Et}_{2} \mathrm{O}:$ EtOAc as the eluent $\left(0.018 \mathrm{~g}, 0.063 \mathrm{mmol}, 40 \%\right.$ yield). ${ }^{1} \mathrm{H} \mathrm{NMR}\left(\mathrm{CDCl}_{3}, \delta\right)$ : Major: 5.81 (ddd, $J=10.3,3.7,2.2,1 \mathrm{H}, \mathrm{H} 5), 5.58(\mathrm{dd}, J=10.3,1.0,1 \mathrm{H}, \mathrm{H} 4), 4.80(\mathrm{~m}, 1 \mathrm{H}, \mathrm{H} 6), 3.90(\mathrm{dd}, J=11.1,1.8$, $1 \mathrm{H}, \mathrm{H} 2$ ), 3.77 (s, 3H, Ester-Me), 3.76 (s, 3H, Ester-Me'), 3.33 (d, J = 6.9, 1H, H9), 3.03 (d, J = 11.1, $\left.1 \mathrm{H}, \mathrm{H} 2^{\prime}\right), 3.00(\mathrm{~m}, 1 \mathrm{H}, \mathrm{H} 3), 2.14\left(\mathrm{~s}, 3 \mathrm{H}\right.$, Amide-Me), $1.55\left(\mathrm{~m}, 2 \mathrm{H}\right.$, Ethyl- $\left.\mathrm{CH}_{2}\right), 0.92(\mathrm{t}, J=7.7$, Ethyl$\left.\mathrm{CH}_{3}\right)$, Minor: $5.78(\mathrm{~m}, 2 \mathrm{H}, \mathrm{H} 4 / \mathrm{H} 5), 4.66(\mathrm{dd}, J=12.5,5.4,1 \mathrm{H}, \mathrm{H} 2), 4.00(\mathrm{dd}, J=6.8,6.6,1 \mathrm{H}, \mathrm{H} 6)$, 3.76 (s(shoulder of major), 3H, Ester-Me), 3.74 (s, 3H, Ester-Me'), 3.36 (d, J = 7.1, 1H, H9), 3.00 (m(buried), 1H, H3), 2.61 (dd, $J=12.5,12.5,1 \mathrm{H}, \mathrm{H} 2$ '), 2.10 (s, 3H, Amide-Me), 1.66 (m, 2H, Ethyl$\mathrm{CH}_{2}$ ), $0.97\left(\mathrm{t}, J=7.4\right.$, Ethyl- $\left.\mathrm{CH}_{3}\right) .{ }^{13} \mathrm{C} \mathrm{NMR}\left(\mathrm{CDCl}_{3}, \delta\right)$ : Major: 169.3 (Amide-CO), 168.2 (EsterCO/Ester-CO'), 131.3 (C5), 125.6 (C4), 53.9 (C9), 52.9 (Ester-Me), 52.8 (Ester-Me'), 51.5 (C6), 43.3 (C2), 35.7 (C3), 26.6 (Ethyl- $\mathrm{CH}_{2}$ ), 21.8 (Amide-Me), 10.6 (Ethyl- $\mathrm{CH}_{3}$ ), Minor: 169.3 (Amide-CO), 168.3 (Ester-CO/Ester-CO'), 129.1/127.6 (C4/C5), 56 (C6), 53.7 (C9), 52.8 (Ester-Me), 52.6 (EsterMe'), 37.7 (C2), 34.7 (C3), 27.7 (Ethyl- $\mathrm{CH}_{2}$ ), 21.7 (Amide-Me), 10.9 (Ethyl- $\mathrm{CH}_{3}$ ). Isomer Ratio: 1.9:1 (Chemical Exchange Observed). IR: $v_{\text {ester }}=1735 \mathrm{~cm}^{-1}, v_{\text {amide }}=1632 \mathrm{~cm}^{-1}$. ESI-MS: obs'd (\%), calc'd (\%), ppm, (M+Na) $)^{+}: 306.1309$ (100), 306.1312 (100), 0.9. 


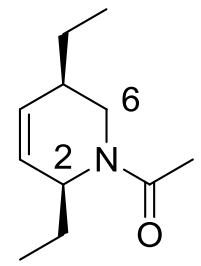

1-(2,5-diethyl-5,6-dihydropyridin-1(2H)-yl)ethanone. 31. Silica (11 g) was added to a $100 \mathrm{~mL}$ 14/20 pear shaped round bottom flask containing 19 ( $0.102 \mathrm{~g} ; 0.066 \mathrm{~g}, 0.097 \mathrm{mmol}$, adjusted for 3 impurity) and $50 \mathrm{~mL}$ MeCN. Parafilm was placed over the opening and a small hole was poked in it. The solution was allowed to stir rapidly for 23 hours. The solution was filtered through 1 $\mathrm{cm}$ celite on top of $1 \mathrm{~cm}$ sand and washed with $200 \mathrm{~mL}$ EtOAc. The solvent was evaporated, the residue was loaded onto a $\mathrm{SiO}_{2}$ predatory TLC plate and eluted with EtOAc. The band between $r_{f}$ $=0.38$ and $r_{f}=0.52$ was removed from the plate, loaded onto a $30 \mathrm{~mL}$ coarse porosity fritted funnel containing $2 \mathrm{~cm}$ celite on top of $2 \mathrm{~cm}$ sand and covered with $1 \mathrm{~cm}$ sand. The product was washed off with $300 \mathrm{~mL}$ EtOAc and the solvent evaporated from the filtrate. The residue was transferred to a tared vial with DCM, the solvent removed in vacuo and the vial placed under vacuum (0.007 g, $0.0386 \mathrm{mmol}, 40 \%$ yield). ${ }^{1} \mathrm{H}$ NMR $\left(\mathrm{CDCl}_{3}, \delta\right): 5.78-5.61(\mathrm{~m}, 2 \mathrm{H}$, $\mathrm{H} 3 / \mathrm{H} 4(\operatorname{maj}, \min )) 4.78(\mathrm{br} \mathrm{s}, 1 \mathrm{H}, \mathrm{H} 2), 4.65(\mathrm{dd}, J=12.4,5.1,1 \mathrm{H}, \mathrm{H} 6(\mathrm{~min})), 3.97$ (br s, $1 \mathrm{H}$, $\mathrm{H} 2(\min )), 3.67(\mathrm{dd}, J=13.5,5.3,1 \mathrm{H}, \mathrm{H} 6), 2.79\left(\mathrm{dd}, J=13.5,11.2,1 \mathrm{H}, \mathrm{H} 6^{\prime}\right), 2.27$ (dd, $J=12.4$, 10.9, 1H, H6'(min)), 2.15 (br s, 1H, H5), 2.10 (s, 3H, Amide-Me), 2.09 (s, 3H, Amide-Me(min)), 1.75-1.48 (m, 2H, Et-CH $), 1.41-1.19\left(\mathrm{~m}, 2 \mathrm{H}, \mathrm{Et}-\mathrm{CH}_{2}\right), 1.03-0.87\left(\mathrm{~m}, 6 \mathrm{H}, \mathrm{Et}-\mathrm{CH}_{3}\right) .{ }^{13} \mathrm{C} \mathrm{NMR}^{\left(\mathrm{CDCl}_{3}\right.}$,

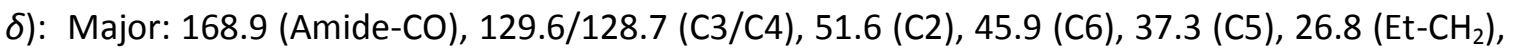
25.9 (Et-CH${ }^{\prime}$ ), 22.0 (Amide-Me), Minor: 169.2 (Amide-CO), 131.6/127.0 (C3/C4), 56.1 (C2), 40.2

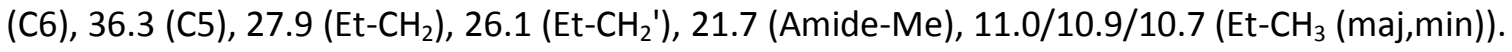
Isomer Ratio: 1:1.3 (Chemical Exchange Observed). IR: $v_{\text {amide }}=1634 \mathrm{~cm}^{-1}$. ESI-MS: obs'd (\%), calc'd (\%), ppm, (M+Na) $)^{+}: 204.1371$ (100), 204.1359 (100), 5.7. 


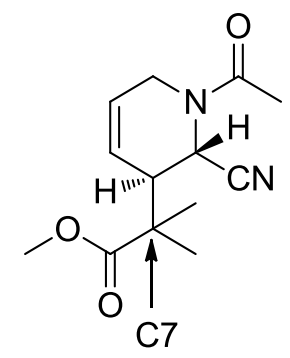

Methyl 2-1-acetyl-2-cyano-1,2,3,6-tetrahydropyridin-3-yl)-2-methylpropanoate. 32. A solution of DABCO (0.062 g, $0.553 \mathrm{mmol})$ in MeCN (1.0 g) was added to an oven dried test tube containing a tan solution of $22(0.105 \mathrm{~g}, 0.116 \mathrm{mmol})$ in $\mathrm{MeCN}(1.90 \mathrm{~g})$ and the resulting mixture was allowed to stir in a $58{ }^{\circ} \mathrm{C}$ oil bath. After $7 \mathrm{~h} 45 \mathrm{~min}$., the solution was removed from the glovebox, diluted with $30 \mathrm{~mL} \mathrm{DCM}$, extracted with $3 \times 15 \mathrm{~mL} \mathrm{NaHCO}$ (saturated, aqueous), backextracted with $2 \times 15 \mathrm{~mL} \mathrm{DCM}$, the combined organic layers were dried with $\mathrm{MgSO}_{4}$, filtered through a $60 \mathrm{~mL}$ coarse porosity fritted funnel, and the solvent removed in vacuo. An oxidation was attempted with $\mathrm{O}_{2}(\mathrm{~g})$ in a manner similar to general procedure $2 . \mathrm{SiO}_{2}(10.0 \mathrm{~g})$; reaction time: $17 \mathrm{~h}$. A crude NMR in $\mathrm{CDCl}_{3}$ of the residue of evaporated solvent revealed that only $\mathrm{SM}$ remained, indicating the oxidation had failed. Oxidation similar to General Procedure 4 was performed with DDQ using MeCN as the solvent. The residue was dissolved in MeCN (3.7 g) and diluted with a solution of DDQ $(0.060 \mathrm{~g}, 0.264 \mathrm{mmol})$ in $\mathrm{MeCN}(1.3 \mathrm{~g})$ to make a purple solution that was allowed to stir. After 23 minutes, the reaction solution was removed from the glovebox and worked up according to General Procedure 4. General procedure 5 was followed to isolate the product. Pale yellow oil from the band located between $r_{f}=0.35$ and $r_{f}=0.47$ when $E t_{2} \mathrm{O}$ was used as the eluent $\left(0.016 \mathrm{~g}, 0.064 \mathrm{mmol}, 55 \%\right.$ yield). ${ }^{1} \mathrm{H} \mathrm{NMR}\left(\mathrm{CDCl}_{3}, \delta\right): 6.08(\mathrm{~d}, J=11.1,1 \mathrm{H}$, H5(minor)), $5.98(\mathrm{~m}, 1 \mathrm{H}, \mathrm{H} 5), 5.88(\mathrm{~s}, 1 \mathrm{H}, \mathrm{H} 2), 5.82(\mathrm{~m}, 1 \mathrm{H}, \mathrm{H} 4), 5.02(\mathrm{~s}, 1 \mathrm{H}, \mathrm{H} 2$ (minor)), $4.43(\mathrm{~d}, J$ $=19.5,1 \mathrm{H}, \mathrm{H} 6($ minor) ) , $4.08(\mathrm{~m}, 1 \mathrm{H}, \mathrm{H} 6), 4.02$ (ddd, $J=17.7,4.9,2.5,1 \mathrm{H}, \mathrm{H} 6$ '), $3.71(\mathrm{~s}, 3 \mathrm{H}$, EsterMe), $3.64\left(\mathrm{~d}, J=19.5,1 \mathrm{H}, \mathrm{H} 6^{\prime}(\right.$ minor)), $3.02(\mathrm{ddd}, J=5.3,2.5,1.1,1 \mathrm{H}, \mathrm{H} 3), 2.88(\mathrm{~d}(\mathrm{br}), J=4.8,1 \mathrm{H}$, H3(minor)), 2.22 (s, 3H, Amide-Me(minor)), 2.13 (s, 3H, Amide-Me), 1.29 (s, 3H, Gem- 
Me(minor)), 1.19 (s, 3H, Gem-Me), 1.14 (s, 3H, Gem-Me'(minor)), 1.12 (s, 3H, Gem-Me'). ${ }^{13} \mathrm{C}$ NMR (CDCl $3, \delta$ ): 176.4 (Ester-CO), 170.0 (Amide-CO), 127.5 (C5(minor)), 125.5 (C5), 123.3 (C4), 120.7 (C4(minor)), 117.6 (Nitrile), 52.5 (Ester-Me), 46.0 (C7), 45.3 (C3), 42.9 (C6), 39.1 (C2), 22.5 (Gem-Me), 22.2 (Gem-Me'). Isomer Ratio: 5.5:1 (Chemical Exchange Observed). IR: $v=2983 \mathrm{~cm}^{-}$ ${ }^{1}, v=2951 \mathrm{~cm}^{-1}, v=2851 \mathrm{~cm}^{-1}, v_{\text {nitrile }}=2236 \mathrm{~cm}^{-1}, v_{\text {ester }}=1725 \mathrm{~cm}^{-1}, v_{\text {amide }}=1659 \mathrm{~cm}^{-1}, 1408 \mathrm{~cm}^{-1}$, $1131 \mathrm{~cm}^{-1}$. ESI-MS: obs'd (\%), calc'd (\%), ppm, $(\mathrm{M}+\mathrm{Na})^{+}: 273.12(100), 273.121(100), 3.7$.

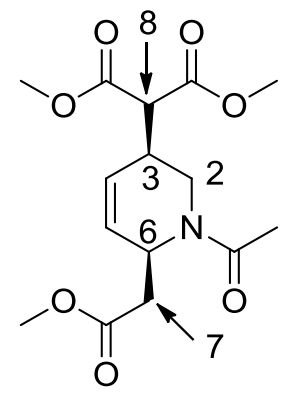

Dimethyl-2-(1-acetyl-6-(2-methoxy-2-oxoethyl)-1,2,3,6-tetrahydropyridin-3-yl)malonate. 33. One pot method: General procedure 1 was used to generate the tetrahydropyridine complex precursor. Test tube 1: 7 (0.100 g, $0.143 \mathrm{mmol})$; HOTf (0.023 g, $0.154 \mathrm{mmol})$; MeCN (1.16 g). Test tube 2: LiDMM (0.062 g, $0.449 \mathrm{mmol})$; MeCN (0.775 g). Oxidation of the complex was performed following general procedure $2 . \mathrm{SiO}_{2}(10.3 \mathrm{~g})$; reaction time: $15 \mathrm{~h}$. General procedure 5 was followed to isolate the product. Pale yellow oil from the band located between $r_{f}=0.30$ and $r_{f}=0.45$ when 1:1 EtOAc:Et ${ }_{2} \mathrm{O}$ was used as the eluent $\left(0.013 \mathrm{~g}, 0.0406 \mathrm{mmol}, 28 \%\right.$ yield). ${ }^{1} \mathrm{H}$ $\operatorname{NMR}\left(\mathrm{CDCl}_{3}, \delta\right)$ : Major: 5.85 (ddd, $\left.J=10.5,3.6,2.3,1 \mathrm{H}, \mathrm{H} 3\right), 5.67(\mathrm{ddd}, J=10.5,1.9,1.6,1 \mathrm{H}, \mathrm{H} 4$ ), $5.19(\mathrm{~m}, 1 \mathrm{H}, \mathrm{H} 2), 3.94$ (q, J = 9.9, 1H, H6), 3.77 (s, 3H, C8-Ester-Me), 3.76 (s, 3H, C8-Ester-Me'), 3.66 (s, 3H, C2-Ester-Me), 3.35 (d, J = 7.3, 1H, C8), 3.03 (m, 1H, H6'), 3.00 (m, 1H, H5), 2.53 (dq, J $\left.=14.5,7.0,2 \mathrm{H}, \mathrm{H} 7 / \mathrm{H}^{\prime}\right), 2.13$ (s, 3H, Amide-Me). Minor: 6.83 (buried, 1H, $\mathrm{H} 4$ ), 5.78 (ddd, $J=$ 10.3, 3.8, 2.5, 1H, H3), 4.64 (m, 2H, H2/H6), 3.76 (s, 3H, C8-Ester-Me), 3.75 (s, 3H, C8-Ester-Me'), $3.69(\mathrm{~s}, 3 \mathrm{H}, \mathrm{C} 2$-Ester-Me), $3.38(\mathrm{~d}, J=6.5,1 \mathrm{H}, \mathrm{H} 8), 3.00$ (buried, 1H, H5), $2.63(\mathrm{~m}, 3 \mathrm{H}$, 
H6/H7/H7'), 2.15 (s, 3H, Amide-Me). ${ }^{13} \mathrm{C} N M R\left(\mathrm{CDCl}_{3}, \delta\right): 171.2$ (C2-Ester-CO) 169.3 (Amide-CO), 168.1 (C8-Ester-CO/C8-Ester-CO'), 129.8 (C3), 127.0 (C4), 53.6 (C8), 52.9 (C8-Ester-Me), 52.8 (C8Ester-Me'), 51.9 (C2-Ester-Me), 47.4 (C2), 43.4 (C6), 37.8 (C7), 35.5 (C5), 21.8 (Amide-Me) Minor: 171 (C2-Ester-CO), 169.5 (Amide-CO), 168.2 (C8-Ester-CO), 168.1 (C8-Ester-CO'), 128.9 (C4), 128.1 (C3), 53.4 (C8), 52.8 (C8-Ester-Me), 52.7 (C8-Ester-Me'), 52.1 (C2-Ester-Me), 51.4 (C2), 39.0 (C7), 37.6 (C6), 34.4 (C5), 21.5 (Amide-Me). Isomer Ratio: 2.1:1 (Chemical Exchange Observed). IR: $v_{\text {ester }}=1732 \mathrm{~cm}^{-1}, v_{\text {ester }}=1639 \mathrm{~cm}^{-1}$. ESI-MS: obs'd (\%), calc'd (\%), ppm, $(\mathrm{M}+\mathrm{Na})^{+}$: 350.1231 (100), 350.1216 (100), 4.3.

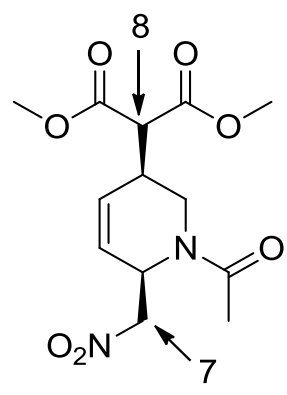

Dimethyl 2-(1-acetyl-6-(nitromethyl)-1,2,3,6-tetrahydropyridin-3-yl)malonate. 34. One pot method: General procedure 1 was used to generate the tetrahydropyridine complex precursor. Test tube 1: 10 (0.101 g, $0.147 \mathrm{mmol}) ; \operatorname{HOTf}(0.023 \mathrm{~g}, 0.156 \mathrm{mmol}) ; \mathrm{MeCN}(1.15 \mathrm{~g})$. Test tube 2: LiDMM (0.062 g, $0.449 \mathrm{mmol}) ; \operatorname{MeCN}(0.73 \mathrm{~g})$. Oxidation of the complex was performed following general procedure 3. Acetone ( $4.1 \mathrm{~g})$; CAN (0.083 g, $0.151 \mathrm{mmol})$; reaction time: $1 \mathrm{~h} 15$ minutes. General procedure 5 was followed to isolate the product. Pale yellow oil from the band located between $r_{f}=0.29$ and $r_{f}=0.43$ when $3: 1$ EtOAc:Et ${ }_{2} \mathrm{O}$ was used as the eluent $(0.031 \mathrm{~g}$, $0.0986 \mathrm{mmol}, 67 \%$ yield). ${ }^{1} \mathrm{H}$ NMR $\left(\mathrm{CDCl}_{3}, \delta\right):$ Major: 5.89 (ddd, $\left.J=10.3,3.6,1.9,1 \mathrm{H}, \mathrm{H} 4\right), 5.81$ (ddd, $J=10.3,3.1,2.3,1 \mathrm{H}, \mathrm{H} 5), 5.38(\mathrm{~m}, 1 \mathrm{H}, \mathrm{H6}), 4.59$ (dd, $J=11.4,5.2,1 \mathrm{H}, \mathrm{H} 7), 4.49$ (dd, $J=$ 11.4, 5.8, 1H, H7'), 4.00 (d(br), 1H, H2), 3.77 (s, 3H, Ester-Me), 3.76 (s, 3H, Ester-Me'), 3.38 (d, J = 7.5, 1H, H8), 2.99 (shoulder, 1H, H3), 2.97 (dd, $\left.J=11.4,10.8,1 \mathrm{H}, \mathrm{H} 2{ }^{\prime}\right), 2.17$ (s, 3H, Amide-Me), 
Minor: 6.03 (d, $J=10.5,1 \mathrm{H}, \mathrm{H} 4), 5.73(\mathrm{ddd}, J=10.5,4.0,2.4,1 \mathrm{H}, \mathrm{H} 5), 4.98(\mathrm{~m}, 1 \mathrm{H}, \mathrm{H} 6), 4.68$ (dd, $J=13.3,5.7,1 \mathrm{H}, \mathrm{H} 2$ ), 3.76 (s, 3H, Ester-Me), 3.75 (s, 3H, Ester-Me'), 3.44 (d, J = 5.9, 1H, H8), 2.97 (buried, $1 \mathrm{H}, \mathrm{H} 3$ ), 2.74 (dd, $J=13.3,11.5,1 \mathrm{H}, \mathrm{H} 2$ '), 2.11 (s, 3H, Amide-Me). ${ }^{13} \mathrm{C} \mathrm{NMR}\left(\mathrm{CDCl}_{3}, \delta\right)$ : Major: 170.2 (Amide-CO), 167.9 (Ester-CO/Ester-CO'), 130.2 (C4), 125.3 (C5), 76.5 (C7), 53.2 (C8), 53.0 (Ester-Me), 52.9 (Ester-Me'), 48.6 (C6), 43.6 (C2), 35.1 (C3), 21.8 (Amide-Me), Major: 169.7 (Amide-CO), 168.1 (Ester-CO), 167.9 (Ester-CO'), 132.4 (C4), 123.6 (C5), 76.1 (C7), 52.9/52.8/52.7 (Ester-Me/Ester-Me/C8/C6), 37.3 (C2), 34.2 (C3), 21.2 (Amide-Me). Isomer Ratio: 5.5:1 (Chemical Exchange Observed). IR: $v_{\text {ester }}=1735 \mathrm{~cm}^{-1}, v_{\text {ester }}=1641 \mathrm{~cm}^{-1}$. ESI-MS: obs'd (\%), calc'd (\%), ppm, (M+Na) ${ }^{+}: 337.1(100), 337.1006$ (100), 1.8.

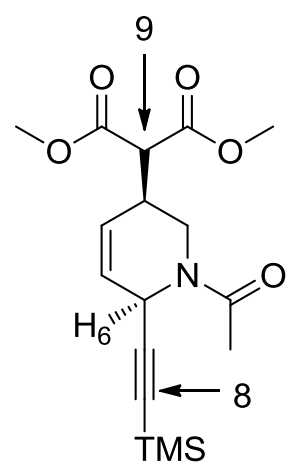

Dimethyl-2-(1-acetyl-6-((trimethylsilyl)ethynyl)-1,2,3,6-tetrahydropyridin-3-yl)malonate. 35. One pot method: General procedure 1 was used to generate the tetrahydropyridine complex precursor. Test tube 1: 9 (0.100 g, $0.138 \mathrm{mmol})$; HOTf (0.022 g, $0.146 \mathrm{mmol})$; MeCN (1.09 g). Test tube 2: LiDMM (0.057 g, $0.413 \mathrm{mmol}) ; \operatorname{MeCN}(0.74 \mathrm{~g})$. Oxidation of the complex was performed following general procedure 3. Acetone $(4.1 \mathrm{~g})$; CAN (0.077 g, $0.140 \mathrm{mmol})$; reaction time: $1 \mathrm{~h}$. General procedure 5 was followed to isolate the product. Pale yellow oil from the band located between $r_{f}=0.45$ and $r_{f}=0.65$ when $\mathrm{Et}_{2} \mathrm{O}$ was used as the eluent $(0.027 \mathrm{~g}, 0.0768$ mmol, $55 \%$ yield). ${ }^{1} \mathrm{H} \mathrm{NMR}\left(\mathrm{CDCl}_{3}, \delta\right): 5.74-5.44$ (m, 3H, $\mathrm{H} 4$ (maj,min)/H5(maj,min)/H6(maj)) 4.70 (s, $1 \mathrm{H}, \mathrm{H} 6(\min )), 4.50(\mathrm{dd}, J=12.7,4.2,1 \mathrm{H}, \mathrm{H} 2(\min )), 3.83(\mathrm{dd}, J=13.6,4.3,1 \mathrm{H}, \mathrm{H} 2), 3.64(\mathrm{~s}, 6 \mathrm{H}$, Ester-Me/Ester-Me'), 3.64/3.62 (s, 6H, Ester-Me(min)/Ester-Me'(min)), 3.24 (d, J = 8.1, 1H, 
H9(maj,min)), 3.11 (dd, $\left.J=13.6,12.7,1 \mathrm{H}, \mathrm{H} 2{ }^{\prime}\right), 2.88(\mathrm{~m}, 1 \mathrm{H}, \mathrm{H} 3$ (maj,min)), 2.55 (dd, $J=12.7$, 11.0, 1H, H2'(min)), 2.04 (s, 3H, Amide-Me(min)), 2.02 (s, 3H, Amide-Me), 0.00 (s, 9H, TMS). ${ }^{13} \mathrm{C}$ NMR $\left(\mathrm{CDCl}_{3}, \delta\right)$ : Major: 168.7 (Amide-CO), 168.1 (Ester-CO/Ester-CO'), 128.2/126.4 (C4/C5), 102.1 (C7), 88.3 (C8), 53.7 (C9), 52.9 (Ester-Me/Ester-Me'), 43.8 (C2), 42.6 (C6), 35.5 (C3), 21.4 (Amide-Me), 0.04 (TMS), Minor: 169.6 (Amide-CO), 168.1 (Ester-CO/Ester-CO'), 128.4/125.6 (C4/C5), 101.1 (C7), 89.7 (C8), 53.7 (C9), 52.9/52.7 (Ester-Me/Ester-Me'), 46.9 (C6), 38.5 (C2), 34.6 (C3), 21.7 (Amide-Me), 0.04 (TMS). Isomer Ratio: 1.8:1 (Chemical Exchange Observed). IR: $V_{\text {alkyne }}=2170 \mathrm{~cm}^{-1}, v_{\text {ester }}=1734 \mathrm{~cm}^{-1}, v=1661 \mathrm{~cm}^{-1}$. ESI-MS: obs'd (\%), calc'd (\%), ppm, (M+Na) $)^{+}$: 374.1381 (100), 374.1394 (100), 3.6.

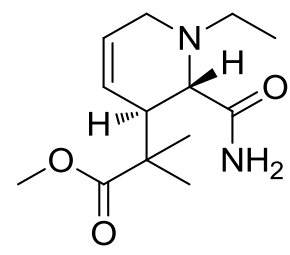

Methyl 2-carbamoyl-1-ethyl-1,2,3,6-tetrahydropyridin-3-yl)-2-methylpropanoate. 36. $\mathrm{NaBH}_{4}$ (0.106 g, $2.80 \mathrm{mmol})$ was added directly to a $25 \mathrm{~mL}$ flame dried Erlenmeyer flask containing a $\tan$ homogeneous solution of $22(0.102 \mathrm{~g}, 0.113 \mathrm{mmol})$ in $\mathrm{MeOH}$ (4.65 g) giving vigorous effervescence. 10 minutes later, after effervescence had ceased, the solution was removed from the glovebox, diluted with $50 \mathrm{~mL} \mathrm{DCM}$, extracted with $3 \times 20 \mathrm{~mL} \mathrm{NaHCO}$ (saturated, aqueous), back-extracted with $2 \times 20 \mathrm{~mL} \mathrm{DCM}$, the combined organic layers were dried with $\mathrm{MgSO}_{4}$, filtered through a $60 \mathrm{~mL}$ medium porosity fritted funnel, and the solvent removed in vacuo. General Procedure 2 was followed to liberate the organic compound. $\mathrm{SiO}_{2}(10.0 \mathrm{~g})$; reaction time: $16 \mathrm{~h}$. The residue of the evaporated material revealed that oxidation was incomplete with 3:1 ratio of 22:24. The crude material was replaced in a $250 \mathrm{~mL}$ flask with the original $\mathrm{SiO}_{2}$ and $\mathrm{EtOAc}$ and General Procedure 2 was resumed to enable complete liberation. Reaction time: $171 \mathrm{~h}$. General Procedure 5 was followed to isolate the piperidine. Pale yellow solid from the band located 
between $r_{f}=0.21$ and $r_{f}=0.29$ when $\mathrm{Et}_{2} \mathrm{O}$ was used as the eluent $(0.010 \mathrm{~g}, 0.038 \mathrm{mmol}, 34 \%$ yield). Melting Point: $64-68{ }^{\circ} \mathrm{C} .{ }^{1} \mathrm{H}$ NMR $\left(\mathrm{CDCl}_{3}, \delta\right): 6.10$ (s(br), $\left.1 \mathrm{H}, \mathrm{NH}\right), 5.99$ (dddd, $\mathrm{J}=10.2,4.0$, 2.4, 1.8, $1 \mathrm{H}, \mathrm{H} 5$ ), 5.65 (dddd, $\mathrm{J}=10.2,4.6,2.6,2.3,1 \mathrm{H}, \mathrm{H} 4), 5.30(\mathrm{~s}(\mathrm{br}), 1 \mathrm{H}, \mathrm{NH}), 3.71(\mathrm{~s}, 3 \mathrm{H}$, Ester-Me), 3.44 (dddd, J = 17.5, 2.8, 2.6, 2.4, 1H, H6), 3.31 (d, J = 1.0, 1H, H2), 3.24 (dddd, J = 17.5, 24.0, 2.3, 1.6, $\left.1 \mathrm{H}, \mathrm{H} 6^{\prime}\right), 2.75$ (ddddd, J = 4.6, 2.8, 1.8, 1.6, 1.0, $1 \mathrm{H}, \mathrm{H} 3$ ), 2.7 (dq, J = 12.5, 7.3, 1H, H7), 2.63 (dq, J = 12.5, 7.3, 1H, H7'), 1.24 (s, 3H, Gem-Me), 1.23 (s, 3H, Gem-Me'), 1.06 (t, J = 7.3, 3H, Ethyl-Me). ${ }^{13} \mathrm{C}$ NMR (CDCl $\left.3, \delta\right): 179.0$ (Ester-CO), 175.7 (Amide-CO), 129.4 (C5), 121.6 (C4), 61.3 (C2), 52.2 (Ester-Me), 49.3 (C7), 47.3 (C8), 47.2 (C6), 45.0 (C3), 25.1 (Gem-Me), 21.6 (Gem-Me'), 13.2 (C8). IR: $v=3438(\mathrm{br}) \mathrm{cm}^{-1}, v=3341(\mathrm{br}) \mathrm{cm}^{-1}, v=3194(\mathrm{br}) \mathrm{cm}^{-1}, v=2975 \mathrm{~cm}^{-1}$, $v=2935 \mathrm{~cm}^{-1}, v_{\text {ester }}=1723 \mathrm{~cm}^{-1}, v_{\text {amide }}=1669 \mathrm{~cm}^{-1}, v=1246 \mathrm{~cm}^{-1}, v=1133 \mathrm{~cm}^{-1}$. ESI-MS: obs'd (\%), calc'd (\%), ppm, (M+H)+: 255.1709 (100), 255.1703 (100), 2.1.

\section{References.}

(1) Davies, S. G.; Shipton, M. R. In Journal of the Chemical Society, Chemical Communications 1989, p 995-996.

(2) Fish, R. H.; Kim, H. S.; Fong, R. H. Organometallics 1989, 8, 1375-1377.

(3) Wucherer, E. J.; Muetterties, E. L. Organometallics 1987, 6, 1691-1695.

(4) Meiere, S. H.; Brooks, B. C.; Gunnoe, T. B.; Sabat, M.; Harman, W. D. Organometallics $2001,20,1038-1040$.

(5) Cordone, R.; Harman, W. D.; Taube, H. J. Am. Chem. Soc. 1989, 111, 2896-2900.

(6) Cordone, R.; Taube, H. J. Am. Chem. Soc. 1987, 109, 8101-8102.

(7) Bonanno, J. B.; Viege, A. S.; Wolczanski, P. T.; Lobkovsky, E. B. Inorganica Chimica Acta $2003,345,173-184$. 
(8) Kleckley, T. S.; Bennett, J. L.; Wolczanski, P. T.; Lobkovsky, E. B. J Am. Chem. Soc. 1997, $119,247-248$.

(9) Covert, K. J.; Neithamer, D. R.; Zonnevylle, M. C.; LaPointe, R. E.; Schaller, C. P.; Wolczanski, P. T. Inorg. Chem. 1991, 30, 2493-2508.

(10) Neithamer, D. R.; Parkanyi, L.; Mitchell, J. F.; Wolczanski, P. T. J. Am. Chem. Soc. 1988, $110,4421-4423$.

(11) Davies, S. G.; Edwards, A. J.; Shipton, M. R. J. Chem. Soc., Perkin Trans. 1991, 1009-1017.

(12) Harrison, D. P.; Welch, K. D.; Nichols-Nielander, A. C.; Sabat, M.; Myers, W. H.; Harman, W. D. J. Am. Chem. Soc. 2008, 130, 16844-16845.

(13) Welch, K. D.; Harrison, D. P.; Lis, E. C.; Liu, W.; Salomon, R. J.; Harman, W. D.; Myers, W. H. Organometallics 2007, 26, 2791-2794.

(14) Kosturko, G. W.; Harrison, D. P.; Sabat, M.; Myers, W. H.; Harman, W. D. Organometallics 2009, 28, 387-389.

(15) The term dihydropyridine is a generic description of the 2-substituted 1-acetyl-1,2dihydropyridine ligands found in Scheme 2.

(16) Harrison, D. P.; Zottig, V. E.; Kosturko, G. W.; Welch, K. D.; Sabat, M.; Myers, W. H.; Harman, W. D. Organometallics 2009, 28, 5682-5690.

(17) Carbery, D. R. Org. Biomol. Chem. 2008, 6, 3455-3460.

(18) Lis, E. C.; Delafuente, D. A.; Lin, Y.; Mocella, C. J.; Todd, M. A.; Liu, W.; Sabat, M.; Myers, W. H.; Harman, W. D. Organometallics 2006, 25, 5051-5058.

(19) Liu, W.; You, F.; Mocella, C. J.; Harman, W. D. J. Am. Chem. Soc. 2006, 128, 1426-1427.

(20) Schilling, B. E. R.; Hoffmann, R.; Faller, J. W. J. Am. Chem. Soc. 1979, 101, 592-598.

(21) Villanueva, L. A.; Ward, Y. D.; Lachicotte, R.; Liebeskind, L. S. Organometallics 1996, 15, 4190-4200. 
(22) Tsang, J. Y. K.; Buschhaus, M. S. A.; Fujita-Takayama, C.; Patrick, B. O.; Legzdins, P. Organometallics 2008, 27, 1634-1644.

Mocella, C. J.; Delafuente, D. A.; Keane, J. M.; Warner, G. R.; Friedman, L. A.; Sabat, M.; Harman, W. D. Organometallics 2004, 23, 3772-3779.

Due to the diastereotopic nature of the purported resulting methylene group, deprotonation of such a species likely would also be exo-stereoselective, thus preventing net deuterium incorporation.

(25) McEwen, W. E.; Calabro, M. A.; Mineo, I. C.; Wang, I. C. J. Am. Chem. Soc. 1973, 95, 2392-2393.

(26) McEwen, W. E.; Cobb, R. L. Chemical Reviews 1955, 55, 511-549.

(27) Perrin, S.; Monnier, K.; Laude, B.; Kubicki, M.; Blacque, O. Eur. J. Org. Chem. 1999, 297303.

(28) Keane, J. M.; Harman, W. D. Organometallics 2005, 24, 1786-1798.

(29) Control reactions have deterimined that silica was not necessary for demetallation with $\mathrm{O}_{2}(\mathrm{~g})$, but that its inclusion significantly decreases the required reaction time (from 1 week to $<15 \mathrm{~h})$.

(30) Molander, G. A.; Jean-Gérard, L. The J. Org. Chem. 2009, 74, 5446-5450.

(31) Schoeps, D.; Sashuk, V.; Ebert, K.; Plenio, H. Organometallics 2009, 28, 3922-3927.

(32) Fors, B. P.; Krattiger, P.; Strieter, E.; Buchwald, S. L. Organic Letters 2008, 10, 3505-3508.

(33) Yuan, X.; Liu, K.; Li, C. The Journal of Organic Chemistry 2008, 73, 6166-6171.

(34) Taniguchi, T.; Yonei, D.; Sasaki, M.; Tamura, O.; Ishibashi, H. Tetrahedron 2008, 64, 26342641.

(35) Schleich, S.; Helmchen, G. n. Eur. J. Org. Chem. 1999, 2515-2521. 
(36) Evans, D. A.; Campos, K. R.; Tedrow, J. S.; Michael, F. E.; Gagné, M. R. J. Am. Chem. Soc. $2000,122,7905-7920$.

(37) Miller, J. F.; Termin, A.; Koch, K.; Piscopio, A. D. J. Org. Chem. 1998, 63, 3158-3159. 
Chapter 5

Reversing the Polarization of the Pyridine: Formal [4+2] Cycloadditions with Dihydropyridine Complexes of $\left\{\mathrm{TpW}\left(\mathrm{PMe}_{3}\right)(\mathrm{NO})\right\}$ and the Generation of Tri- and Tetrasubstituted Piperidines. 


\section{Introduction:}

Expanding "chemical space" plays an important role in the discovery of new biologically active compounds. Methodologies that allow for easy substituent derivation allows for the possibility of performing structure activity relationships within a biological pathway and are highly sought out.

Piperidines are among the simplest core frameworks of naturally occurring biologically active compounds. As such, fundamental methodologies that are capable of producing derivatives of piperidine in a highly controlled manner have been and are currently under investigation. Most notably, the Comins group has developed a program that has allowed for the selective modification of every position of the piperidine ring. ${ }^{1}$ Their elegant research has allowed for the subsequent synthesis of more than 40 enantiomerically enriched natural products, not to mention countless other unnatural products made throughout the process. Other key players in the field of piperidine methodology development include Marazano ${ }^{2,3}$ and Charette ${ }^{4}$, Bosch, ${ }^{5}$ and Husson and Royer $^{6}$ who utilize chiral pyridinium salts, bicyclic lactams, and cyanide substituent modifications, respectively.

Less is known about transition metal based methodologies for the generation of piperidine compounds. That being said, the Liebeskind group has taken significant strides in the development of a methodology which uses stoichiometric quantities of molybdenum, a cheap transitional metal, to enable novel organic reaction schemes and has led to the enantioselective synthesis of several natural products. Piperidine precursors are derived from an aza-Achmatowicz rearrangement of furans and holds 
great promise as useful starting materials for more enantiomerically pure piperidine compounds. $^{7}$

Our approach, which utilizes pyridines coordinated to $\left\{\mathrm{TpW}(\mathrm{NO})\left(\mathrm{PMe}_{3}\right)\right\}$ as starting materials (because of its low cost, availability, and our experience with dearomatization chemistry), provides a complementary synthetic sequence for the development of piperidine compounds. Initially, we were hampered by nitrogen coordination to the $\mathrm{W}$ atom, which leaves the aromatic system intact and still difficult to modify. ${ }^{8-11}$ However, we found that blocking the nitrogen with borane (e.g. pyridine borane) prevents nitrogen coordination and provides access to the aromatic system, which is disrupted by $\eta^{2}$ coordination. Conversion to an acetyl pyridinium complex, $\mathbf{1}$, has proven useful as a synthon for nove piperidines. ${ }^{12-16}$ Mild regio- and stereoselective synthesis of carbon bound, $\eta^{2}$ 1,2-dihydropyridine (DHP) complexes are easily obtained from 1d (Scheme 1). ${ }^{14}$ The coordination diasteriomer ratio (cdr) of the starting material is maintained in the isolated DHP complexes.

In a recent report, we employed this array of DHP complexes in the generation of 1,3-disubstituted and 1,2,5-trisubstituted tetrahydropyridine (THP) complexes in a tandem protonation/nucleophilic addition methodology. ${ }^{13}$ Importantly, we utilized the metal not only to block addition to one face of the coordinated ligand to give complete stereocotrolled addition but also utilized the metal to reverse (i.e. umpolung) the polarity of the alkene conjugated to the amide (i.e. enamide), and produce novel piperidinamide organic compounds with complete regiocontrol (Figure 1). 


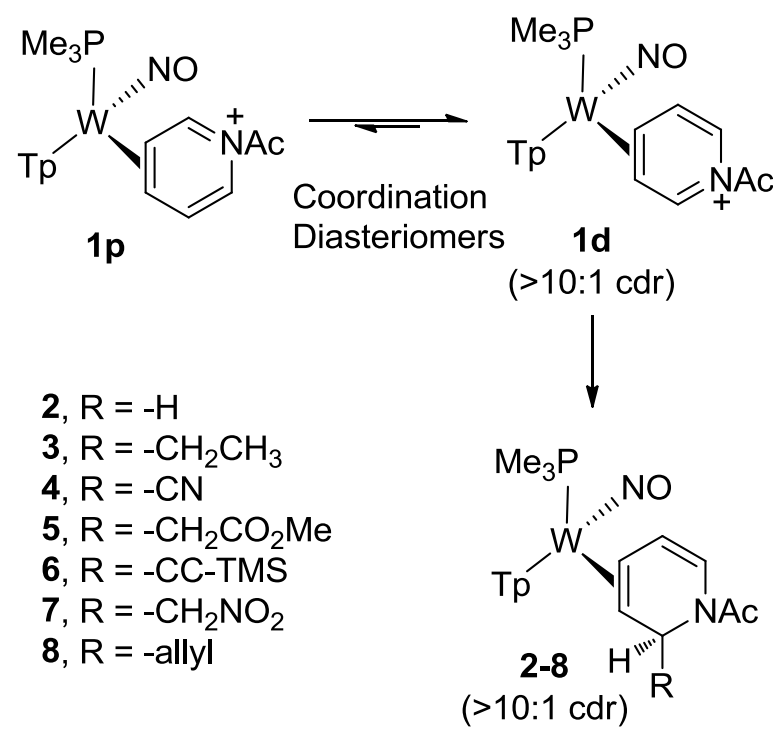

Scheme 1: Synthesis of DHP complexes.

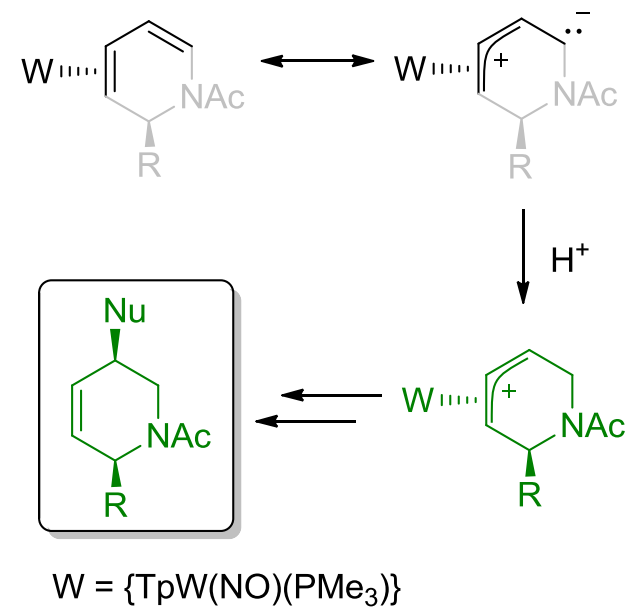

Figure 1: Metal umpolung of DHP complexes produce novel piperidinamides. ${ }^{13}$

With the fundamental reactivity of the DHP complexes in mind and desiring to expand chemical space, we set out to determine whether or not $\left\{\mathrm{TpW}(\mathrm{NO})\left(\mathrm{PMe}_{3}\right)\right\}$ could (1) facilitate stereoselective cycloaddition reactions with DHP complexes (2) utilize the metal repolarization of the DHP complexes to produce azabicyclooctene cores with 
unnatural regiochemistries and (3) use these new complexes as divergence points for additional metal mediated modification. The following report details our findings.

\section{Results and Discussion:}

First, monitoring reactions with ${ }^{31} \mathrm{P} N M R$, we explored the possibility of adding traditional dienophiles such as $\mathrm{N}$-methyl maleamide, phenyl vinyl sulfone, methyl vinyl ketone (MVK), other Michael acceptors, etc. to the DHP complexes and found that no reactions took place at room or slightly elevated temperature in non-polar, polar aprotic, or protic solvents without the use of a Lewis acid. However, when a solution of MVK and $\mathrm{Yb}(\mathrm{OTf})_{3}$ in $\mathrm{MeOH}$ were exposed to 2 in ${ }^{31} \mathrm{P} N M R$, the disappearance of $\mathbf{2}$ and the appearance of two new species, the major species having a $J_{W P}=267 \mathrm{~Hz}$, a $14 \mathrm{~Hz}$ difference from $2\left(J_{W P}=281 \mathrm{~Hz}\right)$, indicated a reaction had occurred. The reaction scale was increased and material was isolated in a in a ratio of $7: 1$ and $44 \%$ yield. The lack of alkene resonances and the appearance of three new methine signals at 5.27, 3.15, and $3.13 \mathrm{ppm}$, two geminal sets, and two methyl signals indicated that MVK had been incorporated into the pyridine ring core (Scheme 2). COSY data indicates that the methine at $5.27 \mathrm{ppm}(\mathrm{H} 1)$ couples to a geminal set, which couples to the acyl methine, which couples to a methine at $3.13 \mathrm{ppm}(\mathrm{H} 4)$. This methine in turn couples to the second geminal set and a bound proton (H5) that couples to another bound proton. NOESY data shares these COSY correlations and additional signals that offer some regiochemical insight. The key interactions of $\mathrm{H} 1$ with $\mathrm{PMe}_{3}$ and $\mathrm{H} 4$ with a pyrazole proton trans-to- $\mathrm{PMe}_{3}$ indicates the orientation of the THP ligand is that shown in 
Scheme 4. Supported by HSQC and HMBC data, COSY and NOESY data indicates that the methylene of MVK (i.e. the electrophilic portion) has been incorporated into the DHP ring $\alpha$-to- $\mathrm{N}$ followed by ring closure of the enolate, to generate the formal $[4+2]$ cycloadduct, 9. Additionally, an nOe interaction between the acetyl methyl at $2.14 \mathrm{ppm}$ and a bound proton at $0.97 \mathrm{ppm}$ indicated that the acetyl group is oriented over the bound alkene, to give the endo adduct. The reversal of the enamide polarity previously discovered by our group is maintained with the addition of MVK $\alpha$-to-N. Characterization of the minor species was difficult due to overlapping resonances with the major species. However, the minor species is likely a stereoisomer (e.g. amide rotamer or acyl configurational isomer) of the major species due to the similarity of the signals for each of the non-overlapping resonances. Of note, exposure of $\mathbf{2}$ in $\mathrm{CDCl}_{3}$ to MVK, 2,6-di-tert-butylpyridine (DTBP), and $\mathrm{BF}_{3} \cdot \mathrm{Et}_{2} \mathrm{O}(0.018,0.228,0.094$, and $0.042 \mathrm{M}$, respectively), accelerates the completion of the reaction to within $0.5 \mathrm{~h}$ (rather than overnight for $\mathrm{Yb}(\mathrm{OTf})_{3}$ conditions).

As with MVK, ${ }^{1} \mathrm{H}$ and/or ${ }^{31} \mathrm{P}$ NMR was used to monitor reactions of other dienophiles with 2 when using either the $\mathrm{Yb}(\mathrm{OTf})_{3}$ or $\mathrm{BF}_{3}$ conditions. Cyclohex-2-enone, methyl acrylate, maleimide, $N$-phenyl maleimide, phenyl vinyl sulfone, methyl propiolate, or dimethyl but-2-ynedioate did not undergo the desired cycloaddition reactions. $\beta$-nitrostyrene and $\mathrm{Yb}(\mathrm{OTf})_{3}$ are promising via ${ }^{31} \mathrm{P} \mathrm{NMR}$ as one major species of a desirable $J_{W P}(259 \mathrm{~Hz})$ was observed alongside 2 additional signals (5:1.5:1). With acrolean, numerous species resulted but the major complex signals resembled that of 9 $\left({ }^{1} \mathrm{H},{ }^{31} \mathrm{P}\right.$, and $\left.J_{W P}\right)$. Likewise, methyl acrolean and crotin aldehyde both produced spectra 
where the major species also resemble 9 but again have several minor species. However, when $\mathrm{BF}_{3} \cdot \mathrm{Et}_{2} \mathrm{O}$ is added to a solution of $\mathbf{2}, \mathrm{CDCl}_{3}$, trans-cinnimaldehyde, and DTBP a precipitate immediately forms. When this precipitate is dissolved in DMSO- $d_{6}$ shortly after precipitation, three species are observed. The major species resembles 9 via ${ }^{1} \mathrm{H} \delta^{\prime} s,{ }^{31} \mathrm{P} \delta$ 's and $J_{W P}$ 's, while the two minor species have resonances that are characteristic of pyridinyl allyic species of $\left\{\mathrm{TpW}(\mathrm{NO})\left(\mathrm{PMe}_{3}\right)\right\} .{ }^{13}$ When the precipitate that initially forms is allowed to stir overnight, the enolate of the presumed allylic intermediate (from the Michael addition) closes down on the allyl to complete the formal [4+2] cycloadditions and allows for the isolation of one compound, 10 . The structure of $\mathbf{1 0}$ has been fully characterized via 2D NMR techniques as is consistent with the proposed structure. Interestingly, the upfield shift of the amide methyl in ${ }^{1} \mathrm{H} N M R$, from typical values of $\sim 2.1$ to $1.34 \mathrm{ppm}$, indicates that the amide is in the shielding region of the phenyl group and allowed us to assign the stereochemistry of the carbon atom that is attached to the phenyl group. Combined with an nOe interaction of the aldehyde and $\mathrm{H5}$, this data indicates the formal [4+2] endo cycloadduct formed.

Unfortunately, we were unable to induce a [4+2] cycloaddition reaction with the 2-substituted DHP complexes with $\mathrm{Yb}(\mathrm{OTf})_{3}$. However, addition of $\mathrm{BF}_{3} \cdot \mathrm{Et}_{2} \mathrm{O}$ to a solution of 3, $\mathrm{CDCl}_{3}$, trans-cinnimaldehyde, and DTBP produced one major (and several minor) complex overnight. NMRs of the crude reaction solution revealed ${ }^{1} \mathrm{H}$ methine signals and a $J_{\mathrm{WP}}=261 \mathrm{~Hz}\left({ }^{31} \mathrm{P}\right.$ NMR) that are characteristic of the azabicyclooctene complexes 9 and 10. Although it was not pursued further in this work, the results of the reaction with 3 and cinnimaldehyde suggest that upon optimization of reaction conditions formal 
[4+2] cycloadditions with 2-substitued DHP complexes and Michael acceptors are accessible.

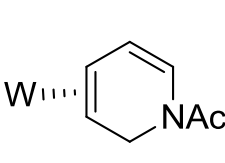

2

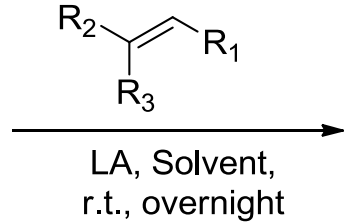

9: $44 \%$ yield; $\mathrm{Yb}(\mathrm{OTf})_{3}, \mathrm{MeOH}$

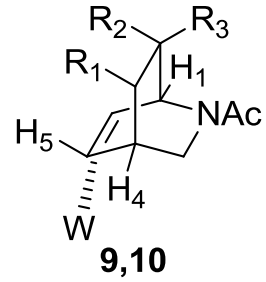

10: $65 \%$ yield; $\mathrm{BF}_{3} \cdot \mathrm{Et}_{2} \mathrm{O}, \mathrm{DTBP}, \mathrm{CDCl}_{3}$

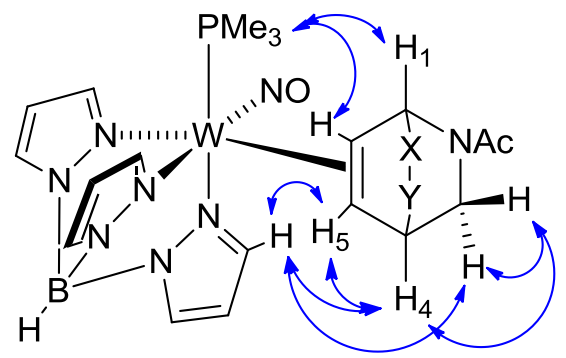

9: $\mathrm{R}_{1}=(\mathrm{CO}) \mathrm{CH}_{3}, \mathrm{R}_{2}=\mathrm{R}_{3}=\mathrm{H}, X=\mathrm{CH}_{2}, \mathrm{Y}=\mathrm{CH}(\mathrm{CO}) \mathrm{CH}_{3}$ 10: $\mathrm{R}_{1}=(\mathrm{CO}) \mathrm{H}, \mathrm{R}_{2}=\mathrm{H}, \mathrm{R}_{2}=\mathrm{Ph}, \mathrm{X}=\mathrm{CHPh}, \mathrm{Y}=\mathrm{CH}(\mathrm{CO}) \mathrm{H}$

Scheme 2: MVK addition of $\mathbf{2}$ and key NOE interactions (in blue) for the major species.

Next, we decided to investigate the ability of nitroso reagents to react with DHP complexes. Nitroso Diels-Alder reactions with dienes are a valuable source of heteroatom incorporation into structural frameworks. ${ }^{17-20}$ Also, in one report nitrosobenzene was found to undergo [4+2] hetero Diels-Alder cycloaddition reactions at room temperature (without the assistance of Lewis acids) with stable organic DHP compounds similar to the ligands of the DHP complexes presented here. ${ }^{21}$ The report found that oxygen attachment occurs $\alpha-$ to-N of the DHP compounds. We were curious 
whether coordination of the DHP compounds to the $\left\{\mathrm{TpW}(\mathrm{NO})\left(\mathrm{PMe}_{3}\right)\right\}$ would produce a different regiochemical connectivity.

When the commercially available nitrosobenzene (NOB) was exposed to several DHP complexes, a reaction proceeded slowly over a period of several days before stalling and decomposition proceeded, as monitored by ${ }^{1} \mathrm{H}$ and ${ }^{31} \mathrm{P} N M R$. We found that addition of LiOTf to a solution of NOB, DCM, and MeCN drove the reaction to completion overnight and led to the isolation of new compounds, albeit in low to moderate yields (Figure $2 ; \mathbf{3} \rightarrow \mathbf{1 1}, 48 \% ; \mathbf{5} \rightarrow \mathbf{1 2}, \mathbf{5 2 \% ;} \mathbf{8} \rightarrow \mathbf{1 3}, \mathbf{3 6 \%}$ ). Proton NMR spectra of each of the isolated complexes revealed three unbound methine signals and two bound core pyridine ring resonances. Two of the methine chemical shifts resembled that 9 and 10, where the third methine signal is shifted significantly downfield to, on average, $6.82 \mathrm{ppm}$ (e.g. $1.55 \mathrm{ppm}$ further downfield from the bridgehead methine $\alpha$-to$\mathrm{N}$ of 9). Analysis of the NOESY spectrum of 11-13 indicated an nOe interaction between the phenyl group and one of the upfield shifted methine resonances, which in turn had an NOE with one of the pyrazole protons. This data, accompanied by HSQC, HMBC, and COSY spectra, lead to the regiochemical assignment where the oxygen of NOB added $\alpha$ to-N. A crystal was grown, and although disorder prevented meaningful bond length analysis, X-ray analysis confirmed the proposed connectivity. Therefore, coordination of the metal does not alter the reactivity of the DHPs with nitroso reagents. 

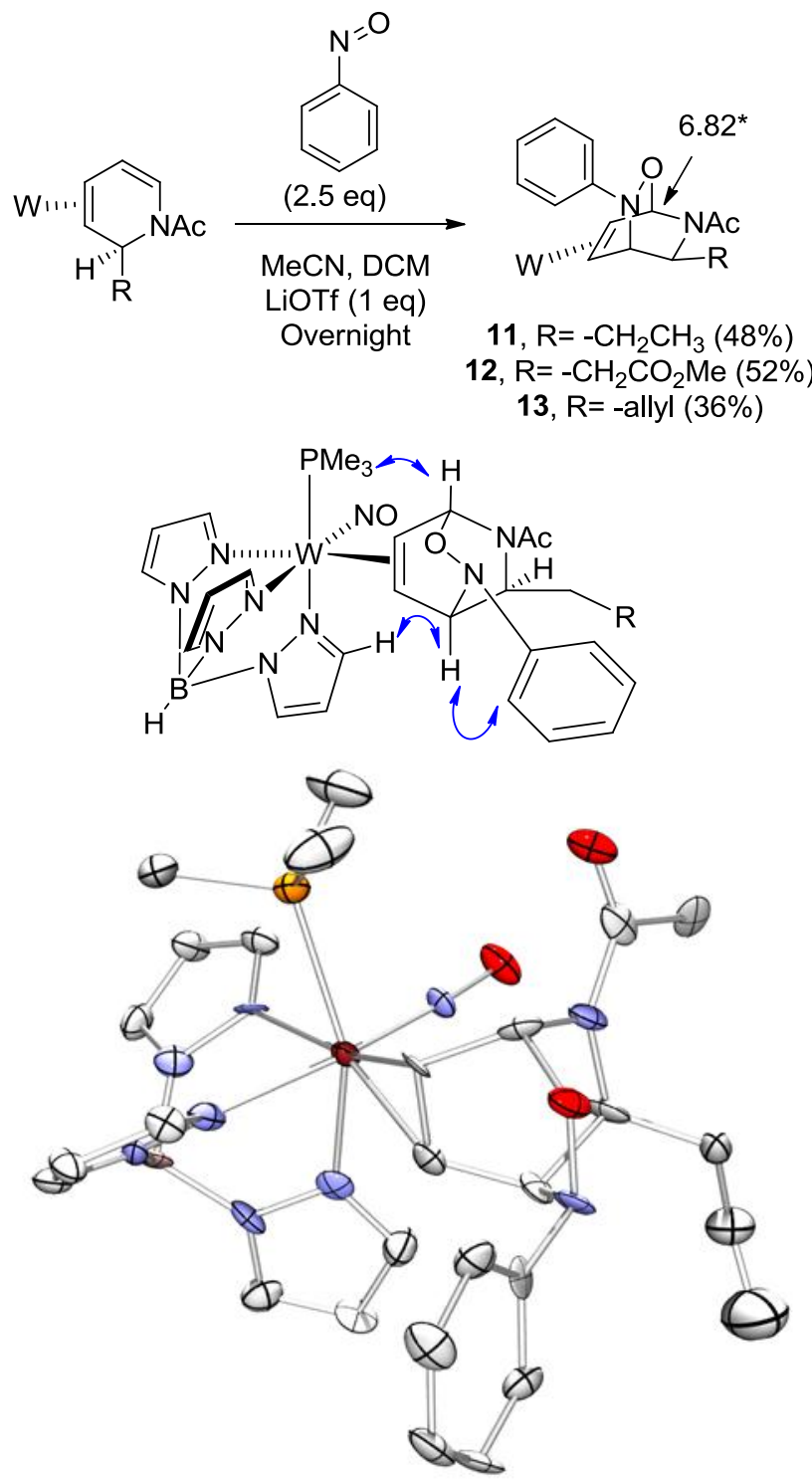

Figure 2: Reaction of NOB with 3, 5, and 8, selected NOESY Interactions of cycloadducts (in blue), and crystal structure of $13 .{ }^{*}$ - average ${ }^{1} \mathrm{H} \delta$ for $11-13$ in ppm.

Recently, our group discovered that ketenes react with an $\eta^{2}$ phenol complex to produce [2+2] cycloadducts, with the electrophilic portion of the ketene adding meta to the oxygen of phenol, which represented a repolarization of phenol as a result of coordination to the metal. ${ }^{22}$ We were inspired by this discovery and wondered if 
ketenes were compatible with DHP complexes and capable of [4+2] cycloadditions additions similar to MVK and NOB. Unfortunately, oxidative decomposition or the formation of intractable mixtures resulted when DHP complexes were exposed to our ketene reaction conditions. ${ }^{22}$ Alternatively, we wondered if isocyanates would be a reasonable and milder alternative for the desired [4+2] additions with the DHP complexes, since the nitrogen congeners to ketenes are more stable and, as a result of this stability, are often commercially available.

Therefore, tosyl isocyanate, Ts-ICN, was added to a solution of $\mathbf{3}$ in $\mathrm{CDCl}_{3}(0.29$ $\mathrm{M}, 0.14 \mathrm{M}$; Ts-ICN, 3). Monitoring the reaction via ${ }^{31} \mathrm{P}$ and ${ }^{1} \mathrm{H} N M R$, revealed the appearance of a single new compound as the starting material was consumed in less than $1 \mathrm{~h}$. For example, a $26 \mathrm{~Hz}$ change in tungsten-phosphorous coupling constant $\left(J_{\mathrm{WP}}=\right.$ $258 \mathrm{~Hz}$ from 284 for $\mathbf{3}$ ) and $0.8 \mathrm{ppm}$ change in ${ }^{31} \mathrm{P}$ chemical shift (-12.9 from -12.09 for $\mathbf{3}$ ) was the first indication that a significantly different species was present. $\ln { }^{1} \mathrm{H} N M R$, the corresponding disappearance of alkene ${ }^{1} \mathrm{H}$ resonances (5.88 and $5.78 \mathrm{ppm}$ ) and the generation of slightly more upfield proton resonances at 5.42 and $5.23 \mathrm{ppm}$ with different coupling patterns, helped support the notion that a new tetrasubstituted piperidine complex that was initially indicated via ${ }^{31} \mathrm{P}$ NMR had formed. The new product, 14, was isolated via precipitation in $84 \%$ yield (Figure 3). Multidimensional NMR data (COSY, NOESY, HSQC, and HMBC) are consistent with a [4+2] cycloadduct. Key NOE interactions indicated in Figure 3 helped confirm that the formal [4+2] cycloadduct had in fact formed. 


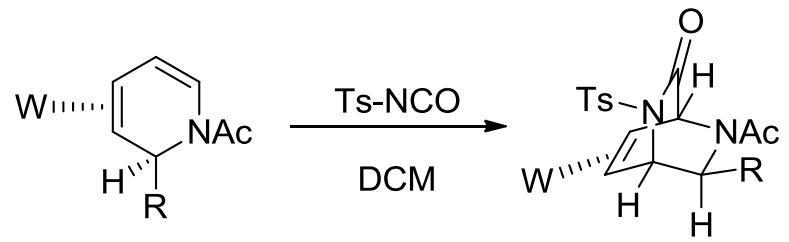

14, $\mathrm{R}=-\mathrm{CH}_{2} \mathrm{CH}_{3}(84 \%)$

15, $\mathrm{R}=-\mathrm{CH}_{2} \mathrm{CO}_{2} \mathrm{Me}(67 \%)$

16, $\mathrm{R}=$-allyl $(80 \%)$

$17, \mathrm{R}=-\mathrm{CC}-\mathrm{TMS}(38 \%)^{*}$

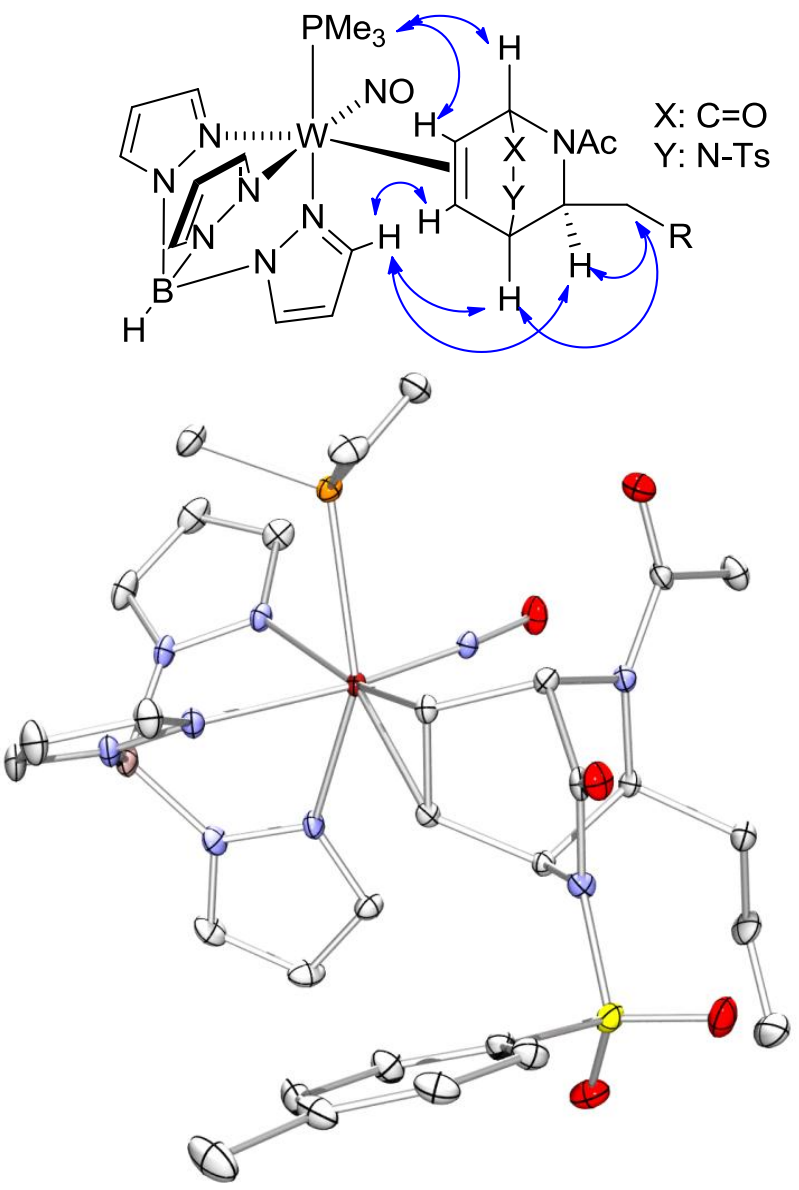

Figure 3: [4+2] Ts-ICN cyclcoadduct synthesis, NOE interactions (blue arrows) for 14-17, and X-ray structure of $16 .^{*}$ - spontaneously precipitated from reaction

To ensure that the reaction was not limited to $\mathbf{3}$, we performed analogous reactions with other DHP complexes. Addition of Ts-ICN to 2 immediately (i.e. $<3$ minutes; the time it took to get to the NMR spectrometer) generated the desired 
species, a result of diminished steric repulsion, but not exclusively as several minor isomers were generated, as observed by ${ }^{31} \mathrm{P}$ NMR. Ts-ICN and 4 began to generate the desired product as observed via ${ }^{31} \mathrm{P}$ NMR but was quite slow under similar concentrations used with $\mathbf{2}$ and $\mathbf{3}$ (e.g. the reaction had not exceeded $80 \%$ conversion after 2 days) and generated several minor side products. Heating the reaction solution to $60{ }^{\circ} \mathrm{C}$ led to the retro-addition of the isocyanate. 5 and $\mathbf{8}$ cleanly generate the desired formal [4+2] cycloadducts 15 and 16 in $67 \%$ and $80 \%$ isolated yields. Also, addition of Ts-ICN to 6 induced a spontaneous precipitation of 17 from the reaction solution in $38 \%$ isolated yield. The structures of $\mathbf{1 4 - 1 7}$ are supported by 2D NMR.

A crystal of 16 was grown and the X-ray data again confirms our initial NMR assignment as the [4+2] adduct (Figure 3). Additionally, the structure confirms the connectivity in which the electrophilic portion of the isocyanate (i.e. $\mathrm{C}=\mathrm{O}$ ) added $\alpha$-to- $\mathrm{N}$ of the DHP ring and the expected anti-to-metal stereoselectivity. We were happy to see that the umpolung discovered in our previous work is maintained with the Ts-ICN cycloadditions and MVK. ${ }^{13}$

After sitting in solution for several days, we noticed that all of the cycloadducts began to convert to two species. One of the species was a new compound while the second was the DHP that was used as the starting material. Eventually, we found that acetic acid catalyzed the conversion of the cycloaddition products, 14 and 15 , to new complexes, 16 and 17 , each with a ${ }^{183} \mathrm{~W}-{ }^{31} \mathrm{P}$ coupling constant of $272 \mathrm{~Hz}, 14 \mathrm{~Hz}$ difference from the cycloadduct and $12 \mathrm{~Hz}$ different than the DHP starting material, without regenerating the DHP starting materials (Figure 4). Isolation of the product was 
achieved after removal of acetic acid with a basic water workup $\left(\mathrm{NaHCO}_{3}\right.$; saturated, aqueous) followed by precipitation of the products from hexanes. NMR data $\left({ }^{1} \mathrm{H},{ }^{13} \mathrm{C}\right.$, COSY, NOESY, HSQC, HMBC) indicated that the azabicyclooctene core was no longer intact (Figure 4). For example, COSY data indicates that 18 has a three proton spin system $(\mathrm{H} 3<->\mathrm{H} 4<->\mathrm{H} 5)$ containing two bound protons and an alkene resonance $(2.42$, 2.79 , and $7.46 \mathrm{ppm}$, respectively), as well as a ${ }^{1} \mathrm{H}$ resonance at $5.54 \mathrm{ppm}$ that couples to the geminal set of the ethyl group but not any other protons. Consistent with other DHP complexes, ${ }^{14}$ we rationalized that the proton at $5.54 \mathrm{ppm}$ is actually adjacent to a bound carbon atom, but simply displaying a small coupling constant (i.e. $<3 \mathrm{~Hz}$ ) due to an appropriate Karplus angle with one of the bound protons (H2; Figure 4). Therefore, we rationalized that the proton $\alpha$-to- $\mathrm{N}(\mathrm{H} 6)$, had been transferred to the Ts-Amide regenerating a DHP, and completing an overall step-wise electrophilic substitution $\alpha$-toN. An X-ray structure of $\mathbf{1 8}$ was obtained and confirmed that an overall electrophilic substitution had taken place (Figure 4). Again, the electrophile adds $\alpha$-to- $\mathrm{N}$ rather than $\beta$-to-N, which organic enamides produce. Addition of acetic acid to 16 also produces features $\left({ }^{1} \mathrm{H}, J_{W P}\right.$, etc.) similar to that of 18 and 19 , indicating by analogy that $\mathbf{1 8 - 2 0}$ are all electrophilic substitution products.

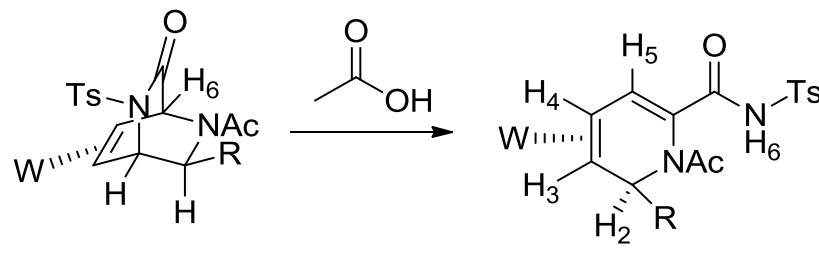

18, $\mathrm{R}=-\mathrm{CH}_{2} \mathrm{CH}_{3}(87 \%)$

19, $\mathrm{R}=-\mathrm{CH}_{2} \mathrm{CO}_{2} \mathrm{Me}(57 \%)$

20, R=-allyl (NMR expt) 


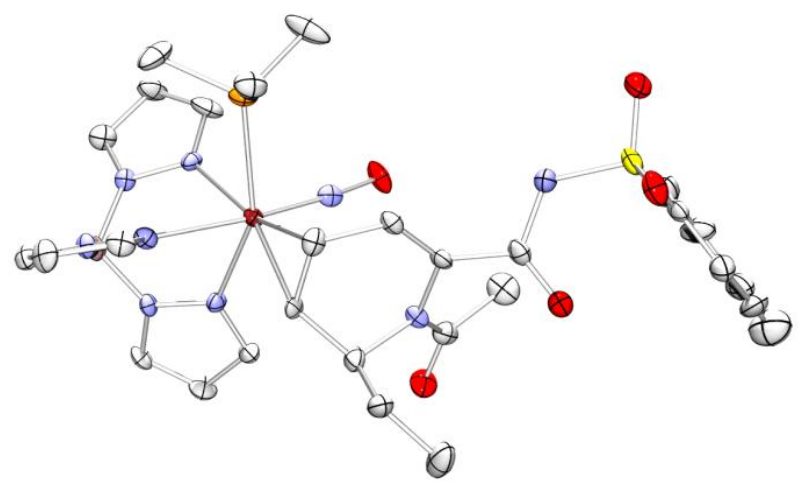

Figure 4: Synthesis of electrophilic substitution products of Ts-ICN and X-tal structure of 18 (hydrogen-bonded $\mathrm{H}_{2} \mathrm{O}$ omitted).

We desired to expand the scope of isocyanate additions by performing the cycloadditions with the less activated isocyanate, phenyl isocyanate. Unfortunately, phenyl isocyanate did not induce the desired addition to DHP complexes, even after elevating reaction temperatures, and varying solvents and Lewis acid conditions. Addition of the more activated chlorosulfonyl isocyanate (CSI), led to intractable mixtures or oxidation of the electron rich DHP complexes.

Alternatively, addition of trichloroacetyl isocyanate (TCA-ICN) to $\mathbf{3}$, resulted kinetically in a mixture of [4+2] cycloadduct and electrophilic substitution $\alpha$-to- $\mathrm{N}$, and eventually converted solely to the electrophilic substitution product, $\mathbf{2 1}$, as monitored via ${ }^{1} \mathrm{H},{ }^{31} \mathrm{P}$ NMR, and $J_{W P}$ (Scheme 3). 21 was isolated in $47 \%$ yield and $2 \mathrm{D}$ data confirmed our assignment. An NMR tube experiment was performed with $\mathbf{5}$ and TCAICN also kinetically formed a mixture of isomers that eventually converted to the electrophilic substitution product, 22. Attempts to isolate the cycloadducts of TCA-ICN solely were unsuccessful. 


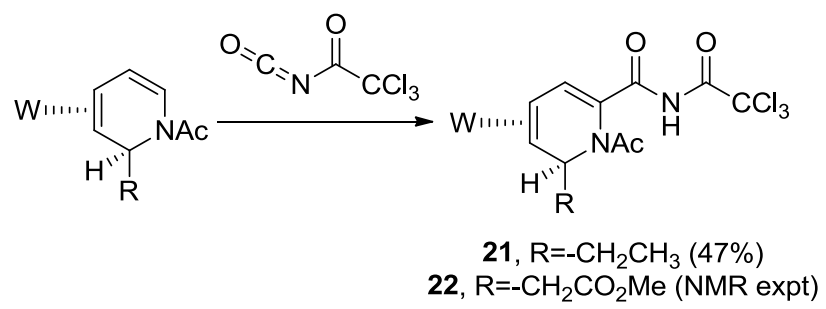

Scheme 3: Electrophilic substitution with TCA-NCO.

Interestingly, addition of TCA-ICN to 2 quickly produced a new complex that did not contain a diastereotopic geminal methylene group. The lack of this feature indicated that a simple electrophilic substitution, analogous to other DHP complexes had not occured. Multidimensional NMR data suggests that $\mathbf{2 3}$ was produced (Scheme 4). The substitution pattern of the DHP core indicates that electrophilic addition occurred $\alpha$-to$\mathrm{N}$ followed by rapid proton transfer from the $\delta$ allyl carbon (rather than the ipsomethine proton that would have served to complete the $\mathrm{E}^{+}$substitution) and generated a DHP complex, which then rapidly underwent an electrophilic substitution $\alpha$-to-N. This explanation is consistent with the notion that the metal fragment has a strong thermodynamic preference to place the positive charge buildup at one of the terminal positions of the coordinated allyl, making the anti proton vicinal to this position kinetically acidic. ${ }^{23}$ Since no anti proton exists at the 2 position of $\mathbf{3}$ and $\mathbf{5}$, electrophilic substitution is the remaining reaction pathway to follow. Addition of TCA-ICN to an NMR solution of $2 p$ in $\mathrm{CDCl}_{3}$, solely produced the $p$-to- $\mathrm{N} \mathrm{E}^{+}$substitution product, 24 (as confirmed by COSY, NOESY, HSQC, HMBC data on the crude reaction solution). 

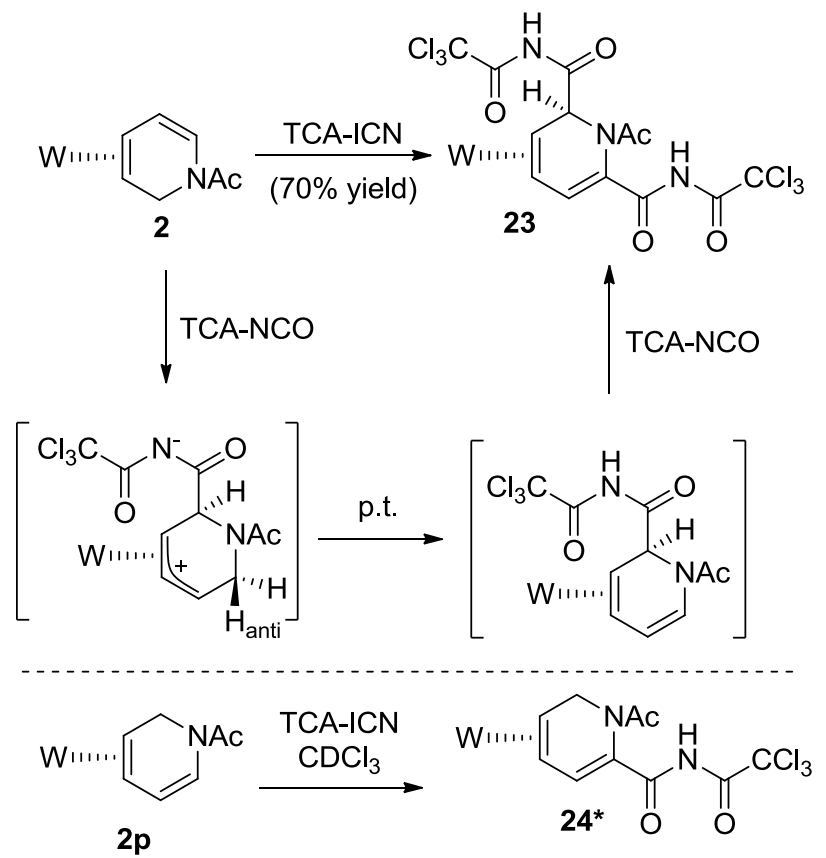

Scheme 4: Reaction of TCA-NCO with 2 and $\mathbf{2 p} .{ }^{*}$ - Generated in situ and confirmed by

2D NMR

Organic $N$-alkoxycarbonyl-1,2-dihydropyridines undergo cycloaddition reactions with MVK after mild heating $\left(50^{\circ} \mathrm{C}\right)$ for 6 days ${ }^{24}$ and, in a separate report, with $\mathrm{N}$ acryloyl-(1S)-2,10-camphorsultam with strong Lewis acids. ${ }^{25,26}$ Enantioselective DielsAlder reactions with $\alpha, \beta$-unsaturated aldehydes are possible $\left(0{ }^{\circ} \mathrm{C} ; 1 \mathrm{~d}\right) .{ }^{27}$ Other Michael acceptors undergo Diels-Alder [4+2] cycloadditions as well. $^{28} \mathrm{~N}$-alkyl-1,2dihydropyridines react with methyl acrylate to produce a [2+2] cycloadduct at low temperature $\left(-10^{\circ} \mathrm{C}\right)$ after 4 days but the $[4+2]$ cycloadduct at elevated temperature (80 ${ }^{\circ} \mathrm{C}$ ) overnight. ${ }^{29,} 30$ The regiochemical outcome of each of the reactions is what is expected for dienamides or dienamines where the electrophiles add $\delta / \beta$-to-N. ${ }^{24-26,28-30}$ Although the DHP complexes did not react with maleimides under our conditions, 
maleimides do undergo [4+2] cycloadditions with DHP compounds. ${ }^{31}$ Since we could find no reports of DHP cycloadditions with isocyanates and because the DHP complex reactivity are similar to dienes, ${ }^{32}$ control reactions with cyclohexa-1,3-diene were performed. Mildly heating cyclohexadiene and TCA-NCO produced no reaction after several days. Heating Ts- $I C N$ and cyclohexadiene in a mixture of $\mathrm{CD}_{3} \mathrm{CN}$ and $\mathrm{CDCl}_{3}$ produced compounds inconsistent with a [4+2] bicycle and is corroberated with patented results. ${ }^{33}$ From the literature, when cyclohexadiene is subjected to $\mathrm{CSI},[2+2]$ cycloadducts kinetically form while [4+2] cycloadducts and electrophilic substitution

products are produced thermodynamically. ${ }^{34,35}$ All of these control reaction lead us to the conclusion that coordination of the DHP complexes to the metal has fundamentally enhanced their reactivity toward addition with isocyanates relative to their organic counterparts.

\section{Post Cyclization Modification:}

Hoping to enter into new chemical space and armed with the knowledge that the metal is capable of supporting allylic species and suspecting that the [2.2.2] cycloadducts proceed through allylic intermediates, we were curious about whether we could produce allylic species by the addition of acid. Trifluoromethanesulfonic acid (HOTf) was therefore added to Ts-ICN [4+2] adducts of $\mathbf{2}$ (generated in situ by the stepwise addition of Ts-ICN to $\mathbf{2}$ followed by addition of HOTf) and $\mathbf{3}$ (generated from isolated 14). They each produced species consistent with highly asymmetric $\eta^{2}$ allyls (Schemes 5 and 6). ${ }^{23}$ Addition of LiDMM to a room temperature solution of $\mathbf{2 5}$ 
reproduced the [4+2] cycloadduct $\left(J_{\mathrm{WP}}=260 \mathrm{~Hz}\right)$, via deprotonation and ring closure, as the major species ( 10:1:1 ratio; two minor isomers present). Over time, these signals converted to a new major isomer $\left(J_{\mathrm{WP}}=277 \mathrm{~Hz}\right)$ consistent with the $\mathrm{C} 6$ electrophilic substitution product (vide supra), as monitored via ${ }^{31} \mathrm{P}$ NMR (Scheme 5). Addition of other nucleophiles or bases to $\mathbf{2 5}$ produce similar results (i.e. deprotonation), no reaction, or intractable mixtures. However, when triethyl amine ( $\mathrm{NEt}_{3}$ ) is added to $\mathbf{2 6}$, a 2-substituted diene complex, 27, was produced and the reaction indicated that nucleophiles may have access to the allyl of the pyridine ring core (Scheme 6). A crystal structure confirmed our 2D NMR assignment of $\mathbf{2 7}$ (see Scheme 6).

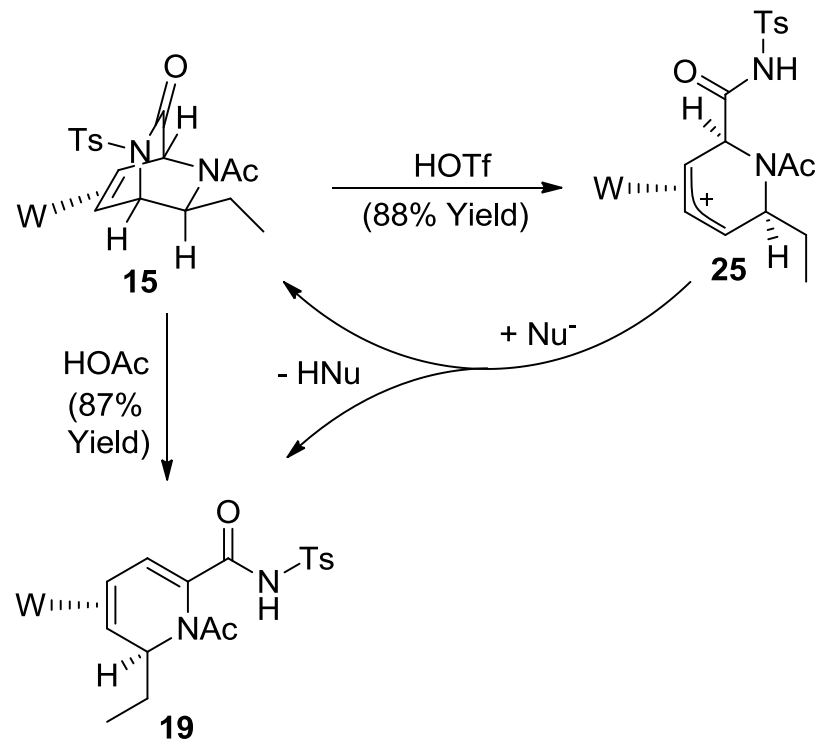

Scheme 5: Synthesis of $\mathbf{2 5}$ and nucleophilic deprotonation of $\mathbf{2 5 .}$

When LiDMM is added to 26 at $0{ }^{\circ} \mathrm{C}$, one clean new species was produced in 78 $\%$ isolated yield (Scheme 7). Methine signals at 5.65 and $2.48 \mathrm{ppm}$, a geminal set, and 2D NMR techniques indicate that the 1,2,5-substituted THP complex, 28, was generated, 
rather than a 1,2,3-THP resulting from vicinal addition. Similarly, nucleophilic addition to $\mathbf{2 6}$ with either $\mathrm{ZnEt}_{2}$ or indole also produce THP complexes, $\mathbf{2 9}$ and $\mathbf{3 0}$ with similar features, confirmed by 2D NMR, in $47 \%$ and $66 \%$ yield, respectively. Presumably, the combined steric bulk of the $\mathrm{C} 2$ and $\mathrm{C} 6$ substituents prevents nucleophilic addition to the allylic fragment and kinetically selects for deprotonation kinetically instead, while the lack of one of these substituents allows access to a terminal allylic position.

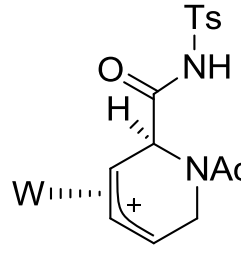

26

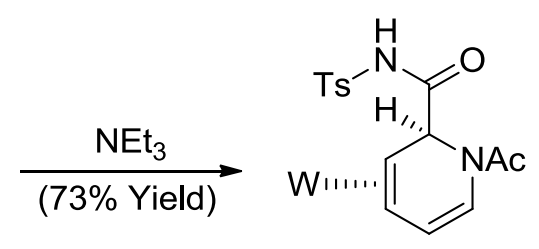

27

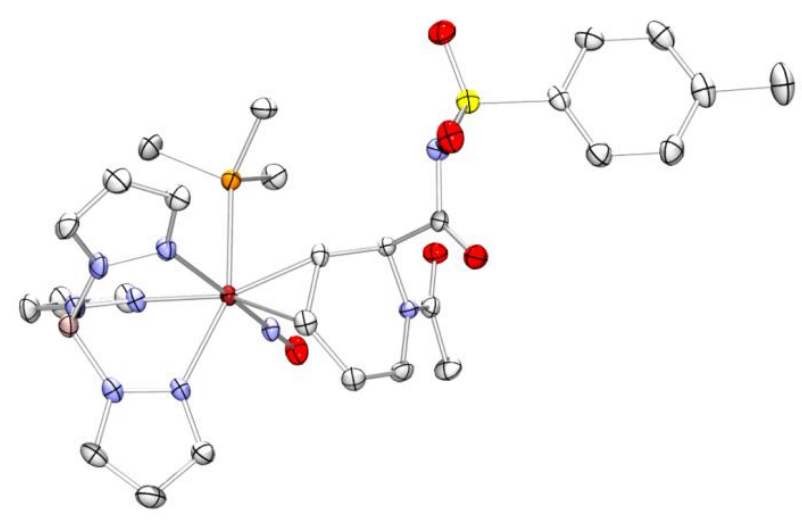

Scheme 6: Deprotonation of $\mathbf{2 6}$ to produce DHP $\mathbf{2 7}$ and X-ray structure of $\mathbf{2 7 .}$

Analogously, addition of HOTf to 9 produced a complex with similar features to that of $\mathbf{2 6}$ but addition of $\mathrm{NEt}_{3}$ or $\mathrm{ZnEt}_{2}$ deprotonated the allyl to produce a species with resonances similar to $\mathbf{2 7}$ or regeneration of $\mathbf{9}$. When LiDMM was added to the allyl of $\mathbf{9}$, a mixture of $\mathbf{9}$ and an additional compound not resembling a diene was produced ( 1:1) but was not pursued further due to the low expected yield and lack of scope. Addition of 
HOTf to 12 led to the decomposition of the complex and prevented any further modification. Attempts to reduce the $\mathrm{N}-\mathrm{O}$ bond eluded us, as our hydrogenation conditions resulted in the retrocycloaddition products, intractable mixtures, or no reaction at all. ${ }^{36,37}$

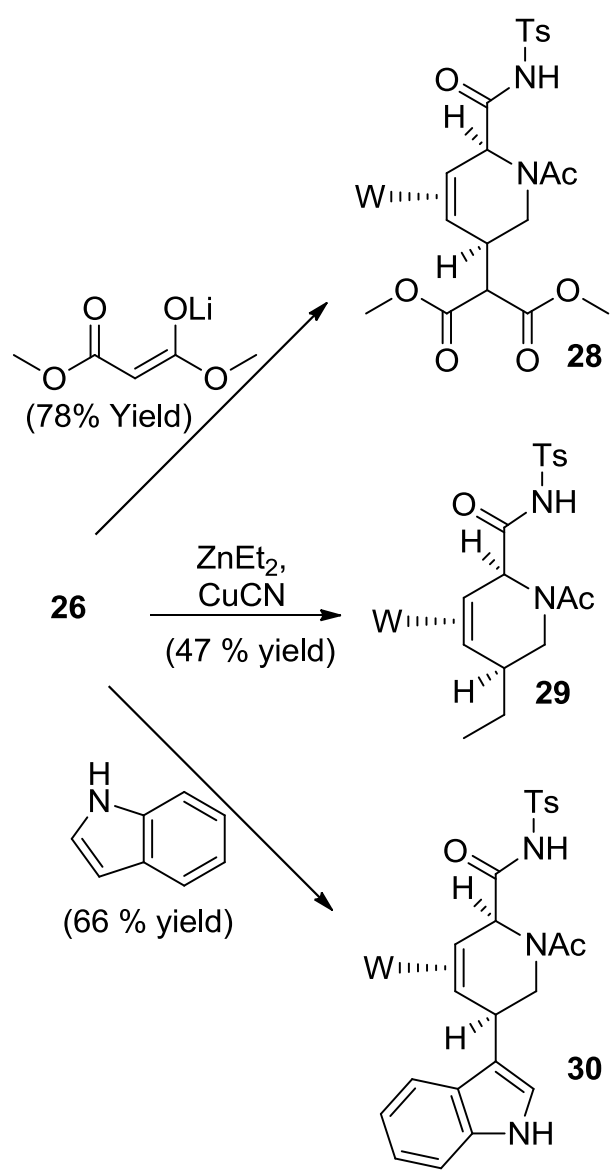

Scheme 7: Nucleophilic addition to 26.

\section{Oxidative Demetallation:}

The most common strategy that we use to remove coordinated ligands is oxidation of the metal complexes. Metal oxidation reduces the electron density utilized to form stable $\pi$ bonds with the coordinated ligand, thus weakening its hold on the $\pi$ ligands and releasing free alkenes. Unfortunately, attempts to liberate the nitroso 
cycloadducts, 11-13, failed. ${ }^{38}$ Oxidation of 9 with molecular oxygen generated several products, likely due to epimerization and the presence of amide rotational isomers. Oxidation of $\mathbf{9}, \mathbf{1 0}, \mathbf{1 4 - 1 7}, \mathbf{2 8}$, and 29 was achieved with 2,3-dichloro-5,6dicyanobenzoquinone (DDQ) and resulted in the liberation of 31-38 (Scheme 10). Oxidation of $\mathbf{3 0}$ with DDQ failed but molecular oxygen was sufficient to liberate $\mathbf{3 9}$ (Scheme 8). ${ }^{13}$ Because additional materials can be found throughout discarded material of the isolation procedure for isocyanate derivatives, the low isolated yields $(19-49 \%)$ are not optimized yields.

Brevianamides, which are toxic metabolites that were first isolated from penicillin in 1969, contain a related bisamide [2.2.2] bicyclooctane core as their main structural feature. ${ }^{39}$ In nature, these compounds are suspected to be produced through intramolecular Diels-Alder cycloadditions of pyrazinones, ${ }^{40,41}$ which have been performed on model pyrazine systems. ${ }^{42-46}$ Compounds 33-36 possess a similar core to the brevianamides and related compounds. ${ }^{47-49}$ Additionally, the indole derivative 39 is structurally quite similar to several serotonin agonists and antagonists. ${ }^{50}$ Some simple 3substituted piperidines can be produced using radical cyclizations or ring closing metathesis of open chain enamides, ${ }^{51-55}$ but in no cases other than our own are tri- or tetrasubstituted piperidines produced with these connectivity patterns in this manner. ${ }^{13}$ As for nucleophilic addition $\beta$-to- $\mathrm{N}$ or electrophiles $\alpha$-to- $\mathrm{N}$, palladium coupling, $\alpha$ lithiation, or other techniques, ${ }^{56-59}$ can produce the desired regiochemistry, but not without rearomatization of the pyridine. Additionally, we have been unable to find any reports of direct electrophilic substitution $\alpha$-to- $\mathrm{N}$ of unsubstituted pyridine. As far as we 
can tell, only one report ${ }^{60}$ exists where electrophilic substitution of a pyridine derivative occurs $\alpha$-to- $N$ with electrophiles other than hydrogen atoms. ${ }^{61}$ Specifically, 3,5dimethoxypyridine 1-oxide incorporates an $\mathrm{N}$-oxide and 2-methoxy groups to help direct electrophilic attack of a nitro group. ${ }^{60}$ Carbamoyl groups can be incorporated $\alpha$-to- $\mathrm{N}$ in pyridine via hydration of 2-cyanopyridine ${ }^{62}$ or $\mathrm{Pd}(0)$ catalysis with pyridyl halides and formamide. ${ }^{63}$
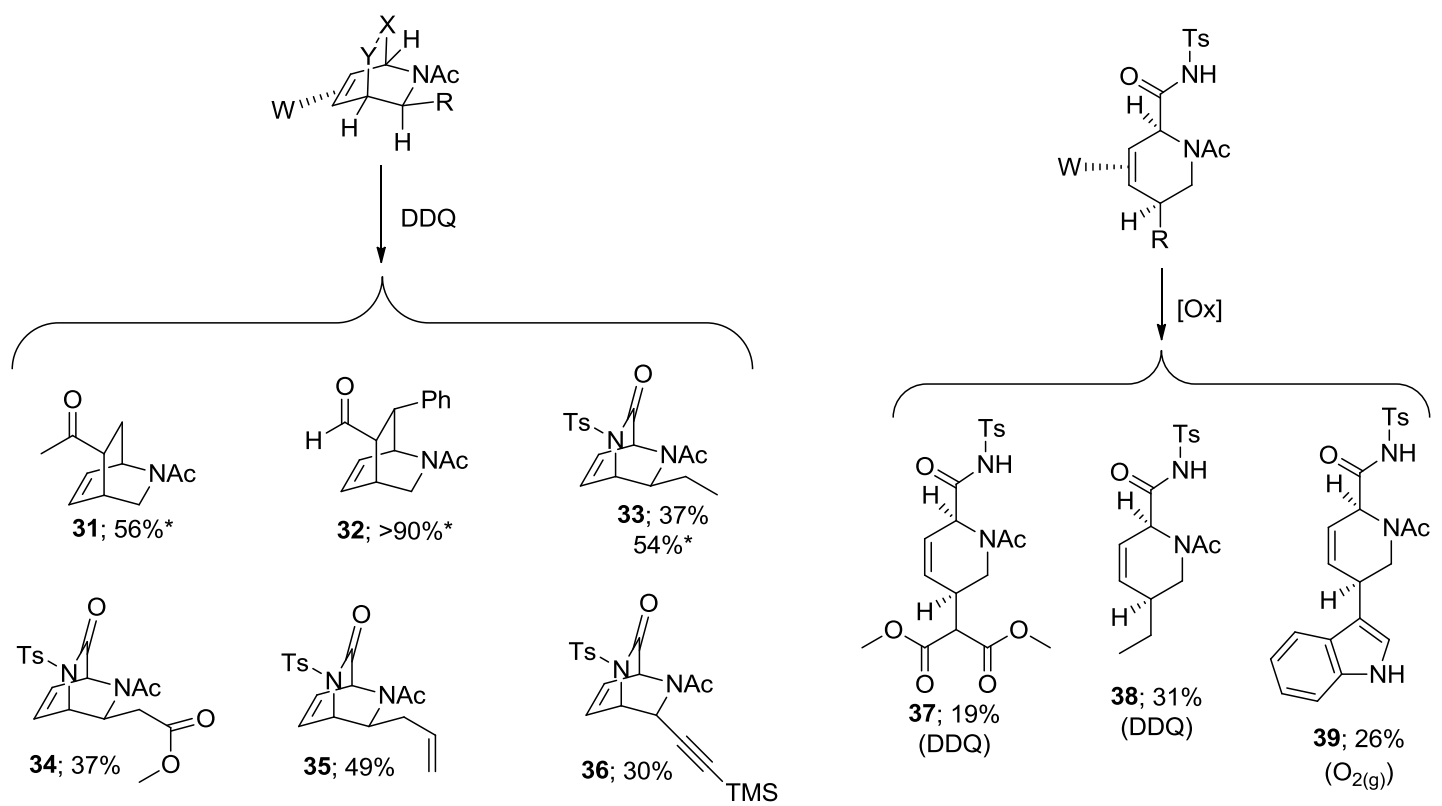

Scheme 8: Liberation of azabicyclooctene, diazabicyclooctane, and carboxamoyl piperidinamides. ${ }^{*}$ - NMR yield; ${ }^{\text {a }}$ - not isolated

\section{Concluding Remarks:}

Several different classes of dieneophiles (e.g. Michael acceptors, nitroso benzene, ketenes, and isocyanates) were explored to determine their ability to perform formal [4+2] cycloadditions with DHP complexes of $\left\{\mathrm{TpW}(\mathrm{NO})\left(\mathrm{PMe}_{3}\right)\right\}$. Except for 
ketenes, each of the dienophile classes that were exposed to the complexes reacted favorably to produce the formal [4+2] cycloadducts. Although we only presented two fully characterized cycloadducts derived from Michael acceptors, preliminary ${ }^{31} \mathrm{P}$ experiments are promising and suggest that the scope may be expanded to include other Michael acceptors as well as 2-substituted DHP complexes. Most importantly, the electrophilic portion of the dieneophiles, with the exception of nitrosobenzene, added to the DHP ring regioselectively $\alpha$-to- $N$, rather than $\beta$-to- $N$, as is obtained from cycloadditions with organic DHP compounds. ${ }^{24-26,28-30}$ Also, dienophile addition is stereoselective anti-to-W, as confirmed by X-ray crystallography for $\mathbf{1 3}$ and $\mathbf{1 6}$. Of note, the [4+2] additions described in this report are fundamentally different than those accessed by exposed dienes and azadienes via $\eta^{2}$ coordination of aromatic systems. ${ }^{9-11,}$ 64

Addition of HOTf to the [4+2] diazabicyclooctene complex of $\mathbf{2}$ produces asymmetric allyls which can then be attacked by mild nucleophiles to produce a different class of THP complexes (1,2,5-trisubstituted piperidines), but only when a single steric group is present $\alpha$-to-N. Nucleophilic addition to the allyl is sterically hindered when both $\alpha$-to- $N$ positions of the ring are occupied by substituents. Importantly, oxidative demetallation with DDQ or molecular oxygen liberates several piperidinamides with two different structural motifs. Starting from a common $\mathrm{N}$-acetylpyridinium complex, $\mathbf{1}$, we have added two new and diverging synthetic pathways to the methodological arsenal of $\left\{\mathrm{TpW}(\mathrm{NO})\left(\mathrm{PMe}_{3}\right)\right\}$ and its ability to modify aromatic pyridine to generate novel 1,2,5,6-tetrasubstituted piperidine compounds. Thus, the W system 
has expanded our access to unexplored chemical space, which cannot be easily achieved without the described metal system.

\section{Experimental Section:}

General Methods: NMR spectra were obtained on a 300, 500, or $600 \mathrm{MHz}$ spectrometer (Varian INOVA or Bruker Avance). All chemical shifts are reported in ppm and proton and carbon shifts are referenced to tetramethylsilane (TMS) utilizing residual ${ }^{1} \mathrm{H}$ or ${ }^{13} \mathrm{C}$ signals of the deuterated solvents as an internal standard. Phosphorus NMR signals are referenced to $85 \%$ $\mathrm{H}_{3} \mathrm{PO}_{4}(\delta=0.00)$ using a triphenylphosphate external standard $(\delta=-16.58)$. Coupling constants $(J)$ are reported in hertz $(\mathrm{Hz})$. Infrared spectra (IR) were recorded as a glaze on a MIDAC Prospect Series (Model PRS) spectrometer fitted with a Horizontal Attenuated Total Reflectance (HATR) accessory (Pike Industries), or on a Nicolet Avatar 360 FT-IR spectrometer equipped with an ASIDiComp diamond anvil ATR assembly. Electrochemical experiments were performed under a dinitrogen atmosphere using a BAS Epsilon EC-2000 potentiostat. Cyclic voltammetry data was taken at ambient temperature at $100 \mathrm{mV} / \mathrm{s}\left(\sim 25^{\circ} \mathrm{C}\right)$ in a standard three-electrode cell with a glassy carbon working electrode, $\mathrm{N}, \mathrm{N}$-dimethylacetamide (DMA) or acetonitrile (MeCN) solvent (unless otherwise specified), and tetrabutylammonium hexaflurophosphate (TBAH) electrolyte (approx. 0.5 M). All potentials are reported versus NHE (Normal Hydrogen Electrode) using cobaltocenium hexafluorophosphate $\left(E_{1 / 2}=-0.78 \mathrm{~V}\right)$, ferrocene $\left(E_{1 / 2}=+0.55 \mathrm{~V}\right)$, or decamethylferrocene $\left(E_{1 / 2}=+0.04 \mathrm{~V}\right)$ as an internal standard. The peak-to-peak separation was less than $100 \mathrm{mV}$ for all reversible couples. Elemental analyses (EA) were obtained from Atlantic Microlabs and agree to within $0.4 \%$ for $\mathrm{C}, \mathrm{H}$, and $\mathrm{N}$. High resolution electrospray ionization mass spectrometry (ESI-MS) analyses were obtained from the University of Richmond from samples dissolved in acetonitrile then mixed 3:1 with $0.1 \mathrm{M}$ aqueous sodium trifluoroacetate (NaTFA), 
and using $[\mathrm{Na}(\mathrm{NaTFA}) \mathrm{x}]^{+}$clusters as an internal standard. Data are reported for the dominant peaks in the isotopic envelope as their observed and calculated masses and their percentage abundance relative to the parent ion, followed by the difference between the observed and calculated masses in parts per million, and the ion analyzed, e.g. (obs'd (\%), calc'd (\%), ppm, $\left.(M+Z)^{+}\right)$, where $Z^{+}=$proton or sodium ion.Unless otherwise noted, all synthetic reactions were performed in a glovebox under a dry nitrogen atmosphere. $\mathrm{CH}_{2} \mathrm{Cl}_{2}$ and benzene were purified by passage through a column packed with activated alumina. Other solvents and liquid reagents were thoroughly purged with dry nitrogen prior to use. Triflate salts were synthesized by addition of an $\mathrm{Et}_{2} \mathrm{O}$ solution of triflic acid to the appropriate conjugate base dissolved in $\mathrm{Et}_{2} \mathrm{O}$. Deuterated solvents were used as received from Cambridge Isotopes. Pyrazole, Pz, protons of the (tris-pyrazolyl)borate, Tp, ligand were uniquely assigned using a combination of 2dimensional NMR experiments and phosphorous-proton coupling(see Figure S1 in supplemental information). ${ }^{60}$ When unambiguous assignments were not possible, Pz protons were labeled as Tp protons. Coordination diastereomers are described by the defining feature's (i.e. carbocationic center) proximity to the $\mathrm{PMe}_{3}$ ligand relative to the $\mathrm{W}-\mathrm{PMe}_{3}$ bond (e.g. the fewer number of bonds from the $\mathrm{PMe}_{3}$ passing through the upper portion of the coordinated ring system to the defining feature dictates the proximal (P) ligand). Synthesis of compounds 2-8 have been previously reported. Ts-ICN, TCA-ICN, CSI, and NOB are commercially available and used as received. Nitroso reagents can also be synthesized using previously reported procedures. $^{61-64}$

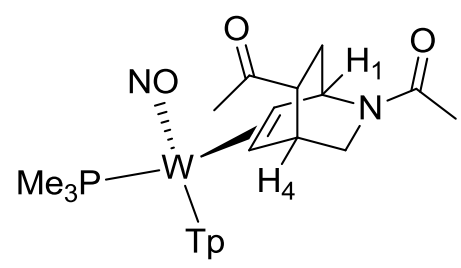




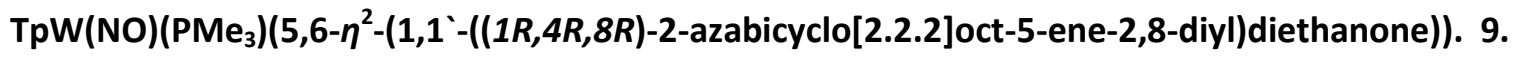
$\mathrm{Yb}(\mathrm{OTf})_{3}(0.068 \mathrm{~g}, 0.11 \mathrm{mmol})$ was added to a homogeneous yellow solution of $2(0.454 \mathrm{~g}, 0.725$ $\mathrm{mmol}), \mathrm{MeOH}(4.13 \mathrm{~g})$ and MVK $(0.132 \mathrm{~g}, 1.88 \mathrm{mmol})$. The solution was stirred for $17.5 \mathrm{~h}$ then diluted with DCM $\left(25 \mathrm{~mL}\right.$ ) and extracted with $3 \times 15 \mathrm{~mL}$ portions of $\mathrm{NaHCO}_{3}$ (aqueous, saturated) solution. The combined aqueous solution was back extracted with $2 \times 15 \mathrm{~mL}$ portions of DCM and combined with the original DCM extract. The resulting organic layer was dried with $\mathrm{MgSO}_{4}$ and filtered through medium-porosity fritted funnel. The filtrate solvent was evaporated and the residue was dissolved in pre-mixed solution of DCM $(6 \mathrm{~mL})$ and EtOAc $(6 \mathrm{~mL}) . \mathrm{Et}_{2} \mathrm{O}(130$ $\mathrm{mL}$ ) was added to this yellow solution to make a precipitate form. The solution was filtered through medium-porosity fritted funnel and the filtrate solvent was evaporated. The residue was dissolved with a pre-mixed solution of DCM $(6 \mathrm{~mL})$ and EtOAc $(6 \mathrm{~mL})$. Hexanes $(130 \mathrm{~mL})$ was added to this solution to make additional precipitate form. The flask was kept in ice bath for 30 min. while stirring. The yellow precipitate was collected on medium-porosity fritted funnel and dried in vacuo to give the 9 as a yellow powder $\left(0.224 \mathrm{~g}, 0.322 \mathrm{mmol}, 44 \%\right.$ yield). ${ }^{1} \mathrm{H} \mathrm{NMR}$ $\left(\mathrm{CDCl}_{3}, \delta\right): 8.15(\mathrm{~d}, J=2.0,1 \mathrm{H}, \mathrm{PzB} 3), 7.92(\mathrm{~d}, J=2.0,1 \mathrm{H}, \mathrm{PzA} 3), 7.74(\mathrm{~d}, J=2.0,1 \mathrm{H}, \mathrm{PzB} 5), 7.66$ $(\mathrm{d}, J=2.0,1 \mathrm{H}, \mathrm{PzC} 5), 7.58(\mathrm{~d}, J=2.0,1 \mathrm{H}, \mathrm{PzA} 5), 7.20(\mathrm{~d}, J=2.0,1 \mathrm{H}, \mathrm{PzC} 3), 6.34(\mathrm{t}, J=2.0,1 \mathrm{H}$, PzB4), $6.23(\mathrm{t}, J=2.0,1 \mathrm{H}, \mathrm{PzA} 4), 6.13(\mathrm{t}, J=2.0,1 \mathrm{H}, \mathrm{PzC} 4), 5.27(\mathrm{dd}, J=6.8,2.7,1 \mathrm{H}, \mathrm{H} 1), 4.00$ (dd, $J=10.1,3.1,1 \mathrm{H}, \mathrm{H} 3$ ), $3.41(\mathrm{dt}, J=10.1,1.7,1 \mathrm{H}, \mathrm{H} 3), 3.15$ (ddd, $J=9.4,4.3,2.2,1 \mathrm{H}, \mathrm{H} 8), 3.13$ (s, 1H, H4), $2.58(\mathrm{~m}, 1 \mathrm{H}, \mathrm{H} 7), 2.53$ (m, 1H, H6), 2.18 (m, 1H, H7), 2.14 (s, 3H, Acetyl-Me), 2.02 (s, 3H, Amide-Me), 1.27 (d, $\left.J=8.5,9 \mathrm{H}, \mathrm{PMe}_{3}\right), 0.97(\mathrm{~d}, J=11.6, \mathrm{~m}, 1 \mathrm{H}, \mathrm{H} 5) .{ }^{13} \mathrm{C} \mathrm{NMR}\left(\mathrm{CDCl}_{3}, \delta\right)$ : 209.0 (Acetyl CO), 169.8 (Amide CO), 144.2 (PzA3), 142.8 (PzB3), 140.3 (PzC3), 136.5 (PzC5), 135.7 (PzB5), 134.7 (PzA5), 106.4 (PzB4), 106.0 (PzA4), 105.8 (PzC4), 60.7 (C6), 54.0 (C8), 53.1 (C3), 51.0 (C5), 46.9 (C1), 37.7 (C4), 32.3 (C7), 28.5 (Acetyl Me), 21.9 (Amide Me), 13.5 (d, $J=$ 28.8, $\left.\mathrm{PMe}_{3}\right) .{ }^{31} \mathrm{P} \mathrm{NMR}\left(\mathrm{CDCl}_{3}, \delta\right):-12.90\left(J_{\mathrm{WP}}=267\right),-13.25\left(J_{\mathrm{WP}}=266\right) . \mathrm{CV}(\mathrm{DMA}): E_{\mathrm{p}, \mathrm{a}}=+0.65 \mathrm{~V}$ 
IR: $v_{\mathrm{BH}}=2448 \mathrm{~cm}^{-1}, v_{\mathrm{CO}}=1701 \mathrm{~cm}^{-1}, v_{\text {amide }}=1624 \mathrm{~cm}^{-1}, v_{\mathrm{NO}}=1554 \mathrm{~cm}^{-1}$. ESI-MS: obs'd (\%), calc'd (\%), ppm (M+H) : 695.2142 (84.2), 695.2149 (83.5), 1.0; 696.2157 (69.2), 696.2175 (80.4), 2.6; 697.2169 (100), 697.2174 (100), 0.6; 698.2197 (39.3), 698.2214 (44.2), 2.4; 699.2196 (77.0), 699.2206 (83.5), 1.5 .

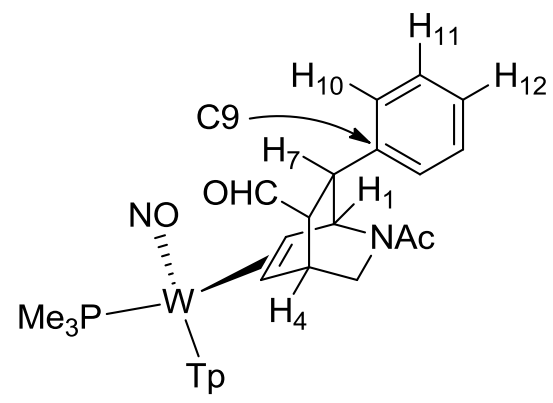

\section{$\operatorname{TpW}(\mathrm{NO})\left(\mathrm{PMe}_{3}\right)\left(5,6-\eta^{2}-((1 S, 4 R, 7 S, 8 S)-2\right.$-acetyl-7-phenyl-2-azabicyclo[2.2.2]oct-5-ene-8-}

carbaldehyde). 10. 2 (0.101 g, $0.161 \mathrm{mmol})$ was added to a vial, followed by DTBP (0.184 g, $0.962 \mathrm{mmol})$, then $\mathrm{CDCl}_{3}(6.86 \mathrm{~g})$, then trans-cinnimaldehyde $(0.178 \mathrm{~g}, 1.35 \mathrm{mmol})$ resulting in a homogeneous yellow solution. Addition of $\mathrm{BF}_{3} \cdot \mathrm{Et}_{2} \mathrm{O}(0.064 \mathrm{~g}, 0.45 \mathrm{mmol})$ to the vial containing the homogeneous solution induced a precipitation of a white solid. The heterogeneous solution was stirred rapidly overnight. After $21.5 \mathrm{~h}$, the solution was removed from the glovebox and centrifuged for 10 minutes. The solvent was decanted and discarded. The solid was dissolved in $9 \mathrm{~mL} \mathrm{DCM}$ and diluted with $50 \mathrm{mLEt} \mathrm{E}_{2} \mathrm{O}$ to precipitate some material in the separation funnel. The solution was extracted with $3 \times 25 \mathrm{~mL} \mathrm{NaHCO}$ (saturate, aqueous), back-extracted with $2 \times 25$ $\mathrm{mL} \mathrm{Et} 2 \mathrm{O}$, dried with $\mathrm{MgSO}_{4}$, filtered through a $30 \mathrm{~mL}$ course porosity fritted funnel, and washed with $25 \mathrm{~mL} \mathrm{DCM}$. The solvent was removed in vacuo and the residue dissolved in $1 \mathrm{~mL} \mathrm{DCM}$, then $2 \mathrm{~mL}$ EtOAc, followed by $10 \mathrm{~mL} \mathrm{Et}{ }_{2} \mathrm{O}$. Hexanes $(50 \mathrm{~mL}$ ) was added to the resulting homogeneous solution to induce a precipitation of a white solid. The solution was cooled to $0{ }^{\circ} \mathrm{C}$ for $0.5 \mathrm{~h}$ then the precipitate was collected on a $15 \mathrm{~mL}$ medium porosity fritted funnel, rinsed with $2 \times 10 \mathrm{~mL}$ hexanes and dried under static vacuum (0.086 g, $0.105 \mathrm{mmol}, 65 \%$ yield). ${ }^{1} \mathrm{H}$ NMR 
$\left(\mathrm{CDCl}_{3}\right)$ : $9.69(\mathrm{~s}, 1 \mathrm{H}, \mathrm{CHO}), 8.12(\mathrm{~d}, J=2.0,1 \mathrm{H}, \mathrm{PzB} 3), 7.93(\mathrm{~d}, J=2.0,1 \mathrm{H}, \mathrm{PzA} 3), 7.74(\mathrm{~d}, J=2.0$, 1H, PzB5), $7.68(\mathrm{~d}, J=2.0,1 \mathrm{H}, \mathrm{PzC} 5), 7.58(\mathrm{~d}, J=2.0,1 \mathrm{H}, \mathrm{PzA} 5), 7.35(\mathrm{t}, J=7.8,2 \mathrm{H}, \mathrm{H} 11), 7.24(\mathrm{t}, J$ $=7.8,1 \mathrm{H}, \mathrm{H} 12), 7.21(\mathrm{~d}, J=7.8,2 \mathrm{H}, \mathrm{H} 10), 7.19(\mathrm{~d}, J=2.0,1 \mathrm{H}, \mathrm{PzC} 3), 6.32(\mathrm{t}, J=3.0,1 \mathrm{H}, \mathrm{PzB} 4)$, $6.23(\mathrm{t}, J=3.0,1 \mathrm{H}, \mathrm{PzA} 4), 6.17(\mathrm{t}, J=3.0,1 \mathrm{H}, \mathrm{PzC} 4), 4.15(\mathrm{~m}, 1 \mathrm{H}, \mathrm{H} 1), 4.09(\mathrm{dd}, J=5.0,1.8,1 \mathrm{H}$, H7), 3.96 (dd, $J=12.2,2.7,1 \mathrm{H}, \mathrm{H} 3$-syn), 3.77 (ddd, $J=12.2,1.8,1.8,1 \mathrm{H}, \mathrm{H} 3$-anti), 3.36 (s(br), $1 \mathrm{H}$, H4), $3.30(\mathrm{dd}, J=5.0,1.8,1 \mathrm{H}, \mathrm{H} 8), 2.78\left(\mathrm{ddd},{ }^{3} J_{\mathrm{PH}}=14.3, J=11.5,2.9,1 \mathrm{H}, \mathrm{H} 6\right), 1.35(\mathrm{~s}, 3 \mathrm{H}$, Amide-Me), $1.19\left(\mathrm{~d},{ }^{2} \mathrm{~J}_{\mathrm{PH}}=8.1,9 \mathrm{H}, \mathrm{PMe}_{3}\right), 1.06$ (dddd, $\left.{ }^{3} \mathrm{JPH}_{\mathrm{PH}}=1.7, J=11.5,3.9,1.8,1 \mathrm{H}, \mathrm{H} 5\right) .{ }^{13} \mathrm{C}$ NMR (CDCl ${ }_{3}$ ): 202.7 (Aldehyde-CO), 168.7 (Amide-CO), 144.8 (PzA3), 143 (C9), 142.9 (PzB3), 140.1 (PzC3), 136.7 (PzC5), 136.2 (PzB5), 135.1 (PzA5), 129.2 (C11), 128.4 (C10), 126.9 (C12), 106.9 (PzB4), 106.4/106.3 (PzA4/PzC4), 62.0 (C1), 61.5 (d, $\left.{ }^{2} J_{P C}=14.5, C 6\right), 60.0$ (C8), 53.1 (C5), 51.9 (C3), 50.9 (C7), 34.8 (C4), 20.9 (Amide-Me), 13.6 (d, $\left.{ }^{2} J_{\mathrm{PC}}=27.8, \mathrm{PMe}_{3}\right) .{ }^{31} \mathrm{P} \mathrm{NMR}\left(\mathrm{CDCl}_{3}\right)$ : $13.17\left(J_{\mathrm{WP}}=266\right) . \mathrm{IR}: \mathrm{v}_{\mathrm{BH}}=2485 \mathrm{~cm}^{-1}, \mathrm{v}_{\mathrm{CHO}}=1718 \mathrm{~cm}^{-1}, \mathrm{~V}_{\text {amide }}=1633 \mathrm{~cm}^{-1}, \mathrm{v}_{\mathrm{NO}}=1564 \mathrm{~cm}^{-1} . \mathrm{CV}$ $(\mathrm{MeCN}): E_{\mathrm{p}, \mathrm{a}}=+0.67 \mathrm{~V}$

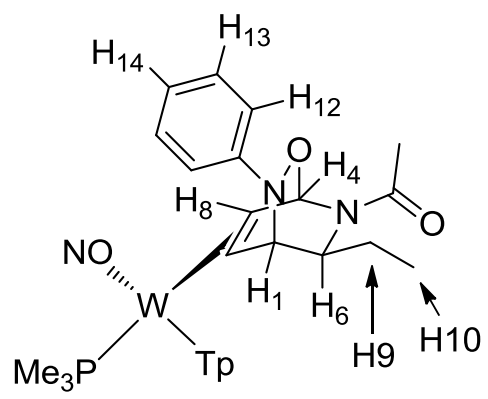

\section{$\operatorname{TpW}(\mathrm{NO})\left(\mathrm{PMe}_{3}\right)\left(7,8-\eta^{2}\right.$-(1-(-6-ethyl-2-phenyl-3-oxa-2,5-diazabicyclo[2.2.2]oct-7-en-5-}

yl)ethanone))). 11. DCM (4.20 g) and MeCN (6.50 g) were added to a vial containing 3 (0.655 g, $1.001 \mathrm{mmol}), \mathrm{NOB}(0.265 \mathrm{~g}, 2.474 \mathrm{mmol})$, and LiOTf $(0.156 \mathrm{~g}, 1.000 \mathrm{mmol})$ to make a homogeneous dark yellow-brown solution. After $14.5 \mathrm{~h}$, the reaction solution was removed from the glovebox, diluted with $70 \mathrm{~mL} \mathrm{DCM}$, extracted with $3 \times 50 \mathrm{~mL} \mathrm{NaHCO}$ (saturated, aqueous), back-extracted with $2 \times 50 \mathrm{~mL} \mathrm{DCM}$, dried with $\mathrm{MgSO}_{4}$, filtered through a $150 \mathrm{~mL}$ 
coarse porosity fritted funnel, and the solvent removed. The residue was dissolved in $10 \mathrm{~mL}$ DCM and diluted with $175 \mathrm{~mL} \mathrm{Et}{ }_{2} \mathrm{O}$ to precipitate a tan solid that was collected on a $30 \mathrm{~mL}$ medium porosity fritted funnel, washed with $2 \times 15 \mathrm{~mL} \mathrm{Et}{ }_{2} \mathrm{O}$, and discarded. The yellow filtrate solvent was removed. The residue was dissolved in $2 \mathrm{~mL}$ EtOAc, began to precipitate, and $100 \mathrm{~mL}$ hexanes was added to aid in precipitation. The solution was cooled to $0{ }^{\circ} \mathrm{C}$ for $2 \mathrm{~h}$. A tan-peach solid was collected on a $30 \mathrm{~mL}$ medium porosity fritted funnel, washed with $2 \times 15 \mathrm{~mL}$ hexanes, and placed under vacuum $\left(0.368 \mathrm{~g}, 0.483 \mathrm{mmol}, 48 \%\right.$ yield). ${ }^{1} \mathrm{H} \mathrm{NMR}\left(\mathrm{CDCl}_{3}, \delta\right): 8.21(\mathrm{~d}, J=2.0$, $1 \mathrm{H}, \mathrm{PzB} 3), 7.82(\mathrm{~d}, J=2.0,1 \mathrm{H}, \mathrm{PzA} 3), 7.75(\mathrm{~d}, J=2.0,1 \mathrm{H}, \mathrm{PzB} 5), 7.62(\mathrm{~d}, J=2.0,1 \mathrm{H}, \mathrm{PzC}$ ), 7.56 (d, $J=2.0,1 \mathrm{H}, \mathrm{PzA} 5), 7.18(\mathrm{~m}, 2 \mathrm{H}, \mathrm{H} 13), 7.14(\mathrm{~m}, 2 \mathrm{H}, \mathrm{H} 12), 7.09$ (d, J = 2.0, 1H, PzC3), 6.84 (d, J = 3.8, 1H, H4), $6.79(\mathrm{~m}, 1 \mathrm{H}, \mathrm{H} 14), 6.36(\mathrm{t}, J=2.0,1 \mathrm{H}, \mathrm{PzB} 4), 6.26(\mathrm{t}, J=2.0,1 \mathrm{H}, \mathrm{PzA} 4), 6.08(\mathrm{t}, J=$ 2.0, $1 \mathrm{H}, \mathrm{PzC} 4), 4.65(\mathrm{dd}, J=4.9,2.7,1 \mathrm{H}, \mathrm{H} 1), 4.15(\mathrm{~m}, 1 \mathrm{H}, \mathrm{H} 6), 2.80\left(\mathrm{ddd}, J=11.6,3.8,{ }^{3} J_{\mathrm{PH}}=11.6\right.$, $1 \mathrm{H}, \mathrm{H} 8), 2.41(\mathrm{~m}, 1 \mathrm{H}, \mathrm{H} 9), 2.16\left(\mathrm{~s}, 3 \mathrm{H}\right.$, Amide-Me), $2.03\left(\mathrm{~m}, 1 \mathrm{H}, \mathrm{H} 9\right.$ '), 1.50 (ddd, $J=11.6,4.9,{ }^{3} \mathrm{PH}_{\mathrm{P}}$ $=2.5,1 \mathrm{H}, \mathrm{H} 7), 1.27\left(\mathrm{~d},{ }^{2} \mathrm{~J}_{\mathrm{PH}}=8.6,9 \mathrm{H}, \mathrm{PMe}_{3}\right), 1.20(\mathrm{t}, J=7.5,3 \mathrm{H}, \mathrm{H} 10) .{ }^{13} \mathrm{C} \mathrm{NMR}\left(\mathrm{CDCl}_{3}, \delta\right): 169.4$ (Amide-CO), 152.1 (C11), 144.8 (PzA3), 142.5 (PzB3), 140.1 (PzC3), 136.7 (PzC5), 136.0 (PzB5), 135.0 (PzA5), 128.5/116.4 (C12/C13), 120.5 (C14), 106.8 (PzB4), 106.5 (PzA4), 106.2 (PzC4), 83.7 (C4), 63.8 (C10), 51.3 (C6), 56.6 (d, J = 14.3, C8), 50.0 (C7), 25.2 (C9), 23.7 (Amide-Me), 13.7 (d, J $\left.=28.8, \mathrm{PMe}_{3}\right), 11.1(\mathrm{C} 10) .{ }^{31} \mathrm{P}\left(\mathrm{CDCl}_{3}, \delta\right): \sim-14\left(J_{\mathrm{WP}}=263\right) . \mathrm{IR}: v_{\mathrm{BH}}=2486 \mathrm{~cm}^{-1}, v_{\text {amide }}=1624 \mathrm{~cm}^{-1}$, $V_{\mathrm{NO}}=1563 \mathrm{~cm}^{-1} . \mathrm{CV}(\mathrm{MeCN}): E_{\mathrm{p}, \mathrm{a}}=+0.53 \mathrm{~V} . \mathrm{ESI}-\mathrm{MS}:$ obs'd (\%), calc'd (\%), ppm, $(\mathrm{M}+\mathrm{H})^{+}: 760.2391$ (110.5), 760.2415 (81.2), 3.2; 761.2438 (89.4), 761.2441 (81.2), 0.4; 762.2438 (100), 762.244 (100), 0.3; 763.2459 (60.3), 763.2479 (47.2), 2.6; 764.2467 (95.6), 764.2472 (82.5), 0.7. 


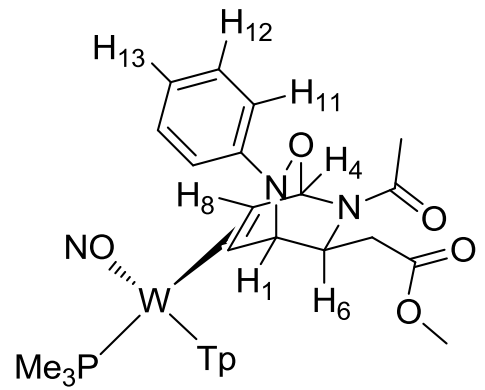

\section{TpW(NO)( $\left.\mathrm{PMe}_{3}\right)\left(7,8-\eta^{2}\right.$-(methyl 2-(5-acetyl-2-phenyl-3-oxa-2,5-diazabicyclo[2.2.2]oct-7-en-6-}

yl)acetate). 12. DCM (4.12 g) was added to a heterogeneous solution of 5 (0.698 g, $1.006 \mathrm{mmol})$, NOB $(0.273 \mathrm{~g}, 0.273 \mathrm{mmol})$, LiOTf $(0.157 \mathrm{~g}, 1.006 \mathrm{mmol})$ and MeCN (6.44 g) to make a dark brown homogeneous solution. After $21 \mathrm{~h}$, the reaction solution was removed from the glovebox, diluted with $70 \mathrm{~mL} \mathrm{DCM}$, extracted with $3 \times 50 \mathrm{~mL} \mathrm{NaHCO}$ (saturated, aqueous), backextracted with $2 \times 50 \mathrm{~mL} \mathrm{DCM}$, dried with $\mathrm{MgSO}_{4}$, filtered through a $150 \mathrm{~mL}$ coarse porosity fritted funnel, and the solvent removed. The residue was dissolved in $10 \mathrm{~mL} \mathrm{DCM}$ and diluted with $175 \mathrm{~mL} \mathrm{Et}_{2} \mathrm{O}$ to precipitate a tan solid that was collected on a $30 \mathrm{~mL}$ medium porosity fritted funnel, washed with $2 \times 15 \mathrm{~mL} \mathrm{Et}_{2} \mathrm{O}$, and discarded. The yellow filtrate solved was removed. The residue was dissolved in $2 \mathrm{~mL}$ EtOAc, began to precipitate and $100 \mathrm{~mL}$ hexanes was added to aid in precipitation. The solution was cooled to $0 \mathrm{C}$ for $2 \mathrm{~h}$. A tan-peach solid was collected on a $30 \mathrm{~mL}$ medium porosity fritted funnel, washed with $2 \times 15 \mathrm{~mL}$ hexanes, and placed under vacuum $\left(0.422 \mathrm{~g}, 0.524 \mathrm{mmol}, 52 \%\right.$ yield). ${ }^{1} \mathrm{H}$ NMR $\left(\mathrm{CDCl}_{3}, \delta\right): 8.19(\mathrm{~d}, \mathrm{~J}=2.0,1 \mathrm{H}, \mathrm{PzB} 3)$, 8.09 (d, $J=2.0,1 \mathrm{H}, \mathrm{PzA} 3), 7.75(\mathrm{~d}, J=2.0,1 \mathrm{H}, \mathrm{PzB} 5), 7.62$ (d, $J=2.0,1 \mathrm{H}, \mathrm{PzA} 5), 7.55$ (d, $J=2.0$, $1 \mathrm{H}, \mathrm{PzC} 5), 7.15$ (dd, $J=8.4,7.4,2 \mathrm{H}, \mathrm{H} 12$ ), 7.08 (d, $J=8.4,2 \mathrm{H}, \mathrm{H} 11), 7.07$ (d, $J=2.0,1 \mathrm{H}, \mathrm{PzC} 3$ ), $6.80(\mathrm{~m}, 2 \mathrm{H}, \mathrm{H} 4+\mathrm{H} 13), 6.36(\mathrm{t}, J=2.0,1 \mathrm{H}, \mathrm{PzB} 4), 6.3(\mathrm{t}, J=2.0,1 \mathrm{H}, \mathrm{PzA} 4), 6.08(\mathrm{t}, J=2.0,1 \mathrm{H}$, PzC4), 4.89 (dd, $J=5.1,2.5,1 \mathrm{H}, \mathrm{H} 1), 4.74(\mathrm{dt}, J=10.4,2.5,1 \mathrm{H}, \mathrm{H} 6), 3.8$ (s, 3H, Ester-Me), 3.71 (dd, $J=17.2,10.4,1 \mathrm{H}, \mathrm{H} 9), 2.95\left(\mathrm{dd}, J=17.2,2.5,1 \mathrm{H}, \mathrm{H} 9\right.$ '), 2.81 (ddd $J=11.4,4.0,{ }^{3} J_{\mathrm{PH}}=11.9$, $1 \mathrm{H}, \mathrm{H} 8), 2.16\left(\mathrm{~s}, 3 \mathrm{H}\right.$, Amide-Me), $1.44\left(\mathrm{ddd}, J=11.4,5.1,{ }^{3} J_{\mathrm{PH}}=2.7,1 \mathrm{H}, \mathrm{H} 7\right), 1.28\left(\mathrm{~d},{ }^{2} J_{\mathrm{PH}}=8.5\right.$, 
9H, $\left.\mathrm{PMe}_{3}\right) .{ }^{13} \mathrm{C} \mathrm{NMR}\left(\mathrm{CDCl}_{3}, \delta\right): 172.9$ (Ester-CO), 169.3 (Amide-CO), 151.7 (C10), 145.4 (PzA3), 142.5 (PzB3), 140.0 (pzC3), 136.7 (PzA5), 136 (PzB5), 134.9 (PzC5), 128.5 (C12), 120.8 (C13), 116.7 (C11), 106.8 (PzA4/PzB4), 106.1 (PzC4), 83.6 (C4), 65.5 (C1), 56.3 (C6), 56.2 (d, ${ }^{2} J_{\mathrm{PC}}=14.3$, C8), 51.8 (Ester-Me), 49.4 (C7), 36.6 (C9), 23.4 (Amide-Me), $13.9\left(\mathrm{~d},{ }^{1} J_{\mathrm{PC}}=28.8, \mathrm{PMe}_{3}\right) .{ }^{31} \mathrm{P}\left(\mathrm{CDCl}_{3}\right.$,

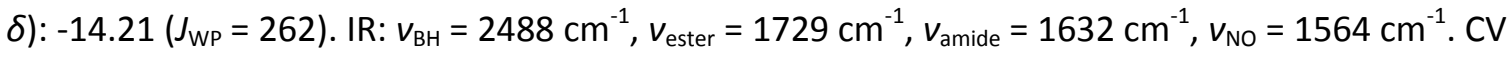
(MeCN): $E_{\mathrm{p}, \mathrm{a}}=+0.65 \mathrm{~V} . \mathrm{ESI}-\mathrm{MS}:$ obs'd (\%), calc'd (\%), ppm, $(\mathrm{M}+\mathrm{H})^{+}: 804.2314(91.9), 804.2314$ (80.4), 0.0; 805.2336 (89.7), 805.2339 (81.2), 0.4; 806.2329 (100), 806.2339 (100), 1.2; 807.2375 (52.8), 807.2377 (48.1), 0.3; 808.2371 (91.3), 808.2371 (82.4), 0.0.

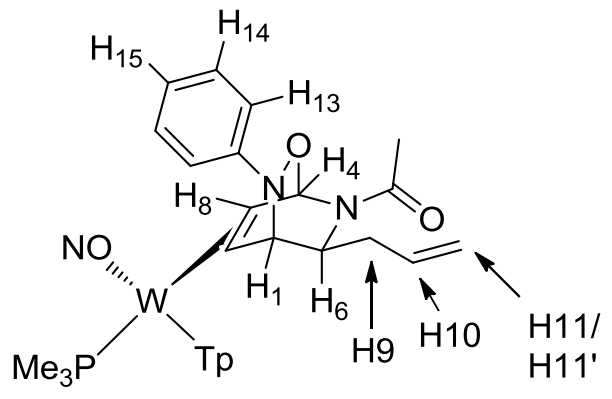

\section{$\mathrm{TpW}(\mathrm{NO})\left(\mathrm{PMe}_{3}\right)\left(7,8-\eta^{2}\right.$-(1-(-6-allyl-2-phenyl-3-oxa-2,5-diazabicyclo[2.2.2]oct-7-en-5-}

yl)ethanone))). 13. DCM (4.14 g) and MeCN (6.49 g) were added to a vial containing 8 (0.672 g, $1.009 \mathrm{mmol}), \operatorname{NOB}(0.273 \mathrm{~g}, 2.549 \mathrm{mmol})$, and LiOTf $(0.161 \mathrm{~g}, 1.032 \mathrm{mmol})$ to become a homogenous dark yellow-brown solution. After $13 \mathrm{~h}$, the reaction solution was removed from the glovebox, diluted with $70 \mathrm{~mL} \mathrm{DCM}$, extracted with $3 \times 50 \mathrm{~mL} \mathrm{NaHCO}$ (saturated, aqueous), back-extracted with $2 \times 50 \mathrm{~mL} \mathrm{DCM}$, dried with $\mathrm{MgSO}_{4}$, filtered through a $150 \mathrm{~mL}$ coarse porosity fritted funnel, and the solvent removed. The residue was dissolved in $10 \mathrm{~mL} \mathrm{DCM}$ and diluted with $175 \mathrm{~mL} \mathrm{Et}_{2} \mathrm{O}$ to precipitate a tan solid that was collected on a $30 \mathrm{~mL}$ medium porosity fritted funnel, washed with $2 \times 15 \mathrm{~mL} \mathrm{Et}_{2} \mathrm{O}$, and discarded. The yellow filtrate solvent was removed. The residue was dissolved in $2 \mathrm{~mL}$ EtOAc, began to precipitate, and $100 \mathrm{~mL}$ hexanes was added to aid in precipitation. The solution was cooled to $0{ }^{\circ} \mathrm{C}$ for $1 \mathrm{~h}$. A tan-peach solid was 
collected on a $30 \mathrm{~mL}$ medium porosity fritted funnel, washed with $2 \times 15 \mathrm{~mL}$ hexanes, and placed under vacuum $\left(0.284 \mathrm{~g}, 0.367 \mathrm{mmol}, 36 \%\right.$ yield). ${ }^{1} \mathrm{H} \mathrm{NMR}\left(\mathrm{CDCl}_{3}, \delta\right): 8.17(\mathrm{~d}, J=2.0,1 \mathrm{H}, \mathrm{PzB} 3)$, $7.74(\mathrm{~d}, J=2.0,1 \mathrm{H}, \mathrm{PzA} 3), 7.73(\mathrm{~d}, J=2.0,1 \mathrm{H}, \mathrm{PzB} 5), 7.6(\mathrm{~d}, J=2.0,1 \mathrm{H}, \mathrm{PzC} 5), 7.52(\mathrm{~d}, J=2.0,1 \mathrm{H}$, PzA5), 7.15 (dd, $J=8.4,7.1,2 \mathrm{H}, \mathrm{H} 14$ ), 7.09 (d, $J=8.4,2 \mathrm{H}, \mathrm{H} 13$ ), 7.07 (d, $J=2.0,1 \mathrm{H}, \mathrm{PzC}$ ), 6.82 $(\mathrm{d}, J=3.9,1 \mathrm{H}, \mathrm{H} 4), 6.77(\mathrm{~m}, 1 \mathrm{H}, \mathrm{H} 15), 6.34(\mathrm{t}, J=2.0,1 \mathrm{H}, \mathrm{PzB} 4), 6.23(\mathrm{t}, J=2.0,1 \mathrm{H}, \mathrm{PzA} 4), 6.06$ $(\mathrm{m}+\mathrm{t}, J=2.0,2 \mathrm{H}, \mathrm{PzC} 4+\mathrm{H} 10), 5.36(\mathrm{~d}, J=17.1,1 \mathrm{H}, \mathrm{H} 11), 5.29\left(\mathrm{~d}, J=10.2,1 \mathrm{H}, \mathrm{H} 11^{\prime}\right), 4.58(\mathrm{dd}, J=$ 4.8, 2.6, $1 \mathrm{H}, \mathrm{H1}$ ), 4.28 (ddd, $J=10.5,3.2,2.6,1 \mathrm{H}, \mathrm{H} 6$ ), 3.16 (ddd, $J=13.4,10.5,9.7,1 \mathrm{H}, \mathrm{H} 9$ ), 2.79 (ddd, $\left.J=11.6,3.9,{ }^{3} J_{\mathrm{PH}}=11.6,1 \mathrm{H}, \mathrm{H} 8\right), 2.76$ (m(bur), $1 \mathrm{H}, \mathrm{H9}{ }^{\prime}$ ), 2.18 (s, 3H, Amide-Me), 1.43 (ddd, $J=11.6,4.8,2.6,1 \mathrm{H}, \mathrm{H} 7), 1.25\left(\mathrm{~d},{ }^{2} J_{\mathrm{PH}}=8.2,9 \mathrm{H}, \mathrm{PMe}_{3}\right) .{ }^{13} \mathrm{C} \mathrm{NMR}\left(\mathrm{CDCl}_{3}, \delta\right): 169.5$ (Amide-CO), 152.1 (C12), 144.9 (PzA3), 142.5 (d, $J=2.2$, PzB3), 140.1 (PzC3), 136.8 (PzC5), 136 (PzB5), 135.2 (C10), 135.0 (PzA5), 128.5 (C14), 120.6 (C15), 118.6 (C11), 116.4 (C13), 106.8 (PzB4), 106.6 (PzA4), 106.2 (PzC4), 83.7 (C4), 64.7 (C1), 59.2 (C6), 56.7 (d, 2JPC = 14.8, C8), 49.8 (C7), 37 (C9), 23.7 (Amide-Me), $13.7\left(\mathrm{~d},{ }^{1} J_{\mathrm{PC}}=28.8, \mathrm{PMe}_{3}\right) .{ }^{31} \mathrm{P}\left(\mathrm{CDCl}_{3}, \delta\right):-14.19\left(J_{\mathrm{WP}}=263\right) . \mathrm{IR}: v_{\mathrm{BH}}=2483 \mathrm{~cm}^{-1}$, $V_{\text {amide }}=1626 \mathrm{~cm}^{-1}, V_{\mathrm{NO}}=1563 \mathrm{~cm}^{-1} . \mathrm{CV}(\mathrm{MeCN}): E_{\mathrm{p}, \mathrm{a}}=+0.59 \mathrm{~V} . \mathrm{ESI}-\mathrm{MS}:$ obs'd (\%), calc'd (\%), ppm, $(\mathrm{M}+\mathrm{H})^{+}: 772.2401$ (78.7), 772.2416 (80.7), 1.9; 773.2425 (76.8), 773.2441 (81.4), 2.0; 774.2436 (100), 774.2441 (100), 0.6; 775.2459 (44.6), 775.2479 (47.8), 2.6; 776.246 (69.7), 776.2473 (82.3), 1.7.

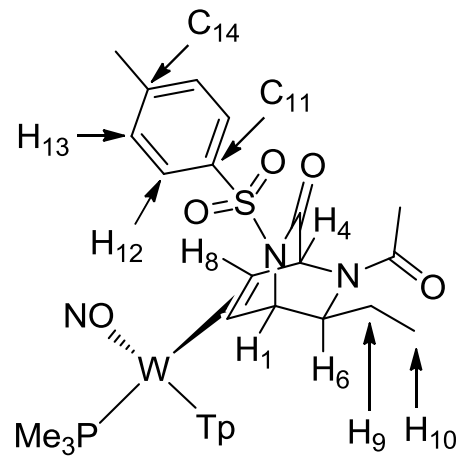

$\mathrm{TpW}(\mathrm{NO})\left(\mathrm{PMe}_{3}\right)\left(7,8-\eta^{2}\right.$-(5-acetyl-6-ethyl-2-tosyl-2,5-diazabicyclo[2.2.2]oct-7-en-3-one). 14. A solution of Ts-ICN (0.256 g, $1.298 \mathrm{mmol})$ in DCM (3.79 g) was added to a vial containing 3 (0.760 
$\mathrm{g}, 1.162 \mathrm{mmol}$ ) to make a homogenous dark yellow-pink solution. After 66 minutes, the reaction solution was removed from the glovebox, transferred to a $500 \mathrm{~mL}$ round bottom, diluted with $12 \mathrm{~mL} \mathrm{DCM}$, followed by $375 \mathrm{~mL} \mathrm{Et}{ }_{2} \mathrm{O}$ to precipitate a tan solid. The solution was cooled to $0 \mathrm{C}$ for $\sim 0.5 \mathrm{~h}$. The precipitate was collected on a $60 \mathrm{~mL}$ medium porosity fritted funnel, washed with $2 \times 15 \mathrm{~mL} \mathrm{Et}_{2} \mathrm{O}$ and transferred to the $500 \mathrm{~mL}$ round bottom flask. The solid was dissolved in $12 \mathrm{~mL} \mathrm{DCM}$ and diluted with $180 \mathrm{~mL}$ of hexanes. The solution was cooled to $0{ }^{\circ} \mathrm{C}$ for $\sim 1 \mathrm{~h}$ and the tan precipitate was collected on a fresh $60 \mathrm{~mL}$ medium porosity fritted funnel, washed with $2 \times 30 \mathrm{~mL}$ hexanes and placed under vacuum $(0.834 \mathrm{~g}, 0.980 \mathrm{mmol}, 84 \%$ yield $) .{ }^{1} \mathrm{H} \mathrm{NMR}\left(\mathrm{CDCl}_{3}\right.$, $\delta): 8.08(\mathrm{~d}, J=2.0,1 \mathrm{H}, \mathrm{PzB} 3) 7.83(\mathrm{~d}, J=8.4,2 \mathrm{H}, \mathrm{H} 12), 7.67(\mathrm{~d}, J=2.0,2 \mathrm{H}, \mathrm{PzA} 3 / \mathrm{PzB} 5), 7.63(\mathrm{~d}, J$ $=2.0,1 \mathrm{H}, \mathrm{PzC} 5), 7.52(\mathrm{~d}, J=2.0,1 \mathrm{H}, \mathrm{PzA} 5), 7.13(\mathrm{~d}, J=8.4,2 \mathrm{H}, \mathrm{H} 13), 7.01(\mathrm{~d}, J=2.0,1 \mathrm{H}, \mathrm{PzC} 3$ ), $6.26(\mathrm{t}, J=2.0,1 \mathrm{H}, \mathrm{PzB} 4), 6.21(\mathrm{t}, J=2.0,1 \mathrm{H}, \mathrm{PzC} 4), 6.09(\mathrm{t}, J=2.0,1 \mathrm{H}, \mathrm{PzA} 4), 5.42(\mathrm{~d}, J=2.9,1 \mathrm{H}$, H4), 5.23 (dd, $J=4.9,1.6,1 \mathrm{H}, \mathrm{H} 1$ ), 4.12 (ddd, $J=10.6,2.1,1.6,1 \mathrm{H}, \mathrm{H} 6), 2.41$ (ddd, $J=11.7,2.9$, $\left.{ }^{3} J_{\mathrm{PH}}=11.7,1 \mathrm{H}, \mathrm{H} 8\right), 2.30(\mathrm{~s}, 3 \mathrm{H}, \mathrm{Ts}-\mathrm{Me}), 2.10$ (s, 3H, Amide-Me), 2.00 (ddd, $J=11.7,4.9,2.8,1 \mathrm{H}$, $\mathrm{H} 7), 1.76 / 1.47\left(\mathrm{~m}, 2 \mathrm{H}, \mathrm{H} 9 / \mathrm{H}^{\prime}\right), 1.17\left(\mathrm{~d},{ }^{2} \mathrm{~J}_{\mathrm{PH}}=8.8,9 \mathrm{H}, \mathrm{PMe}_{3}\right), 1.13(\mathrm{t}, J=6.6,3 \mathrm{H}, \mathrm{H} 10) .{ }^{13} \mathrm{C} \mathrm{NMR}$ $\left(\mathrm{CDCl}_{3}, \delta\right): 172.4$ (C3) 171.3 (Amide-CO), 145.2 (PzA3), 144.7/136.6/136.5 (C11/C14/PzB5), 142.7 (PzB3), 140.4 (PzC3), 137.1 (PzC5), 136.6 (PzB5), 135.2 (PzA5), 129.8 (C12), 128.6 (C13), 107 (PzB4), 106.8 (PzC4) 106.3 (PzA4), 65.2 (C1), 62.8 (C6), 59.3 (C7), 58.3 (C4), 58.2 (d, ${ }^{2} J_{P C}=12.8$, C8), 26 (C9), 24.3 (Amide-Me), 21.8 (Ts-Me), 13.4 (d, $\left.{ }^{1} J_{\mathrm{PC}}=30.2, \mathrm{PMe}_{3}\right), 10.4$ (C10). ${ }^{31} \mathrm{P}$ NMR $\left(\mathrm{CDCl}_{3}, \delta\right):-13.54\left(J_{\mathrm{WP}}=261\right) . \mathrm{IR}: v_{\mathrm{BH}}=2495 \mathrm{~cm}^{-1}, 1712 \mathrm{~cm}^{-1}, 1620 \mathrm{~cm}^{-1}, v_{\mathrm{NO}}=1562 \mathrm{~cm}^{-1}, 1408 \mathrm{~cm}^{-}$ 1, $1165 \mathrm{~cm}^{-1}, 1049 \mathrm{~cm}^{-1} . \mathrm{CV}(\mathrm{DMA}): E_{\mathrm{p}, \mathrm{a}}=+1.08 \mathrm{~V} . \mathrm{ESI}-\mathrm{MS}$ : obs'd (\%), calc'd (\%), ppm, $(\mathrm{M}+\mathrm{H})^{+}$: 850.2173 (88), 850.2191 (76.7), 2.2; 851.2227 (69.7), 851.2216 (79.4), 1.3; 852.2187 (100), 852.2214 (100), 3.2; 853.2228 (40.3), 853.2248 (51), 2.3; 854.2235 (79.5), 854.2245 (83.6), 1.1. Anal. Calc'd for $\mathrm{C}_{29} \mathrm{H}_{39} \mathrm{BN}_{9} \mathrm{O}_{5}$ PSW'2/3-hexanes: $\mathrm{C}, 43.61 ; \mathrm{H}, 5.36 ; \mathrm{N}, 13.87$; Found: $\mathrm{C}, 43.69 ; \mathrm{H}$, $5.03 ; \mathrm{N}, 13.59$. 


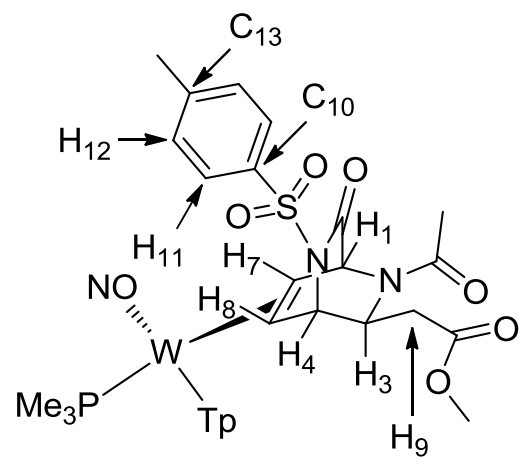

\section{$\mathrm{TpW}(\mathrm{NO})\left(\mathrm{PMe}_{3}\right)\left(7,8-\eta^{2}\right.$-(methyl 2-(2-acetyl-6-oxo-5-tosyl-2,5-diazabicyclo[2.2.2]oct-7-en-3-}

yl)acetate). 15. A solution of Ts-ICN (0.248 g, $1.258 \mathrm{mmol})$ in DCM (3.37 g) was added to a vial containing 5 ( $0.750 \mathrm{~g}, 1.074 \mathrm{mmol})$ to make a homogeneous orange-pink solution. After $1 \mathrm{~h} 45$ min, the solution was removed from the glovebox, transferred to a $500 \mathrm{~mL}$ round bottom flask with $12 \mathrm{~mL} \mathrm{DCM}$ and slowly diluted with $380 \mathrm{~mL} \mathrm{Et} \mathrm{O}_{2} \mathrm{O}$. The solution was cooled in a $0{ }^{\circ} \mathrm{C}$ bath for $\sim 0.5 \mathrm{~h}$. The precipitate collected on a $30 \mathrm{~mL}$ medium porosity fritted funnel, washed with $2 \times 15$ $\mathrm{mLEt}{ }_{2} \mathrm{O}$. The precipitate was dissolved in $12 \mathrm{~mL} \mathrm{DCM}$ and slowly diluted with $380 \mathrm{~mL}$ hexanes. The solution was cooled to $0{ }^{\circ} \mathrm{C}$ for $0.5 \mathrm{~h}$, and the yellow-tan precipitate was collected on a 30 $\mathrm{mL}$ medium porosity fritted funnel, washed with $2 \times 15 \mathrm{~mL}$ hexanes, and placed under vacuum (0.646 g, $0.721 \mathrm{mmol}, 67 \%$ yield). ${ }^{1} \mathrm{H}$ NMR $\left(\mathrm{CDCl}_{3}, \delta\right): 8.10(\mathrm{~d}, J=2.0,1 \mathrm{H}, \mathrm{PzA} 3) 8.07(\mathrm{~d}, J=2.0$, 1H, PzB3), $7.82(\mathrm{~d}, J=8.4,2 \mathrm{H}, \mathrm{H} 11), 7.67(\mathrm{~d}, J=2.0,1 \mathrm{H}, \mathrm{PzB} 5), 7.63(\mathrm{~d}, J=2.0,1 \mathrm{H}, \mathrm{PzC} 5), 7.51(\mathrm{~d}$, $J=2.0,1 \mathrm{H}, \mathrm{PzA} 5), 7.12(\mathrm{~d}, J=8.4,2 \mathrm{H}, \mathrm{H} 12), 6.96(\mathrm{~d}, J=2.0,1 \mathrm{H}, \mathrm{PzC} 3), 6.26(\mathrm{~m}, 2 \mathrm{H}, \mathrm{PzA} 4 / \mathrm{PzB} 4)$, $6.07(\mathrm{t}, J=2.0,1 \mathrm{H}, \mathrm{PzC} 4), 5.42(\mathrm{~d}, J=3.0,1 \mathrm{H}, \mathrm{H} 1), 5.33(\mathrm{dd}, J=5.0,1.5,1 \mathrm{H}, \mathrm{H} 4), 4.80$ (ddd,$J=$ 10.6, 2.7, 1.5, 1H, H3), 3.72 (s, 3H, Ester-Me) 2.77 (dd, $J=18.0,2.7,1 \mathrm{H}, \mathrm{H} 9), 2.67$ (dd, $J=18.0$, 10.6, $\left.1 \mathrm{H}, \mathrm{H} 9^{\prime}\right), 2.39$ (ddd, $\left.J=11.6,3.0,3_{\mathrm{PH}}=11.8,1 \mathrm{H}, \mathrm{H} 7\right), 2.29$ (s, 3H, Ts-Me), 2.00 (s, 3H, Amide-Me), $1.73\left(\mathrm{ddd}, J=11.6,5.0,{ }^{3} J_{\mathrm{PH}}=2.7,1 \mathrm{H}, \mathrm{H} 8\right), 1.09\left(\mathrm{~d},{ }^{2} \mathrm{~J}_{\mathrm{PH}}=8.8,9 \mathrm{H}, \mathrm{PMe}_{3}\right) .{ }^{13} \mathrm{C} \mathrm{NMR}$ $\left(\mathrm{CDCl}_{3}, \delta\right): 172.3$ (C6) 171.5 (Ester-CO), 171.2 (Amide-CO), 146.0 (PzA3), 144.7/136.4/136.4 (C10/C13/PzB5), 142.6 (PzB3), 140.2 (PzC3), 138 (C13), 137 (PzC5), 135.1 (PzA5), 129.4 (C12), 128.6 (C11), 107 (PzA4/PzB4) 106.2 (PzC4), 66.9 (C4), 58.9 (C8), 58.3 (C1), 57.4 (d, ${ }^{2} \mathrm{JPC}_{\mathrm{PC}}=16.5$, 
C7), 57.3 (C3), 52.1 (Ester-Me), 37.3 (C9), 24.2 (Amide-Me), 21.8 (Ts-Me), 13.4 (d, ${ }^{1} J_{P C}=30.1$, $\left.\mathrm{PMe}_{3}\right) \cdot{ }^{31} \mathrm{P}$ NMR $\left(\mathrm{CDCl}_{3}, \delta\right):-13.56\left(J_{\mathrm{WP}}=259\right) \cdot \mathrm{CV}(\mathrm{DMA}): E_{\mathrm{p}, \mathrm{a}}=+1.11 \mathrm{~V} \cdot \mathrm{IR}: v_{\mathrm{BH}}=2488 \mathrm{~cm}^{-1}, 1720$ $\mathrm{cm}^{-1}, 1631(\mathrm{br}) \mathrm{cm}^{-1}, v_{\mathrm{NO}}=1566 \mathrm{~cm}^{-1}, 1408 \mathrm{~cm}^{-1}, 1308 \mathrm{~cm}^{-1}, 1156 \mathrm{~cm}^{-1}, 1053 \mathrm{~cm}^{-1}$. ESI-MS: obs'd (\%), calc'd (\%), ppm, $(\mathrm{M}+\mathrm{H})^{+}: 894.2085$ (67), 894.209 (76), 0.5; 895.2112 (74.1), 895.2114 (79.3), 0.2; 896.2109 (100), 896.2113 (100), 0.4; 897.213 (44.7), 897.2146 (51.9), 1.8; 898.2135 (72.5), 898.2143 (83.6), 0.9. Anal. Calc'd for $\mathrm{C}_{30} \mathrm{H}_{39} \mathrm{BN}_{9} \mathrm{O}_{7} \mathrm{PSW} 1 / 6$-hexanes: $\mathrm{C}, 40.93 ; \mathrm{H}, 4.58 ; \mathrm{N}, 13.86$; Found: C, 40.78; H, 4.49; N, 13.67 .

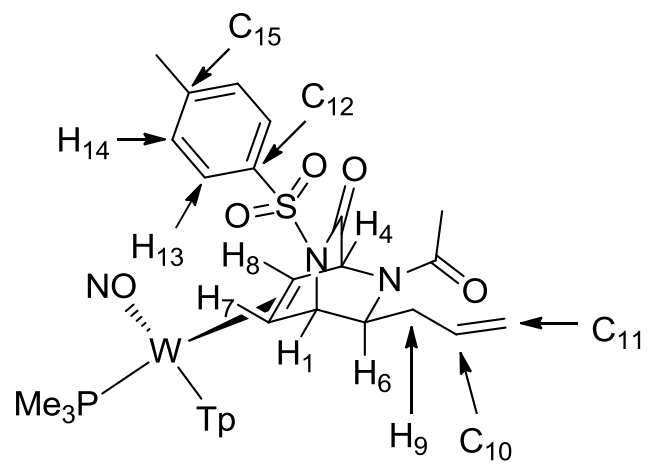

$\operatorname{TpW}(\mathrm{NO})\left(\mathrm{PMe}_{3}\right)\left(7,8-\eta^{2}\right.$-(5-acetyl-6-allyl-2-tosyl-2,5-diazabicyclo[2.2.2]oct-7-en-3-one). 16. A solution of Ts-ICN (0.103 g, $0.522 \mathrm{mmol})$ in DCM (1.44 g) was added to a vial containing 8 (0.302 $\mathrm{g}, 0.453 \mathrm{mmol}$ ) to become a homogeneous pinkish solution. After $95 \mathrm{~min}$, the reaction solution was removed from the glovebox, transferred to a $200 \mathrm{~mL}$ round bottom flask, diluted with DCM $(\sim 5 \mathrm{~g})$ then $150 \mathrm{~mL} \mathrm{Et}{ }_{2} \mathrm{O}$. The solution was cooled to $0{ }^{\circ} \mathrm{C}$ for $\sim 1 \mathrm{~h}$. The precipitate was collected on a $30 \mathrm{~mL}$ medium porosity fritted funnel, washed with $2 \times 15 \mathrm{~mL} \mathrm{Et}_{2} \mathrm{O}$. The precipitate was redissolved in $5 \mathrm{~mL} \mathrm{DCM}$ and slowly diluted with $75 \mathrm{~mL}$ hexanes, cooled to $0{ }^{\circ} \mathrm{C}$ for $\sim 1 \mathrm{~h}$, collected on a $30 \mathrm{~mL}$ medium porosity fritted funnel, washed with $2 \times 15 \mathrm{~mL}$ hexanes, and placed under vacuum $\left(0.313 \mathrm{~g}, 0.363 \mathrm{mmol}, 80 \%\right.$ yield). ${ }^{1} \mathrm{H} \mathrm{NMR}\left(\mathrm{CDCl}_{3}, \delta\right): 8.17$ (d, $\left.J=2.0,1 \mathrm{H}, \mathrm{PzB} 3\right)$ $7.92(\mathrm{~d}, J=7.7,2 \mathrm{H}, \mathrm{H} 13), 7.76(\mathrm{~d}, J=2.0,1 \mathrm{H}, \mathrm{PzB} 5), 7.72(\mathrm{~m}, 2 \mathrm{H}, \mathrm{PzA} / \mathrm{PzC}$ ), 7.6 (d, $J=2.0,1 \mathrm{H}$, PzC3), 7.21 (d, J = 7.7, 2H, H14), 7.07 (d, J=2.0, 1H, PzA5), $6.36(t, J=2.0,1 \mathrm{H}, \mathrm{PzB} 4), 6.28(\mathrm{t}, J=$ 2.0, 1H, PzC4), $6.17(\mathrm{t}, J=2.0,1 \mathrm{H}, \mathrm{PzA} 4), 6.06(\mathrm{~m}, 1 \mathrm{H}, \mathrm{H} 10), 5.52(\mathrm{~d}, J=3.0,1 \mathrm{H}, \mathrm{H} 4), 5.39(\mathrm{~d}, J=$ 
$17.1,1 \mathrm{H}, \mathrm{H} 11), 5.32\left(\mathrm{~d}, J=10.3,1 \mathrm{H}, \mathrm{H} 11^{\prime}\right) 5.28(\mathrm{~d}, J=4.6,1 \mathrm{H}, \mathrm{H} 1), 4.37(\mathrm{dt}, J=10.4,2.1,1 \mathrm{H}, \mathrm{H} 6)$, $2.59(\mathrm{dd}, J=14.5,6.7,1 \mathrm{H}, \mathrm{H} 9), 2.47$ (ddd $\left.J=11.8,3.1,{ }^{3} J_{\mathrm{PH}}=11.8,1 \mathrm{H}, \mathrm{H} 8\right), 2.43$ (buried, $1 \mathrm{H}, \mathrm{H} 9{ }^{\prime}$ ), 2.39 (s, 3H, Ts-Me), 2.15 (s, 3H, Amide-Me), 1.92 (ddd, $\left.J=11.8,4.6,{ }^{3} J_{\mathrm{PH}}=2.8,1 \mathrm{H}, \mathrm{H} 7\right), 1.17$ (d, $\left.{ }^{2} J_{\mathrm{PH}}=8.9,9 \mathrm{H}, \mathrm{PMe}_{3}\right) \cdot{ }^{13} \mathrm{C} \mathrm{NMR}\left(\mathrm{CDCl}_{3}, \delta\right): 172.4$ (C3) 171.3 (Amide-CO), 145.2 (PzA3), 144.6/137.1/136.6/134.6 (C12/C15/PzC5/PzB5), 142.7 (PzB3), 140.3 (PzA5), 135.2 (PzC3), 133.4 (C10), 129.3 (C14), 128.7 (C13), 119.6 (C11), 107 (PzB4), 106.8 (PzC4) 106.2 (PzA4), 65.8 (C1), 61.3 (C6), 59.3 (C7), 58.3 (C4), 58.1 (d, ${ }^{2} J_{\mathrm{PC}}=16.3, \mathrm{C} 8$ ), 37.2 (C9), 24.4 (Amide-Me), 21.8 (Ts-Me), $13.4\left(\mathrm{~d},{ }^{1} J_{\mathrm{PC}}=29.3, \mathrm{PMe}_{3}\right) \cdot{ }^{31} \mathrm{P} \mathrm{NMR}\left(\mathrm{CDCl}_{3}, \delta\right):-13.54\left(J_{\mathrm{WP}}=259\right) . \mathrm{IR}: v_{\mathrm{BH}}=2492 \mathrm{~cm}^{-1}, v=1712$ $\mathrm{cm}^{-1}, v=1631 \mathrm{~cm}^{-1}, v_{\mathrm{NO}}=1566 \mathrm{~cm}^{-1}, v=1165 \mathrm{~cm}^{-1}, v=1049 \mathrm{~cm}^{-1} . \mathrm{CV}$ (DMA): $E_{\mathrm{p}, \mathrm{a}}=+1.03 \mathrm{~V} . \mathrm{ESI}-$ MS: obs'd (\%), calc'd (\%), ppm, (M+H)+: 862.2193 (66.6), 862.2191 (76.2), 0.2; 863.2219 (80), 863.2216 (79.5), 0.4; 864.2204 (100), 864.2214 (100), 1.2; 865.2244 (49.6), 865.2248 (51.7), 0.5; 866.2233 (76.2), $866.2245(83.4), 1.4$

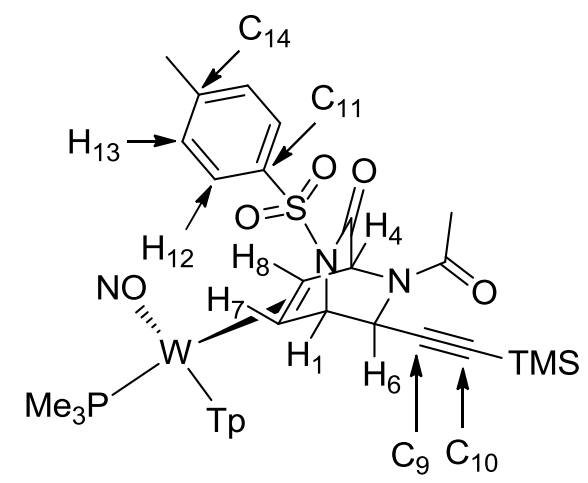

$\mathrm{TpW}(\mathrm{NO})\left(\mathrm{PMe}_{3}\right)\left(7,8-\eta^{2}\right.$-(5-acetyl-2-tosyl-6-((trimethylsilyl)ethynyl)-2,5-diazabicyclo[2.2.2]oct-

7-en-3-one). 17. A solution of Ts-ICN $(0.087 \mathrm{~g}, 0.441 \mathrm{mmol})$ was dissolved in DCM (1.0 g) and added to a vial containing $6(0.300 \mathrm{~g}, 0.415 \mathrm{mmol})$ to make a homogeneous yellow-orange solution. After $2.5 \mathrm{~h}$, a solid was present in the reaction vessel. After an additional $5 \mathrm{~h}$, the reaction solution was decanted from the solid. The solid that precipitated in the reaction vessel was transferred to a $200 \mathrm{~mL}$ round bottom flask with $2 \mathrm{~mL}$ THF and $10 \mathrm{~mL} \mathrm{DCM}$. The solvent was concentrated to $<1 \mathrm{~mL}$, diluted with $4 \mathrm{~mL} \mathrm{DCM}$, then diluted with $100 \mathrm{~mL}$ hexanes to precipitate 
a white solid. The solution was cooled to $0{ }^{\circ} \mathrm{C}$ for $0.5 \mathrm{~h}$. The precipitate was collected on a $15 \mathrm{~mL}$ medium porosity fritted funnel, washed with $2 \times 15 \mathrm{~mL}$ hexanes, and placed under vacuum $(0.145$ g, $0.158 \mathrm{mmol}, 38 \%$ yield). ${ }^{1} \mathrm{H}$ NMR $\left(\mathrm{CDCl}_{3}, \delta\right): 8.07$ (d, $\left.J=2.0,1 \mathrm{H}, \mathrm{PzB} 3\right) 7.87(\mathrm{~d}, J=8.1,2 \mathrm{H}$, H12), $7.78(\mathrm{~d}, J=2.0,1 \mathrm{H}, \mathrm{PzA} 3), 7.67(\mathrm{~d}, J=2.0,1 \mathrm{H}, \mathrm{PzB} 5), 7.62(\mathrm{~d}, J=2.0,1 \mathrm{H}, \mathrm{PzC} 5), 7.51(\mathrm{~d}, J=$ 2.0, 1H, PzA5), 7.11 (d, $J=8.1,2 \mathrm{H}, \mathrm{H} 13), 6.99(\mathrm{~d}, J=2.0,1 \mathrm{H}, \mathrm{PzC} 3), 6.27(\mathrm{t}, J=2.0,1 \mathrm{H}, \mathrm{PzB} 4)$, $6.22(\mathrm{t}, J=2.0,1 \mathrm{H}, \mathrm{PzA} 4), 6.08(\mathrm{t}, J=2.0,1 \mathrm{H}, \mathrm{PzC} 4), 5.42(\mathrm{~d}, J=3.1,1 \mathrm{H}, \mathrm{H} 4), 5.36(\mathrm{dd}, J=4.9,1.9$, $1 \mathrm{H}, \mathrm{H} 1), 5.11(\mathrm{~d}, J=1.9,1 \mathrm{H}, \mathrm{H} 6) 2.41\left(\mathrm{ddd}, J=11.7,3.1 \mathrm{~s}^{3} \mathrm{PH}_{\mathrm{H}}=11.8,1 \mathrm{H}, \mathrm{H} 8\right), 2.29(\mathrm{~s}, 3 \mathrm{H}, \mathrm{Ts}-\mathrm{Me}$ ), $2.17\left(\mathrm{~s}, 3 \mathrm{H}\right.$, Amide-Me), $1.77(\mathrm{ddd}, J=11.7,4.8,3 \mathrm{JPH}=2.8,1 \mathrm{H}, \mathrm{H} 7), 1.07\left(\mathrm{~d},{ }^{2} J_{\mathrm{PH}}=8.7,9 \mathrm{H}\right.$, $\mathrm{PMe}_{3}$ ), 0.12 (s, 9H, TMS). $\left.{ }^{13} \mathrm{C} \mathrm{NMR} \mathrm{(CDCl} 3, \delta\right): 172.0$ (C3) 171.6 (Amide-CO), 145.7 (PzA3), 144.2/137.4 (C11/C14), 142.9 (PzB3), 140.4 (PzC3), 137.2 (PzC5), 136.5 (PzB5), 135.3 (PzA5), 129.2 (C13), 128.7 (C12), 107.1 (PzB4), 106.8 (PzA4) 105.3 (PzC4), 103..0 (C9), 90.4 (C10), 67.4 (C1), $58.1\left(\mathrm{~d},{ }^{2} \mathrm{~J}_{\mathrm{PC}}=2.0, \mathrm{C} 7\right), 57.9\left(\mathrm{~d},{ }^{2} \mathrm{~J}_{\mathrm{PC}}=16.3, \mathrm{C} 8\right), 57.7$ (C4), 54.3 (C6), 23.8 (Ts-Me), 21.8 (Amide-Me), $13.4\left(\mathrm{~d},{ }^{1} J_{\mathrm{PC}}=29.1, \mathrm{PMe}_{3}\right),-0.13(\mathrm{TMS}) .{ }^{31} \mathrm{P} \mathrm{NMR}\left(\mathrm{CDCl}_{3}, \delta\right):-13.34\left(J_{\mathrm{WP}}=258\right) . \mathrm{CV}$ (DMA): $E_{\mathrm{p}, \mathrm{a}}=+1.08$ V. IR: $v_{\mathrm{BH}}=2488 \mathrm{~cm}^{-1}, v_{\text {alkyne }}=2183$ (weak) $\mathrm{cm}^{-1}, v=1720 \mathrm{~cm}^{-1}, v=1639(\mathrm{br})$ $\mathrm{cm}^{-1}, v_{\mathrm{NO}}=1566 \mathrm{~cm}^{-1}, v=1408 \mathrm{~cm}^{-1}, v=1169 \mathrm{~cm}^{-1}, v=1053 \mathrm{~cm}^{-1}$. ESI-MS: obs'd (\%), calc'd (\%), ppm, $(\mathrm{M}+\mathrm{H})^{+}: 918.2277$ (75.7), 918.2274 (71.3), 0.3; 919.2299 (82.5), 919.2297 (78.9), 0.2; 920.2304 (100), 920.2296 (100), 0.9; 921.231 (61.1), 921.2324 (57.0), 1.6; 922.2329 (88.5), 922.2325 (83.7), 0.4 .

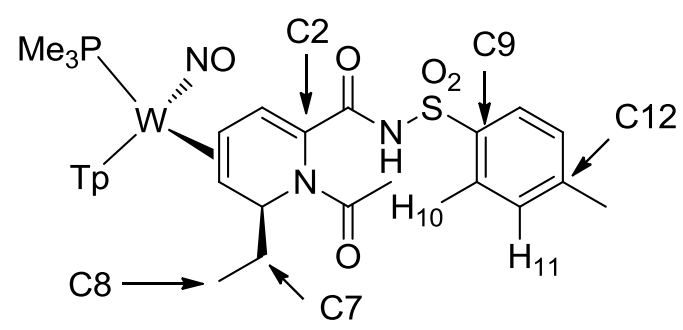

$\mathrm{TpW}(\mathrm{NO})\left(\mathrm{PMe}_{3}\right)\left(4,5-\eta^{2}\right.$-(1-acetyl-6-ethyl-N-tosyl-1,6-dihydropyridine-2-carboxamide)).

18. Acetic acid ( $1.75 \mathrm{~g}$; glacial) was added to a homogeneous pink-yellow solution of 14 (0.750 g, 
$1.147 \mathrm{mmol}$ ) in DCM (4.93 g). After $5 \mathrm{~h}$, the reaction solution was removed from the glovebox, diluted with $50 \mathrm{~mL} \mathrm{DCM}$, carefully extracted with $3 \times 20 \mathrm{~mL} \mathrm{NaHCO}$ (saturated, aqueous), backextracted with $2 \times 20 \mathrm{~mL} \mathrm{DCM}$, dried with $\mathrm{MgSO}_{4}$, filtered through a $150 \mathrm{~mL}$ coarse porosity fritted funnel, then a $30 \mathrm{~mL}$ medium porosity fritted funnel, and the solvent removed. The precipitate was removed from the wall of the flask with $8 \mathrm{~mL} \mathrm{DCM}$ and further precipitated with $200 \mathrm{~mL}$ hexanes. The yellow solid was collected on a $30 \mathrm{~mL}$ medium porosity fritted funnel, washed with $2 \times 15 \mathrm{~mL}$ hexanes, and placed under vacuum $\left(0.656 \mathrm{~g}, 1.003 \mathrm{mmol}, 87 \%\right.$ yield). ${ }^{1} \mathrm{H}$ $\operatorname{NMR}\left(\mathrm{CDCl}_{3}, \delta\right): 8.53(\mathrm{~d}, J=2.0,1 \mathrm{H}, \mathrm{PzA} 3), 8.00(\mathrm{~d}, J=8.3,2 \mathrm{H}, \mathrm{H} 10), 7.96(\mathrm{~d}, J=2.0,1 \mathrm{H}, \mathrm{PzB} 3)$, $7.73(\mathrm{~d}, J=2.0,1 \mathrm{H}, \mathrm{PzC} 5), 7.68$ (d, $J=2.0,1 \mathrm{H}, \mathrm{PzB} 5), 7.57$ (d, $J=2.0,1 \mathrm{H}, \mathrm{PzA} 5), 7.46$ (d, $J=6.8$, $1 \mathrm{H}, \mathrm{H3}), 7.31(\mathrm{~d}, J=8.3,2 \mathrm{H}, \mathrm{H} 11), 7.25(\mathrm{~d}, J=2.0,1 \mathrm{H}, \mathrm{PzC} 3), 6.24(\mathrm{~m}, 3 \mathrm{H}, \mathrm{PzA} 4+\mathrm{PzB} 4+\mathrm{PzC} 4), 5.54$ (t(br), 1H, H6), 2.79 (ddd, $\left.J=9.8,6.8,{ }^{3} J_{\mathrm{PH}}=12.6,1 \mathrm{H}, \mathrm{H} 4\right), 2.42(\mathrm{~s}, 3 \mathrm{H}, \mathrm{Ts}-\mathrm{Me}), 1.81(\mathrm{~d}, J=9.8,1 \mathrm{H}$, $\mathrm{H} 5), 1.75\left(\mathrm{~s}, 3 \mathrm{H}\right.$, Amide-Me), $1.53(\mathrm{~m}, 1 \mathrm{H}, \mathrm{H} 7), 1.37\left(\mathrm{~m}, 1 \mathrm{H}, \mathrm{H} 7{ }^{\prime}\right), 1.20\left(\mathrm{~d},{ }^{2} \mathrm{~J}_{\mathrm{PH}}=8.4,9 \mathrm{H}, \mathrm{PMe}_{3}\right)$, $0.93(\mathrm{t}, J=7.4,3 \mathrm{H}, \mathrm{H} 8) .{ }^{13} \mathrm{C} \mathrm{NMR}\left(\mathrm{CDCl}_{3}, \delta\right): 171.6$ (Amide-CO), 163.1 (Ts-Amide-CO), 145.6 (PzA3), 144.7/136.3/136.3 (C9+PzB4+C12), 142.7 (PzB3), 139.9 (PzC3), 138.8 (C3), 136.8 (PzC5), 135.5 (PzA5), 129.5 (C11), 128.5 (C10), 107.0/106.6/106.3 (PzA4+PzB4+PzC4), 70.0 (C5), 51.4 (C6), $46.9\left(\mathrm{~d},{ }^{2} \mathrm{~J}_{\mathrm{PC}}=8.7, \mathrm{C} 4\right), 30.5$ (C7), 25.2 (Amide-Me), 21.8 (Ts-Me), $13.9\left(\mathrm{~d},{ }^{1} \mathrm{~J}_{\mathrm{PC}}=28.6, \mathrm{PMe}_{3}\right)$, $11.9(\mathrm{C} 10) \cdot{ }^{31} \mathrm{P}$ NMR $\left(\mathrm{CDCl}_{3}, \delta\right):-13.02\left(J_{\mathrm{WP}}=271\right) . \mathrm{IR}: v_{\mathrm{BH}}=2492 \mathrm{~cm}^{-1}, v=1682 \mathrm{~cm}^{-1}, v=1630 \mathrm{~cm}^{-}$ ${ }^{1}, v=1589 \mathrm{~cm}^{-1}, v_{\mathrm{NO}}=1570 \mathrm{~cm}^{-1}, v=1408 \mathrm{~cm}^{-1}, v=1049 \mathrm{~cm}^{-1} . \mathrm{CV}(\mathrm{MeCN}): E_{\mathrm{p}, \mathrm{a}}=+0.80 \mathrm{~V}$. ESI-MS: obs'd (\%), calc'd (\%), ppm, (M+H)+: 850.2156 (88.4), 850.2191 (76.7), 4.1; 851.2202 (72.5), 851.2216 (79.4), 1.6; 852.2216 (100), 852.2214 (100), 0.2; 853.225 (59.5), 853.2248 (51.0), 0.3; 854.2235 (72.1), 854.2245 (83.6), 1.2. Anal. Calc'd for $\mathrm{C}_{29} \mathrm{H}_{39} \mathrm{BN}_{9} \mathrm{O}_{5} \mathrm{PSW} \cdot \mathrm{CH}_{2} \mathrm{Cl}_{2}: \mathrm{C}, 38.48 ; \mathrm{H}, 4.41$; N, 13.46; Found: C, 38.31; H, 4.55; N, 13.68 . 


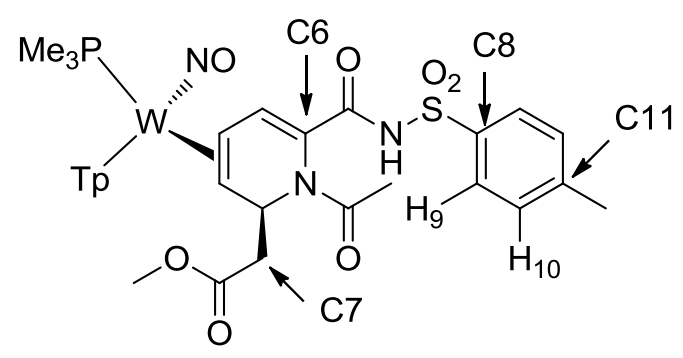

\section{TpW(NO)(PMe $)\left(3,4-\eta^{2}\right.$-(methyl-2-(1-acetyl-6-(tosylcarbamoyl)-1,2-dihydropyridin-2-}

yl)acetate). 19. A solution of Ts-ICN $(0.039,0.195 \mathrm{mmol})$ in DCM $(0.59 \mathrm{~g})$ was added to a vial containing 5 ( $0.126 \mathrm{~g}, 0.183 \mathrm{mmol})$ to make a homogeneous dark yellow solution. After $3.5 \mathrm{~h}$, the reaction solution was removed from the glovebox, transferred to a $250 \mathrm{~mL}$ round bottom flask with $2 \times 1 \mathrm{~mL} \mathrm{DCM}$, and slowly diluted with $50 \mathrm{~mL} \mathrm{Et}{ }_{2} \mathrm{O}$. The solution was cooled to $0{ }^{\circ} \mathrm{C}$ for 1 h. The fine tan precipitate was collected on a $15 \mathrm{~mL}$ medium porosity fritted funnel, washed with $2 \times 7 \mathrm{mLEt}{ }_{2} \mathrm{O}$, and placed under vacuum. Outside of the glovebox, the isolated material was dissolved in DCM (0.84 g) followed by acetic acid (0.29 g, glacial) to make a heterogeneous solution. DCM $(0.31 \mathrm{~g})$ was added to the solution to redissolve the precipitate to make a homogeneous dark yellow solution. After $3.5 \mathrm{~h}$, the reaction solution was diluted with $25 \mathrm{~mL}$ DCM, extracted with $3 \times 25 \mathrm{~mL} \mathrm{NaHCO}$ (saturated, aqueous), back-extracted with $2 \times 15 \mathrm{~mL} \mathrm{DCM}$, dried with $\mathrm{MgSO}_{4}$, filtered through a $60 \mathrm{~mL}$ coarse porosity fritted funnel, then a $30 \mathrm{~mL}$ medium porosity fritted funnel, and the filtrate solvent removed in vacuo. The residue was dissolved in 2 $\mathrm{mL} \mathrm{DCM}$, then diluted with $2 \mathrm{~mL}$ EtOAc, and $75 \mathrm{~mL}$ hexanes to precipitate a tan-yellow solid that was cooled to $0{ }^{\circ} \mathrm{C}$ for $0.5 \mathrm{~h}$. The precipitate was collected on a $15 \mathrm{~mL}$ medium porosity fritted funnel, washed with $2 \times 7 \mathrm{~mL}$ hexanes and placed under vacuum $(0.093 \mathrm{~g}, 0.105 \mathrm{mmol}, 57 \%$ yield). ${ }^{1} \mathrm{H} N M R\left(\mathrm{CDCl}_{3}, \delta\right): 10.88(\mathrm{~s}, 1 \mathrm{H}, \mathrm{NH}), 8.42(\mathrm{~d}, J=2.0,1 \mathrm{H}, \mathrm{PzA} 3), 8.02(\mathrm{~d}, J=8.5,2 \mathrm{H}, \mathrm{H} 9)$, $7.96(\mathrm{~d}, J=2.0,1 \mathrm{H}, \mathrm{PzB} 3), 7.74(\mathrm{~d}, J=2.0,1 \mathrm{H}, \mathrm{PzC} 5), 7.68(\mathrm{~d}, J=2.0,1 \mathrm{H}, \mathrm{PzB} 5), 7.58(\mathrm{~d}, J=2.0$, 1H, PzA5), 7.35 (d, J = 6.9, 1H, H5), $7.31(\mathrm{~d}, J=8.5,2 \mathrm{H}, \mathrm{H} 10), 7.23(\mathrm{~d}, J=2.0,1 \mathrm{H}, \mathrm{PzC} 3), 6.27(\mathrm{t}, J$ $=2.0,1 \mathrm{H}, \mathrm{PzA} 4), 6.25(\mathrm{t}, J=2.0,1 \mathrm{H}, \mathrm{PzB} 4), 6.23(\mathrm{t}, J=2.0,1 \mathrm{H}, \mathrm{PzC} 4), 5.99(\mathrm{~m}, 1 \mathrm{H}, \mathrm{H} 2), 3.78(\mathrm{~s}$, 
$3 \mathrm{H}$, Ester-Me), $2.72\left(\mathrm{ddd}, J=9.7,6.9,{ }^{3} \mathrm{~J}_{\mathrm{PH}}=12.2,1 \mathrm{H}, \mathrm{H} 4\right), 2.42(\mathrm{~s}, 3 \mathrm{H}, \mathrm{Ts}-\mathrm{Me}), 2.35(\mathrm{~m}, 2 \mathrm{H}$, $\left.\mathrm{H} 7 / \mathrm{H}^{\prime}\right), 1.95$ (s, 3H, Amide-Me), $1.67\left(\mathrm{~d}, J=9.6,1 \mathrm{H}, \mathrm{H} 3\right.$ ), $1.23\left(\mathrm{~d},{ }^{2} J_{\mathrm{PH}}=8.3,9 \mathrm{H}, \mathrm{PMe}_{3}\right) .{ }^{13} \mathrm{C} \mathrm{NMR}$ $\left(\mathrm{CDCl}_{3}, \delta\right): 174.9$ (Ester-CO), 171.6 (Amide-CO), 164.4 (Ts-Amide-CO), 145.4 (PzA3), 144.4/136.8 (C8/C11), 143.1 (PzB3), 140 (PzC3), 138.0 (C5), 137.0 (PzC5), 136.4 (PzB5), 135.6 (PzA5), 129.5 (C10), 128.7 (C9), 123.3 (C6), 106.8 (Tp4), 106.6 (Tp4), 106.4 (Tp4), 68.4 (C3), 53.0 (Ester-Me), $48.1(C 2), 46.2\left(d,{ }^{2} J_{P C}=9.5, C 4\right), 41.6(C 7), 25.0$ (Amide-Me), 21.8 (Ts-Me), $13.8\left(d,{ }^{2} J_{P C}=28.7\right.$, $\left.\mathrm{PMe}_{3}\right) .{ }^{31} \mathrm{P} \mathrm{NMR}\left(\mathrm{CDCl}_{3}, \delta\right):-13.07\left(J_{\mathrm{WP}}=272\right) . \mathrm{CV}(\mathrm{MeCN}): E_{\mathrm{p}, \mathrm{a}}=+0.88 \mathrm{~V} . \mathrm{IR}: v_{\mathrm{BH}}=2485 \mathrm{~cm}^{-1}, v=$ $1739(\mathrm{w}) \mathrm{cm}^{-1}, v=1689 \mathrm{~cm}^{-1}, v=1651(\mathrm{br}) \mathrm{cm}^{-1}, v=1593 \mathrm{~cm}^{-1}, v=1570 \mathrm{~cm}^{-1}, v=1408 \mathrm{~cm}^{-1}, v=$ $1053 \mathrm{~cm}^{-1}$. ESI-MS: obs'd (\%), calc'd (\%), ppm, (M+H) ${ }^{+}: 894.2077$ (74.1), 894.209 (76), 1.4; 895.2081 (73.5), 895.2114 (79.3), 3.7; 896.2102 (100), 896.2113 (100), 1.2; 897.2105 (51.0), 897.2146 (51.9), 4.5; 898.2129 (77.5), 898.2143 (83.6), 1.6.

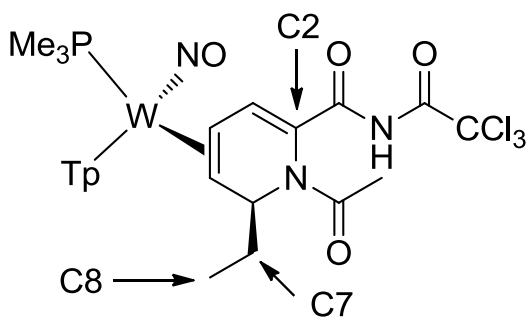

\section{$\mathrm{TpW}(\mathrm{NO})\left(\mathrm{PMe}_{3}\right)\left(4,5-\eta^{2}\right.$-(1-acetyl-6-ethyl-N-(2,2,2-trichloroacetyl)-1,6-dihydropyridine-2-}

carboxamide)). 21. A solution of TCA-ICN $(0.025 \mathrm{~g}, 0.134 \mathrm{mmol})$ in $\mathrm{CDCl} 3(1.02 \mathrm{~g})$ was added to a vial containing $3(0.075 \mathrm{~g}, 0.115 \mathrm{mmol})$ to make a homogeneous yellow solution that was transferred to an NMR tube. After $2 \mathrm{~h}$, the reaction solution was transferred to a $125 \mathrm{~mL}$ Erlenmeyer flask with $2 \times 1 \mathrm{~mL} \mathrm{DCM}$ and diluted with $50 \mathrm{~mL} \mathrm{Et}{ }_{2} \mathrm{O}$ to precipitate a purple-brown material that was collected on a $15 \mathrm{~mL}$ medium porosity fritted funnel and washed with $2 \times 15 \mathrm{~mL}$ $\mathrm{Et}_{2} \mathrm{O}$. The precipitate was discarded and the filtrate solvent removed in vacuo. The residue was dissolved in $1 \mathrm{~mL}$ DCM, diluted with $1 \mathrm{~mL}$ EtOAc, and diluted with $50 \mathrm{~mL}$ hexanes to precipitate a bright yellow solid that was collected on a fresh $15 \mathrm{~mL}$ medium porosity fritted funnel, washed 
with $2 \times 7 \mathrm{~mL}$ hexanes, and placed under vacuum $\left(0.045 \mathrm{~g}, 0.054 \mathrm{mmol}, 47 \%\right.$ yield). ${ }^{1} \mathrm{H}$ NMR $\left(\mathrm{CDCl}_{3}, \delta\right): 8.98(\mathrm{~d}, J=2.0,1 \mathrm{H}, \mathrm{NH}), 8.60(\mathrm{~d}, J=2.0,1 \mathrm{H}, \mathrm{PzA} 3), 8.04(\mathrm{~d}, J=2.0,1 \mathrm{H}, \mathrm{PzB} 3), 7.76(\mathrm{~d}$, $J=2.0,1 \mathrm{H}, \mathrm{Tp} 5), 7.71(\mathrm{~d}, J=2.0,1 \mathrm{H}, \mathrm{Tp} 5), 7.68(\mathrm{~d}, J=6.9,1 \mathrm{H}, \mathrm{H} 3), 7.6(\mathrm{~d}, J=2.0,1 \mathrm{H}, \mathrm{Tp} 5), 7.32$ (d, $J=2.0,1 \mathrm{H}, \mathrm{PzC} 3), 6.27 / 6.28(\mathrm{t}, J=2.0,3 \mathrm{H}, \mathrm{Tp} 4 / \mathrm{Tp} 4 / \mathrm{Tp} 4), 5.67(\mathrm{~m}, 1 \mathrm{H}, \mathrm{H} 6), 2.87$ (ddd, J = 9.5, 6.9, 3JPH = 12.1, 1H, H4), 2.19 (s, 3H, Amide-Me), $1.93(\mathrm{~d}, J=9.5,1 \mathrm{H}, \mathrm{H} 5), 1.57(\mathrm{~m}, 1 \mathrm{H}, \mathrm{H} 7), 1.47$ $\left(\mathrm{m}, 1 \mathrm{H}, \mathrm{H} 7^{\prime}\right), 1.29\left(\mathrm{~d}, 2 \mathrm{JPH}=8.2,9 \mathrm{H}, \mathrm{PMe}_{3}\right), 0.99(\mathrm{t}, J=7.4,3 \mathrm{H}, \mathrm{H} 8) .{ }^{13} \mathrm{C} \mathrm{NMR}\left(\mathrm{CDCl}_{3}, \delta\right): 172.1$ (N1-Amide-CO), 162.6 (N2-Amide-CO), 157.7 (Amide-CO), 145.5 (PzA3), 142.9 (PzB3+C3), 140.0 (PzC3), 137 (Tp5), 136.4 (Tp5), 133.6 (Tp5), 123.6 (C2), 106.7 (Tp4+Tp4), 106.4 (Tp4), 92.6 (CCl3), 71.0 (C5), 51.9 (C6), 47.7 (d, $\left.{ }^{2} J_{P C}=8.7, C 4\right), 30.5$ (C7), 25.6 (Amide-Me), 14.1 (d, ${ }^{1} J_{P C}=28.7$, $\left.\mathrm{PMe}_{3}\right), 12.3(\mathrm{C} 8) .{ }^{31} \mathrm{P} \mathrm{NMR}\left(\mathrm{CDCl}_{3}, \delta\right):-13.07\left(J_{\mathrm{WP}}=271\right) . \mathrm{CV}(\mathrm{MeCN}): E_{\mathrm{p}, \mathrm{a}}=+0.84 \mathrm{~V}, E_{\mathrm{p}, \mathrm{c}}=-1.05 \mathrm{~V}$ IR: $v_{\mathrm{BH}}=2488 \mathrm{~cm}^{-1}, v=1763 \mathrm{~cm}^{-1}, v=1682 \mathrm{~cm}^{-1}, v=1631 \mathrm{~cm}^{-1}, v=1581 \mathrm{~cm}^{-1}, v=1560 \mathrm{~cm}^{-1}, v=$ $1554 \mathrm{~cm}^{-1}$. ESI-MS: obs'd (\%), calc'd (\%), ppm, $(\mathrm{M}+\mathrm{Na})^{+}: 862.0851$ (50.2), 862.0858 (40.6), 0.8 ; 863.0891 (55.6), 863.0878 (47.4), 1.4; 864.0856 (91.0), 864.0858 (87.7), 0.2; 865.0879 (61.7), 865.0877 (62.5), 0.2; 866.0857 (100), 866.0871 (100), 1.6; 867.0897 (49.1), 867.0885 (45.0), 1.3; 868.0849 (51.2), 868.0869 (57.3), 2.2; 869.0891 (18.7), 869.0887 (19.3), 0.5.

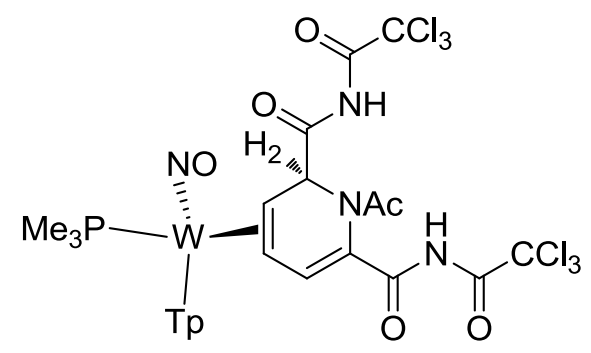

$\operatorname{TpW}(\mathrm{NO})\left(\mathrm{PMe}_{3}\right)\left(3,4-\eta^{2}\right.$-(1-acetyl- $N^{2}, N^{6}$-bis(2,2,2-trichloroacetyl)-1,2-dihydropyridine-2,6-

dicarboxamide)). 23. A solution of TCA-ICN $(0.055 \mathrm{~g}, 0.300 \mathrm{mmol})$ in $\mathrm{CDCl} 3(1.06 \mathrm{~g})$ was added to a vial containing $2(0.075 \mathrm{~g}, 0.120 \mathrm{mmol})$ to become homogeneous tan solution that became bright yellow over the next several minutes. After 45 minutes the bright yellow reaction solution was transferred to $50 \mathrm{~mL}$ of stirring $\mathrm{Et}_{2} \mathrm{O}$ to make a yellow solution. The solvent was removed in 
vacuo and the residue dissolved in $\sim 0.5 \mathrm{~mL} \mathrm{DCM}$, then $\sim 0.5 \mathrm{~mL}$ EtOAc, and diluted with $50 \mathrm{~mL}$ hexanes to precipitate a bright yellow solid that was collected on a $15 \mathrm{~mL}$ medium porosity fritted funnel, washed with $2 \times 7 \mathrm{~mL}$ hexanes, and placed under vacuum $(0.084 \mathrm{~g}, 0.084 \mathrm{mmol}, 70$ \% yield). ${ }^{1} \mathrm{H} \mathrm{NMR}\left(\mathrm{CDCl}_{3}, \delta\right): 10.46(\mathrm{~s}, 1 \mathrm{H}, \mathrm{NH}), 8.62(\mathrm{~s}, 1 \mathrm{H}, \mathrm{NH}), 8.2$ (d, J = 2.0, 1H, PzA3), 8.01 (d, $J=2.0,1 \mathrm{H}, \mathrm{PzB} 3), 7.84(\mathrm{~d}, J=7.8,1 \mathrm{H}, \mathrm{H5}), 7.78(\mathrm{~d}, J=2.0,1 \mathrm{H}, \mathrm{PzC} 5), 7.77(\mathrm{~d}, J=2.0,1 \mathrm{H}, \mathrm{PzB} 5)$, $7.58(\mathrm{~d}, J=2.0,1 \mathrm{H}, \mathrm{PzA} 5), 7.53(\mathrm{~d}, J=2.0,1 \mathrm{H}, \mathrm{PzC} 3), 6.38(\mathrm{~s}, 1 \mathrm{H}, \mathrm{H} 2), 6.35(\mathrm{t}, J=2.0,1 \mathrm{H}, \mathrm{PzB} 4)$, $6.31(\mathrm{t}, J=2.0,1 \mathrm{H}, \mathrm{PzC} 4), 6.20(\mathrm{t}, J=2.0,1 \mathrm{H}, \mathrm{PzA} 4), 4\left(\mathrm{dd}, J=9.4{ }^{3} J_{\mathrm{PH}}=10.4,1 \mathrm{H}, \mathrm{H} 3\right), 2.22(\mathrm{~s}, 3 \mathrm{H}$, Amide-Me), $2.01\left(\mathrm{ddd}, J=9.4,7.8,{ }^{3} J_{\mathrm{PH}}=1.0,1 \mathrm{H}, \mathrm{H} 4\right), 1.28\left(\mathrm{~d},{ }^{2} J_{\mathrm{PH}}=8.4,9 \mathrm{H}, \mathrm{PMe}_{3}\right) .{ }^{13} \mathrm{C} \mathrm{NMR}$ $\left(\mathrm{CDCl}_{3}, \delta\right): 174.1$ (N2-Amide-CO), 173.3 (N1-Amide-CO), 163.6 (N6-Amide-CO), 159.3 (AmideCO), 158.7 (Amide-CO), 150.5 (C5), 147.6 (PzA3), 143.4 (PzB3), 140.5 (PzC3), 137.2/136.9 (PzB5/PzC5), 135.5 (PzA5), 120.9 (C6), 107.2 (PzB4), 106.7/106.5 (PzA4/PzC4), 92.5 (CCl3), 92.3 (CCl3'), $67.5\left(\mathrm{~d},{ }^{2} J_{\mathrm{PC}}=15.1, \mathrm{C} 3\right), 59.1(\mathrm{C} 2), 49.1(\mathrm{C} 4), 25.9$ (Amide-Me), $13.2\left(\mathrm{~d},{ }^{1} \mathrm{~J}_{\mathrm{PC}}=29.2, \mathrm{PMe}_{3}\right)$. ${ }^{31} \mathrm{P} \mathrm{NMR}\left(\mathrm{CDCl}_{3}, \delta\right):-9.34\left(J_{\mathrm{WP}}=273\right) . \mathrm{CV}(\mathrm{MeCN}): E_{\mathrm{p}, \mathrm{a}}=+0.99 \mathrm{~V}, E_{\mathrm{p}, \mathrm{c}}=-1.08 \mathrm{~V} . \mathrm{IR}: v_{\mathrm{BH}}=2488 \mathrm{~cm}^{-1}$, $v=1778(\mathrm{br}) \mathrm{cm}^{-1}, v=1666(\mathrm{br}) \mathrm{cm}^{-1}, v=1593(\mathrm{br}) \mathrm{cm}^{-1}, v=1477 \mathrm{~cm}^{-1}$. ESI-MS: obs'd (\%), calc'd (\%), ppm, (M+Na) $)^{+}: 1020.9537$ (20.7), 1020.9539 (20.6), 0.2; 1021.9552 (33.5), 1021.9556 (28.3), $0.4 ; 1022.9532$ (72.9), 1022.9531 (64.3), $0.1 ; 1023.9534$ (52.3), 1023.9546 (56.7), $1.1 ; 1024.9525$ (100), 1024.9531 (100), 0.6; 1025.9532 (67.0), 1025.954 (61.9), $0.7 ; 1026.9517$ (96.0), 1026.9526 (92.6), 0.9; 1027.9525 (38.8), 1027.9535 (43.4), 1.0; 1028.9511 (47.1), 1028.9515 (53.5), 0.3; 1029.9514 (20.6), 1029.9527 (20.5), 1.2; 1030.9491 (20.4), 1030.95 (19.7), 0.9.

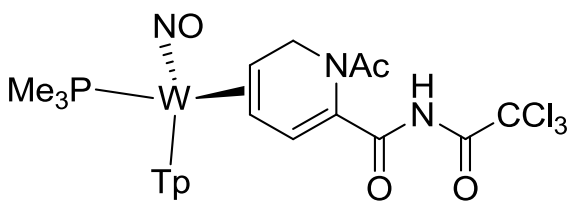

TpW(NO)(PMe $)\left(4,5-\eta^{2}\right.$-(1-acetyl-N-(2,2,2-trichloroacetyl)-1,6-dihydropyridine-2carboxamide)). 24. TCA-ICN (0.020 g, $0.11 \mathrm{mmol})$ was added to a vial containing a 
heterogeneous pale yellow solution of $2(0.011 \mathrm{~g})$ and $\mathrm{CDCl}_{3}(1.00 \mathrm{~g})$ to make a bright yellow solution. The heterogeneous solution was transferred to an NMR tube and sonicated for about 1 minute to help dissolve 2 . The reaction was complete at $8 \mathrm{~min}$ (the time the sample arrived at the NMR spectrometer) and 2D NMR experiment data was collected. ${ }^{1} \mathrm{H} N M R\left(\mathrm{CDCl}_{3}, \delta\right): 8.80(\mathrm{~s}$, $1 \mathrm{H}, \mathrm{NH}), 8.14(\mathrm{~d}, J=2.0,1 \mathrm{H}, \mathrm{PzA} 3), 8.02(\mathrm{~d}, J=2.0,1 \mathrm{H}, \mathrm{PzB} 3), 7.85(\mathrm{~d}, J=7.4,1 \mathrm{H}, \mathrm{H} 3), 7.76(\mathrm{~d}, J=$ 2.0, 1H, PzC5), 7.75 (d, J = 2.0, 1H, PzB5), 7.57 (d, $J=2.0,1 \mathrm{H}, \mathrm{PzA} 5), 7.41$ (d, $J=2.0,1 \mathrm{H}, \mathrm{PzC} 3$ ), $6.33(\mathrm{t}, J=2.0,1 \mathrm{H}, \mathrm{PzB} 4), 6.27(\mathrm{t}, J=2.0,1 \mathrm{H}, \mathrm{PzC} 4), 6.22(\mathrm{t}, J=2.0,1 \mathrm{H}, \mathrm{PzA} 4), 5.67(\mathrm{~d}, J=13.1$, $1 \mathrm{H}, \mathrm{H} 6), 4.53$ (ddd, $\left.J=13.1,3.1,1.5,1 \mathrm{H}, \mathrm{H} 6^{\prime}\right), 3.28\left(\mathrm{ddd},{ }^{3} J_{\mathrm{PH}}=11.2, J=9.5,3.1,1 \mathrm{H}, \mathrm{H} 5\right), 2.14(\mathrm{~s}$, $3 \mathrm{H}$, Amide-Me), $1.96(\mathrm{dd}, J=9.5,7.4,1 \mathrm{H}, \mathrm{H} 4), 1.24\left(\mathrm{~d},{ }^{2} J_{\mathrm{PH}}=8.6,9 \mathrm{H}, \mathrm{PMe}_{3}\right) .{ }^{13} \mathrm{C} \mathrm{NMR}\left(\mathrm{CDCl}_{3}, \delta\right)$ : 171.6 (HMBC), 162.0 (HMBC), 149.0 (С3), 146.8 (PzA3), 143.1 (РzB3), 140.1 (PzC3), 137.1+136.6 (PzC4+PzB5), 135.3 (PzA5), 123.8 (C2), 106.9 (PzB4), 106.5+106.5 (PzC4+PzA4), $92.6\left(\mathrm{CCl}_{3}\right), 68.3$ $\left(d,{ }^{2} J_{P C}=14.7, C 5\right), 49.7(C 4), 45.4(C 6), 25.4$ (Amide-Me), 13.4 (d, $\left.{ }^{1} J_{P C}=28.7, \mathrm{PMe}_{3}\right) .{ }^{31} \mathrm{P}\left(\mathrm{CDCl}_{3}\right.$, $\delta):-9.24\left(J_{\mathrm{WP}}=276\right) . \mathrm{CV}(\mathrm{DMA}): E_{\mathrm{p}, \mathrm{a}}=+0.76 \mathrm{~V} . \mathrm{IR}: v_{\mathrm{BH}}=2496 \mathrm{~cm}^{-1}, v=1753 \mathrm{~cm}^{-1}, v=1676 \mathrm{~cm}^{-1}, v$ $=1640 \mathrm{~cm}^{-1}, v=1622 \mathrm{~cm}^{-1}, v=1578 \mathrm{~cm}^{-1}, v=1550 \mathrm{~cm}^{-1}$. ESI-MS: obs'd (\%), calc'd (\%), ppm, (M$H)^{+}: 810.0571$ (81.4), 810.0569 (41.0), $0.4 ; 811.0578$ (90.1), 811.0589 (47.2), 1.4; 812.0581 (42.4), 812.0569 (87.9), 1.5; 813.0602 (100), 813.0587 (61.4), 1.8; 814.0589 (69.3), 814.0582 (100), 0.9; 815.0593 (79.5), 815.0595 (43.4), 0.2; 816.0616 (39.2), 816.0579 (57.1), 4.5.

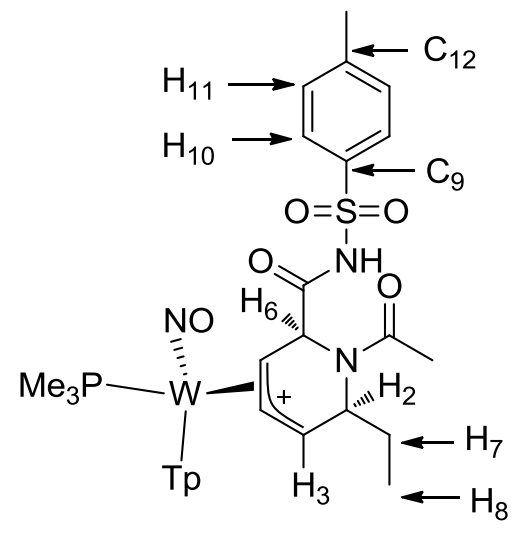


$\mathrm{TpW}(\mathrm{NO})\left(\mathrm{PMe}_{3}\right)\left(4,5-\eta^{2}\right.$-(1-acetyl-2-ethyl-6-(tosylcarbamoyl)piperidin-4-ylium)(OTf). $\quad 25 . \quad$ А solution of HOTf $(0.021 \mathrm{~g}, 0.138 \mathrm{mmol})$ in $\mathrm{MeCN}(0.80 \mathrm{~g})$ was added to a vial containing 14 (0.101 $\mathrm{g}, 0.119 \mathrm{mmol})$ to make a deep yellow homogeneous solution. After 9 minutes, the reaction solution was added to $50 \mathrm{~mL}$ of stirring $\mathrm{Et}_{2} \mathrm{O}$ to precipitate a tan solid and was allowed to stir for $1.5 \mathrm{~h}$. The precipitate was collected on a $15 \mathrm{~mL}$ medium porosity fritted funnel, washed with $2 \times 7 \mathrm{~mL} \mathrm{Et} \mathrm{t}_{2} \mathrm{O}$, and placed under vacuum $\left(0.104 \mathrm{~g}, 0.104 \mathrm{mmol}, 88 \%\right.$ yield). ${ }^{1} \mathrm{H}$ NMR $\left(\mathrm{CD}_{3} \mathrm{CN}, \delta\right): 9.92(\mathrm{~s}(\mathrm{br}), 1 \mathrm{H}, \mathrm{NH}) 8.36(\mathrm{~d}, J=2.0,1 \mathrm{H}, \mathrm{PzB} 3), 8.14(\mathrm{~d}, J=2.0,1 \mathrm{H}, \mathrm{PzA} 3), 8.06(\mathrm{~d}, J=$ 2.0, 1H, PzC5), 8.02 (d, J = 2.0, 1H, PzC3), 7.97 (d, J = 2.0, 1H, PzB5), 7.9 (d, J = 8.7, 2H, H10), 7.84 $(\mathrm{d}, J=2.0,1 \mathrm{H}, \mathrm{PzA} 5), 7.46(\mathrm{~d}, J=8.7,2 \mathrm{H}, \mathrm{H} 11), 6.56(\mathrm{t}, J=2.0,1 \mathrm{H}, \mathrm{PzC} 4), 6.53(\mathrm{t}, J=2.0,1 \mathrm{H}$, PzB4), $6.36(\mathrm{~m}, 2 \mathrm{H}, \mathrm{H} 3 / \mathrm{PzA} 4), 5.36(\mathrm{~d}, J=1.5,1 \mathrm{H}, \mathrm{H} 6), 5.31(\mathrm{t}, J=7.7,1 \mathrm{H}, \mathrm{H} 4) 5.02(\mathrm{~m}, 1 \mathrm{H}, \mathrm{H} 2)$, 4.11 (dddd, $\left.J=7.7,1.5,{ }^{3} J_{\mathrm{HH}}=1.9,{ }^{3} \mathrm{JPH}_{\mathrm{PH}}=13.5,1 \mathrm{H}, \mathrm{H} 5\right), 2.47(\mathrm{~s}, 3 \mathrm{H}, \mathrm{Ts}-\mathrm{Me}), 2.20(\mathrm{~s}, 3 \mathrm{H}$, Amideme), $1.25\left(\mathrm{~m}, 2 \mathrm{H}, \mathrm{H} 7 / \mathrm{H}^{\prime}\right), 1.17\left(\mathrm{~d},{ }^{2} J_{\mathrm{PH}}=10.0,9 \mathrm{H}, \mathrm{PMe}_{3}\right), 0.85(\mathrm{t}, J=7.5,3 \mathrm{H}, \mathrm{H} 8) .{ }^{13} \mathrm{C} \mathrm{NMR}$ ( $\left.\mathrm{CD}_{3} \mathrm{CN}, \delta\right): 174.7$ (Amide-CO) 171.0 (Ts-Amide-CO), 149.1 (PzA3), 146.8/136.4 (C9/C12), 145.4 (PzB3), 143.5 (PzC3), 140.0 (PzA5), 139.9 (PzC5), 139.8 (PzB5), 130.8 (C3), 130.7 (C11), 129.2 (C10), 109.6 (PzB4) 109.2 (PzC4), 108.4 (PzA4), $98.5\left(d,{ }^{2} J_{P C}=3.4, C 4\right), 63.3\left(d,{ }^{2} J_{P C}=14.9, C 5\right)$, 57.7 (C2), 54.6 (C6), 32.8 (C7), 22.9 (Amide-Me), 21.7 (Ts-Me), 13.0 (d, ${ }^{1} \mathrm{~J}_{\mathrm{PC}}=33.4, \mathrm{PMe}_{3}$ ), 10.6 (C8). ${ }^{31}$ P NMR $\left(\mathrm{CDCl}_{3}, \delta\right):-7.55\left(J_{\mathrm{WP}}=255\right),-7.31$ (rotamer; 5:1). IR: $v_{\mathrm{BH}}=2507 \mathrm{~cm}^{-1}, v_{\text {amide }}=1720$ $\mathrm{cm}^{-1}, v_{\text {amide/NO }}=1651 \mathrm{~cm}^{-1} . \mathrm{CV}(\mathrm{MeCN}): E_{\mathrm{p}, \mathrm{a}}=+2.13 \mathrm{~V}, E_{\mathrm{p}, \mathrm{c}}=-0.79 \mathrm{~V}$. obs'd (\%), calc'd (\%), ppm, $\mathrm{M}^{+}: 850.2184$ (84.0), 850.2191 (76.7), 0.9; 851.2211 (78.6), 851.2216 (79.4), 0.6; 852.2207 (100), 852.2214 (100), 0.8; 853.2245 (50.7), 853.2248 (51), 0.3; 854.2236 (83.8), 854.2245 (83.6), 1.0. 


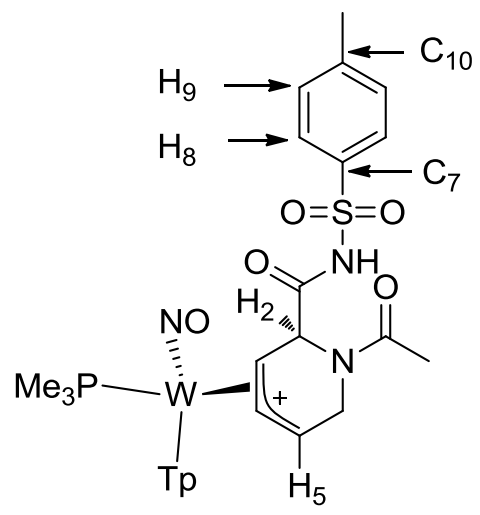

$\mathrm{TpW}(\mathrm{NO})\left(\mathrm{PMe}_{3}\right)\left(3,4-\eta^{2}\right.$-(1-acetyl-6-(tosylcarbamoyl)-1,2,3,6-tetrahydropyridin-3-ylium)][OTf].

26. A solution of Ts-ICN $(0.255 \mathrm{~g}, 1.293 \mathrm{mmol})$ in DCM (1.88 g) was added to a vial containing 2 $(0.756 \mathrm{~g}, 1.207 \mathrm{mmol})$ in DCM (1.84 g) to make a dark yellow homogeneous solution. After 8 minutes, a solution of HOTf $(0.202 \mathrm{~g}, 0.743 \mathrm{mmol})$ in MeCN $(1.4 \mathrm{~g})$ was additionally added to the vial. After 5 minutes the reaction solution was diluted with $4 \mathrm{~mL} \mathrm{MeCN}$ and slowly added to 625 $\mathrm{mL}$ of stirring $\mathrm{Et}_{2} \mathrm{O}$ to precipitate a tan solid. The precipitate was collected on a $30 \mathrm{~mL}$ medium porosity fritted funnel, washed with $2 \times 15 \mathrm{~mL} \mathrm{Et}_{2} \mathrm{O}$, and placed under vacuum $(1.077 \mathrm{~g}, 1.106$

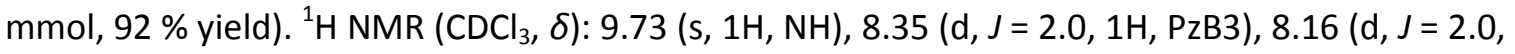
$1 \mathrm{H}, \mathrm{PzA} 3), 8.05+8.00+7.97(\mathrm{~d}, J=2.0,3 \mathrm{H}, \mathrm{PzC} 3+\mathrm{PzC} 5+\mathrm{PzB} 5), 7.89(\mathrm{~d}, J=8.1,2 \mathrm{H}, \mathrm{H} 8), 7.83(\mathrm{~d}, J=$ 2.0, 1H, PzA5), $7.45(\mathrm{~d}, J=8.1,2 \mathrm{H}, \mathrm{H} 9), 6.58(\mathrm{~d}(\mathrm{br}), J=8.0,1 \mathrm{H}, \mathrm{H} 5), 6.56+6.53(\mathrm{t}, J=2.0,2 \mathrm{H}$, PzB4+PzC4), 6.36 (t, J = 2.0, 1H, PzA4), 5.24-5.14 (m, 3H, H4+H6+H2), 4.89 (ddd, J = 19.8, 3.0, 3.0, $\left.1 \mathrm{H}, \mathrm{H} 6^{\prime}\right), 4.10$ (dddd, J=7.7, 1.9, 1.9, ${ }^{3} \mathrm{~J}_{\mathrm{PH}}=13.9,1 \mathrm{H}, \mathrm{H} 3$ ), 2.47 (s, 3H, Ts-Me), 2.10 (s, 3H, AmideMe), $1.21\left(\mathrm{~d},{ }^{2} J_{\mathrm{PH}}=10.1,9 \mathrm{H}, \mathrm{PMe}_{3}\right) .{ }^{13} \mathrm{C} \mathrm{NMR}\left(\mathrm{CDCl}_{3}, \delta\right):$ 172.9/172.7 (Amide-CO/Ts-Amide-CO), 149.1 (PzA3), 146.4/136.9 (C7/C10), 145.8 (PzB3), 143.5 (PzC3), 139.7/139.1 (PzA5/PzB5/PzC5), 131.6 (C5), 130.6 (C9), 128.9 (C10), 109.6/109.1 (PzB4/PzC4), 108.2 (PzA4), 97.0 (C4), 63.2 (d, ${ }^{2} \mathrm{JC}_{\mathrm{PC}}$ $=15.3, \mathrm{C} 3$ ), 56.2 (C2), 45.1 (C6), 22.3 (Ts-Me), 21.7 (Amide-Me), 12.9 (d, ${ }^{1} J_{\mathrm{PC}}=22.6, \mathrm{PMe}_{3}$ ). ${ }^{31} \mathrm{P}$ $\operatorname{NMR}\left(\mathrm{CD}_{3} \mathrm{CN}, \delta\right):-5.45\left(J_{\mathrm{WP}}=259\right) . \mathrm{IR}: v_{\mathrm{BH}}=2499 \mathrm{~cm}^{-1}, v_{\text {amide }}=1720 \mathrm{~cm}^{-1}, v_{\text {amide } / \mathrm{NO}}=1651 \mathrm{~cm}^{-1}, v=$ $1408 \mathrm{~cm}^{-1} . \mathrm{CV}(\mathrm{MeCN}): E_{\mathrm{p}, \mathrm{a}}=+2.11 \mathrm{~V}, E_{\mathrm{p}, \mathrm{c}}=-0.77 \mathrm{~V}$. obs'd (\%), calc'd (\%), ppm, $(\mathrm{M}-\mathrm{H}+\mathrm{Na})^{+}:$ 
844.1671 (85.2), 844.1697 (77.7), 3.2; 845.1687 (72.3), 845.1722 (79.0), 4.1; 846.1692 (100), 846.172 (100), 3.3; 847.173 (52.9), 847.1754 (49.7), 2.9; 848.1726 (77.0), 848.1751 (84.0), 2.9.

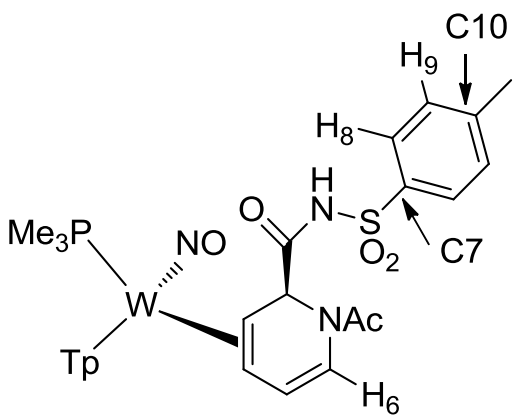

$\mathrm{TpW}(\mathrm{NO})\left(\mathrm{PMe}_{3}\right)\left(3,4-\eta^{2}\right.$-(1-acetyl-N-tosyl-1,2-dihydropyridine-2-carboxamide)). 27. $\mathrm{NEt}_{3}(0.042$ $\mathrm{g}, 0.415 \mathrm{mmol})$ was added to a yellow homogenous solution of $26(0.146 \mathrm{~g}, 0.150 \mathrm{mmol})$ in DCM (0.95 g). After $14 \mathrm{~h}$, the reaction solution was removed from the glovebox, diluted with $50 \mathrm{~mL}$ DCM, extracted with $25 \mathrm{~mL} \mathrm{NaHCO}$ (saturated, aqueous) and $15 \mathrm{~mL}$ brine (saturate, aqueous), then $15 \mathrm{~mL} \mathrm{NaHCO}$ (saturated, aqueous) and $15 \mathrm{~mL}$ brine (saturate, aqueous), followed by $2 \times 25$ $\mathrm{mL} \mathrm{NaHCO}_{3}$ (saturated, aqueous). The aqueous layer was back-extracted with $2 \times 25 \mathrm{~mL} \mathrm{DCM}$, dried with $\mathrm{MgSO}_{4}$, filtered through a $60 \mathrm{~mL}$ coarse porosity fritted funnel, and the solvent removed in vacuo. DCM $(2 \mathrm{ml})$ was added to the residue to cause a precipitate to form. Hexanes $(50 \mathrm{~mL}$ ) was added to aid in precipitation. The white solid was collected on a $15 \mathrm{~mL}$ medium porosity fritted funnel, washed with $2 \times 7 \mathrm{~mL}$ hexanes, and placed under vacuum $(0.108 \mathrm{~g}, 0.131$ mmol, $17 \mathrm{~mol} \%$ impurity of $\mathrm{NEt}_{3}{ }_{3} \mathrm{HOTf} ; 0.090 \mathrm{~g}, 0.109 \mathrm{mmol}, 73 \%$ yield after adjustment for impurity). ${ }^{1} \mathrm{H} N M R\left(\mathrm{CDCl}_{3}, \delta\right): 9.12(\mathrm{~s}(\mathrm{br}), 1 \mathrm{H}, \mathrm{NH}), 8.12(\mathrm{~d}, J=2.0,1 \mathrm{H}, \mathrm{PzA}), 7.96(\mathrm{~d}, J=2.0,1 \mathrm{H}$, PzB3), 7.94 (d, $J=8.3,2 \mathrm{H}, \mathrm{H8}$ ), $7.72(\mathrm{~d}, J=2.0,1 \mathrm{H}, \mathrm{PzB} 5), 7.70 / 7.58(\mathrm{~d}, J=2.0,2 \mathrm{H}, \mathrm{PzC} 5 / \mathrm{PzA} 5)$, $7.31(\mathrm{~d}, J=8.3,2 \mathrm{H}, \mathrm{H9}), 7.28(\mathrm{~d}, J=2.0,1 \mathrm{H}, \mathrm{PzC} 3), 6.30(\mathrm{t}, J=2.0,1 \mathrm{H}, \mathrm{PzB} 4), 6.25(\mathrm{dd}, J=7.5$, 6.1, 1H, H5), $6.19(\mathrm{~m}, 2 \mathrm{H}, \mathrm{PzA} 4+\mathrm{PzB} 4), 5.84(\mathrm{~d}, J=7.5,1 \mathrm{H}, \mathrm{H} 6), 5.82(\mathrm{~s}, 1 \mathrm{H}, \mathrm{H} 2), 3.08$ (dd, $J=$ $10.3,{ }^{3} J_{\mathrm{PH}}=10.3,1 \mathrm{H}, \mathrm{H} 3$ ), 2.42 (s, 3H, Ts-Me), 2.23 (s, 3H, Amide-Me), 1.61 (ddd, $J=10.3,6.1,{ }^{3} J_{\mathrm{PH}}$ $=1.7,1 \mathrm{H}, \mathrm{H} 4), 1.15\left(\mathrm{~d},{ }^{2} \mathrm{~J}_{\mathrm{PH}}=8.2,9 \mathrm{H}, \mathrm{PMe}_{3}\right) .{ }^{13} \mathrm{C} \mathrm{NMR}\left(\mathrm{CDCl}_{3}, \delta\right): 172.8$ (Ts-Amide-CO), 170.8 
(Amide-CO), 144.8/136.0 (C7/C10), 144.4 (РzA3), 143.4 (РzB3), 140.4 (PzC3), 136.9/135.5 (PzA5/PzC5), 136.3 (PzB5), 129.6 (C9), 128.4 (C8), 122.1 (C5), 113.6 (C6), 106.6 (PzB4), 106.1/105.8 (PzA4/PzC4), 59.9 (d, $\left.{ }^{2} J_{\mathrm{PC}}=13.6, \mathrm{C} 3\right), 57.4$ (C2), 44.1 (C4), 23.6 (Amide-Me), 21.8 (Ts-Me), $13.3\left(\mathrm{~d},{ }^{1} J_{\mathrm{PC}}=28.1, \mathrm{PMe}_{3}\right) .{ }^{31} \mathrm{P}$ NMR $\left(\mathrm{DMSO}-d_{6}, \delta\right):-8.28\left(J_{\mathrm{WP}}=278\right) . \mathrm{IR}: v=1562 \mathrm{~cm}^{-1}, v=$ $1616 \mathrm{~cm}^{-1}, v=1651 \mathrm{~cm}^{-1}, v=1716 \mathrm{~cm}^{-1}, v=1408 \mathrm{~cm}^{-1} . \mathrm{CV}$ (DMA): $E_{\mathrm{p}, \mathrm{a}}=+0.46$ V. ESI-MS: obs'd (\%), calc'd (\%), ppm, (M+Na) $)^{+}: 844.1671$ (85.2), 844.1697 (77.7), 3.2; 845.1687 (72.3), 845.1722 (79.0), 4.1; 846.1692 (100), 846.172 (100), 3.3; 847.173 (52.9), 847.1754 (49.7), 2.9; 848.1726 (77.0), 848.1751 (84.0), 2.9.

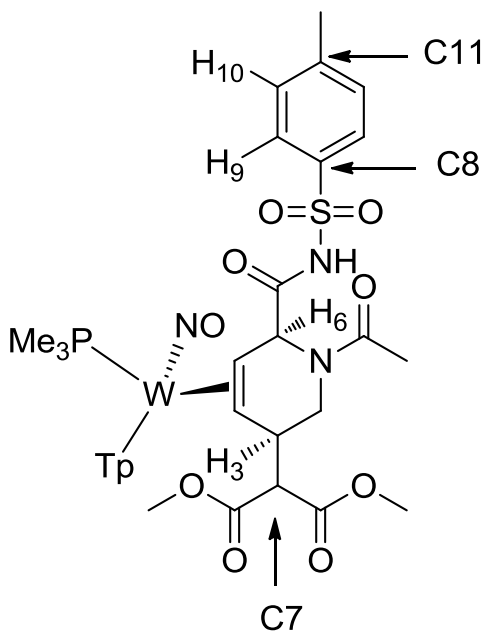

\section{TpW(NO)(PMe 3 )(4,5- $\eta^{2}$-(dimethyl 2-(1-acetyl-6-(tosylcarbamoyl)-1,2,3,6-tetrahydropyridin-3-}

yl)malonate). 28. To separate oven dried test tubes, solutions of $26(0.200 \mathrm{~g}, 0.206 \mathrm{mmol})$ in MeCN (2.34 g) and LiDMM (0.082 g, $0.596 \mathrm{mmol})$ in MeCN (1.46 g) were prepared and added to a $0{ }^{\circ} \mathrm{C}$ cold bath. After equilibrating for 12 minutes, the solution was quickly transferred to the stirring LiDMM solution in 2 portions with a $2 \mathrm{~mL}$ Pasteur pipette. After $16 \mathrm{~h}$, the solution was removed from the cold bath and allowed to warm to room temperature for 15 minutes. The solution was removed from the glovebox, then diluted with $50 \mathrm{~mL} \mathrm{DCM}$, extracted with $3 \times 25 \mathrm{~mL}$ portions of $\mathrm{NaHCO}_{3}$ (saturated, aqueous) to make a slowly separating emulsion. The water layer was back-extracted with $2 \times 25 \mathrm{~mL}$ of DCM. The organic layer was dried with $\mathrm{MgSO}_{4}$, filtered 
through a $60 \mathrm{~mL}$ coarse porosity fritted funnel and the solvent removed in vacuo. The residue was dissolved in $4 \mathrm{~mL} \mathrm{DCM}$, diluted with $4 \mathrm{~mL}$ EtOAc, and $75 \mathrm{~mL}$ hexanes was slowly added to precipitate a fine off-white solid. The solution was cooled to $0{ }^{\circ} \mathrm{C}$ for about $1.5 \mathrm{~h}$ and the solid collected on a $15 \mathrm{~mL}$ fine porosity fritted funnel, washed with $2 \times 7 \mathrm{~mL}$ hexanes, and the sample placed under vacuum $\left(0.154 \mathrm{~g}, 0.161 \mathrm{mmol}, 78 \%\right.$ yield). ${ }^{1} \mathrm{H} \mathrm{NMR}\left(\mathrm{CDCl}_{3}, \delta\right): 9.84(\mathrm{~s}, 1 \mathrm{H}, \mathrm{NH}), 8.00$ $(\mathrm{d}, J=8.4,2 \mathrm{H}, \mathrm{H9}), 8.00(\mathrm{~d}, J=2.0,1 \mathrm{H}, \mathrm{PzB} 3), 7.94(\mathrm{~d}, J=2.0,1 \mathrm{H}, \mathrm{PzA} 3), 7.70(\mathrm{~d}, J=2.0,1 \mathrm{H}$, PzB5), 7.68 (d, J = 2.0, 1H, PzC5), 7.60 (d, J = 2.0, 1H, PzA5), 7.34 (d, J = 8.4, 2H, H10), 7.25 (d, $J=$ 2.0, $1 \mathrm{H}, \mathrm{PzC} 3), 6.30(\mathrm{t}, J=2.0,1 \mathrm{H}, \mathrm{PzB} 4), 6.22(\mathrm{t}, J=2.0,1 \mathrm{H}, \mathrm{PzA} 4), 6.17(\mathrm{t}, J=2.0,1 \mathrm{H}, \mathrm{PzC} 4)$, $5.65(\mathrm{~s}, 1 \mathrm{H}, \mathrm{H} 6), 4.04$ (dd, J = 12.9, 3.9, 1H, H2), 3.74 (br, 2H, H3+H7), 3.72 (s, 3H, Ester-Me), 3.60 (s, 3H, Ester-Me'), 3.10 (dd, J=12.9, 4.0,1H, H2'), $2.84\left(\mathrm{dd}, J=11.5,{ }^{3} J_{\mathrm{PH}}=11.5,1 \mathrm{H}, \mathrm{H} 5\right), 2.44(\mathrm{~s}$, 3H, Ts-Me), 2.18 (s, 3H, Acyl-Me), $1.18(\mathrm{~d}, J=11.5,1 \mathrm{H}, \mathrm{H} 4), 1.07\left(\mathrm{~d},{ }^{2} J_{\mathrm{PH}}=8.3,9 \mathrm{H}, \mathrm{PMe}_{3}\right) .{ }^{13} \mathrm{C}$ NMR $\left(\mathrm{CDCl}_{3}, \delta\right):$ 174.2/174.1 (Ts-Amide-CO+Amide-CO), 169.7 (Ester-CO), 169.2 (Ester-CO'), 144.6 (C8orC11), $\quad 143.0 / 142.7 \quad$ (PzB3/PzA3), $\quad 140.3 \quad$ (PzC3), $\quad 136.8 / 136.4 / 136.3 / 136.2$ (PzA5/PzB5/PzC5+C8orC11), 129.6 (C10), 128.5 (C9), 106.8 (PzB4), 106.2/106.0 (PzA4/PzB4), 59.5 (C3/C7), 58.7 (d, J = 3.9, C6), 52.7 (Ester-Me), 52.6 (Ester-Me'), $50.9\left(d,{ }^{2} J_{P C}=12.0, C 5\right), 46.0$ (C3/C7), 23.0 (Amide-Me), 21.8 (Ts-Me), 12.9 (d, $\left.{ }^{1} \mathrm{JPC}_{\mathrm{PC}}=28.1, \mathrm{PMe}_{3}\right) .{ }^{31} \mathrm{P} \mathrm{NMR}\left(\mathrm{CDCl}_{3}, \delta\right):-10.96$ $\left(J_{\mathrm{WP}}=275\right) . \mathrm{IR}: v_{\mathrm{BH}}=2488 \mathrm{~cm}^{-1}, v=1728 \mathrm{~cm}^{-1}, v=1620(\mathrm{br}) \mathrm{cm}^{-1}, v_{\mathrm{NO}}=1558 \mathrm{~cm}^{-1}, v=1408 \mathrm{~cm}^{-1}$. CV (DCM): $E_{\mathrm{p}, \mathrm{a}}=+0.76$ V. ESI-MS: obs'd (\%), calc'd (\%), ppm, (M+Na) ${ }^{+}: 976.2139(61.7), 976.2121$ (74.7), 1.9; 977.2165 (87.8), 977.2145 (79.4), 2.1; 978.2161 (100), 978.2155 (100), 0.6; 979.22 (47.2), 979.2177 (53.4), 2.4; 980.2191 (86.2), 980.2175 (83.4), 1.7. 


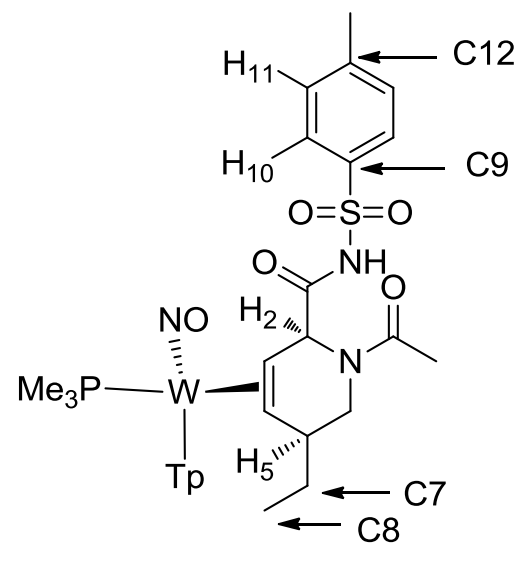

\section{TpW(NO)(PMe 3 )(3,4- $\eta^{2}$-(1-acetyl-5-ethyl-N-tosyl-1,2,5,6-tetrahydropyridine-2-carboxamide)).}

29. A solution of ZnEt2 ( $0.136 \mathrm{~g}, 1.101 \mathrm{mmol})$ in THF ( $1.5 \mathrm{~g})$ was transferred to a vial containing CuCN $(0.198 \mathrm{~g}, 2.211 \mathrm{mmol})$ and the slurry was rapidly transferred to a vial containing 26 (0.211

g, $0.235 \mathrm{mmol})$. The solid complex solubilized within a minute to make a yellow-brown heterogeneous solution as a black solid formed. After 10 minutes, the reaction solution was removed from the glovebox and slowly diluted with $50 \mathrm{~mL} \mathrm{DCM}$ to precipitate a white solid. The precipitate was removed via filtration through a $60 \mathrm{~mL}$ coarse porosity fritted funnel containing $2 \mathrm{~cm}$ celite. The yellow filtrate was extracted with $3 \times 20 \mathrm{~mL} \mathrm{NaHCO}$ (saturated, aqueous), backextracted with $2 \times 20 \mathrm{~mL} \mathrm{DCM}$, dried with $\mathrm{MgSO}_{4}$, filtered through a $60 \mathrm{~mL}$ coarse porosity fritted funnel then a $30 \mathrm{~mL}$ medium porosity fritted funnel. The filtrate solvent was removed and the residue was dissolved in $2 \mathrm{~mL} \mathrm{DCM}$, then $2 \mathrm{MLEtOAc}$, and diluted with $75 \mathrm{~mL}$ hexanes to precipitate a tan solid. The solution was cooled in an ice bath for $0.5 \mathrm{~h}$ and the precipitate collected on a $15 \mathrm{~mL}$ medium porosity fritted funnel $(0.102 \mathrm{~g}, 0.131 \mathrm{mmol}, 56 \%$ yield; $47 \%$ corrected for co-isolation of 38 in 1:5 molar ratio). ${ }^{1} \mathrm{H}$ NMR $\left(\mathrm{CDCl}_{3}, \delta\right): 9.76(\mathrm{~s}(\mathrm{br}), 1 \mathrm{H}, \mathrm{NH}), 8.03$ (d, $J=2.0,1 \mathrm{H}, \mathrm{PzA} 3), 8.01(\mathrm{~d}, J=7.9,2 \mathrm{H}, \mathrm{H} 10), 8.00(\mathrm{~d}, J=2.0,1 \mathrm{H}, \mathrm{PzB} 3), 7.72(\mathrm{~d}, J=2.0,1 \mathrm{H}$, PzB5), 7.7 (d, $J=2.0,1 \mathrm{H}, \mathrm{PzC5}), 7.62(\mathrm{~d}, J=2.0,1 \mathrm{H}, \mathrm{PzA5}), 7.36$ (d, $J=7.9,2 \mathrm{H}, \mathrm{H} 11), 7.32(\mathrm{~d}, J=$ 2.0, 1H, PzC3), $6.31(\mathrm{t}, J=2.0,1 \mathrm{H}, \mathrm{PzB} 4), 6.2(\mathrm{t}, J=2.0,1 \mathrm{H}, \mathrm{PzA} 4), 6.19(\mathrm{t}, J=2.0,1 \mathrm{H}, \mathrm{PzC} 4), 5.86$ (s(br), $1 \mathrm{H}, \mathrm{H} 2), 3.78(\mathrm{dd}, J=12.9,5.4,1 \mathrm{H}, \mathrm{H} 6), 3.11(\mathrm{~m}, 1 \mathrm{H}, \mathrm{H} 5), 2.86\left(\mathrm{dd},{ }^{3} \mathrm{~J}_{\mathrm{PH}}=11.6, J=11.6,1 \mathrm{H}\right.$, 
H3), 2.63 (dd, J = 12.9, 9.3, 1H, H6'), 2.47 (s, 3H, Ts-Me), 2.22 (s, 3H, Amide-Me), 1.45 (m, 1H, H7), $1.24\left(\mathrm{~m}, 1 \mathrm{H}, \mathrm{H} 7^{\prime}\right), 1.06\left(\mathrm{~d},{ }^{2} \mathrm{~J}_{\mathrm{PH}}=8.0,9 \mathrm{H}, \mathrm{PMe}_{3}\right), 0.89\left(\mathrm{t}, J=7.5,3 \mathrm{H}\right.$, Ethyl- $\left.\mathrm{CH}_{3}\right) .{ }^{13} \mathrm{C}$ NMR $\left(\mathrm{CDCl}_{3}, \delta\right): 173.8$ (Ts-Amide-CO), 173.6 (Amide-CO), 144.6/136.5 (C9/C12), 143.2 (PzB3), 141.9 (PzA3), 140.4 (PzC3), 136.6/136.1/136.0 (PzA4/PzB4/PzC4), 129.6 (C11), 128.5 (C10), 106.7 (PzB4), 106.1/105.5 (PzA4/PzC4), 59.2 (d, $J=4.8, C 2$ ), 54.1 (C4), 48.5 (C6), 47.0 (d, ${ }^{2} J_{\mathrm{PC}}=11.5$, C3), 39.3 (C5), 31.5 (C7), 22.9 (Amide-Me), 21.8 (Ts-Me), 13.2 (d, ${ }^{1} \mathrm{JPC}_{\mathrm{PC}}=27.7, \mathrm{PMe}_{3}$ ), 11.9 (Ethyl$\left.\mathrm{CH}_{3}\right) .{ }^{31} \mathrm{P} \mathrm{NMR}\left(\mathrm{CDCl}_{3}, \delta\right):-10.22\left(J_{\mathrm{WP}}=280\right) . \mathrm{IR}: \mathrm{v}=3130 \mathrm{~cm}^{-1}(\mathrm{w}), \mathrm{v}_{(\mathrm{BH})}=2491 \mathrm{~cm}^{-1}, \mathrm{v}=1726 \mathrm{~cm}^{-1}$, $v=1599 \mathrm{~cm}^{-1}, v_{(\mathrm{NO})}=1557 \mathrm{~cm}^{-1}, \mathrm{v}=1408 \mathrm{~cm}^{-1} . \mathrm{CV}(\mathrm{MeCN}): E_{\mathrm{p}, \mathrm{a}}=+0.56 \mathrm{~V}$. ESI-MS: obs'd (\%), calc'd (\%), ppm, (M+Na) ${ }^{+}: 874.216$ (78.1), 874.2167 (76.7), 0.8; 875.2193 (76.6), 875.2192 (79.4), $0.2 ; 876.2185$ (100), 876.219 (100), 0.6; 877.2218 (45.9), 877.2224 (51.0), 0.7; 878.2204 (77.1), $878.2221(83.6), 1.9$.

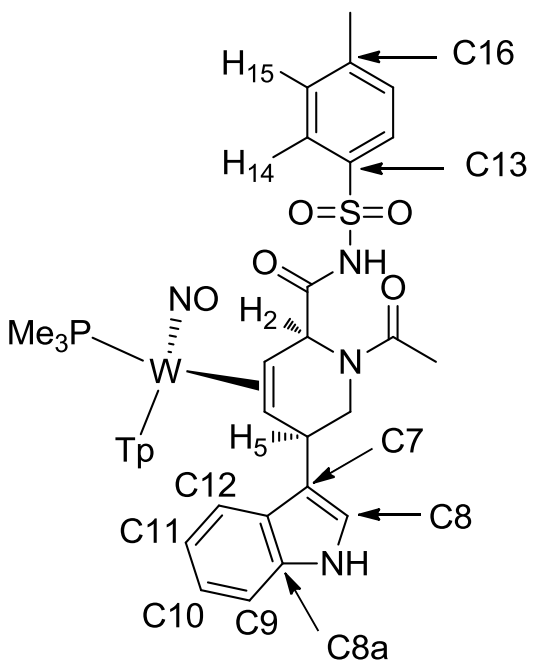

\section{$\operatorname{TpW}(\mathrm{NO})\left(\mathrm{PMe}_{3}\right)\left(3,4-\eta^{2}\right.$-(1-acetyl-5-(1H-indol-3-yl)-N-tosyl-1,2,5,6-tetrahydropyridine-2-}

carboxamide)). 30. $\mathrm{CHCl}_{3}(3.30 \mathrm{~g})$ was added to a vial containing $26(0.102 \mathrm{~g}, 0.114 \mathrm{mmol})$ and indole $(0.142 \mathrm{~g}, 1.212 \mathrm{mmol})$ to make a homogeneous yellow solution. EtOH (0.010 g) was added to the solution. After $21 \mathrm{~h}$, the reaction solution was removed from the glovebox and diluted with $50 \mathrm{~mL} \mathrm{Et}{ }_{2} \mathrm{O}$ to precipitate a pale-yellow-orange solid. The precipitate was collected 
on a $15 \mathrm{~mL}$ medium porosity fritted funnel, washed with $2 \times 7 \mathrm{~mL} \mathrm{Et}_{2} \mathrm{O}$, and placed under vacuum (0.078 g, $0.090 \mathrm{mmol}, 79 \%$ yield; $66 \%$ corrected for $16 \mathrm{~mol} \%$ co-isolation of 27 ). ${ }^{1} \mathrm{H}$ NMR $\left(\mathrm{DMSO}_{6} \mathrm{~d}_{6}, \delta\right): 11.41$ (s(br), 1H, Ts-NH), 10.67 (s(br), 1H, Indole-NH), 8.23 (d, J = 2.0, 1H, PzA3), $7.99(\mathrm{~d}, J=2.0,1 \mathrm{H}, \mathrm{PzB} 3), 7.98$ (d, $J=2.0,1 \mathrm{H}, \mathrm{PzB} 5), 7.91$ (d, $J=2.0,1 \mathrm{H}, \mathrm{PzC}$ ), 7.83 (d, $J=8.0$, $2 \mathrm{H}, \mathrm{H} 14), 7.69$ (d, J = 2.0, 1H, PzA5), 7.48 (d, J = 8.0, 1H, H12), 7.44 (d, J = 2.0, 1H, PzC3), 7.37 (d, $J=8.0,2 \mathrm{H}, \mathrm{H} 15), 7.27(\mathrm{~d}, J=8.2,1 \mathrm{H}, \mathrm{H} 9), 7.25(\mathrm{~d}, J=2.0,1 \mathrm{H}, \mathrm{H} 8), 6.99$ (dd, $J=8.2,6.9,1 \mathrm{H}, \mathrm{H} 10)$, $6.71(\mathrm{dd}, J=8.2,6.9,1 \mathrm{H}, \mathrm{H} 11), 6.42(\mathrm{t}, J=2.0,1 \mathrm{H}, \mathrm{PzB} 4), 6.27(\mathrm{t}, J=2.0,1 \mathrm{H}, \mathrm{PzC} 4), 5.98(\mathrm{t}, J=$ 2.0, 1H, PzA4), 5.93 (s(br), 1H, H2), 4.87 (m, 1H, H5), 3.70 (dd, J = 13.5, 5.3, 1H, H6), 2.95 (m, 2H, H3+H6'), 2.39 (s, 3H, Ts-Me), $2.12\left(\mathrm{~s}, 3 \mathrm{H}\right.$, Amide-Me), $1.52(\mathrm{~d}(\mathrm{br}), J=11.3,1 \mathrm{H}, \mathrm{H} 4), 1.07\left(\mathrm{~d},{ }^{2} J_{\mathrm{PH}}=\right.$ 8.3, 9H, $\mathrm{PMe}_{3}$ ). ${ }^{1} \mathrm{H}$ NMR (DMSO- $d_{6}, \delta$ ): 174.9 (Ts-Amide-CO), 170.7 (Amide-CO), 143.9 (C13 or C16), 142.8 (PzB3), 142.4 (PzA3), 140.5 (PzC3), 137.0 (PzB5), 136.7 (C13 or C16), 136.7 (IndoleQuat.), 136.2 (PzC5), 135.9 (PzA5), 129.5 (C15), 128.1 (C14), 125.7 (Indole-Quat.), 122.3 (C8), 120.5 (C10), 120.3 (C7), 118.9 (C12), 118.0 (C11), 111.5 (C9), 106.6 (PzB4), 106.2 (PzC4), 104.9 (PzA4), $57.8(\mathrm{~d}, J=4.9, \mathrm{C} 2), 57.8(\mathrm{~d}, J=4.9, \mathrm{C} 2), 52.2(\mathrm{C} 4), 49.8(\mathrm{C} 6), 49.2\left(\mathrm{~d},{ }^{2} \mathrm{JC}_{\mathrm{PC}}=11.1, \mathrm{C} 3\right), 35.7$ (C5), 23.3 (Amide-Me), 21.1 (Ts-Me), 12.1 (d, $\left.{ }^{1} J_{\mathrm{PC}}=27.6, \mathrm{PMe}_{3}\right) .{ }^{31} \mathrm{P}$ NMR (DMSO-d 6 , $\delta$ ): -8.03 (JWP =284). IR: $v_{\mathrm{BH}}=2480 \mathrm{~cm}^{-1}, \mathrm{v}=1720 \mathrm{~cm}^{-1}, \mathrm{v}=1632 \mathrm{~cm}^{-1}, v_{\mathrm{NO}}=1561 \mathrm{~cm}^{-1} . \mathrm{CV}(\mathrm{DMA}): E_{\mathrm{p}, \mathrm{a}}=+0.51$ V. ESI-MS: obs'd (\%), calc'd (\%), ppm, (M+Na)+: 961.2293 (69.1), 961.2277 (73.7), 1.6; 962.2285 (69.3), 962.2301 (80.2), 1.6; 963.2306 (100), 963.2301 (100), 0.6; 964.2341 (61.6), 964.2333 (55.0), 0.9; 965.2338 (74.4), 965.2331 (82.7), 0.7.

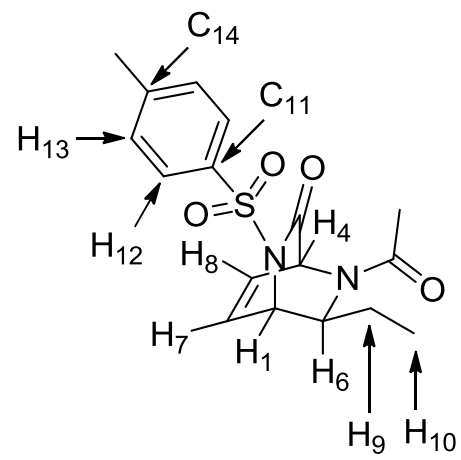


5-acetyl-6-ethyl-2-tosyl-2,5-diazabicyclo[2.2.2]oct-7-en-3-one. 33. A yellow solution of DDQ $(0.062 \mathrm{~g}, 0.273 \mathrm{mmol})$ in $\mathrm{MeCN}$ (2.93 g) was added to a vial containing $14(0.105 \mathrm{~g}, 0.123 \mathrm{mmol})$ to make a dark purple solution and was allowed to stir. After $1 \mathrm{~h}$ and $10 \mathrm{~min}$, the reaction solution was removed from the glovebox, diluted with $20 \mathrm{~mL} \mathrm{DCM}$, extracted with $3 \times 20 \mathrm{~mL}$ $\mathrm{NaHCO}_{3}$ (saturated, aqueous), back-extracted with $2 \times 10 \mathrm{~mL} \mathrm{DCM}$, dried with $\mathrm{MgSO}_{4}$, filtered through a $60 \mathrm{~mL}$ coarse porosity fritted funnel, followed by a $30 \mathrm{~mL}$ medium porosity fritted funnel. The solvent was removed and the residue was transferred to a vial with DCM. The residue transferred to a $500 \mu \mathrm{m} \times 20 \mathrm{~cm} \times 20 \mathrm{~cm}$ preparatory TLC plate and eluted with 1:1 EtOAc: $\mathrm{Et}_{2} \mathrm{O}$. The band between $\mathrm{rf}=0.32$ and $\mathrm{r} f=0.44$ was removed from the plate, sonicated in a test tube containing $15 \mathrm{~mL}$ EtOAc for $5 \mathrm{~min}$, collected on a $30 \mathrm{~mL}$ medium porosity fritted funnel, washed with $200 \mathrm{~mL}$ EtOAc, and the solvent removed. The residue was loaded onto a second preparatory TLC plate and eluted with 1:1 EtOAc: $\mathrm{Et}_{2} \mathrm{O}$. The band between $\mathrm{rf}=0.37$ and $r f=0.44$ was removed from the plate, sonicated in a test tube containing $15 \mathrm{~mL}$ EtOAc for $5 \mathrm{~min}$, collected on a $30 \mathrm{~mL}$ medium porosity fritted funnel, washed with $200 \mathrm{~mL}$ EtOAc, and the solvent removed to yield a tan solid $\left(0.023 \mathrm{~g}, 0.066 \mathrm{mmol}, 54 \%\right.$ yield). m.p.: $160-163{ }^{\circ} \mathrm{C}$. Amide Conformer Ratio: 3.3:1. ${ }^{1} \mathrm{H}$ NMR $\left(\mathrm{CDCl}_{3}, \delta\right): 7.87(\mathrm{~d}, J=8.0,2 \mathrm{H}, \mathrm{H} 12) 7.32(\mathrm{~d}, J=8.0,2 \mathrm{H}, \mathrm{H} 13$ ), 6.75 (ddd, $J=7.4,5.8,1.4,1 \mathrm{H}, \mathrm{H} 8$ ), 6.68 (dd, $J=6.4,6.0,1 \mathrm{H}, \mathrm{H} 8$-minor), 6.57 (dd, $J=6.4,5.9,1 \mathrm{H}$, H7-minor), 6.50 (ddd, $J=7.4,5.7,1.5,1 \mathrm{H}, \mathrm{H7}$ ), 5.64 (d, $J=5.0,1 \mathrm{H}, \mathrm{H} 4$-minor), 5.39 (d, $J=5.0,1 \mathrm{H}$, H1-minor), 5.36 (ddd, $J=5.7,1.8,1.4,1 \mathrm{H}, \mathrm{H} 1$ ), 4.72 (dd, $J=5.8,1.5,1 \mathrm{H}, \mathrm{H} 4), 3.46$ (dd, $J=10.2$, 1.8, 1H, H6), 3.27 (d, J = 10.6, 1H, H6-minor), 2.43 (s, 3H, Ts-Me), 2.21 (m, 1H, H9) 2.10 (s, 3H, Amide-Me), 2.05 (s, 3H, Amide-Me-minor), 2 (m, 1H, H9-minor), 1.71 (m, 1H, H9'-minor), 1.27 (m, 1H, H9'), $1.14\left(\mathrm{t}, J=7.1,3 \mathrm{H}, \mathrm{H} 10\right.$-minor), $1.07(\mathrm{t}, J=7.5,3 \mathrm{H}, \mathrm{H} 10) .{ }^{13} \mathrm{C} \mathrm{NMR}\left(\mathrm{CDCl}_{3}, \delta\right): 170.0$ (Amide-CO) 166.2 (C3), 145.7/135.0 (C11/C14), 136.1 (C8), 131 (C7), 129.7 (C13), 128.4 (C12), 60.0 (C4), 58.9 (C6), 55.0 (C1), 23.1 (C9), 22.4 (Amide-Me), 21.8 (Ts-Me) 9.9 (C10). IR: v = 1730 
$\mathrm{cm}^{-1}, \mathrm{v}=1657 \mathrm{~cm}^{-1}, \mathrm{v}=1170 \mathrm{~cm}^{-1}$. ESI-MS: obs'd (\%), calc'd (\%), ppm, (M+Na) $)^{+}: 371.1035(100)$, $371.1036(100), 0.2$.

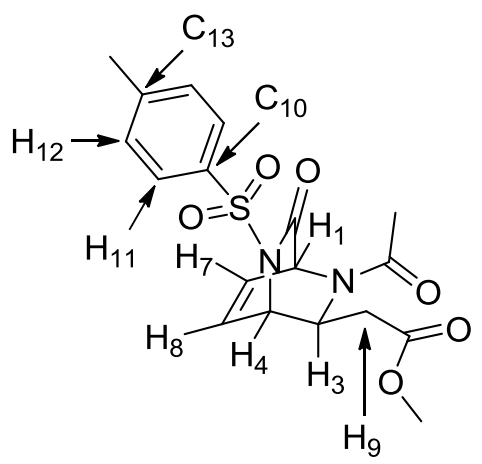

methyl 2-(2-acetyl-6-oxo-5-tosyl-2,5-diazabicyclo[2.2.2]oct-7-en-3-yl)acetate). 34. A yellow solution of DDQ $(0.071 \mathrm{~g}, 0.313 \mathrm{mmol})$ in acetone was added to a flame dried test tube containing 15 ( $0.125 \mathrm{~g}, 0.140 \mathrm{mmol})$ to make a dark red homogeneous solution that was added to a $55^{\circ} \mathrm{C}$ oil bath for $1 \mathrm{~h}$. The reaction solution was allowed to stir for $1 \mathrm{~h}$ at room temperature, then diluted with acetone and allowed to stir outside of a glovebox overnight. After $15 \mathrm{~h}$, the gray precipitate from the heterogeneous solution was collected on a $15 \mathrm{~mL}$ medium porosity fritted funnel and the filtrate solvent removed. The residue was dissolved in $3 \mathrm{~mL}$ acetone and added to $50 \mathrm{~mL}$ stirring $\mathrm{Et}_{2} \mathrm{O}$. The precipitate was collected on a $30 \mathrm{~mL}$ medium porosity fritted funnel. The precipitate was redissolved in $3 \mathrm{~mL}$ acetone and added to $50 \mathrm{~mL}$ of stirring $\mathrm{Et}_{2} \mathrm{O}$ and the precipitate collected on the same funnel. The combined filtrate solvent was removed and the residue triturated in $4 \mathrm{~mL} \mathrm{CHCl}$ and filtered through celite to remove fine particulate. The filtrate solvent was removed and loaded onto a $1500 \mu \mathrm{m} \times 20 \mathrm{~cm} \times 20 \mathrm{~cm}$ preparatory TLC plate and eluted with EtOAc. The band between $\mathrm{rf}=0.40$ and $\mathrm{rf}=0.64$ was removed from the plate, sonicated in a test tube containing $15 \mathrm{~mL}$ EtOAc for 10 minutes, collected on a $60 \mathrm{~mL}$ medium porosity fritted funnel, washed with $200 \mathrm{~mL}$ EtOAc, and the solvent removed. The residue was loaded onto a $500 \mu \mathrm{m} \times 20 \mathrm{~cm} \times 20 \mathrm{~cm}$ preparatory TLC plate, eluted with $60 \% \mathrm{Et}_{2} \mathrm{O}: 40 \% \mathrm{EtOAc}$. The band between $r f=0.31$ and $r f=0.41$ was removed from the plate, sonicated in a test tube 
containing $15 \mathrm{~mL}$ EtOAc for $10 \mathrm{~min}$. The solution was filtered through a $30 \mathrm{~mL}$ medium porosity fritted funnel, washed with $200 \mathrm{~mL}$ EtOAc, and the solvent removed in vacuo to produce a tan solid (0.020 g, $0.051 \mathrm{mmol}, 37 \%$ yield). m.p.: degraded without melting at $180{ }^{\circ} \mathrm{C} .{ }^{1} \mathrm{H}$ NMR $\left(\mathrm{CD}_{3} \mathrm{CN}, \delta\right): 7.84(\mathrm{~d}, J=8.5,2 \mathrm{H}, \mathrm{H} 11) 7.42(\mathrm{~d}, J=8.5,2 \mathrm{H}, \mathrm{H} 12), 6.83$ (ddd, $J=7.5,5.9,1.5,1 \mathrm{H}$, H8), 6.57 (ddd, $J=7.5,5.7,1.9,1 \mathrm{H}, \mathrm{H7}), 5.44(\mathrm{~d}, J=5.9,1 \mathrm{H}, \mathrm{H} 4), 4.86(\mathrm{~d}, J=5.7,1 \mathrm{H}, \mathrm{H} 1), 3.94$ (d, $J=9.6,1 \mathrm{H}, \mathrm{H} 3$ ), $3.73(\mathrm{~s}, 3 \mathrm{H}$, Ester-Me), 3.20 (dd, J = 17.7, 2.0, 1H, H9), 2.44 (s+shoulder, 4H, Ts$\mathrm{Me} / \mathrm{H} 9$ '), 2.06 (s, 3H, Amide-Me). $\left.{ }^{13} \mathrm{C} \mathrm{NMR} \mathrm{(} \mathrm{CD}_{3} \mathrm{CN}, \delta\right): 172.1$ (Ester-CO) 171.1 (Amide-CO), 167.2 (C6), 147.1/135.8 (C10/C13), 136.8 (C8), 132.3 (C7), 130.8 (C12), 129.0 (C11), 60.2 (C1), 57.6 (C4), 54.6 (C3), 52.4 (Ester-Me), 35.4 (C9) 22.5 (Amide-Me), 21.7 (Ts-Me). IR: v = $1732 \mathrm{~cm}^{-1}, \mathrm{v}=$ $1658 \mathrm{~cm}^{-1}, v=1171 \mathrm{~cm}^{-1}$. ESI-MS: obs'd (\%), calc'd (\%), ppm, (M+Na)+: $415.0934(100), 415.0934$ (100), 0.0 .

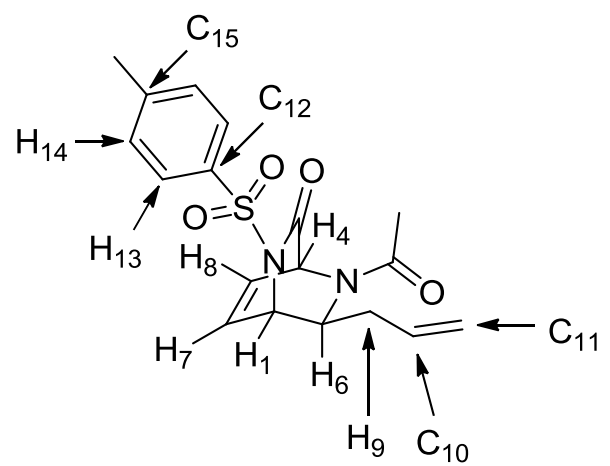

5-acetyl-6-allyl-2-tosyl-2,5-diazabicyclo[2.2.2]oct-7-en-3-one. 35. A yellow solution of DDQ $(0.060 \mathrm{~g}, 0.264 \mathrm{mmol})$ in acetone $(2.7 \mathrm{~g})$ was added to a heterogeneous tan solution of 16 (0.101 $\mathrm{g}, 0.117 \mathrm{mmol})$ in acetone $(2.7 \mathrm{~g})$ in a flame dried test tube to become a dark brown-black nearly homogeneous solution and was added to a $55^{\circ} \mathrm{C}$ oil bath. After 1 hour the reaction solution was removed from the oil bath, solvent removed, dissolved in $3 \mathrm{~mL}$ acetone, added to $50 \mathrm{~mL}$ stirring $\mathrm{Et}_{2} \mathrm{O}$, filtered through a $30 \mathrm{~mL}$ medium porosity fritted funnel. The precipitate was redissolved in $3 \mathrm{~mL}$ acetone, added to $50 \mathrm{~mL}$ stirring $\mathrm{Et}_{2} \mathrm{O}$, and the precipitate collected on a $30 \mathrm{~mL}$ medium porosity fritted funnel. The combined filtrate solvent was removed, the filtrate sonicated in 
$3 \times 4 \mathrm{~mL} \mathrm{CHCl}$, filtered through celite, and the solvent removed. The residue was loaded onto a $500 \mu \mathrm{m} \times 20 \mathrm{~cm} \times 20 \mathrm{~cm}$ preparatory TLC plate and eluted with 1:1 EtOAc: $\mathrm{Et}_{2} \mathrm{O}$. The band between $\mathrm{rf}=0.44$ and $\mathrm{rf}=0.58$ was removed from the plate, sonicated in a test tube containing 15 $\mathrm{mL}$ EtOAc for $10 \mathrm{~min}$, collected on a $30 \mathrm{~mL}$ medium porosity fritted funnel, washed with $200 \mathrm{~mL}$ EtOAc, solvent removed and the residue loaded onto a second preparatory TLC plate. The band between $\mathrm{rf}=0.45$ and $\mathrm{rf}=0.54$ was removed from the plate, sonicated in a test tube containing 15 $\mathrm{mL}$ EtOAc for $10 \mathrm{~min}$, collected on a $30 \mathrm{~mL}$ medium porosity fritted funnel, washed with $200 \mathrm{~mL}$ EtOAc, and the solvent removed to produce a tan solid $(0.021 \mathrm{~g}, 0.058 \mathrm{mmol}, 50 \%$ yield). m.p.: 124-127 ${ }^{\circ} \mathrm{C} .{ }^{1} \mathrm{H}$ NMR $\left(\mathrm{CD}_{3} \mathrm{CN}, \delta\right): 7.84(\mathrm{~d}, J=8.5,2 \mathrm{H}, \mathrm{H} 13) 7.41(\mathrm{~d}, J=8.5,2 \mathrm{H}, \mathrm{H} 12), 6.81$ (ddd, $J=$ $7.5,5.9,1.5,1 \mathrm{H}, \mathrm{H} 7), 6.53$ (ddd, $J=7.5,5.7,1.9,1 \mathrm{H}, \mathrm{H} 8), 5.98(\mathrm{~m}, 1 \mathrm{H}, \mathrm{H} 10), 5.47(\mathrm{~s}(\mathrm{br}), 1 \mathrm{H}, \mathrm{H} 4-$ minor), 5.42-5.19 (m, 3H, H11/H11'/H1), 4.84 (d, J = 5.7, 1H, H4), 3.57 (ddd, J = 10.3, 2.9, 2.1, 1H, H6), 2.90 (d(br), J = 14.0, 1H, H9), 2.45 (s, 3H, Ts-Me), 2.19 (s(br), 1H, H9'), 2.07 (s, 3H, AmideMe). ${ }^{13} \mathrm{C}$ NMR ( $\mathrm{CD}_{3} \mathrm{CN}, \delta$ ): 171.2 (Amide-CO) 167.5 (Ts-CO), 147.0/136.0 (C12/C15), 137.1 (C7), 134.3 (C10), 131.8 (C8), 130.7 (C14), 129.1 (C13), 119.3 (C11), 60.4 (C4), 57.7 (C6), 56.8 (C1), 35.4 (C9) 22.6 (Amide-Me), 21.7 (Ts-Me). IR: v $=1732 \mathrm{~cm}^{-1}, v=1650 \mathrm{~cm}^{-1}, \mathrm{v}=1169 \mathrm{~cm}^{-1}$. ESI-MS: obs'd (\%), calc'd (\%), ppm, (M+Na) ${ }^{+}: 383.1036$ (100), 383.1036 (100), 0.0.

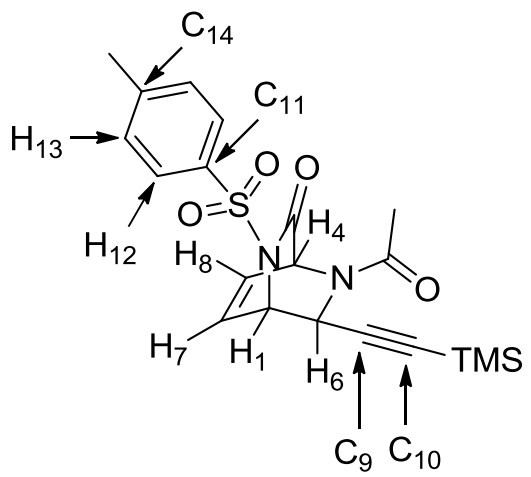

5-acetyl-2-tosyl-6-((trimethylsilyl)ethynyl)-2,5-diazabicyclo[2.2.2]oct-7-en-3-one. 36. A yellow solution of DDQ $(0.056 \mathrm{~g}, 0.247 \mathrm{mmol})$ in acetone- $\mathrm{d} 6(1.65 \mathrm{~g})$ was added to a flame dried test 
tube containing $17(0.101 \mathrm{~g}, 0.090 \mathrm{mmol})$ to make a heterogeneous solution that was allowed to stir for $0.5 \mathrm{~h}$. The test tube was added to a $57{ }^{\circ} \mathrm{C}$ oil bath for $1 \mathrm{~h}$. NMR data indicated that starting material was still present. An additional amount of DDQ $(0.028 \mathrm{~g}, 0.123 \mathrm{mmol})$ in acetone-d6 ( $0.3 \mathrm{~g})$ was added to the reaction solution and returned to the oil bath. After $1 \mathrm{~h}$, the test tube was removed from the oil bath and the mostly homogeneous solution was allowed to stir overnight. After $15.5 \mathrm{~h}$, the now homogeneous solution was transferred to a vial and the solvent removed. The solid was triturated the $\mathrm{Et}_{2} \mathrm{O}$ and allowed to stir for $2 \mathrm{~h}$. The precipitate was collected on a $15 \mathrm{~mL}$ medium porosity fritted funnel, washed with $2 \times 15 \mathrm{~mL} \mathrm{Et}_{2} \mathrm{O}$. The precipitate was redissolved in acetone, the solvent removed and the residue triturated and stirred again in $15 \mathrm{~mL} \mathrm{Et} \mathrm{t}_{2} \mathrm{O}$. The precipitate was removed via filtration using a $15 \mathrm{~mL}$ medium porosity fritted funnel. The filtrate solvent was removed and the residue was sonicated in $\mathrm{CHCl}_{3}$ $(3 \times 4 \mathrm{~mL})$, filtered through a celite pipette, and the solvent removed. The residue was loaded onto a $500 \mu \mathrm{m} \times 20 \mathrm{~cm} \times 20 \mathrm{~cm} \mathrm{SiO}{ }_{2}$ preparatory TLC plate and eluted with 9:1 $\mathrm{Et}_{2} \mathrm{O}: \mathrm{EtOAc}$. The $\mathrm{SiO}_{2}$ band between $\mathrm{rf}=0.18$ and $\mathrm{rf}=0.28$ was removed from the plate, sonicated in $15 \mathrm{~mL}$ EtOAc for $10 \mathrm{~min}$. The silica was collected on a $60 \mathrm{~mL}$ medium porosity fritted funnel, layered with 2 $\mathrm{cm}$ sand, washed with $200 \mathrm{~mL}$ EtOAc, and the solvent removed. The residue was loaded onto another preparatory TLC plate and eluted with $60 \% \mathrm{Et}_{2} \mathrm{O}: 40 \% \mathrm{EtOAC}$. The band between $\mathrm{rf}=0.38$ and $\mathrm{rf}=0.49$ was removed from the plate, sonicated in $15 \mathrm{ML}$ EtOAC for $10 \mathrm{~min}$. The silica was collected on a $60 \mathrm{~mL}$ medium porosity fritted funnel, layered with $2 \mathrm{~cm}$ sand, washed with 200 $\mathrm{mL}$ EtOAc, and the solvent removed to leave a brown residue.(0.014 g, $0.034 \mathrm{mmol}, 37 \%$ yield). Amide Conformer Ratio: 2.5:1. ${ }^{1} \mathrm{H}$ NMR $\left(\mathrm{CD}_{3} \mathrm{CN}, \delta\right): 7.83(\mathrm{~d}, J=8.4,2 \mathrm{H}, \mathrm{H} 12) 7.41(\mathrm{~d}, J=8.4,2 \mathrm{H}$, H13), 6.78/6.54 (t, J = 6.4, 2H, H7/H8), 5.52 (m, 2H, H1/H4), 5.45 (s(br), 1H, H1-minor), 4.88 (d, J $=4.9,1 \mathrm{H}, \mathrm{H} 4-$ minor), $4.4(\mathrm{~s}, 1 \mathrm{H}, \mathrm{H} 6), 4.32(\mathrm{~s}, 1 \mathrm{H}, \mathrm{H} 6$-minor), $2.44(\mathrm{~s}, 3 \mathrm{H}, \mathrm{Tos}-\mathrm{Me}), 2.16(\mathrm{~s}, 3 \mathrm{H}$, Amide-Me), 2.1 (s, 3H, Amide-Me-minor), 0.23 (s, 9H, TMS), 0.2 (s, 9H, TMS-minor). ${ }^{13} \mathrm{C}$ NMR 
$\left(\mathrm{CD}_{3} \mathrm{CN}, \delta\right): 170.7$ (Amide-CO) 167.2 (C3), 146.9/136.7 (C11/C14), 136.3/133.7/133.0 (C7/C8MaJor/Minor), 130.7 (C13), 128.9 (C12), 101.8 (C9), 92.1 (C10), 59.6/55.1 (C1/C4), 59.9 (C4Minor), 59.1 (C1-Minor), 51.3 (C6), 50.6 (C6-Minor) 23 (Amide-Me), 21.7 (Ts-Me), -0.14 (TMSMinor), -0.33 (TMS). IR: $v=2178$ (weak) $\mathrm{cm}^{-1}, v=1733 \mathrm{~cm}^{-1}, v=1661 \mathrm{~cm}^{-1}, v=1172 \mathrm{~cm}^{-1}$.ESI-MS: obs'd (\%), calc'd (\%), ppm, (M+Na) ${ }^{+}: 439.1111$ (100), 439.1118 (100), 1.7.

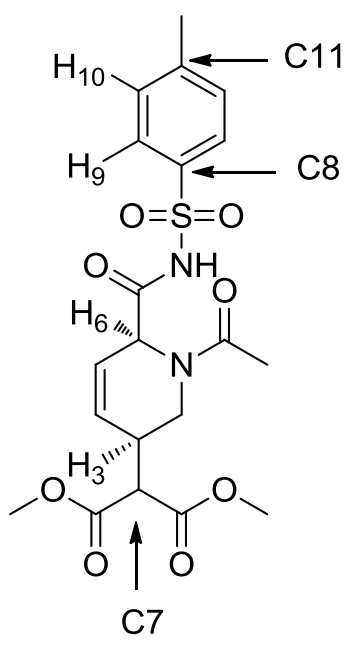

Dimethyl 2-(1-acetyl-6-(tosylcarbamoyl)-1,2,3,6-tetrahydropyridin-3-yl)malonate. 37. To flame dried test tubes, a bright yellow solution of $28(0.106 \mathrm{~g}, 0.118 \mathrm{mmol})$ in $\mathrm{MeCN}(1.17 \mathrm{~g})$ and a heterogeneous solution of LiDMM $(0.046 \mathrm{~g}, 0.333 \mathrm{mmol})$ in $\mathrm{MeCN}(0.76 \mathrm{~g})$ were added to a $0{ }^{\circ} \mathrm{C}$ cold bath. After 15 minutes, the solution was quickly added to the stirring LiDMM solution to become nearly colorless. After $1 \mathrm{~h}$ the reaction was removed from the cold bath and allowed to warm to room temperature. DDQ $(0.058 \mathrm{~g}, 0.256 \mathrm{mmol})$ was added to the nearly colorless reaction solution to become dark purple. The solution was allowed to stir for $1 \mathrm{~h}$. The reaction solution was then added to $50 \mathrm{~mL}$ stirring $\mathrm{Et}_{2} \mathrm{O}$ to precipitate some material that was collected on a $60 \mathrm{~mL}$ medium porosity fritted funnel. The filtrate was set aside. The material on the fritted funnel was dissolved with $\mathrm{DCM}$ and $\mathrm{MeCN}$, the solvent removed, and the residue transferred to $50 \mathrm{~mL} \mathrm{Et}{ }_{2} \mathrm{O}$ with $3 \mathrm{~mL} \mathrm{MeCN}$ to precipitate additional material that was collected on a $60 \mathrm{~mL}$ medium porosity fritted funnel. The $\mathrm{Et}_{2} \mathrm{O}$ filtrate was combined with the first $\mathrm{Et}_{2} \mathrm{O}$ filtrate. The 
precipitate was redissolved in $\mathrm{MeCN}(3 \mathrm{~mL})$ a third time, added to $50 \mathrm{~mL} \mathrm{Et} \mathrm{O}_{2} \mathrm{O}$ to precipitate additional material that was collected on a $30 \mathrm{~mL}$ medium porosity fritted funnel, washed with 2 $\mathrm{x} 15 \mathrm{~mL} \mathrm{Et}{ }_{2} \mathrm{O}$, and discarded. The $\mathrm{Et}_{2} \mathrm{O}$ filtrate was combined with the first two $\mathrm{Et}_{2} \mathrm{O}$ filtrates and the solvent removed. The residue was sonicated with $5 \times 2 \mathrm{~mL} \mathrm{CHCl}$ that was filtered through a pipette fitted with $1 \mathrm{~cm}$ celite and the filtrate solvent removed in vacuo. The residue was loaded onto a $500 \mu \mathrm{m} \times 20 \mathrm{~cm} \times 20 \mathrm{~cm} \mathrm{SiO} 2$ preparatory TLC plate with $4 \times 0.25 \mathrm{~g}$ DCM using a $1 \mathrm{~mL}$ syringe and eluted with 1:1 Et $\mathrm{t}_{2} \mathrm{O}$ :EtOAc. The band between $\mathrm{rf}=0.43$ and $\mathrm{rf}=0.53$ was scraped from the plate and sonicated in a test tube containing $15 \mathrm{~mL}$ EtOAc for 10 minutes. The material was collected on a $30 \mathrm{~mL}$ medium porosity fritted funnel, washed with $200 \mathrm{~mL}$ EtOAc, and the solvent removed in vacuo. The residue was transferred to another preparatory TLC plate and eluted again with 1:1 EtOAc: $\mathrm{Et}_{2} \mathrm{O}$. The band between $\mathrm{rf}=0.20$ and $\mathrm{rf}=0.47$ was removed from the plate, sonicated in a test tube containing $\sim 15 \mathrm{~mL}$ EtOAc. The material was collected on a 30 $\mathrm{mL}$ fine porosity fritted funnel, washed with $200 \mathrm{~mL} E t O A c$, the solvent removed to yield an offwhite solid $(0.010 \mathrm{~g}, 0.023 \mathrm{mmol}, 19 \%$ yield). Additional material was found elsewhere but could not be separated from other impurities. ${ }^{1} \mathrm{H}$ NMR $\left(\mathrm{CDCl}_{3}\right): 9.75(\mathrm{~s}(\mathrm{br}), 1 \mathrm{H}, \mathrm{NH}), 7.90(\mathrm{~d}, J=$ 8.3, 2H, H9), 7.31 (d, $J=8.3,2 \mathrm{H}, \mathrm{H} 10$ ), 5.85 (d(br), $J=10.5,1 \mathrm{H}, \mathrm{H} 4$ ), 5.78 (ddd, $J=10.5,3.3,2.3$, $1 \mathrm{H}, \mathrm{H} 5), 5.22(\mathrm{~s}(\mathrm{br}), 1 \mathrm{H}, \mathrm{H} 6), 3.99$ (dd, $J=12.5,3.0,1 \mathrm{H}, \mathrm{H} 2), 3.76(\mathrm{~s}, 3 \mathrm{H}$, Ester-Me), 3.75 (s, 3H, Ester-Me'), 3.34 (d, J = 8.5, 1H, H7), 3.00 (m, 2H, H2'+H3), 2.43 (s, 3H, Ts-Me), 2.22 (s, 3H, Amide-Me). ${ }^{13} \mathrm{C} \mathrm{NMR}\left(\mathrm{CDCl}_{3}\right.$ ): 172.1 (Amide-CO), 167.9/167.2 (Ester-CO/Ester-CO'/Ts-Amide-CO), 145.2/135.7 (C8/C11), 129.7 (C10), 129.6 (C4), 128.5 (C9), 123.3 (C5), 54.7 (C6), 53.2 (C7), 53.1 (Ester-Me/Ester-Me'), 45.1 (C2), 35.0 (C3), 21.8/21.5 (Ts-Me/Amide-Me). IR: v = $1731 \mathrm{~cm}^{-1}, \mathrm{v}=$ $1618 \mathrm{~cm}^{-1}$.Melting Point: $182-185{ }^{\circ} \mathrm{C}$. ESI-MS: obs'd (\%), calc'd (\%), ppm, $(\mathrm{M}+\mathrm{Na})^{+}: 475.1146$ (100), 475.1146 (100), 0.0 . 


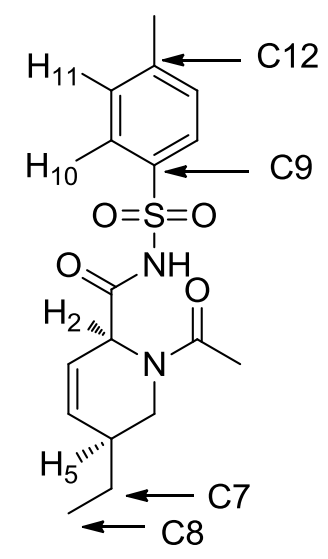

1-acetyl-5-ethyl-N-tosyl-1,2,5,6-tetrahydropyridine-2-carboxamide. 38. A solution of $\mathrm{ZnEt}_{2}$ (0.086 g, $0.049 \mathrm{mmol})$ in THF (1.5 g) was added to $\mathrm{CuCN}(0.096 \mathrm{~g}, 1.072 \mathrm{mmol})$ and the suspension was quickly added to a vial containing $29(0.100 \mathrm{~g}, 0.111 \mathrm{mmol})$. After 13 minutes, the reaction solution was diluted with $25 \mathrm{~mL}$ DCM and a precipitate formed. The solution was was removed from the glovebox, filtered through a $60 \mathrm{~mL}$ coarse porosity fritted funnel containing $2 \mathrm{~cm}$ celite, and was washed with $2 \times 20 \mathrm{~mL} \mathrm{DCM}$. The filtrate solvent was removed and the residue was returned to a glovebox atmosphere. A yellow solution of DDQ $(0.061 \mathrm{~g}$, $0.269 \mathrm{mmol}$ ) in $\mathrm{MeCN}$ (1.95 g) was added to the residue to make a dark purple solution that was allowed to stir for $1.2 \mathrm{~h}$. The solution was then added to $50 \mathrm{~mL}$ stirring $\mathrm{Et}_{2} \mathrm{O}$. The precipitate was collected on a $60 \mathrm{~mL}$ medium porosity fritted funnel, redissolved in $\mathrm{MeCN}(3 \mathrm{~mL}$ ), added to 50 $\mathrm{mL}$ stirring $\mathrm{Et}_{2} \mathrm{O}$, the precipitate was collected again and discarded. The $\mathrm{Et}_{2} \mathrm{O}$ filtrate solvent was removed and the residue was sonicated with $3 \times 4 \mathrm{~mL} \mathrm{CHCl}$, each time filtering through $1 \mathrm{~cm}$ celite in a $2 \mathrm{~mL}$ Pasteur pipette. The solvent was removed and the residue loaded onto a $500 \mu \mathrm{m}$ $\times 20 \mathrm{~cm} \times 20 \mathrm{~cm} \mathrm{SiO} 2$ preparatory TLC plate with 4 × $0.25 \mathrm{~g} \mathrm{DCM}$ using a $1 \mathrm{~mL}$ syringe. The plate was eluted with 1:1 EtOAc: $\mathrm{Et}_{2} \mathrm{O}$. The band between $\mathrm{rf}=0.62$ and $\mathrm{rf}=0.84$ was removed from the plate, sonicated for $\sim 10$ minutes in a test tube containing $\sim 15 \mathrm{~mL}$ EtOAc. The material was collected on a $30 \mathrm{~mL}$ fine porosity fritted funnel, washed with $200 \mathrm{~mL}$ EtOAc and the solvent removed. The material was sonicated with $3 \times 2 \mathrm{~mL} \mathrm{CHCl}$, filtered through a pipette fitted with 
celite, and the solvent removed. The residue was loaded onto another preparatory TLC plate and eluted with 1:1 $\mathrm{Et}_{2} \mathrm{O}: \mathrm{EtOAc}$. The band between $\mathrm{rf}=0.50$ and $\mathrm{rf}=0.71$ was removed from the plate, sonicated in a test tube containing $\sim 15 \mathrm{~mL}$ EtOAc. The material was collected on a $30 \mathrm{~mL}$ fine porosity fritted funnel, washed with $200 \mathrm{~mL}$ EtOAc, and the solvent removed in vacuo to leave a pale yellow solid (0.012 g, $0.035 \mathrm{mmol}, 31 \%$ yield). ${ }^{1} \mathrm{H}$ NMR: 9.69 (s(br), 1H, NH), 7.92 (d, $J=8.3,2 \mathrm{H}, \mathrm{H} 11), 7.31(\mathrm{~d}, J=8.3,2 \mathrm{H}, \mathrm{H} 10), 5.92(\mathrm{~d}(\mathrm{br}), J=10.3,1 \mathrm{H}, \mathrm{H} 4), 5.67(\mathrm{ddd}, J=10.3,3.8$, 2.7, $1 \mathrm{H}, \mathrm{H} 3$ ), 5.19 (ddd, $J=3.8,2.7,2.7,1 \mathrm{H}, \mathrm{H} 2$ ), 3.73 (dd, $J=13.6,5.2,1 \mathrm{H}, \mathrm{H} 6), 2.83$ (dd, $J=$ 13.6, 11.2, 1H, H6'), 2.43 (s, 3H, Ts-Me), 2.19 (s, 3H, Amide-Me), 2.18 (m, 1H, H5), 1.36 (m, 2H, $\mathrm{H} 7 / \mathrm{H}^{\prime}$ ), $0.96\left(\mathrm{t}, \mathrm{J}=7.4,3 \mathrm{H}, \mathrm{Et}-\mathrm{CH}_{3}\right) .{ }^{13} \mathrm{C}$ NMR: 171.7 (Amide-CO), 167.6 (Ts-Amide-CO), 145.1/135.9 (C9/C12), 133.3 (C4), 129.7 (C10), 128.6 (C11), 120.8 (C3), 54.8 (C2), 47.3 (C6), 36.8 (C5), 25.3 (C7), 21.8 (Ts-Me), 21.6 (Amide-Me), 11.0 (C8). IR: v = $1782 \mathrm{~cm}^{-1}, v=1731 \mathrm{~cm}^{-1}, v=$ $1614 \mathrm{~cm}^{-1}, v=1449 \mathrm{~cm}^{-1}$. Melting Point: $148-158^{\circ} \mathrm{C}$. ESI-MS: obs'd (\%), calc'd (\%), ppm, (M+Na) ${ }^{+}$: $373.118(100), 373.1193(100), 3.4$.

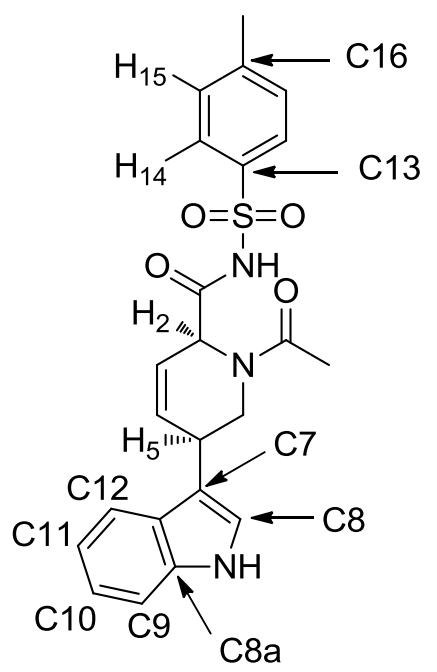

1-acetyl-5-(1H-indol-3-yl)-N-tosyl-1,2,5,6-tetrahydropyridine-2-carboxamide. 39. Indole (0.140 $\mathrm{g}, 1.120 \mathrm{mmol})$ was added to a homogeneous yellow solution of $30(0.102 \mathrm{~g}, 0.114 \mathrm{mmol})$ and $\mathrm{CHCl}_{3}(3.40 \mathrm{~g})$ followed by the addition of EtOH $(0.008 \mathrm{~g})$. After $16 \mathrm{~h}$, the reaction solution was 
transferred to a $125 \mathrm{~mL}$ E-flask and diluted with $50 \mathrm{~mL} \mathrm{Et}{ }_{2} \mathrm{O}$ to precipitate a light orange solid that was collected on a $15 \mathrm{~mL}$ medium porosity fritted funnel $(0.112 \mathrm{~g})$ outside of a glovebox. The solid was transferred to a $1 \mathrm{~L}$ side arm flask containing $\mathrm{SiO}_{2}(12.1 \mathrm{~g})$ and diluted with $250 \mathrm{~mL}$ EtOAc. The atmosphere of the flask was purged for $\sim 30 \mathrm{~s}$ with $\mathrm{O}_{2}(\mathrm{~g})$. The flask and attached balloon were filled, vented and refilled with $\mathrm{O}_{2}(\mathrm{~g})$. The solution was allowed to stir rapidly for $21 \mathrm{~h}$, then the reaction contents were collected on a $150 \mathrm{~mL}$ medium porosity fritted funnel, washed with $400 \mathrm{~mL}$ EtOAc, and the solvent removed in vacuo. The residue was transferred to a vial, loaded onto a $500 \mu \mathrm{m} \times 20 \mathrm{~cm} \times 20 \mathrm{~cm} \mathrm{SiO}{ }_{2}$ preparatory TLC plate, and eluted with 1:1 EtOAc: $\mathrm{Et}_{2} \mathrm{O}$. The band between $\mathrm{r} f=0.23$ and $\mathrm{r} f=0.47$ was removed from the plate, sonicated in a test tube containing $15 \mathrm{~mL}$ EtOAc for $\sim 10$ minutes. The material was collected on a $30 \mathrm{~mL}$ medium porosity fritted funnel, washed with $200 \mathrm{~mL}$ EtOAc, and the solvent removed to leave a $\tan$ solid $\left(0.013 \mathrm{~g}, 0.030 \mathrm{mmol}, 26 \%\right.$ yield). ${ }^{1} \mathrm{H} \mathrm{NMR}\left(\mathrm{CDCl}_{3}, \delta\right): 9.78(\mathrm{~s}(\mathrm{br}), 1 \mathrm{H}, \mathrm{Ts}-\mathrm{NH}), 8.23$ (s(br), 1H, Indole-NH), 7.96 (d, J = 8.6, 2H, H15), 7.59 (d, J = 8.0, 1H, H12), $7.42(\mathrm{~d}, J=8.2,1 \mathrm{H}$, H9), $7.33(\mathrm{~d}, J=8.6,2 \mathrm{H}, \mathrm{H} 14), 7.25$ (dd, $J=8.0,7.2,1 \mathrm{H}, \mathrm{H} 10), 7.16(\mathrm{dd}, J=8.0,7.2,1 \mathrm{H}, \mathrm{H} 11), 7.05$ $(\mathrm{d}, J=2.4,1 \mathrm{H}, \mathrm{H} 8), 6.23(\mathrm{ddd}, J=10.1,3.0,1.6,1 \mathrm{H}, \mathrm{H} 4), 5.88$ (ddd, $J=10.1,3.9,2.8,1 \mathrm{H}, \mathrm{H} 3$ ), 5.34 (ddd, $J=3.9,3.0,2.8,1 \mathrm{H}, \mathrm{H} 2$ ), 3.98 (dd, $J=13.6,5.2,1 \mathrm{H}, \mathrm{H6}$ ), 3.87 (ddddd, $J=10.9,5.2,2.8$, 2.8, 1.6, 1H, H5), 3.31 (dd, $\left.J=13.6,10.9,1 \mathrm{H}, \mathrm{H} 6^{\prime}\right), 2.44$ (s, 3H, Ts-Me), 2.26 (s, 3H, Amide-Me). ${ }^{13} \mathrm{C} \mathrm{NMR}\left(\mathrm{CDCl}_{3}, \delta\right): 171.8$ (Amide-CO), 167.6 (Ts-Amide-CO), 145.1 (C13 or C16), 136.6 (C12a or C8a), 135.9 (C13 or C16), 133.4 (C4), 129.7 (C14), 128.5 (C15), 126.3 (C12a or C8a), 122 (C10), 121.8 (C8), 121.4 (C3), 120.1 (C11), 118.7 (C12a or C8a), 114.7 (C7), 111.7 (C9), 54.8 (C2), 48.4 (C6), 33.5 (C5), 21.8+21.7 (Ts-Me+Amide-Me). IR: $v=1778 \mathrm{~cm}^{-1}, v=1728 \mathrm{~cm}^{-1}, v=1616 \mathrm{~cm}^{-1}$. Melting Point: $108-114{ }^{\circ} \mathrm{C}$. ESI-MS: obs'd (\%), calc'd (\%), ppm, $(\mathrm{M}+\mathrm{H})^{+}: 460.1313$ (100), 460.1302 (100), 2.5 . 


\section{References:}

(1) Joseph, S.; Comins, D. L., Current Opinion in Drug Discovery \& Development 2002, $5(6), 870-880$.

(2) Guilloteau-Bertin, B.; Compère, D.; Gil, L.; Marazano, C.; Das, Bhupesh C., European Journal of Organic Chemistry 2000, 2000 (8), 1391-1399.

(3) Maia, Alessandra A.; Mons, S.; Pereira de Freitas Gil, R.; Marazano, C., European Journal of Organic Chemistry 2004, 2004 (5), 1057-1062.

(4) Lemire, A.; Charette, A. B., Organic Letters 2005, 7 (13), 2747-2750.

(5) Amat, M.; Escolano, C.; Lozano, O.; Llor, N.; Bosch, J., Organic Letters 2003, 5 (17), 3139-3142.

(6) Husson, H.-P.; Royer, J., Chemical Society Reviews 1999, 28 (6), 383-394.

(7) Coombs, T. C.; Lee; Wong, H.; Armstrong, M.; Cheng, B.; Chen, W.; Moretto, A. F.; Liebeskind, L. S., The Journal of Organic Chemistry 2008, 73 (3), 882-888.

(8) Delafuente, D. A.; Kosturko, G. W.; Graham, P. M.; Harman, W. H.; Myers, W. H.; Surendranath, Y.; Klet, R. C.; Welch, K. D.; Trindle, C. O.; Sabat, M.; Harman, W. D., Journal of the American Chemical Society 2006, 129 (2), 406-416.

(9) Graham, P. M.; Delafuente, D. A.; Liu, W.; Myers, W. H.; Sabat, M.; Harman, W. D., Journal of the American Chemical Society 2005, 127 (30), 10568-10572.

(10) Kosturko, G. W.; Graham, P. M.; Myers, W. H.; Smith, T. M.; Sabat, M.; Harman, W. D., Organometallics 2008, 27 (17), 4513-4522.

(11) Surendranath, Y.; Welch, K. D.; Nash, B. W.; Harman, W. H.; Myers, W. H.; Harman, W. D., Organometallics 2006, 25 (25), 5852-5853. 
(12) Harrison, D. P.; Welch, K. D.; Nichols-Nielander, A. C.; Sabat, M.; Myers, W. H.; Harman, W. D., Journal of the American Chemical Society 2008, 130 (50), 1684416845.

(13) Harrison, D. P.; Sabat, M.; Myers, W. H.; Harman, W. D., Journal of the American Chemical Society 2010, 132 (48), 17282-17295.

(14) Harrison, D. P.; Zottig, V. E.; Kosturko, G. W.; Welch, K. D.; Sabat, M.; Myers, W. H.; Harman, W. D., Organometallics 2009, 28 (19), 5682-5690.

(15) Kosturko, G. W.; Harrison, D. P.; Sabat, M.; Myers, W. H.; Harman, W. D., Organometallics 2009, 28 (2), 387-389.

(16) Harrison, D. P.; Kosturko, G. W.; Ramdeen, V. M.; Nichols-Nielander, A. C.; Payne, S. J.; Sabat, M.; Myers, W. H.; Harman, W. D., Organometallics 2010, 29 (8), 1909-1915.

(17) Li, F.; Yang, B.; Miller, M. J.; Zajicek, J.; Noll, B. C.; Möllmann, U.; Dahse, H.-M.; Miller, P. A., Organic Letters 2007, 9 (15), 2923-2926.

(18) Yang, B.; Miller, M. J., Organic Letters 2009, 12 (2), 392-395.

(19) Machin, B. P.; Ballantine, M.; Mandel, J. r. m.; Blanchard, N.; Tam, W., The Journal of Organic Chemistry 2009, 74 (19), 7261-7266.

(20) Surman, M. D.; Miller, M. J., Organic Letters 2001, 3 (4), 519-521.

(21) Knaus, E. E.; Avasthi, K.; Giam, C. S., Can J. Chem. 1980, 58, 2447-2451.

(22) Todd, M. A.; Sabat, M.; Myers, W. H.; Harman, W. D., Journal of the American Chemical Society 2007, 129 (36), 11010-11011. 
(23) Harrison, D. P.; Nichols-Nielander, A. C.; Zottig, V. E.; Strausberg, L. J.; Salomon, R. J.; Trindle, C. O.; Sabat, M.; Gunnoe, T. B.; Iovan, D. A.; Myers, W. H.; Harman, W. D., Accepted to Organometallic, 2011.

(24) Krow, G. R.; Huang, Q.; Szczepanski, S. W.; Hausheer, F. H.; Carroll, P. J., The Journal of Organic Chemistry 2007, 72 (9), 3458-3466.

(25) Hirama, M.; Kato, Y.; Seki, C.; Nakano, H.; Takeshita, M.; Oshikiri, N.; Iyoda, M.; Matsuyama, H., Tetrahedron 2010, 66 (38), 7618-7624.

(26) Sundberg, R. J.; Hamilton, G.; Trindle, C., The Journal of Organic Chemistry 1986, $51(19), 3672-3679$.

(27) Nakano, H.; Osone, K.; Takeshita, M.; Kwon, E.; Seki, C.; Matsuyama, H.; Takano, N.; Kohari, Y., Chemical Communications 2010, 46 (26), 4827-4829.

(28) Arakawa, Y.; Murakami, T.; Ozawa, F.; Arakawa, Y.; Yoshifuji, S., Tetrahedron 2003, 59 (38), 7555-7563.

(29) Weinstein, B.; Lin, L.-C. C.; Fowler, F. W., The Journal of Organic Chemistry 1980, 45 (9), 1657-1661.

(30) Marazano, C.; Yannic, S.; Genisson, Y.; Mehmandoust, M.; Das, B. C., Tetrahedron Letters 1990, 31 (14), 1995-1998.

(31) Krow, G. R.; Carey, J. T.; Zacharias, D. E.; Knaus, E. E., The Journal of Organic Chemistry 1982, 47 (11), 1989-1993.

(32) Liu, W.; You, F.; Mocella, C. J.; Harman, W. D., Journal of the American Chemical Society 2006, 128 (5), 1426-1427. 
(33) Zeller, M. Preparation of 7-azabicyclo[4.2.0]oct-4-en-8-one derivatives as plant microbicides. PCT/EP96/03955, September 10, 1996, 1997.

(34) Malpass, J. R.; Tweddle, N. J., J Chem Soc Chem Comm 1972, (22), 1247-\&.

(35) Malpass, J. R.; Tweddle, N. J., J Chem Soc Perk T 1 1977, (8), 874-884.

(36) Lin, W.; Gupta, A.; Kim, K. H.; Mendel, D.; Miller, M. J., Organic Letters 2009, 11 (2), 449-452.

(37) Lin, W.; Virga, K. G.; Kim, K.-H.; Zajicek, J.; Mendel, D.; Miller, M. J., The Journal of Organic Chemistry 2009, 74 (16), 5941-5946.

(38) Oxidants attempted include DDQ, $\mathrm{O} 2$ (g), CAN, I2, AgOTf, mCPBA, CuBr2, NCS, or DIB.

(39) Williams, R. M.; Glinka, T.; Kwast, E.; Coffman, H.; Stille, J. K., Journal of the American Chemical Society 1990, 112 (2), 808-821.

(40) Williams, R. M.; Cox, R. J., Accounts of Chemical Research 2002, 36 (2), 127-139.

(41) Ding, Y.; Gruschow, S.; Greshock, T. J.; Finefield, J. M.; Sherman, D. H.; Williams, R. M., Journal of Natural Products 2008, 71 (9), 1574-1578.

(42) Sanz-Cervera, J. F.; Williams, R. M.; Alberto Marco, J.; María López-Sánchez, J.; González, F.; Eugenia Martínez, M.; Sancenón, F., Tetrahedron 2000, 56 (34), 6345-6358.

(43) Alen, J.; Smets, W. J.; Dobrzańska, L.; De Borggraeve, W. M.; Compernolle, F.; Hoornaert, G. J., European Journal of Organic Chemistry 2007, 2007 (6), 965-971. 
(44) Rombouts, F. J. R.; Vanraes, D. A. J.; Wynendaele, J.; Loosen, P. K.; Luyten, I.; Toppet, S.; Compernolle, F.; Hoornaert, G. J., Tetrahedron 2001, 57 (15), 32093220.

(45) Buysens, K. J.; Vandenberghe, D. M.; Hoornaert, G. J., Tetrahedron 1996, 52 (27), 9161-9178.

(46) Machin, P. J.; Porter, A. E. A.; Sammes, P. G., Journal of the Chemical Society, Perkin Transactions 1 1973, 404-409.

(47) Capon, R. J.; Skene, C.; Stewart, M.; Ford, J.; O'Hair, R. A. J.; Williams, L.; Lacey, E.; Gill, J. H.; Heiland, K.; Friedel, T., Organic \& Biomolecular Chemistry 2003, 1 (11), 1856-1862.

(48) Lee, D. L.; Rapoport, H., The Journal of Organic Chemistry 1975, 40 (24), 34913495.

(49) Sturm, P. A.; Henry, D. W.; Thompson, P. E.; Zeigler, J. B.; McCall, J. W., Journal of Medicinal Chemistry 1974, 17 (5), 481-487.

(50) Alcalde, E.; Mesquida, N.; López-Pérez, S.; Frigola, J.; Mercè, R.; Holenz, J.; Pujol, M.; Hernández, E., Bioorganic \& Medicinal Chemistry 2009, 17 (20), 7387-7397.

(51) Yuan, X.; Liu, K.; Li, C., The Journal of Organic Chemistry 2008, 73 (16), 61666171.

(52) Taniguchi, T.; Yonei, D.; Sasaki, M.; Tamura, O.; Ishibashi, H., Tetrahedron 2008, $64,2634-2641$.

(53) Evans, D. A.; Campos, K. R.; Tedrow, J. S.; Michael, F. E.; Gagnv C, M. R., Journal of the American Chemical Society 2000, 122 (33), 7905-7920. 
(54) Schleich, S.; Helmchen, G. n., Eur. J. Org. Chem. 1999, 2515-2521.

(55) Miller, J. F.; Termin, A.; Koch, K.; Piscopio, A. D., The Journal of Organic Chemistry $1998,63(10), 3158-3159$.

(56) Schoeps, D.; Sashuk, V.; Ebert, K.; Plenio, H., Organometallics 2009, 28 (13), 3922-3927.

(57) Molander, G. A.; Jean-GeÃÅrard, L., The Journal of Organic Chemistry 2009, 74 (15), 5446-5450.

(58) Fors, B. P.; Krattiger, P.; Strieter, E.; Buchwald, S. L., Organic Letters 2008, 10 (16), 3505-3508.

(59) Schlosser, M.; Mongin, F., Chemical Society Reviews 2007, 36 (7), 1161-1172.

(60) Johnson, C. D.; Katritzky, A. R.; Shakir, N.; Viney, M., Journal of the Chemical Society B: Physical Organic 1967, 1213-1219.

(61) Bean, G. P.; Brignell, P. J.; Johnson, C. D.; Katritzky, A. R.; Ridgewell, B. J.; Tarhan, H. O.; White, A. M., Journal of the Chemical Society B: Physical Organic 1967, $1222-1226$.

(62) Schnyder, A.; Beller, M.; Mehltretter, G.; Nsenda, T.; Studer, M.; Indolese, A. F., The Journal of Organic Chemistry 2001, 66 (12), 4311-4315.

(63) Crisóstomo, C.; Crestani, M. G.; García, J. J., Inorganica Chimica Acta 2010, 363 (6), 1092-1096.

(64) Salomon, R. J.; Lis, E. C.; Kasbekar, M. U.; Bassett, K. C.; Myers, W. H.; Trindle, C. O.; Sabat, M.; Harman, W. D., Organometallics 2009, 28 (16), 4724-4734. 
Chapter 6

Tungsten-Promoted Pyridine Ring Scission: The Selective Formation of $\eta^{2}$-Cyanine and $\eta^{2}$-Merocyanine Complexes and their Derivatives 


\section{Introduction:}

Cyanines and merocyanines, polyene systems with an electron-donor group at one terminus and an electron-withdrawing group at the other, are widely studied not only in their historical context in the dye industry, but also for their nonlinear optical and solvatochromism properties, and their potential uses in laser technology, data storage, photosensitizers, and phototheraputics. ${ }^{1}$ In the course of investigating the reactivity of $\eta^{2}$-coordinated pyridine complexes of tungsten, ${ }^{2,3}$ we discovered that a bound $\mathrm{N}$-acetylpyridinium ligand, upon treatment with certain nucleophiles, spontaneously underwent ring-scission to form a cyanine with the tungsten fragment still coordinated. Given the broad interest in cyanines and the novelty of the resulting metallocyanine products, we mounted an investigation of this new organometallic reaction type.

\section{Results and Discussion:}

The acetylpyridinium species $\mathbf{1}$ is conveniently formed from pyridine-borane, acetic anhydride, and $\mathrm{TpW}(\mathrm{NO})\left(\mathrm{PMe}_{3}\right)\left(\eta^{2}\right.$-benzene). ${ }^{3}$ With tungsten coordinating $\mathrm{C} 3$ and C4, the acetylated pyridine ring of 1 readily undergoes regio- and stereoselective nucleophilic addition at $C 2$, providing a facile route to a broad range of $\eta^{2}-(1,2-$ dihydropyridine) complexes. ${ }^{3}$ When the newly attached C2 substituent is capable of donating $\pi$-electrons, a Zincke-König ${ }^{4,5}$-like ring scission becomes possible, thereby generating a cyanine with the complexing agent still attached. For example, when a solution of 1 was treated with indoline, a single new compound (2) was isolated in $88 \%$ 
yield. The spectroscopic features of $\mathbf{2}$ differed widely from those observed for $3,4-\eta^{2}$ 1,2-dihydropyridine complexes. ${ }^{3}$ Electrochemical and ${ }^{31} \mathrm{P}$ NMR data indicated that the $\left\{\mathrm{TpW}(\mathrm{NO})\left(\mathrm{PMe}_{3}\right)\right\}$ system of $\mathbf{2}$ was still intact, but was coordinated to a highly electrondeficient organic ligand. Proton and ${ }^{13} \mathrm{C}$ NMR data along with an HSQC experiment indicated that this new ligand has a total of nine methine groups. Two of these were associated with tungsten-bound carbons and four were associated with the aromatic ring, leaving three methine signals in the range of 5.8-8.2 ppm $\left(\mathrm{CDCl}_{3}\right)$. In addition, a broad peak at $9.56 \mathrm{ppm}$ was present that diminished upon the addition of $\mathrm{D}_{2} \mathrm{O}$. This feature along with an IR absorption at $1643 \mathrm{~cm}^{-1}$ indicated the presence of a secondary amide. COSY, NOESY, and HMBC experiments confirmed the structure of $\mathbf{2}$ portrayed in Scheme 1.

Presumably, the formation of the cyanine complex $\mathbf{2}$ is driven in part by the $\pi$ basic nature of the metal fragment. ${ }^{6}$ The cleavage of the $\mathrm{C}-\mathrm{N}$ bond results in a $\pi$-acid superior to the purported dihydropyridine precursor, (i.e, with a lower energy $\pi$ symmetry LUMO). This ring-scission appears to be general, provided that it renders a better $\pi$-acid than the dihydropyridine precursor. For example, when malononitrile in $\mathrm{CH}_{2} \mathrm{Cl}_{2}$ is combined with 1 and 2,6-lutidine followed by an aqueous hydroxide wash, merocyanine complex 3 is produced in $29 \%$ yield. Proton, ${ }^{31} \mathrm{P}$, and ${ }^{13} \mathrm{C}$ NMR features for $\mathbf{3}$ are similar to 2 . Additionally, diastereotopic nitrile groups are present $\left({ }^{13} \mathrm{C}: 114.1\right.$ and 116.3 ppm; IR: 2210, $2217 \mathrm{~cm}^{-1}$ ). Even mild nucleophiles such as pyrrole can add to C2 of the acylpyridinium complex (1). Combining the acetylpyridinium complex (1) with pyrrole in the presence of lutidine generated the dihydropyridine complex $4^{\prime}$, a 
compound that has been previously reported (Scheme 2). ${ }^{3}$ However, if the lutidine was omitted, NMR data of the product mixture suggested the formation of a new species that did not share the signature NMR features of our tungsten dihydropyridine complexes. Optimal results were obtained with 2,4-dimethylpyrrole, in which case cyanine complex 4 was isolated in $53 \%$ yield.
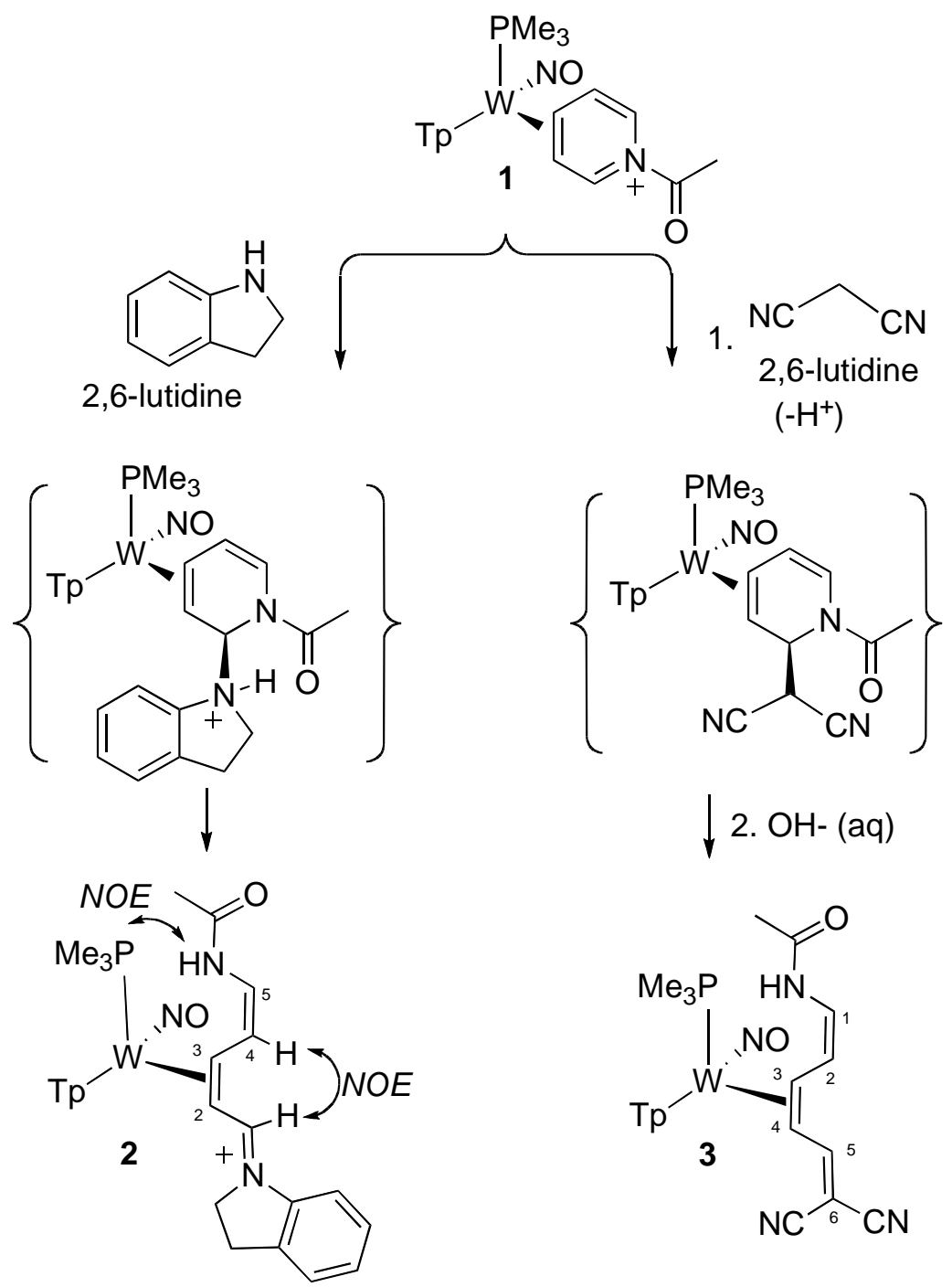

Scheme 1: Indoline and malononitrile ring scission of 1 (cationic complexes have triflate counterions). 
As mentioned above, an important driving force for these ring scissions is the stabilization of the tungsten system through $\pi$-backbonding into the low energy $\pi *$ orbitals associated with the cyanine or merocyanine ligands. Providing support for this notion is the nitrosyl stretching frequency that shifts from $1554 \mathrm{~cm}^{-1}$ for typical dihydropyridine complexes to 1608,1585 , or $1608 \mathrm{~cm}^{-1}$, for $\mathbf{2}, \mathbf{3}$, or 4 respectively. ${ }^{3}$ Meanwhile, the $\mathrm{W}(\mathrm{I} / 0)$ reduction potential for $\mathbf{2 - 4}$ is nearly $0.5 \mathrm{~V}$ more positive than that of dihydropyridine complexes.

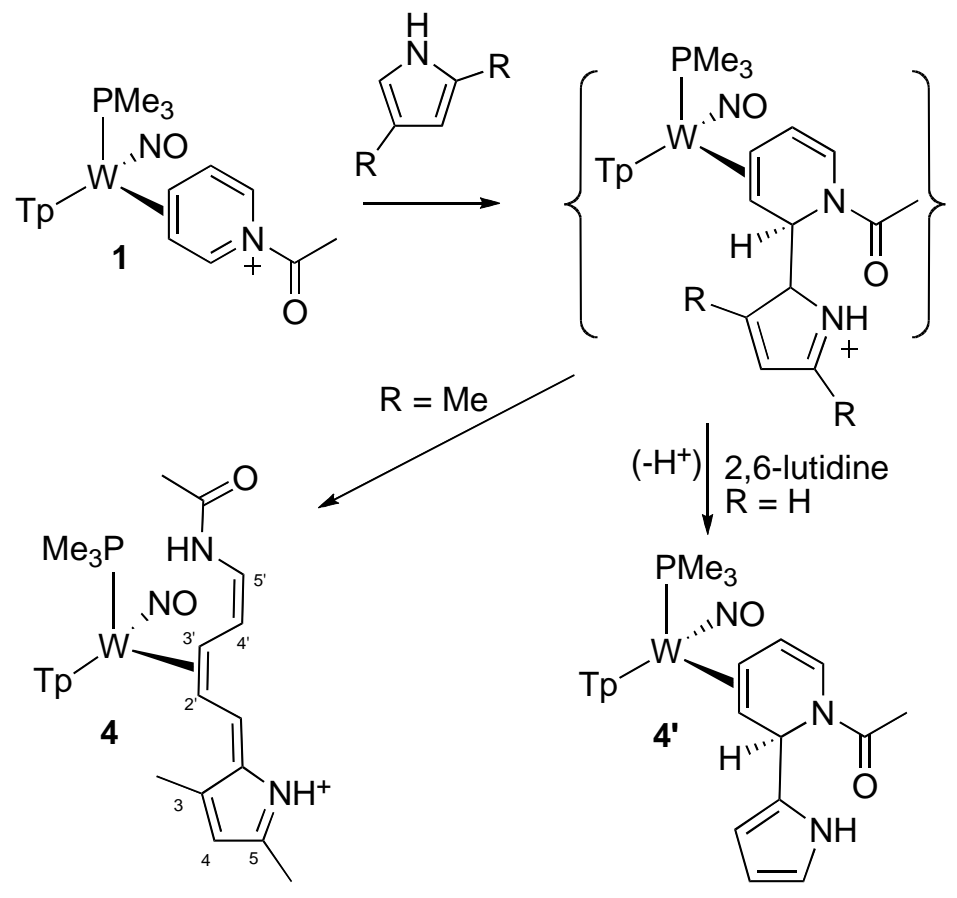

Scheme 2: Addition of pyrroles to 1.

X-ray quality crystals of $\mathbf{2}$ were grown and the molecular structure determined by X-ray diffraction (Figure 1). The structure of $\mathbf{2}$ indicates that conjugation between the donor (amide) and acceptor (iminium) portions of the polymethine ligand is lost as a 
result of partial $\mathrm{sp}^{2} \rightarrow \mathrm{sp}^{3}$ rehybridization of the coordinated alkene. Without this extended conjugation to help maintain the cyanine's planarity, a presumed steric repulsion from the $\mathrm{PMe}_{3}$ contributes to a loss of planarity in the cyanine ligand (C1-C2C3-C4 dihedral angle $\left.121^{\circ}\right)$.
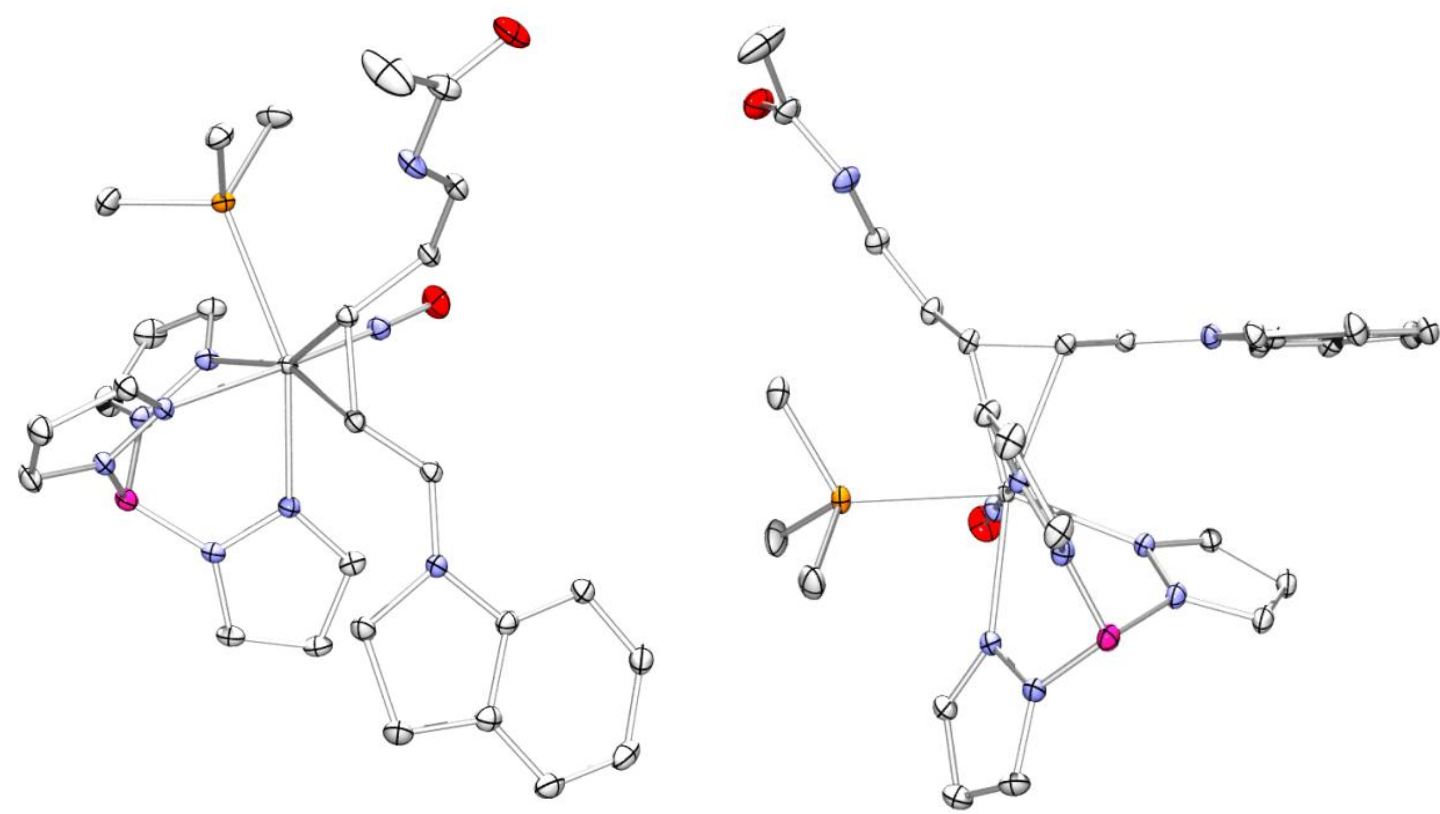

Figure 1: Front and side-view ORTEP of 2. The triflate anion and protons have been omitted for clarity.

We expanded our study to include semi-saturated pyridine complexes. In particular, the dialkoxylated 5,6-dihydropyridine complex 5 , is readily prepared from $\mathbf{1}$ and Selectfluor in $\mathrm{MeOH}^{2}{ }^{2}$ True to expectation, the reaction of $\mathbf{5}$ with indoline or malononitrile resulted in clean conversion to ring-opened products 6 and 7 , according to Scheme 3. A single crystal of $\mathbf{7}$ was grown suitable for X-ray analysis, and its molecular 
structure is provided in Figure 2. When the TMS-protected enolate of acetophenone is added to 1 followed by treatment with KF, dienone 8 is formed in $67 \%$ yield. NOE and coupling data indicate a 3Z,5E s-trans stereochemistry. Finally, a "protected" hydroxy group can effectively be added by reaction with sodium acetate. Loss of the acetyl group and ring-opening results in the enal complex 9.

Significantly, in the proton spectra of complexes 6-9, the $\mathrm{PMe}_{3}$ signal is unexpectedly broad, suggesting hindered rotation along the W-P axis. The molecular structure diagrams for 7 and 9 (Figure 2) indicate that the broadening in the proton spectrum of 6-9 is caused by intramolecular hydrogen bonds between the amide protons and the vicinal methoxy groups (i.e., C4 in 7 or C2 in 9). This interaction apparently orients the associated methyl groups such that they interfere with the phosphine rotation.
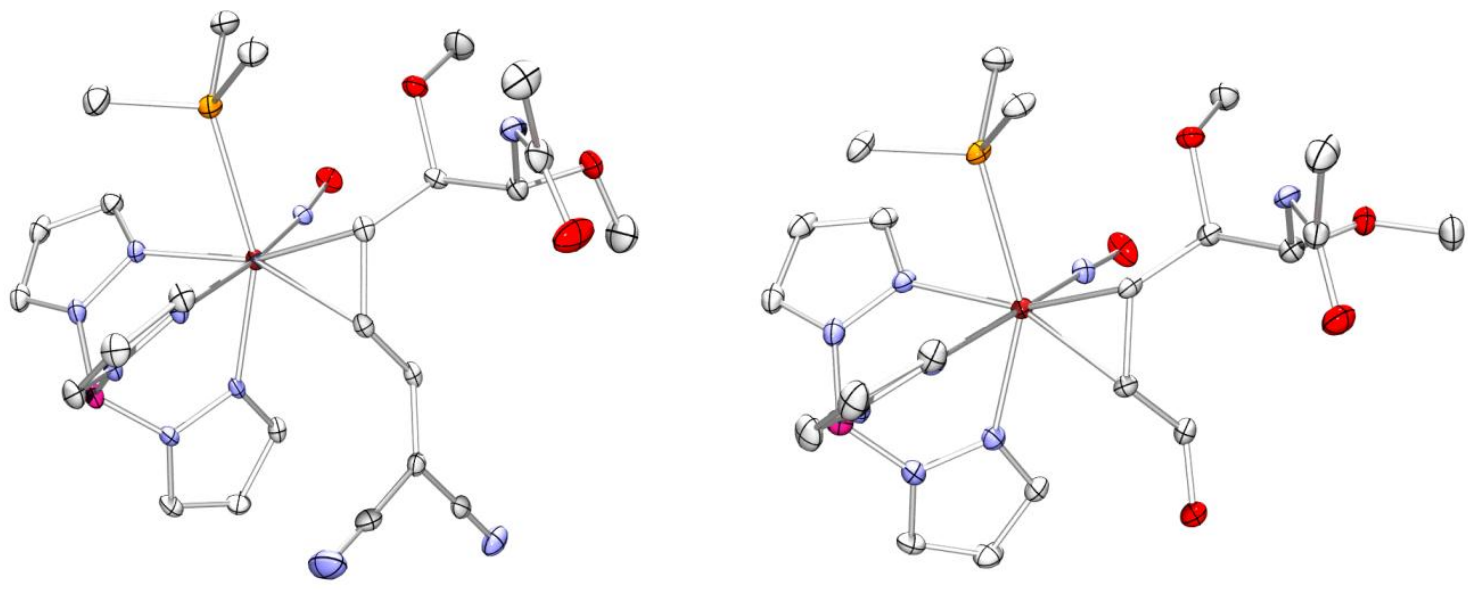

Figure 2: ORTEP diagrams of the dinitrile complex 7 and enal complex 9. 
While methods exist to prepare similar cyanines, none of those formed in this study on tungsten have been reported. Thus, releasing the organic derivative may be of value in certain cases. Unfortunately, exposure of 2-4 to $m$-chloroperbenzoic acid ( $m \mathrm{CPBA})$, AgOTf, or stoichiometric or substoichiometric amounts of cerric ammonium nitrate (CAN) failed to liberate the expected cyanines. Decomplexations of one of the diether ligands was also explored. A solution of the dinitrile 7 was treated with an excess of $m C P B A$ in $\mathrm{CDCl}_{3}$ and $43 \%$ of the ligand was recovered, 10 (Eqn 1). Relevant to this is a recent study from Comins et al. that demonstrates the value of highly functionalized piperidines as sources of acyclic amino alcohols via a similar C-N bond cleavage. $^{7}$
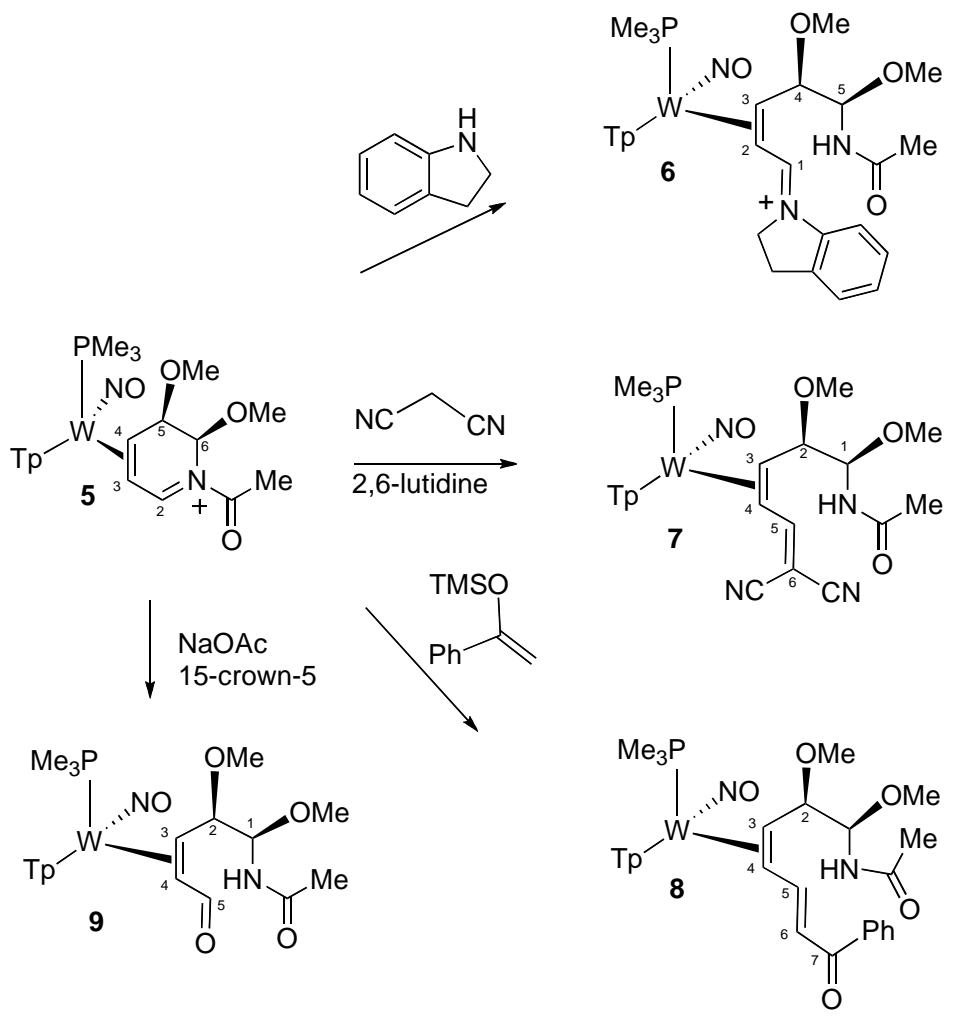

Scheme 3: Ring scission of $\mathbf{3}$ (cationic complexes have triflate counterions). 

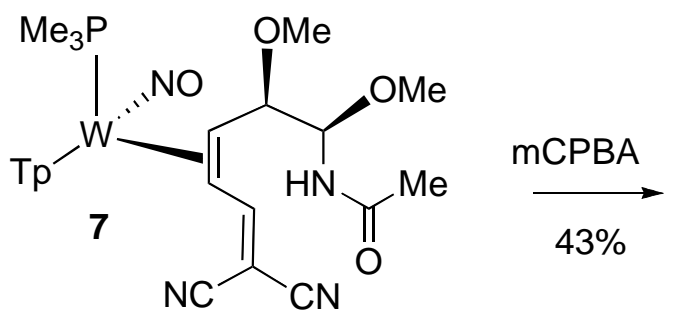<smiles>CO[C@H](/C=C\C=C(C#N)C#N)NC(C)=O</smiles>

Eqn 1.

\section{Photolytic Demetallation:}

A solution of cyanine complex $\mathbf{2}$ is an intense yellow with an absorption $\lambda_{\max }=$ $351 \mathrm{~nm}\left(\mathrm{MeCN} ; \varepsilon=21,700 \mathrm{~cm}^{-1} \mathrm{M}^{-1}\right.$ ). However, we noted that upon standing in ambient light this solution slowly turned orange. When a similar solution was protected from light, no color change or decomposition was detected, even after several weeks and mild heating.

Irradiation of $\mathbf{2}$ with $15 \mathrm{~W}$ longwave UV lightbulb in $\mathrm{CDCl}_{3}$ produce an orange-red solution after several minutes and a blood red solution overnight ( $\sim 15 \mathrm{~h})$. Broadening in the ${ }^{1} \mathrm{H}$ NMR spectrum of the reaction solution suggested the formation of paramagnetic material, but new chemical shifts including a doublet at $8.35 \mathrm{ppm}$, triplets at $8.19 \mathrm{ppm}$ and $6.13 \mathrm{ppm}$, and several signals around $7.25 \mathrm{ppm}$ signaled the formation of a new organic compound (11). A series of control experiments determined that light and water were requirements for satisfactory formation of $\mathbf{1 1}$ but that oxygen was detrimental to its preparation in the presence of light. Proton NMR, HRMS, and UV-vis data $\left(\lambda_{\max }=525\right.$ $\mathrm{nm})$, confirmed that $\mathbf{1 1}$ was the indoline cyanine shown below, previously synthesized 
from 1-(2,4-dinitrophenyl)pyridinium chloride. ${ }^{8}$ Repeating the photolysis in the presence of an excess of free indoline increased the NMR yield of 11 to $80 \%$ (Eqn 2).
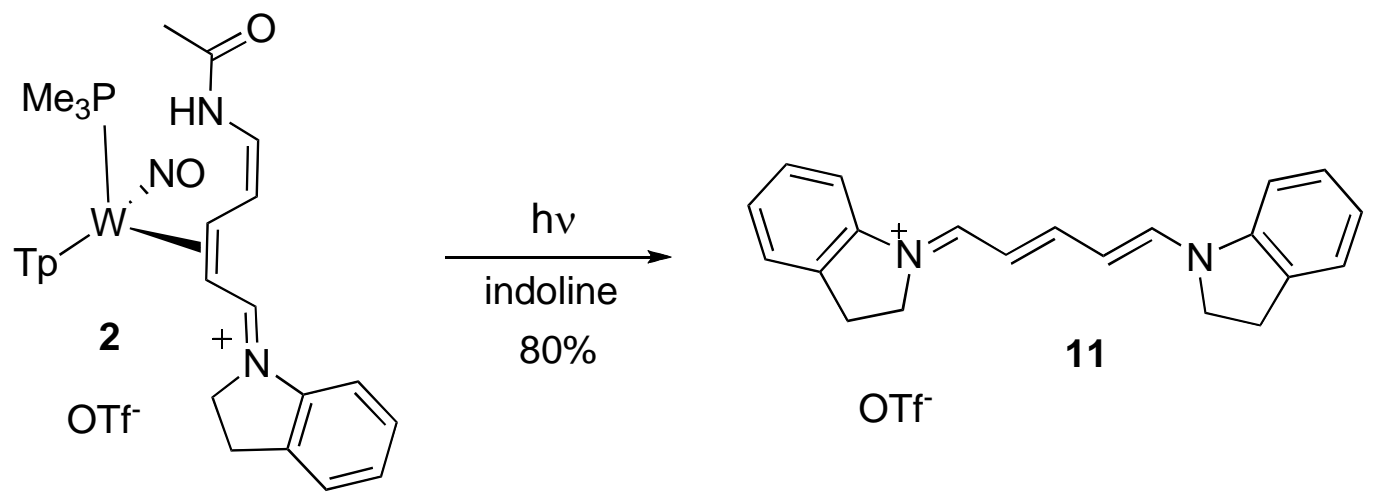

Eqn. 2

When solutions of $\mathbf{3}$ or $\mathbf{4}$ were subjected to similar photolysis conditions, color changes were observed, but ${ }^{1} \mathrm{H}$ NMR spectra indicated a complex mixture, preventing a meaningful quantitative analysis. For comparison, when the complex $\operatorname{TpW}(\mathrm{NO})\left(\mathrm{PMe}_{3}\right)\left(3,4-\eta^{2}-(1-(2-\right.$ ethylpyridin-1(2H)-yl)ethanone))) was irradiated with longwave UV light or fluorescent light, liberation of the coordinated dihydropyridine was not observed.

Of note, irradiation of $\mathbf{2}$ with a $15 \mathrm{~W}$ household compact fluorescent light (CFL) was sufficient to generate $\mathbf{1 1}$. While $\mathbf{1 1}$ has been previously synthesized, its fluorescence has not been previously documented. When irradiated with longwave UV (490 nm), intense orange fluorescence $\left(\lambda_{\max }=563 \mathrm{~nm}\right)$ was observed, even at ambient temperature $\left(\sim 22^{\circ} \mathrm{C}\right)$. Metallocyanines $\mathbf{3}$ and $\mathbf{4}$, showed no fluorescence, even at $77 \mathrm{~K}$.

The ability of transition metals to modulate the chemical and photochemical properties of cyanines, ${ }^{9,10}$ phthalocyanines, ${ }^{11-17}$ porphryins $^{18-24}$ and other highly conjugated $\pi$-systems ${ }^{16}$ is well known, but little is known about the effect of a metal on these systems when dihapto-coordinated $(C, C)$ to a transition metal. Wolczanski et al. 
have reported the ring scission of dihapto-coordinated pyridines bound to $\mathrm{Ta}^{25}$ but no organic products from these reactions were reported. Also relevant to this work, both Wigley ${ }^{26}$ and Mindiola ${ }^{27}$ have observed metal insertion into the $\mathrm{C}-\mathrm{N}$ bond of pyridine, forming azametallocycles. Synthesizing complexes of functionalized $\eta^{2}$-polyenes such as described herein directly from the polyene ligand would be futile, owing to the many potential coordination sites and stereochemistries. Considering the non-coplanarity of the metallated species (2), coordination of the metal to the polyene clearly interrupts the extended $\pi$-conjugation of the cyanine ligand.

\section{Concluding Remarks:}

Pyridine ring scission is accomplished within a tungsten coordination complex by acetylation of the heterocycle followed by addition of the appropriate nucleophile at C2 to form a cyanine or merocyanine complex. The ring-opening is driven by the enhanced $\pi$-acidity of the heteropolyene, relative to its dihydropyridine predecessor, which stabilizes the $\pi$-base. The resulting products comprise a new type of metallocyanine in which a conjugated heteropolyene is dihapto-coordinated to a transition metal. In one case, photolytic conditions resulted in liberation of a highly fluorescent cyanine dye.

\section{Experimental Section:}

General Methods. NMR spectra were obtained on a 300 or $500 \mathrm{MHz}$ spectrometer (Varian INOVA or Bruker Avance). All chemical shifts are reported in ppm. Proton and carbon shifts are referenced to tetramethylsilane (TMS) utilizing residual ${ }^{1} \mathrm{H}$ or ${ }^{13} \mathrm{C}$ signals of the deuterated 
solvents as an internal standard. Phosphorus NMR signals are referenced to $85 \% \mathrm{H}_{3} \mathrm{PO}_{4}(\delta=$ 0.00) using a triphenylphosphate external standard $(\delta=-16.58)$. Coupling constants $(J)$ are reported in hertz $(\mathrm{Hz})$. Infrared spectra (IR) were recorded on a MIDAC Prospect Series (Model PRS) spectrometer as a glaze on a Horizontal Attenuated Total Reflectance (HATR) accessory (Pike Industries). Electrochemical experiments were performed under a dinitrogen atmosphere using a BAS Epsilon EC-2000 potentiostat. Cyclic voltammetry data was taken at ambient temperature $\left(\sim 22{ }^{\circ} \mathrm{C}\right)$ at $100 \mathrm{mV} / \mathrm{s}$ in a standard three-electrode cell from +1.7 to $-1.7 \mathrm{~V}$ with a glassy carbon working electrode, $N, N$-dimethylacetamide (DMA) solvent (unless otherwise specified), and tetrabutylammonium hexaflurophosphate (TBAH) electrolyte (approx. 0.5 M). All potentials are reported versus NHE (Normal Hydrogen Electrode) using cobaltocenium hexafluorophosphate $\left(E_{1 / 2}=-0.78 \mathrm{~V}\right)$, ferrocene $\left(E_{1 / 2}=+0.55 \mathrm{~V}\right)$, or decamethylferrocene $\left(E_{1 / 2}=\right.$ +0.04 V) as an internal standard. The peak-to-peak separation was $100 \mathrm{mV}$ or less for all reversible couples. High resolution electrospray ionization mass spectrometry (ESI-MS) analyses were obtained from the University of Illinois at Urbana-Champaign Mass Spectrometry Laboratory or at the University of Richmond on a Bruker BioTOF-Q running in ESI mode using a 1:3 water:acetonitrile solution with sodium trifluoroacetate as an internal standard. For tungsten metal complexes, this data is reported using the five most intense peaks from the isotopic envelope for either $\mathrm{M}+\left(\right.$ for monocationic complexes) or for $(\mathrm{M}+\mathrm{H})^{+}$or $(\mathrm{M}+\mathrm{Na})^{+}$(for neutral complexes). The data is listed as $\mathrm{m} / \mathrm{z}$ with the intensity relative to the most abundant peak of the isotopic envelope given in parentheses for both the calculated and observed peaks. The difference between calculated and observed peaks is reported in ppm. For neutral organic species, the calculated and observed peaks for $(\mathrm{M}+\mathrm{H})^{+}$or $(\mathrm{M}+\mathrm{Na})^{+}$are reported, with the difference between them reported in ppm. Unless otherwise noted, all synthetic reactions were performed in a glovebox under a dry nitrogen atmosphere. When reactions required stirring, a 
magnetic Teflon stirbar was used. UV-Vis measurements were obtained using a Perkin-Elmer lambda 25 UV-Vis Spectrophotometer or Hitachi-High Technologies Diode Array Bio Photometer U-0080D. Fluorescence measurements were obtained using a Spex 2+2 Fluorolog spectrofluorometer with an ozone free mercury arc lamp. A General Electric $15 \mathrm{~W}$ fluorescent light bulb (Helical 15W, 120VAC 60Hz 230mA, FLE15HT3/2/XL/SW) and a General Electric $15 \mathrm{~W}$ F15T8-BLB fluorescent black light (i.e. longwave UV) bulb were used for photolysis experiments. Drysolve ${ }^{\circledR}$ dichloromethane (DCM) and benzene was purified by passage through a column packed with activated alumina. Drisolve ${ }^{\circledR}$ THF (tetrahydrofuran) was used as received. Other solvents and liquid reagents were thoroughly purged with nitrogen prior to use. Deuterated solvents were used as received from Cambridge Isotopes. Pyrazole, $\mathrm{Pz}$, protons of the (trispyrazolyl)borate, $\mathrm{Tp}$, ligand were uniquely assigned using a combination of 2-dimensional NMR experiments and phosphorus-proton coupling (Figure S1, see supplemental information). ${ }^{1}$ When unambiguous assignments were not possible, $\mathrm{Pz}$ protons were labeled as $\mathrm{Tp}$ protons. Coordination diastereomers are described by the defining feature's (i.e. heteroatom's) proximity to the $\mathrm{PMe}_{3}$ ligand relative to the W-PMe 3 bond (e.g. the fewer number of bonds from the $\mathrm{PMe}_{3}$ passing through the upper portion of the coordinated ring system to the defining feature dictates the proximal (P) ligand).

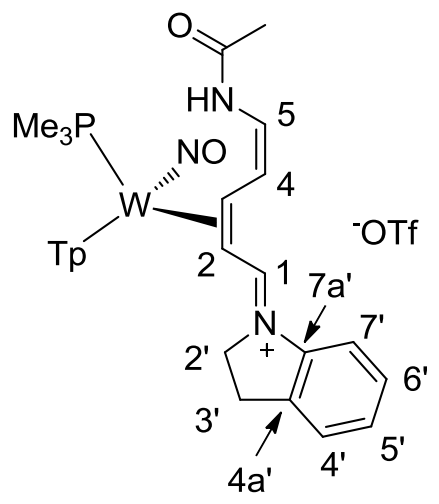


$\mathrm{TpW}(\mathrm{NO})\left(\mathrm{PMe}_{3}\right)\left(2,3-\eta^{2}-((E)-1-((2 Z, 4 Z)-5\right.$-acetamidopenta-2,4-dienylidene)indolinium)) (OTf). 2. Indoline $(0.470 \mathrm{~g}, 3.944 \mathrm{mmol})$ in a DCM $(0.85 \mathrm{~g})$ solution was added to a deep red homogeneous solution of $1(2.005 \mathrm{~g}, 2.590 \mathrm{mmol}), \operatorname{DCM}(23.67 \mathrm{~g})$, and 2,6-lutidine $(0.654 \mathrm{~g}, 6.104 \mathrm{mmol})$ in a $500 \mathrm{~mL}$ round bottom flask to become a dark yellow-brown solution within about 2 minutes. After 15 minutes the reaction solution was slowly diluted with $\mathrm{Et}_{2} \mathrm{O}(400 \mathrm{~mL})$ to precipitate a dark yellow solid that was collected on a $30 \mathrm{~mL}$ medium porosity fritted funnel. Residual material remaining in the round bottom flask was redissolved in DCM ( 8g), precipitated with $\mathrm{Et}_{2} \mathrm{O}(200 \mathrm{~mL})$, collected on the same fritted funnel as the first crop, washed with $2 \times 15 \mathrm{~mL} \mathrm{Et}{ }_{2} \mathrm{O}$ and dried under vacuum $(2.028 \mathrm{~g}, 2.270 \mathrm{mmol}, 88 \%)$. Trace indoline impurity was detected by $\mathrm{CV}$ and could be removed by stirring the isolated material in THF ( $4.66 \mathrm{~g}) .12$ hours later, a bright yellow solid was collected on a $15 \mathrm{~mL}$ medium porosity fritted funnel, washed with $4 \times 0.5 \mathrm{~g}$ portions of THF, and placed under vacuum $(1.094 \mathrm{~g}, 1.225 \mathrm{mmol}, 47 \%) .{ }^{1} \mathrm{H} \mathrm{NMR}\left(\mathrm{CDCl}_{3}, \delta\right): 9.56$ (d, $J=10.7,1 \mathrm{H}$, Amide-NH) $8.43(\mathrm{~d}, J=2.0,1 \mathrm{H}, \mathrm{PzC} 3), 8.23$ (d, $J=11.9,1 \mathrm{H}, \mathrm{H} 1), 8.05$ (d, $J=2.0$, $1 \mathrm{H}, \mathrm{PzB} 3), 7.83(\mathrm{~d}, J=2.0,1 \mathrm{H}, \mathrm{PzC} 5), 7.81(\mathrm{~d}, J=2.0, J=2.0,1 \mathrm{H}, \mathrm{PzB} 5), 7.69(\mathrm{~d}, J=2.0, J=2.0,1 \mathrm{H}$, PzA5), 7.52-7.25 (m, 4H, H4'/H5'/H6'/H7'), 7.19 (d, $J=2.0, J=2.0,1 \mathrm{H}, \mathrm{PzA} 3), 6.85$ (dd, $J=10.7$, 9.0, 1H, H5), $6.56(\mathrm{t}, J=2.0,1 \mathrm{H}, \mathrm{PzC} 4), 6.41(\mathrm{t}, J=2.0,1 \mathrm{H}, \mathrm{PzB} 4), 6.04(\mathrm{t}, J=2.0,1 \mathrm{H}, \mathrm{PzA} 4) 5.83$ $(\mathrm{dd}, J=10.7,9.0,1 \mathrm{H}, \mathrm{H} 4), 4.71(\mathrm{ddd}, J=10.7,9.0,3 \mathrm{PH}=9.9,1 \mathrm{H}, \mathrm{H} 3), 4.24(\mathrm{dd}, J=10.7,9.0,1 \mathrm{H}$, $\left.\mathrm{H}^{\prime}\right), 3.42(\mathrm{dd}, J=11.9,9.0,1 \mathrm{H}, \mathrm{H} 2), 3.23\left(\mathrm{~m}, 1 \mathrm{H}, \mathrm{H} 3^{\prime}\right), 2.96\left(\mathrm{~m}, 2 \mathrm{H}, \mathrm{H} 2^{\prime} / \mathrm{H}^{\prime}\right), 2.32(\mathrm{~s}, 3 \mathrm{H}$, Amide$\mathrm{Me}), 1.22\left(\mathrm{~d},{ }^{3} \mathrm{JH}_{\mathrm{PH}}=9.3,9 \mathrm{H}, \mathrm{PMe}_{3}\right) .{ }^{13} \mathrm{C} \mathrm{NMR}\left(\mathrm{CDCl}_{3}, \delta\right): 170.2$ (Amide-CO) 159.6 (C1), 144.2/144.1

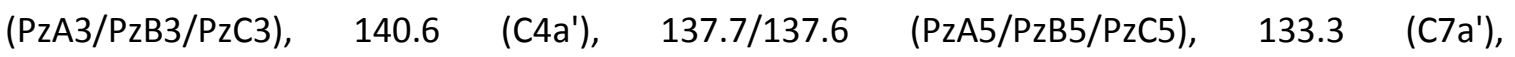
129.0/127.9/126.8/111.5 (C4'/C5'/C6'/C7'), 124.9 (C5), 109.8 (C4), 108.3 (PzC4), 107.7 (PzB4), 106.4 (PzA4), 66.9 (d, $\left.J_{\mathrm{PC}}=12.5, \mathrm{C} 3\right) 65.3$ (C2), 49.4 (C2'), 27.4 (C3'), 23.1 (Amide-Me), 12.9 (d, J $J_{\mathrm{PC}}$ $\left.=31.3, \mathrm{PMe}_{3}\right) \cdot{ }^{31} \mathrm{P}$ NMR $\left(\mathrm{CDCl}_{3}, \delta\right):-5.39\left(J_{\mathrm{WP}}=288\right) . \mathrm{CV}: E_{\mathrm{p}, \mathrm{a}}=+1.13 \mathrm{~V} . \mathrm{IR}: v_{\mathrm{BH}}=2499 \mathrm{~cm}^{-1}, v_{\mathrm{NO}}=$ $1608 \mathrm{~cm}^{-1}, v_{\text {iminium }}=1566 \mathrm{~cm}^{-1}, v=1685 \mathrm{~cm}^{-1}, v=1643 \mathrm{~cm}^{-1}$. ESI-MS: obs'd (\%), calc'd (\%), ppm, 
$\mathrm{M}^{+}: 742.2294$ (80.6), 742.231 (81.4), 2.1; 743.232 (78.8), 743.2335 (81.3), 2.0; 744.2323 (100), 744.2335 (100), 1.6; 745.2357 (45), 745.2373 (47), 2.1; 746.2352 (67.2), 746.2367 (82.5), 2.0. UV-Vis (MeCN; $\lambda, \mathrm{nm}\left(\varepsilon, \mathrm{cm}^{-1} \mathrm{M}^{-1}\right): 229(33,900), 351(21,700)$.

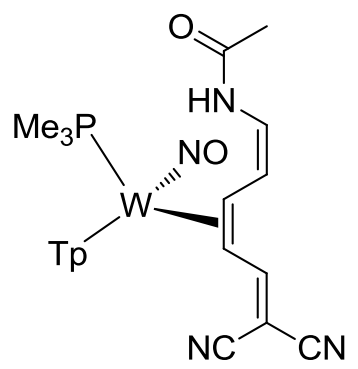

$\mathrm{TpW}(\mathrm{NO})\left(\mathrm{PMe}_{3}\right)\left(3,4-\eta^{2}-(N-((1 Z, 3 Z)-6,6-\right.$ dicyanohexa-1,3,5-trienyl)acetamide). $\quad 3 . \quad$ Under a nitrogen atmosphere, 2,6-lutidine $(0.040 \mathrm{~g}, 0.373 \mathrm{mmol})$ was added to $\sim 2 \mathrm{~mL} \mathrm{DCM}$, followed by the addition of malononitrile $(0.022 \mathrm{~g}, 0.333 \mathrm{mmol}) .1(0.201 \mathrm{~g}, 0.259 \mathrm{mmol})$ was added to the reaction mixture, resulting in a red solution that turned a deep yellow brown within $\sim 30 \mathrm{~s}$ of addition of $\mathbf{1}$. After stirring for 45 minutes, the reaction flask was removed from the nitrogen atmosphere. The solution was extracted with $3 \times 2 \mathrm{~mL}$ of $1 \mathrm{M} \mathrm{NaOH}$ (aq). The organic and aqueous layers were collected separately, and the aqueous layer, which was light pink in color, was back extracted with $2 \mathrm{~mL} \mathrm{DCM}$. The aqueous layer was then discarded and the organic layer, which was a heterogenous mixture of a brown solution and yellow solid, was evaporated to 1 $\mathrm{mL}$ using a weak $\mathrm{N}_{2}$ stream. The heterogenous solution was filtered through a $15 \mathrm{~mL}$ medium porosity fritted funnel. A yellow solid was collected, and it was subsequently stirred in a small amount of $\mathrm{CDCl}_{3}$, resulting in a yellow heterogenous solution. The mixture was filtered through a $2 \mathrm{~mL}$ medium porosity fritted funnel. A yellow solid was collected and dessicated in vacuo to a constant mass of $0.063 \mathrm{~g}(0.075 \mathrm{mmol}, 29 \%) .{ }^{1} \mathrm{H}$ NMR (DMSO- $\left.d_{6}, \delta\right): 9.70$ (d, J=10.7 Hz, $1 \mathrm{H}$, Amide-NH) , 7.65 (d, J=12.7 Hz, 1H, H5), 6.45 (buried, H1), 5.54 (dd, J=9.2 Hz, $11.0 \mathrm{~Hz}, 1 \mathrm{H}, \mathrm{H3}$ ), 4.15 (ddd, J=11.0, 10.7, 9.2 Hz. 1H), 2.50 (buried, H4), 2.09 (s, 3H, amide methyl protons), 8.21, 8.13, 8.09, 8.05, 7.53 (Tp doublets, $6 \mathrm{H}), 6.59,6.47$ (Tp triplets, $3 \mathrm{H}) .{ }^{13} \mathrm{C}$ NMR (DMSO- $\left.d_{6}, \delta\right)$ : 
173.4/167.4 ( Amide-CO/C5), 145.4 (Tp), 142.6 (Tp), 142.5 (Tp), 138.7 (Tp), 138.6 (Tp), 138.3 (Tp), 120.7 (C1), 116.3 (CN), 114.1 (CN'), 112.2 (C2), 108.2 (Tp), 107.7 (Tp), 107.1 (Tp), 68.2 (C6), $64.8(\mathrm{C} 4), 63.8$ (d, $J=11.8, \mathrm{C} 3$ ), 22.8 (Amide-Me), 11.7 (d, $\left.J=30.7, \mathrm{PMe}_{3}\right) .{ }^{31} \mathrm{P}$ NMR (DMSO- $\left.d_{6}, \delta\right):$ $-4.77\left(J_{\mathrm{WP}}=285 \mathrm{~Hz}\right) . \mathrm{CV}(\mathrm{DMSO}): E_{\mathrm{p}, \mathrm{a}}=+0.90 \mathrm{~V} . \mathrm{IR}: v_{\mathrm{BH}}=2515 \mathrm{~cm}^{-1}, v_{\mathrm{CN}}=2210 \mathrm{~cm}^{-1}, 2217 \mathrm{~cm}^{-1}$, $v_{\mathrm{NO}}=1585 \mathrm{~cm}^{-1}, v=1693 \mathrm{~cm}^{-1}, v=1639 \mathrm{~cm}^{-1}, v=1527 \mathrm{~cm}^{-1}$. ESI-MS: obs'd (\%), calc'd (\%), ppm, $(\mathrm{M}+\mathrm{Na})^{+}: 711.159$ (81.4), 711.1612 (83.9), 3.1; 712.1616 (81.5), 712.1637 (80.4), 2.9; 713.1627 (100), 713.1635 (100), 1.2; 714.1667 (44.2), 714.1676 (43.8), 1.3; 715.1669 (90.3), 715.1668 (83.6), 0.2. UV-Vis (MeCN; $\lambda, \mathrm{nm}\left(\varepsilon, \mathrm{cm}^{-1} \mathrm{M}^{-1}\right): 227(38,500), 325 \mathrm{~nm}(22,600)$.

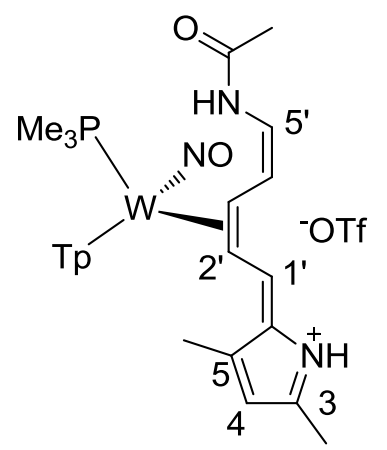

\section{$\mathrm{TpW}(\mathrm{NO})\left(\mathrm{PMe}_{3}\right)\left(2^{\prime}, 3^{\prime}-\eta^{2}-\left((E)-2^{\prime}-\left(\left(2^{\prime} Z, 4^{\prime} Z\right)-5^{\prime}-\right.\right.\right.$-acetamidopenta-2',4'-dienylidene)-3,5-dimethyl-}

2H-pyrrolium))(OTf). 4. 2,4-dimethyl-pyrrole (0.190 g, $1.997 \mathrm{mmol})$ in DCM (4.63 g) was added to a vial containing $1(0.400 \mathrm{~g}, 0.517 \mathrm{mmol})$ to make a deep red homogeneous solution. After 2 hours, the solution was transferred to a $50 \mathrm{~mL}$ Erlenmeyer flask with additional DCM (4.6 g) and diluted slowly with $\mathrm{Et}_{2} \mathrm{O}(20 \mathrm{~mL})$ to precipitate an orange-red solid which was removed via filtration of a $15 \mathrm{~mL}$ medium porosity fritted funnel. The solid was washed with $\mathrm{Et}_{2} \mathrm{O}(40 \mathrm{~mL})$. The filtrate solvent was removed in vacuo and the precipitate that was in the solution became a residue upon concentration. The residue was dissolved in DCM $(8.6 \mathrm{~g})$, diluted with $\mathrm{Et}_{2} \mathrm{O}(20 \mathrm{~mL})$, followed by hexanes $(120 \mathrm{~mL})$, to precipitate a bright orange-red solid that was collected on a 15 $\mathrm{mL}$ medium porosity fritted funnel. The solid was washed with $2 \times 5 \mathrm{~mL}$ hexanes and placed under vacuum to remove residual solvents $(0.237 \mathrm{~g}, 0.273 \mathrm{mmol}, 53 \%) .{ }^{1} \mathrm{H} \mathrm{NMR}\left(\mathrm{CDCl}_{3}, \delta\right)$ : 
10.18 (br-s, 1H, Pyrrole-NH) 9.06 (d, $J=10.7,1 \mathrm{H}$, Amide-NH), 8.26 (d, $J=2.0,1 \mathrm{H}, \mathrm{PzC}$ ), 8.02 (d, $J$ $=2.0,1 \mathrm{H}, \mathrm{PzB} 3), 7.85\left(\mathrm{~d}, J=13.9,1 \mathrm{H}, \mathrm{H} 1^{\prime}\right), 7.8(\mathrm{~d}, J=2.0,1 \mathrm{H}, \mathrm{PzC} 5), 7.78(\mathrm{~d}, J=2.0,1 \mathrm{H}, \mathrm{PzB} 5)$, $6.88(\mathrm{~d}, J=2.0,1 \mathrm{H}, \mathrm{PzA} 3), 6.86\left(\mathrm{dd}, J=10.2,8.9,1 \mathrm{H}, \mathrm{H} 5^{\prime}\right), 6.5(\mathrm{t}, J=2.0,1 \mathrm{H}, \mathrm{PzC} 4), 6.38(\mathrm{t}, J=$ 2.0, 1H, PzB4), 6.07 (s, 1H, H4), $5.95\left(\mathrm{t}, J=8.9,1 \mathrm{H}, \mathrm{H} 4^{\prime}\right) 5.87(\mathrm{t}, J=2.0,1 \mathrm{H}, \mathrm{PzA} 4), 4.55\left(\mathrm{dt},{ }^{3} J_{\mathrm{PH}}=\right.$ 11.2, $\left.J=8.7,1 \mathrm{H}, \mathrm{H} 3^{\prime}\right), 4.39\left(\mathrm{dd}, J=13.9,8.7,1 \mathrm{H}, \mathrm{H} 2^{\prime}\right), 2.39(\mathrm{~s}, 3 \mathrm{H}, \mathrm{C} 5-\mathrm{Me}), 2.20$ (s, 3H, AmideMe), 2.18 (s, 3H, C3-Me), 1.14 (d, $\left.\mathrm{J}_{\mathrm{PH}}=9.2,9 \mathrm{H}, \mathrm{PMe}_{3}\right) \cdot{ }^{13} \mathrm{C} \mathrm{NMR}\left(\mathrm{CDCl}_{3}, \delta\right): 169.9$ (Amide-CO) 155.1 (C1'), 150.1 (С3), 144.3 (PzB3), 143.4 (PzC3), 142.6 (РzA3), 139.7 (C5), 137.9/137.7 (PzB5/PzC5), 137.4 (PzA5), 133.7 (C1'), 125.7 (C5'), 116.0 (C4), 111.1 (C4') 107.9 (PzC4), 107.8 (PzB4), 105.1 (PzA4), 78.3 (C2'), 70.7 ( $\left({ }^{3}{ }^{3} J_{P C}=13.5, C 3^{\prime}\right), 23.0$ (Amide-Me), 13.9 (C3-Me), 12.7 (d, $\left.J_{\mathrm{PC}}=31.0, \mathrm{PMe}_{3}\right), 11.8(\mathrm{C} 5-\mathrm{Me}) \cdot{ }^{31} \mathrm{P} \mathrm{NMR}\left(\mathrm{CDCl}_{3}, \delta\right):-5.46\left(J_{\mathrm{WP}}=282\right) . \mathrm{CV}: E_{\mathrm{p}, \mathrm{a}}=+0.96 \mathrm{~V} . \quad \mathrm{IR}: v_{\mathrm{BH}}=$ $2499 \mathrm{~cm}^{-1}, v_{\mathrm{NO}}=1608 \mathrm{~cm}^{-1}, v=1678 \mathrm{~cm}^{-1}, v=1643 \mathrm{~cm}^{-1}, v=1589 \mathrm{~cm}^{-1}$. ESI-MS: obs'd (\%), calc'd (\%), ppm, $\mathrm{M}^{+}: 718.2303$ (66.2), 718.2310 (82.4), 0.9; 719.2327 (78.8), 719.2335 (81.0), 1.0; 720.2310 (100), 720.2334 (100), 3.3; 721.2346 (42.7), 721.2373 (45.7), 3.8; 722.2357 (79.2), 722.2366 (82.9), 1.3. UV-Vis (MeCN; $\lambda, \mathrm{nm}\left(\varepsilon, \mathrm{cm}^{-1} \mathrm{M}^{-1}\right): 227(30,800), 426 \mathrm{~nm}(20,200)$

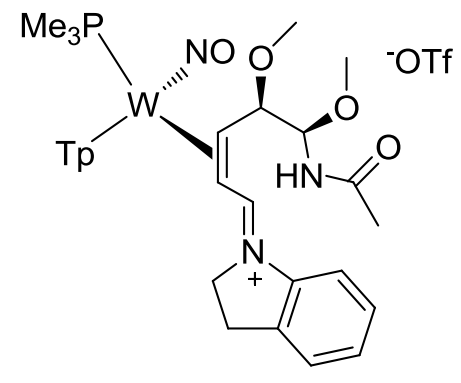

\section{$\mathrm{TpW}(\mathrm{NO})\left(\mathrm{PMe}_{3}\right)\left(2,3-\eta^{2}-((\mathrm{E})-1-((\mathrm{Z})-5\right.$-acetamido-4,5-dimethoxypent-2-}

enylidene)indolinium))(OTf). 6. Indoline $(0.047 \mathrm{~g}, 0.395 \mathrm{mmol})$ was dissolved in $\mathrm{CH}_{3} \mathrm{CN}(0.620$ g). The resulting orange homogeneous solution was added to a pre-weighed vial containing $\mathbf{5}$ $(0.055 \mathrm{~g}, 0.0658 \mathrm{mmol})$. The resulting yellow-orange solution was allowed to react at ambient temperature for $2 \mathrm{~h}$. After $2 \mathrm{~h}$, the solution was concentrated to a residue and re-solvated with $\mathrm{CH}_{2} \mathrm{Cl}_{2}$ and filtered through a celite plug. The organic solution was concentrated to a residue. 
The residue was re-dissolved with THF $(0.5 \mathrm{~g})$ and added to $75 \mathrm{~mL}$ of a stirring hexanes solution. A fine yellow precipitate was isolated by filtering the hexanes solution through a $15 \mathrm{~mL}$ fine porosity fritted funnel and was stored in vacuo for an isolated yield of $84 \%(0.053 \mathrm{~g}, 0.0642$ mmol). ${ }^{1} \mathrm{H} N M R\left(\mathrm{CD}_{3} \mathrm{CN}, \delta\right): 8.12(1 \mathrm{H}, \mathrm{d}, J=12.1, \mathrm{H} 1), 8.06(1 \mathrm{H}, \mathrm{d}, J=2.0, \mathrm{Tp}), 8.01(1 \mathrm{H}, \mathrm{d}, J=2.0$, Tp), $7.93(1 \mathrm{H}, \mathrm{d}, J=2.0, T p), 7.83(1 \mathrm{H}, \mathrm{d}, J=2.0, T p), 7.67(1 \mathrm{H}, \mathrm{d}, J=2.0, T p), 7.60(1 \mathrm{H}, \mathrm{d}, J=8.1$, Ar), $7.42(1 \mathrm{H}, \mathrm{t}, J=8.1,15.6, \operatorname{Ar}), 7.36(1 \mathrm{H}, \mathrm{d}, J=7.5, \operatorname{Ar}), 7.26(1 \mathrm{H}, \mathrm{t}, J=7.5,15.6, \operatorname{Ar}), 6.98(1 \mathrm{H}$, $\mathrm{d}, J=2.0, \mathrm{Tp}), 6.97(1 \mathrm{H}, \mathrm{d}, J=9.6, \mathrm{NH}), 6.51(1 \mathrm{H}, \mathrm{t}, J=2.0, \mathrm{Tp}), 6.43(1 \mathrm{H}, \mathrm{t}, J=2.0, \mathrm{Tp}), 5.91(1 \mathrm{H}$, $\mathrm{d}, J=2.0, \mathrm{Tp}), 5.47(1 \mathrm{H}, \mathrm{dd}, J=1.1,9.6, \mathrm{H} 5), 3.93(1 \mathrm{H}, \mathrm{ddd}, J=1.1,5.9,8.4, \mathrm{H} 4), 3.79(1 \mathrm{H}, \mathrm{m}, \alpha \mathrm{H}$ to indoline), $3.72\left(3 \mathrm{H}, \mathrm{s}, \mathrm{C} 4-\mathrm{OCH}_{3}\right), 3.36\left(3 \mathrm{H}, \mathrm{s}, \mathrm{C} 5-\mathrm{OCH}_{3}\right), 3.05(1 \mathrm{H}, \mathrm{ddd}, J=5.4,10.2,16.2, \beta \mathrm{H}$ on indoline), $2.76(1 \mathrm{H}, \mathrm{m}, \mathrm{H} 2), 2.69(1 \mathrm{H}, \mathrm{m}, \beta \mathrm{H}$ on indoline), $2.20(1 \mathrm{H}, \mathrm{m}, \alpha \mathrm{H}$ to indoline), 1.95 (3H, s, Acyl-Me), 1.10 (9H, broad singlet, $\left.\mathrm{PMe}_{3}\right) .{ }^{13} \mathrm{C}$ NMR $\left(\mathrm{CD}_{3} \mathrm{CN}, \delta\right): 170.1$ (Amide-CO), 154.5 (Tp), 145.5 (Tp), 143.9 (Tp), 141.3 (Tp), 138.7 (Tp), 138.5 (Tp), 138.0 (Tp), 128.5 (Ar), 127.3 (Ar), 126.5 (Ar), 111.3 (Ar), 107.5 (Tp), 107.1 (Tp), 106.3 (Tp), 86.6 (C5), 83.2 (C4), 70.1 (d, J = 14.4, $\mathrm{C} 3), 65.5(\mathrm{C} 2), 58.8\left(\mathrm{C} 4-\mathrm{OCH}_{3}\right), 55.3\left(\mathrm{C} 5-\mathrm{OCH}_{3}\right), 48.4$ ( $\mathrm{C}-\alpha$ indoline protons), 26.7 (C- $\beta$ indoline), $22.1(\mathrm{~N}-\mathrm{acyl}), 12.5\left(\mathrm{~d}, J=33.2, \mathrm{PMe}_{3},\right) \cdot{ }^{31} \mathrm{P} \mathrm{NMR}\left(\mathrm{CD}_{3} \mathrm{CN}, \delta\right):-6.10 \mathrm{ppm}\left(J_{\mathrm{WP}}=289\right) . \mathrm{IR}: v_{\mathrm{CO}}=1724$ $\mathrm{cm}^{-1}, v_{\text {amide }}=1643 \mathrm{~cm}^{-1}, v_{\mathrm{NO}}=1570 \mathrm{~cm}^{-1}$. ESI-MS: obs'd (\%), calc'd (\%), ppm, (M-OTf) ${ }^{+}: 804.2679$ (77.4), 804.2684 (79.9), 0.6; 805.2707 (79.9), 805.2709 (81.4), 0.2; 806.2682 (100), 806.2709 (100), 3.3; 807.2662 (48.1), 807.2747 (48.6), 10.5; 808.2709 (79.9), 808.2741 (82.1), 4.0.

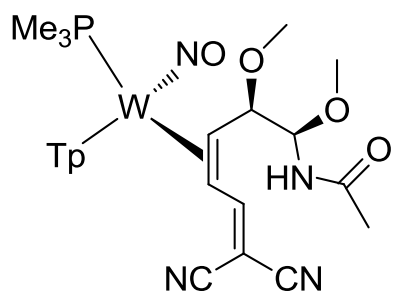

TpW(NO)(PMe $\left.{ }_{3}\right)\left(3,4-\eta^{2}-N-((Z)-N-(6,6-d i c y a n o-1,2-d i m e t h o x y h e x a-3,5-d i e n y l) a c e t a m i d e) . \quad 7\right.$. Malononitrile $(0.036 \mathrm{~g}, 0.545 \mathrm{mmol})$ was solvated with a minimal amount of THF and added to a 
pre-weighed vial containing $\mathrm{NaH}(0.010 \mathrm{~g}, 0.365 \mathrm{mmol})$. The resulting homogeneous solution was added to $5(0.152 \mathrm{~g}, 0.182 \mathrm{mmol})$ and allowed to react at ambient temperature for $2 \mathrm{~h}$. After $2 \mathrm{~h}$, the solution was concentrated to a residue and re-solvated with a minimal amount of DCM and filtered through a celite plug. The organic solution was concentrated to a residue. The residue was re-dissolved with THF $(0.5 \mathrm{~g})$ and added to $75 \mathrm{~mL}$ of a stirring hexanes solution. A fine yellow precipitate, 7 was isolated by filtering the hexanes solution through a $15 \mathrm{~mL}$ fine porosity fritted funnel and was stored in vacuo for an isolated yield of $72 \%(0.119 \mathrm{~g}, 0.159$ mmol). ${ }^{1} \mathrm{H}$ NMR (Acetone- $\left.d_{6}, \delta\right): 8.14 \mathrm{ppm}(1 \mathrm{H}, \mathrm{d}, J=J=2.0, \mathrm{Tp}), 8.08(1 \mathrm{H}, \mathrm{d}, J=2.0, \mathrm{Tp}), 8.06$ $(1 \mathrm{H}, \mathrm{d}, J=2.0, \mathrm{Tp}), 7.94(1 \mathrm{H}, \mathrm{d}, J=2.0, \mathrm{Tp}), 7.66(1 \mathrm{H}, \mathrm{d}, J=2.0, \mathrm{Tp}), 7.60(1 \mathrm{H}, \mathrm{d}, J=13.0, \mathrm{H} 5), 7.54$ $(1 \mathrm{H}, \mathrm{d}, J=2.0, \mathrm{Tp}), 7.47(1 \mathrm{H}, \mathrm{d}, J=6.1, \mathrm{NH}), 6.50(1 \mathrm{H}, \mathrm{t}, J=2.1,4.4, \mathrm{Tp}), 6.45(1 \mathrm{H}, \mathrm{t}, J=2.3,4.4$, Tp), $6.42(1 \mathrm{H}, \mathrm{d}, J=2.3,4.6, \mathrm{Tp}), 5.48(1 \mathrm{H}, \mathrm{dd}, J=1.6,9.6, \mathrm{H} 1), 3.88(1 \mathrm{H}, \mathrm{dd}, J=1.6,11.0, \mathrm{H} 2)$, $3.79(1 \mathrm{H}, \mathrm{dd}, J=9.5,12.8, \mathrm{H} 3), 3.68\left(3 \mathrm{H}, \mathrm{s}, \mathrm{C} 2-\mathrm{OCH}_{3}\right), 3.41\left(3 \mathrm{H}, \mathrm{s}, \mathrm{C} 1-\mathrm{OCH}_{3}\right), 2.67(1 \mathrm{H}, \mathrm{dd}, J=9.5$, 13.0, H4), 2.08 (3H, s, Acyl-Me), $1.14\left(9 \mathrm{H}\right.$, broad singlet, $\left.\mathrm{PMe}{ }_{3}\right) .{ }^{13} \mathrm{C}$ NMR (Acetone- $\left.d_{6}, \delta\right): 170.1$ (Amide-CO), 144.1 (2Tp), 141.0 (Tp), 138.1 (Tp), 137.8 (Tp), 137.7 (Tp), 116.9 (CN), 114.1 (CN) 107.8 (Tp), 107.4 (Tp), 106.4 (Tp), 87.1 (C1), 84.6 (C2), 69.1 (C6), 68.5 (d, J = 15.1, C3), 66.1 (C4), $59.1\left(\mathrm{C} 2-\mathrm{OCH}_{3}\right), 55.7\left(\mathrm{C} 1-\mathrm{OCH}_{3}\right), 22.6$ (Acyl-Me), 13.1 (d, $\left.J=30.6, \mathrm{PMe}_{3}\right) .{ }^{31} \mathrm{P}$ NMR (Acetone- $d_{6}$, )): -8.82 ppm (JWP 287$)$. IR: $v_{\mathrm{CO}}=1724 \mathrm{~cm}^{-1}, v_{\text {amide }}=1643 \mathrm{~cm}^{-1}, v_{\mathrm{NO}}=1570 \mathrm{~cm}^{-1}$. ESI-MS: obs'd (\%), calc'd (\%), ppm, $(\mathrm{M}+\mathrm{H})^{+}: 751.2189$ (84.2), 751.2166 (82.4), 3.1; 752.2172 (84.9), 752.2191 (80.6), 2.5; 753.2218 (100), 753.2191 (100), 3.6; 754.2214 (50.1), 754.223 (45.4), 2.1; 755.2216 (85.2), 755.2223 (83.2), 0.9.

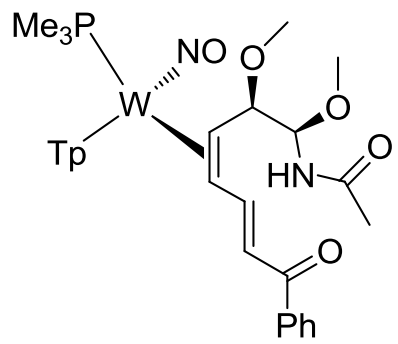


TpW(NO)(PMe $)\left(3,4-\eta^{2}-N\right.$-((3Z,5E)-1,2-dimethoxy-7-oxo-7-phenylhepta-3,5-dienyl)acetamide).

8. 1-phenyl-1-trimethylsiloxyethylene $(0.108 \mathrm{~g}, 0.562 \mathrm{mmol})$ was dissolved in $\mathrm{CH}_{3} \mathrm{CN}(0.880 \mathrm{~g})$.

The resulting homogeneous solution was added to a pre-weighed vial containing 5 (0.094 g, $0.112 \mathrm{mmol})$ and potassium fluoride $(0.052 \mathrm{~g}, 0.896 \mathrm{mmol})$. The resulting yellow-orange solution was allowed to react at ambient temperature for $2 \mathrm{~h}$. After $2 \mathrm{~h}$, the solution was diluted with 20 $\mathrm{mL}$ of DCM and washed with $5 \mathrm{~mL}$ of $\mathrm{H}_{2} \mathrm{O}$. The resulting organic layer was dried with $\mathrm{MgSO}_{4}$ and filtered over a $15 \mathrm{~mL}$ fine porosity fritted funnel. The yellow organic solution was concentrated to a residue. The residue was re-solvated with $1 \mathrm{~mL}$ of DCM and purified with silica chromatography $\left(\mathrm{R}_{\mathrm{f}}\right.$ : 0.41 in $\left.30 \% \mathrm{CH}_{3} \mathrm{CN} / \mathrm{Et}_{2} \mathrm{O}\right)$. Compound 8 was collected and isolated as a bright yellow residue, for an isolated yield of $67 \%(0.060 \mathrm{~g}, 0.0753 \mathrm{mmol}) .{ }^{1} \mathrm{H} \mathrm{NMR}\left(\mathrm{CDCl}_{3}, \delta\right)$ : $8.05(1 \mathrm{H}, \mathrm{d}, J=2.0, \mathrm{Tp}), 7.99(1 \mathrm{H}, \mathrm{dd}, J=12.5,14.3, \mathrm{H} 5), 7.86(2 \mathrm{H}, \mathrm{d}, J=7.0, \operatorname{Ar}), 7.75(2 \mathrm{H}, \mathrm{m}, \mathrm{Tp})$, $7.65(1 \mathrm{H}, \mathrm{d}, J=2.0, \mathrm{Tp}), 7.57(1 \mathrm{H}, \mathrm{d}, J=2.0, \mathrm{Tp}), 7.45(2 \mathrm{H}, \mathrm{m}, \operatorname{Ar}), 7.37(1 \mathrm{H}, \mathrm{m}, \mathrm{Ar}), 7.33(1 \mathrm{H}, \mathrm{d}, J=$ 1.7, Tp), $6.54(1 \mathrm{H}, \mathrm{d}, J=9.8, \mathrm{NH}), 6.34(1 \mathrm{H}, \mathrm{t}, J=2.0, \mathrm{Tp}), 6.29(1 \mathrm{H}, \mathrm{t}, J=2.0, \mathrm{Tp}), 6.25(1 \mathrm{H}, \mathrm{d}, J=$ 14.3, H6), $6.00(1 \mathrm{H}, \mathrm{t}, J=2.0, \mathrm{Tp}), 5.54(1 \mathrm{H}, \mathrm{d}, J=9.8, \mathrm{H} 1), 3.91(1 \mathrm{H}, \mathrm{d}, J=10.3, \mathrm{H} 2), 3.68(3 \mathrm{H}, \mathrm{s}$, $\left.\mathrm{C} 2-\mathrm{OCH}_{3}\right), 3.51\left(3 \mathrm{H}, \mathrm{s}, \mathrm{C} 1-\mathrm{OCH}_{3}\right), 3.43(1 \mathrm{H}, \mathrm{dd}, \mathrm{J}=10.3,11.5, \mathrm{H} 3), 2.29(1 \mathrm{H}, \mathrm{dd}, \mathrm{J}=11.5,12.5, \mathrm{H} 4)$,

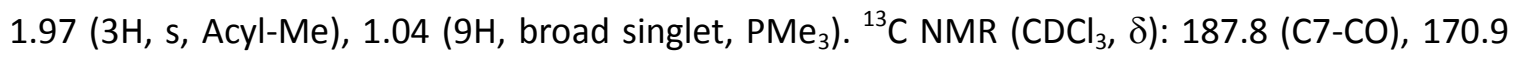
(Amide-CO), 158.7 (C5), 145.4 (Tp), 143.2 (Tp), 139.9 (Tp), 136.8 (Ar), 136.2 (Tp), 131.6 (Ar), $128.4(\mathrm{Ar}), 128.3$ (Ar), 120.2 (C6), 107.3 (Tp), 106.6 (Tp), 105.7 (Tp), 84.4 (C1/C2), 63.8 (C4), 63.6 $(\mathrm{d}, J=13.0, \mathrm{C} 3) 58.8\left(\mathrm{C} 2-\mathrm{OCH}_{3}\right), 57.3\left(\mathrm{C} 1-\mathrm{OCH}_{3}\right), 22.1$ (Acyl-Me), 13.7 (d, $\left.J=29.9, \mathrm{PMe}_{3}\right) .{ }^{31} \mathrm{P} \mathrm{NMR}$ $\left(\mathrm{CH}_{3} \mathrm{CN}\right):-8.62 \mathrm{ppm}\left(J_{\mathrm{WP}}=286\right) . \mathrm{IR}: v_{\mathrm{CO}}=1724 \mathrm{~cm}^{-1}, v_{\text {amide }}=1643 \mathrm{~cm}^{-1}, v_{\mathrm{NO}}=1570 \mathrm{~cm}^{-1}$. ESI-MS: obs'd (\%), calc'd (\%), ppm, (M+H) ${ }^{+}: 805.2496$ (79.1), 805.2524 (80.0), 3.5; 806.2516 (84.1), 806.2549 (79.4), 4.1; 807.2516 (100), 807.2549 (100), 4.1; 808.2563 (48.4), 808.2587 (48.5), 3.0; 809.2542 (80.0), 809.2581 (82.3), 4.8. 


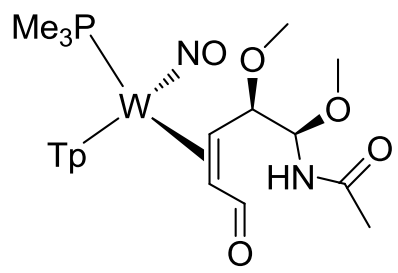

$\operatorname{TpW}(\mathrm{NO})\left(\mathrm{PMe}_{3}\right)\left(3,4-\eta^{2}-((Z)-N-(1,2-\right.$ dimethoxy-5-oxopent-3-enyl)acetamide)). 9. A solution of 15-crown-5 (0.065 g, $0.295 \mathrm{mmol})$ and $5(0.061 \mathrm{~g}, 0.0729 \mathrm{mmol})$ in $\mathrm{CH}_{3} \mathrm{CN}(0.571 \mathrm{~g})$ was added to a 4-dram vial containing sodium acetate $(0.036 \mathrm{~g}, 0.439 \mathrm{mmol})$ to turn red-brown instantly. After 6 hours, the resulting solution was concentrated and re-solvated with a minimal amount of DCM, filtered through a celite plug, the solvent evaporated, and the residue was purified via silica preparatory TLC (500 $\mu \mathrm{m}$ plate, $\left.60 \% \mathrm{CH}_{3} \mathrm{CN} / \mathrm{Et}_{2} \mathrm{O}\right)(0.029 \mathrm{~g}, 0.411 \mathrm{mmol}$, with $15 \mathrm{~mol} \%$ impurity of 15-crown-5; $0.027 \mathrm{mg}, 0.0391 \mathrm{mmol}, 54 \%$ yield after adjustment for impurity). ${ }^{1} \mathrm{H}$ $\operatorname{NMR}\left(\right.$ Acetone- $\left.d_{6}, \delta\right): 9.34 \mathrm{ppm}(1 \mathrm{H}, \mathrm{d}, J=8.2, \mathrm{H} 5) 8.17 \mathrm{ppm}(1 \mathrm{H}, \mathrm{d}, J=2.0, \mathrm{Tp}), 8.06(1 \mathrm{H}, \mathrm{d}, J=$ 2.0, Tp), $7.99(1 \mathrm{H}, \mathrm{d}, J=2.0, \mathrm{Tp}), 7.78(1 \mathrm{H}, \mathrm{d}, J=2.0, \mathrm{Tp}), 7.68(1 \mathrm{H}, \mathrm{d}, J=2.0, \mathrm{Tp}), 7.44(1 \mathrm{H}, \mathrm{d}, J=$ 2.0, Tp), $7.32(1 \mathrm{H}, \mathrm{d}, J=8.7, \mathrm{NH}), 6.50(1 \mathrm{H}, \mathrm{t}, J=2.0, \mathrm{Tp}), 6.45(1 \mathrm{H}, \mathrm{t}, J=2.0, \mathrm{Tp}), 6.42(1 \mathrm{H}, \mathrm{d}, J=$ 2.0, Tp), $5.55(1 \mathrm{H}, \mathrm{dd}, J=1.1,9.6, \mathrm{H} 1), 4.38(1 \mathrm{H}, \mathrm{d}, J=11.1, \mathrm{H} 2), 3.65\left(3 \mathrm{H}, \mathrm{s}, \mathrm{C} 2-\mathrm{OCH}_{3}\right), 3.36(3 \mathrm{H}$, s, $\left.\mathrm{C} 1-\mathrm{OCH}_{3}\right), 3.30\left(1 \mathrm{H}, \mathrm{dd}, J=10.8,{ }^{3} \mathrm{JH}_{\mathrm{PH}}=23.4, \mathrm{H} 3\right), 2.04(4 \mathrm{H}, \mathrm{m}$, Acyl-Me/H4), $1.07(9 \mathrm{H}$, broad singlet, $\left.\mathrm{PMe}_{3}\right) .{ }^{31} \mathrm{P}$ NMR (Acetone- $\left.d_{6}, \delta\right):-8.34 \mathrm{ppm}\left(J_{\mathrm{WP}}=286\right)$ IR: $v_{\mathrm{CO}}=1654 \mathrm{~cm}^{-1}, v_{\mathrm{NO}}=1558 \mathrm{~cm}^{-}$ 1.<smiles>COC(NC(C)=O)[C@@H](/C=C\C=C(C#N)C#N)OC</smiles>

(Z)-N-(6,6-dicyano-1,2-dimethoxyhexa-3,5-dienyl)acetamide (10). 5 (0.107 g, 0.142 mmol) was added to a vial containing recrystallized $m$ CPBA $(0.125 \mathrm{~g}, 0.727 \mathrm{mmol})$. The reagents were dissolved in $\mathrm{CDCl}_{3}(1.8 \mathrm{~g})$ and allowed to react at ambient temperature for $6 \mathrm{~h}$. The resulting 
homogeneous solution was diluted with $20 \mathrm{ml}$ of $\mathrm{DCM}$ and washed with a $\mathrm{NaHCO}_{3}$ (saturated, aqeous) solution. The resulting organic was extracted, dried with $\mathrm{MgSO}_{4}$ and filtered over a 15 $\mathrm{mL}$ fine porosity fritted funnel. The yellow organic solution was concentrated to a residue. The residue was re-solvated with $1 \mathrm{~mL}$ of $\mathrm{DCM}$ and purified with silica chromatography and concentrated to a yellow residue, ( $0.015 \mathrm{~g}, 0.0612 \mathrm{mmol}, 43 \%$ yield) ( $\mathrm{R}_{\mathrm{f}}: 0.38$ in $\left.5 \% \mathrm{CH}_{3} \mathrm{CN} / \mathrm{Et}_{2} \mathrm{O}\right)$. ${ }^{1} \mathrm{H} \operatorname{NMR}\left(\mathrm{CDCl}_{3}, \delta\right): 7.49(1 \mathrm{H}, \mathrm{d}, J=11.7, \mathrm{H} 5), 6.82(1 \mathrm{H}, \mathrm{dd}, J=11.7,15.3, \mathrm{H} 4), 6.41(1 \mathrm{H}, \mathrm{dd}, J=$ 5.6, 15.3, H3), $6.02(1 \mathrm{H}, \mathrm{d}, J=10.1, \mathrm{NH}), 5.21(1 \mathrm{H}, \mathrm{dd}, J=1.0,10.1, \mathrm{H} 1), 4.12(1 \mathrm{H}, \mathrm{dd}, J=1.0,5.6$, $\mathrm{H} 2), 3.48\left(3 \mathrm{H}, \mathrm{s}, \mathrm{C} 2-\mathrm{OCH}_{3}\right), 3.37\left(3 \mathrm{H}, \mathrm{s}, \mathrm{C} 1-\mathrm{OCH}_{3}\right), 2.05(3 \mathrm{H}, \mathrm{s}, \mathrm{Acyl}-\mathrm{Me}) .{ }^{13} \mathrm{C} \mathrm{NMR}\left(\mathrm{CDCl}_{3}, \delta\right): 170.9$ (Amide-CO), 159.1 (C5), 149.2/127.1 (C3/C4), 112.9 (CN), 111.2 (CN), 86.3 (C6), 82.0 (C1), 81.5 (C2), $59.5\left(\mathrm{C} 2-O C H_{3}\right), 56.4\left(\mathrm{C} 1-\mathrm{OCH}_{3}\right), 23.6(\mathrm{C} 8-\mathrm{N}-\mathrm{acyl}) . \mathrm{IR}: v_{\mathrm{CN}}=2233 \mathrm{~cm}^{-1}, v_{\text {amide }}=1666 \mathrm{~cm}^{-1} . \mathrm{ESI}-$ MS: obs'd (\%), calc'd (\%), ppm, (M+Na) ${ }^{+}: 272.1047$ (100), 272.1035 (100), 4.4.

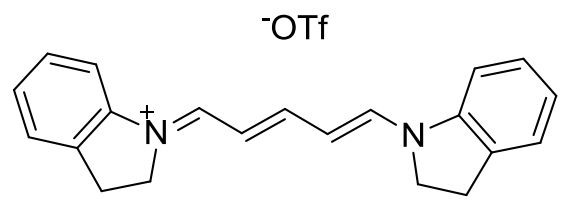

(E)-1-((2E,4E)-5-(indolin-1-yl)penta-2,4-dien-1-ylidene)indolin-1-ium triflate. 11. A solution of indoline $(0.0067 \mathrm{~g}, 0.056 \mathrm{mmol})$ in $\mathrm{CDCl}_{3}(1.32 \mathrm{~g})$ was added to a flame dried test tube containing $2(0.101 \mathrm{~g}, 0.113 \mathrm{mmol})$ and $\mathrm{CDCl}_{3}(8.98 \mathrm{~g})$ to make a deep yellow homogeneous solution. The test tube cap was tightly screwed on using Teflon tape and the cap was wrapped with parafilm and electrical tape twice. The sample was irradiated with a 15 watt blacklight bulb. After 46 hours, the reaction solvent was removed. The solid was partially dissolved in DCM (2 $\mathrm{mL})$, and acetone $(10 \mathrm{~mL})$ was added. The solution was cooled to $0{ }^{\circ} \mathrm{C}$ for a few minutes. The solvent was removed and acetone $(2 \mathrm{~mL})$ was added to the flask to precipitate a purple solid. The solid was collected on a $15 \mathrm{~mL}$ medium porosity fritted funnel and dried under vacuum $(0.0081 \mathrm{~g}, 0.0180 \mathrm{mmol}, 16 \%) .{ }^{1} \mathrm{H}$ NMR indicates pure product was present. ${ }^{1} \mathrm{H}$ coupling 
constant data matches that of the previously published compound. ${ }^{8}$ Additional material could be isolated with some impurities by stirring the filtrate residue in THF ( $2 \mathrm{~mL}, 0.0075 \mathrm{~g}, 0.017$ mmol, $15 \%$ without adjustment for impurity). Fluorescence Experiment: When the sample was dissolved in $\mathrm{CHCl}_{3}$ and placed in a quartz cuvette and excited with $490 \mathrm{~nm}$ light, an orange fluorescence was observed ( $\lambda_{\text {excitation }}=490 \mathrm{~nm}$; Emission $\left.\lambda_{\max }=563 \mathrm{~nm}\right)$. ESI-MS: obs'd (\%), calc'd (\%), ppm, $\mathrm{M}^{+}: 301.1698(100), 301.1699$ (100), 0.3.

\section{References:}

(1) Mishra, A.; Behera, R. K.; Behera, P. K.; Mishra, B. K.; Behera, G. B. Chem. Rev. 2000, 100, 1973.

(2) Kosturko, G. W.; Harrison, D. P.; Sabat, M.; Myers, W. H.; Harman, W. D. Organometallics 2009, 28, 387.

(3) Harrison, D. P.; Welch, K. D.; Nichols-Nielander, A. C.; Sabat, M.; Myers, W. H.; Harman, W. D. J. Am Chem. Soc. 2008, 130, 16844.

(4) König, W. J. Prakt Chem. 1904, 69, 105. Zincke, T. Ann. Chim. 1903, 330, 361

(5) . Becher J., Synthesis 1980, 589.

(6) Keane, J. M.; Harman, W. D. Organomet. 2005, 24, 1786.

(7) McCall, W. S.; Grillo, A.; Comins, D. L. J. Org. Chem. 2008, 73, 9744.

(8) Parikh, I.; Hilpert, H.; Hermann, K.; Dreiding, A. S. Helv. Chim. Acta 1986, 69, 1588.

(9) Abd El-Aal, R. M.; Belal, A. A. M. Dyes Pigm. 2004, 65, 129.

(10) Idriss, K. A.; Seleim, M. M.; Khalil, M. M. Monatsh. Chem. 1978, 109, 1383.

(11) Gottfried, J. M.; Marbach, H. Z. Phys. Chem. (Muenchen, Ger.) 2009, 223, 53.

(12) Imahori, H.; Umeyama, T.; Ito, S. Acc. Chem. Res. 2009, 42, 1809.

(13) Inabe, T.; Taketsugu, T.; Matsuda, M.; Tajima, H.; Hanasaki, N. Kotai Butsuri 2008, 43, 795. 
(14) Jiang, J.; Ng, D. K. P. Acc. Chem. Res. 2009, 42, 79.

(15) Mimura, M. Electrochemistry (Tokyo, Jpn.) 2007, 75, 829.

(16) Maclachlan, M. J. Front. Transition Met.-Containing Polym. 2007, 16.

(17) McKeown, N. B. Compr. Coord. Chem. I/ 2004, 1, 50.

(18) Siebbeles, L. D. A.; Huijser, A.; Savenije, T. J. J. Mater. Chem. 2009, 19, 6067.

(19) Pacholska-Dudziak, E.; Latos-Grazynski, L. Coord. Chem. Rev. 2009, 253, 2036.

(20) Fukuzumi, S.; Honda, T.; Ohkubo, K.; Kojima, T. Dalton Trans. 2009, 3880.

(21) Yoon, Z. S.; Osuka, A.; Kim, D. Nat. Chem. 2009, 1, 113.

(22) Callot, H. J. Dalton Trans. 2008, 6346.

(23) Suijkerbuijk, B. M. J. M.; Klein Gebbink, R. J. M. Angew. Chem., Int. Ed. 2008, 47, 7396.

(24) Alstrum-Acevedo, J. H.; Brennaman, M. K.; Meyer, T. J. Inorg. Chem. 2005, 44, 6802.

(25) Kleckley, T. S.; Bennett, J. L.; Wolczanski, P. T.; Lobkovsky, E. B. J. Am. Chem. Soc. 1997, 119, 247.

(26) Weller, K. J.; Filippov, I.; Briggs, P. M.; Wigley, D. E. Organometallics 1998, 17, 322.

(27) Bailey, B. C.; Fan, H.; Huffman, J. C.; Baik, M.-H.; Mindiola, D. J. J. Am. Chem. Soc 2006, 128, 6798. Fout, A. R.; Bailey, B. C.; Tomaszewski, J.; Mindiola, D. J. J. Am. Chem. Soc 2007, 129, 12640. 


\section{Chapter 7}

\section{Hyper-Distorted Tungsten Allyl Complexes}

\section{and their Stereoselective Deprotonation to}

Form Dihapto-Coordinated Dienes 


\section{Introduction:}

Our ongoing interest in the activation of aromatic molecules by $\pi$-basic transition metals such as $\left\{\mathrm{Os}\left(\mathrm{NH}_{3}\right)_{5}\right\}^{2+1,2}\{\mathrm{TpRe}(\mathrm{CO})(\mathrm{Melm})\}$ (Melm $=N$-methylimidazole; $\mathrm{Tp}=$ hydridotris(pyrazolyl)borate), ${ }^{3,4}$ and $\left\{\mathrm{TpW}(\mathrm{NO})\left(\mathrm{PMe}_{3}\right)\right\}{ }^{3,4}$ has led us to explore the feasibility of 1,2- and 1,4-tandem addition reactions of cyclic $\eta^{2}$-diene complexes. ${ }^{5-9}$ The ability of a transition metal complex to alter or promote organic reactions of conjugated dienes has been well documented, ${ }^{10}$ but in the vast majority of cases, the diene is bound through all four carbons. ${ }^{11-14}$ By comparison, less is understood about the ability of an $\eta^{2}$-coordinated metal to affect ligand-based reactions in such complexes, especially in the uncoordinated portion of the diene..$^{9,15,16}$ Previously, we have demonstrated that dihapto-coordinated cyclic 1,3-dienes can undergo both 1,2- and 1,4- tandem addition reactions of electrophiles followed by nucleophiles. While both addition reactions occur to the face of the diene opposite to that which is coordinated, ${ }^{5-9}$ the ability to control the absolute stereochemistry of this reaction sequence ultimately relies not only on access to an enantio-enriched, chiral $\pi$-base $\left(M^{*}\right),{ }^{17-19}$ but also on being able to obtain a single coordination diastereomer of the diene precursor (Scheme 1). Unfortunately, for $\mathrm{TpW}(\mathrm{NO})$ and TpMo(NO) systems, syntheses of such materials directly from organic diene precursors typically result in mixtures of coordination diastereomers., ${ }^{9,16,20}$ 
<smiles>C1CC2CCC1CC2</smiles>

$\downarrow E^{+}$<smiles>[CH2-][C@H]1C=CCC[C@H]1C</smiles>

$\downarrow \mathrm{Nu}^{-}$<smiles></smiles><smiles>[Mg][Mg]</smiles><smiles>[CH2-][C@@H]1C=CCC[C@H]1N</smiles>

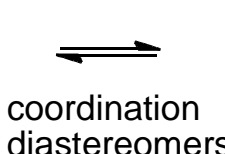

diastereomers<smiles>CC1CC2CCC1CC2</smiles>

$\downarrow E^{+}$

diastereomers

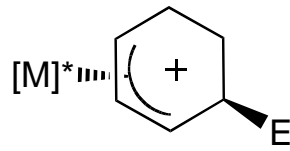

$\downarrow \mathrm{Nu}^{-}$

diastereomers<smiles>CC1CC[C@H](C)[C@H](N)C1</smiles>

$\downarrow[\mathrm{O}]$

enantiomers

Scheme 1: Enantioselective functionalization of cyclohexadiene.

The ability of an asymmetric complexing agent to control the regiochemistry of nucleophilic addition to an allyl ligand has been widely demonstrated. ${ }^{21-28} \mathrm{We}$ speculated that the same factors responsible for governing this reaction might be used to control a stereoselective deprotonation of a $\pi$-allyl complex, thereby rendering an $\eta^{2}$ diene complex formed in high diastereomeric excess (Eqn. 1).

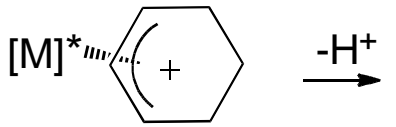

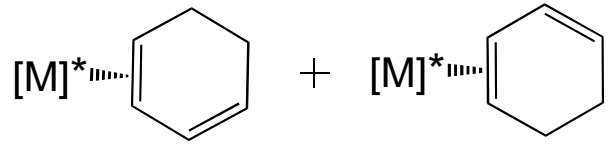

Eqn 1. 


\section{Results and Discussion:}

Examples of $\pi$-allyl complexes undergoing deprotonation to form diene complexes are rare, ${ }^{29}$ especially for cases in which the resulting diene is dihapto-coordinated. However, the allyl complex $\left[\mathrm{TpMo}(\mathrm{NO})(\mathrm{Melm})\left(\pi-\mathrm{C}_{6} \mathrm{H}_{9}\right)\right]^{+}(\mathbf{1})$ has been reported to readily undergo deprotonation $\left(\mathrm{pK}_{\mathrm{a}} \sim 2\right.$ ) to form the corresponding $\eta^{2}$-diene complex (2) as a mixture of coordination diastereomers. ${ }^{9,16}$ We chose for our initial studies to pursue the tungsten analog $\left[\mathrm{TpW}(\mathrm{NO})\left(\mathrm{PMe}_{3}\right)\left(\pi-\mathrm{C}_{6} \mathrm{H}_{9}\right)\right]^{+}$(3) because of its anticipated improved kinetic stability compared to $\mathbf{2}$, and the availability of several related systems featuring an $\eta^{2}$ diene linkage prepared from aromatic precursors (Scheme 2). ${ }^{8,30,31}$
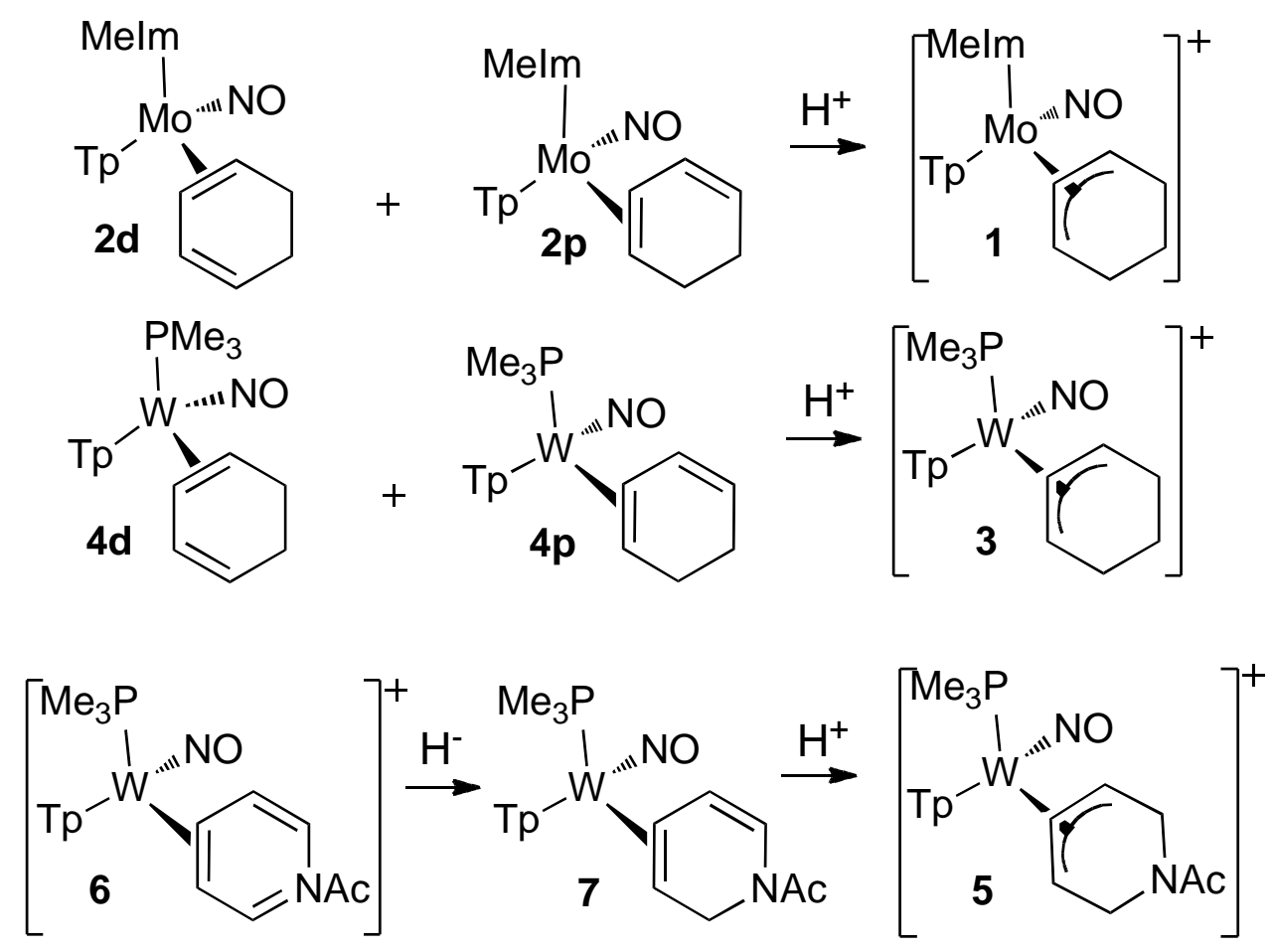

Scheme 2: Synthesis of 6-membered cyclic allyl complexes. 


\section{Stereoselective Preparation of $\eta^{2}$-diene Complexes.}

Our studies commenced with the preparation of the $\eta^{2}$-cyclohexadiene complex $\operatorname{TpW}(\mathrm{NO})\left(\mathrm{PMe}_{3}\right)\left(\eta^{2}-\mathrm{C}_{6} \mathrm{H}_{8}\right)(\mathbf{4 d}, \mathbf{4 p})^{32}$ from its benzene precursor, $\operatorname{TpW}(\mathrm{NO})\left(\mathrm{PMe}_{3}\right)\left(\eta^{2}-\right.$ $\left.\mathrm{C}_{6} \mathrm{H}_{6}\right)$, in $36 \%$ yield as a $1.1: 1$ mixture of coordination diastereomers $(\mathbf{4 d}, \mathbf{4 p}) .{ }^{31,33}$ This diastereomeric mixture of diene complexes was then treated with a solution of triflic acid (HOTf) in acetonitrile (MeCN) to produce the $\pi$-allyl complex $\left[\mathrm{TpW}(\mathrm{NO})\left(\mathrm{PMe}_{3}\right)(\pi\right.$ $\left.\mathrm{C}_{6} \mathrm{H}_{9}\right)$ ]OTf (3). Alternatively, pure compound 3 could be isolated in $61 \%$ yield by collecting the yellow solid that spontaneously precipitated from a one-pot reaction sequence (starting from $\left.\operatorname{TpW}(\mathrm{NO})\left(\mathrm{PMe}_{3}\right)\left(\eta^{2}-\mathrm{C}_{6} \mathrm{H}_{6}\right)\right)$. As with its molybdenum congener $1,{ }^{16}$ the acidity of allyl complex 3 could be estimated ( $\mathrm{pK}_{\mathrm{a}}$ (DMSO) of $\sim 7.0$ ) by observing the reaction of $\mathbf{4}$ with various acids. Treating $\mathbf{3}$ with various amine bases (e.g., 1,8diaza[5.4.0]bicycloundecene (DBU), N,N-diisopropylethylamine (DIEA), 2,6-lutidine, morpholine, aniline) gave dienes $\mathbf{4 d}$ and $\mathbf{4 p}$ in varying ratios. In general, weaker bases gave lower coordination diastereomer ratios (cdr) and stronger bases led to an increased amount of $\mathbf{4 d}(>10: 1)$. The reaction with the non-nucleophilic base $\mathrm{NaH}$ also delivered diene 4 , but in a modest cdr of only 4:1 (d:p). Ultimately, we settled on reaction conditions that incorporated DBU, which gave the highest isolated yield of $91 \%$ $(\mathbf{d r}=10: 1)$. NOE experiments confirmed that the uncoordinated diene in $\mathbf{4 d}$ is distal to the $\mathrm{PMe}_{3}$ group (Scheme 3). Allowing a $\mathrm{CDCl}_{3}$ solution of $\mathbf{4 d}$ to stand at ambient conditions in the presence of $\mathrm{DBUH}^{+}$forms an equilibrium mixture of $1.1: 1(\mathbf{4 d}: \mathbf{4 p})$ over a period of several days $(\Delta G=0.2 \mathrm{kcal} / \mathrm{mol})$. 
Interestingly, ${ }^{31} \mathrm{P}$ and ${ }^{1} \mathrm{H}$ NMR data revealed that immediately after the addition of either DBU or DMAP to allyl 3, a third compound was present in the crude reaction mixture, which converted to $\mathbf{4 d}$ and $\mathbf{4 p}$ over several days. We speculate that these intermediates $(\mathbf{8} \mathbf{a}, \mathbf{8 b})$ are likely to be the addition products shown in Scheme 3, but facile elimination prevented their full characterization. In contrast, the addition of $\mathrm{PMe}_{3}$ to allyl $\mathbf{3}$ generated phosphonium complex $\mathbf{8 c}$ stereoselectively, which was isolated and fully characterized.
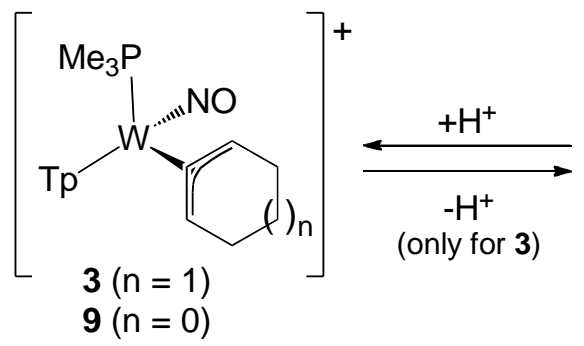

(only for 3 ) $9(\mathrm{n}=0)$

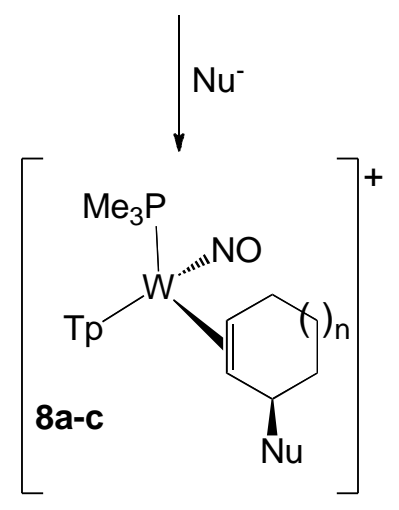

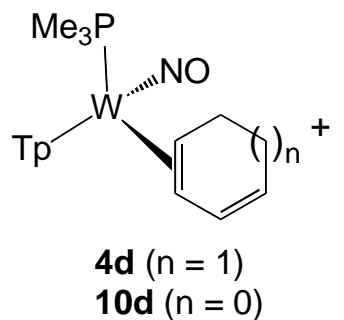

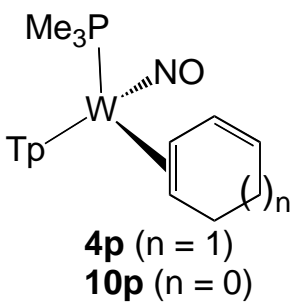

$\mathbf{4 d : 4 p}=10: 1$ (from $\mathbf{3}, \mathbf{8 a}$, or $\mathbf{8 b}$ ) or 1.1:1 at equilibrium

Scheme 3: Stereoselective synthesis of $\eta^{2}$-cyclohexadiene complexes.

Cyclopentadiene also forms a complex with $\left\{\mathrm{TpW}(\mathrm{NO})\left(\mathrm{PMe}_{3}\right)\right\}$ in which the diene is dihapto-coordinated (10). ${ }^{34}$ As with the cyclohexadiene analogs, the initially formed coordination diastereomer ratio of the isolated mixture is low (2.3:1). Protonation of 
this mixture produces a single diastereomer of the allyl complex 9. However, the reaction of 9 with any of the bases mentioned above failed to return any of the cyclopentadiene complex 10 (see Scheme 3). Rather, ${ }^{31}$ P NMR spectroscopic data ( $\delta$ and $J_{\text {WP }}$ ) are consistent with nucleophilic addition products similar to $\mathbf{8 a - c}$, which failed to eliminate even when exposed to $1 \mathrm{M} \mathrm{NaOH}$ (aq). Their identities were not pursued further.

Dihydropyridine complexes of $\left\{\mathrm{TpW}(\mathrm{NO})\left(\mathrm{PMe}_{3}\right)\right\}$ provide another context where a method for the stereoselective formation of $\eta^{2}$-diene complexes could have synthetic implications (see Scheme 1 ), ${ }^{30}$ as a wide variety of such complexes are readily available from the acetylpyridinium complex $6 .^{30,35}$ Protonation of the parent 1-acetyl-1,2dihydropyridine $7 p$ results in the $\pi$-allyl species 5 (Scheme 4). The reaction of the allyl complex $\mathbf{5}$ with a broad range of nucleophiles results exclusively in nucleophilic addition to the allylic carbon distal to the phosphine. ${ }^{35}$ The acid-catalyzed equilibration of $7 \mathbf{p}$ and $\mathbf{7 d}$ provides a 1:1 ratio of these coordination diastereomers (cdr). However, the treatment of allyl $5\left(\mathrm{pK}_{\mathrm{a}} \sim 4.5\right)$ with a variety of bases (e.g., DBU, DIEA, 2,6-lutidine, morpholine) effects deprotonation to form $\mathbf{7 d}$ in preference to $\mathbf{7 p}$. Best results were obtained using morpholine in $\mathrm{MeCN}$, where spontaneous precipitation resulted in analytically pure $\mathbf{7 d}$ ( $d r>20: 1 ; 72 \%$ yield). We speculate that differences in the relative ease of deprotonation for the six-membered allyls (3 and 5) and their five-membered analog (9) is a result of the greater ring-strain encountered for cyclopentadiene compared to its cyclohexyl counterpart. 


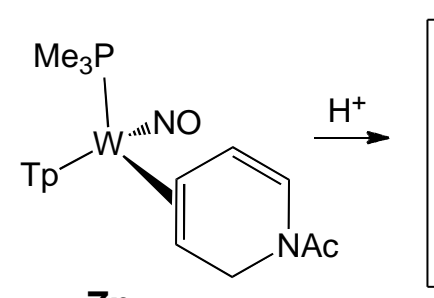

$7 p$

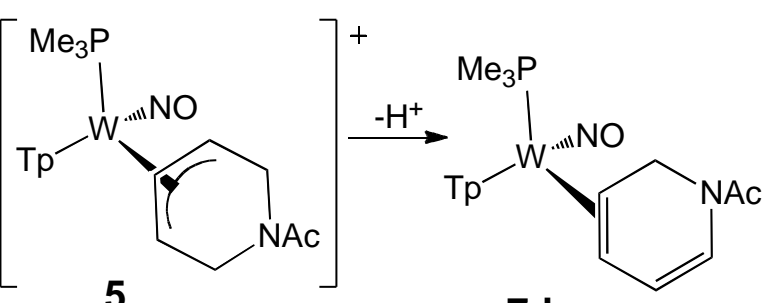

$7 d$

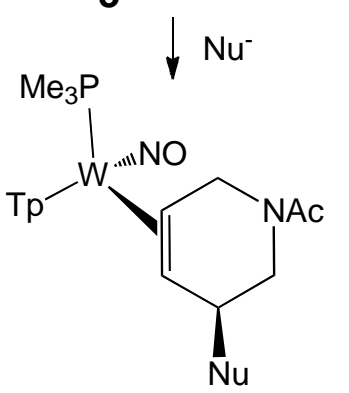

Scheme 4: Synthesis of $\mathbf{5}$ and its stereoselective nucleophilic addition and deprotonation.

\section{Structural Analysis of $\mathrm{TpW}(\mathrm{NO})\left(\mathrm{PMe}_{3}\right)(\pi$-allyl) complexes.}

Given the prominent role of $\pi$-allyl intermediates in $\eta^{2}$-aromatic chemistry, ${ }^{3,4}$ and their potential as synthons for $\eta^{2}$-dienes (vide supra), we sought to understand better the structural features of the $\mathrm{TpW}(\mathrm{NO})\left(\mathrm{PMe}_{3}\right)(\pi$-allyl) complexes. X-ray data were obtained from single crystals of allyl complexes $\mathbf{3}$ and $\mathbf{5}$. The resulting molecular structure determinations reveal that C2 and C3 (Figure 1) are nearly equidistant from the tungsten center (ranging from 2.28-2.31 $\AA$ ), with the W-C1 distance markedly elongated (2.60 ̊̊ for 3; $2.59 \AA$ for 5 ). ${ }^{1} \mathrm{H}$ and ${ }^{13} \mathrm{C}$ NMR spectroscopic data also indicate a stark contrast between the two terminal carbons of the allyl ligand [e.g., for 3 : $\left({ }^{1} \mathrm{H},{ }^{13} \mathrm{C}\right.$ ppm) C3: 4.38, 70.0; C1: 6.59, 138.3], which suggested a buildup of positive charge at the $\mathrm{C} 1$ terminus. Similar structural features were observed for the molybdenum system 1, in which the Mo-C1 bond was determined to be $2.64 \AA$ ( $c f .2 .33 \AA$ for $\mathrm{C} 2$ and $\mathrm{C} 3$ ). ${ }^{9}$ In 
Figure $1 \mathrm{~W}$-C distances of the $\pi$-allyl complexes $(3,5)$ are compared to the limiting case of the $\eta^{2}$-bound dihydropyridine $\mathbf{7 d}$ in which bonding to the allylic carbon would be considered non-existent.
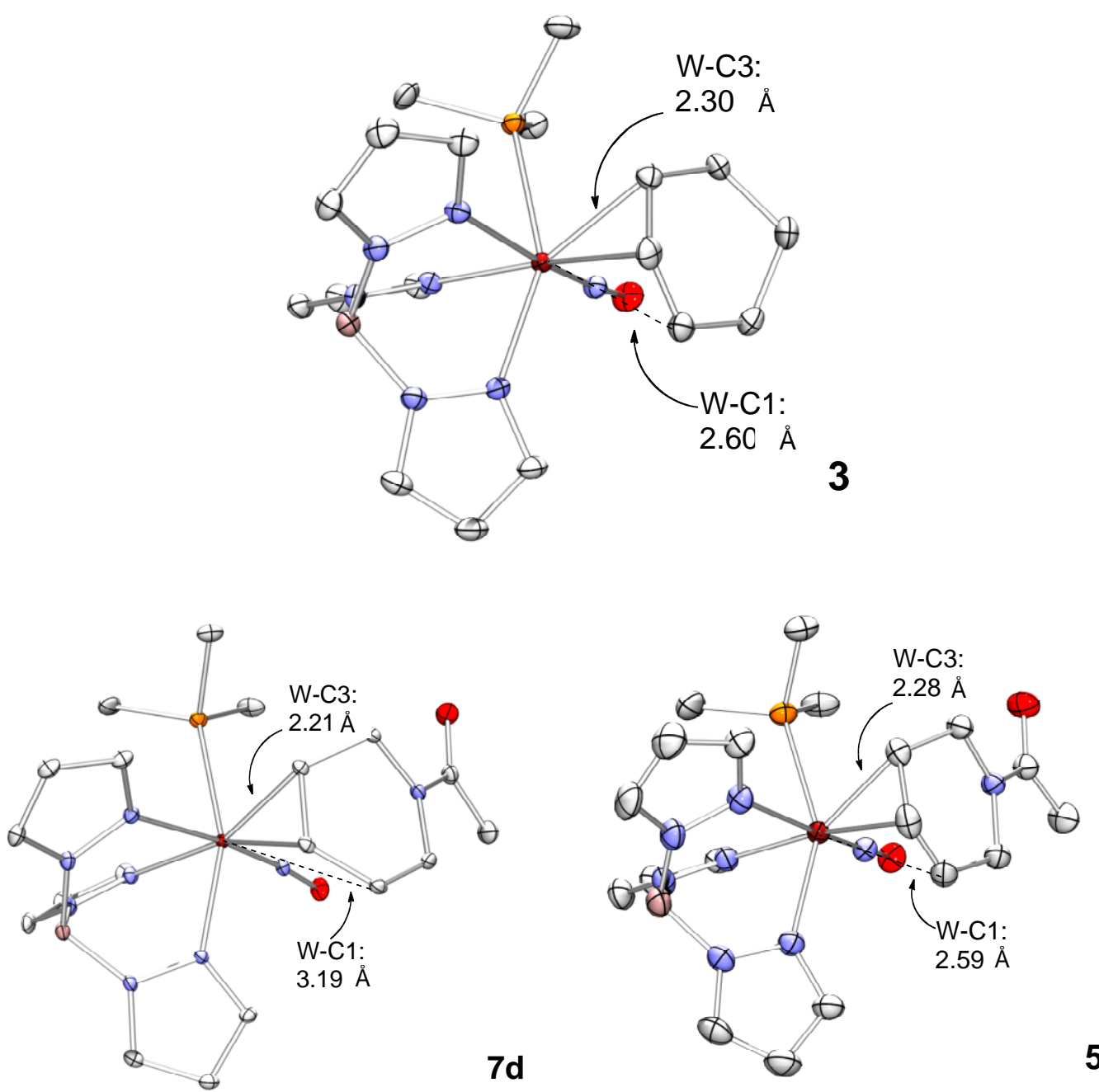

Figure 1: ORTEP diagrams (30\% probability) for allyl complexes $\left[\mathrm{TpW}(\mathrm{NO})\left(\mathrm{PMe}_{3}\right)(\pi-\right.$

$\left.\left.\mathrm{C}_{6} \mathrm{H}_{9}\right)\right] \mathrm{OTf}, \mathbf{3}$, and [TpW(NO) $\left.\left(\mathrm{PMe}_{3}\right)\left(\pi-\mathrm{C}_{7} \mathrm{H}_{10} \mathrm{NO}\right)\right] \mathrm{OTf}, \mathbf{5}$, showing $\eta^{3} \rightarrow \eta^{2}$ distortion (OTf omitted), and the dihydropyridine complex $\operatorname{TpW}(\mathrm{NO})\left(\mathrm{PMe}_{3}\right)\left(\eta^{2}-\mathrm{C}_{7} \mathrm{H}_{9} \mathrm{NO}\right), \mathbf{7 d}$, for comparison. See Table 1 for additional pertinent bond distances. 
While other groups have documented " $\sigma-\pi$ " or " $\eta^{3} \rightarrow \eta^{2 \text { " } \pi \text {-allyl complexes, }}$, ${ }^{28,36-39}$ differences between the $\mathrm{M}-\mathrm{C}$ bond lengths of the terminal allylic carbons in these species tend to be less than $0.2 \AA$. Yet, Legzdins et al. have observed more significant deviations in complexes of the form $\mathrm{Cp} * \mathrm{~W}(\mathrm{NO})(\mathrm{R})\left(\pi-\mathrm{CH}_{2} \mathrm{CHC}(\mathrm{Me})_{2}\right) .{ }^{36,39}$ The authors attribute the unusually large distortions (e.g., $\mathrm{R}=\mathrm{CH}_{2} \mathrm{TMS}, \Delta=0.69 \AA$ ) to steric factors. $^{39}$ The $\sigma-\pi$ distortion formalism describes the metal as forming a sigma bond with one terminal carbon (C3), and a dative bond with the remaining two carbons of the allyl ligand $(C 2=C 1)$. Of course, the closely related $\left\{\mathrm{TpW}(\mathrm{NO})\left(\mathrm{PMe}_{3}\right)\right\}$ systems could also be described this way (Eqn 2).

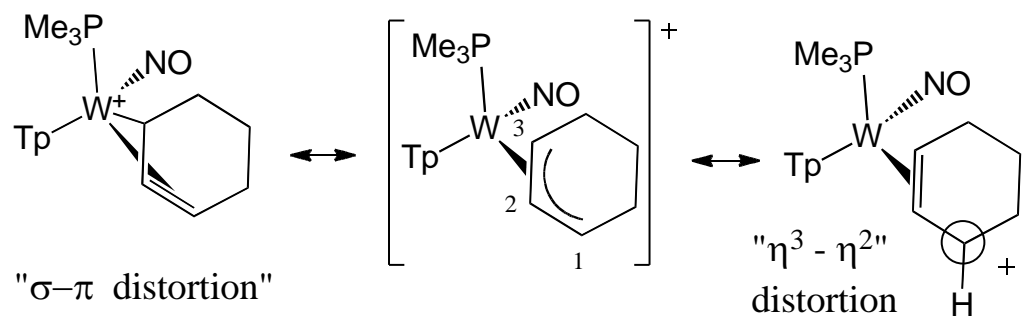

Eqn 2.

However, the alternative representation of a $W(0)$ center with an $\eta^{2}$-distorted allyl cation is appealing as it readily provides a foundation for the observed reactivity with nucleophiles and bases as well as for the observed structural and spectroscopic features. For example, the W-C2 (2.30 $)$ and W-C3 (2.31 $\AA$ ) bond lengths of 3 or $\mathbf{5}$ are virtually identical, and are only $0.05 \AA$ longer than typical alkene complexes of the form $\mathrm{TpW}(\mathrm{NO})\left(\mathrm{PMe}_{3}\right)(\mathrm{L})$ (e.g., $\mathrm{L}=$ cyclopentene) or for the diene complex 7p (Figure 1); the C2-C3 bond distance of $1.43 \AA$ is also in the range of typical alkene complexes of the $\left\{\mathrm{TpW}(\mathrm{NO})\left(\mathrm{PMe}_{3}\right)\right\}$ system. ${ }^{8,18,40}$ Most significantly, the purported cationic character of 
the $\mathrm{C} 1$ terminus in $\mathbf{3}$ and $\mathbf{5}$ provides a convenient rationale for the observed stereoselectivity of the deprotonation reaction (Eqn 3). ${ }^{41}$

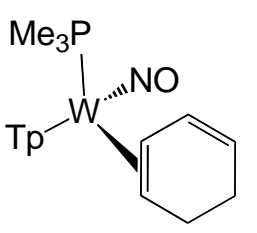

4p (disfavored)

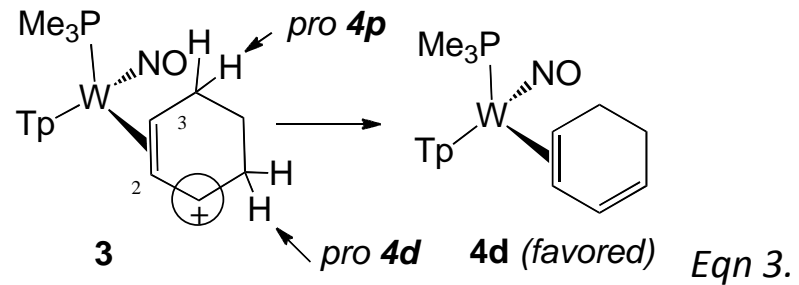

Eqn 3.

If the $\eta^{3} \rightarrow \eta^{2}$ distortion is directly correlated to the cationic character at $\mathrm{C} 1$, then it stands to reason that the $\eta^{3} \rightarrow \eta^{2}$ distortion should be strongly influenced by substituents of $\mathrm{C} 1$ that can stabilize carbocation character. Thus, the addition of alkyl groups would be expected to enhance the allyl distortion. As a means of testing this hypothesis, the parent $\pi$-allyl complex 11 and an alkylated variant $\mathbf{1 2}$ were synthesized. The parent allyl 11 was generated from $\mathrm{TpW}(\mathrm{NO})\left(\mathrm{PMe}_{3}\right)\left(\eta^{2}\right.$-benzene) and diallyl ether, while the trimethylated allyl 12 was prepared using 2,3-dimethylbutadiene (Scheme 5). In both cases these allyl complexes exist in solution as mixtures of two diastereomers (vide infra), in which the allyl group opens out toward (exo) or away (endo) from the nitrosyl. No chemical exchange was observed for the two isomers of $\mathbf{1 1}$ or $\mathbf{1 2}$ in NOESY experiments, and heating solutions of these complexes to $102{ }^{\circ} \mathrm{C}\left(\mathrm{DMF}-\mathrm{d}_{7}\right)$ failed to alter the shape of the signals for the two isomers, indicating a high exo/endo isomerization barrier. However, allowing a sample to stand $\left(12 \mathrm{~h}, 20^{\circ} \mathrm{C}\right)$ resulted in a shift in the ratio of isomers to favor the more bulky dimethylbutyl analog (12) from an initial ratio of 1:1 to an equilibrium value of about 2:1 favoring the exo-12 isomer. 
Crystals of 11 and 12 suitable for X-ray analysis were grown, and their molecular structures were determined (Figure 2). Interestingly, in both the case of $\mathbf{1 1}$ and 12, the exo and endo isomers co-crystallize, with a common location for C3 for each isomer.

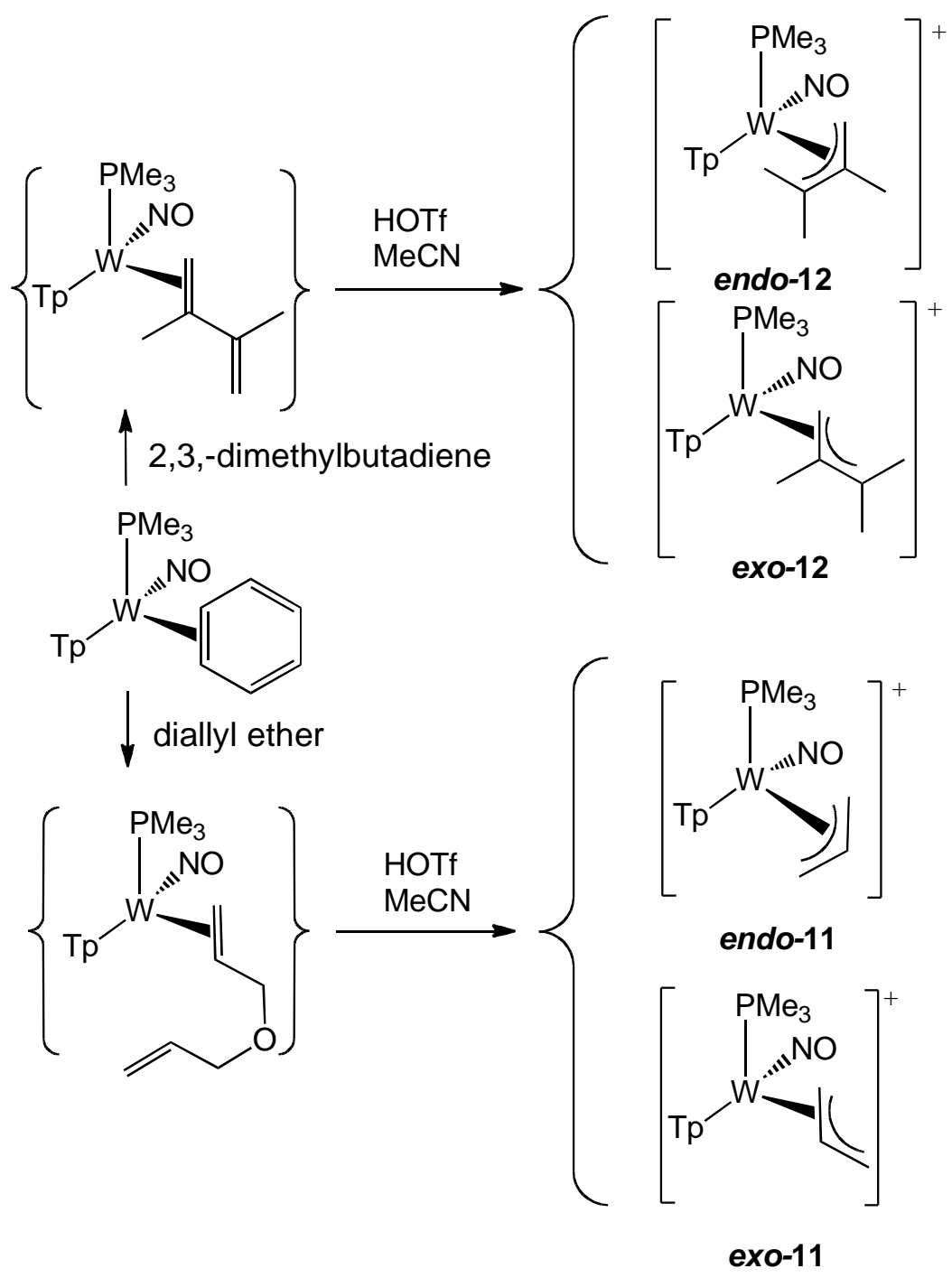

Scheme 5: Synthesis of allyl complexes 11 and 12.

Observed bond lengths and calculated values for the allyl complexes $\mathbf{3 , 5}, \mathbf{1 1}$, and 12 are presented in Table 1. For comparison, complexes where $L=2 H-m$-cresol (13) and 
$\mathrm{L}=2 \mathrm{H}-(\mathrm{N}, \mathrm{N}$-dimethyl)anilinium (14) are included, as these represent the limiting cases of an amino or oxo group as the $\pi$-donors conjugated to an allyl system. In addition, $L=$ 1,2-dihydro- $N$-acetylpyridine (7p) is included as a limiting case of an $\eta^{2}$-diene.

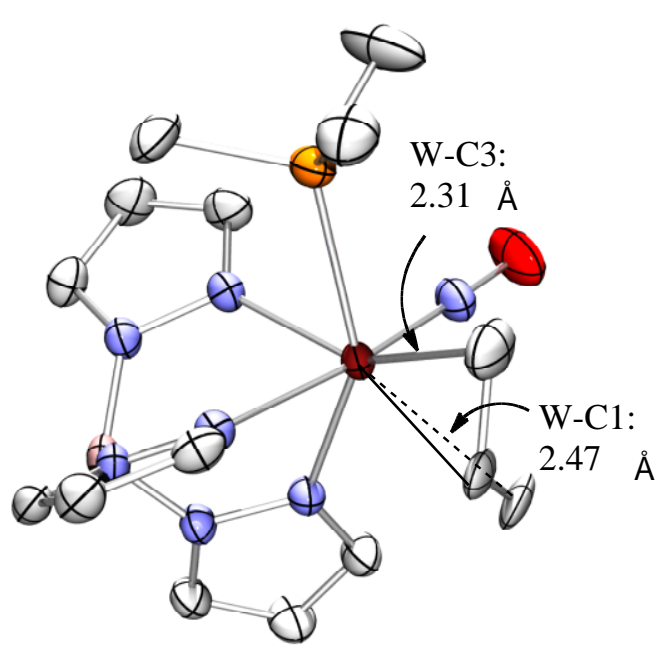

exo-11

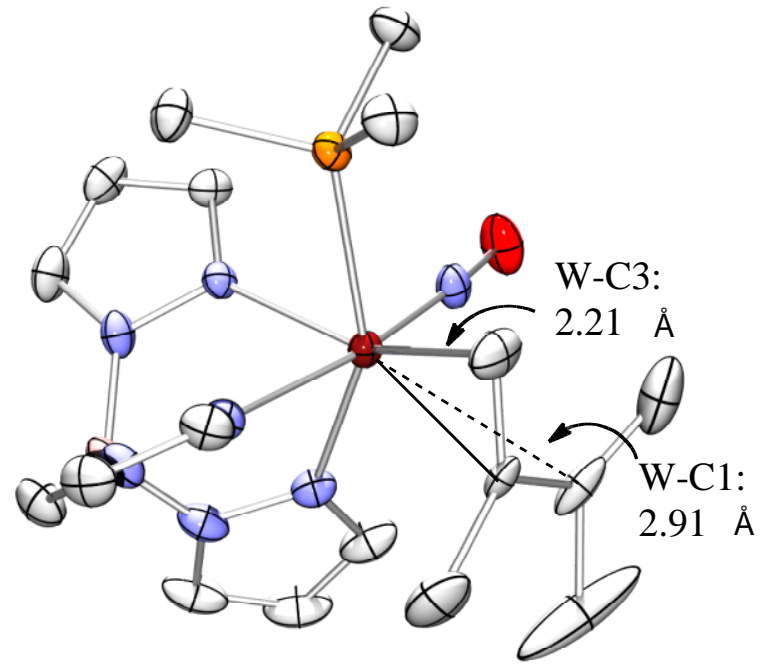

exo-12

Figure 2: ORTEP diagrams (30\% probability) of $\left[\mathrm{TpW}(\mathrm{NO})\left(\mathrm{PMe}_{3}\right)\left(\pi-\mathrm{C}_{3} \mathrm{H}_{5}\right)\right] \mathrm{OTf}$, exo-11, and $\left[\mathrm{TpW}(\mathrm{NO})\left(\mathrm{PMe}_{3}\right)\left(\pi-\mathrm{C}_{6} \mathrm{H}_{11}\right)\right] \mathrm{OTf}$, exo-12. See Table 1 for pertinent bond distances.

For the parent allyl (i.e., no C1 substituents; 11), the exo W-C1 bond length is $2.47 \AA$. When a single alkyl group is attached to $\mathrm{C} 1$, the exo $\mathrm{W}-\mathrm{C} 1$ bond length increases to $2.59 \AA$ and $2.60 \AA$, for $\mathbf{5}$ and 3, respectively. With two alkyl groups at C1 in $\mathbf{1 2}$, the WC1 bond lengthens to $2.91 \AA$ for the exo isomer. Note that this is only $0.3 \AA$ less than what is observed for dihydropyridine 7p (3.19 $\AA$ ), $13\left(\mathrm{~L}=2 \mathrm{H}-\mathrm{m}\right.$-cresol $(3.15 \AA),{ }^{42}$ or 14 ( $\mathrm{L}=\mathrm{N}, \mathrm{N}$-dimethyl-2H-anilinium $(3.14 \AA),{ }^{43}$ where the metal is considered to interact solely with the alkene portion of the ring (Figure 3). The increase in W-C1 bond length 
indicates less interaction of the metal with the allyl ligand, as the number of alkyl groups attached to the distended carbon increases from 0 to 2 . It is tempting to attribute these enhanced distortions to steric factors, but we believe that hyperconjugation plays an important role, as only minimal distortions (0.05-0.19 $\AA$ ) are observed for the related Tp systems $\operatorname{TpMo}(\mathrm{CO})_{2}(\pi \text {-allylR })^{37,44}$ and $\operatorname{TpW}(\mathrm{CO})_{2}(\pi \text {-allyIR })^{38}$ where $\mathrm{R}$ is not a $\pi$ donor. Additional evidence is found in the increased back-donation to the nitrosyl ligand as the number of alkyl substituents for $C 1$ increases from 0 to $2\left(v_{\mathrm{NO}}=1647 \mathrm{~cm}^{-1}(\mathbf{1 1}), 1635 \mathrm{~cm}^{-}\right.$ $\left.{ }^{1}(3), 1624 \mathrm{~cm}^{-1}(12)\right)$.

Table 1: Experimental and [calculated] bond lengths for $\eta^{3}$-allyl and $\eta^{2}$-alkene complexes of the form $\mathrm{TpW}(\mathrm{NO})\left(\mathrm{PMe}_{3}\right)(\mathrm{L})$. Calculated values are in brackets $(\Delta=(\mathrm{W}-\mathrm{C} 1)$ $(\mathrm{W}-\mathrm{C} 3))$.

\begin{tabular}{|c|c|c|c|c|c|c|}
\hline Compound, (L) & $\mathrm{W}-\mathrm{C} 1, \AA$ & $\mathrm{W}-\mathrm{C} 2, \AA$ & $\mathrm{W}-\mathrm{C} 3, \AA$ & $\Delta, \AA$ & $\mathrm{C} 1-\mathrm{C} 2, \AA$ & $\mathrm{C} 2-\mathrm{C} 3, \AA$ \\
\hline exo-11 $\left(\mathrm{C}_{3} \mathrm{H}_{5}^{+}\right)$ & $\begin{array}{l}2.47 \\
{[2.53]}\end{array}$ & $\begin{array}{l}2.38 \\
{[2.38]}\end{array}$ & $\begin{array}{l}2.31 \\
{[2.33]}\end{array}$ & $\begin{array}{l}0.16 \\
{[0.20]}\end{array}$ & $\begin{array}{l}1.32 \\
{[1.38]}\end{array}$ & $\begin{array}{l}1.43 \\
{[1.42]}\end{array}$ \\
\hline exo-3 $\left(\mathrm{C}_{6} \mathrm{H}_{9}{ }^{+}\right)$ & $\begin{array}{l}2.60 \\
{[2.72]}\end{array}$ & $\begin{array}{l}2.30 \\
{[2.33]}\end{array}$ & $\begin{array}{l}2.31 \\
{[2.31]}\end{array}$ & $\begin{array}{l}0.29 \\
{[0.41]}\end{array}$ & $\begin{array}{l}1.38 \\
{[1.38]}\end{array}$ & $\begin{array}{l}1.43 \\
{[1.44]}\end{array}$ \\
\hline $\begin{array}{l}\text { exo-5 } \\
\left(\mathrm{C}_{7} \mathrm{H}_{10} \mathrm{NO}^{+}\right)\end{array}$ & $\begin{array}{l}2.59 \\
{[2.72]}\end{array}$ & $\begin{array}{l}2.29 \\
{[2.34]}\end{array}$ & $\begin{array}{l}2.28 \\
{[2.28]}\end{array}$ & $\begin{array}{l}0.31 \\
{[0.44]}\end{array}$ & $\begin{array}{l}1.36 \\
{[1.38]}\end{array}$ & $\begin{array}{l}1.43 \\
{[1.44]}\end{array}$ \\
\hline exo-12 $\left(\mathrm{C}_{6} \mathrm{H}_{11}{ }^{+}\right)$ & $\begin{array}{l}2.91 \\
{[3.01]}\end{array}$ & $\begin{array}{l}2.40 \\
{[2.45]}\end{array}$ & $\begin{array}{l}2.21 \\
{[2.21]}\end{array}$ & $\begin{array}{l}0.70 \\
{[0.80]}\end{array}$ & $\begin{array}{l}1.39 \\
{[1.39]}\end{array}$ & $\begin{array}{l}1.47 \\
{[1.47]}\end{array}$ \\
\hline $\begin{array}{l}\text { exo-18 }(p- \\
\left.\mathrm{C}_{7} \mathrm{H}_{9} \mathrm{O}^{+}\right)\end{array}$ & [3.04] & {$[2.40]$} & {$[2.23]$} & {$[0.81]$} & [1.38] & {$[1.46]$} \\
\hline $\begin{array}{l}\text { exo-14 } \\
\left(\mathrm{C}_{8} \mathrm{H}_{12} \mathrm{~N}^{+}\right)\end{array}$ & $\begin{array}{l}3.11 \\
{[3.17]}\end{array}$ & $\begin{array}{l}2.26 \\
{[2.30]}\end{array}$ & $\begin{array}{l}2.23 \\
{[2.24]}\end{array}$ & $\begin{array}{l}0.88 \\
{[0.93]}\end{array}$ & $\begin{array}{l}1.42 \\
{[1.42]}\end{array}$ & $\begin{array}{l}1.45 \\
{[1.47]}\end{array}$ \\
\hline $\begin{array}{l}\text { exo-13 }(m- \\
\left.\mathrm{C}_{7} \mathrm{H}_{9} \mathrm{O}\right)\end{array}$ & $\begin{array}{l}3.15 \\
{[3.19]}\end{array}$ & $\begin{array}{l}2.21 \\
{[2.24]}\end{array}$ & $\begin{array}{l}2.23 \\
{[2.28]}\end{array}$ & $\begin{array}{l}0.92 \\
{[0.91]}\end{array}$ & $\begin{array}{l}1.45 \\
{[1.47]}\end{array}$ & $\begin{array}{l}1.45 \\
{[1.45]}\end{array}$ \\
\hline
\end{tabular}




\begin{tabular}{lllllll} 
exo-7d & 3.19 & 2.22 & 2.21 & 0.98 & 1.46 & 1.45 \\
$\left(\mathrm{C}_{7} \mathrm{H}_{9} \mathrm{NO}\right)$ & {$[3.23]$} & {$[2.25]$} & {$[2.24]$} & {$[0.99]$} & {$[1.47]$} & {$[1.45]$} \\
\hline endo-11 & 2.43 & 2.35 & 2.31 & 0.12 & 1.37 & 1.46 \\
$\left(\mathrm{C}_{3} \mathrm{H}_{5}^{+}\right)$ & {$[2.48]$} & {$[2.41]$} & {$[2.33]$} & {$[0.15]$} & {$[1.38]$} & {$[1.42]$} \\
& & & & & & \\
endo-12 & 2.77 & 2.45 & 2.21 & 0.56 & 1.30 & 1.54 \\
$\left(\mathrm{C}_{6} \mathrm{H}_{11}^{+}\right)$ & {$[2.97]$} & {$[2.50]$} & {$[2.22]$} & {$[0.75]$} & {$[1.39]$} & {$[1.46]$} \\
\hline
\end{tabular}

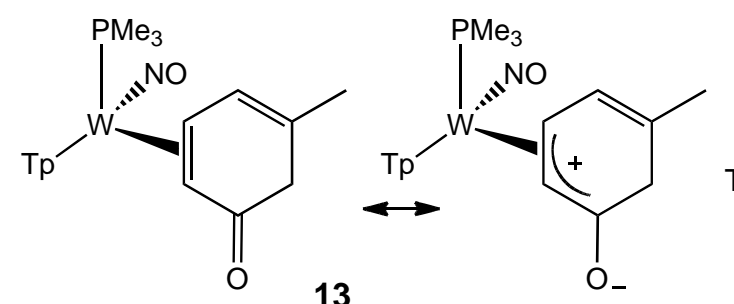

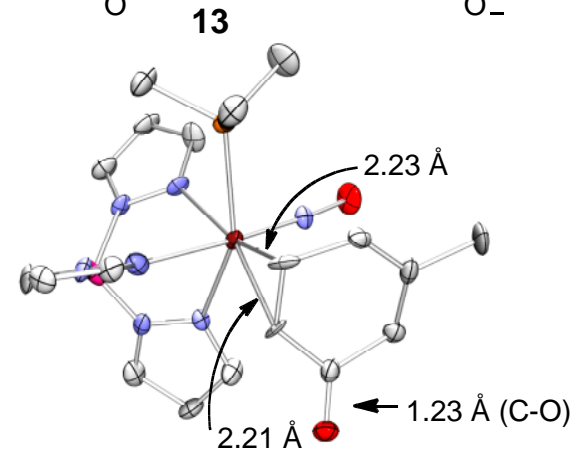

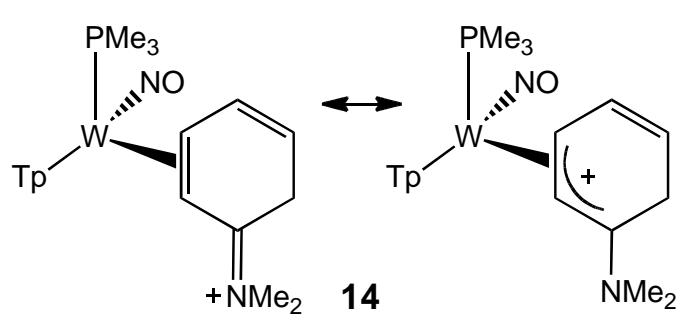

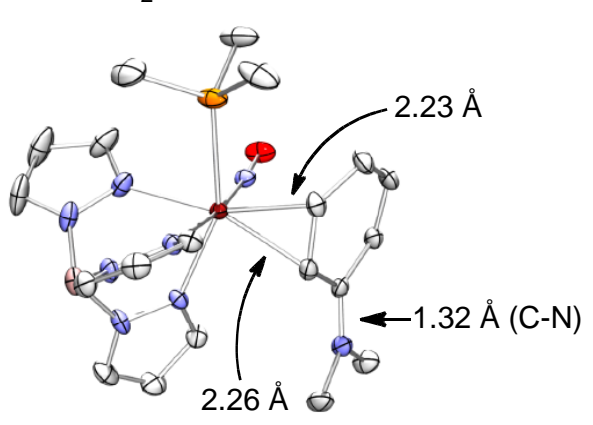

Figure 3: The resonance forms and crystal structures (30\% ellipsoids) of $2 \mathrm{H}$ - $\mathrm{m}$-cresol $(\mathbf{1 3})^{42}$ and $\mathrm{N}, \mathrm{N}$-dimethyl-2H-anilinium $(\mathbf{1 4})^{43}$ complexes.

A particularly interesting illustration of the ability of alkyl groups to enhance $\eta^{3} \rightarrow \eta^{2}$ allyl distortion through hyperconjugation was earlier documented in protonation studies of alkylated benzenes bound to pentaammineosmium(II). ${ }^{45}$ Whereas protonation of benzene in the complex $\left[\mathrm{Os}\left(\mathrm{NH}_{3}\right)_{5}\left(\eta^{2} \text {-benzene }\right)\right]^{2+}(\mathrm{Scheme} 6)$ results in an $\eta^{3}$-benzenium complex (15) with carbon resonances typical of symmetrical allyl 
species of this metal fragment, protonation of the analogous $m$-xylene complex $\left(-40{ }^{\circ} \mathrm{C}\right)$ forms complex 16 with carbon resonances reminiscent of the type of $\eta^{2}$-allyl systems described herein. ${ }^{45}$
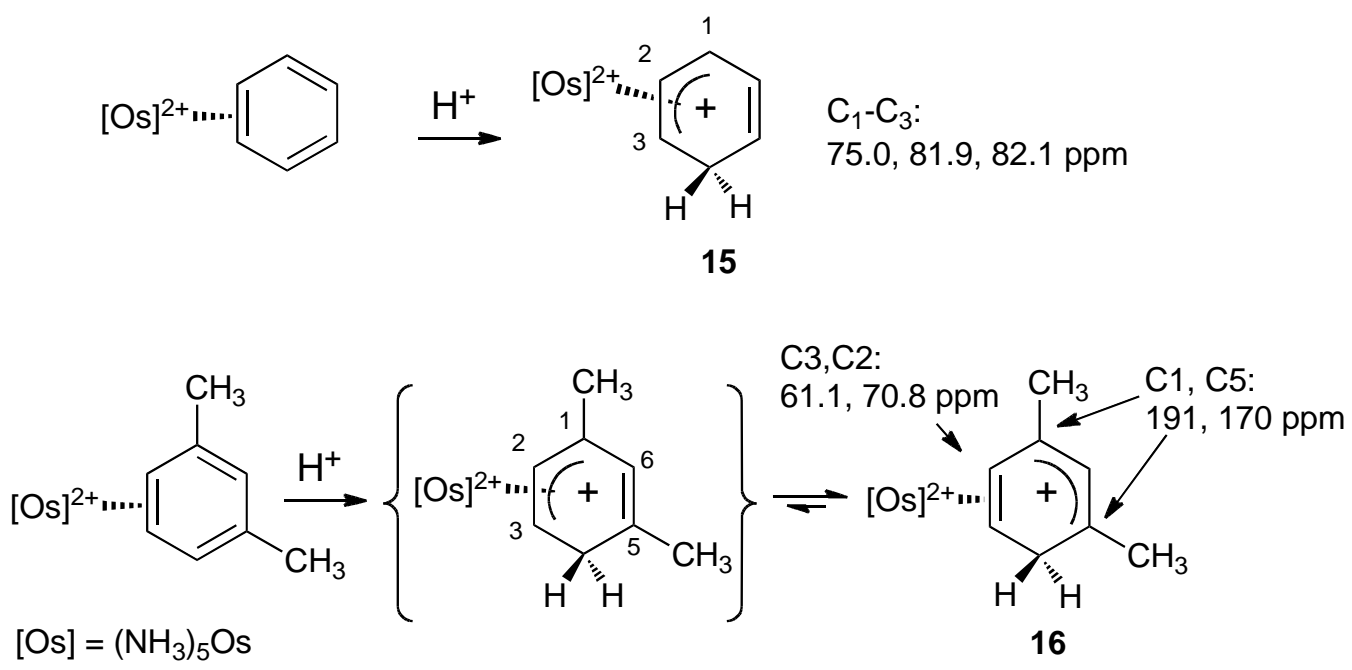

Scheme 6: Protonation and ${ }^{13} \mathrm{C}$ NMR chemical shift data for arenium complexes of osmium.

Protonation at the meta carbon of the para-cresol ligand of $\left\{\mathrm{TpW}(\mathrm{NO})\left(\mathrm{PMe}_{3}\right)(p\right.$ cresol)\} (17) results in an allyl species, 18. In this complex, there is an incentive to keep C3 $\mathrm{sp}^{2}$ hybridized, thus allowing for good interaction of the $\pi$-acidic carbonyl and the $\pi$ basic $W(0)$ center. This runs counter to the notion of a $\sigma-\pi$ distortion (18B in Eqn 4), since $\mathrm{C3}$, which would be considered to form the $\sigma$ bond, would take on $\mathrm{sp}^{3}$ character, and thus, isolate the carbonyl $\pi$ system. Infrared data ( $v_{\mathrm{CO}}$ and $v_{\mathrm{NO}}$ overlap, but are between $1610-1660 \mathrm{~cm}^{-1}$ ) indicate that there is still a significant $\pi$-interaction of the metal with the carbonyl group (c.f. in $17 v_{\mathrm{CO}}$ is $1620 \mathrm{~cm}^{-1}$; a typical carbonyl stretch is 
$\left.\sim 1700 \mathrm{~cm}^{-1}\right)$. Furthermore, $\mathrm{C} 1$ of $18(184.1 \mathrm{ppm})$ is even more deshielded than for the dimethylbutadiene-derived allyl 12 (endo: 176.8 ppm exo: 152.8 ppm). These data, along with DFT calculations (vide infra) indicate a lengthening of the W-C1 bond in $\mathbf{1 8}$ to greater than $3 \AA$ (Table 1), which supports the notion that $\mathbf{1 8}$ is most accurately described as an $\eta^{2}$-allyl complex (resonance contributor 18A in Eqn 4).
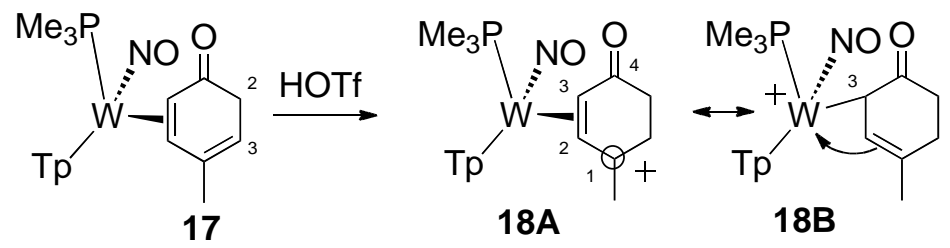

C1: $184.1 \mathrm{ppm}$
C2: $96.9 \mathrm{ppm}$
C3: $73.1 \mathrm{ppm}$
C4: $201.2 \mathrm{ppm}$
(OTf- not shown) Eqn 4.

\section{Calculations.}

In their pioneering studies, Hoffman, Faller, et al. $^{24}$ and later Curtis and Eisenstein, ${ }^{46}$ described how orbital interactions can be used to rationalize regiochemical preferences of nucleophilic addition to asymmetric Mo(II) allyl(-1) complexes. Templeton, Pregosin, et al. ${ }^{38}$ investigated similar orbital interactions in order to understand allyl orientations for the related system $\left\{\mathrm{TpW}^{\prime \prime}(\mathrm{CO})_{2}(\pi\right.$-allyl)\}. To better understand the origins of this $\eta^{3} \rightarrow \eta^{2}$ distortion for the $\left\{\mathrm{TpW}(\mathrm{NO})\left(\mathrm{PMe}_{3}\right)\right\}$ complexes reported herein, we embarked on a series of DFT studies using the B3LYP method using a "hybrid" basis set with the LANL2DZ pseudopotential and basis set on $\mathrm{W}$ and 6-31G(d) on all other atoms. As Table 1 shows, computed bond lengths in the B3LYP/hybrid model are in semi-quantitative agreement with those derived from X-ray analysis. Specifically, the shortest $\mathrm{M}-\mathrm{C}$ bonds are to $\mathrm{C} 3$ in all cases, most markedly so for the $\mathrm{C}_{6} \mathrm{H}_{11}{ }^{+}$ligand. The calculated W-C1 distances are considerably longer than what is indicated by X-ray 
data, especially for the substituted allyl ions. The W-C3 and W-C2 distances support the notion that the $\eta^{2}$ coordination is unsymmetrical. This asymmetry is slightly overestimated in the computed structures. In all cases, W-C and C-C bond lengths for the bound allyl fragment of the calculated compounds are semi-quantitatively reproduced (Table 1) for both endo and exo isomers. The most serious errors are the over-estimates of the W-C distances, by up to $0.12 \AA$ (4\%).

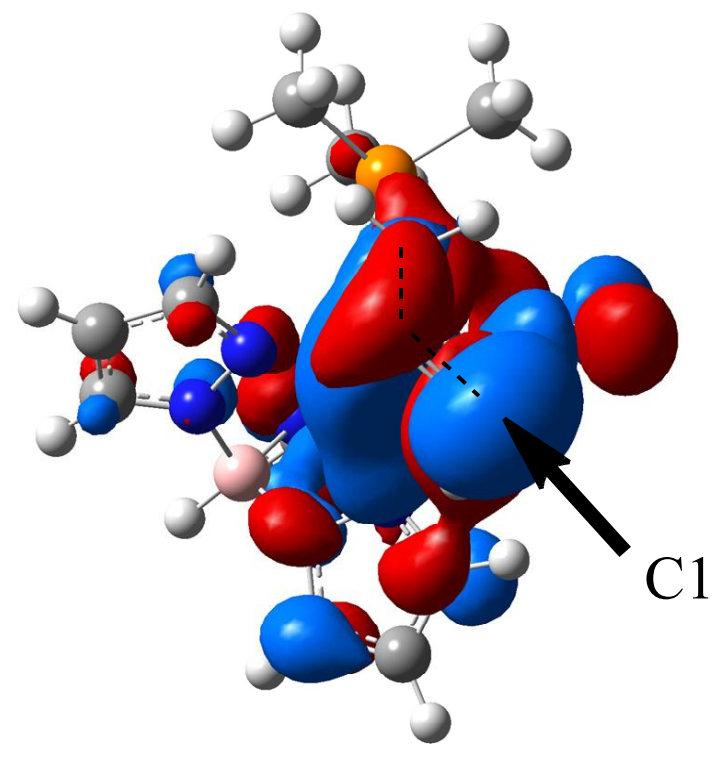

Figure 4: LUMO for the complex $\left[\mathrm{TpW}(\mathrm{NO})\left(\mathrm{PMe}_{3}\right)\left(\text { exo- } \mathrm{C}_{3} \mathrm{H}_{5}\right)\right]^{+}($exo-11a) showing the large contribution from the $2 \mathrm{p}$ orbital of $\mathrm{C} 1$.

The isomer of 12 with an exo orientation of the $\mathrm{C}_{6} \mathrm{H}_{11}{ }^{+}$ligand is calculated to be favored by $1-2 \mathrm{kcal} / \mathrm{mol}$ over the endo isomer, and exo and endo isomers differ by a similar amount for the unsubstituted allyl complex 11. In contrast, the exo-3 isomer is favored over endo-3 by about $10 \mathrm{kcal} / \mathrm{mol}$. Inspection of the computed structure of endo-3 reveals a large steric repulsion between one of the Tp pyrazole rings and that of 
the cyclohexane-based ligand. Supporting the notion that the allyl complexes have carbocation character at $\mathrm{C} 1$, all of the DFT calculations suggest substantial $2 p$ character localized on C1 of the LUMO. The LUMO of exo-11 is shown in Figure 4 as an example.

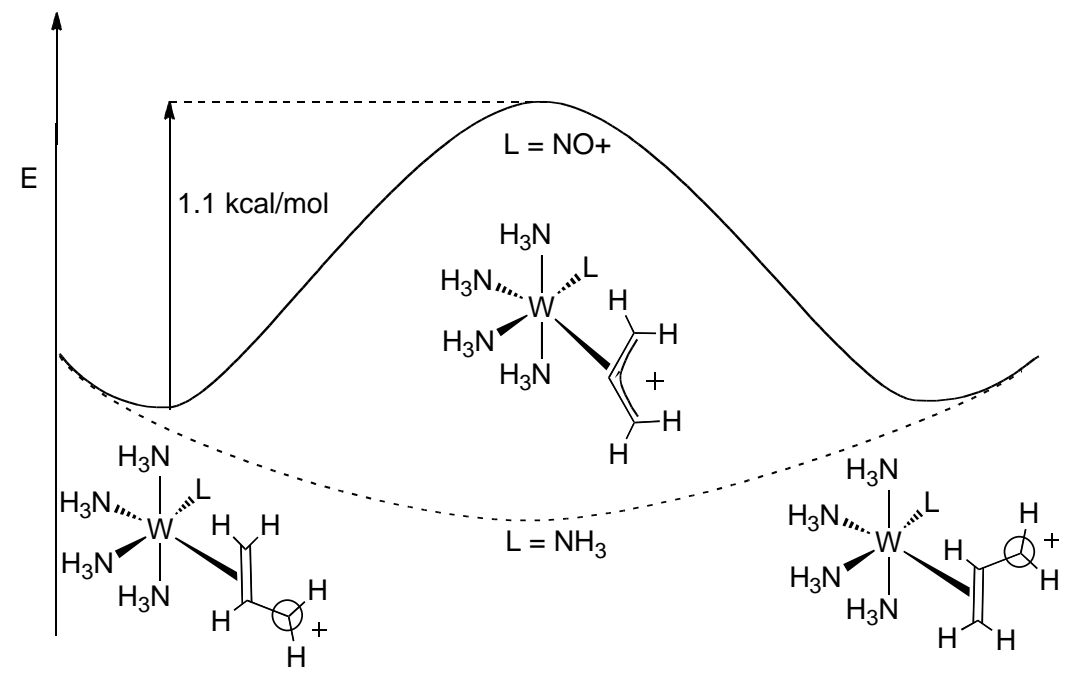

Figure 5: Reaction coordinate diagram for allyl cation isomerization in the complex

$$
\left[\mathrm{W}\left(\mathrm{NH}_{3}\right)_{5-n}(\mathrm{NO})_{n}\left(\mathrm{C}_{3} \mathrm{H}_{5}\right)\right]^{(\mathrm{n}+1)+} \text {, where } \mathrm{n}=0,1 \text {. }
$$

In order to better understand what causes the $\eta^{3} \rightarrow \eta^{2}$ distortion for complexes of $\left\{\mathrm{TpW}(\mathrm{NO})\left(\mathrm{PMe}_{3}\right)\right\}$, we first considered the hypothetical complex $\left[\mathrm{W}\left(\mathrm{NH}_{3}\right)_{5}\left(\pi-\mathrm{C}_{3} \mathrm{H}_{5}\right)\right]^{+}$, which is isoelectronic to the previously reported $\left[\mathrm{Os}\left(\mathrm{NH}_{3}\right)_{5}(\pi \text {-allyl) }]^{3+}\right.$ systems. ${ }^{47}$ DFT calculations reveal that, as was observed for the osmium species, ${ }^{47}$ the tungsten allyl complex is completely symmetrical, with $\mathrm{W}-\mathrm{C} 1$ and $\mathrm{W}-\mathrm{C} 3$ bond lengths of $2.23 \AA$, somewhat longer than the calculated $\mathrm{W}-\mathrm{C} 2$ bond length of $2.16 \AA$. When a nitrosyl ligand replaces one of the cis ammines, its strong backbonding interaction with the metal drives two of the $\pi$-symmetry tungsten orbitals lower in energy, leaving only the 
$\mathrm{d}_{\mathrm{xy}}$ (where the W-NO bond is along the $\mathrm{z}$ axis) to interact with the allyl fragment. For cis$\left\{\mathrm{W}\left(\mathrm{NH}_{3}\right)_{4}(\mathrm{NO})\left(\pi-\mathrm{C}_{3} \mathrm{H}_{5}\right)\right\}^{2+}$, the considerable $\eta^{3} \rightarrow \eta^{2}$ distortion $(\mathrm{W}-\mathrm{C} 3=2.34 \AA$, $\mathrm{W}-\mathrm{C} 1=$ $2.57 \AA$ A) cannot be attributed to asymmetry in the ligand set. In fact, the symmetryconstrained $C_{s}$ allyl complex is a transition state with a kinetic barrier lying $1.1 \mathrm{kcal} / \mathrm{mol}$ above the two symmetrically equivalent distorted forms (Figure 5).

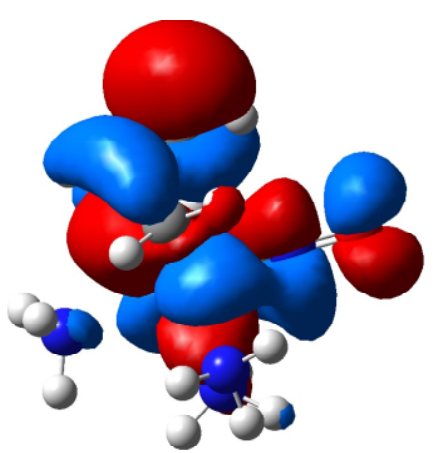

LUMO

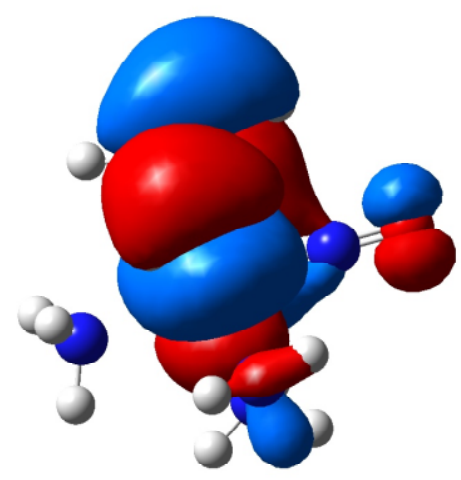

HOMO-2

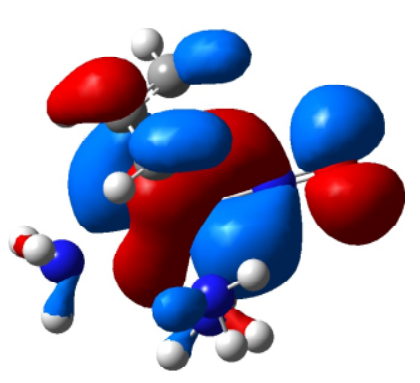

HOMO-1

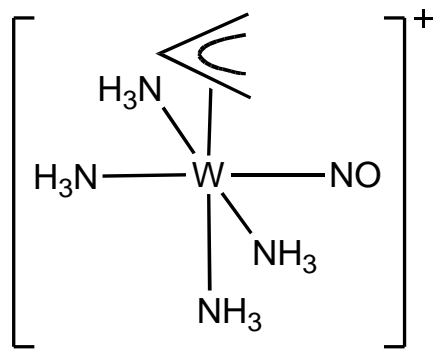

Figure 6: Molecular orbitals for the allyl complex $\left[\mathrm{W}\left(\mathrm{NH}_{3}\right)_{4}(\mathrm{NO})\left(\mathrm{C}_{3} \mathrm{H}_{5}\right)\right]^{2+}$.

As with the $\left\{\mathrm{TpW}(\mathrm{NO})\left(\mathrm{PMe}_{3}\right)\right\}$ analog, the LUMO of the complex $\left[\mathrm{W}\left(\mathrm{NH}_{3}\right)_{4}(\mathrm{NO})(\pi-\right.$ $\left.\left.\mathrm{C}_{3} \mathrm{H}_{5}\right)\right]^{2+}$ has a large $2 p$ component at the terminal carbon (C1) farthest from the metal (Figure 6). The highest occupied and subjacent MOs are dominated by W-NO local $\pi$ 
interactions, and the HOMO-2 displays the strong mixing of the high energy $W d_{x y}$ atomic orbital (AO) with the $\pi$ non-bonding orbital of the allyl cation. Significantly, the allyl distortion allows a stabilizing admixture of the allyl $\pi^{*}$ with the $W d_{x y} A O$ in accordance with Figure 7. When the $\mathrm{C}_{3} \mathrm{H}_{5}{ }^{+}$allyl ligand in Figure 7 is replaced with $\mathrm{C}_{6} \mathrm{H}_{9}{ }^{+}$ and $\mathrm{L}=\mathrm{NO}^{+}$, the isomerization barrier is calculated to be $5.7 \mathrm{kcal} / \mathrm{mol}$. For comparison, $\left[\mathrm{TpW}(\mathrm{NO})\left(\mathrm{PMe}_{3}\right)\left(\mathrm{C}_{6} \mathrm{H}_{9}\right)\right]^{+}$is calculated to have a transition state for this isomerization of $6.2 \mathrm{kcal} / \mathrm{mol}$ with an isomerization energy of $3.7 \mathrm{kcal} / \mathrm{mol}$.
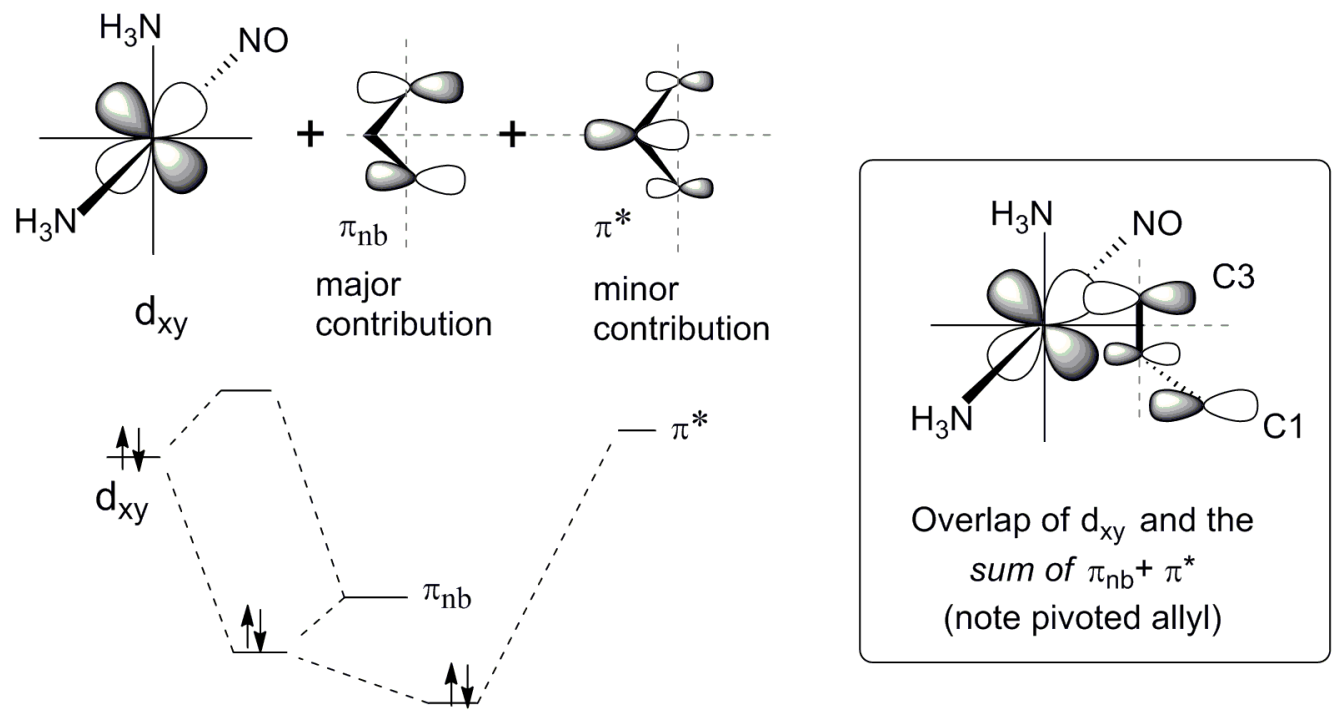

Figure 7: Schematic representation of the mixing of the HOMO of $\left\{\mathrm{W}\left(\mathrm{NH}_{3}\right)_{4}(\mathrm{NO})\right\}^{+}\left(\mathrm{d}_{\mathrm{xy}}\right)$ with the non-bonding $\left(\pi_{\mathrm{nb}}\right)$ and antibonding $\left(\pi^{*}\right)$ orbitals of $\mathrm{C}_{3} \mathrm{H}_{5}{ }^{+}$. Better overlap of $\mathrm{d}_{\mathrm{xy}}$ and $\pi^{*}$ is achieved by partial rotation (moving C1 toward NO).

Charges on atoms or fragments in molecules are not well-defined; there are many alternative partitionings of the total charge density. ${ }^{48}$ We chose Mulliken ${ }^{49}(\mathrm{M})$ and Weinhold's Natural Atomic Charges ${ }^{50}$ (NA) to describe the charge distribution in the 
symmetric model system cis- $\left\{\mathrm{W}\left(\mathrm{NH}_{3}\right)_{4}(\mathrm{NO})\left(\pi-\mathrm{C}_{3} \mathrm{H}_{5}\right)\right\}^{2+}$. In each case the terminal methylene $(C 1)$ is calculated to possess cationic charge $(M=+0.150, N A=+0.088|e|)$, while the opposite terminal methylene (C3) is calculated to possess negative charge density $(\mathrm{M}=-0.013, \mathrm{NA}=-0.113|\mathrm{e}|)$. There is considerable charge transfer to the allyl cation upon complexation. The allyl fragment of the complex carries a net charge of $M=$ +0.245 , or $N A=-0.011|e|$.

We now consider why the allyl ligand in $\left\{\mathrm{TpW}(\mathrm{NO})\left(\mathrm{PMe}_{3}\right)\left(\pi-\mathrm{C}_{3} \mathrm{H}_{5}\right)\right\}^{+}$distorts in such a way as to place the electrophilic methylene (C1) distal rather than proximal to $\mathrm{PMe}_{3}$ ligand. Inspection of the HOMO for the fragment $\left\{\mathrm{TpW}(\mathrm{NO})\left(\mathrm{PMe}_{3}\right)\right\}$ reveals a significant interaction of a $\pi$-orbital of the pyrazole ligand trans to $\mathrm{PMe}_{3}$ with the tungsten $\mathrm{d}_{\mathrm{xy}}$ orbital (Figure 9; W-NO is the $\mathrm{z}$ axis). The HOMO is represented by the antibonding combination of these orbitals. The result of this $\pi^{*}$ interaction is a distortion of the $d_{x y}$ orbital, causing the major lobes to extend toward the $\mathrm{PMe}_{3}$ (Figure 8). Optimal overlap is achieved when the $\pi$ non-bonding orbital of the allyl fragment twists in such a way as to maximize overlap of one of these major lobes with a terminal carbon. Thus, the W-C1 bond is weakened in order to achieve better overlap with C2 and C3 (Figure 9). The cost of such a distortion is to lessen the interaction of the allyl $\pi^{*}$ orbital with $\mathrm{d}_{\mathrm{xz}}$. However, as the $\mathrm{d}_{\mathrm{xz}}$ orbital has been stabilized by its interaction with the nitrosyl, the interaction of the $d_{x z}$ and allyl $\pi^{*}$ orbitals is inconsequential. 

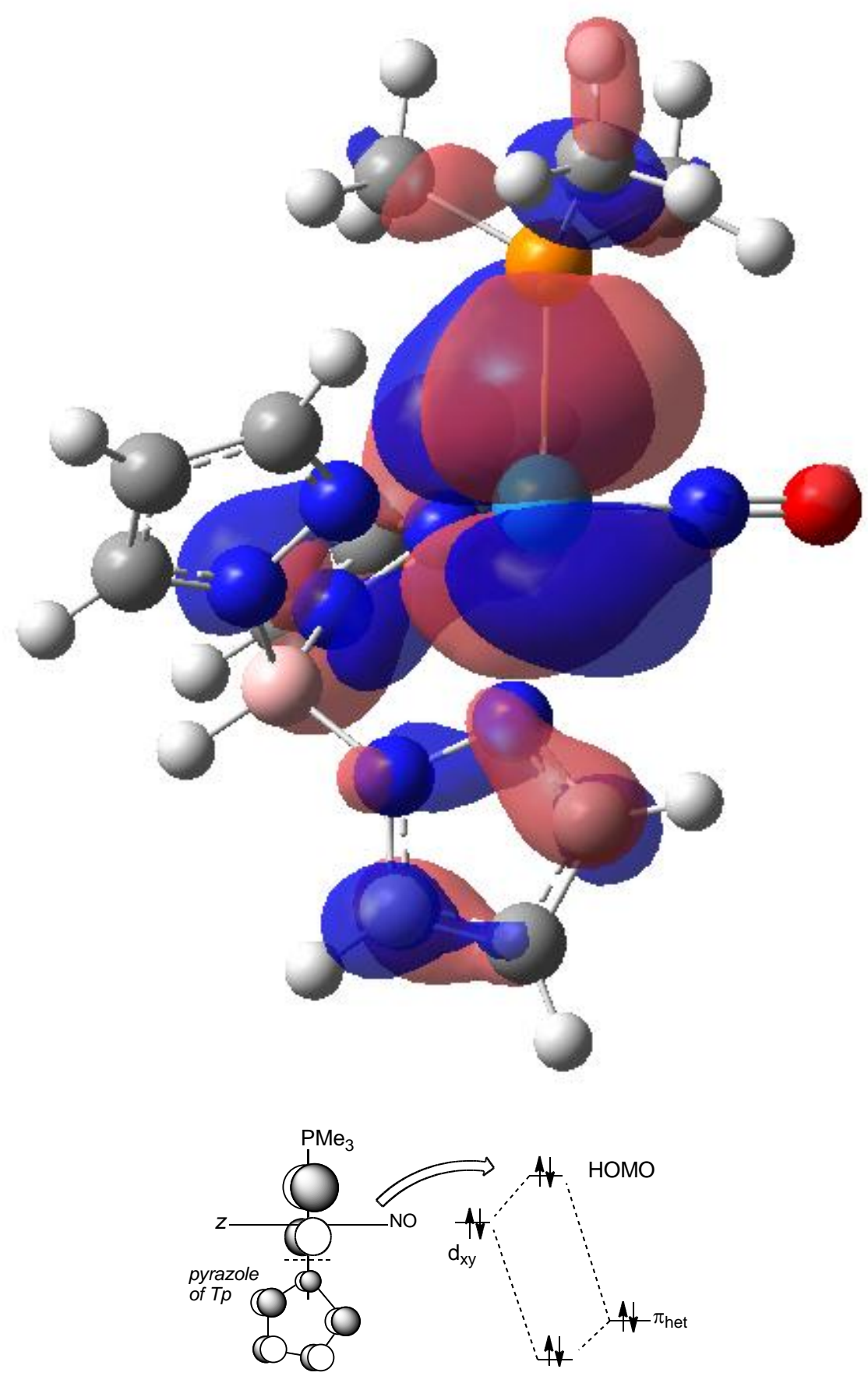

Figure 8: $\mathrm{HOMO}$ of the fragment $\left\{\mathrm{TpW}(\mathrm{NO})\left(\mathrm{PMe}_{3}\right)\right\}$ showing the participation of the pyrazole ring trans to the phosphine (note the asymmetric $d_{x y}$ orbital). The $\pi$ orbital of the heterocycle distorts and raises the energy of the HOMO. 


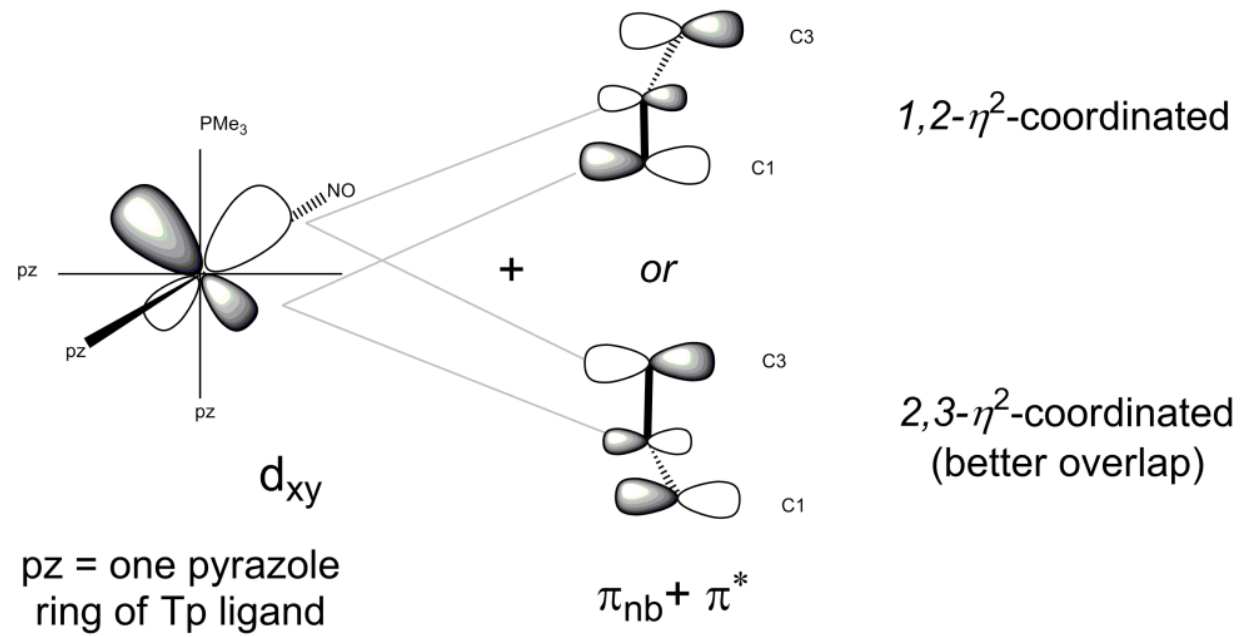

Figure 9: Overlap of the allyl $\pi_{\mathrm{nb}}$ and $\pi^{*}$ orbital combination with the asymmetric HOMO $\left(d_{x y}\right)$ of $\left\{T p W(N O)\left(\mathrm{PMe}_{3}\right)\right\}$ for the two possible $\eta^{3} \rightarrow \eta^{2}$ distortions of the allyl ligand.

When we replaced an ammine of the theoretical allyl complex $\left[\mathrm{W}\left(\mathrm{NH}_{3}\right)_{4}(\mathrm{NO})(\pi-\right.$ $\left.\left.\mathrm{C}_{6} \mathrm{H}_{9}\right)\right]^{2+}$ with $\mathrm{PMe}_{3}$ (cis to both the allyl and NO), the difference between the distal and proximal distorted allyl isomers is only $0.2 \mathrm{kcal} / \mathrm{mol}$ (TS $=4.9 \mathrm{kcal} / \mathrm{mol})$. However, if three ammines of $\left[\mathrm{W}\left(\mathrm{NH}_{3}\right)_{4}(\mathrm{NO})\left(\mathrm{C}_{6} \mathrm{H}_{9}\right)\right]^{2+}$ are replaced with Tp, the difference between distorted allyls becomes $4.1 \mathrm{kcal} / \mathrm{mol}$. For comparison, this isomerization energy is calculated to be $3.7 \mathrm{kcal} / \mathrm{mol}$ for the $\left\{\mathrm{TpW}\left(\mathrm{PMe}_{3}\right)(\mathrm{NO})\left(\pi-\mathrm{C}_{6} \mathrm{H}_{9}\right)\right\}^{+}$system $(\mathrm{TS}=6.2$ $\mathrm{kcal} / \mathrm{mol}$; see Figure S2 in Supporting Information). Thus, while the $\mathrm{NO}^{+}$is primarily responsible for the $\eta^{3} \rightarrow \eta^{2}$ distortion in these $\left\{\mathrm{TpW}(\mathrm{NO})\left(\mathrm{PMe}_{3}\right)\right\}$ systems, it is the $\mathrm{Tp}$, and not the $\mathrm{PMe}_{3}$, that determines the direction of the allyl distortion.

\section{Reverse-Distorted Allyl Complexes.}


Finally, we queried whether it would be possible to reverse the orientation of the $\eta^{3} \rightarrow \eta^{2}$ distortion by altering the electronic properties of the allyl group. Whereas an electron-donating group (e.g., $\mathrm{X}=$ alkyl, $\mathrm{O}, \mathrm{NR}_{2}$ ) in conjugation with the distal (d) terminal allyl carbon supports the buildup of positive charge at this position (Scheme 7), ${ }^{51}$ a withdrawing group to the distal carbon should have the opposite effect.

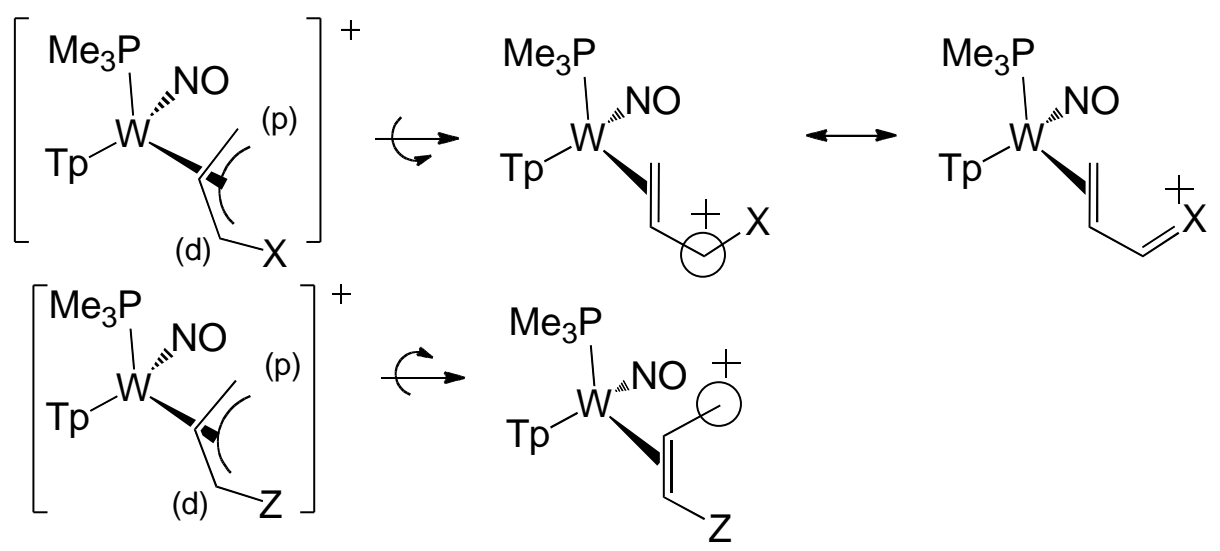

Scheme 7: Expected distortion effects of donating $(X)$ and withdrawing $(Z)$ groups. The $\eta^{3} \rightarrow \eta^{2}$ distortion is enhanced by either a $\pi$-donor or $\pi$-acceptor at the distal carbon (Circle represents $\mathrm{p}$ orbital).

An allyl complex conjugated to an electron-withdrawing group is expected to be highly electrophilic. Protonation at C4 with either the $2 \mathrm{H}$-phenol $(\mathbf{1 9 p}, \mathbf{1 9 d})$ or $\mathrm{N}, \mathrm{N},-$ dimethyl-2H-anilinium (14) complexes described earlier would provide allyl complexes (20d, 20p, 21p) in which a $\pi$-withdrawing group is in conjugation with the allyl system (Scheme 8). 

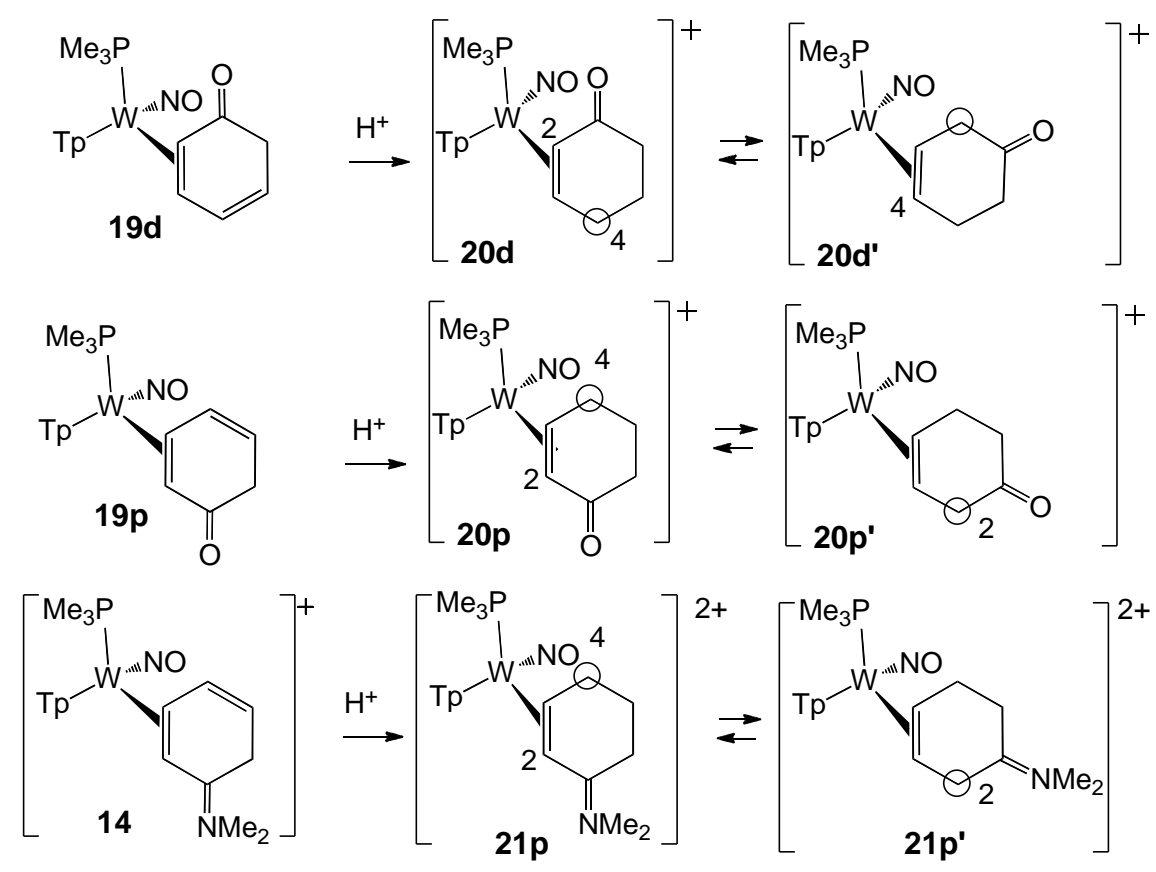

Scheme 8: Protonation results in a $\pi$-withdrawing group in conjugation with the allyl group.

Indeed, these allyls have been previously postulated as intermediates in diene tandem addition reactions of 14 and $19 p .,{ }^{8,43}$ Our efforts to characterize $20 p$ and $\mathbf{2 1 p}$ spectroscopically were hampered by their thermal instability. For example, ${ }^{1} \mathrm{H}$ NMR spectroscopic data recorded for a mixture of phenol complex diastereomers (19p and 19d) treated with triflic acid indicate that while 20d survives for several days, 20p decomposes rapidly (e.g., $\mathrm{t}_{1 / 2} \sim 10 \mathrm{~min}$ at $20^{\circ} \mathrm{C}$ ) under the same conditions. Consistent with these findings, DFT calculations indicate that $20 \mathrm{~d}$ is $6.5 \mathrm{kcal} / \mathrm{mol}$ more stable than its diastereomer 20p (see Supporting Information). However, in the case of the anilinium dication 21p, a single crystal that provided X-ray diffraction data was obtained from a methylene chloride solution of triflic acid at $-20{ }^{\circ} \mathrm{C} .{ }^{52}$ Figure 10 shows the 
molecular structure of $21 \mathrm{p}$ along with pertinent bond lengths of this dicationic allylic ligand. The allyl fragment is now distorted, with the terminal allyl carbon proximal to the $\mathrm{PMe}_{3}$ ligand. ${ }^{1} \mathrm{H}$ NMR spectroscopic data for the phenolium complex 20p (H2: 4.24; H3: 6.05; H4: $7.05 \mathrm{ppm})$ and the anilinium dication 21p (H2: 3.93; H3: 5.92; H4: $7.17 \mathrm{ppm})$ are very similar, with the downfield allylic proton of both complexes $(\mathrm{H} 4)$ showing NOE interactions with the $\mathrm{PMe}_{3}$. Additionally, the internal protons $(\mathrm{H} 3)$ of both complexes also have NOE interactions with the $\mathrm{PMe}_{3}$. Two-dimensional NMR data (COSY, NOESY, HMBC, HSQC) support our assignments of 20p and 21p.

Similar to other $\{\mathrm{W}(\mathrm{NO})\}^{+}$allyl complexes (Figure 5), 20p and 21p are each envisioned to exist as an equilibrium mixture of isomers (20p/20p' or $\mathbf{2 1 p} / \mathbf{2 1} \mathbf{p}^{\prime}$ that differ by the location of the "uncoordinated" $\mathrm{sp}^{2}$ carbon (represented by a circle). DFT calculations generally support these findings for $20 p$ and $21 p$ (Table 2 ) and indicate that the unobserved isomers of the dicationic allyls $\mathbf{2 0 \mathbf { p } ^ { \prime }}$ and $\mathbf{2 1 \mathbf { p } ^ { \prime }}$ are $\geq 4 \mathrm{kcal} / \mathrm{mol}$ less stable. This estimate is based on the computed energies of systems constrained to the $\mathbf{p}^{\prime}$ isomer connectivities. Upon release of the constraints, geometry optimization of $\mathbf{2 0 p ^ { \prime }}$ led to the 20p isomer; that is, we found no (relative) minimum energy structure with the connectivity portrayed in Scheme 8. However, we did capture a 21p' isomer, as summarized in Table 2. 


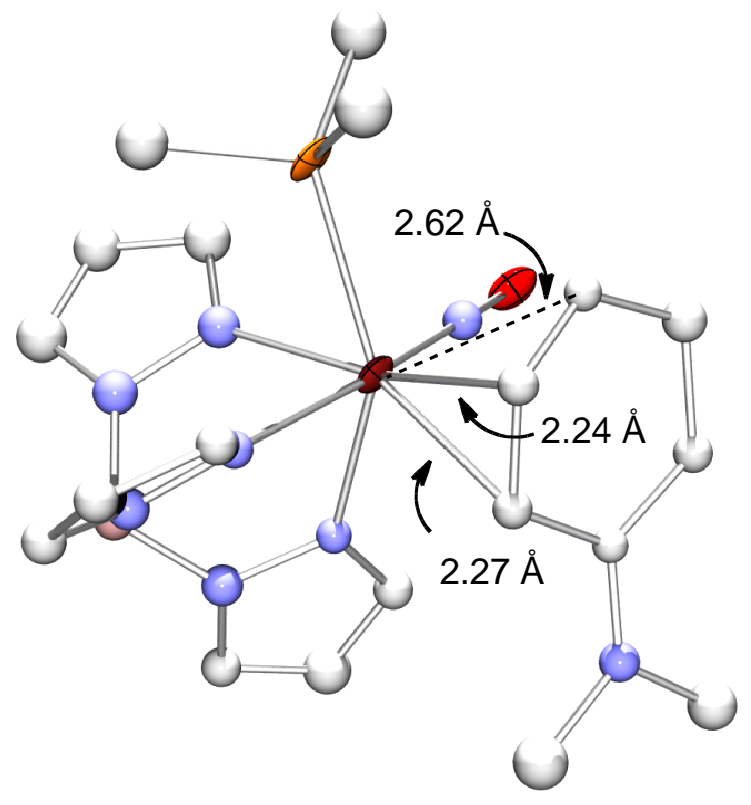

Figure 10: Molecular structure of the anilinium dication complex, 21p.

Table 2: Experimental and [calculated] bond lengths for "reverse-distorted" $\eta^{2}$-allyl complexes derived from aniline and phenol. Calculated values are in brackets.

\begin{tabular}{lllllll}
\hline Compound, L & $\mathrm{W}-\mathrm{C} 4, \AA$ & $\mathrm{W}-\mathrm{C} 3, \AA$ & $\mathrm{W}-\mathrm{C} 2, \AA$ & $\Delta, \AA$ & $\mathrm{C} 3-\mathrm{C} 4, \AA$ & $\mathrm{C} 2-\mathrm{C} 3, \AA$ \\
\hline $\begin{array}{l}20 \mathrm{p} \\
\left(\mathbf{p h e n o l} \cdot \mathbf{H}^{+}\right)\end{array}$ & {$[2.58]$} & {$[2.38]$} & {$[2.36]$} & {$[0.22]$} & {$[1.39]$} & {$[1.41]$} \\
$\quad\left(\right.$ calc'd only) $^{\prime}$ & & & & & & \\
$21 \mathrm{p}$ & 2.63 & 2.24 & 2.27 & 0.38 & 1.39 & 1.38 \\
$\begin{array}{l}\text { (aniline•2H } \\
\text { (calculated) }\end{array}$ & {$[2.74]$} & {$[2.34]$} & {$[2.40]$} & {$[0.34]$} & {$[1.38]$} & {$[1.46]$} \\
$\begin{array}{l}21 \mathrm{p} \text { (calc'd } \\
\text { only) }\end{array}$ & {$[2.47]$} & {$[2.38]$} & {$[2.56]$} & {$[0.09]$} & {$[1.40]$} & {$[1.41]$} \\
\hline
\end{tabular}

\section{Reduction of $\mathrm{TpW}(\mathrm{NO})\left(\mathrm{PMe}_{3}\right)($ allyl) complexes.}

Cyclic voltammograms for neutral alkene and diene complexes of $\left\{\mathrm{TpW}(\mathrm{NO})\left(\mathrm{PMe}_{3}\right)\right\}$ (e.g., cyclohexadiene complex 4; a, in Figure 11) show no reduction 
activity out to a switching potential of $-1.6 \mathrm{~V}(\mathrm{NHE})$, consistent with the behavior expected for an $18 \mathrm{e}^{-}$complex. Allylic complexes reported herein are typically also resistant to reduction, showing a broad cathodic wave near $-1.0 \mathrm{~V}$ (e.g., 11; b, in Figure 11). A remarkable exception is the trimethylated allyl complex $\mathbf{1 2}$ (c, in Figure 11). In this case, electrochemical analysis using cyclic voltammetry reveals that this 18 e complex shows two chemically and electrochemically reversible couples corresponding to $\mathrm{E}^{0} \sim$ 0.78 and $-1.66 \mathrm{~V}(100 \mathrm{mV} / \mathrm{s}) .^{53}$ The long-lived $\left(\mathrm{t}_{1 / 2}>10 \mathrm{~s}\right)$ nature of the initially formed reduction product $(\mathbf{1 2} \bullet)$ caused us to question whether the $\pi$ allylic structure was still intact. DFT calculations suggested that $12 \cdot$ exists as a ${ }^{1}$ species (Scheme 9), making an open shell 17 e- complex in which the unpaired electron is centered on the metal and C1-C2 is no longer associated with the metal center. Calculations further indicate that the second reduction (c, Figure 11) is also metal-centered and produces a closed shell anionic complex [12] with very little change for the $\kappa^{1}$ structure of one-electron reduced species. These observations led us to speculate that the $\pi$-allyl complex $\mathbf{1 2}$ may be in equilibrium with a $\mathrm{k}^{1}$ isomer (12k), which as a $16 \mathrm{e}^{-}$complex is amenable to two single electron reductions forming first $12 \bullet$ then [12]- Rates for isomerization from $\eta^{3}$ to $\mathrm{k}^{1}$ for allyl complexes have been measured in a few cases, and they can be rapid at ambient temperature. ${ }^{54}$ Starting with geometry for the optimized $\mathrm{k}^{1}$ radical $\mathbf{1 2} \bullet$, DFT calculations located an isomer of $\mathbf{1 2}$ in which the allyl is bound $\mathrm{K}^{1}$ (no meaningful contact of the metal with C2 or C3) and is $13 \mathrm{kcal} / \mathrm{mol}$ higher in energy than the $\pi$-bound isomer. This estimate for the $\mathrm{k}^{1} \rightarrow \eta^{2}$ isomerization energy in 12 rises to $\sim 18 \mathrm{kcal} / \mathrm{mol}$ when a similar analysis is done for the parent allyl 11, offering a possible reason for the more 
poorly defined electrochemical behavior for 11 (Figure 11). We note that without invoking the isomerization prior to reduction of the allyl, the fact that replacement of three hydrogens in $\mathbf{1 1}$ for methyl groups results in a more facile reduction of $\mathbf{1 2}$ would be counter-intuitive.

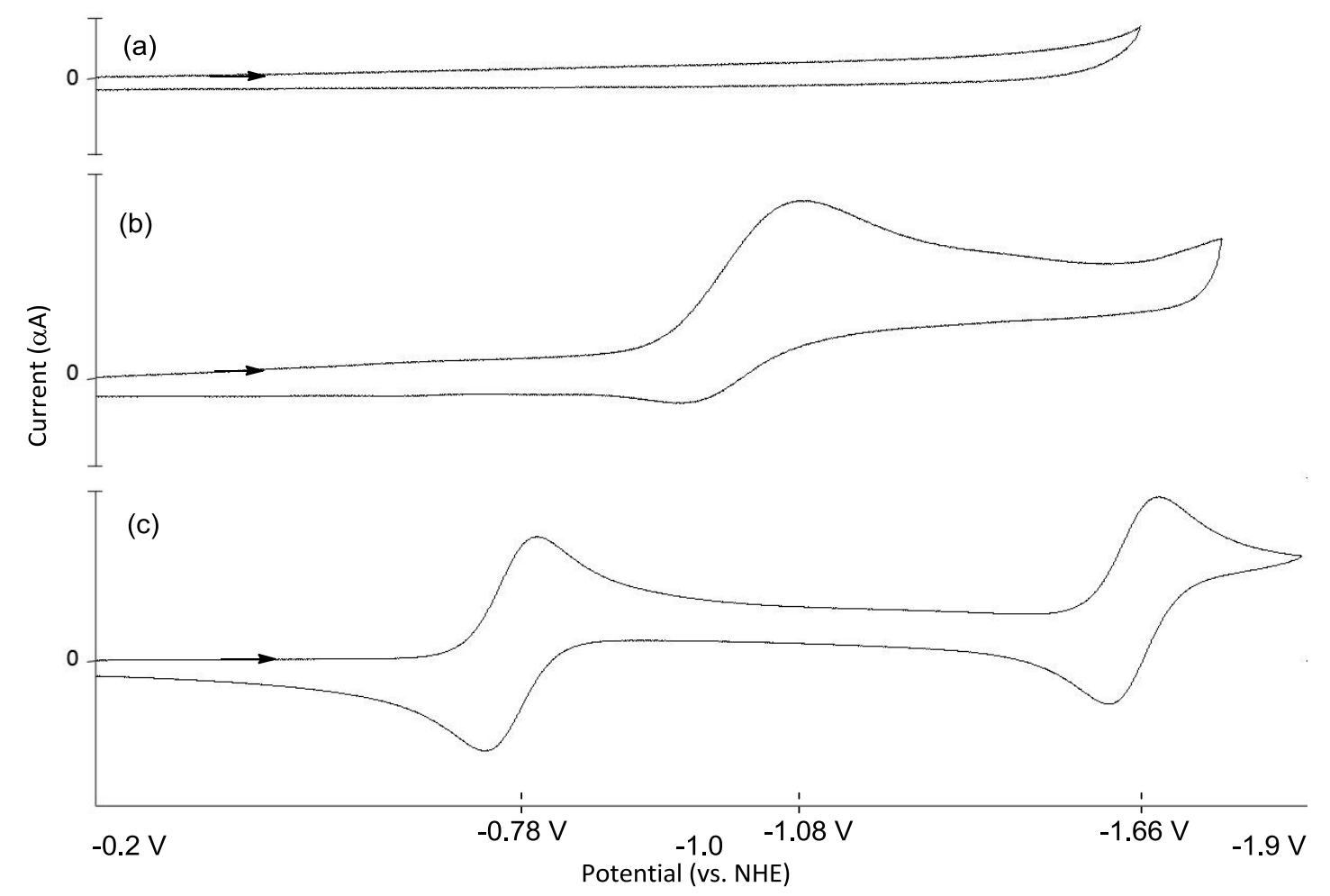

Figure 11: Cyclic voltammetric data for (a) TpW(NO) $\left(\mathrm{PMe}_{3}\right)\left(\mathrm{C}_{6} \mathrm{H}_{8}\right)(4)$, (b)

$\left[\mathrm{TpW}(\mathrm{NO})\left(\mathrm{PMe}_{3}\right)\left(\mathrm{C}_{3} \mathrm{H}_{5}\right)\right]^{+}(\mathbf{1 1})$, and (c) $\left[\mathrm{TpW}(\mathrm{NO})\left(\mathrm{PMe}_{3}\right)\left(\mathrm{C}_{6} \mathrm{H}_{11}\right)\right]^{+}(\mathbf{1 2})$. Values are vs. NHE at $100 \mathrm{mV} / \mathrm{s}$ scan rate.

Although CV experiments indicate the presence of a relatively long-lived radical species, $\mathbf{1 2} \bullet$, attempts to isolate the radical proved futile. However, treatment of 12 with $\mathrm{Na} / \mathrm{Hg}$ amalgam in DME resulted in the production of three complexes, 22, exo-23, and endo-23. Each compound was independently synthesized by hydride reduction of 12 with $\mathrm{NaBH}_{4}$ in $\mathrm{MeOH}$ (exo-23, endo-23) or by deprotonation of 12 with base (Scheme 
9). Also, 22 could be synthesized as a single diastereomer by mild heating of the mixture of the two coordination isomers generated from the substitution of 2,3dimethylbutadiene with $\mathrm{TpW}(\mathrm{NO})\left(\mathrm{PMe}_{3}\right)\left(\eta^{2}\right.$-benzene) in the presence of catalytic acid.

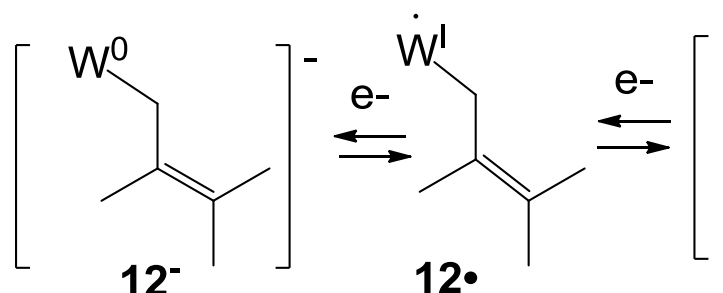

$12^{-}$

12•

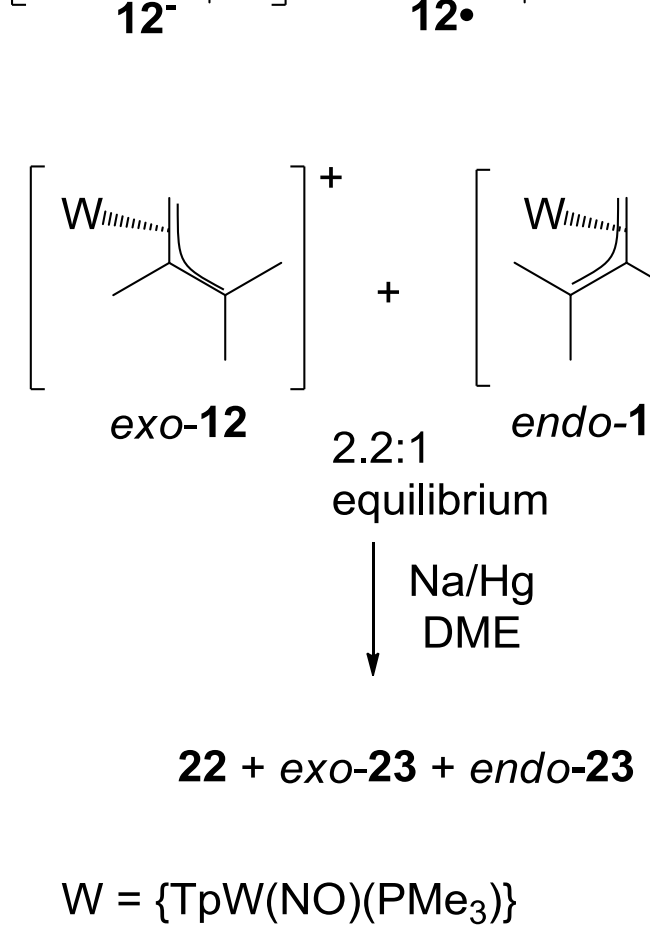

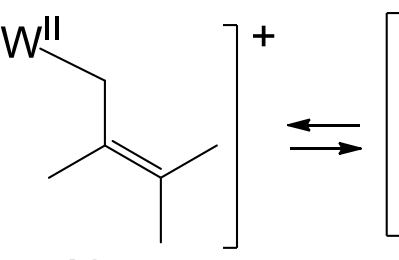

$12 \kappa$

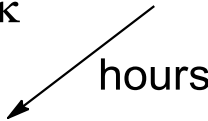

exo-12 (via 22)
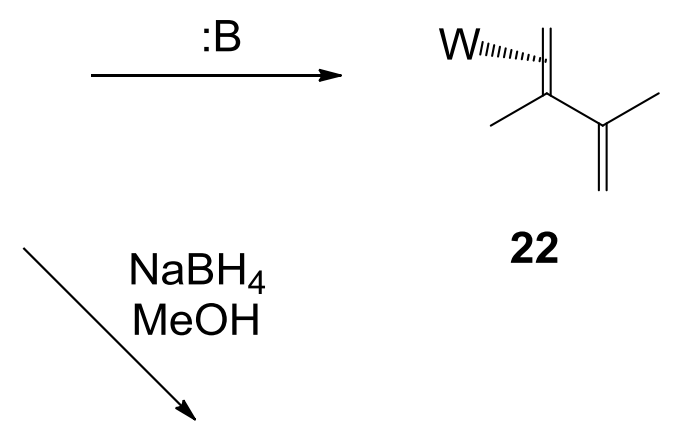

$\uparrow \operatorname{HOTf}(x s)$

22
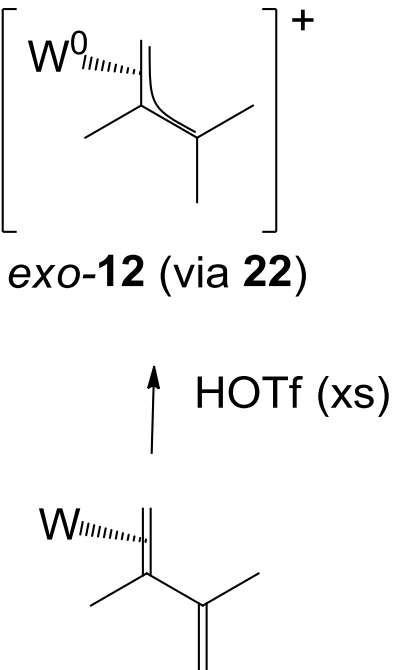

exo-23 endo-23

Scheme 9: Reduction and manipulation of allyl 12.

\section{Conclusions:}

We have prepared series of $\pi$-allyl complexes of tungsten that show an unusually large degree of $\eta^{3} \rightarrow \eta^{2}$ distortion. The degree of distortion, in which the W-C bond of one terminus ( $\mathrm{C} 1$; distal to the $\mathrm{PMe}_{3}$ ) elongates and the allylic $\mathrm{C} 1-\mathrm{C} 2$ bond shortens, is 
greatly enhanced by an electron donor(s) at $\mathrm{C} 1(\mathrm{O}, \mathrm{N}$, alkyl) or by a $\pi$-acceptor (EWG) at C3. DFT calculations for several of these allyl complexes reproduce the general distortions observed and indicate a significant buildup of positive charge at C1 along with a large component of the $2 p$ orbital at this carbon. The presence of a single powerful $\pi$-acid $\left(\mathrm{NO}^{+}\right)$in the fragment $\left\{\mathrm{TpW}(\mathrm{NO})\left(\mathrm{PMe}_{3}\right)\right\}$ results in a single high-energy $\mathrm{d} \pi$ orbital (orthogonal to the nitrosyl), and its interaction with both the $\pi_{\mathrm{nb}}$ and allyl $\pi^{*}$ orbitals is thought to cause the observed distortion of the $\pi$-allyl ligand. In the case of cyclohexyl or piperidyl allyls, this allyl distortion can be utilized to prepare stereoselectively $\eta^{2}$-1,3-diene and 3-substituted piperidine complexes. ${ }^{35}$

\section{Experimental Section:}

General Experimental Methods. NMR spectra were obtained on a 300, 500, or $600 \mathrm{MHz}$ spectrometer (Varian INOVA or Bruker Avance). All chemical shifts are reported in ppm and proton and carbon shifts are referenced to tetramethylsilane (TMS) utilizing residual ${ }^{1} \mathrm{H}$ or ${ }^{13} \mathrm{C}$ signals of the deuterated solvents as an internal standard. Phosphorus NMR signals are referenced to $85 \% \mathrm{H}_{3} \mathrm{PO}_{4}(\delta=0.00)$ using a triphenylphosphate external standard $(\delta=-16.58)$. Coupling constants $(J)$ are reported in hertz $(\mathrm{Hz})$. Infrared spectra (IR) were recorded as a glaze on a MIDAC Prospect Series (Model PRS) spectrometer fitted with a Horizontal Attenuated Total Reflectance (HATR) accessory (Pike Industries), or on a Nicolet Avatar 360 FT-IR spectrometer equipped with an ASI-DiComp diamond anvil ATR assembly. Electrochemical experiments were performed under a dinitrogen atmosphere using a BAS Epsilon EC-2000 potentiostat. Cyclic voltammetry data were aquired at ambient temperature $\left(\sim 25^{\circ} \mathrm{C}\right)$ at $100 \mathrm{mV} / \mathrm{s}$ in a standard three-electrode cell with a glassy carbon working electrode, $\mathrm{N}, \mathrm{N}$-dimethylacetamide (DMA) or 
acetonitrile (MeCN) solvent (unless otherwise specified), and tetrabutylammonium hexaflurophosphate (TBAH) electrolyte (approx. $0.5 \mathrm{M}$ ). All potentials are reported versus NHE (Normal Hydrogen Electrode) using cobaltocenium hexafluorophosphate $\left(E_{1 / 2}=-0.78 \mathrm{~V}\right)$, ferrocene $\left(E_{1 / 2}=+0.55 \mathrm{~V}\right)$, or decamethylferrocene $\left(E_{1 / 2}=+0.04 \mathrm{~V}\right)$ as an internal standard. The peak-to-peak separation was less than $100 \mathrm{mV}$ for all reversible couples. Elemental analyses (EA) were obtained from Atlantic Microlabs and agree to within $0.4 \%$ for $\mathrm{C}, \mathrm{H}$, and $\mathrm{N}$. High resolution electrospray ionization mass spectrometry (ESI-MS) analyses were obtained from the University of Richmond from samples dissolved in acetonitrile then mixed 3:1 with $0.1 \mathrm{M}$ aqueous sodium trifluoroacetate (NaTFA) using $\left[\mathrm{Na}(\mathrm{NaTFA})_{\mathrm{x}}\right]^{+}$clusters as an internal standard. Data are reported for the dominant peaks in the isotopic envelope as their observed and calculated masses and their percentage abundance relative to the parent ion, followed by the difference between the observed and calculated masses in ppm, and the ion analyzed, e.g. (obs'd (\%), calc'd (\%), ppm, $\left.(\mathrm{M}+\mathrm{Z})^{+}\right)$, where $\mathrm{Z}^{+}=$proton or sodium ion. Unless otherwise noted, all synthetic reactions were performed in a glovebox under a dry nitrogen atmosphere. $\mathrm{CH}_{2} \mathrm{Cl}_{2}$ and benzene were purified by passage through a column packed with activated alumina. Other solvents and liquid reagents were thoroughly purged with dry nitrogen prior to use. Deuterated solvents were used as received from Cambridge Isotopes. Pyrazole (pz) protons of the (tris-pyrazolyl)borate, Tp, ligand were uniquely assigned using a combination of 2-dimensional NMR experiments and phosphorous-proton coupling (see Figure S1 in supplemental information). ${ }^{31}$ When unambiguous assignments were not possible, pz protons were labeled as Tp protons. Coordination diastereomers are described as either proximal $(p)$ or distal $(d)$ based on the proximity of a defining feature (e.g., the "carbocationic" center of an allyl ligand) to the $\mathrm{PMe}_{3}$ ligand. Synthesis of compounds $\operatorname{TpW}(\mathrm{NO})\left(\mathrm{PMe}_{3}\right)\left(\eta^{2}\right.$-benzene $),{ }^{31} \mathbf{5},{ }^{35} \mathbf{7 p},{ }^{30}, \mathbf{9},,^{34} \mathbf{1 4},,^{43}$ and $\mathbf{1 9 ^ { 5 5 }}$ 
have been previously reported. 19 can be isolated as a single isomer or a mixture of coordination diastereomers. $^{55}$

DFT Calculations. ${ }^{56}$ Initial structures were built in $\operatorname{Spartan}^{56 a}$ and optimized with the extended version of the PM3 semi-empirical method available in that package, or in GAUSSVIEW (5.0.8) with the PM6 semi-empirical method in GAUSSIAN 09. ${ }^{56 b, c}$ These structures were refined stepwise in Spartan and Gaussian using B3LYP and a series of basis functions incorporating LANL2 pseudopotentials and associated basis functions provided in those packages or directly from the PM6 structures. The most demanding calculations reported here put the LANL2DZ pseudopotential and its basis only on the $W$ atom, and used the 6-31G(d) basis for all other atoms.

For transition state structures, vibrational analysis revealed the presence of a single imaginary frequency. In all other cases, vibrational analyses verified that optimized structures were located at local minima, with the presence of only real frequencies.

Many of the systems calculated herein have very soft vibrational modes. This has the consequence that in many cases reports from vibrational calculations showed small violations of the convergence criteria on the predicted root-mean-square and/or maximum displacement, for structures which had satisfied all convergence criteria in the optimization step. This unsatisfactory behavior can be remedied by reoptimization, computing the force matrix at each optimization step, and using the UltraFine grid for numerical integrations. Our spot checks showed that structures and zero point vibrational energies were unchanged by this expensive refinement. For this reason we believe that the structures, calculated energies, and zero-point energy values computed with default convergence criteria (FinGrid) for optimization, are reliable for comparisons reported here. 


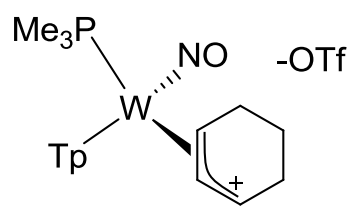

[TpW(NO)(PMe $)\left(2,3-\eta^{2}\right.$-cyclohexan-2-en-1-ylium)][OTf]. 3. 1,3-Cyclohexadiene (1.05 g, 13.1 mmol) was added to an oven-dried test tube containing a heterogeneous yellow solution of $\operatorname{TpW}(\mathrm{NO})\left(\mathrm{PMe}_{3}\right)\left(\eta^{2}\right.$-benzene) $(0.525 \mathrm{~g}, 0.904 \mathrm{mmol})$ in DME $(2.71 \mathrm{~g})$. The solution was added to a $60{ }^{\circ} \mathrm{C}$ oil bath and allowed to stir. Upon warming the solution became a brown-slightly purple homogeneous solution. After $1.5 \mathrm{~h}$, the solution was removed from the warm bath and allowed to cool for 5 minutes. A solution of HOTf $(0.135 \mathrm{~g}, 0.900 \mathrm{mmol})$ in $\mathrm{MeCN}(0.695 \mathrm{~g})$ was added to the solution to make a yellow solution that precipitated a yellow solid from the shortly thereafter. After $2 \mathrm{~h} 15 \mathrm{~min}$, the yellow precipitate was collected on a $15 \mathrm{~mL}$ medium porosity fritted funnel, washed with 4x0.2 g DME, and placed under vacuum $(0.403 \mathrm{~g}, 0.550 \mathrm{mmol}, 61 \%$ yield). ${ }^{1} \mathrm{H}$ NMR $\left(\mathrm{CD}_{3} \mathrm{CN}, \delta\right): 8.41(\mathrm{~d}, J=2.0,1 \mathrm{H}, \mathrm{PzB} 3), 8.13$ (d, $\left.J=2.0,1 \mathrm{H}, \mathrm{PzA} 3\right), 8.03$ (d, $J=2.0$, 1H, PzB5), 7.97 (d, $J=2.0,1 \mathrm{H}, \mathrm{PzC} 5), 7.96(\mathrm{~d}, J=2.0,1 \mathrm{H}, \mathrm{PzC} 3), 7.81$ (d, $J=2.0,1 \mathrm{H}, \mathrm{PzA} 5), 6.59$ $(\mathrm{m}, 1 \mathrm{H}, \mathrm{H} 1), 6.55(\mathrm{t}, J=2.0,1 \mathrm{H}, \mathrm{PzC} 4), 6.53(\mathrm{t}, J=2.0,1 \mathrm{H}, \mathrm{PzB} 4), 6.34(\mathrm{t}, J=2.0,1 \mathrm{H}, \mathrm{PzA} 4), 5.13$ $(\mathrm{t}, J=7.4,1 \mathrm{H}, \mathrm{H} 2), 4.38\left(\mathrm{dtt}, J=7.4,1.6,{ }^{3} \mathrm{JPH}_{\mathrm{PH}}=14.5,1 \mathrm{H}, \mathrm{H} 3\right), 3.34(\mathrm{~m}, 1 \mathrm{H}, \mathrm{H} 6), 3.26(\mathrm{~m}, 2 \mathrm{H}$, H6'/H4), 2.47 (dddd, $\left.J=15.4,10.8,6.4,1.4,1 \mathrm{H}, \mathrm{H} 4^{\prime}\right), 1.59$ (m, 1H, H5), 1.33 (m, 1H, H5'), 1.20 (d, $\left.J_{\mathrm{PH}}=9.8,9 \mathrm{H}, \mathrm{PMe}_{3}\right) .{ }^{13} \mathrm{C} \mathrm{NMR}\left(\mathrm{CD}_{3} \mathrm{CN}, \delta\right): 142.3$ (PzA3), 146.4 (PzB3), 143.2 (PzC3), 139.6 (PzA5), 139.5 (PzB5/PzC5), 138.3 (C1), 109.5/109.0 (PzB4/PzC4), 108.1 (PzA4), 103.8 (C2, d, $\left.{ }^{2} \mathrm{JC}_{\mathrm{PC}}=3.5\right)$, $70.0\left(C 3, d, J_{P C}=12.6\right), 27.1(C 4), 27.0(C 6), 26.9(C 5), 13.4\left(\mathrm{PMe}_{3}, d^{1}, J_{P C}=32.7\right) .{ }^{31} \mathrm{P} \mathrm{NMR}\left(\mathrm{CDCl}_{3}\right.$, $\delta):-7.85\left(J_{\mathrm{WP}}=273\right)$. IR: $v_{\mathrm{BH}}=2522 \mathrm{~cm}^{-1}, v_{\mathrm{NO}}=1635 \mathrm{~cm}^{-1} . \mathrm{CV}(\mathrm{MeCN}): E_{\mathrm{p}, \mathrm{a}}=+1.83 \mathrm{~V}, E_{\mathrm{p}, \mathrm{c}}=-0.95$. ESI-MS: obs'd (\%), calc'd (\%), ppm (M-OTf) ${ }^{+}: 582.1675$ (89.7), 582.1672 (86.8), 0.5; 583.1697 (63.2), 583.1698 (79.3), 0.1; 584.1698 (100), 584.1695 (100), 0.5; 585.1759 (52.2), 585.1739 
(40.1), 3.3; 586.1731 (100), 586.1728 (84.9), 0.5. Anal. Calc'd for $\mathrm{C}_{19} \mathrm{H}_{30} \mathrm{BF}_{3} \mathrm{~N}_{7} \mathrm{O}_{4} \mathrm{PSW}: \mathrm{C}, 31.04 ; \mathrm{H}$, 4.11; N, 13.34. Found: C, 31.26; H, 3.90; N, 13.33.

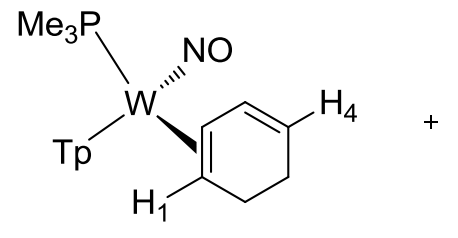

$\mathrm{P}($ roximal)

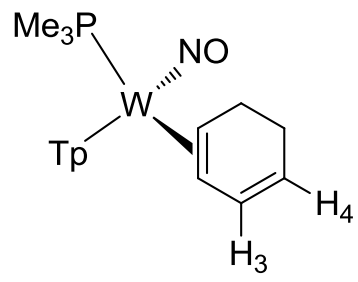

$\mathrm{D}$ (istal)

TpW(NO)(PMe $\left.{ }_{3}\right)\left(1,2-\eta^{2}\right.$-cyclohexa-1,3-diene). 4p, 4d. 1,3-Cyclohexadiene (0.261 g, $\left.3.3 \mathrm{mmol}\right)$ was added to a homogeneous yellow solution of $\mathrm{TpW}(\mathrm{NO})\left(\mathrm{PMe}_{3}\right)\left(\eta^{2}\right.$-benzene) $(0.151 \mathrm{~g}, 0.260$ $\mathrm{mmol}$ ) in DME (3.0 g), and allowed to stir at room temperature for 20 hours. The resulting dark brown solution was precipitated over a stirring mixture of $20 \mathrm{~mL}$ ether and $50 \mathrm{~mL}$ hexanes. The brown/purple precipitate was filtered over a $30 \mathrm{~mL}$ fine-porosity fritted funnel and discarded. The yellow filtrate was evaporated to dryness and dissolved in minimal DME. About $0.5 \mathrm{~mL}$ acetonitrile was added to the solution, which stirred ten minutes and evaporated to dryness. 1 $\mathrm{mL}$ acetonitrile was triturated with the residue; ether was added dropwise to encourage precipitation. Majority of solvent was evaporated, but did not give precipitation. Residue was dissolved in minimal DME and precipitated dropwise over $40 \mathrm{~mL}$ stirring water. A pale tan solid was filtered over a $15 \mathrm{~mL}$ fine-porosity fritted funnel and stored overnight in a desiccator to give $0.054 \mathrm{~g}(0.093 \mathrm{mmol}, 36 \%$ yield $) .{ }^{1} \mathrm{H}$ NMR $\left(\mathrm{CDCl}_{3}, \delta\right): 8.25(\mathrm{~d}, J=2.0,1 \mathrm{H}, \mathrm{PzA}(\mathrm{d})), 8.08(\mathrm{~m}, 1 \mathrm{H}$, $\operatorname{PzB} 3(p+d)), 8.05(d, J=2.0,1 \mathrm{H}, \operatorname{PzA} 3(p)), 7.70(d, J=2.0,1 \mathrm{H}, \operatorname{PzB} 5(p)), 7.68(d, J=2.0,1 \mathrm{H}$, $\operatorname{PzB} 5(\mathrm{~d})), 7.61(\mathrm{~d}, J=2.0,1 \mathrm{H}, \operatorname{PzA} 5(\mathrm{p})), 7.57(\mathrm{~d}, J=2.0,1 \mathrm{H}, \operatorname{PzA5}(\mathrm{d})), 7.34(\mathrm{~d}, J=2.0,1 \mathrm{H}, \operatorname{PzC}(\mathrm{d}))$, $7.28(\mathrm{~d}, J=2.0,1 \mathrm{H}, \operatorname{PzC} 3(\mathrm{p})), 6.29(\mathrm{t}, J=2.0,1 \mathrm{H}, \operatorname{PzB} 4(\mathrm{~d})), 6.27(\mathrm{t}, J=2.0,1 \mathrm{H}, \operatorname{PzB} 4(\mathrm{p})), 6.21(\mathrm{t}, J=$ 2.0, 1H, PzA4(p)), $6.18(t, J=2.0,1 \mathrm{H}, \operatorname{PzA} 4(d)), 6.17 / 6.16(t, J=2.0,1 \mathrm{H}, \operatorname{PzC} 4(p+d)), 1.28(d, J=$ 8.3, 9H, $\left.\mathrm{PMe}_{3}(\mathrm{p})\right), 1.27\left(\mathrm{~d}, J=8.2,9 \mathrm{H}, \mathrm{PMe}_{3}(\mathrm{~d})\right.$ ), Distal Diene (d-Major isomer): $6.68(\mathrm{ddd}, J=9.0$, 5.6, 2.9, $1 \mathrm{H}, \mathrm{H3}$ ), 5.23 (ddd, J = 9.0, 6.6, 2.0,1H, H4), $3.65(\mathrm{~m}, 1 \mathrm{H}, \mathrm{H} 6), 2.66\left(\mathrm{~m}, 1 \mathrm{H}, \mathrm{H} 1 / \mathrm{H} 6^{\prime}\right), 2.45$ 
(m, 1H, H5), $1.94(m, 1 H, H 5 '), 1.68(m, 1 H, H 2)$, Proximal Diene (p-minor isomer): 6.48 (ddd, $J=$ 9.0, 4.8, 2.7, $1 \mathrm{H}, \mathrm{H} 3$ ), $5.24(\mathrm{~m}, 1 \mathrm{H}, \mathrm{H} 4), 3.33\left(\mathrm{~m}, 1 \mathrm{H}, \mathrm{H} 6\right.$ (anti)), 2.89 (ddd, $J=10.3,5.0,{ }^{3} \mathrm{JPH}_{\mathrm{PH}}=14.2$, $1 \mathrm{H}, \mathrm{H} 2), 2.66(\mathrm{~m}, 1 \mathrm{H}, \mathrm{H} 6(\mathrm{syn})), 2.45(\mathrm{~m}, 1 \mathrm{H}, \mathrm{H} 5), 1.95\left(\mathrm{~m}, 1 \mathrm{H}, \mathrm{H} 55^{\prime}\right), 1.38$ (d, J = 10.1, $\left.1 \mathrm{H}, \mathrm{H} 1\right) .{ }^{13} \mathrm{C}$ NMR $\left(\mathrm{CDCl}_{3}, \delta\right): 144.5$ (PzA3(d)), 143.4/143.3 (PzB3(p,d)), $142.1 \quad(\operatorname{PzA} 3(p)), \quad$ 140.2/140.1 (PzC3(p,d)), 136.4 (Tp5), 136.2 (Tp5), 135.6 (2 Tp5's), 135.2 (Tp5), 134.8 (Tp5), 106.3 (Tp4), 106.1 (Tp4), 105.7 (Tp4), 105.5 (3 Tp4's), $14.0\left(\mathrm{~d},{ }^{1} \mathrm{~J}_{\mathrm{PC}}=27.8, \mathrm{PMe}_{3}(\mathrm{p})\right), 13.4\left(\mathrm{~d},{ }^{1} \mathrm{~J}_{\mathrm{PC}}=27.8, \mathrm{PMe}_{3}(\mathrm{~d})\right)$, Distal Diene: 133.4 (C3), 120.8 (C4), 56.6 (d, JPC 11.9, C1), 50.8 (C2), 23.5 (C5), 21.6 (C6), Proximal Diene: 130.8 (C3), 120.8 (C4), $55.4(\mathrm{C} 1), 50.8$ (d, $\left.J_{\mathrm{PC}}=8.4, \mathrm{C} 2\right), 26.5$ (C6), 23.5 (C5). ${ }^{31} \mathrm{P}$ NMR: $\left(\mathrm{CDCl}_{3}, \delta\right):-9.75\left(J_{\mathrm{WP}}=286 \mathrm{~Hz}\right),-11.94\left(J_{\mathrm{WP}}=284 \mathrm{~Hz}\right) . \mathrm{IR}: v_{\mathrm{BH}}=2488 \mathrm{~cm}^{-1}, v_{\mathrm{NO}}=1554 \mathrm{~cm}^{-1}$. CV (DMA): $E_{\mathrm{p}, \mathrm{a}}=+0.44$ V. ESI-MS: obs'd (\%), calc'd (\%), ppm, $(\mathrm{M}+\mathrm{H})^{+}: 594.1664$ (86.9), 594.1672 (86.2), 1.3; 595.1688 (90), 595.1698 (79.6), 1.7; 596.1687 (100), 596.1696 (100), 1.4; 597.1751 (45.4), 597.1739 (40.8), 2.0; 598.1749 (77.5), 598.1728 (84.6), 3.5.

Single isomer synthesis of $\mathbf{4 d}$. To separate oven-dried test tubes, $3(0.099 \mathrm{~g}, 0.135 \mathrm{mmol})$ in $\mathrm{CHCl}_{3}(2.02 \mathrm{~g})$ and DBU $(0.192 \mathrm{~g}, 1.261 \mathrm{mmol})$ in $\mathrm{CHCl}_{3}(2.01 \mathrm{~g})$ were added to a $0{ }^{\circ} \mathrm{C}$ cold bath and allowed to equilibrate. After 10 minutes, the heterogeneous allyl solution was quickly added to the DBU solution to become homogeneous and pale yellow after a few seconds. The reaction was removed from the cold bath and glovebox after 10 minutes and allowed to warm to room temperature for 10 minutes. The solution was diluted with $75 \mathrm{~mL} \mathrm{Et}_{2} \mathrm{O}$, extracted with $5 \times 25 \mathrm{~mL}$ of $\mathrm{NaOH}\left(1 \mathrm{M}\right.$, aqueous), back-extracted with $2 \times 25 \mathrm{~mL} \mathrm{Et}_{2} \mathrm{O}$, dried with $\mathrm{MgSO}_{4}$, filtered through a $60 \mathrm{~mL}$ coarse porosity fritted funnel, and the solvent removed to produce a yellow solid. The material was moved to the a tared 4 dram vial with $\mathrm{DCM}(5 \times 1 \mathrm{~mL})$, and the solvent removed to produce a yellow solid that was free flowing once scraped with a spatula $(0.073 \mathrm{~g}, 0.125 \mathrm{mmol}$, 93\% yield). The solid was pure via NMR and produced a single isomer of the cyclohexadiene complex $(10: 1 \mathrm{cdr})$. 


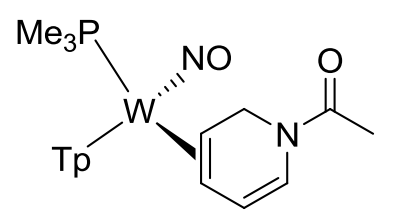

$\operatorname{TpW}(\mathrm{NO})\left(\mathrm{PMe}_{3}\right)\left(3,4-\eta^{2}-(1-(\right.$ pyridin-1(2H)-yl)ethanone)). 7d. A solution of HOTf $(0.121 \mathrm{~g}, 0.806$ $\mathrm{mmol}$ ) in $\mathrm{MeCN}(6.31 \mathrm{~g})$ was added to a vial containing $7 \mathrm{p}(0.501 \mathrm{~g}, 0.800 \mathrm{mmol})$ to make a yellow homogenous solution. After 1 minute, the solution was transferred to a vial containing morpholine ( $0.087 \mathrm{~g}, 0.999 \mathrm{mmol})$. After 10 minutes, a some crystalline material began coating the reaction vial. The solution remained undisturbed for $23 \mathrm{~h}$, when the reaction solution was decanted away from the solid. The precipitate was washed with MeCN ( $2 \times \sim 0.3 \mathrm{~g})$ and placed under vacuum. After several days under vacuum, the yellow crystalline material was scraped from the reaction vial and transferred to a new vial $\left(0.364 \mathrm{~g}, 0.581 \mathrm{mmol}, 73 \%\right.$ yield). ${ }^{1} \mathrm{H}$ NMR $\left(\mathrm{CDCl}_{3}, \delta\right): 8.24(\mathrm{~d}, J=2.0,1 \mathrm{H}, \mathrm{PzA} 3), 8.02(\mathrm{~d}, J=2.0,1 \mathrm{H}, \mathrm{PzB} 3), 7.71(\mathrm{~m}, 2 \mathrm{H}, \mathrm{PzB} 5 / \mathrm{Tp}), 7.58(\mathrm{~d}, J$ $=2.0,1 \mathrm{H}, \mathrm{Tp}), 7.31(\mathrm{~d}, J=2.0,1 \mathrm{H}, \mathrm{PzC} 3), 6.29(\mathrm{t}, J=2.0,1 \mathrm{H}, \mathrm{PzB} 4), 6.19(\mathrm{t}, J=2.0,2 \mathrm{H}$, PzA4/PzB4), 6.14 (dd, J = 7.4, 5.8, 1H, H5), 5.95 (d, J = 7.4, 1H, H6), 5.34 (d, J = 13.0, 1H, H2(syn)), $4.63(\mathrm{dd}, J=13.0,3.2,1 \mathrm{H}, \mathrm{Hs}($ anti) ), 2.97 (ddd, $J=10.8,10.2,3.2,1 \mathrm{H}, \mathrm{H} 3$ ), 2.15 (s, 3H, AmideMe), $1.63(\mathrm{ddd}, J=10.2,5.8,1.8,1 \mathrm{H}, \mathrm{H} 4), 1.24\left(\mathrm{~d}, J=8.2,9 \mathrm{H}, \mathrm{PMe}_{3}\right) \cdot{ }^{13} \mathrm{C} \mathrm{NMR}\left(\mathrm{CDCl}_{3}, \delta\right): 169.1$ (Amide-CO), 144.3 (PzA3), 143.6 (PzB3), 140.2 (PzC3), 136.6 (Tp), 136 (Tp), 135.2 (Tp), 119.8 (C5), 117.8 (C6), 106.4 (PzB4), 105.9/105.7 (PzA4/PzC4), 59.4 (C3, d, J = 13.4), 45.7 (C4), 44.2 (C2), 23.2 (Amide-Me), $13.7\left(\mathrm{PMe}_{3}, \mathrm{~d}, J=27.9\right) .{ }^{31} \mathrm{P} \mathrm{NMR}\left(\mathrm{CDCl}_{3}, \delta\right):-9.19\left(J_{\mathrm{WP}}=281\right)$. IR: $v_{\mathrm{BH}}=$ $2488 \mathrm{~cm}^{-1}, v=1643 \mathrm{~cm}^{-1}, v=1616 \mathrm{~cm}^{-1}, v_{\mathrm{NO}}=1562 \mathrm{~cm}^{-1}$. CV (DMA): $E_{\mathrm{p}, \mathrm{a}}=+0.34$ V. ESI-MS: obs'd (\%), calc'd (\%), ppm, (M+Na) $)^{+}: 647.1559$ (80.8), 647.155 (85.9), 1.5; 648.1585 (91.6), 648.1575 (79.6), 1.5; 649.158 (100), 649.1573 (100), 1.1; 650.1621 (39.9), 650.1616 (41.2), $0.7 ; 651.1618$ (94.6), 651.1606 (84.6), 1.9. Anal. Calc'd for $\mathrm{C}_{19} \mathrm{H}_{28} \mathrm{BN}_{8} \mathrm{O}_{2} \mathrm{PW}: \mathrm{C}, 36.45 ; \mathrm{H}, 4.51 ; \mathrm{N}, 17.90$; Found: C, 36.60; H, 4.52; N, 17.94 . 


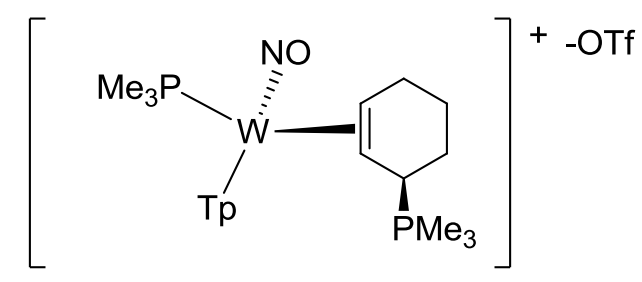

$\left[\mathrm{TpW}(\mathrm{NO})\left(\mathrm{PMe}_{3}\right)\left(2,3-\eta^{2}-\left(\right.\right.\right.$ cyclohex-2-en-1-yltrimethylphosphonium)](OTf). 8c. $\mathrm{PMe}_{3}(0.037 \mathrm{~g}$,

$0.473 \mathrm{mmol}$ ) was added to a heterogeneous yellow solution of $\mathbf{3}(0.036 \mathrm{~g}, 0.049 \mathrm{mmol})$ in $\mathrm{CHCl}_{3}$ $(2.01 \mathrm{~g})$ to become homogeneous and pale yellow. After two minutes, the stirring reaction solution was diluted with $20 \mathrm{~mL} \mathrm{Et}{ }_{2} \mathrm{O}$ to precipitate a white solid that was collected on a $15 \mathrm{~mL}$ medium porosity fritted funnel. The white residue on the reaction flask was dissolved in $1 \mathrm{~mL}$ $\mathrm{CHCl}_{3}$ and precipitated with $20 \mathrm{mLEt}{ }_{2} \mathrm{O}$. The solid was collected on the same $15 \mathrm{~mL}$ medium porosity fritted funnel, washed with $2 \times 7 \mathrm{~mL} \mathrm{Et}{ }_{2} \mathrm{O}$ and placed under vacuum $(0.022 \mathrm{~g}, 0.027$ mmol, $55 \%$ yield). ${ }^{1} \mathrm{H}$ NMR $\left(\mathrm{CDCl}_{3}, \delta\right): 8.00(\mathrm{~d}, J=2.0,1 \mathrm{H}, \mathrm{PzB} 3), 7.98(\mathrm{~d}, J=2.0,1 \mathrm{H}, \mathrm{PzA} 3), 7.74$ (d, $J=2.0,1 \mathrm{H}, \mathrm{PzC} 5), 7.70$ (d, $J=2.0,1 \mathrm{H}, \mathrm{PzB} 5), 7.68$ (d, $J=2.0,1 \mathrm{H}, \mathrm{PzA} 5), 7.29$ (d, $J=2.0,1 \mathrm{H}$, PzC3), 6.30+6.29 (t, $J=2.0,2 \mathrm{H}, \mathrm{PzB} 4 / \mathrm{PzC} 4), 6.22(\mathrm{t}, J=2.0,1 \mathrm{H}, \mathrm{PzA} 4), 3.60$ (ddd, ${ }^{2} J_{\mathrm{PH}}=8.9, J=$ 6.7, 6.7, $1 \mathrm{H}, \mathrm{H} 1), 3.24(\mathrm{~m}, 1 \mathrm{H}, \mathrm{H} 4), 2.77\left(\mathrm{~m}, 2 \mathrm{H}, \mathrm{H} 3+\mathrm{H} 4{ }^{\prime}\right), 2.07(\mathrm{~m}, 1 \mathrm{H}, \mathrm{H} 6), 1.87(\mathrm{~m}, 1 \mathrm{H}, \mathrm{H} 5), 1.64$ $\left(\mathrm{d},{ }^{2} J_{\mathrm{PH}}=13.3,9 \mathrm{H}, \mathrm{C}-\mathrm{PMe}_{3}\right), 1.60\left(\mathrm{~m}, 1 \mathrm{H}, \mathrm{H} 6^{\prime}\right), 1.5\left(\mathrm{~m}, 1 \mathrm{H}, \mathrm{H} 5^{\prime}\right), 1.22\left(\mathrm{~d},{ }^{2} J_{\mathrm{PH}}=8.3,9 \mathrm{H}, \mathrm{W}-\mathrm{PMe}_{3}\right)$, $0.62\left(\mathrm{dd},{ }^{3} \mathrm{PHH}_{\mathrm{PH}}=22.9, J=11.1,1 \mathrm{H}, \mathrm{H} 2\right) .{ }^{13} \mathrm{C} \mathrm{NMR}\left(\mathrm{CDCl}_{3}, \delta\right): 143.3(\mathrm{PzB} 3), 141.9(\mathrm{PzA} 3), 140.1$ (PzC3), 137.5 (PzA5), 137.1 (PzC5), 136.6 (PzB5), 129.9 ( $\left(\mathrm{q},{ }^{1}{ }_{\mathrm{FC}}=320\right.$, triflate), 107.0/106.7/106.6 $(\mathrm{PzA} 4 / \mathrm{PzB} 4 / \mathrm{PzC} 4), 49.7\left(\mathrm{~d},{ }^{2} J_{\mathrm{PC}}=11.3, \mathrm{C} 3\right), 45.4\left(\mathrm{~d}, J_{\mathrm{PC}}=3.0, \mathrm{C} 2\right), 33.4\left(\mathrm{~d},{ }^{1} J_{\mathrm{PC}}=42.6, \mathrm{C} 1\right), 29.1(\mathrm{~d}$, $\left.J_{\mathrm{PC}}=3.3, \mathrm{C} 4\right), 23.1\left(\mathrm{~d},{ }^{2} J_{\mathrm{PC}}=3.6, \mathrm{C} 6\right), 21.4\left(\mathrm{~d},{ }^{3} J_{\mathrm{PC}}=9.5, \mathrm{C} 5\right), 13.8\left(\mathrm{~d},{ }^{1} J_{\mathrm{PC}}=28.3, \mathrm{~W}-\mathrm{PMe}_{3}\right), 6.9(\mathrm{~d}$, $\left.\left.{ }^{1} J_{\mathrm{PC}}=53.5, \mathrm{C}-\mathrm{PMe}\right)_{3}\right) .{ }^{31} \mathrm{P} \mathrm{NMR}\left(\mathrm{CDCl}_{3}, \delta\right):-10.04\left(J_{\mathrm{WP}}=286\right), 35.41\left(\mathrm{C}-\mathrm{PMe}_{3}\right) . \mathrm{IR}: \mathrm{V}_{\mathrm{BH}}=2481 \mathrm{~cm}^{-1}$, $\mathrm{v}_{\mathrm{NO}}=1542 \mathrm{~cm}^{-1} . \mathrm{CV}(\mathrm{MeCN}): E_{\mathrm{p}, \mathrm{a}}=+0.54 \mathrm{~V} . \mathrm{ESI}-\mathrm{MS}:$ obs'd (\%), calc'd (\%), ppm, M+: 658.2128 (81.8), 658.2114 (85.1), 2.1; 659.2139 (95.5), 659.214 (80.1), 0.1; 660.2156 (100), 660.2138 (100), 2.7; 661.2296 (31.8), 661.2180 (42.3), 17.5; 662.2158 (72.7), 662.2171 (84), 1.9. 


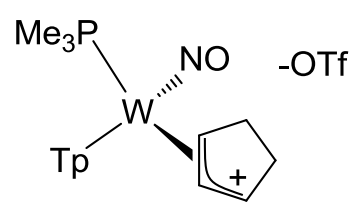

[TpW(NO)(PMe $)\left(2,3-\eta^{2}\right.$-cyclopent-2-en-ylium)][OTf]. 9. A solution of HOTf $(0.058 \mathrm{~g}, 0.386$ $\mathrm{mmol}$ ) in MeCN (0.25 g), was added to a solution of 10p,d (0.195 g, $0.343 \mathrm{mmol})$ in MeCN (0.33 g) to make a deep yellow homogeneous solution. After $30 \mathrm{~s}$, the reaction solution was added to $125 \mathrm{~mL}$ of stirring $\mathrm{Et}_{2} \mathrm{O}$ to precipitate a tan-yellow solid that was collected on a $15 \mathrm{~mL}$ medium porosity fritted funnel, washed with $2 \times 7 \mathrm{~mL} \mathrm{Et}{ }_{2} \mathrm{O}$, and placed under vacuum $(0.183 \mathrm{~g}, 0.254$ mmol, $74 \%$ yield). $\mathrm{CV}(\mathrm{MeCN}): E_{\mathrm{p}, \mathrm{a}}=+1.77 \mathrm{~V}, E_{\mathrm{p}, \mathrm{c}}=-0.93 \mathrm{~V}$. Characterization for 9 has previously been published.

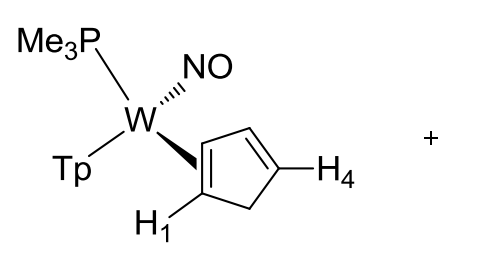

$\mathrm{P}($ roximal)

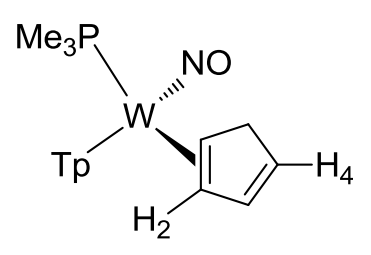

$\mathrm{D}$ (istal)

TpW(NO)(PMe $)\left(1,2-\eta^{2}\right.$-cyclopenta-1,3-diene): 10p, 10d. To a flame-dried test tube with a stir bar was added $\mathrm{TpW}(\mathrm{NO})\left(\mathrm{PMe}_{3}\right)\left(\eta^{2}\right.$-benzene) $(0.100 \mathrm{~g}, 0.172 \mathrm{mmol})$ and DME $(2.0 \mathrm{~g})$, to give a homogeneous yellow solution, to which cyclopentadiene $(0.212 \mathrm{~g}, 3.207 \mathrm{mmol})$ was added. The test tube was placed in a $67^{\circ} \mathrm{C}$ oil bath for 16 hours. A dark brown solution was cooled to room temperature and precipitated over a mixture of $37 \mathrm{~mL}$ hexanes and $13 \mathrm{~mL}$ ether. A brown/purple precipitate was filtered using a $15 \mathrm{~mL}$ fine-porosity fritted funnel and discarded. The light yellow filtrate was evaporated to dryness and dissolved in minimal dichloromethane for transfer to a 4 dram vial with stirbar. The dichloromethane was evaporated and $2 \mathrm{~mL}$ ether added to the vial and allowed to stir overnight. An orange liquid was carefully pipeted out of the vial, leaving a pale tan solid. One $\mathrm{mL}$ of hexanes and 5 drops ether was added to the vial and 
allowed to stir overnight. One $\mathrm{mL}$ of hexanes was added to the vial and the pale tan solid was filtered over a $2 \mathrm{~mL}$ fine-porosity fritted funnel to give $0.058 \mathrm{~g}(0.102 \mathrm{mmol}, 60 \%$ yield $) .{ }^{1} \mathrm{H}$ NMR $\left(\mathrm{CDCl}_{3}, \delta\right): 8.42(\mathrm{~d}, J=1.7,1 \mathrm{H}, \operatorname{PzA} 3(\mathrm{p})), 8.25(\mathrm{~d}, J=1.7,1 \mathrm{H}, \operatorname{PzA} 3(\mathrm{~d})), 8.05(\mathrm{~d}, J=1.8,1 \mathrm{H}$, PzB3(p)), $8.04(d, 1 H, P z B 3(d)), 7.72(m, 1 H, P z B 5(p+d)), 7.67(m, 1 H, P z C 5(p+d)), 7.61(d, J=2.0$, 1H, PzA5(p)), $7.59(d, 1 H, P z A 5(d)), 7.28(m, 1 H, P z C 5(p+d)), 6.29(m, 1 H, P z B 4(p+d)), 6.23(m$, 1H, PzA4(p+d)), $6.15(m, 1 \mathrm{H}, \operatorname{PzC} 4(p+d)), 1.31\left(d, J=7.5,9 \mathrm{H}, \mathrm{PMe}_{3}(\mathrm{p})\right), 1.27(\mathrm{~d}, J=7.7,9 \mathrm{H}$, $\left.\mathrm{PMe}_{3}(\mathrm{~d})\right)$, Proximal diene (p - Major isomer): $6.41(\mathrm{dd}, J=4.8,1.9,1 \mathrm{H}, \mathrm{H} 3), 5.37(\mathrm{~m}, 1 \mathrm{H}, \mathrm{H} 4)$, $4.50(\mathrm{~m}, 1 \mathrm{H}, \mathrm{H} 5), 3.95\left(\mathrm{~m}, 1 \mathrm{H}, \mathrm{H} 5^{\prime}\right), 3.72(\mathrm{dd}, \mathrm{J}=12.5,7.3,1 \mathrm{H}, \mathrm{H} 2), 2.15(\mathrm{~m}, 1 \mathrm{H}, \mathrm{H} 1)$, Distal diene (d-minor isomer): $6.68(\mathrm{dd}, J=5.0,2.1,1 \mathrm{H}, \mathrm{H} 3), 5.30(\mathrm{~m}, 1 \mathrm{H}, \mathrm{H} 4), 4.54(\mathrm{~m}, 1 \mathrm{H}, \mathrm{H} 5), 3.54(\mathrm{~m}, 1 \mathrm{H}$, $\left.\mathrm{H} 5^{\prime}\right), 3.40(\mathrm{dt}, J=14.0,7.0,1 \mathrm{H}, \mathrm{H} 1), 2.44(\mathrm{dd}, J=7.4,2.3,1 \mathrm{H}, \mathrm{H} 2) .{ }^{13} \mathrm{C} \mathrm{NMR}\left(\mathrm{CDCl}_{3}, \delta\right): 144.4(\mathrm{Tp})$, 144.3 (Tp), 143.9 (Tp), 141.2 (Tp), 140.9 (Tp), 140.6 (Tp), 136.3 (Tp), 136.2 (Tp), 135.8 (Tp), 135.7 (Tp), 135.1 (Tp), 134.8 (Tp), 106.4 (Tp), 106.3 (Tp), 105.9 (Tp), 105.7 (Tp), 105.6 (Tp), 105.5 (Tp), $14.5\left(\mathrm{~d}, J_{\mathrm{P}-\mathrm{C}}=27.5,3 \mathrm{C}, \mathrm{PMe}_{3}\right), 14.1\left(\mathrm{~d}, J_{\mathrm{PC}}=27.1,3 \mathrm{C}, \mathrm{PMe}_{3}\right)$, Proximal diene: 136.4 (C3), 123.0 (C4), 67.9 (C2), 57.3 (C1), 43.0 (C5), Distal diene: 138.0 (C3), 121.9 (C4), 66.4 (C2), 58.6 (C1), 43.2 $(\mathrm{C} 5) .{ }^{31} \mathrm{P}$ NMR $\left(\mathrm{CDCl}_{3}, \delta\right):-11.11\left(J_{\mathrm{WP}}=280\right),-11.88\left(J_{\mathrm{WP}}=290\right) . \mathrm{IR}: v_{\mathrm{BH}}=2484 \mathrm{~cm}^{-1}, v_{\mathrm{NO}}=1554 \mathrm{~cm}^{-}$

1. CV (DMA): $E_{\mathrm{p}, \mathrm{a}}=+0.36$ V. HRMS: Overlapping signals for hydride loss $(\mathrm{M}-\mathrm{H})+$ and protonation $(\mathrm{M}+\mathrm{H})+$ complicated the spectrum and caused overlapping $M / Z$ peaks to not fit within the acceptable 5 ppm difference from that of the calculated. ESI-MS ((M-H)+): obs'd (\%), calc'd (\%), ppm: 566.1355 (61.8), 566.1359 (87.3), 0.7; 567.139 (56.2), 567.1385 (79.1), 0.9; 568.1419 (100), 568.1382 (100), 6.5; 569.1484 (45.2), 569.1427 (39.3), 10.0; 570.1451 (89.3), 570.1415 (85.2), 6.3. ESI-MS ((M+H) $\left.)^{+}\right): 568.1419$ (112), 568.1515 (87.3), 16.9; 569.1484 (50.7), 569.1541 (79.1), 10.1; 570.1451 (100), 570.1538 (100), 15.4; 571.1514 (22.7), 571.1583 (39.3), 12.2; 572.1573 (36.2), 572.1571 (85.2), 0.3. 

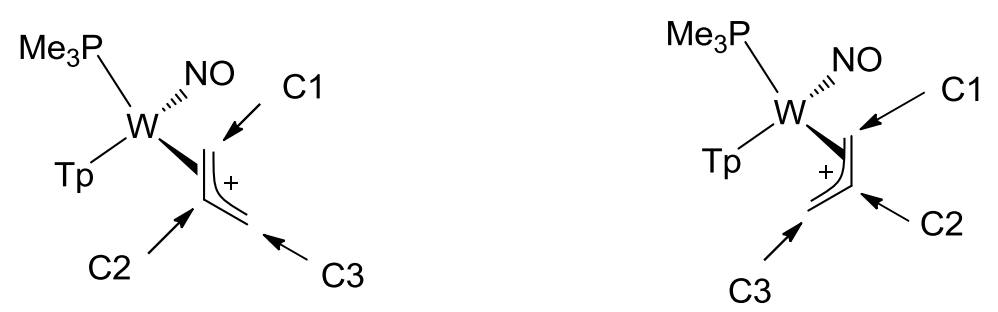

$\left[\mathrm{TpW}(\mathrm{NO})\left(\mathrm{PMe}_{3}\right)\left(2,3-\eta^{2}\right.\right.$-propan-1-ylium)][OTf]. exo-11, endo-11. Diallyl ether $(0.92 \mathrm{~g}, 9.4$ mmol) was added to a flame dried test tube containing $\mathrm{TpW}(\mathrm{NO})\left(\mathrm{PMe}_{3}\right)\left(\eta^{2}\right.$-benzene) $(0.506 \mathrm{~g}$, $0.871 \mathrm{mmol})$ in DME (2.62 g) to make a homogeneous yellow solution that was allowed to stir in a $57^{\circ} \mathrm{C}$ oil bath. After $1.5 \mathrm{~h}$, the dark purple-brown solution was removed from the warm bath. A solution of HOTf $(0.127 \mathrm{~g}, 0.846 \mathrm{mmol})$ in $\mathrm{MeCN}(0.640 \mathrm{~g})$ was added to the reaction solution to make a dark yellow solution. The reaction solution was placed in a $0{ }^{\circ} \mathrm{C}$ cold bath overnight. After $15 \mathrm{~h}$, the solution was removed from the cold bath and added to $100 \mathrm{~mL}$ of stirring $\mathrm{Et}_{2} \mathrm{O}$. The tan-yellow precipitate was then collected on a $30 \mathrm{~mL}$ medium porosity fritted funnel, washed with $2 \times 15 \mathrm{~mL} \mathrm{Et} \mathrm{t}_{2} \mathrm{O}$ and placed under vacuum ( $0.298 \mathrm{~g}, 0.430 \mathrm{mmol}, 49 \%$ yield). ${ }^{1} \mathrm{H} \mathrm{NMR}$ $\left(\mathrm{CD}_{3} \mathrm{CN}, \delta\right): 8.4(\mathrm{~d}, J=2.0,1 \mathrm{H}, \mathrm{PzB} 3(\mathrm{exo})), 8.16(\mathrm{~d}, J=2.0,1 \mathrm{H}, \mathrm{PzA} 3(\mathrm{exo})), 8.1(\mathrm{~s}(\mathrm{br}), 2 \mathrm{H}, 2 \mathrm{Tp}$ 's), $8.08(\mathrm{~d}, J=2.0,1 \mathrm{H}, \mathrm{PzB} 3($ endo)) $, 8.00 / 7.99(\mathrm{~m}, 2 \mathrm{H}, \mathrm{PzC} 5(\mathrm{exo}) / \mathrm{Tp}), 7.98(\mathrm{~d}, J=2.0,1 \mathrm{H}$, PzA3(endo)), 7.89 (m, 2H, PzC3(exo)/Tp), 7.81 (d, J = 2.0, 1H, PzA5(exo)), 7.71 (d, $J=2.0,1 \mathrm{H}$, PzC3(endo)), 6.55/6.54/6.52/6.50 (t, $J=2.0,4 \mathrm{H}, \mathrm{PzC} 4($ endo) $/ 3 \mathrm{Tp} 4 \mathrm{~s}), 6.38(\mathrm{t}, J=2.0,1 \mathrm{H}$, PzC4(exo)), 6.35 (t, $J=2.0,1 \mathrm{H}, \mathrm{PzA} 4(\mathrm{exo})), 1.24\left(\mathrm{~d}, J=10.4,9 \mathrm{H}, \mathrm{PMe}_{3}(\mathrm{exo})\right), 1.21(\mathrm{~d}, J=10.1,9 \mathrm{H}$, $\mathrm{PMe}_{3}\left(\right.$ endo)), Exo Isomer: 5.36 (ddddd, $J=14.6,13.3,8.3,8.0,{ }^{3} J_{\mathrm{PH}}=1.8,1 \mathrm{H}, \mathrm{H} 3$ ), 5.05 (ddd, $J=$ $\left.14.6,1.0,{ }^{3} J_{P H}=2.6,1 \mathrm{H}, \mathrm{H} 5\right), 4.83$ (dddd, $\left.J=8.3,2.9,1.1,{ }^{3} J_{\mathrm{PH}}=1.2,1 \mathrm{H}, \mathrm{H} 4\right), 3.83(\mathrm{dddd}, J=8.0$, 2.9, 2.9, ${ }^{3} J_{\mathrm{PH}}=13.4,1 \mathrm{H}, \mathrm{H} 2$ ), 2.57 (ddddd, $J=13.3,2.9,1.1,1.0,{ }^{3} J_{\mathrm{PH}}=8.8,1 \mathrm{H}, \mathrm{H} 1$ ), Endo Isomer: $6.33\left(\right.$ ddddd $, J=14.3,10.5,7.8,7.4,{ }^{3} J_{\mathrm{PH}}=1.1,1 \mathrm{H}, \mathrm{H} 3$ ), 4.53 (ddddd, $J=7.8,3.2,1.2,0.8,3 \mathrm{JPH}=$ $1.0,1 \mathrm{H}, \mathrm{H} 4$ ), 3.70 (dddd, $J=7.4,3.6,3.2,3 \mathrm{JPH}=14.3,1 \mathrm{H}, \mathrm{H} 2$ ), 3.60 (dddd, $J=14.3,1.2,0.5,{ }^{3} J_{\mathrm{PH}}$ $=1.9,1 \mathrm{H}, \mathrm{H} 5), 2.35$ (ddddd, $J=10.5,3.6,0.8,0.5,3 \mathrm{JPH}=9.4,1 \mathrm{H}, \mathrm{H} 1) .{ }^{13} \mathrm{C} \mathrm{NMR}\left(\mathrm{CD}_{3} \mathrm{CN}, \delta\right): 149.0$ 
(PzA3(exo)), 147.9 (PzA3(endo)), $146.9\left(\mathrm{~d},{ }^{4} \mathrm{~J}_{\mathrm{PC}}=2.4, \mathrm{PzB} 3(\mathrm{exo})\right), 145.3\left(\mathrm{~d},{ }^{4} \mathrm{~J}_{\mathrm{PC}}=2.4, \mathrm{PzB} 3(\right.$ endo $\left.)\right)$, $144.4 \quad$ (PzC3(endo)), $144.1 \quad$ (PzC3(exo)), $140.5 / 140.1 / 139.8 / 139.2 \quad(6 \quad$ Tp5's), 109.4/108.8/108.6/108.4/108.1 (6 Tp4's), 13.7 (d, $\left.J_{\mathrm{PC}}=33.8, \mathrm{PMe}_{3}(\mathrm{exo})\right), 13.0$ (d, $J_{\mathrm{PC}}=33.8$, $\mathrm{PMe}_{3}\left(\right.$ endo)), Allyl ligand signals for the Exo Isomer: $115.1\left(\mathrm{~d}, J_{\mathrm{PC}}=5.8, \mathrm{C} 3\right), 100.9\left(\mathrm{~d}, J_{\mathrm{PC}}=2.4\right.$, C2), $60.7\left(d, J_{P C}=11.3, C 1\right)$. Allyl ligand signals for the Endo Isomer: $120.6\left(d, J_{P C}=5.8, C 3\right), 100.1$ $\left(d, J_{P C}=1.8, C 2\right), 62.3\left(d, J_{P C}=12.5, C 1\right) .{ }^{31} \mathrm{P} N M R\left(C D_{3} C N, \delta\right):-2.91\left(J_{W P}=252\right),-7.40\left(J_{W P}=256\right)$. IR: $v_{\mathrm{BH}}=2515 \mathrm{~cm}^{-1}, v_{\mathrm{NO}}=1647 \mathrm{~cm}^{-1} . \mathrm{CV}(\mathrm{MeCN}): E_{\mathrm{p}, \mathrm{a}}=+2.07 \mathrm{~V}, E_{\mathrm{p}, \mathrm{c}}=-1.08 \mathrm{~V}$. ESI-MS: obs'd (\%), calc'd (\%), ppm, (M-OTf) ${ }^{+}: 542.1376$ (84.4), 542.1359 (88.4), 3.2; 543.1397 (64.4), 543.1384 (78.5), 2.3; 544.1392 (100), 544.1381 (100), 1.9; 545.1441 (32.2), 545.1427 (37.8), 2.5; 546.1428 (87.2), 546.1414 (85.9), 2.6.

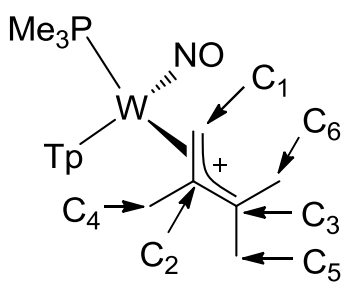

Exo

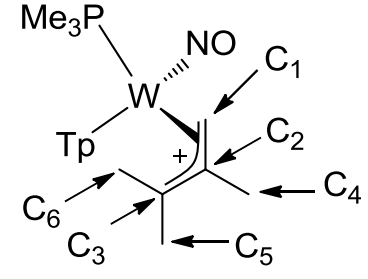

Endo

$\mathrm{TpW}(\mathrm{NO})\left(\mathrm{PMe}_{3}\right)\left(1,2-\eta^{2}-(2,3-\right.$ dimethylbut-3-en-2-ylium)][OTf]. exo-12, endo-12. In a flame dried test tube, 2,3-dimethylbutadiene $(0.91 \mathrm{~g}, 11.1 \mathrm{mmol})$ was added to a homogeneous yellow solution of $\mathrm{TpW}(\mathrm{NO})\left(\mathrm{PMe}_{3}\right)\left(\eta^{2}\right.$-benzene) $(0.501 \mathrm{~g}, 0.862 \mathrm{mmol})$ in DME (2.62 g). The tube was added to a $57{ }^{\circ} \mathrm{C}$ oil bath and allowed to stir. The dark purple-brown solution was removed from the warm bath after $1.5 \mathrm{~h}$. An HOTf $(0.130 \mathrm{~g}, 0.866 \mathrm{mmol})$ in MeCN (0.62 g) was added to the solution to make a dark yellow solution. After 45 minutes the solution becaome heterogeneous. The solution was allowed to stir for an additional $15 \mathrm{~h}$ and the yellow precipitate was collected on a $15 \mathrm{~mL}$ medium porosity fritted funnel. The precipitate was washed with 3x0.3 g DME and placed under vacuum (0.298 g, $0.405 \mathrm{mmol}, 47 \%$ yield). ${ }^{1} \mathrm{H}$ NMR $\left(\mathrm{CD}_{3} \mathrm{CN}, \delta\right)$ : Endo: $8.28(\mathrm{~d}, \mathrm{~J}=$ 2.0, 1H, PzC3), $8.18(\mathrm{~d}, J=2.0,1 \mathrm{H}, \mathrm{PzB} 3), 8.04(\mathrm{~d}, J=2.0,1 \mathrm{H}, \mathrm{PzC} 5), 7.92(\mathrm{~d}, J=2.0,1 \mathrm{H}, \mathrm{PzA} 5)$, 
$7.87(\mathrm{~d}, J=2.0,1 \mathrm{H}, \mathrm{PzB} 5), 7.67$ (d, J = 2.0, 1H, PzA3), 6.55 (t, J = 2.0, 1H, PzC4), 6.40 (m(overlap), $2 \mathrm{H}, \mathrm{PzB} 4), 6.35(\mathrm{t}, J=2.0,1 \mathrm{H}, \mathrm{PzA} 4), 3.36\left(\mathrm{dd}, J=7.2,^{3} J_{\mathrm{PH}}=10.9,1 \mathrm{H}, \mathrm{H} 1\right), 3.12\left(\mathrm{dd}, J=7.2,{ }^{3} J_{\mathrm{PH}}=\right.$ 10.1, 1H, H1'), $2.25(\mathrm{~s}, 3 \mathrm{H}, \mathrm{H} 6), 1.92(\mathrm{~s}, 3 \mathrm{H}, \mathrm{H} 5) 1.34(\mathrm{~s}, 3 \mathrm{H}, \mathrm{H} 4), 1.27\left(\mathrm{~d}, J_{\mathrm{PH}}=9.8,9 \mathrm{H}, \mathrm{PMe}_{3}\right)$. Exo: $8.07(\mathrm{~m}, 2 \mathrm{H}, \mathrm{PzC} 5 / \mathrm{PzC} 3), 7.99$ (d, J = 2.0, 1H, PzA5), 7.93 (d, J = 2.0, 1H, PzB3), 7.91 (d, J = 2.0, 1H, PzB5), 7.83 (d, $J=2.0,1 \mathrm{H}, \mathrm{PzA} 3), 6.53$ (t, $J=2.0,1 \mathrm{H}, \mathrm{PzC} 4), 6.4$ (m(overlap), 1H, PzA4), 6.38 $(\mathrm{t}, J=2.0,1 \mathrm{H}, \mathrm{PzB} 4), 3.71\left(\mathrm{dd}, J=6.3,{ }^{3} \mathrm{JH}_{\mathrm{PH}}=15.2,1 \mathrm{H}, \mathrm{H} 1\right), 2.80\left(\mathrm{dd}, J=6.3,{ }^{3} J_{\mathrm{PH}}=5.7,1 \mathrm{H}, \mathrm{H} 1^{\prime}\right)$, $2.38(\mathrm{~s}, 3 \mathrm{H}, \mathrm{H} 6), 1.78(\mathrm{~s}, 3 \mathrm{H}, \mathrm{H} 5), 1.28\left(\mathrm{~d}, \mathrm{~J}_{\mathrm{PH}}=9.8,9 \mathrm{H}, \mathrm{PMe}_{3}\right), 1.00(\mathrm{~s}, 3 \mathrm{H}, \mathrm{H} 4) .{ }^{13} \mathrm{C} \mathrm{NMR}\left(\mathrm{CD}_{3} \mathrm{CN}\right.$, ס): Endo: 176.8 (C3), 147.9 (PzA3), 145.8 (d, J = 2.4, PzB3), 145.1 (PzC3), 140.7 (PzA5), 139.6/139.5 (PzB5/PzC5), 122.2 (q, $J_{C F}=321 \mathrm{~Hz}$, Triflate), 108.7 (PzB4), 108.4 (PzC4), 108.2 (PzA4), 102.3 (d, $\left.J_{\mathrm{PC}}=3.8, \mathrm{C} 2\right), 65.2\left(\mathrm{~d}, J_{\mathrm{PC}}=14.2, \mathrm{C} 1\right), 29.1(\mathrm{C} 5), 27.0(\mathrm{C} 6), 22.0(\mathrm{C} 4), 13.0\left(\mathrm{~d},{ }^{1} \mathrm{~J}_{\mathrm{PC}}\right.$ = 32.6, PMe3). Exo: 152.8 (С3), 147.4 (РzA3), 145.4/145.3 (PzB3/PzC3), 141.5 (PzA5), 139.9/139.8 (PzB5/PzC5), $112.6\left(\mathrm{~d}, J_{\mathrm{PC}}=4.6, \mathrm{C} 2\right), 108.8(\mathrm{PzC} 4), 108.6 / 108.5$ (PzA4/BzB4), $65.2(\mathrm{~d}$, $\left.J_{\mathrm{PC}}=14.2, \mathrm{C} 1\right), 27.4(\mathrm{C} 5), 24.5(\mathrm{C} 4), 24(\mathrm{C} 6), 13.2\left(\mathrm{~d},{ }^{1} J_{\mathrm{PC}}=32.8, \mathrm{PMe}_{3}\right) \cdot{ }^{31} \mathrm{P} \mathrm{NMR}\left(\mathrm{CD}_{3} \mathrm{CN}, \delta\right):-4.09$ $\left(J_{\mathrm{WP}}=259\right),-7.35\left(J_{\mathrm{WP}}=258\right) . \mathrm{IR}: v_{\mathrm{BH}}=2511 \mathrm{~cm}^{-1}, v_{\mathrm{NO}}=1624 \mathrm{~cm}^{-1} . \mathrm{CV}(\mathrm{MeCN}): E_{\mathrm{p}, \mathrm{a}}=+1.93 \mathrm{~V}, E_{1 / 2}$ $=-0.78 \mathrm{~V}, E_{1 / 2}=-1.66 \mathrm{~V}$. ESI-MS: obs'd (\%), calc'd (\%), ppm, $\mathrm{M}^{+}: 584.1828(71.7), 584.1828(86.8)$, $0.1 ; 585.1858$ (65.7), 585.1854 (79.3), 0.6; 586.1863 (100), 586.1852 (100), 1.9; 587.1899 (33), 587.1896 (40.1), 0.5; 588.1903 (62.3), 588.1884 (84.9), 3.1. Anal. Calc'd for $\mathrm{C}_{19} \mathrm{H}_{30} \mathrm{BF}_{3} \mathrm{~N}_{7} \mathrm{O}_{4} \mathrm{PSW}$ : C, 31.04; H, 4.11; N, 13.34; Found: C, 31.17; H, 4.29; N, 13.50.

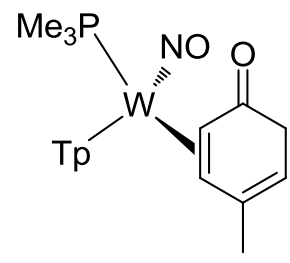

$\mathrm{TpW}(\mathrm{NO})\left(\mathrm{PMe}_{3}\right)\left(5,6-\eta^{2}-4-m e t h y l c y c l o h e x a-2,4-d i e n o n e\right) .17$. Sodium dispersion (4.09 g, 0.053 mmol, $30-35 \%$ in wax) was added to a $2 \mathrm{~L}$ round-bottom flask containing a stir bar and was stirred in $40 \mathrm{~mL}$ of hexanes for $20 \mathrm{~min}$. The hexanes was decanted. The sodium wax dispersion 
was stirred in an additional $40 \mathrm{~mL}$ of hexanes for $20 \mathrm{~min}$ and the hexanes decanted. Benzene $(400 \mathrm{~mL})$ was added to the round-bottom flask containing $\mathrm{TpW}(\mathrm{NO})\left(\mathrm{PMe}_{3}\right) \mathrm{Br}(5.997 \mathrm{~g}, 0.0103$ mol). After $24 \mathrm{~h}$, the reaction was filtered through $2 \mathrm{~cm}$ of Celite in a $350 \mathrm{~mL}$ medium porosity fritted funnel into a $2 \mathrm{~L}$ filter flask, containing a stirbar and $p$-cresol $(20.798 \mathrm{~g}, 0.1923 \mathrm{mmol})$. The Celite was washed with $200 \mathrm{~mL}$ of benzene. After $24 \mathrm{~h}$, the reaction mixture was chromatographed on silica $(3 \mathrm{~cm})$ in a $350 \mathrm{~mL}$ medium porosity fritted funnel by first eluting with toluene $(200 \mathrm{~mL})$, then $\mathrm{Et}_{2} \mathrm{O}(800 \mathrm{~mL})$, then $\mathrm{EtOAc}(1 \mathrm{~L})$. A separate brown band came off of the column with each change in eluent. The EtOAc fraction solvent was removed in vacuo, dissolved in $30 \mathrm{~mL}$ of $\mathrm{DCM}$, and added to $500 \mathrm{~mL}$ of stirring hexanes. A tan precipitate was collected (2.553 g, 0.0419 mol, $41 \%$ yield). ${ }^{1} \mathrm{H}$ NMR $\left(\mathrm{CDCl}_{3}, \delta\right): 7.97$ (d, $\left.1 \mathrm{H}, J=2.0, \mathrm{PzB} 3\right), 7.92$ (d, 1H, J=2.0, PzA3), 7.80 (d, 1H, J=2.0, PzC5), $7.72(\mathrm{~d}, 1 \mathrm{H}, J=2.0, \mathrm{PzB} 5), 7.64(\mathrm{~d}, 1 \mathrm{H}, J=2.0$, PzA5), $7.38(\mathrm{~d}, 1 \mathrm{H}, J=2.0, \mathrm{PzC}$ ), 6.29 (t overlaps with PzB4, 1H, J = 2.0, PzC4), 6.28 (t overlaps with $\mathrm{PzC} 4,1 \mathrm{H}, J=2.0, \mathrm{PzB} 4), 6.17(\mathrm{t}, 1 \mathrm{H}, J=2.0, \mathrm{PzA} 4), 4.82(\mathrm{br} \mathrm{s}, 1 \mathrm{H}, \mathrm{H} 3), 3.51(\mathrm{~d}, 1 \mathrm{H}, J=22.3$, $\mathrm{H} 2$ ), $3.37\left(\mathrm{ddd}, 1 \mathrm{H},{ }^{3} J_{\mathrm{PH}}=12.0, J=9.1,2.5, \mathrm{H} 6\right), 2.97\left(\mathrm{~d}, 1 \mathrm{H}, J=22.3, \mathrm{H} 2^{\prime}\right), 1.93(\mathrm{~d}, 1 \mathrm{H}, J=9.1$, $\mathrm{H} 5), 1.55(\mathrm{~s}, 3 \mathrm{H}, \mathrm{Me}), 1.26\left(\mathrm{~d}, 9 \mathrm{H},{ }^{2} J_{\mathrm{PH}}=8.9, \mathrm{PMe}_{3}\right) .{ }^{13} \mathrm{C} \mathrm{NMR}\left(\mathrm{CDCl}_{3}, \delta\right): 208.7(\mathrm{~s}, \mathrm{C} 1), 143.9$ (s, PzA3), 143.6 (s, PzB3), 140.4 (s, PzC3), 139.3 (s, C4), 136.9 (s, PzC5) 136.3 (s, PzB5), 136.0 (s, PzA5), 111.6 (s, C3), 106.6 (s, PzB4 or PzC4), 106.4 (s, PzB4 or PzC4), 105.6 (s, PzA4), 64.9 (s, C5), $58.6\left(\mathrm{~d},{ }^{2} J_{\mathrm{PC}}=6.8, \mathrm{C} 6\right), 40.5(\mathrm{~s}, \mathrm{C} 2), 25.1(\mathrm{~s}, \mathrm{Me}), 13.1\left(\mathrm{~d},{ }^{1} J_{\mathrm{PC}}=28.3, \mathrm{PMe}_{3}\right) .{ }^{31} \mathrm{P} \mathrm{NMR}\left(\mathrm{CD}_{3} \mathrm{CN}, \delta\right):-$ $12.30\left(J_{\mathrm{WP}}=273\right) . \mathrm{CV}(\mathrm{DMA}): E_{\mathrm{p}, \mathrm{a}}=+0.68 \mathrm{~V} . \mathrm{IR}: \mathrm{v}_{\mathrm{BH}}=2495 \mathrm{~cm}^{-1}, \mathrm{v}_{\mathrm{CO}}=1620 \mathrm{~cm}^{-1}, \mathrm{v}_{\mathrm{NO}}=1566 \mathrm{~cm}^{-1}$ ESI-MS: obs'd (\%), calc'd (\%), ppm, (M+H)+: 610.1614 (66.6), 610.1621 (86.1), 1.1; 611.1649 (73.4), 611.1647 (79.5), 0.3; 612.1639 (100), 612.1645 (100), 1.0; 613.1681 (39.3), 613.1688 (40.9), 1.1; 614.1685 (80.2), 614.1677 (84.7), 1.3. 


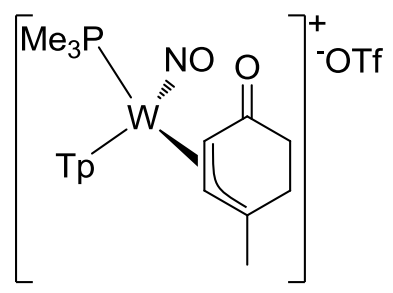

[TpW(NO)(PMe $)\left(2,3-\eta^{2}\right.$-1-methyl-4-oxocyclohex-2-en-1-ylium)][OTf]. 18. HOTf (0.018 g, 0.122 $\mathrm{mmol})$ in $\sim 1 / 2 \mathrm{~mL}$ MeCN was added to a vial containing 17 (0.050 g, $0.082 \mathrm{mmol})$ in $\sim 1 / 2 \mathrm{~mL}$ of MeCN. After 5 minutes, the dark yellow homogeneous solution was added to $75 \mathrm{~mL}$ of stirring $\mathrm{Et}_{2} \mathrm{O}$ resulting in a brown precipitate. The precipitate was collected on a $15 \mathrm{~mL}$ fine porosity fritted funnel and rinsed with $3 \times 5 \mathrm{~mL} \mathrm{Et}{ }_{2} \mathrm{O}\left(0.040 \mathrm{~g}, 0.052 \mathrm{mmol}, 63 \%\right.$ yield). ${ }^{1} \mathrm{H} \mathrm{NMR}\left(\mathrm{CD}_{3} \mathrm{CN}\right.$, ठ): $8.16(\mathrm{~d}, 1 \mathrm{H}, J=2.0, \mathrm{PzB} 3), 8.10(\mathrm{~d}, 1 \mathrm{H}, J=2.0, \mathrm{PzC} 5), 8.02(\mathrm{~d}, 1 \mathrm{H}, J=2.0, \mathrm{PzC}), 7.97(\mathrm{~d}, 1 \mathrm{H}, J$ = 2.0, PzB5), $7.94(\mathrm{~d}, 1 \mathrm{H}, J=2.0, \mathrm{PzA} 5), 7.67(\mathrm{~d}, 1 \mathrm{H}, J=2.0, \mathrm{PzA} 3), 6.61(\mathrm{t}, 1 \mathrm{H}, J=2.0, \mathrm{PzC} 4), 6.48$ $(\mathrm{t}, 1 \mathrm{H}, J=2.0, \mathrm{PzB} 4) 6.36(\mathrm{t}, 1 \mathrm{H}, J=2.0, \mathrm{PzA} 4), 4.74\left(\mathrm{ddd}, 1 \mathrm{H},{ }^{3} J_{\mathrm{PH}}=13.7, J=6.5,1.3, \mathrm{H} 3\right), 4.69$ (dd, $1 \mathrm{H}, J=6.5,1.5, \mathrm{H} 2$ ), 3.33 (ddddd, $1 \mathrm{H}, J=21.7,9.8,2.1,1.5,1.3, \mathrm{H} 6), 3.26$ (ddd, $J=21.7,9.0$, 6.8, 1H, H6'), 2.42 (ddd, $1 \mathrm{H}, J=19.0,9.8,6.8, H 5^{\prime}$ ), 2.25 (ddd, $1 \mathrm{H}, J=19.0,9.0,2.1, H 5^{\prime}$ ), 1.89 (s, 3H, Me), $1.19\left(\mathrm{~d}, 9 \mathrm{H},{ }^{2} \mathrm{~J}_{\mathrm{PH}}=10.6, \mathrm{PMe}_{3}\right) .{ }^{13} \mathrm{C} \mathrm{NMR}\left(\mathrm{CD}_{3} \mathrm{CN}, \delta\right): 201.2(\mathrm{~s}, \mathrm{C} 4), 184.1(\mathrm{~s}, \mathrm{C} 1), 146.6$ (s, PzA3), 145.9 (s, PzB3), 143.5 (s, PzC3), 140.9 (s, PzA5), 140.3 (s, PzB5), 139.9 (s, PzC5) 109.4 (s, PzB4), 109.2 (s, PzC4), 108.4 (s, PzA4), 96.9 (d, J = 2.5, C2), 73.1 (d, $\left.{ }^{2} J_{\mathrm{WP}}=10.7, \mathrm{C} 3\right), 32.9$ (s, C5 or C6), 32.9 (s, C5 or C6), 30.0 (s, Me), $12.9\left(\mathrm{~d},{ }^{1} J_{P C}=32.8, \mathrm{PMe}_{3}\right) .{ }^{31} \mathrm{P} \mathrm{NMR}\left(\mathrm{CDCl}_{3}, \delta\right):-0.59\left(J_{\mathrm{WP}}=\right.$ 267). $C V(M e C N): E_{\mathrm{p}, \mathrm{a}}=+2.10 \mathrm{~V}, E_{\mathrm{p}, \mathrm{c}}=-0.67 \mathrm{~V} . \mathrm{IR}: v_{\mathrm{BH}}=2510 \mathrm{~cm}^{-1}, v=1608 \mathrm{~cm}^{-1}$ (broad). ESI-MS: obs'd (\%), calc'd (\%), ppm, M+: 610.1615 (103.3), 610.1621 (86.1), 0.9; 611.1628 (81.8), 611.164 (79.5), 3.1; 612.1636 (100), 612.1644 (100), 1.3; 613.168 (54.2), 613.1688 (40.9), 0.1; 614.1680 (68.7), 614.1677 (84.7), 0.6. 


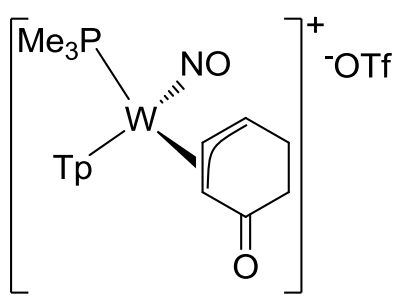

[TpW(NO)(PMe $)\left(2,3-\eta^{2}\right.$-(4-oxocyclohex-2-en-1-ylium)][OTf]. 20p. HOTf (0.025-0.030 g, 0.167$0.200 \mathrm{mmol}$ ) was added to a pale yellow homogeneous solution of $19 \mathrm{p}(0.015 \mathrm{~g}-0.027 \mathrm{~g}, 0.025-$ $0.045 \mathrm{mmol})$ in $\mathrm{CD}_{3} \mathrm{CN}(0.45-0.55 \mathrm{~g})$ to immediately become dark yellow-brown. The solution was transferred to an NMR tube, removed from a glovebox, frozen in $N_{2(l)}$ and thawed just prior to inserting a sample into the NMR spectrometer set to $235 \mathrm{~K} .{ }^{1} \mathrm{H},{ }^{13} \mathrm{C},{ }^{31} \mathrm{P}, \mathrm{COSY}, \mathrm{NOESY}, \mathrm{HSQC}$, and $\mathrm{HMBC}$ data was collected at this temperature. Several minor species were produced in $<1: 10$ ratio to $20 \mathrm{p} .{ }^{1} \mathrm{H}$ NMR $\left(\mathrm{CD}_{3} \mathrm{CN}, \delta, 235 \mathrm{~K}\right): 8.29$ (d, $\left.J=2.0,1 \mathrm{H}, \mathrm{PzB} 3\right), 8.20(\mathrm{~d}, J=2.0,2 \mathrm{H}$, PzC3+PzC5), 8.10 (d, $J=2.0,1 \mathrm{H}, \mathrm{PzB} 5), 8.02$ (d, $J=2.0,1 \mathrm{H}, \mathrm{PzA} 5), 7.25$ (d, J=2.0, 1H, PzA3), 7.03 $(\mathrm{m}, 1 \mathrm{H}, \mathrm{H} 1), 6.64(\mathrm{t}, J=2.0,1 \mathrm{H}, \mathrm{PzC} 4), 6.57(\mathrm{t}, J=2.0,1 \mathrm{H}, \mathrm{PzB} 4), 6.38(\mathrm{t}, J=2.0,1 \mathrm{H}, \mathrm{PzA} 4), 6.05$ $(\mathrm{m}, 1 \mathrm{H}, \mathrm{H} 2), 4.24(\mathrm{~d}, J=5.3,1 \mathrm{H}, \mathrm{H} 3), 3.72(\mathrm{dd}, J=21.5,10.5,1 \mathrm{H}, \mathrm{H} 6), 3.19$ (dd, $J=21.5,10.2,1 \mathrm{H}$, $\left.H 6^{\prime}\right), 3.13(d d, J=22.3,10.5,1 \mathrm{H}, \mathrm{H} 5), 2.61\left(\mathrm{dd}, J=22.3,10.2,4.2,1 \mathrm{H}, \mathrm{H} 5^{\prime}\right), 1.12\left(\mathrm{~d},{ }^{2} J_{\mathrm{PH}}=10.4\right.$,

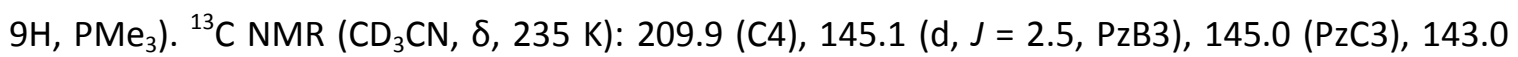
(PzA3), 140.7 (PzA5+PzB5+PzC5), 135.8 (C1), 119.9 (q, ${ }^{1} J_{C F}=320$, OTf), 109.9 (PzB4), 109.4 (PzC4), 108.6 (PzA4), 93.2 (C2), 66.8 (C3), 26.3 (C5), $23.7(\mathrm{C} 4), 11.7$ (d, ${ }^{1} J_{\mathrm{PC}}=34.3, \mathrm{PMe}_{3}$ ). ${ }^{31} \mathrm{P}$ $\operatorname{NMR}\left(\mathrm{CD}_{3} \mathrm{CN}, \delta, 298 \mathrm{~K}\right):-1.91\left(J_{\mathrm{WP}}=243\right)$.

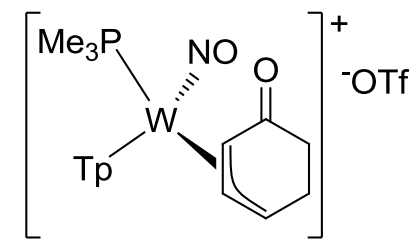

[TpW(NO)(PMe $)\left(2,3-\eta^{2}\right.$-(4-oxocyclohex-2-en-1-ylium)][OTf]. 20d (and 20p). HOTf (0.025-0.030 g, $0.167-0.200 \mathrm{mmol}$ ) was added to a pale yellow homogeneous solution of a mixture of 
coordination isomers of $19 \mathrm{p}, \mathrm{d}(2.5: 1 ; 0.020-0.028 \mathrm{~g}, 0.034-0.047 \mathrm{mmol})$ in $\mathrm{CD}_{3} \mathrm{CN}(\sim 0.5 \mathrm{~g})$ to make a dark yellow-brown solution. The solution was transferred to an NMR tube, removed from a glovebox, frozen in $\mathrm{N}_{2(l)}$ and thawed just prior to inserting a sample into the NMR spectrometer set to $235 \mathrm{~K} .{ }^{1} \mathrm{H},{ }^{13} \mathrm{C},{ }^{31} \mathrm{P}, \mathrm{COSY}, \mathrm{NOESY}, \mathrm{HSQC}$, and $\mathrm{HMBC}$ data was collected at this temperature and revealed an allylic mixture in 2.2:1 ratio. Due to multiple overlapping signals from the Major isomer, only the phenol ligand resonances of $20 q$ are reported. ${ }^{1} \mathrm{H} N M R\left(\mathrm{CD}_{3} \mathrm{CN}\right.$, $\delta, 235 \mathrm{~K}): 6.75$ (broad, $1 \mathrm{H}, \mathrm{H} 1), 5.66\left(\mathrm{dd},{ }^{2} J_{\mathrm{PH}}=11.0, J=5.7,1 \mathrm{H}, \mathrm{H} 2\right), 5.28(\mathrm{dd}, J=7.7,5.7,1 \mathrm{H}$, H3), 3.70 (burried, $1 \mathrm{H}, \mathrm{H6}$ ), 3.47 (dd, $J=22.0,9.5,1 \mathrm{H}, \mathrm{H} 6$ '), 3.26 (ddd, $J=21.4,11.7,2.9,1 \mathrm{H}, \mathrm{H} 5$ ), $2.85\left(\mathrm{dd}, J=21.4,9.5,1 \mathrm{H}, \mathrm{H} 5^{\prime}\right) .{ }^{13} \mathrm{C}$ NMR $\left(\mathrm{CD}_{3} \mathrm{CN}, \delta, 235 \mathrm{~K}\right): 212.7$ (C4), $148.3(\mathrm{C} 1), 98.9\left(\mathrm{~d},{ }^{2} J_{\mathrm{PC}}=\right.$ 2.2, C2), $63.4\left(d,{ }^{2} J_{P C}=5.9, C 3\right), 28.1(C 5), 24.4(C 6) .{ }^{31} \mathrm{P} \mathrm{NMR}\left(\mathrm{CD}_{3} \mathrm{CN}, \delta, 298 \mathrm{~K}\right):-0.37\left(J_{\mathrm{WP}}=252\right)$.

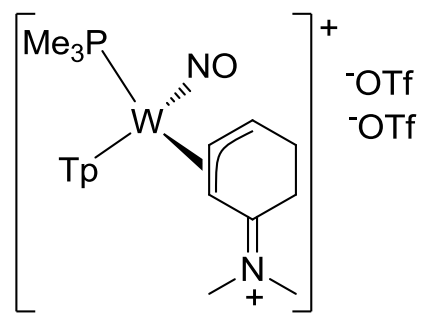

$\left[\mathrm{TpW}(\mathrm{NO})\left(\mathrm{PMe}_{3}\right)\left(2,3-\eta^{2}\right.\right.$-(4-(dimethyliminio)cyclohex-2-en-1-ylium))](OTf) 2 . 21p. A solution of HOTf $(0.023 \mathrm{~g}, 0.15 \mathrm{mmol})$ in $\mathrm{CH}_{3} \mathrm{CN}(1.07 \mathrm{~g})$, was added to a polypropylene vial containing 14 $(0.103 \mathrm{~g}, 0.13 \mathrm{mmol})$ to make a homogeneous yellow solution. After ${ }^{31} \mathrm{P}$ NMR analysis confirmed the completion of the reaction, the reaction solution was transferred to vial and the solvent evaporated under reduced pressure. The yellow film was dissolved in $\mathrm{CH}_{2} \mathrm{Cl}_{2}$ and added to $50 \mathrm{~mL}$ of stirring hexanes to precipitate a pale yellow solid. The solid was dried in vacuo $(0.105 \mathrm{~g}, 0.114$ mmol, 85\%). Note: every piece of glassware used throughout the coarse of the reaction was flame dried immediately before use and the $\mathrm{DCM}$ was dried by passage through basic $\mathrm{Al}_{2} \mathrm{O}_{3} \cdot{ }^{1} \mathrm{H}$ $\operatorname{NMR}\left(\mathrm{CD}_{3} \mathrm{CN}, \delta\right): 8.22(\mathrm{~d}, J=2.0,1 \mathrm{H}, \mathrm{Tp}), 8.20(\mathrm{~d}, J=2.0,1 \mathrm{H}, \mathrm{Tp}), 8.19(\mathrm{~d}, J=2.0,1 \mathrm{H}, \mathrm{Tp}), 8.09$ (d, $J=2.0,1 \mathrm{H}, \mathrm{Tp}), 8.07(\mathrm{~d}, J=2.0,1 \mathrm{H}, \mathrm{Tp}), 7.17(\mathrm{~m}, 1 \mathrm{H}, \mathrm{H} 4), 7.12(\mathrm{~d}, J=2.0,1 \mathrm{H}, \mathrm{Tp}), 6.65(\mathrm{t}, J=2.0$, 
$1 \mathrm{H}, \mathrm{Tp} 4), 6.58(\mathrm{t}, J=2.0,1 \mathrm{H}, \mathrm{Tp} 4), 6.47(\mathrm{t}, J=2.0,1 \mathrm{H}, \mathrm{Tp} 4), 5.92($ broad, $1 \mathrm{H}, \mathrm{H} 3), 3.93(\mathrm{~d}, J=6.4$, $1 \mathrm{H}, \mathrm{H} 2), 3.69(\mathrm{~m}, 1 \mathrm{H}, \mathrm{H} 5), 3.56(\mathrm{~s}, 3 \mathrm{H}, \mathrm{N}-\mathrm{Me}), 3.32(\mathrm{~m}, 1 \mathrm{H}, \mathrm{H} 5), 2.91(\mathrm{dd}, \mathrm{J}=20.1,9.5,1 \mathrm{H}, \mathrm{H} 6)$, $2.74\left(\mathrm{~s}, 3 \mathrm{H}, \mathrm{N}-\mathrm{Me}^{\prime}\right), 2.47$ (dd, $\left.J=20.1,6.2,1 \mathrm{H}, \mathrm{H} 6\right), 1.22\left(\mathrm{~d}, J=10.1,9 \mathrm{H}, \mathrm{PMe}_{3}\right) .{ }^{13} \mathrm{CNMR}\left(\mathrm{CD}_{3} \mathrm{CN}\right.$, ठ): 182.8 (C1), 145.5 (Tp), 145.0 (Tp), 142.4 (Tp), 140.9 (Tp), 140.7 (Tp), 140.5 (Tp), 133.3 (C4), 109.8 (Tp4), 109.5 (Tp4), 109.0 (Tp4), 94.9 (C3), 62.6 (C2), 44.0 (NMe), 43.7 (NMe), 24.7 (C5), $24.5(\mathrm{C} 6), 12.4\left(\mathrm{~d},{ }^{2} J_{\mathrm{PC}}=34.0, \mathrm{PMe}_{3}\right) .{ }^{31} \mathrm{P}\left(\mathrm{CD}_{3} \mathrm{CN}, \delta\right):-5.29\left(J_{\mathrm{PW}}=248\right) . \mathrm{CV}(\mathrm{MeCN}): E_{\mathrm{p}, \mathrm{a}}=+2.35 \mathrm{~V}$, $E_{\mathrm{p}, \mathrm{c}}=-0.30$ V. IR: $v_{\mathrm{BH}}=2506 \mathrm{~cm}^{-1}, v=1678 \mathrm{~cm}^{-1}, v=1581 \mathrm{~cm}^{-1}$ (broad). ESI-MS: Sample was too unstable to collect HRMS data.

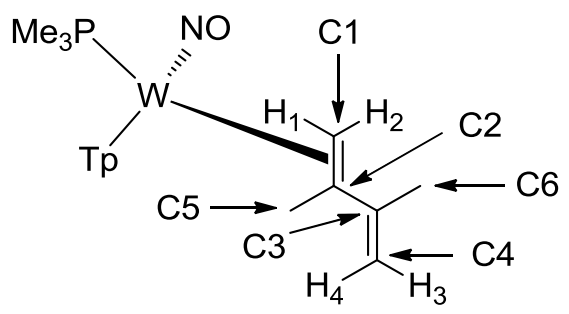

TpW(NO)(PMe ${ }_{3}$ (Exo-1,2- $\eta^{2}$-2,3-dimethylbutadiene). 22 (exo-22). $\mathrm{NEt}_{3}(0.100 \mathrm{~g}, 0.988$ mmol) was added to a heterogeneous yellow solution of $12(0.101 \mathrm{~g}, 0.137 \mathrm{mmol})$ in $\mathrm{CHCl}_{3}(6.68 \mathrm{~g})$ to make a homogeneous solution that was added to a $54{ }^{\circ} \mathrm{C}$ oil bath and was allowed to stir. After 1 hour, the yellow solution was remove from the oil bath and glovebox. The solution was diluted with $100 \mathrm{~mL} \mathrm{Et} 2 \mathrm{O}$ and extracted with $4 \times 25 \mathrm{~mL} \mathrm{NaHCO}$ (saturated, aqueous). The water layer was back-extracted with $2 \times 25 \mathrm{~mL} \mathrm{Et}{ }_{2} \mathrm{O}$. The organic layer was dried with $\mathrm{MgSO}_{4}$, filtered through a $60 \mathrm{~mL}$ coarse porosity fritted funnel and the solvent removed to yield a pale yellow solid $\left(0.079 \mathrm{~g}, 0.135 \mathrm{mmol}, 98 \%\right.$ yield; uncorrected for small amount of residual DCM). ${ }^{1} \mathrm{H}$ NMR $\left(\mathrm{CDCl}_{3}, \delta\right): 8.33(\mathrm{~d}, J=2.0,1 \mathrm{H}, \mathrm{PzA} 3), 8.10$ (d, $\left.J=2.0,1 \mathrm{H}, \mathrm{PzB} 3\right), 7.7$ (d, $\left.J=2.0,1 \mathrm{H}, \mathrm{PzC} 5\right), 7.66$ (d, $J=2.0,1 \mathrm{H}, \mathrm{PzB} 5), 7.64(\mathrm{~d}, J=2.0,1 \mathrm{H}, \mathrm{PzA} 5), 7.58(\mathrm{~d}, J=2.0,1 \mathrm{H}, \mathrm{PzC} 3), 6.25(\mathrm{t}, J=2.0,1 \mathrm{H}, \mathrm{PzB} 4)$, $6.21(\mathrm{t}, J=2.0,1 \mathrm{H}, \mathrm{PzC} 4), 6.17(\mathrm{t}, J=2.0,1 \mathrm{H}, \mathrm{PzA} 4), 4.71(\mathrm{br}(\mathrm{s}), 1 \mathrm{H}, \mathrm{H} 3), 4.28(\mathrm{~d}, J=2.6,1 \mathrm{H}, \mathrm{H} 4)$, $2.55\left(\mathrm{dd},{ }^{3} J_{\mathrm{PH}}=10.3, J=5.9,1 \mathrm{H}, \mathrm{H} 2\right), 1.72(\mathrm{br}(\mathrm{s}), 3 \mathrm{H}, \mathrm{Me}-6), 1.44\left(\mathrm{dd},{ }^{3} J_{\mathrm{PH}}=9.0, J=5.9,1 \mathrm{H}, \mathrm{H} 1\right)$, 
$1.35\left(\mathrm{~d},{ }^{2} J_{\mathrm{PH}}=8.1,9 \mathrm{H}, \mathrm{PMe} 3\right), 0.88(\mathrm{~d}, J=1.2,3 \mathrm{H}, \mathrm{Me}-5) .{ }^{13} \mathrm{C} \mathrm{NMR}\left(\mathrm{CDCl}_{3}, \delta\right): 157.1\left(\mathrm{~d},{ }^{3} \mathrm{~J}_{\mathrm{PC}}=1.5\right.$, С3), 143.4 (PzB3), 141.8 (PzC3), 141.0 (PzA3), 136.4 (PzC5), 135.8 (PzA5), 135.6 (PzB5), 106.9 (C4), 106.0 (PzB4), 105.7 (PzA4), 105.6 (PzC4), 60.8 (C2), $50.2\left(\mathrm{~d},{ }^{2} J_{\mathrm{PC}}=11.0, \mathrm{C} 1\right), 24.0\left(\mathrm{~d},{ }^{3} \mathrm{JC}_{\mathrm{PC}}=\right.$ 1.7, C5), $21.2(\mathrm{C} 6), 13.7\left(\mathrm{~d},{ }^{1} J_{\mathrm{PC}}=27.7, \mathrm{PMe} 3\right) .{ }^{31} \mathrm{P} N M R\left(\mathrm{CDCl}_{3}, \delta\right):-13.95\left(J_{\mathrm{WP}}=266\right) . \mathrm{IR}: \mathrm{v}_{\mathrm{BH}}=$ $2482 \mathrm{~cm}^{-1}, \mathrm{v}=1592 \mathrm{~cm}^{-1}, \mathrm{v}_{\mathrm{NO}}=1545 \mathrm{~cm}^{-1} . \mathrm{CV}(\mathrm{MeCN}): E_{\mathrm{p}, \mathrm{a}}=+0.37$ V. ESI-MS: obs'd (\%), calc'd (\%), ppm, (M+H) ${ }^{+}: 584.1828$ (93.4), 584.1828 (86.8), 0.0; 585.1861 (94.3), 585.1854 (79.3), 1.1; 586.185 (100), 586.1852 (100), 0.3; 587.1899 (47.6), 587.1896 (40.1), 0.5; 588.1888 (108.8), $588.1884(84.9), 0.5$.

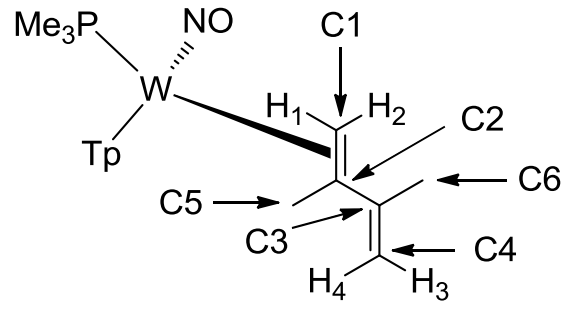

Exo

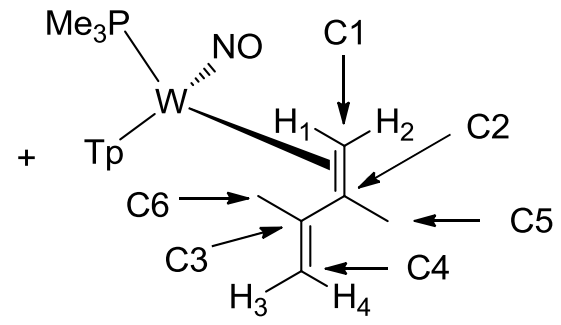

Endo

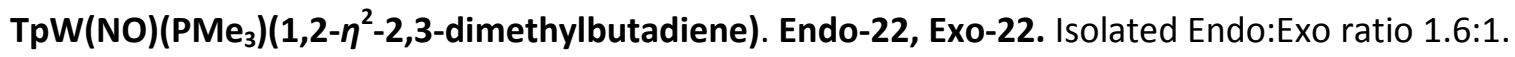

Butadiene $(0.200 \mathrm{~g}, 2.44 \mathrm{mmol})$ was added to an oven-dried test tube containing a heterogeneous solution of $\mathrm{TpW}(\mathrm{NO})\left(\mathrm{PMe}_{3}\right)\left(\eta^{2}\right.$-benzene) $(0.105 \mathrm{~g}, 0.181 \mathrm{mmol})$ and $\mathrm{DME}(1.51$ g). The solution was added to a $54{ }^{\circ} \mathrm{C}$ oil bath and allowed to stir for $1 \mathrm{~h} 40 \mathrm{~min}$. The solution was removed from the oil bath and diluted with $40 \mathrm{~mL}$ hexanes in a $125 \mathrm{~mL}$ filter flask to precipitate a small amount of material. As the solvent was removed and the solution cooled down, some brown precipitate formed. The solvent was removed completely. The residue was redissolved in $1 \mathrm{~mL} \mathrm{DCM}$ and $25 \mathrm{~mL} \mathrm{Et} \mathrm{O}_{2} \mathrm{O}$ was added to the solution followed by the addition of $25 \mathrm{~mL}$ of hexanes.The solution was cooled via evaporation for $\sim 5$ minutes and a brown precipitate formed and was collected on a $15 \mathrm{~mL}$ fine-porosity fritted funnel and was discarded. The filtrate solvent was removed in vacuo, the residue was transferred to a vial tared vial with 
DCM, andthe solvent was removed in vacuo to produce a light brown solid $(0.084 \mathrm{~g}, 0.144$ mmol, $79 \%$ yield). ${ }^{1} \mathrm{H} N M R\left(\mathrm{CDCl}_{3}, \delta\right)$ : Endo: 8.11 (d, $\left.J=2.0,1 \mathrm{H}, \mathrm{PzA} 3\right), 8.03(\mathrm{~d}, J=2.0,1 \mathrm{H}, \mathrm{PzB} 3)$, $7.64(\mathrm{~d}, J=2.0,2 \mathrm{H}, \mathrm{Tp5}+\mathrm{Tp5}), 7.62(\mathrm{~d}, J=2.0,1 \mathrm{H}, \mathrm{Tp5}), 7.44$ (d, J = 2.0, 1H, PzC3), 6.23 (t, J = 2.0, 1H, PzB4), $6.18(\mathrm{t}, J=2.0,1 \mathrm{H}, \mathrm{PzA} 4), 6.12(\mathrm{t}, J=2.0,1 \mathrm{H}, \mathrm{PzC} 4), 4.52(\mathrm{~d}, J=2.5,1 \mathrm{H}, \mathrm{H} 4), 4.14(\mathrm{dd}$, $J=2.5,1.0,1 \mathrm{H}, \mathrm{H} 3), 2.28(\mathrm{~s}, 3 \mathrm{H}, \mathrm{Me}-5), 2.15\left(\mathrm{dd},{ }^{3} J_{\mathrm{PH}}=11.1, J=5.4,1 \mathrm{H}, \mathrm{H} 1\right), 1.92\left(\mathrm{dd},{ }^{3} J_{\mathrm{PH}}=8.7, J\right.$ $=5.4,1 \mathrm{H}, \mathrm{H} 2), 1.34\left(\mathrm{~d},{ }^{2} J_{\mathrm{PH}}=8.1,9 \mathrm{H}, \mathrm{PMe}_{3}\right), 0.45(\mathrm{~d}, J=1.0,3 \mathrm{H}, \mathrm{Me}-6) .{ }^{13} \mathrm{C} \mathrm{NMR}\left(\mathrm{CDCl}_{3}, \delta\right):$ Endo: $155.1\left(\mathrm{~d},{ }^{3} \mathrm{JPC}_{\mathrm{PC}}=2.4, \mathrm{C} 3\right), 143.7(\mathrm{~d}, J=1.6, \mathrm{PzB} 3), 143.3$ (PzA3), 142.6 (PzC3), 136.1 (Tp5), 135.8 (Tp5), 135.6 (Tp5), 108.1 (C4), 105.9/105.9 (PzA4/PzB4), 105.2 (PzC4), 60.9 (C2), 48.8 (d, ${ }^{2} J_{P C}=$ 11.1, C1), 29.9 (C5), 21.1 (C6), 13.9 (d, $\left.{ }^{1} J_{\mathrm{PC}}=27.8, \mathrm{PMe}_{3}\right) .{ }^{31} \mathrm{P}$ NMR $\left(\mathrm{CDCl}_{3}, \delta\right):-14.29\left(J_{\mathrm{WP}}=267\right.$ $\mathrm{Hz}$ ). The exo isomer was characterized independently. IR: $v_{\mathrm{BH}}=2482 \mathrm{~cm}^{-1}, v=1592 \mathrm{~cm}^{-1}, v_{\mathrm{NO}}=$ $1545 \mathrm{~cm}^{-1} . \mathrm{CV}(\mathrm{MeCN}): E_{\mathrm{p}, \mathrm{a}}=+0.38$ V. ESI-MS: obs'd (\%), calc'd (\%), ppm, $(\mathrm{M}+\mathrm{H})^{+}: 584.1836$ (104.7), 584.1828 (86.8), 1.4; 585.1866 (69.4), 585.1854 (79.3), 1.9; 586.1877 (100), 586.1852 (100), 4.3; 587.1916 (42.1), 587.1896 (40.1), 3.5; 588.1899 (94.6), 588.1884 (84.9), 2.5.

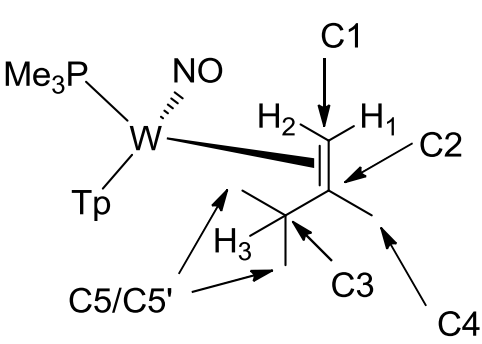

Endo (Major)

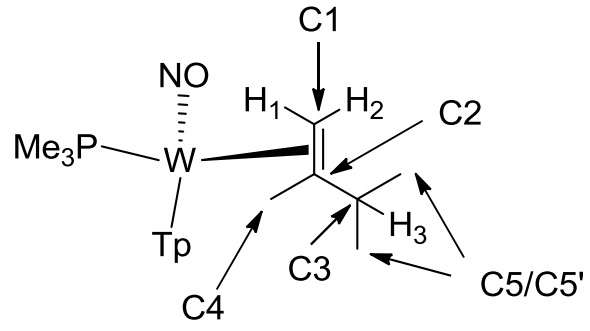

Exo (Minor)

$2.7: 1$

$\mathrm{TpW}(\mathrm{NO})\left(\mathrm{PMe}_{3}\right)\left(1,2-\eta^{2}-2,3-\right.$ dimethylbut-1-ene). endo-23, exo-23. $\mathrm{NaBH}_{4}$ reduction of 12 . $\mathrm{MeOH}(0.43 \mathrm{~g})$ was added to a vial containing $\mathrm{NaBH}_{4}(0.028 \mathrm{~g}, 0.740 \mathrm{mmol})$ and the heterogeneous solution quickly transferred to a vial containing a bright yellow solution of $\mathbf{1 2}$ $(0.021 \mathrm{~g}, 0.029 \mathrm{mmol})$ in $\mathrm{MeOH}(0.43 \mathrm{~g})$. Vigorous effervescence occurred and the solution color becoming pale yellow. After 20 minutes, the reaction solution was removed from the glovebox, 
diluted with $\mathrm{DCM}(15 \mathrm{~mL})$, extracted with $3 \times 15 \mathrm{~mL} \mathrm{NaHCO}_{3}$ (saturated, aqueous), back-extracted with $2 \times 15 \mathrm{~mL} \mathrm{DCM}$, dried with $\mathrm{MgSO}_{4}$, filtered through a $60 \mathrm{~mL}$ coarse-porosity fritted funnel, and the filtrate solvent removed in vacuo. The residue was transferred to a tared vial with $4 \times 2$ $\mathrm{mL} \mathrm{DCM}$, and upon evaporation of the solvent, a thin flaky tan solid was produced $(0.012 \mathrm{~g}$, $0.020 \mathrm{mmol}, 72 \%$ yield; 2.7:1 Endo-23:Exo-23). ${ }^{1} \mathrm{H} \mathrm{NMR}\left(\mathrm{CDCl}_{3}, \delta\right)$ : Endo isomer: 8.20 (d, $J=2.0$, 1H, PzA3), 7.95 (d, $J=2.0,1 \mathrm{H}$, PzB3), $7.69(\mathrm{~d}, J=2.0,1 \mathrm{H}, \mathrm{PzC} 5), 7.67 / 7.63(\mathrm{~d}+\mathrm{d}, J=2.0,1+1 \mathrm{H}$, PzA5/PzB5), $7.42(\mathrm{~d}, J=2.0,1 \mathrm{H}, \mathrm{PzC} 3), 6.2(\mathrm{t}+\mathrm{t}, J=2.0,1+1 \mathrm{H}, \mathrm{PzA} 4 / \mathrm{PzB} 4), 6.18(\mathrm{t}, J=2.0,1 \mathrm{H}$, PzC4), 2.06 (s, 3H, Me-4), $1.98\left(\mathrm{dd},{ }^{3} J_{\mathrm{PH}}=10.0, J=4.9,1 \mathrm{H}, \mathrm{H} 1\right), 1.49\left(\mathrm{dd},{ }^{3} J_{\mathrm{PH}}=10.7, J=4.9,1 \mathrm{H}\right.$, $\mathrm{H} 2$ ), $1.33\left(\mathrm{~d},{ }^{2} J_{\mathrm{PH}}=7.9,9 \mathrm{H}, \mathrm{PMe}_{3}\right), 0.98(\mathrm{~d}, J=6.9,3 \mathrm{H}, \mathrm{Me}-5), 0.87$ (septet, $J=6.9,1 \mathrm{H}, \mathrm{H} 2$ ), -0.23 $\left(\mathrm{d}, J=6.9,3 \mathrm{H}, \mathrm{Me}-5^{\prime}\right)$, Selected minor isomer (Exo) signals:, $8.37(\mathrm{~d}, J=2.0,1 \mathrm{H}, \mathrm{PzA} 3), 8.2(\mathrm{~d}, J=$ 2.0, 1H, PzB3), 7.67 (d, J = 2.0, 1H, PzB5), 7.58 (d, $J=2.0,1+1 \mathrm{H}, \mathrm{PzA} 5 / \mathrm{PzC} 5), 6.26(\mathrm{t}, J=2.0,1 \mathrm{H}$, PzB4), $2.12(\mathrm{~m}, 1 \mathrm{H}, \mathrm{H} 3), 2.10\left(\mathrm{dd},{ }^{3} J_{\mathrm{PH}}=12.1, J=5.2,1 \mathrm{H}, \mathrm{H} 1 \mathrm{orH} 2\right), 1.35(\mathrm{~d}, J=6.9,3 \mathrm{H}, \mathrm{Me}-5)$, $1.29\left(\mathrm{dd},{ }^{3} J_{\mathrm{PH}}=8.3, J=5.3,1 \mathrm{H}, \mathrm{H} 1 \mathrm{orH} 2\right), 1.24\left({ }^{2} J_{\mathrm{PH}}=8.3,9 \mathrm{H}, \mathrm{PMe}_{3}\right), 1.16\left(\mathrm{~d}, J=6.9,3 \mathrm{H}, \mathrm{Me}-5^{\prime}\right)$, 1.01 (s, 2H, Me-4). ${ }^{13} \mathrm{C}$ NMR ( $\left.\mathrm{CDCl}_{3}, \delta\right):$ Endo Isomer (Major): 143.6 (PzA3orPzB3), 143.5 (d, $J=$ 1.8, PzA3orPzB3), 141.6 (PzC3), 136 (Tp5), 135.9 (Tp5), 135.3 (Tp5), 105.6 (Tp4+Tp4), 105.3 (Tp4), $60.7(\mathrm{C} 2), 50.0\left(\mathrm{~d},{ }^{2} J_{\mathrm{PC}}=11.2, \mathrm{C} 1\right), 37(\mathrm{~d}, J=1.9, \mathrm{C} 3), 26.5(\mathrm{C} 5), 21.6(\mathrm{~d}, J=1.4, \mathrm{C} 4), 18.4$ (C5'), $13.9\left(\mathrm{~d},{ }^{1} J_{\mathrm{PC}}=27.5, \mathrm{PMe}_{3}\right.$ ), Exo Isomer (Minor): 145.5 (PzA3), $143.4(\mathrm{~d}, J=1.5, \mathrm{PzB} 3), 141.8$ (PzC3), 136.2 (Tp5), 135.3 (Tp5), 135.1 (Tp5), 105.9 (Tp4), 105.3 (Tp4), , 105.2 (Tp4), 62.3 (C2), $50.5\left(d,{ }^{2} J_{P C}=11.0, C 1\right), 41.8(C 3), 25.2(C 5), 24.2(C 5), 20.1(d, J=2.1, C 4), 13.1\left(d,{ }^{2} J_{P C}=27.9\right.$, $\left.\mathrm{PMe}_{3}\right) .{ }^{31} \mathrm{P} \mathrm{NMR}\left(\mathrm{CDCl}_{3}, \delta\right):-13.42\left(J_{\mathrm{WP}}=264 ; \mathrm{exo}\right),-14.48\left(J_{\mathrm{WP}}=261 ; \mathrm{Endo}\right) . \mathrm{CV}(\mathrm{MeCN}): E_{\mathrm{p}, \mathrm{a}}=$ $+0.24 \mathrm{~V}$. When the scan rate is increased to $>200 \mathrm{mV} / \mathrm{s}$ the $E_{\mathrm{p}, \mathrm{a}}$ become an $E_{1 / 2}=+0.20 \mathrm{~V}$. IR: $v_{\mathrm{BH}}=$ $2485 \mathrm{~cm}^{-1}, v_{\mathrm{NO}}=1540 \mathrm{~cm}^{-1}$. ESI-MS: obs'd (\%), calc'd (\%), ppm, (M+H) ${ }^{+}: 586.2002$ (106.7), 586.1985 (86.8), 2.9; 587.2021 (79.3), 587.2011 (79.3), 1.8; 588.1998 (100), 588.2008 (100), 1.8; 589.2059 (41.8), 589.2052 (40.1), 1.1; 590.2064 (99.2), 590.2041 (84.9), 3.9. 

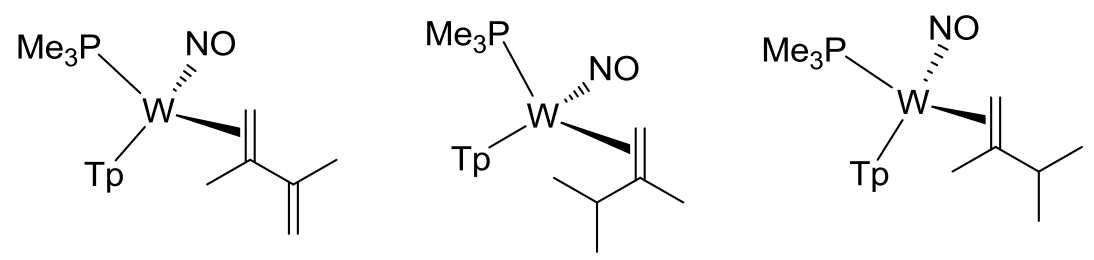

$\mathrm{Na} / \mathrm{Hg}$ amalgam reduction of $12: \mathrm{Na} / \mathrm{Hg}(1 \% ; 4.01 \mathrm{~g}, 1.740 \mathrm{mmol})$ was added to a yellow heterogeneous solution of $12(0.022 \mathrm{~g}, 0.030 \mathrm{mmol})$ and DME $(6.41 \mathrm{~g})$. The solution was allowed to stir and within 2 minutes the solution had become purple. After $2.25 \mathrm{~h}$, the murky purple solution was filtered through a pipette containing celite and the filtrate solvent removed in vacuo. The crude residue was dissolved in $\mathrm{CDCl}_{3}$ to produce a pale yellow solution and left a white solid in the evaporating flask. NMR: Three isomers are present in a 2.6:1:1.1 ratio (exo23:exo-22:endo-23).

\section{References.}

(1) Harman, W. D. Chem. Rev. 1997, 97, 1953-1978.

(2) Smith, P. L.; Chordia, M. D.; Harman, W. D. Tetrahedron 2001, 8203-8225.

(3) Meiere, S. H.; Brooks, B. C.; Gunnoe, T. B.; Sabat, M.; Harman, W. D. Organometallics $2001,20,1038-1040$.

(4) Keane, J. M.; Harman, W. D. Organometallics 2005, 24, 1786-1798.

(5) Winemiller, M. D.; Harman, W. D. J. Am. Chem. Soc. 1998, 120, 7835-7840.

(6) Winemiller, M. D.; Harman, W. D. J. Org. Chem. 2000, 65, 1249-1256.

(7) Valahovic, M. T.; Gunnoe, T. B.; Sabat, M.; Harman, W. D. J. Am. Chem. Soc. 2002, 124, 3309-3315.

(8) Todd, M. A.; Sabat, M.; Myers, W. H.; Smith, T. M.; Harman, W. D. J. Am. Chem. Soc. $2008,130,6906-6907$.

(9) Liu, W.; You, F.; Mocella, C. J.; Harman, W. D. J. Am. Chem. Soc. 2006, 128, 1426-1427. 
(10) Collman, J. P.; Hegedus, L. S.; Norton, J. R.; Finke, R. G. Principles and Applications of Organotransition Metal Chemistry; 2nd ed.; University Science Books: Mill Valley, 1987.

(11) Crocker, M.; Green, M.; Morton, C. E.; Nagle, K. R.; Orpen, A. G. J. Chem. Soc., Dalton Trans. 1985, 2145-2153.

(12) Pearson, A. J. K., Md. N. I.; Clardy, J. C.; Cun-heng, H. J. Am. Chem. Soc. 1985, 107, 27482757.

(13) Pankayatselvan, R.; Nicholas, K. M. J. Organomet. Chem. 1990, 384, 361-380.

(14) Bjurling, E.; Johansson, M. H.; Andersson, C.-M. Organometallics 1999, 18, 5606-5613.

(15) Tsang, J. Y. K.; Buschhaus, M. S. A.; Legzdins, P. J. Am. Chem. Soc. 2007, 129, 5372-5373.

(16) Mocella, C. J.; Delafuente, D. A.; Keane, J. M.; Warner, G. R.; Friedman, L. A.; Sabat, M.; Harman, W. D. Organometallics 2004, 23, 3772-3779.

(17) Meiere, S. H.; Valahovic, M. T.; Harman, W. D. J. Am. Chem. Soc. 2002, 124, 1509915103.

(18) Graham, P. M.; Delafuente, D. A.; Liu, W.; Myers, W. H.; Sabat, M.; Harman, W. D. J. Am. Chem. Soc. 2005, 127, 10568-10572.

(19) Ding, F.; Valahovic, M. T.; Keane, J. M.; Anstey, M. R.; Sabat, M.; Trindle, C. O.; Harman, W. D. J. Org. Chem. 2004, 69, 2257-2267.

(20) Kunsman, M. L. M.S. Dissertation, University of Virginia 1997.

(21) Helmchen, G.; Pfaltz, A. Accounts Chem. Res. 2000, 33, 336-345.

(22) Trost, B. M.; Lautens, M. J. Am. Chem. Soc. 1982, 104, 5543-5545.

(23) Faller, J. W. M., H. H.; White, D. L.; Chao, K. H. Organometallics 1983, 2, 400-409.

(24) Schilling, B. E. R.; Hoffmann, R.; Faller, J. W. J. Am. Chem. Soc.1979, 101, 592-598.

(25) Faller, J. W.; Shvo, Y. J. Am. Chem. Soc. 1980, 102, 5396-5398. 
(26) Vong, W. J.; Peng, S. M.; Lin, S. H.; Lin, W. J.; Liu, R. S. J. Am. Chem. Soc. 1991, 113, 573-

582.

(27) Lin, S.-H.; Chen, C.-C.; Vong, W.-J.; Liu, R.-S. Organometallics 1995, 14, 1619-1625.

(28) Madrahimov, S. T.; Markovic, D.; Hartwig, J. F. J. Am. Chem. Soc. 2009, 131, 7228-7229.

(29) Kirchner, K.; Mereiter, K.; Umfahrer, A.; Schmid, R. Organometallics 1994, 13, 18861892.

(30) Harrison, D. P.; Welch, K. D.; Nichols-Nielander, A. C.; Sabat, M.; Myers, W. H.; Harman, W. D. J. Am. Chem. Soc. 2008, 130, 16844-16845.

(31) Welch, K. D.; Harrison, D. P.; Lis, E. C.; Liu, W.; Salomon, R. J.; Harman, W. D.; Myers, W. H. Organometallics 2007, 26, 2791-2794.

(32) $\quad \mathrm{p}=$ proximal to $\mathrm{PMe}_{3}$ and $\mathrm{d}=$ distal to $\mathrm{PMe}_{3}$

(33) Graham, P.; Meiere, S. H.; Sabat, M.; Harman, W. D. Organometallics 2003, 22, 43644366.

(34) Lis, E. C.; Delafuente, D. A.; Lin, Y.; Mocella, C. J.; Todd, M. A.; Liu, W.; Sabat, M.; Myers, W. H.; Harman, W. D. Organometallics 2006, 25, 5051-5058.

(35) Harrison, D. P.; Sabat, M.; Myers, W. H.; Harman, W. D. J. Am. Chem. Soc. 2010, 132, $17282-17295$.

(36) Tsang, J. Y. K.; Buschhaus, M. S. A.; Fujita-Takayama, C.; Patrick, B. O.; Legzdins, P. Organometallics 2008, 27, 1634-1644.

(37) Villanueva, L. A.; Ward, Y. D.; Lachicotte, R.; Liebeskind, L. S. Organometallics 1996, 15, 4190-4200.

(38) Frohnapfel, D. S.; White, P. S.; Templeton, J. L.; Ruegger, H.; Pregosin, P. S. Organometallics 1997, 16, 3737-3750. 
(39) Ng, S. H. K.; Adams, C. S.; Hayton, T. W.; Legzdins, P.; Patrick, B. O. J. Am. Chem. Soc. $2003,125,15210-15223$.

(40) Myers, W. H.; Welch, K. D.; Graham, P. M.; Keller, A.; Sabat, M.; Trindle, C. O.; Harman, W. D. Organometallics 2005, 24, 5267-5279.

(41) In the general case where the allyl ligand itself is not symmetrical, the deprotonation is expected to be regioselective rather than stereoselective.

(42) Zottig, V. E.; Todd, M. A., Nichols-Nielander, A. C.; Harrison, D. P.; Sabat, M.; Myers, W. H.; Harman, W. D. Organometallics 2010, 29, 4793-4803.

(43) Salomon, R. J.; Todd, M. A.; Sabat, M.; Myers, W. H.; Harman, W. D. Organometallics 2010, 29, 707-709.

(44) Coombs, T. C.; Huang, W.; Garnier-Amblard, E. C.; Liebeskind, L. Organometallics 2010, ASAP.

(45) Winemiller, W. D.; Kopach, M. E.; Harman, W. D. J. Am. Chem. Soc. 1997, 119, 20962102.

(46) Curtis, M. D.; Eisenstein, O. Organometallics 1984, 3, 887-895.

(47) Spera, M. L.; Chin, R. M.; Winemiller, M. D.; Lopez, K. W.; Sabat, M.; Harman, W. D. Organometallics 1996, 15, 5447-5449.

(48) Jensen, F. An Introduction to Computational Chemistry; Wiley \& Sons: Chichester, 1999.

(49) Mulliken, R. S. J. Chem. Phys. 1962, 36, 3428-3439.

(50) Reed, A. E.; Curtiss, L. A.; Weinhold, F. Chem. Rev. 1988, 88, 899-926.

(51) Chen, W.; Liebeskind, L. J. Am. Chem. Soc. 2009, 131, 12546-12547.

(52) A small single crystal of $\mathbf{2 1 d}$ was obtained by vapor diffusion of an acidic methylene chloride solution of 19 with hexanes at $-20^{\circ} \mathrm{C}$. From this crystal limited X-ray diffraction data were obtained. The complex co-crystallized with one equivalent of $\mathrm{HOTf} \cdot \mathrm{CH}_{2} \mathrm{Cl}_{2}$. The small 
crystal yielded only 1748 usable reflections (out of 11436, 15\%). Despite the small data set, a structural determination was obtained with a good Rvalue of 0.0308 . The limited data set lowers the accuracy of the structural parameters, nonetheless, all bond lengths and angles for the metal fragment are within the range of analogous data for other complexes with $\left\{\mathrm{TpW}(\mathrm{NO})\left(\mathrm{PMe}_{3}\right)\right.$

(53) Bard, A. J.; Faulkner, L. R. Electrochemical Methods Fundamentals and Applications; John Wiley \& Sons: New York, 1980.

(54) Abrams, M. B.; Yoder, J. C.; Loeber, C.; Day, M. W.; Bercaw, J. E. Organometallics, 1999, 18, $1389-1401$

(55) Todd, M. A.; Sabat, M.; Myers, W. H.; Harman, W. D. J. Am. Chem. Soc. 2007, 129, $11010-11011$.

(56a) Shao, Y. et al., Phys. Chem. Chem. Phys., 2006, 8, 3172

(56b) http://www.gaussian.com/g_tech/gv5ref/gv5ref_toc.htm

(56c) Gaussian 09, Revision A.1, Frisch, M. J. et al. Gaussian, Inc., Wallingford CT, 2009. 


\section{Chapter 8}

\section{Concluding Remarks}


Our first goal was to overcome the detrimental binding of pyridine's nitrogen with tungsten. We were able to avert this problem by masking the nitrogen with borane prior to binding with tungsten. Next, we were able to deprotect the pyridine and replace it with several different electrophilic groups. Nucleophilic addition to one of these complexes, $\mathrm{N}$-acetylpyridinium, produced an array of mild and highly regio and stereoselective nucleophilic additions to generate dihydropyridine complexes, which are the first of their kind. Stepwise tandem electrophilic/nucleophilic additions and cycloadditions produced di-, tri-, and tetrasubstituted tetrahydropyridine complexes. Most of these tetrahydropyridine complexes could be removed from the metal via oxidation (Scheme 1).

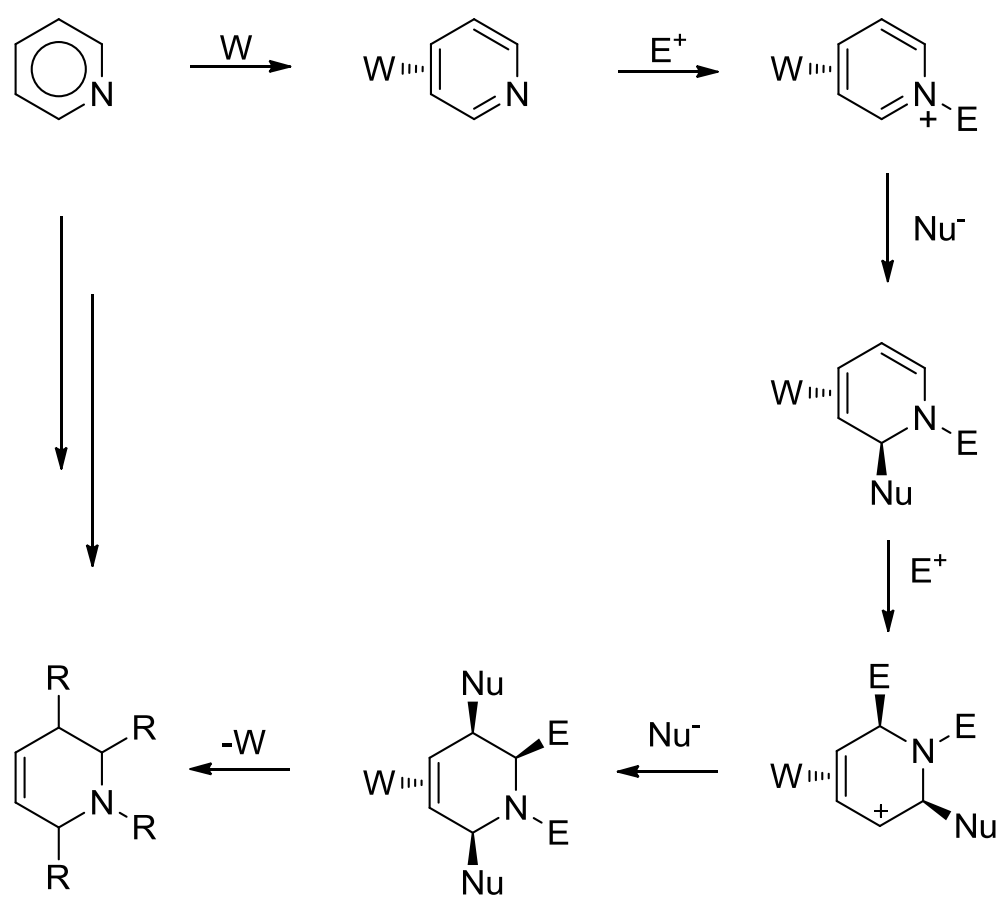

Scheme 1: Modification of Pyridine with $\left\{\mathrm{TpW}(\mathrm{NO})\left(\mathrm{PMe}_{3}\right)\right\}$. 
By using the methods summarized above, we have been able to convert the simple parent pyridine molecule into new organic compounds in such a way as to selectively add two, three, or four groups at specific locations of pyridine, to fully utilize the available reaction sites of pyridine that are allowed by the $16 \mathrm{e}^{-}$metal fragment $\left\{\mathrm{TpW}(\mathrm{NO})\left(\mathrm{PMe}_{3}\right)\right\}$. The tungsten complex has reversed the polarity of the ring carbons by polarizing the conjugated enamide such that electrophiles add $\alpha$-to- $\mathrm{N}$ and nucleophiles $\beta$-to- $N$. Because these additions are opposite to the typical reactivity of pyridine, new chemical patterns are produced (Scheme 2). This umpolung of reactivity has allowed for the introduction of new classes of organic piperidinamides in ways previously inaccessible to chemists by other methods.
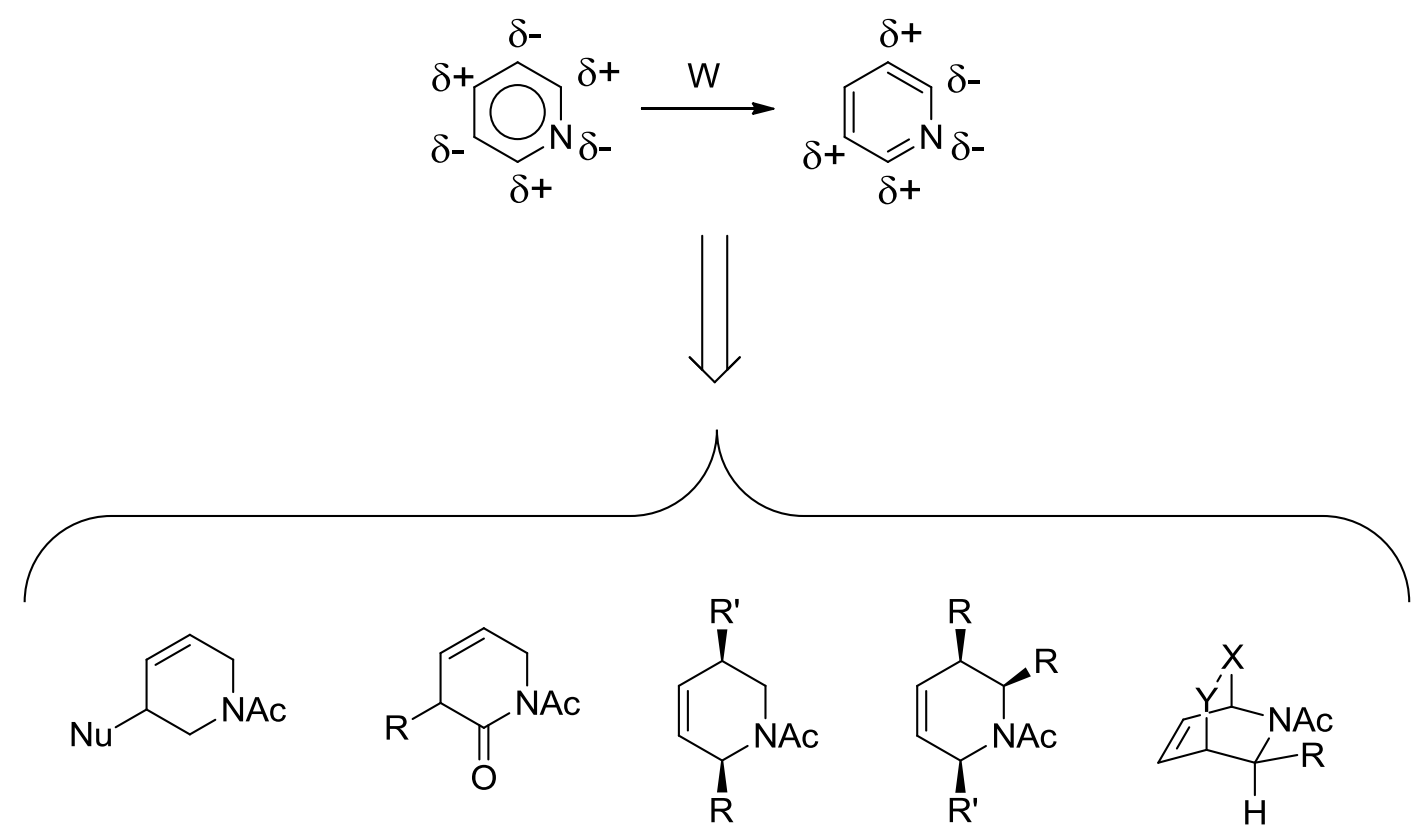

Scheme 2: Metal Re-Polarization of Pyridine Leading to the Isolation of Several Classes of Piperidines. 
When comparing the reactivity of the $N$-acetylpyridine to that of substituted pyridines with the tungsten system, the versatility of the parent pyridine becomes apparent. For example, while substituted $\eta^{2}$-coordinated pyridines (e.g. 2,6-lutidine and 2,6-dimethoxypyridine) are capable of concerted [4+2] Diels-Alder cycloaddition reactions with the exposed diene motif, additional metal mediated modification of the resultant cycloadduct is limited, as $\pi$ systems are not in conjugation with the metal. However, in the case of the parent pyridine multiple linear synthetic routes are possible, each of which is intimately dictated by the coordinated metal.

Comparing our piperidine work to that of the methodological forerunners in the field helps to put our work in context by giving us a peak at the "bigger picture". The methodologies of the Comins and Liebskinds groups are those that are well developed and most closely resemble ours. First we can analyze the possible substituent connectivities that are incorporated into the piperidine core (Table 1). When we do so, it becomes obvious that our work is still in its infancy, but also reveals the potential chemical arenas that we might possibly enter. For example, while we have developed methods to produce tetra-substituted piperidine cores, the Comins group has elegantly been able to incorporate substituents into every position of the piperidine core, producing up to hexa-substituted piperidines, and in nearly every possible combination on connections (e.g. substituents at 2,$3 ; 2,4 ; \ldots 2,3,4 ; \ldots 2,3,4,5 ; \ldots 2,3,4,5,6$ ).

The relative stereochemistry of the attached groups is clearly most varied with Comins methodology (see Table 1). Liebeskind work complements Comins well with additional relative stereochemistries possible. Specifically, the relative stereochemistry 
of Comins' 2,3-substituted and 2,3,6-substituted piperidines are opposite one another. Harman's methodology complements the Liebeskind methodology by adding 2,5substituted piperidines to the possible metal mediated transformations. When compared to Comins piperidines, the 2,3,6-substituted piperidines are complementary to one another.

Table 1: Relative stereochemistry of piperidine substituents produced by selected research groups. Values are based upon published results but probably do not include every product synthesized by the three research groups. - no published results yet; * selectivity dictated by oxidation procedure

\begin{tabular}{rccc}
\hline Substituents & Comins & Liebeskind & Harman \\
\hline $\mathbf{2 , 3 -}$ & anti & syn & anti \\
$\mathbf{2 , 4 -}$ & syn & - & - \\
$\mathbf{2 , 5}-$ & syn & - & syn \\
$\mathbf{2 , 6 -}$ & anti & syn & - \\
$\mathbf{2 , 3 , 4 -}$ & anti, syn & - & - \\
$\mathbf{2 , 3 , 5 -}$ & anti, syn; & - & - \\
$\mathbf{2 , 3 , 6 -}$ & syn, anti & & syn, syn \\
$\mathbf{2 , 4 , 6 -}$ & syn, anti & syn*, syn; & - \\
$\mathbf{2 , 3 , 4 , 5 -}$ & syn, syn,; & anti*, syn & - \\
$\mathbf{2 , 3 , 4 , 6 -}$ & anti, syn & - & - \\
$\mathbf{2 , 3 , 5 , 6 -}$ & anti, anti, anti & - & - \\
$\mathbf{2 , 3 , 4 , 5 , 6 -}$ & anti, anti, syn & - & - \\
\hline
\end{tabular}

Even though the Harman methodology has the ability to perform stereoselective transformations, a drawback is the lack of the ability to generate enantioselective products, which is unlike the Comins and Liebeskind groups. Perhaps adoption of a 
similar strategy to Comins by selection of an appropriate chiral nitrogen protecting group could allow for both the simple cleavage of the protecting group and the ability to perform enantioselective chemistry with the tungsten metal system.

Even though Harman's work is still in its infancy, the importance is revealed when we compare where addition groups can be incorporated into the piperidine core (Table 2). For example, incorporation of various electrophilic and nucleophilic groups into the piperidine ring is dictated by the placement of the nitrogen atom for Comins procedures. For the most part, the same is true for the Liebeskind synthetic procedures. Nucleophilic additions have been performed at the 3 position of the piperidine ring, however, with Grignard additions to a ketone at the 3 position and with intramolecular homo- $S_{N} 2^{\prime}$-like reaction conditions. It seems reasonable that expansion of the Liebeskind work to include more and milder nucleophilic addition methodologies to the $\beta$ position might be the natural progression of this work. The Harman group complementarily utilizes the coordinated metal to switch the polarization of both the 3 and 5 positions of the pyridine ring allowing mild nucleophiles to add to positions where electrophiles should without the metal, and vice versa. With this work, we have broken into new chemical space and added to the methodological arsenal that the Comins and Liebeskind groups have developed. Another distinction between Liebeskind and Harman groups work is the starting materials utilized (i.e. modified and rearranged furan vs pyridine, respectively). Thus, these two methodologies complement each other well as the selection of one of the starting materials might lead to a desired target while the other would not. 
Table 2: Positions of piperidine where additions occur.

\begin{tabular}{cccc}
\hline Addition Type & Comins & Liebeskind & Harman \\
\hline Nucleophilic & $2,4,6$ & $2,3,6$ & $2,3,5$ \\
Electrophilic & $1,3,5$ & 1 & $1,2,6$ \\
\hline
\end{tabular}

Throughout the exploration of the Harman group methodology, several projects evolved that, while indirectly related to the modification of pyridine, enhanced our fundamental understanding of the $\pi$-basic tungsten system. For example, nucleophiles capable of $4 \mathrm{e}^{-}$donation ( $2 \sigma$ and $2 \pi$ electrons) induced ring-opening of coordinated pyridine systems and led to the formation of $\eta^{2}$ metallo-cyanines. In all cases examined, the resulting ring-opened ligands have extended $\pi$ systems relative to their precursors. This extended conjugation allows the electron-rich metal center to further disperse its electron density via backbonding into the more $\pi$-acidic ring-opened ligand, thus presenting a driving force for the ring opening reaction. In a second example, the discovery of highly asymmetric allyls of dihydropyridine complexes led us to launch a computational investigation into the origin of the spectroscopically and structurally observed distortions. We found that the potent $\pi$ acid, nitrosyl, in $\left\{\mathrm{TpW}(\mathrm{NO})\left(\mathrm{PMe}_{3}\right)\right\}$ is responsible for causing the observed distortions. The nitrosyl produces a single high energy metal $d$ orbital orthogonal to the axis that it sits on. This high energy orbital is capable of interacting with the allyl $\pi_{\mathrm{nb}}$ and $\pi^{*}$, while the Tp ligand (not the $\mathrm{PMe}_{3}$ ) distorts the HOMO of the metal such that the $\mathrm{C} 1$ terminus of allyls are located distal to the phosphine, rather than proximal to the phosphine.

Over the course of this work, many new organic compounds have been produced that have not previously existed. Additionally, the products of the 
methodologies that we have introduced are reasonably complementary to those put forth by the Comins and Liebeskind groups. The National Institutes of Health and collaborators have collected several of these and have begun testing these compounds for medicinal activity. Also, Sigma-Aldrich has begun the process of supplying precursors to the novel piperidines, which enhances the likelihood that chemists who do not specialize in the organometallic chemistry of $\left\{\mathrm{TpW}(\mathrm{NO})\left(\mathrm{PMe}_{3}\right)\right.$ will use the new methodologies presented in this work. Once again, the value of this work, and all work done in the Harman group, will be amplified exponentially when a resolution of the metal has been successfully achieved. 